\title{
Development of $\mathrm{H}_{8} \mathrm{BINOL-Amine} \mathrm{Ligands} \mathrm{and}$ Their Application in Asymmetric Catalysis
}

\author{
Albert M. DeBerardinis \\ Aston, Pensyinamia \\ B. S. Biochemistry, \\ West Chester University of Pennsylvania, 2004
}

A Dissertation Presented to the Graduate Faculty of the University of Virginia in Candidacy for the Degree of

Doctor of Philosophy

Department of Chemistry

University of Virginia

January, 2011

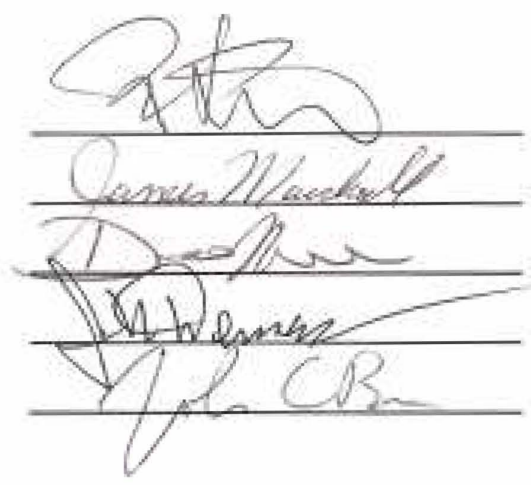




\begin{abstract}
Asymmetric catalysis has grown immensely over the past several decades. This was highlighted by the awarding of the Nobel Prize in Chemistry to Professors Sharpless, Noyori, and Knowles in 2001. As outlined by the Nobel Committee, the pioneering research efforts of these scientists demonstrated the exceedingly high potential of the synthetic methodology. These discoveries have had a vast impact on academic and industrial pursuits for the catalyzed chemical synthesis of chiral compounds.

$\mathrm{Pu}$ lab research in the field of asymmetric catalysis has concentrated on the development of practically useful synthetic methodologies for the preparation of chiral compounds. This approach has centered on utilizing functionally tolerant organozincs and catalytic systems based on optically pure 1,1'-bi-2,2'-naphthol (BINOL) and derivatives of BINOL, such as BINOL-Amines (shown below).
\end{abstract}

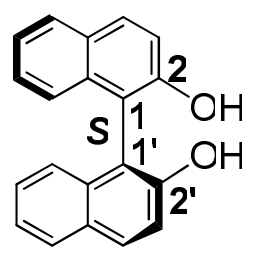

(S)-BINOL

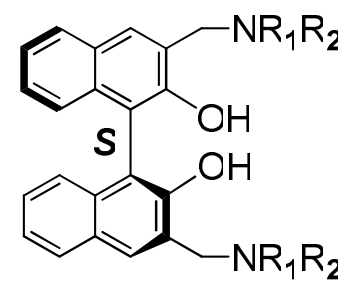

(S)-BINOL-Amine

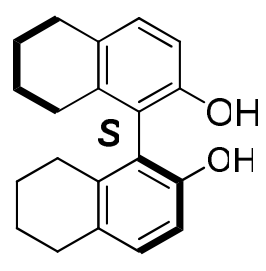

(S)- $\mathrm{H}_{8} \mathrm{BINOL}$

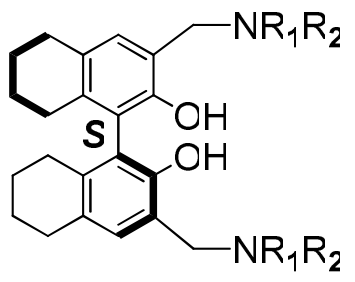

(S)- $\mathrm{H}_{8}$ BINOL-Amine

A family of optically active $\mathrm{H}_{8}$ BINOL-Amine compounds was prepared in a onepot reaction for our continued investigation of simplified and direct protocols describing the synthesis of asymmetric ligands. The compounds were isolated in $45->95 \%$ yields and were used to study their asymmetric induction in a number of nucleophilic organozinc additions.

The search for practical approaches led us to describe modified conditions for the generation of functional aryl- and vinylzincs from the commercially available $\mathrm{Et}_{2} \mathrm{Zn}$. A 
number of protocols were identified for the catalyzed, enantioselective preparation of diaryl and alkyl-aryl carbinols and allylic alcohols. The chiral alcohols were afforded in $60-98 \%$ yields and with moderate to excellent enantioselectivity $(54->99 \%$ ee).

Typical of the privileged organozincs, functional group compatability was highlighted: ethers, nitriles, esters, chlorine, nitrile, ether and silyl ether on the substrates. A heteroaryl iodide and bromide (2-halo-thiophene) were also found to react well using this method. This represented the first arylzinc reported to be formed from the reaction of an aryl bromide with $\mathrm{Et}_{2} \mathrm{Zn}$. A parallel route to the catalyzed asymmetric phenyl addition (from iodobenzene) was described which addresses the high cost of diphenylzinc, the most commonly used reagent in phenylation reactions. Access to four classes of nucleophilic organozincs was identified using the modified conditions. Functional aryl- and phenyl-, functional internal vinyl-, alkynyl-, and alkyl (benzyl)-zincs were generated. The reaction of the typical organozinc species prepared under these conditions was found to be greatly enhanced in the presence of a catalyst generated from $\mathrm{H}_{8} \mathrm{BINOL}-$ Amine ligand and organozinc. 


\section{TABLE OF CONTENTS}

Abstract

i.

Table of Contents

iii.

Dedication

v.

List of Figures

vi.

List of Schemes

vii.

List of Tables

viii.

Chapter 1

11

I. Introduction
a. Asymmetric Catalysis
b. Bifunctional Catalysis
i. Concept of Bifunctional Catalysis
ii. BINOL and BINOL-based Ligands
c. References

\section{Chapter 2}

II. Synthesis and Characterization of Functionalized $\mathrm{H}_{8} \mathrm{BINOL}$ Ligands
a. Introduction to Ligand Design
b. Ligand Synthesis: Development of $\mathrm{H}_{8} \mathrm{BINOL}-\mathrm{Amine}$ Family of Ligands
c. Attempted Kolbe-Schmidt Reaction of $(S)-\mathrm{H}_{8} \mathrm{BINOL}$
d. Experimental and Characterization
e. References

\section{Chapter 3}

III. Functional Arylzinc Generation and Catalytic Asymmetric Additions to
Aldehydes
a. Introduction
b. Generation and Catalytic Asymmetric Arylations to Aldehydes
c. Experimental and Characterization
d. References

\section{Chapter 4}

IV. Vinylzinc Generation and Catalytic Asymmetric Additions to Aldehydes
a. Introduction
b. Generation of Vinylzincs: Attempted Vinyl Iodide Reactions
c. Catalytic Asymmetric Vinylzinc Additions to Aldehydes
d. Experimental and Characterization 
V. Alkynylation of Carbonyls

a. Introduction: Asymmetric Alkynylations and Organocatalysis

b. Studies on the Organocatalytic Methodology for Alkyne Additions to Aldehydes

c. Further Development of Catalytic Asymmetric Alkynylation of Aldehydes

d. Attempted Acetylene Additions using Calcium Carbide as Substrate

e. Experimental and Characterization

f. References

Chapter 6

VI-A. Additional Research Projects, Attempts and Discoveries

a. Catalytic Asymmetric Arylation of Ketones

b. Catalytic Asymmetric Arylation of Aldimines ( $N$-protected imines)

c. Extension of Arylzinc and Vinylzinc Generation Chemistry to an Alkyl Iodide: Catalytic Asymmetric Alkylation of Benzaldehyde

d. Catalytic Asymmetric Allylations of Carbonyls

e. Catalytic Asymmetric Arene-Addition of Carbonyls

f. Attempted Synthesis of Chiral Allenes

g. Miscellaneous Reactivity:

1. 1,4-diol reactivity with methyl propiolate

2. Catalytic Asymmetric Phenylation Attempts Using Commercially Available Phenyl Reagents

3. Attempted Vinylations Directly from Alkyne Reduction and Reaction with Aldehydes

4. Catalytic Asymmertic Vinylation Attempts Using Vinyl Magnesium Bromide

VI-B. Collaborative Work at the University of Virginia

a. Synthesis, Characterization and Reactivity of $\mathrm{C}$

Chlorotris(triphenylphosphine)Iridium(I)

b. Experimental and Characterization

c. References

Appendix

${ }^{1} \mathrm{H}$ NMR and ${ }^{13} \mathrm{C}$ NMR (1D), ${ }^{1} \mathrm{H}$ NMR (2D) 
This dissertation is dedicated to the many people in my life who have inspired and motivated me to realize my goals. 


\section{List of Figures}

Figure 1.1 Examples of Catalytic Asymmetric Hydrogenations.

Figure 1.2 Example of Sharpless Asymmetric Epoxidation Catalyzed by TartrateTitanium Complexes.

Figure 1.3 General Structure of $C_{2}$-Symmetric Ligands (BINOL and BINOL-based) and Example of Intramolecular Independent Bifunctional Ligand.

Figure 2.1. General Structure of BINOL and BINOL-based $C_{2}$-Symmetric Ligands.

Figure 2.2. General Structure of $(S)-\mathrm{H}_{8} \mathrm{BINOL}-\mathrm{AMs}$.

Figure 2.3 Structures of the Newly Prepared Structurally Diverse $\mathrm{H}_{8} \mathrm{BINOL-AM}$ Compounds.

Figure 3.1. Drug Molecules Made from Diaryl Carbinols.

Figure 3.2. Catalytic Asymmetric Diphenylzinc Additions and Ligands Employed.

Figure 3.3 3,3'-bis(aryl)-(S)-H $\mathrm{H}_{8} \mathrm{BINOL}-$ based Ligands That Show Excellent Catalytic Asymmetric Control for the Preparation of Aliphatic-Substituted Propargylic Alcohols.

Figure 3.4 The Relationship of the Enantiomeric Purity of $(S)-2$ With that of the Corresponding Product 38.

Figure 3.5 $(R)$ and $(S)$ - $\alpha$-methoxy- $\alpha$-phenylacetic (MPA) Ester Derivatives of 38.

Figure 3.6 Structures Formed Between the Reaction of $(S)$-2 and Various Equivalents of Arylzinc.

Figure 4.1 Unsuccessful Vinyl Iodides Attempted in the Li(acac) Catalyzed Reaction with Diethylzinc to Form Vinylzincs.

Figure 4.2 Possible Chelation Complex Stabilizing (Phenylacrylate)Zinc Generated.

Figure 4.3 Vinyl Iodides that Successfully Generated Vinylzincs and Reacted with Aldehydes.

Figure 5.1 Example of a "Domino-Process" or Tandem Reaction.

Figure 6.1 Arylzinc Additions to $N$-Tosylaldimines.

Figure 6.2 Potential Substrate-Chelation Control in Asymmetric Thiophenylation of an $\mathrm{O}$-methoxy, $\mathrm{N}$-tosylaldimine. 
Figure 6.3 Proposed Mechanism Leading to Formation of Ethyl Addition Product to $N$ tosylaldimine.

Figure 6.4 Gau et. al. Enantioselective Terminal Vinyl Additions to Ketones From Vinylaluminums.

\section{List of Schemes}

Scheme 1.1 Activation of $\mathrm{Et}_{2} \mathrm{Zn}$ by HMPA Additive

Scheme 2.1 General Synthesis of the $\mathrm{H}_{8} \mathrm{BINOL-AM}$ Compounds.

Scheme 2.2. Synthesis of a Chiral-Armed $\mathrm{H}_{8} B I N O L-A M$ Compound

Scheme 2.3 Synthesis of the Secondary Amine-Substituted $\mathrm{H}_{8}$ BINOL-AM Compound (S)-21.

Scheme 3.1 Preparation of a Substituted Arylzinc and Its Addition to an Aldehyde.

Scheme 3.2 General Functional Arylation Protocol for the Asymmetric Catalysis of Enantioenriched Functional Aryl Alcohols

Scheme 3.3 Asymmetric Reaction of Methyl $p$-Iodobenzoate with $o$ Methoxybenzaldehyde Catalyzed by $\mathrm{H}_{8} \mathrm{BINOL}-\mathrm{AMs}$.

Scheme 3.4 Asymmetric Reaction of $m$-Iodoanisole with $o$-Methoxybenzaldehyde Catalyzed by $\mathrm{H}_{8}$ BINOL-AMs.

Scheme 3.5 The Asymmetric Reaction of $m$-Iodobenzonitrile with $p$ Methoxybenzaldehyde Catalyzed by the $\mathrm{H}_{8}$ BINOL-AMs.

Scheme 3.6 The Asymmetric Reaction of 2-Iodothiophene with Aldehydes Catalyzed by $\mathrm{H}_{8}$ BINOL-AMs.

Scheme 3.7 Using 2-Bromothiophene for the Asymmetric Arylzinc Addition of Thiophene to Benzaldehyde in the Presence of $(S)-12$ and $\mathrm{ZnEt}_{2}$.

Scheme 3.8 Using Iodobenzene for the Asymmetric Phenylzinc Addition in the Presence of $\mathrm{H}_{8}$ BINOL-AMs.

Scheme 3.9 The Asymmetric Reaction of $m$-Iodoanisole With Cyclohexanecarboxaldehyde Catalyzed by $(S)-2$.

Scheme 4.1 General Results of the Vinylzinc Generation and Catalyzed Addition to Enantioenriched Allylic Alcohols.

Scheme 4.2 Reaction of Vinyl Iodides with Aldehydes in the Presence of $\mathrm{ZnEt}_{2}$. 
Scheme 4.3 The Racemic Synthesis of Allylic Alcohol 92.

Scheme 4.4 1:1 Effect of the Vinyl Iodide to $\mathrm{Et}_{2} \mathrm{Zn}$ Stoichiometry on the Vinylzinc Generation and Catalyzed Addition to Benzaldehyde.

Scheme 4.5 The Absolute Configuration Determination of Alcohol 94.

Scheme 5.1 Methods for the Asymmetric Synthesis of Functional Propargylic Alcohols.

Scheme 5.2 General Enantioselective Alkynylations Catalyzed by BINOL-Salen Ligands.

Scheme 5.3 Proposed Mechanism for Synthesis of Enol-protected Propargylic Alcohol (EPPA).

Scheme 5.4 Proposed Propiolate Dimer Formation.

Scheme 5.5 General Conditions Tested for the Catalyzed Asymmetric Methyl Propiolate Addition to $n$-Octylaldehyde.

Scheme 5.6 Liu and Pu's Highly Enantioselective Phenylacetylene Addition to Aromatic Aldehydes Catalyzed by a $\left[\mathrm{H}_{8} \mathrm{BINOL-AM-Titanium]} \mathrm{Complex.}\right.$

Scheme 6.1 Examples of Ishihara et. al. Selective Additions to Ketones From In Situ Generated Zincate.

Scheme 6.2 Lewis Acid Study for the Asymmetric Thiophenylation of $N$-(4chlorobenzylidene)-4-methylbenzenesulfonamide.

Scheme 6.3 Titanocene Catalyzed Asymmetric Allylzinc Addition to Benzaldehyde in the Presence of Substoichiometric Dilithiated Diamine.

Scheme 6.4 (TMP) $)_{2}$ Zinc Base Formation, Bis(Arene)Zinc Generation and Proposed Addition to Benzaldehyde.

Scheme 6.5 Proposed Allene Formation From a Propargylic Alcohol.

Scheme 6.6 Chemical Addition (Chemisorption) Reaction of Chloro tris(triphenylphosphine)Iridium(I) and Hydrogen-Terminated Silicon Surface.

\section{List of Tables}

Table 3.1 Addition of the Arylzinc Generated from $m$-Iodoanisole to Aldehydes in the Presence of $(S)-2$. 
Table 3.2 Conditions for the Reaction of the Arylzinc Generated from Methyl $p$ Iodobenzoate with Benzaldehyde in the Presence of $(S)-2$.

Table 3.3 Addition of the Arylzinc Generated from Methyl $p$-Iodobenzoate to Aldehydes in the Presence of $(S)-2$.

Table 3.4 Conditions for the Reaction of Arylzinc Generated from $m$-Iodobenzonitrile with Benzaldehyde in the Presence of $(S)-2$.

Table 3.5 Addition of the Arylzinc Generated from $m$-Iodobenzonitrile to Aldehydes in the Presence of $(S)-2$.

Table 3.6 Reaction of Methyl $p$-iodobenzoate and $o$-methoxybenzaldehyde in the presence of $\mathrm{ZnEt}_{2}$ and $\mathrm{H}_{8} \mathrm{BINOL}-\mathrm{AMs}$ to Form 55.

Table 3.7 Reaction of Methyl $p$-iodobenzoate and $o$-chlorobenzaldehyde in the presence of $\mathrm{ZnEt}_{2}$ and the $\mathrm{H}_{8}$ BINOL-AMs to Form 56.

Table 3.8 Comparison of $(S)-2$ and $(S)$-12 for the Asymmetric Reaction of Methyl $p$ iodobenzoate with Additional Aldehydes.

Table 3.9 Reaction of $m$-iodoanisole and $o$-methoxybenzaldehyde in the Presence of $\mathrm{ZnEt}_{2}$ and $\mathrm{H}_{8} \mathrm{BINOL}-\mathrm{AMs}$ to Form 60.

Table 3.10 Reaction of $m$-iodoanisole and additional ortho-substituted Benzaldehydes in the Presence of $\mathrm{ZnEt}_{2}$ and $\mathrm{H}_{8} \mathrm{BINOL-AMs.}$

Table 3.11 Reaction of $m$-iodoanisole and Other Aldehydes in the Presence of $\mathrm{ZnEt}_{2}$ and $(S)-2$ and $(S)-12$.

Table 3.12 Reaction of $m$-iodobenzonitrile and $p$-methoxybenzaldehyde in the Presence of $\mathrm{ZnEt}_{2}$ and $\mathrm{H}_{8} \mathrm{BINOL-AMs}$ to Form 52.

Table 3.13 Reaction of 2-iodothiophene With Aldehydes in the Presence of $\mathrm{ZnEt}_{2}$ and $\mathrm{H}_{8}$ BINOL-AMs.

Table 3.14 Varying the Conditions for the Reaction of 2-iodothiophene and Benzaldehyde in the Presence of $\mathrm{ZnEt}_{2}$ and $(S)-12$.

Table 3.15 The Asymmetric Reaction of 2-bromothiophene and Benzaldehyde in the Presence of $(S)-12$ and $\mathrm{ZnEt}_{2}$ to Form 67.

Table 3.16 Functional Arylations of 2-Methoxybenzaldehyde Catalyzed in the Presence of $(S)-18$. 
Table 3.17 The Asymmetric Reaction Using Iodobenzene and $p$-methoxybenzaldehyde in the Presence of $\mathrm{H}_{8}$ BINOL-AMs to Form 72.

Table 4.1 Catalytic Asymmetric Reaction of $(E)$-iodostilbene with Aldehydes in the Presence of $\mathrm{ZnEt}_{2}$ and $(S)-12$.

Table 4.2 Catalytic Asymmetric Reaction of 1-iodo-1-phenyl-pentene and 1-iodo-1phenyl-propene With Aldehydes in the Presence of $\mathrm{ZnEt}_{2}$ and $(S)-12$.

Table 4.3 Catalytic Asymmetric Reaction of Functional Vinyl Iodides With Aldehydes in the Presence of $\mathrm{ZnEt}_{2}$ and $(S)-12$.

Table 4.4 Catalytic Asymmetric Reaction of 1-iodo-3,4-dihydronaphthalene, a Cyclic Vinyl Iodide, With Aldehydes in the Presence of $\mathrm{ZnEt}_{2}$ and $(S)-12$.

Table 4.5 Conditions Examined for the Generation of a Cyclic Vinylzinc From 1-Iodo3,4-dihydronaphthalene and Catalytic Asymmetric Additions to Benzaldehyde in the Presence of $\mathrm{ZnEt}_{2}$ and $(S)-12$.

Table 5.1 Enol-Protected Propargyl Alcohol 108 Synthesis Catalyzed by $O$-Protected, $N$ methylephedrines.

Table 5.2 Screening of Base Additives for the BINOL-Ti Catalyzed Methyl Propiolate Addition to Octyl Aldehyde.

Table 5.3 Summary of Ligand and Condition Screening Results for the 1-Octyne Addition to Aldehydes.

Table 6.1 Lewis Acid Screen for the Thiophenylzinc Addition to $\mathrm{N}$-(4chlorobenzylidene)-4-methylbenzenesulfonamide.

Table 6.2 Conditions Tested for the Generation of Benzylzinc and Its Reaction With Benzaldehyde in the Presence of Catalytic Ligand $(S)-12$. 


\section{Chapter 1: Introduction}

\section{a. Asymmetric Catalysis \\ b. Bifunctional Catalysis \\ i. Concept of Bifunctional Catalysis \\ ii. BINOL and BINOL-based ligands}

\section{c. References}

\section{a. Asymmetric Catalysis}

The asymmetric synthesis of compounds has been widely reported and pursued. This area of research represents a still growing field of synthetic chemistry. Most notable has been the application of synthetic methods towards the synthesis of natural products that produce some biological effect or key synthetic intermediates of pharmaceuticals, agrochemicals and other biologically relevant chemicals ${ }^{1}$. Furthermore, asymmetric synthesis of optically pure materials such as polymers and macromolecules has been accomplished. Intrinsic to the development of increasing the practicality of a chemical system - economical and overall efficiency — is to decrease the necessary amounts of reacting chemical species. In an exemplary addition reaction where substrate $\mathbf{A}$ is added to substrate $\mathbf{B}$ generating new compound $\mathbf{C}$, only a stoichiometric amount of both $\mathbf{A}$ and B are employed (Equation 1).

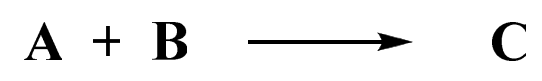

In the case where $\mathbf{C}$ is chiral $\left(\mathbf{C}^{*}\right)$ and a single isomer is desired from racemic or achiral $\mathbf{A}$ and $\mathbf{B}$, then the reaction medium requires the introduction of a source of chirality. To achieve the criteria mentioned above, the source of asymmetric induction must be highly 
selective, obtained readily, and potentially be recyclable. Ultimately, a chiral nonracemic compound that can be supplemented in a catalytic amount is the ideal for theoretical Equation 2.

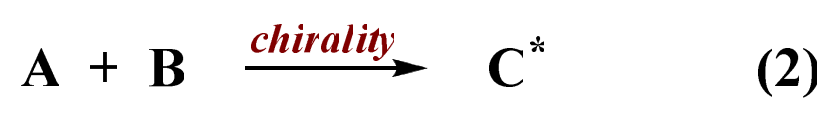

The development of such chiral catalysts describes the field of asymmetric catalysis. This currently represents a broad area of high impact research in synthetic chemistry ${ }^{2}$. The ensuing chapters of this dissertation concentrate on the practical design, development and synthesis of chiral ligands and investigations of their catalytic asymmetric control in various methodologies. This represents our ongoing studies on catalytic asymmetric additions identifying their importance and need in synthetic chemistry ${ }^{3}$.

Systems that efficiently catalyze desired reactivity between selected substrates while simultaneously exhibiting a stereoselective preference in the newly formed stereocenters have been extensively studied over the past two decades. To expand on characteristics of an ideal system, the following features should be considered: utilization of commercially or readily available, inexpensive reagents; employment of catalytic, stereo-discriminatory agents; efficient performance under ambient conditions; applicability across a broad range of substrates while demonstrating chemoselection; afford high yields of compounds in a highly stereoselective fashion; and the generation of minimal waste. Generally, the incorporation of catalytic asymmetric protocols into multi-step (i.e. "total") synthetic preparations or the bulk synthesis of chiral chemicals demonstrates the overall efficacy of the field. The integration of catalytic asymmetric methods can provide access to chirality where the uncatalyzed process does not proceed or is not plausible. This represents a main feature of an asymmetric system operating 
under catalytic control: selective activation of a mode(s) leading to the desired product must be demonstrated. This feature alone describes the fundamental process that occurs in a successful catalytic asymmetric reaction.

The asymmetric synthesis of chemicals has received increasing attention because of the properties they possess, in particular, bioactive molecules that require methodically pure stereochemical preparation ${ }^{4}$. Catalysis has become increasingly important because of a catalyst's ability to achieve a large turnover of substrates cleanly into desired products. Thus, coupling catalysis with asymmetric synthesis provides the synthetic community with methodologies aimed at producing optically pure isomers in an efficient manner, mimicking enzymes, nature's workhorses. The significance of developing catalytic asymmetric synthesis has been recognized. In 2001, three chemists were named Nobel Laureates for their pioneering work: Knowles ${ }^{5}$, Noyori ${ }^{6}$, and Sharpless ${ }^{7}$. The experimental discoveries of these (summarized in the figures below) and other scientists demonstrate the value that the development of catalytic asymmetric methodology has had in chemical synthesis ${ }^{8}$. 
Figure 1.1 Examples of Catalytic Asymmetric Hydrogenations
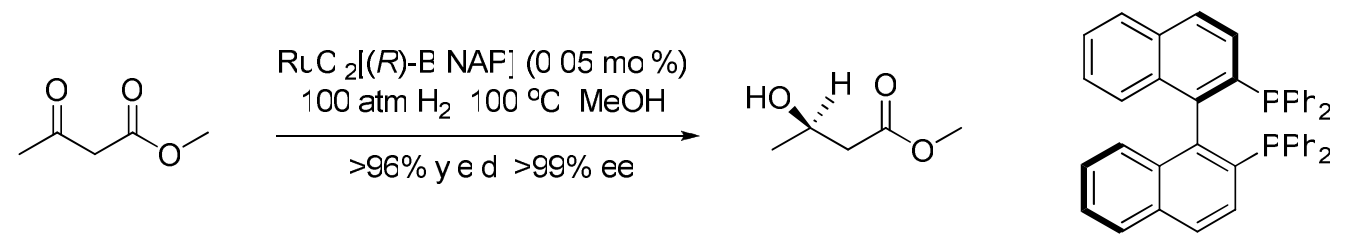

$(R)$-E NAF
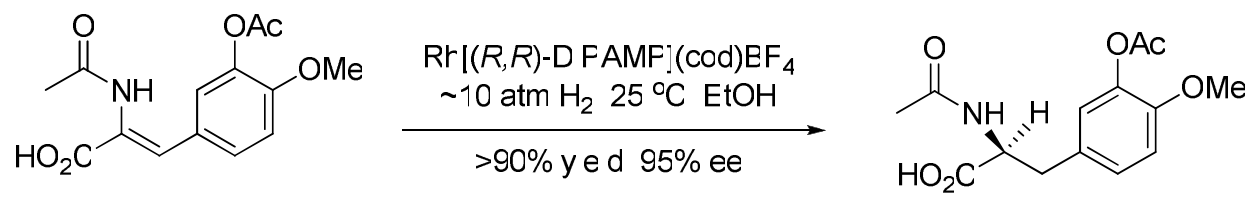

(L)-DOFA precursor

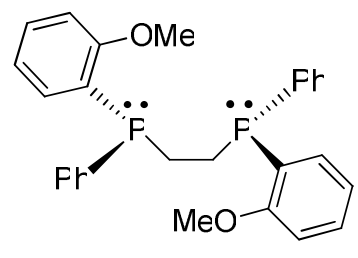

$(R, R)-\mathrm{D}$ FAMF

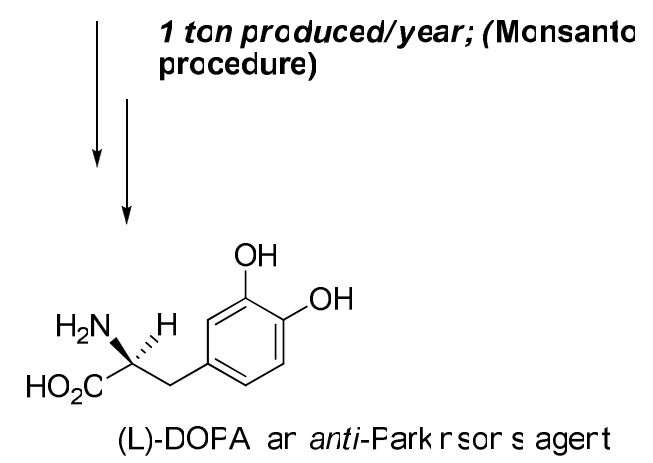

Figure 1.2 Example of Sharpless Asymmetric Epoxidation Catalyzed by Tartrate-

\section{Titanium Complexes}
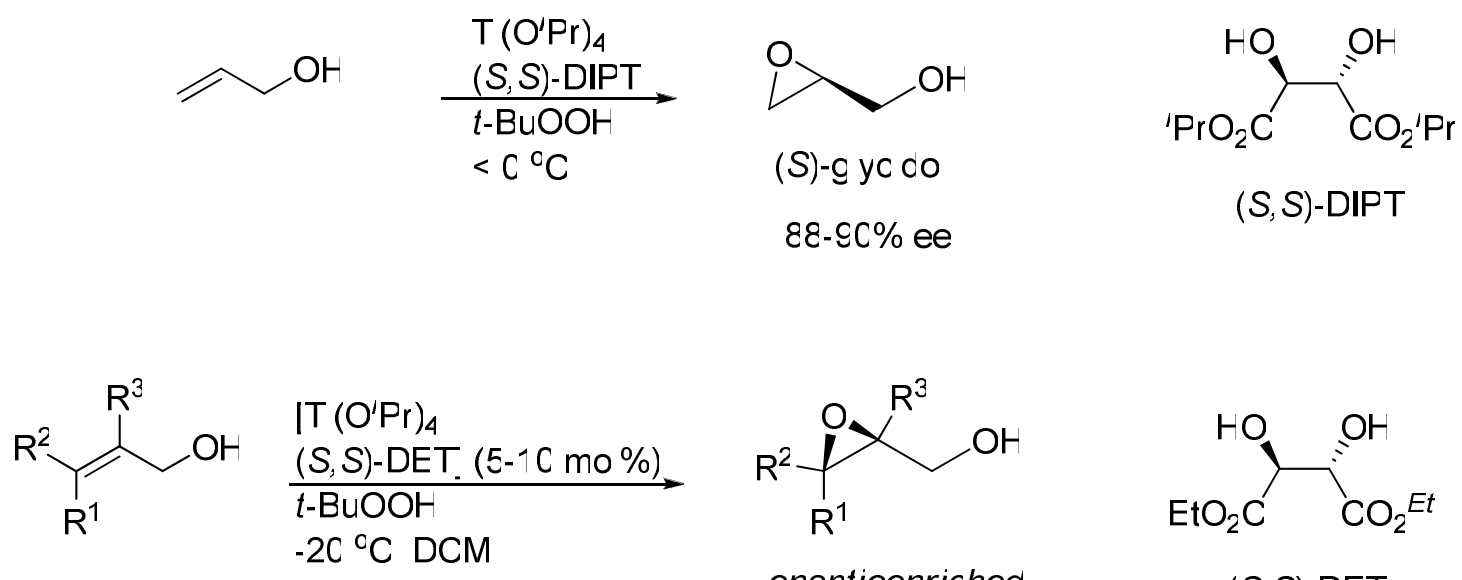<smiles>[R]C1([R])OC1([R])CO</smiles>
enantioenriched epoxide

$65-\mathrm{C} 5 \%$ y e $\mathrm{c}$ ८C-ऽ८\% ee 
This area of research is now expanding from its infancy indicating the enormous potential for continuing research in the field. The number of catalysts described for asymmetric methodological analyses in the literature is well into the thousands of compounds. Advancements will likely center on the identification of simple or complex molecular assemblies that operate under mild, environmentally-friendly conditions and on extensive range substrates.

Catalysts include simple organic molecules, such as single amino acids, organometallic reagents, such as Grubbs' catalysts ${ }^{9}$, and enzymes ${ }^{10}$. Immediately apparent is the variable cost and availability of certain reagents. Certain organic and organometallic ligands require specialized, tedious modification to obtain the desired structure and function. Furthermore, certain transition metals are expensive, harmful, and present disposal issues. Advances have made enzymatic and enzyme-mimic catalysts more readily prepared. However, these reagents are often highly specific and therefore limited in their range of substrate reactivity and effective scope.

\section{b. Bifunctional Catalysis}

\section{i. Concept of Bifunctional/Multifunctional Catalysis}

Many asymmetric methods employ the use of additives to fine-tune reaction features: yields, selectivity, and modification of the reaction temperature. For example, Pu et. al. ${ }^{11}$ discovered the use of HMPA, a polar aprotic compound, for the generation and reaction of a functional (ester) alkynylzinc reagent at room temperature. This was important because the ester-containing alkyne decomposed in previously reported procedures where the alkyne (phenylacetylene) and diethylzinc are heated to reflux in toluene to generate the alkynylzinc. While the simplified procedure had the advantage of 
no separate refluxing step, the system still required a combination of BINOL and a Lewis acid, $\left.\mathrm{TiO}^{i} \mathrm{Pr}\right)_{4}$ along with the alkynylzinc and an additive (HMPA) to achieve high yields and enantioselectivity. The scheme below proposes that this process operates by activating the alkylzinc to deprotonate the alkyne as shown in the scheme below.

\section{Scheme 1.1 Activation of $\mathrm{Et}_{2} \mathrm{Zn}$ by HMPA Additive}

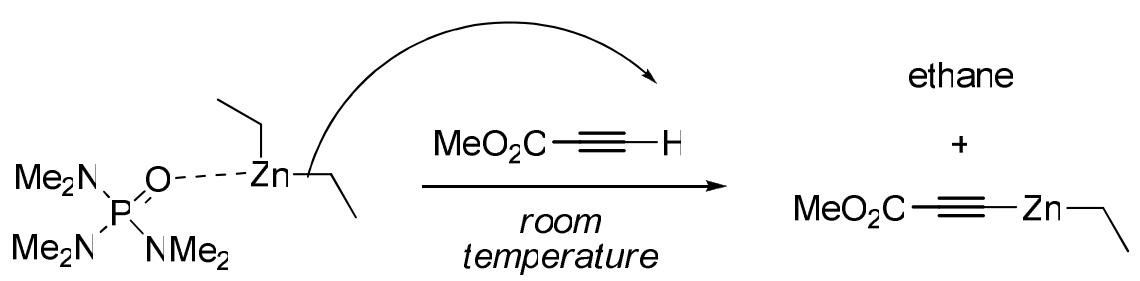

This generally refers to a dual activation strategy ${ }^{\mathbf{1 2}}$. An alternative to using additional additives in the reactions is to modify the structure of the catalyst. The additive function could be incorporated into the catalyst. This should increase the efficiency of a catalytic asymmetric method by decreasing the amount of chemical species required. This represents the concept of bifunctional catalysis ${ }^{13}$. The development of bifunctional catalysts has been a principal area of asymmetric synthetic chemistry. Much research has focused on the discovery of catalytic structures that possess two or more catalytically active and distinct sites. Our research has concentrated on the development of this type of catalyst that are classified as intramolecular bifunctional catalyst. The intramolecular nature has been confirmed by ee linearity correlation experiments (discussed in chapter 3) 14. The figure below introduces general ligand structures that are briefly described below and further discussed in the following chapter. 
Figure 1.3 General Structure of $C_{2}$-Symmetric Ligands (BINOL and BINOL-based) and Example of Intramolecular Independent Bifunctional Ligand

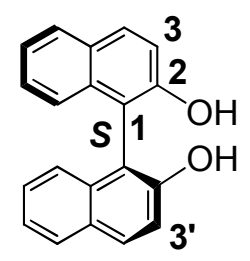

(S)-BINOL

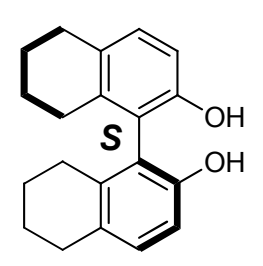

(S)- $\mathrm{H}_{8}$ BINOL

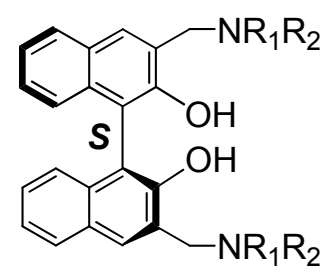

(S)-BINOL-AM

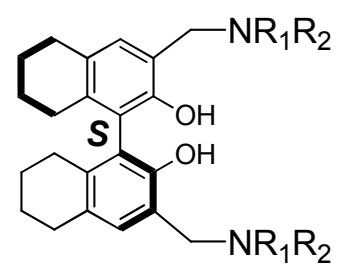

(S)- $\mathrm{H}_{8}$ BINOL-AM

ii. BINOL and BINOL-based Ligands

Optically pure 1,1'-bi-2-naphthol, $(R)$ or $(S)$-BINOL, is a $C_{2}$-symmetric compound ${ }^{15}$. The stereogenic unit in this compound is axial chirality, present because of hindrance to free rotation about the biaryl bond. The research groups of $\mathrm{Pu}$ and others have developed methods for the asymmetric alkylation, arylation, and alkynylation of achiral aldehydes ${ }^{16}$. These additions create a new $\mathrm{C}-\mathrm{C}$ bond and set a stereocenter concomitantly. Most of the systems incorporate BINOL or BINOL-based derivatives and organozincs in the catalytic asymmetric protocols. The acidic sites of BINOL and BINOL-based derivatives react in the presence of organometallic reagents to form a Lewis acid complex which introduces the catalytic chiral environment in the reaction medium. Simple Lewis or Bronsted acids, for example titanium tetraisopropoxide, boron trifluoride, titanium chloride, or $\mathrm{H}^{+}$donors, are commonly used to activate electrophilic substrates. In tandem with a chiral unit such as BINOL, a chiral Lewis acid complex is formed that can provide a platform through which nucleophilic and electrophilic species may proceed to react 
selectively. This practice has been further amended to include attempts to activate the nucleophilic partner (typically organometallic reagent) simultaneously. This defines the concept of bifunctional catalysis which we have pursued extensively. 


\section{d. References:}

1. (a) Noyori, R. Asymmetric Catalysis in Organic Synthesis; Wiley-Interscience: New

York, 1994. (b) Trost, B. PNAS, 2004, 101, 5348.

2. Walsh, P. J.; Kozlowski, M. C. Fundamental of Asymmetric Catalysis; University

Science Books: Sausalito, CA, 2009.

3. Thayer, A. Chem. \& Eng. News, 2005, 83 (36), 40-58.

4. Ager, D. J.; Laneman, S. A. Tetrahedron: Asymmetry 1997, 8, 3327-3355.

5. (a) Knowles, W. S.; Sabacky, M. J. Chem. Commun. 1968, 1445. (b) Vineyard, B. D.;

Knowles, W. S.; Sabacky, M. J.; Bachman, G. L.; Weinkauff, D. J. J. Am. Chem. Soc.

1977, 99, 5946-5952. (c) Knowles, W. S. Acc. Chem. Res. 1983, 16, 106-112.

6. (a) Noyori, R.; Okhuma, T.; Kitamura, M.; Takaya, H.; Sayo, N.; Kumobayashi, H.;

Akuragawa, S. J. Am. Chem. Soc. 1987, 109, 5856-5858.

Kitamura, M.; Tokunaga, M.; Ohkuma, T.; Noyori, R. Org. Synth., 1998, 9, 589.

Kitamura, M.; Tokunaga, M.; Ohkuma, T.; Noyori, R. Org. Synth., 1993, 71, 1.

Takaya, H.; Akutagawa, S.; Noyori, R. Org. Synth., 1993, 8, 57.

Takaya, H.; Akutagawa, S.; Noyori, R. Org. Synth., 1989, 67, 20.

7. (a) Katsuki, T.; Sharpless, K. B. J. Am. Chem. Soc. 1980, 102, 5974.

Rossiter, B.; Katsuki, T.; Sharpless, K. B. J. Am. Chem. Soc. 1981, 103, 464-465.

Martin, V.; Woodard, S.; Katsuki, T.; Yamada, Y.; Ikeda, M.; Sharpless, K. B. J. Am.

Chem. Soc. 1981, 103, 6237-6240.

Finn, M. G.; Sharpless, K. B. J. Am. Chem. Soc. 1991, 113, 113-126.

Johnson, R. A.; Sharpless, K. B. Comp. Org. Syn. 1991, 7, 389-436. 
8. Ahlberg, P. Royal Swedish Academy of Sciences 2001, http://nobelprize.org/nobel_prizes/chemistry/laureates/2001/chemadv.pdf

9. Grubbs, R. H. Tetrahedron, 2004, 60 (34), 7117.

10. Neurath, H. PNAS, 1999, 96 (20), 10962.

11. Gao, G.; Xie, R.; Pu, L. PNAS, 2004, 101, 5417.

12. (a) Shibasaki, M.; Sasai, H.; Arai, T. Angew. Chem. Int. Ed. 1997, 36, 1236.

13. (a) Paull, D. H.; Abraham, C. J.; Scerba, M. T.; Alden-Danforth, E.; Lectka, T.; Acc. Chem. Res.2008, 41, 655-663. (b) Ma, J.-M.; Cahard, D. Angew. Chem. Int. Ed., 2004, 43, 4566-4583. (c) Matsunaga, S.; Ohshima, T.; Shibasaki, M. Adv. Synth. Catal.. 2002, 344, 3-15.

14. (a) Shibasaki, M. ; Matsunaga, S. Chem. Soc. Rev. 2006, 35, 269-279. (b) Connon, S. J. Chem. Commun. 2008, 2499-2510.

15. BINOL-based reviews: (a) Chen, Y.; Yekta, S.; Yudin, A. K. Chem. Rev. 2003, 103, 3155. (b) Brunel, J. M. Chem. Rev. 2005, 105 (3), 857.

16. (a) Pu, L.; Yu, H. Chem Rev. 2001, 101 (3), 757. (b) Pu, L. Tetrahedron, 2003, 59, 9873. (c) Pu, L. Chem. Rev. 1998, 98 (7), 2405. (d) Liu, L.; Pu, L. Tetrahedron, 2004, 60,7427-7430. (e) Qin, Y. Asymmetric Catalysis by Bifunctional BINOL-Based Catalysts, Ph D Chemical Dissertation, 2006, University of Virginia. (f) Li, Z. Enantioselective Fluorescent Sensors for Chiral Acids and Asymmetric Catalysts for Additions to Aldehydes, Ph D Chemical Dissertation, 2006, University of Virginia. (g) Moore, D.; Pu, L. Org. Lett. 2002, 4, 1855. (h) Gao, G.; Moore, D.; Xie, R.; Pu, L. Org. Lett., 2002, 4 (23), 4143. (i) Lu, G.; Li, X.-S.; Chan, W. L.; Chan, A. S. C. J. Chem. Soc., Chem. Commun. 2002, 172. (j) Li, X.-S.; Lu, G.; Kwok, W. H.; Chan, A. S. C. J. Am. 
Chem. Soc., 2002, 124, 12636. (k) Lu, G.; Li, X.-S.; Chen, G.; Chan, W. L.; Chan, A. S. C. Tetrahedron: Asymmetry. 2003, 14, 449. 


\title{
Chapter 2: Synthesis and Characterization of Functionalized $\mathrm{H}_{8}$ BINOL Ligands
}

\author{
a. Introduction to Ligand Design \\ b. Ligand Synthesis: Development of $\mathrm{H}_{8} \mathrm{BINOL-Amine} \mathrm{Family} \mathrm{of} \mathrm{Ligands}$ \\ c. Attempted Kolbe-Schmidt Reaction of $(S)-\mathrm{H}_{8}$ BINOL \\ d. Experimental and Characterization \\ e. References
}

a. Introduction to Ligand Design: Development of $\mathrm{H}_{8} \mathrm{BINOL-Amines}$

1,1'-Bi-2-naphthol (BINOL) and its 3,3'-disubstituted derivatives have been extensively studied in asymmetric catalysis. ${ }^{1}$ The two hydroxyl groups of optically pure BINOL allow easy incorporation of Lewis acidic metal centers to prepare chiral Lewis acid complexes for asymmetric catalysis. Substituents at the 3,3'-positions of BINOL modify both the steric and electronic properties of the Lewis acid complexes and in many cases lead to more efficient chiral catalysts for diverse organic reactions. ${ }^{2}$ Among the 3,3'-substituted BINOL derivatives, compounds containing amino methyl substituents, termed BINOL-AMs, have received special attention in recent years. ${ }^{3}$ The bifunctional nature of these compounds have been studied extensively. They possess a range of activities including action as potent alkylating and DNA cross-linking agents, chiral recognition, and macromolecular studies. ${ }^{4}$ The general structures of these compounds and the structurally-related partially hydrogenated $\left(\mathrm{H}_{8}\right)$ BINOL-AMs are shown in the figure below along with $(S)$-BINOL and $(S)-\mathrm{H}_{8} \mathrm{BINOL}$. 
Figure 2.1. General Structure of BINOL and BINOL-based $C_{2}$-Symmetric Ligands

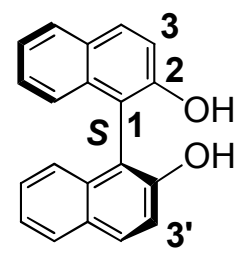

(S)-BINOL

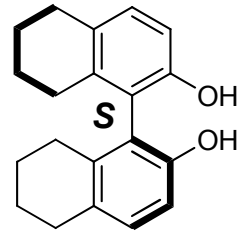

(S)- $\mathrm{H}_{8}$ BINOL<smiles>[R20]NCc1cc2ccccc2c(O)c1-c1c(O)c(CN=[R20])cc2ccccc12</smiles>

(S)-BINOL-AM

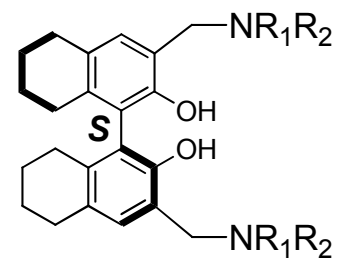

(S)- $\mathrm{H}_{8}$ BINOL-AM

BINOL is a widely used $C_{2}$-symmetric Brönsted acid/Lewis acid precursor in asymmetric catalysis and more recently reported on is the partially hydrogenated derivative $5,5^{\prime}, 6,6^{\prime}$, 7,7', 8,8'-octahydro-BINOL ( $\mathrm{H}_{8}$-BINOL). The differences in the structures of the two compounds have been described by $\mathrm{Chan}^{5}$ and $\mathrm{Walsh}^{6}$. The stability towards racemization of $\mathrm{H}_{8} \mathrm{BINOL}$ is considerably enhanced relative to BINOL. ${ }^{7}$ For example, the crystal structures show a significantly different central biaryl dihedral angle which effectively changes the structures of the ligand and ligand-metal complex. Calculations have shown the difference between BINOL and $\mathrm{H}_{8} \mathrm{BINOL}$ to be greater than $20^{\circ}$ (ChemDraw 3D MM2), whereas the difference between BINOL and $\mathrm{H}_{4} \mathrm{BINOL}$ is only about $5^{\circ}$. Direct comparative studies have been done by $\mathrm{Chan}^{8}$ and $\mathrm{Pu}^{9}$. These studies showed that the increased steric effect of the partially hydrogenated rings of BINOL can demonstrate a higher degree of chiral discrimination than the unsaturated BINOL compounds. Furthermore, the saturation of the rings on BINOL imparts a greater activation to the phenol ring, specifically in that the 3,3'-positions should be more readily 
modified. This feature of optically pure $\mathrm{H}_{8} \mathrm{BINOL}$ also augments the Lewis acidic potential of the ligand-metal complex.

A number of synthetic methods have been developed for the preparation of optically active BINOL-AMs. ${ }^{3}$ Although the most direct method should be the one step Mannich reaction of BINOL with an aminomethanol reagent to generate the 3,3'-BINOLAM, this reaction does not proceed satisfactorily. For example, the synthesis of BINOLAM compound $(S)-\mathbf{1}^{7}$ required an elevated temperature of $110{ }^{\circ} \mathrm{C}$ which led to partial racemization of the BINOL unit. Recrystallization was needed in order to obtain the enantiomerically pure $(S)$-1. However, when the partially hydrogenated BINOL, $(S)$ $\mathrm{H}_{8} \mathrm{BINOL}$, was used, the Mannich reaction with morpholinomethanol could be conducted at a much lower temperature of $60{ }^{\circ} \mathrm{C}$ to produce the optically active $\mathrm{H}_{8} \mathrm{BINOL}-\mathrm{AM}$ compound $(S)$-2 with excellent enantiomeric purity and high yield. Pu et. al. had previously explored the use of $(S)-\mathbf{1}$ and $(S)-\mathbf{2}$ to catalyze the asymmetric reactions of diphenylzinc and alkynylzincs with aldehydes to generate synthetically useful chiral alcohols with high enantioselectivity. ${ }^{10,17}$

The Lewis basic amine atoms in the BINOL-AMs can cooperate with the Lewis acidic metals introduced into the central BINOL unit to enhance the catalytic activity and enantioselectivity when used in asymmetric catalysis. ${ }^{11}$

Figure 2.2. General Structure of $(S)-\mathrm{H}_{8}$ BINOL-AMs.

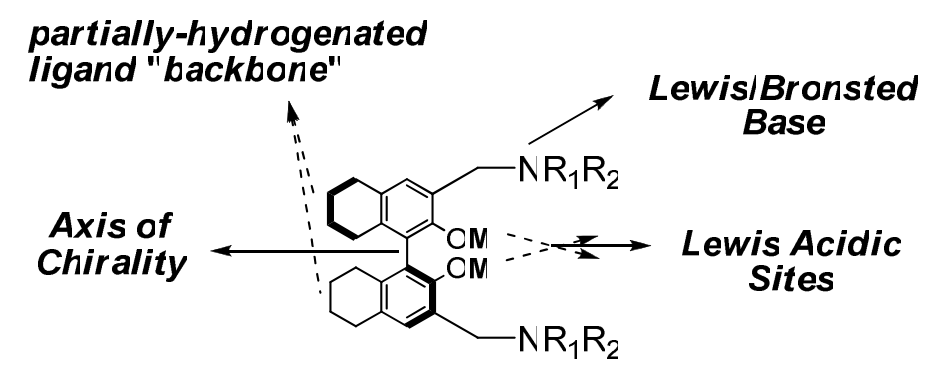


We sought to further expand the synthesis of $(S)-2^{12}$ by introducing structurally diverse 3,3'-bis-aminomethyl groups and studied the use of this family of compounds to catalyze asymmetric organozinc additions to aldehydes. The development of this new $(S)-\mathrm{H}_{8}$ BINOL-AM family of compounds is the subject of this chapter ${ }^{12}$. Attempted syntheses are described in the next section and their catalytic properties are discussed in the following chapters.

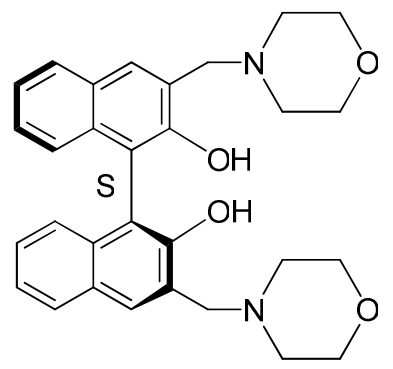

(S)-1

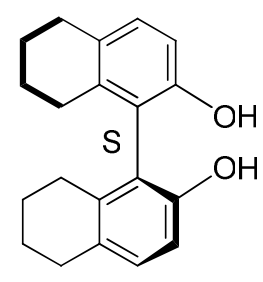

(S)- $\mathrm{H}_{8}$ BINOL

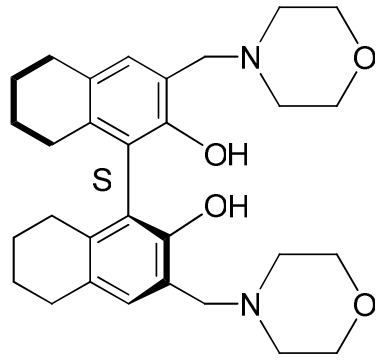

(S)-2

The rationale for the ligand design came from previous results in the Pu Laboratory. $\mathrm{Pu}$ et. al. and others have reported extensively on the use of optically pure 1,1'-bi-2naphthol (BINOL: $R$ - and $S$-) and its derivatives in catalytic asymmetric synthesis and chiral recognition ${ }^{13}$. Examples of catalytic synthetic protocols describe the enantioselective additions to aldehydes using an array of organozincs. Organozincs represent a very useful class of organometallic reagents ${ }^{14}$. Their high degree of functional tolerance allows them to be used in the presence of most functionality where other common organometallic reagents fail, such as Grignards (organomagnesiums) and organolithiums. Various metallic and other additives are sometimes required to obtain high selectivities. ${ }^{15}$ These systems could be classified as multi-functional systems as the catalytic process may be more complex relative to protocols composed of a more straightforward set of reagents. ${ }^{16}$ 
$\mathrm{Pu}, \mathrm{Liu}$, and Qin reported the synthesis and asymmetric catalysis of ligands $(S)-\mathbf{1}$ and $(S)-2^{15 b, 17}$. This is an example of a bifunctional ligand. The reaction of the basic phenol groups with a metallic species provide a Lewis acidic chiral center that works in conjunction with the Lewis basic substituents located at the 3,3'-positions of BINOL. Cooperative effects enhance the reactivity of the reacting electrophile (e.g. carbonylLewis acidic sites) while also activating the nucleophilic species (organometallic reagent; from Lewis basic sites). The concept of bifunctionality and multifunctionality in the design of practical ligands for catalysis has been well-documented in numerous reports and reviews. ${ }^{2}$ Qin and Pu reported the synthesis and asymmetric catalysis of $(S)-2^{17}$. The ligand is prepared in a direct manner from readily available reagents. In a one-pot reaction, morpholinomethanol can be prepared from the reaction of morpholine and paraformaldehyde and then $\mathrm{H}_{8}$-BINOL and dioxane are introduced. The reaction is described in following references. A detailed experimental of the synthesis of $(S)-2$ can be found in Organic Synthesis as described by Mark Turlington. ${ }^{11}$ Key reactivity features identified were the Mannich-type reactivity used to prepare the bifunctional ligand in a multi-step, one-pot reaction, the increased reactivity of $\mathrm{H}_{8}$-BINOL relative to BINOL and the capacity to extend this methodology to the facile synthesis of a new family of bifunctional ligands. $^{12}$

\section{b. Ligand Synthesis: Development of $\mathrm{H}_{8}$ BINOL-Amine Family of Ligands Synthesis of a Family of $\mathrm{H}_{8} B I N O L-A M$ Compounds from the One-Step Mannich Reaction of $\mathrm{H}_{8} \mathrm{BINOL}$}


Scheme 2.1 shows the general scheme used to prepare the $(S)-\mathrm{H}_{8} \mathrm{BINOL}-\mathrm{AM}$ compounds. In the first step, a secondary aliphatic amine is mixed with paraformaldehyde in dioxane at $0{ }^{\circ} \mathrm{C}$ and then heated at $60-90{ }^{\circ} \mathrm{C}$ depending on the amine used. This leads to the formation of an aminomethanol intermediate which can then be heated with the optically pure $(S)-\mathrm{H}_{8} \mathrm{BINOL}$ at varying temperatures, again, depending on the amine used.

\section{Scheme 2.1 General Synthesis of the $\mathrm{H}_{8}$ BINOL-AM Compounds.}

$$
\begin{aligned}
& \mathbf{R}_{1} \mathbf{R}_{2} \mathbf{N H} \underset{\mathbf{R}_{1}, \mathbf{R}_{2}=\text { aky }}{\stackrel{\left(\mathrm{CH}_{2} \mathrm{O}\right)_{n} \text { c oxane }}{\mathrm{C}^{\circ} \mathrm{C} 6 \mathrm{C}-\mathrm{CC}^{\circ} \mathrm{C}}}\left[\mathrm{HOCH}_{2} \mathrm{NR}_{1} \mathbf{R}_{2}\right] \underset{\text { aminomethanol }}{\frac{(\mathrm{S})-\mathrm{H}_{8} \mathrm{BINOL}}{\Delta}} \\
& 45 \text { - } 88 \%
\end{aligned}
$$

This one-pot Mannich reaction quickly produced a family of $\mathrm{H}_{8} \mathrm{BINOL}-\mathrm{AM}$ compounds as listed in Figure 2.3. Among these $\mathrm{H}_{8}$ BINOL-AMs, compounds $(S)-\mathbf{3}-(S)-\mathbf{6}$ are made of acyclic linear and branched aliphatic amines. A series of $N$-alkyl benzylic amines were prepared as compounds $(S)-\mathbf{7}-(S)$-9. $(S)$-10 $-(S)$-17, having structures more closely related to the initially prepared and studied bis(morpholine)- $\mathrm{H}_{8} \mathrm{BINOL}$ ligand $(S$ )2, were prepared from cyclic amines. It was found that in general the less sterically hindered amines react more readily in the preparation of both the aminomethanol intermediate and the $\mathrm{H}_{8} \mathrm{BINOL}-\mathrm{AM}$ products. For example, lower temperature and less time were required for the synthesis of compounds $(S)-\mathbf{4}$ and $(S)$-12, but higher temperature (up to refluxing in dioxane) and longer reaction time were needed to prepare (S)-6 and (S)-9. While imidazole reacted with paraformaldehyde under the normal conditions, the resulting compound failed to react with $\mathrm{H}_{8} \mathrm{BINOL}$ in dioxane at elevated 
temperature. In order to prepare the $\mathrm{H}_{8} \mathrm{BINOL}$-imidazole compound, $(S)-\mathrm{H}_{8} \mathrm{BINOL}$ was heated with imidazole and paraformaldehyde in a sealed tube at $135^{\circ} \mathrm{C}$ which produced the desired product $(S)$-17 without racemization. This demonstrates that $\mathrm{H}_{8} \mathrm{BINOL}$ has a much more stable chiral configuration than BINOL which underwent partial racemization in the preparation of $(S)-\mathbf{1}$ at $110{ }^{\circ} \mathrm{C}$. Compounds $(S)-\mathbf{1 0},(S)-\mathbf{1 1},(S)-\mathbf{1 2},(S)-\mathbf{1 3}$ and $(S)$ 15 containing cyclic amines similar to the previously reported $(S)-\mathbf{2}$ were purified by recrystallization. Compounds $(S)-\mathbf{3},(S)-\mathbf{4},(S)-5,(S)-\mathbf{6},(S)-\mathbf{7},(S)-\mathbf{8}$ and $(S)-9$ containing acyclic amines proved to be more difficult to purify. After workup of their synthesis, the resulting oily residues could not form crystals. Column chromatography on alumina or silica gel was necessary in order to remove a sufficient amount of the excess amino alcohols before recrystallization. Compound $(S)$-14 was prepared from the corresponding enantiomerically pure secondary amine (initially prepared in a multi-step synthesis from L-proline), but compounds $(S)$-15 and $(S)$-16 were made from the corresponding racemic amines and they contained a mixture of diastereomers. The ${ }^{1} \mathrm{H}$ and ${ }^{13} \mathrm{C}$ NMR spectrums collected for these two ligands, $(S)-\mathbf{1 5}$ and $(S)-\mathbf{1 6}$, showed an equal diastereomeric mixture of compounds. (S)-15 was synthesized from a racemic mixture of 2methylpyrrolidine. $(S)$-16 was synthesized from octahydro-1H-indole containing a cisfused ring system, which had initially been prepared from the heterogeneous reduction of indoline. The preparation of $(S)-\mathbf{2}$ was also scaled up with the use of $5 \mathrm{~g}$ of $(S)-\mathrm{H}_{8} \mathrm{BINOL}$ which gave $(S)-2$ in $90 \%$ yield, $>99 \%$ ee and $99 \%$ purity. $^{11}$ 
Figure 2.3 Structures of the Newly Prepared Structurally Diverse $\mathrm{H}_{8}$ BINOL-AM

\section{Compounds.}

Compounds made of acyclic aliphatic amines:<smiles>CCN(CC)Cc1cc2c(c(-c3c(O)c(CN(CC)CC)cc4c3CCCC4)c1O)CCCC2</smiles>

(S)-3 88\%<smiles>CCCCCN(CCCC)Cc1cc2c(c(-c3c(O)c(CN(CCCC)CCCC)cc4c3CCCC4)c1O)CCCC2</smiles>

(S)-4 60\%<smiles>CC(C)N(C)Cc1cc2c(c(-c3c(O)c(CN(C(C)C)C(C)C)cc4c3CCCC4)c1O)CCCC2</smiles>

(S)-5 $60 \%$<smiles>Oc1c(CN(c2ccccc2)c2ccccc2)cc2c(c1-c1c(O)c(CN(c3ccccc3)c3ccccc3)cc3c1CCCC3)CCCC2</smiles>

Compounds made of benzylic amines:<smiles>CN(Cc1ccccc1)Cc1cc(CN(C)Cc2ccccc2)c(O)c(-c2c(O)c(CN(C)Cc3ccccc3)cc3c2CCCC3)c1O</smiles><smiles>CCN(Cc1ccccc1)Cc1cc2c(c(-c3c(O)c(CN(CC)Cc4ccccc4)cc4c3CCCC4)c1O)CCCC2</smiles><smiles>CC(C)N(Cc1ccccc1)Cc1cc2c(c(-c3c(O)c(CN(Cc4ccccc4)C(C)C)cc4c3CCCC4)c1O)CCCC2</smiles>

Compounds made of cyclic amines:<smiles>Oc1c(CN2CCSCC2)cc2c(c1-c1c(O)c(CN3CCSCC3)cc3c1CCCC3)CCCC2</smiles>

$(S)-10 \quad 60 \%$<smiles>COC[C@@H]1CCCN1Cc1cc2c(c(-c3c(O)c(CN4CCC[C@@H]4COC)cc4c3CCCC4)c1O)CCCC2</smiles><smiles>Oc1c(CN2CCCCC2)cc2c(c1-c1c(O)c(CN3CCCCC3)cc3c1CCCC3)CCCC2</smiles>

$(S)-11 \quad 81 \%$<smiles>CC1CCCN1Cc1cc2c(c(-c3c(O)c(CN4CCCC4C)cc4c3CCCC4)c1O)CCCC2</smiles><smiles>Oc1c(CN2CCCC2)cc2c(c1-c1c(O)c(CN3CCCC3)cc3c1CCCC3)CCCC2</smiles>

(S)-12 70\%<smiles>Oc1c(CN2CCC3CCCCC32)cc2c(c1-c1c(O)c(CN3CCC4CCCCC43)cc3c1CCCC3)CCCC2</smiles>

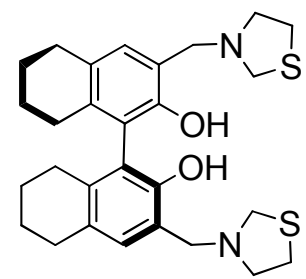

(S)-13 50\%<smiles>Oc1c(Cn2ccnc2)cc2c(c1-c1c(O)c(Cn3ccnc3)cc3c1CCCC3)CCCC2</smiles>

$(S)-17 \quad 82 \%$

A commercially available chiral starting reagent, L-(-)-norephedrine ((1R, 2S)-(-)norephedrine), was used to highlight the practicality of the ligand synthetic strategy.

From an acyclic source of chirality, it is demonstrated that a chiral secondary amine cycle 
could be formed with one equivalent of paraformaldehyde and subsequent reaction between this compound and another equivalent of paraformaldehyde could form the aminomethanol directly in one-pot. The ligand preparation is accomplished in the same manner as the other ligands with the addition of $(S)-\mathrm{H}_{8} \mathrm{BINOL}$ and dioxane (done in the one pot without purification between steps). This is shown in Scheme 2.2.

\section{Scheme 2.2. Synthesis of a Chiral-Armed $\mathrm{H}_{8}$ BINOL-AM Compound}

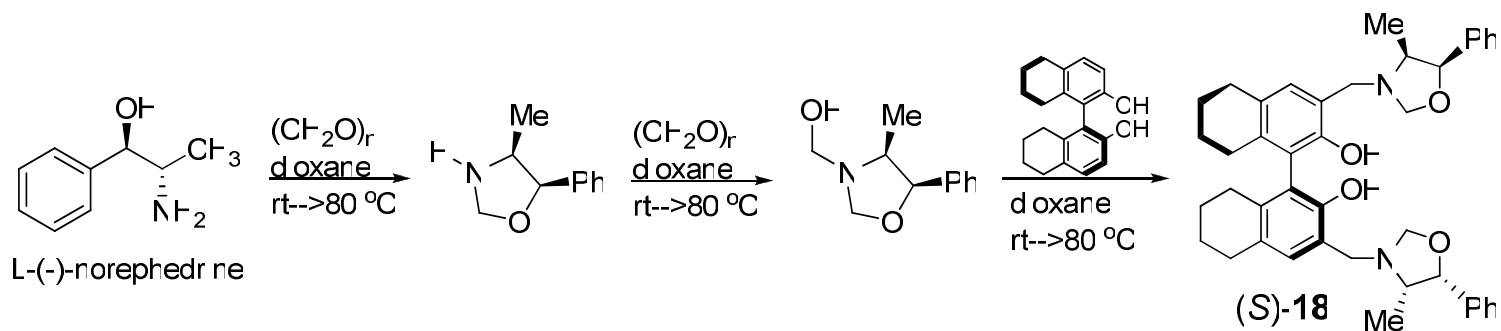

Thus, an optically pure ligand was prepared with multiple stereocenters within the amine "arms" introduced from a commercially available starting material. This represents the potential of this strategy to synthesize a class of compounds incorporating chirality in a one-pot, multi-step reaction where a cyclic amine and aminomethanol are formed by sequential reaction with paraformaldehyde.

\section{Synthesis of a $H_{8} B I N O L-A M$ Compound Containing Secondary Amine Substituents}

A $\mathrm{H}_{8} \mathrm{BINOL}-\mathrm{AM}$ compound containing two secondary amine groups at the 3,3'positions was also prepared to compare its catalytic property with the tertiary aminesubstituted compounds. The secondary amines contain a less sterically crowded environment and are also electronically distinct. The use of a primary amine in combination with paraformaldehyde could not undergo the Mannich-type reaction with $\mathrm{H}_{8} \mathrm{BINOL}$ like that shown in Scheme 2.1 to generate the corresponding amine-substituted $\mathrm{H}_{8} \mathrm{BINOL}-\mathrm{AM}$. Therefore, a multi-step synthesis was conducted to prepare such a compound as shown in Scheme 2.3 below. 
Scheme 2.3 Synthesis of the Secondary Amine-Substituted $\mathrm{H}_{8}$ BINOL-AM

\section{Compound $(S)-21$.}

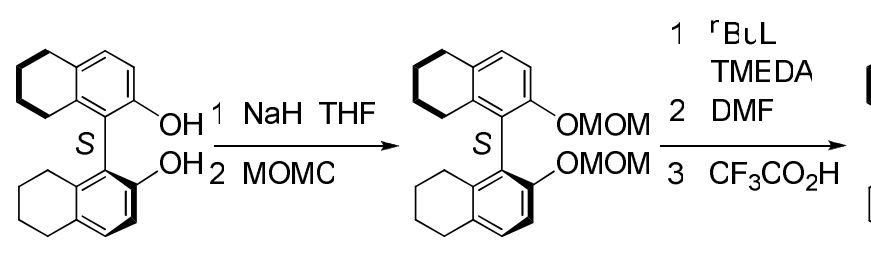

(S)- $\mathrm{H}_{8} \mathrm{E}$ NOL
(S)-19

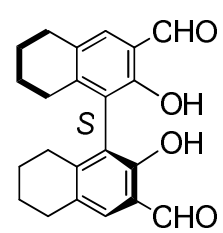

(S)-20

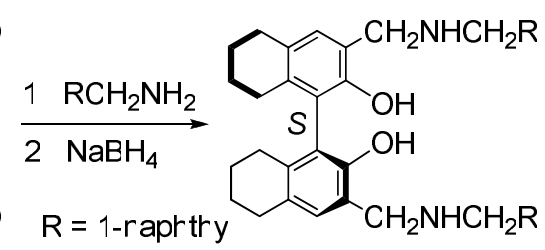

(S)-21

$(S)-\mathrm{H}_{8}$ BINOL was first protected with methoxymethyl groups to yield $(S)$-19. Treatment of $(S)-19$ with ${ }^{\mathrm{n}}$ BuLi and TMEDA followed by reaction with DMF and acidic deprotection (TFA in DCM) afforded the 3,3'-diformylH ${ }_{8} \mathrm{BINOL}(S)$-20. Reaction of (S)-20 with 1-naphthylmethylamine followed by reduction with $\mathrm{NaBH}_{4}$ results in the final synthesis of $\mathrm{H}_{8}$ BINOL-AM derivative $(S)$-21 that contains 3,3'-bis-secondary amine substituents.

\section{c. Attempted Kolbe-Schmidt Reaction of (S)-H $\mathrm{H}_{8} \mathrm{BINOL}$}

The Kolbe-Schmidt reaction ${ }^{18}$ is a base-promoted carboxylation of phenolic substrates. Conditions were applied to $(S)-\mathrm{H}_{8} \mathrm{BINOL}$. Following a reference for the carboxylation of $m$-rescorcinol, $(S)-\mathrm{H}_{8}$ BINOL was heated in a stainless steel, high pressure Parr vessel ("bomb”) with potassium carbonate, potassium bicarbonate, 90 psi ( $\sim 6 \mathrm{~atm}) \mathrm{CO}_{2}$, and glycerol. After 5 hours mixing at $90{ }^{\circ} \mathrm{C}$, no reaction was observed. The reaction was loaded to $50 \mathrm{~atm} \mathrm{CO}_{2}$ and heated to $130^{\circ} \mathrm{C}$ but again resulted in no reaction. $(S)-\mathrm{H}_{8} \mathrm{BINOL}$ was reacted with 2.5 equivalents sodium in toluene overnight in the Parr vessel at room temperature. After this, the vessel was loaded with 100 psi $(\sim 7$ atm) $\mathrm{CO}_{2}$ and heated to $130{ }^{\circ} \mathrm{C}$. After 10 hours at this temperature, the vessel was cooled 
and excess pressure was released. The reaction mixture showed mostly starting material with a small amount of a highly polar new compound. The reaction was stopped to analyze the ee of the starting material $\left((S)-\mathrm{H}_{8} \mathrm{BINOL}\right)$ and attempt to isolate the new compound. $65 \%$ of $(S)-\mathrm{H}_{8}$ BINOL was recovered. HPLC analysis (chiralcel OD column; 2\% IPA in hexanes; $0.5 \mathrm{~mL} / \mathrm{min} ; R T s: 28,30 \mathrm{~min}$ ) showed it had not racemized with $99 \%$ ee. The new spot was separated and determined to be the mono-substituted carboxylic acid- $(S)-\mathrm{H}_{8} \mathrm{BINOL}((S)-\mathbf{2 1})$ with $9 \%$ isolated yield. We then performed the reaction using 5 equivalents sodium with $(S)-\mathrm{H}_{8} \mathrm{BINOL}$ in xylenes. After overnight, the contents were loaded in the Parr vessel with 105 psi $\mathrm{CO}_{2}$ and heated to $135-140{ }^{\circ} \mathrm{C}$. After 24 hours, only starting material was observed. No reaction had taken place. No reaction occurred when $(S)-\mathrm{H}_{8}$ BINOL was mixed with 3 equivalents sodium hydride in toluene, pressurized with 100 psi $\mathrm{CO}_{2}$ and heated to $150{ }^{\circ} \mathrm{C}$.

\section{Summary:}

In summary, a family of optically active $\mathrm{H}_{8} \mathrm{BINOL-AM}$ compounds containing 3,3'-tertiary amine substituents has been prepared. This was accomplished by the Mannich reaction between amino methanols and $\mathrm{H}_{8} \mathrm{BINOL}$ and was based on a chiral ligand shown previously $y^{5,8,17}$ to be an effective ligand in asymmetric catalytic procedures. A method to synthesize a compound with a 3,3'-secondary amine substituent was also accomplished but in a multi-step ( 5 steps) reaction procedure highlighting the efficiency of the tertiary amine-derived $\mathrm{H}_{8}$ BINOL compounds. The ability of the $\mathrm{H}_{8}$ BINOL-AM compounds to catalyze a number of different reactions, such as the asymmetric addition of in situ generated arylzincs or vinylzincs from aryl iodides or vinyl iodides, 
respectively, and $\mathrm{ZnEt}_{2}$ with a variety of aldehydes was studied. The objective is to extend the practicality of designing and synthesizing ligands directly from commercially available starting reagents to the identification of asymmetric catalysis. The prepared ligand family was applied in studies to report simple, practical, and generally useful protocols for the highly enantioenriched synthesis of chiral substrates.

We have shown the successful application of the one-step synthetic strategy to prepare a range of compounds with sterically diverse structures. Both steric and electronic limitations were identified. A modified procedure was found by Mark Turlington to prepare electronically diverse tertiary compounds, for example, ligand $(S)$ 17. However, this procedure failed to yield the desired compound for the bulkier, unreactive aminomethanols. L-(-)-norephedrine was also used as an optically pure and commercially available amino alcohol to synthesize a chiral $\mathrm{H}_{8} \mathrm{BINOL}-\mathrm{AM}$ compound, (S)-18, demonstrating the introduction of additional chirality within the amine "arms". The ability of the $\mathrm{H}_{8}$ BINOL-AM compounds to catalyze a number of different reactions, such as the asymmetric addition of in situ generated arylzincs or vinylzincs from aryl iodides or vinyl iodides, respectively, and $\mathrm{ZnEt}_{2}$ with a variety of aldehydes will be discussed in the following chapters. 


\section{d. Experimental and Characterization}

\section{General Data and Instrumentation}

The following instrumentation was used for the analysis of compounds: ${ }^{1} \mathrm{H}$ and ${ }^{13} \mathrm{C}$ NMR spectra were collected on Varian $300 \mathrm{MHz}$ and Burger $500 \mathrm{MHz}$. Optical rotation measurements were taken on a Jasco digital polarimeter P-2000. All reactions were carried out under nitrogen. Unless otherwise noted, all chemicals were purchased from SigmaAldrich, Alfa Aesar, Strem Chemical, Acros Organics, or TCI America. THF was distilled over sodium and benzophenone under nitrogen and stored over activated $4 \AA$ molecular sieves. The pressurized reactions were carried out in a Parr Non-Stirred Pressure Vessel (Series 4750 1.50” ID). High resolution mass spectral (HRMS) data were obtained from University of California, Riverside (UCR) Mass Spectrometry Facility. Some samples were spiked with ammonium acetate accounting for observation of $\left[\mathrm{MNH}_{4}^{+}\right] \cdot\left[\mathrm{MH}^{+}\right],[\mathrm{M}-\mathrm{H}]^{+}$, or $[\mathrm{M}-\mathrm{OH}]^{+}$ions were otherwise observed (ESI). These samples were dissolved in $\mathrm{MeOH}$ and injected into a $\mathrm{MeOH}$ stream leading to the instrument. ESI/APCI methods were used and analysis performed by Agilent LCTOF. HRMS for compounds $(S)-\mathbf{1 7}$, SI-3, and SI-17 were measured at the University of Illinois (at Urbana-Champaign) Mass Spectrometry Laboratory. (S)-17 was analyzed by ESI.

SI-3 and SI-17 were analyzed by EI.

Copies of ${ }^{1} \mathrm{H}$ and ${ }^{13} \mathrm{C}$ NMR spectra of the ligands and preliminary preparations are included in the Appendix.

\section{Synthesis and Characterization of $\mathrm{H}_{8} B I N O L-A m i n e$ Ligands}

(S)-2 (S)-3,3'-bis-morpholinomethyl-5,5',6,6', 7,7', 8, 8' -octahydro-1,1'-bi-2-naphthol; 
The synthesis and characterization for this ligand has been published previously. For a detailed procedure on a 5 gram scale synthesis of this ligand, see reference $\mathbf{1 2}$.

\section{$(S)-3$}<smiles>CCN(CC)Cc1cc2c(c(-c3c(O)c(CN(CC)CC)cc4c3CCCC4)c1O)CCCC2</smiles>

(S)-3,3'-bis((diethylamino)methyl)-5, 5',6,6',7,7',8,8'-

octahydro-1,1'-binaphthyl-2,2'-diol;

Paraformaldehyde ( $3.4 \mathrm{mmol}, 102.1 \mathrm{mg}, 5$ equiv) was added to a 2-neck round bottom flask fitted with condenser under nitrogen. The flask was then charged with dioxane (5 $\mathrm{mL}$ ) and the mixture was cooled to $0{ }^{\circ} \mathrm{C}$. Diethylamine ( $3.4 \mathrm{mmol}, 353 \mu \mathrm{L}, 5$ equiv) was added dropwise into the mixture cautiously over 15 - 20 min. After the addition was complete, the ice bath was removed and the mixture was warmed to room temperature for 30 min. It was then heated at $50{ }^{\circ} \mathrm{C}$ for about $20 \mathrm{~h}$ during which a slightly-colored solution formed. After the solution was cooled to room temperature, $(S)-\mathrm{H}_{8} \mathrm{BINOL}$ (200 $\mathrm{mg}, 0.68 \mathrm{mmol}$ ) was added and the resulting solution was reheated to $60^{\circ} \mathrm{C}$ for $12 \mathrm{~h}$. Upon completion of the reaction, $\mathrm{CH}_{2} \mathrm{Cl}_{2}(50 \mathrm{~mL})$ was added to the reaction mixture. The organic fraction was washed with $\mathrm{NaHCO}_{3}$ (saturated, aq) $(3 \times 35 \mathrm{~mL})$ and $\mathrm{H}_{2} \mathrm{O}(3 \times$ $50 \mathrm{~mL}$ ). The organic layer was then dried over $\mathrm{Na}_{2} \mathrm{SO}_{4}$, filtered, and concentrated. The residual oil was dissolved in a minimal amount of ethyl acetate and passed through an alumina column eluted with hexanes/ethyl acetate (3-5\%) to give pure $(S)-\mathbf{3}$ as a white powder in $88 \%$ yield. ${ }^{1} \mathrm{H}$ NMR $\left(300 \mathrm{MHz}, \mathrm{CDCl}_{3}\right) \delta 11.13(\mathrm{bs}, 2 \mathrm{H}), 6.70(\mathrm{~s}, 2 \mathrm{H}), 3.86$ (d, $J=14.1 \mathrm{~Hz}, 2 \mathrm{H}), 3.64(\mathrm{~d}, J=14.1 \mathrm{~Hz}, 2 \mathrm{H}), 2.73(\mathrm{~m}, 4 \mathrm{H}), 2.59(\mathrm{~m}, 8 \mathrm{H}), 2.44(\mathrm{~m}, 2 \mathrm{H})$, $2.18(\mathrm{~m}, 2 \mathrm{H}), 1.71(\mathrm{~m}, 8 \mathrm{H}), 1.07(\mathrm{t}, J=7.2 \mathrm{~Hz}, 12 \mathrm{H}) .{ }^{13} \mathrm{C} \mathrm{NMR}\left(75 \mathrm{MHz}, \mathrm{CDCl}_{3}\right) 152.2$, $135.3,128.1,126.7,124.0,119.1,57.0,46.0,29.2,26.8,23.2,14.0 .[\alpha]_{\mathrm{D}}{ }^{25}=-55.6(\mathrm{c}=$ 
0.995, THF). m.p. $95-100{ }^{\circ} \mathrm{C}$. HRMS calcd. for $\mathrm{C}_{30} \mathrm{H}_{44} \mathrm{~N}_{2} \mathrm{O}_{2}+\mathrm{H}$ : 465.3476 . Found for $\mathrm{MH}^{+}: 465.3481$.

$(S)-4$

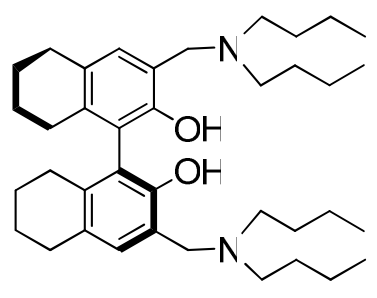

(S)-3,3'-bisdibutylamino-5,5', 6,6', 7,7', 8,8'-octahydro-1,1'-

bi-2-naphthol;

Paraformaldehyde (301 mg, $10.0 \mathrm{mmol}, 5$ equiv) was added to a 2-neck round bottom flask fitted with condenser under nitrogen. The flask was then charged with dioxane (6 $\mathrm{mL})$ and the mixture was cooled to $0{ }^{\circ} \mathrm{C}$. Dibutylamine (1.7 mL, $10.0 \mathrm{mmol}, 5$ equiv) was added dropwise into the mixture cautiously over $15-20 \mathrm{~min}$. In order to prevent the complete freezing of the reaction mixture, the addition was conducted in the following fashion: The ice bath was removed followed by the addition of a few drops of amine, and was then replaced. After the addition was complete, the mixture was warmed to room temperature for $30 \mathrm{~min}$ then heated at $75^{\circ} \mathrm{C}$ for $22 \mathrm{~h}$. An amber-colored, viscous solution formed which was cooled to room temperature and $(S)-\mathrm{H}_{8}$ BINOL (590 mg, 2.01 mmol) was added. The solution was reheated to $75{ }^{\circ} \mathrm{C}$ for $41 \mathrm{~h}$. Upon completion of the reaction, $\mathrm{CH}_{2} \mathrm{Cl}_{2}(50 \mathrm{~mL})$ was added, and the organic fraction was washed with $\mathrm{NaHCO}_{3}$ (saturated, aq) $(3 \times 35 \mathrm{~mL})$ and $\mathrm{H}_{2} \mathrm{O}(2 \times 35 \mathrm{~mL})$. The organic layer was then dried over $\mathrm{Na}_{2} \mathrm{SO}_{4}$, filtered, and concentrated. The residual oil was dissolved in a minimal amount of ethyl acetate and passed through an alumina column eluted with hexanes/ethyl acetate (5\%). This column chromatography separation was repeated to give $(S)-4$ as a white powder in $60 \%$ yield. ${ }^{1} \mathrm{H}$ NMR $\left(300 \mathrm{MHz}, \mathrm{CDCl}_{3}\right) \delta 10.89(\mathrm{~s}, 2 \mathrm{H}), 6.56(\mathrm{~s}, 2 \mathrm{H}), 3.92(\mathrm{~d}$, $J=13.8 \mathrm{~Hz}, 2 \mathrm{H}), 3.47(\mathrm{~d}, J=13.9 \mathrm{~Hz}, 2 \mathrm{H}), 2.73(\mathrm{~m}, 4 \mathrm{H}), 2.54(\mathrm{~m}, 4 \mathrm{H}), 2.37(\mathrm{~m}, 6 \mathrm{H})$, 
$2.11(\mathrm{~m}, 2 \mathrm{H}), 1.69(\mathrm{~m}, 8 \mathrm{H}), 1.46(\mathrm{~m}, 8 \mathrm{H}), 1.25(\mathrm{~m}, 8 \mathrm{H}), 0.85(\mathrm{t}, J=8.3 \mathrm{~Hz}, 12 \mathrm{H}) .{ }^{13} \mathrm{C}$ NMR $\left(75 \mathrm{MHz}, \mathrm{CDCl}_{3}\right) \delta 152.5,135.2,128.1,126.6,123.9,119.2,58.4,53.1,29.2,28.7$, 26.8, 23.2, 20.6, 14.0. $[\alpha]_{\mathrm{D}}{ }^{25}=-13.5\left(\mathrm{c}=0.955\right.$, THF). m.p. 88-93 ${ }^{\circ} \mathrm{C}$. Anal. Calcd. for $\mathrm{C}_{38} \mathrm{H}_{60} \mathrm{~N}_{2} \mathrm{O}_{2}$ : C, 79.11; H, 10.48; N, 4.86. Found: C, 79.17; H, 10.68; N, 4.79. HRMS calcd. for $\mathrm{C}_{38} \mathrm{H}_{60} \mathrm{~N}_{2} \mathrm{O}_{2}+\mathrm{H}: 577.4733$. Found for $\mathrm{MH}^{+}: 577.4735$.

$(S)-5$

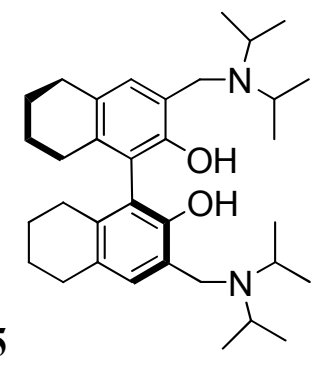

(S)-3,3'-bis((diisopropylamino)methyl)-5, 5',6,6',7,7', $8,8^{\prime}-$

octahydro-1,1'-binaphthyl-2,2'-diol;

Paraformaldehyde $(50 \mathrm{mmol})$ was added to a 2-neck round bottom flask fitted with condenser and vacuum adaptor. Dioxane $(10 \mathrm{~mL}$, degassed) was added.

Diisopropylamine $(50 \mathrm{mmol}, 7.07 \mathrm{~mL})$ was added dropwise over $60 \mathrm{~min}$ at room temperature with aggressive stirring. The mixture was then heated gently to $60^{\circ} \mathrm{C}$. After $16 \mathrm{~h}$, a clear solution was obtained which was then cooled to room temperature and charged with $(S)-\mathrm{H}_{8} \mathrm{BINOL}(1.47 \mathrm{~g}, 5 \mathrm{mmol})$. The solution was heated at $60{ }^{\circ} \mathrm{C}$ for $17 \mathrm{~h}$ and then at $80{ }^{\circ} \mathrm{C}$ for $24 \mathrm{~h}$. After the same workup as in the preparation of $(S)-4$, the oily residue was dissolved in a minimal amount of ethyl acetate and passed through an alumina column eluted with hexanes/acetone (5\%). This chromatography purification was repeated two more times to give pure $(S)-5$ as a light powdery white solid in $60 \%$ yield. ${ }^{1} \mathrm{H}$ NMR (300 MHz, $\left.\mathrm{CDCl}_{3}\right) \delta 11.26(\mathrm{~s}, 2 \mathrm{H}), 6.70(\mathrm{~s}, 2 \mathrm{H}), 3.87$ (d, $J=14.7 \mathrm{~Hz}$, 2H), $3.77(\mathrm{~d}, J=14.4 \mathrm{~Hz}, 2 \mathrm{H}), 3.15$ (septet, $J=6.6 \mathrm{~Hz}, 4 \mathrm{H}), 2.70(\mathrm{~m}, 4 \mathrm{H}), 2.44(\mathrm{~m}, 2 \mathrm{H})$, $2.13(\mathrm{~m}, 2 \mathrm{H}), 1.69(\mathrm{~m}, 8 \mathrm{H}), 1.07(\mathrm{~d}, \mathrm{~J}=6.6 \mathrm{~Hz}, 12 \mathrm{H}), 1.06(\mathrm{~d}, J=6.6 \mathrm{~Hz}, 12 \mathrm{H}) .{ }^{13} \mathrm{C}$ 
NMR (75 MHz, $\left.\mathrm{CDCl}_{3}\right) \delta 153.2,135.1,128.3,126.5,123.8,119.4,48.4,47.2,29.2,26.8$, 23.3, 19.9, 19.4. $[\alpha]_{\mathrm{D}}{ }^{25}=-54.9(\mathrm{c}=0.925$, THF $)$ m.p. $184-188^{\circ} \mathrm{C}$. HRMS calcd. for $\mathrm{C}_{34} \mathrm{H}_{52} \mathrm{~N}_{2} \mathrm{O}_{2}+\mathrm{H}: 521.4102$. Found for $\mathrm{MH}^{+}: 521.4106$.

\section{$(S)-6$}

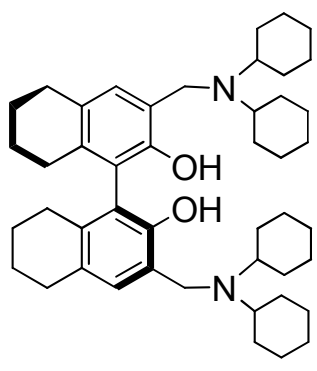

(S)-3,7'-bis((dicyclohexylamino)methyl)-5, 5',6,6', 7,7',8, '-

octahydro-1,5'-binaphthyl-2,6'-diol;

Dicyclohexylamine $(75 \mathrm{mmol})$ was added to paraformaldehyde $(75 \mathrm{mmol})$ under nitrogen at $0{ }^{\circ} \mathrm{C}$. The resulting mixture was stirred at room temperature for another hour and heated at $60{ }^{\circ} \mathrm{C}$ for $2 \mathrm{~d}$. Then, at room temperature $(S)-\mathrm{H}_{8} \mathrm{BINOL}$ and degassed dioxane were added. The reaction mixture was heated at $70{ }^{\circ} \mathrm{C}$ for $24 \mathrm{~h}$ and further heated at reflux for another $12 \mathrm{~h}$. The reaction was shown to be complete by ${ }^{1} \mathrm{H}$ NMR spectroscopy. After the same work-up and purification as in the preparation of $(S)-\mathbf{4}$, the product was further purified by recrystallization in ethanol. Two crops of $(S)-6$ were obtained as a white solid in $55 \%$ yield. One additional column chromatography was necessary to fully purify $(S)-6 .{ }^{1} \mathrm{H}$ NMR $\left(300 \mathrm{MHz}, \mathrm{CDCl}_{3}\right) \delta 11.26(\mathrm{~s}, 2 \mathrm{H}), 6.62(\mathrm{~s}, 2 \mathrm{H})$, $3.99(\mathrm{~d}, J=14.1 \mathrm{~Hz}, 2 \mathrm{H}), 3.79(\mathrm{~d}, J=14.4 \mathrm{~Hz}, 2 \mathrm{H}), 2.91(\mathrm{~m}, 2 \mathrm{H}), 2.66(\mathrm{~m}, 6 \mathrm{H}), 2.43(\mathrm{~m}$, $2 \mathrm{H}), 2.10(\mathrm{~m}, 4 \mathrm{H}), 1.69(\mathrm{~m}, 24 \mathrm{H}), 1.22(\mathrm{~m}, 16 \mathrm{H}) .{ }^{13} \mathrm{C} \mathrm{NMR}\left(75 \mathrm{MHz}, \mathrm{CDCl}_{3}\right) \delta$ 153.4, 135.2, 128.3, 126.7, 124.0, 120.0, 57.3, 49.8, 31.6, 30.0, 29.5, 26.9, 26.4, 26.3, 23.6. $[\alpha]_{\mathrm{D}}{ }^{25}=-4.5(\mathrm{c}=0.785$, THF $)$ m.p. $234-238^{\circ} \mathrm{C}$. HRMS calcd. for $\mathrm{C}_{46} \mathrm{H}_{68} \mathrm{~N}_{2} \mathrm{O}_{2}+\mathrm{H}$ : 681.5354. Found for $\mathrm{MH}^{+}: 681.5362$. 


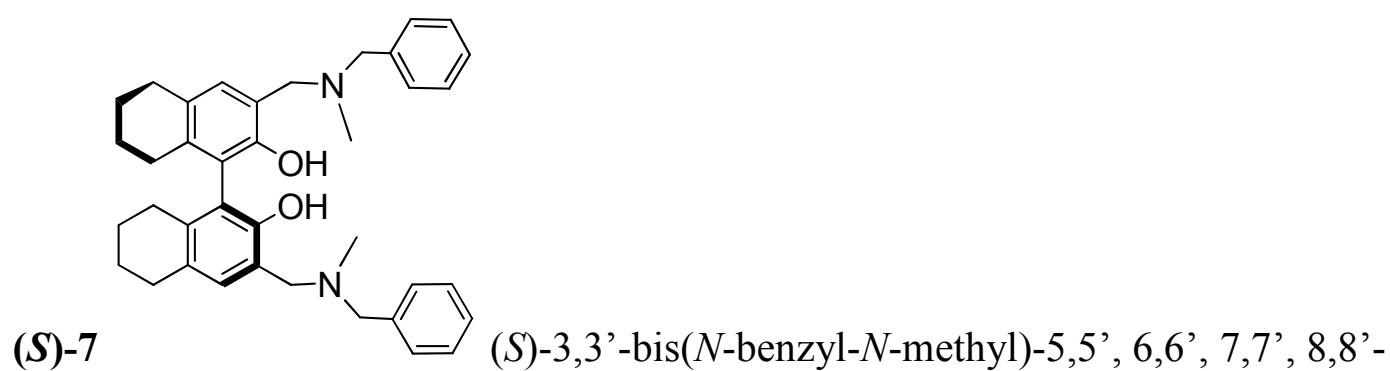

octahydro-1,1'-bi-2-naphthol;

Paraformaldehyde (301 mg, $10.0 \mathrm{mmol}, 5$ equiv) was added to a 2-neck round bottom flask fitted with condenser under nitrogen. The flask was then charged with dioxane (6 $\mathrm{mL}$, degassed $)$ and the mixture was cooled to $0{ }^{\circ} \mathrm{C}$. Benzyl methylamine $(10.0 \mathrm{mmol}, 5$ equiv) was added dropwise into the mixture cautiously over $15-20 \mathrm{~min}$. The ice bath was removed and the mixture was warmed to room temperature for $1 \mathrm{~h}$. The mixture was then heated gently to $75^{\circ} \mathrm{C}$ for $12 \mathrm{~h}$ which gave a yellow-colored solution. This solution was cooled to room temperature and $(S)-\mathrm{H}_{8} \mathrm{BINOL}(590 \mathrm{mg}, 2.01 \mathrm{mmol})$ was added. After the reaction solution was reheated to $75^{\circ} \mathrm{C}$ for $12 \mathrm{~h}, \mathrm{CH}_{2} \mathrm{Cl}_{2}(50 \mathrm{~mL})$ was added to this mixture at room temperature. The organic fraction was then washed with $\mathrm{NaHCO}_{3}$ (saturated, aq) $(3 \times 35 \mathrm{~mL})$ and $\mathrm{H}_{2} \mathrm{O}(2 \times 35 \mathrm{~mL})$. The organic layer was dried over $\mathrm{Na}_{2} \mathrm{SO}_{4}$, filtered, and concentrated. The residual oil was dissolved in a minimal amount of ethyl acetate and passed through an alumina column eluted with hexanes/ethyl acetate (5\%). Multiple column chromatography was sometimes needed which gave $(S)-7$ as a white powder in $>70 \%$ yield. ${ }^{1} \mathrm{H}$ NMR $\left(300 \mathrm{MHz}, \mathrm{CDCl}_{3}\right) \delta 10.67(\mathrm{~s}, 2 \mathrm{H}), 7.29(\mathrm{~m}$, $10 \mathrm{H}), 6.82(\mathrm{~s}, 2 \mathrm{H}), 3.99(\mathrm{~d}, J=13.5 \mathrm{~Hz}, 2 \mathrm{H}), 3.68(\mathrm{~d}, J=12.6 \mathrm{~Hz}, 2 \mathrm{H}), 3.66(\mathrm{~d}, J=13.5$ $\mathrm{Hz}, 2 \mathrm{H}), 3.57(\mathrm{~d}, J=12.6 \mathrm{~Hz}, 2 \mathrm{H}), 2.81(\mathrm{~m}, 4 \mathrm{H}), 2.49(\mathrm{~m}, 2 \mathrm{H}), 2.23$ (m, 8H), 1.79 (m, 8H). ${ }^{13} \mathrm{C} \mathrm{NMR}\left(75 \mathrm{MHz}, \mathrm{CDCl}_{3}\right) \delta 152.3,137.1,135.6,129.4,128.3,128.2,127.2$, $124.0,118.9,61.4,61.3,40.9,29.2,26.9,23.2,23.1 .[\alpha]_{\mathrm{D}}^{25}=-19.0(\mathrm{c}=0.81, \mathrm{THF})$. m.p. 
90-95 ${ }^{\circ}$ C. Anal. Calcd. for $\mathrm{C}_{38} \mathrm{H}_{44} \mathrm{~N}_{2} \mathrm{O}_{2}$ : C, 81.39; H, 7.91; N, 5.00. Found: C, 80.59; H, 7.90; N, 4.85. HRMS calcd. for $\mathrm{C}_{38} \mathrm{H}_{44} \mathrm{~N}_{2} \mathrm{O}_{2}+\mathrm{H}: 561.3481$. Found for $\mathrm{MH}^{+}:$561.3473.

$(S)-8$

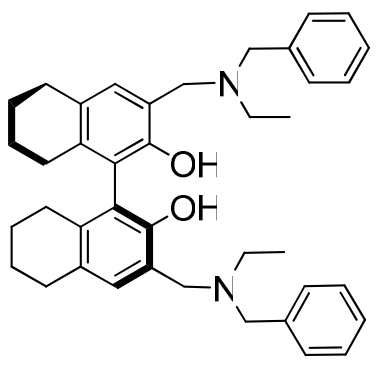

(S)-3,3'-bis((benzyl(ethyl)amino)methyl)-5, 5',6,6', 7, 7', 8, ''-

octahydro-1,1'-binaphthyl-2,2'-diol;

Paraformaldehyde (50 mmol, $1.5 \mathrm{~g}$ ) was placed into a 2-neck, $50 \mathrm{~mL}$ round bottom flask equipped with stir bar, condenser and vacuum adaptor. At $0{ }^{\circ} \mathrm{C}$, benzyl ethylamine was added dropwise to the flask with vigorous stirring. After the addition was complete, the mixture was stirred for $25 \mathrm{~min}$ and then warmed to room temperature for $50 \mathrm{~min}$. The reaction mixture was heated at $50{ }^{\circ} \mathrm{C}$ for $18 \mathrm{~h}$ and then cooled to room temperature. $(S)$ $\mathrm{H}_{8} \mathrm{BINOL}$ (736 mg, $2.5 \mathrm{mmol}$ ) and dioxane (5 mL, degassed) were added. The reaction mixture was heated at $95-100^{\circ} \mathrm{C}$ for $24 \mathrm{~h}$. After the same workup as the preparation of (S)-3, a residual oil was obtained which was purified twice by column chromatography on alumina eluted with hexanes/acetone (5-10\%). The resulting crystals were recrystallized from ethanol to give pure $(S)-8$ in $55 \%$ yield. ${ }^{1} \mathrm{H}$ NMR $\left(300 \mathrm{MHz}, \mathrm{CDCl}_{3}\right)$ $\delta 10.73(\mathrm{~s}, 2 \mathrm{H}), 7.29(\mathrm{~m}, 10 \mathrm{H}), 6.78(\mathrm{~s}, 2 \mathrm{H}), 3.98(\mathrm{~d}, J=13.8 \mathrm{~Hz}, 2 \mathrm{H}), 3.77(\mathrm{~d}, J=13.2$ Hz, 2H), $3.63(\mathrm{~d}, J=13.8 \mathrm{~Hz}, 2 \mathrm{H}), 3.54(\mathrm{~d}, J=13.2 \mathrm{~Hz}, 2 \mathrm{H}), 2.77(\mathrm{~m}, 4 \mathrm{H}), 2.64(\mathrm{~m}, 2 \mathrm{H})$, $2.49(\mathrm{~m}, 4 \mathrm{H}), 2.17(\mathrm{~m}, 2 \mathrm{H}), 1.71(\mathrm{~m}, 8 \mathrm{H}), 1.10(\mathrm{t}, J=7.2 \mathrm{~Hz}, 6 \mathrm{H}) .{ }^{13} \mathrm{C}$ NMR $(75 \mathrm{MHz}$, $\left.\mathrm{CDCl}_{3}\right) \delta 152.3,137.3,135.6,129.5,128.5,128.2,127.1,124.0,119.1,57.5,57.2,46.2$, 29.2, 26.9, 23.2, 10.9. $[\alpha]_{\mathrm{D}}{ }^{25}=-17.6(\mathrm{c}=0.785, \mathrm{THF})$. m.p. $76-82^{\circ} \mathrm{C}$. HRMS calcd. for $\mathrm{C}_{40} \mathrm{H}_{48} \mathrm{~N}_{2} \mathrm{O}_{2}+\mathrm{H}: 589.3789$. Found for $\mathrm{MH}^{+}: 589.3787$. 


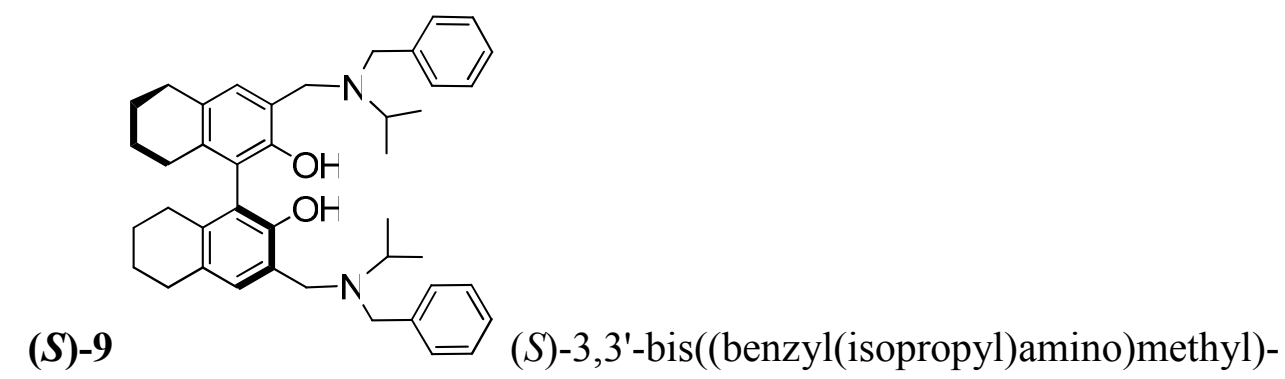

5,5',6,6',7,7',8,8'-octahydro-1,1'-binaphthyl-2,2'-diol;

Under nitrogen, paraformaldehyde $(1.5 \mathrm{~g}, 50 \mathrm{mmol})$ was placed into a 2-neck, $50 \mathrm{~mL}$ round bottom flask equipped with stir bar, condenser and vacuum adaptor. Dioxane (5 $\mathrm{mL}$, degassed) was then added and the slurry was chilled to $0{ }^{\circ} \mathrm{C}$. Benzyl isopropylamine was added dropwise into the mixture with vigorous stirring. After the addition was complete, the mixture was stirred for $25 \mathrm{~min}$ and then warmed to room temperature for $50 \mathrm{~min}$. The reaction mixture was heated at $60-65^{\circ} \mathrm{C}$ for $18 \mathrm{~h}$. Then, $(S)-\mathrm{H}_{8} \mathrm{BINOL}$ (734 $\mathrm{mg}, 2.49 \mathrm{mmol})$ and dioxane $(5 \mathrm{~mL}$, degassed) were added at room temperature. The reaction mixture was heated at $90-100{ }^{\circ} \mathrm{C}$ for $24 \mathrm{~h}$. After the same workup as the preparation of $(S)-3$, the resulting oily residue was purified twice by column chromatography on alumina eluted with hexanes/acetone (5-8\%) and hexanes/acetone (4$10 \%)$ respectively. The resulting crystals were recrystallized from ethanol to give pure (S)-9 in 45\% yield. ${ }^{1} \mathrm{H}$ NMR (300 MHz, $\left.\mathrm{CDCl}_{3}\right) \delta 10.76(\mathrm{~s}, 2 \mathrm{H}), 7.23(\mathrm{~m}, 10 \mathrm{H}), 6.76(\mathrm{~s}$, 2H), $3.94(\mathrm{~d}, J=13.8 \mathrm{~Hz}, 2 \mathrm{H}), 3.71(\mathrm{~d}, J=13.5 \mathrm{~Hz}, 2 \mathrm{H}), 3.60(\mathrm{~d}, J=13.8 \mathrm{~Hz}, 2 \mathrm{H}), 3.52$ (d, $J=13.2 \mathrm{~Hz}, 2 \mathrm{H}), 3.05$ (septet, $J=6.6 \mathrm{~Hz}, 2 \mathrm{H}), 2.74(\mathrm{~m}, 4 \mathrm{H}), 2.44(\mathrm{~m}, 2 \mathrm{H}), 2.10(\mathrm{~m}$, 2H), $1.65(\mathrm{~m}, 8 \mathrm{H}), 1.11(\mathrm{~d}, J=6.9 \mathrm{~Hz}, 6 \mathrm{H}), 1.06(\mathrm{~d}, J=6.6 \mathrm{~Hz}, 6 \mathrm{H}) .{ }^{13} \mathrm{C} \mathrm{NMR}(75$ $\left.\mathrm{MHz}, \mathrm{CDCl}_{3}\right) 152.5,138.2,135.6,129.4,123.9,119.0,53.7,52.2,47.8,29.3,26.9,23.3$, 18.0, 15.4. $[\alpha]_{\mathrm{D}}^{25}=-17.9(\mathrm{c}=0.90$, THF $)$ m.p. $165-168^{\circ} \mathrm{C}$. HRMS calcd. for $\mathrm{C}_{42} \mathrm{H}_{52} \mathrm{~N}_{2} \mathrm{O}_{2}+\mathrm{H}: 617.4122$. Found for $\mathrm{MH}^{+}: 617.4112$. 
(S)-10

octahydro-1,1'-binaphthyl-2,2'-diol;

Under nitrogen, thiomorpholine $(5.0 \mathrm{~mL}, 50 \mathrm{mmol})$ was mixed with paraformaldehyde $(1.5 \mathrm{~g}, 50 \mathrm{mmol})$ at $0{ }^{\circ} \mathrm{C}$. The mixture was warmed to room temperature after $30 \mathrm{~min}$ and then gently heated to $50^{\circ} \mathrm{C}$ for $12 \mathrm{~h}$. The resulting slurry was further heated at $75-80{ }^{\circ} \mathrm{C}$ for $5 \mathrm{~h}$ to give a homogenous solution. To the solution at room temperature, $(S)$ $\mathrm{H}_{8} \mathrm{BINOL}$ (508.2 $\left.\mathrm{mg}, 2 \mathrm{mmol}\right)$ and dioxane $(10 \mathrm{~mL}$, degassed) were added. The reaction solution was heated at $80{ }^{\circ} \mathrm{C}$ for $16 \mathrm{~h}$. After the same workup as the preparation of $(S)-3$, the crude solid was recrystallized from ethanol which gave pure $(S)-10$ (crop 1: $65 \%$ yield). ${ }^{1} \mathrm{H}$ NMR $\left(300 \mathrm{MHz}, \mathrm{CDCl}_{3}\right) \delta 10.37(\mathrm{~s}, 2 \mathrm{H}), 6.71(\mathrm{~s}, 2 \mathrm{H}), 3.79(\mathrm{~d}, J=13.8 \mathrm{~Hz}$, 2H), $3.62(\mathrm{~d}, J=13.8 \mathrm{~Hz}, 2 \mathrm{H}), 2.82(\mathrm{~m}, 8 \mathrm{H}), 2.67(\mathrm{~m}, 8 \mathrm{H}), 2.36(\mathrm{~m}, 2 \mathrm{H}), 2.16(\mathrm{~m}, 2 \mathrm{H})$, $1.67(\mathrm{~m}, 8 \mathrm{H}) .{ }^{13} \mathrm{C} \mathrm{NMR}\left(75 \mathrm{MHz}, \mathrm{CDCl}_{3}\right) \delta 152.1,135.8,128.6,127.5,123.9,117.8$, $62.2,54.3,29.1,27.7,26.9,23.2,23.1 .[\alpha]_{\mathrm{D}}{ }^{25}=-50.8(\mathrm{c}=0.715$, THF $)$ m.p. $162-176^{\circ} \mathrm{C}$. HRMS calcd. for $\mathrm{C}_{30} \mathrm{H}_{40} \mathrm{~N}_{2} \mathrm{O}_{2} \mathrm{~S}_{2}+\mathrm{H}$ : 525.2604. Found for $\mathrm{MH}^{+}$: 525.2611 .

\section{$(S)-11$}<smiles>Oc1c(CN2CCCCC2)cc2c(c1-c1c(O)c(CN3CCCCC3)cc3c1CCCC3)CCCC2</smiles>

(S)-3,3'-bis(piperidin-1-ylmethyl)-5,5',6,6',7,7',8, ''-octahydro- 
Under nitrogen, paraformaldehyde (901 $\mathrm{mg}, 30.0 \mathrm{mmol}$ ) was added to a 2-neck round bottom flask fitted with condenser. Then at $0{ }^{\circ} \mathrm{C}$, piperidine $(3 \mathrm{~mL}, 30.0 \mathrm{mmol})$ was added dropwise cautiously over 15 - 20 min with vigorous stirring. After the addition was complete, the mixture was warmed to room temperature for $30 \mathrm{~min}$ and then heated at $80{ }^{\circ} \mathrm{C}$ for $9 \mathrm{~h}$. The resulting amber-colored viscous solution was cooled to room temperature and $(S)-\mathrm{H}_{8} \mathrm{BINOL}(2.06 \mathrm{~g}, 7 \mathrm{mmol})$ and dioxane $(15 \mathrm{~mL}$, degassed) were added. The reaction solution was reheated at $80^{\circ} \mathrm{C}$ for $12 \mathrm{~h}$. Upon completion of the reaction, ethyl acetate was added to this mixture. The organic fraction was washed with $\mathrm{NaHCO}_{3}$ (saturated, aq) $(3 \times 35 \mathrm{~mL})$ and $\mathrm{H}_{2} \mathrm{O}(2 \times 35 \mathrm{~mL})$. Then, the organic layer was dried over $\mathrm{Na}_{2} \mathrm{SO}_{4}$, filtered, and evaporated. The resulting crude crystals were recrystallized in acetone to give pure $(S)-11$ as a white powder in $81 \%$ yield. ${ }^{1} \mathrm{H}$ NMR $\left(300 \mathrm{MHz}, \mathrm{CDCl}_{3}\right) \delta 11.06(\mathrm{~s}, 2 \mathrm{H}), 6.78(\mathrm{~s}, 2 \mathrm{H}), 3.77(\mathrm{~d}, J=14.1 \mathrm{~Hz}, 2 \mathrm{H}), 3.51(\mathrm{~d}, J=$ $13.8 \mathrm{~Hz}, 2 \mathrm{H}), 2.70(\mathrm{~m}, 4 \mathrm{H}), 2.39(\mathrm{~m}, 9 \mathrm{H}), 2.15(\mathrm{~m}, 2 \mathrm{H}), 1.61$ (m, 22H). ${ }^{13} \mathrm{C} \mathrm{NMR}(75$ $\left.\mathrm{MHz}, \mathrm{CDCl}_{3}\right) \delta 152.6,135.4,128.2,126.8,124.0,118.7,62.2,53.7,29.2,26.9,25.6$, 24.0, 23.2, $[\alpha]_{\mathrm{D}}{ }^{25}=-72.2\left(\mathrm{c}=0.835\right.$, THF) m.p. $128-133{ }^{\circ} \mathrm{C}$. HRMS calcd. for $\mathrm{C}_{32} \mathrm{H}_{44} \mathrm{~N}_{2} \mathrm{O}_{2}+\mathrm{H}: 489.3476$. Found for $\mathrm{MH}^{+}: 489.3480$.

$(S)-12$

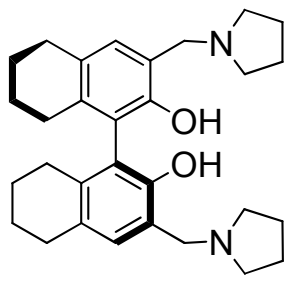

(S)-3,3'-bispyrrolidinylmethyl-5,5', 6,6', 7,7', 8,8'-octahydro1,1'-bi-2-naphthol;

Method A. (1) Preparation of pyrrolidinomethanol. Paraformaldehyde (15.0 g, 0.5 moL) was added into a 2-necked round bottom flask equipped with a stir bar and condenser. The vessel was flushed under nitrogen for $15 \mathrm{~min}$ and then cooled to $0{ }^{\circ} \mathrm{C}$. 
Pyrrolidine (42 mL, $0.5 \mathrm{~mol}$ ) was added dropwise through a sidearm over $30 \mathrm{~min}$ with caution. After complete addition, the mixture was stirred for $1 \mathrm{~h}$. The ice bath was then removed and the mixture was stirred at room temperature for $1 \mathrm{~h}$. It was then heated at $70{ }^{\circ} \mathrm{C}$ overnight to give a homogeneous syrup-like liquid. (2) Preparation of $(S)$-12. $(S)$ $\mathrm{H}_{8} \mathrm{BINOL}$ (2.519 g, $\left.8.56 \mathrm{mmol}\right)$ was dissolved in dioxane $(20 \mathrm{~mL}$, degassed) in a $100 \mathrm{~mL}$ 2-neck round bottom flask equipped with stir bar and condenser. Pyrrolidinomethanol $(20 \mathrm{~mL})$ was added into this solution and the flask was flushed with nitrogen. After 15 min, the mixture was heated at $60{ }^{\circ} \mathrm{C}$ for $15 \mathrm{~h}$. After the reaction was complete as shown by TLC, the mixture was diluted with ethyl acetate $(120 \mathrm{~mL})$ and washed with $\mathrm{NaHCO}_{3}$ (satd., aq) $(3 \times 80 \mathrm{~mL})$ and $\mathrm{H}_{2} \mathrm{O}(3 \times 100 \mathrm{~mL})$. The organic fraction was dried over $\mathrm{Na}_{2} \mathrm{SO}_{4}$, filtered and evaporated. The residue was recrystallized from ethanol to give $(S)$ 12 in $70 \%$ yield (crop 1$)$.

Method B. Alternatively, the reaction could be conducted in one-pot by preparing an appropriate amount of pyrrolidinomethanol (10 to 20 equiv relative to $\left.(S)-\mathrm{H}_{8} \mathrm{BINOL}\right)$. Step one could be carried out in dioxane (to allow for safer addition) in a 2-neck, round bottom flask equipped with stir bar, condenser and vacuum adaptor. After pyrrolidinomethanol was prepared, $(S)-\mathrm{H}_{8} \mathrm{BINOL}$ and degassed dioxane were introduced at room temperature. The reaction was allowed to proceed for $8-12 \mathrm{~h}$. The reaction was monitored by TLC and ${ }^{1} \mathrm{H}-\mathrm{NMR}$.

Characterization of $(S)-12:{ }^{1} \mathrm{H}-\mathrm{NMR}\left(300 \mathrm{MHz}, \mathrm{CDCl}_{3}\right) \delta 11.91(\mathrm{bs}, 2 \mathrm{H}), 6.70(\mathrm{~s}$, 2H), $4.03(\mathrm{~d}, J=13.8 \mathrm{~Hz}, 2 \mathrm{H}), 3.76(\mathrm{~m}, 2 \mathrm{H}), 3.62(\mathrm{~d}, J=13.8 \mathrm{~Hz}, 2 \mathrm{H}), 2.72(\mathrm{~m}, 2 \mathrm{H})$, $2.61(\mathrm{~m}, 8 \mathrm{H}), 2.37(\mathrm{~m}, 2 \mathrm{H}), 2.18(\mathrm{~m}, 2 \mathrm{H}), 1.84(\mathrm{~m}, 2 \mathrm{H}), 1.72(\mathrm{~m}, 16 \mathrm{H}) .{ }^{13} \mathrm{C} \mathrm{NMR}(75$ $\left.\mathrm{MHz}, \mathrm{CDCl}_{3}\right) \delta 152.8,135.5,127.7,127.1,124.1,119.6,67.9,58.8,53.3,29.2,26.9$, 
25.5, 23.6, 23.2, 23.2. $[\alpha]_{\mathrm{D}}^{25}=-56.4(\mathrm{c}=1.07, \mathrm{THF})$. m.p. $152-156^{\circ} \mathrm{C}$. Anal. Calcd. for $\mathrm{C}_{30} \mathrm{H}_{40} \mathrm{~N}_{2} \mathrm{O}_{2}$ : C, 78.22; H, 8.75; N, 6.08. Found: C, 78.20; H, 9.00; N, 6.03. HRMS calcd. for $\mathrm{C}_{30} \mathrm{H}_{40} \mathrm{~N}_{2} \mathrm{O}_{2}+\mathrm{H}: 461.3168$. Found for $\mathrm{MH}^{+}: 461.3177$.

$(S)-13$

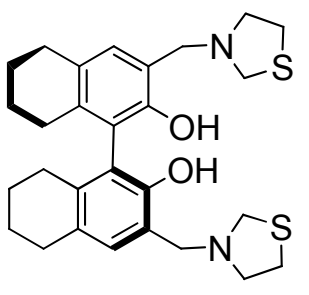

(S)-3,3'-bis(thiazolidin-3-ylmethyl)-5,5',6,6', 7, 7', 8, 8'-octahydro1,1'-binaphthyl-2,2'-diol;

(1) Thiazolidine was prepared by stirring 2 -aminoethanethiol hydrochloride ( $88 \mathrm{mmol})$ with paraformaldehyde $(88 \mathrm{mmol})$ in water $(60 \mathrm{~mL})$ for $20 \mathrm{~h}$. Then, a solution of $\mathrm{NaHCO}_{3}(88 \mathrm{mmol})$ in water $(55 \mathrm{~mL})$ was added rapidly in one addition. $\mathrm{KCl}$ was added to saturate the solution which resulted in a pinkish color. It was extracted with diethyl ether (4 x $150 \mathrm{~mL})$. The organic layers were combined, dried over magnesium sulfate, filtered and evaporated. This gave a clear yellow oil which was shown to be of high purity by ${ }^{1} \mathrm{H}$ NMR spectroscopy and was used without further purification in the next step. (2) Under nitrogen, thiazolidine $(88 \mathrm{mmol})$ was stirred with paraformaldehyde (88 $\mathrm{mmol})$ and heated at $55-62{ }^{\circ} \mathrm{C}$ for $12 \mathrm{~h}$. Then, $(S)-\mathrm{H}_{8} \mathrm{BINOL}(1.1 \mathrm{~g}, 4.1 \mathrm{mmol})$ and dioxane (15 mL, degassed) were added at room temperature. The reaction mixture was reheated at $60{ }^{\circ} \mathrm{C}$ for $10 \mathrm{~h}$. It was then worked up in the manner as the preparation of $(S)$ 3. The resulting oily reside was separated twice by column chromatography on silica gel eluted with hexane/acetone (5\%) and hexanes (10-12\%) respectively to give the impure crystals of $(S)$-13. Recrystallization from acetone yielded pure $(S)-\mathbf{1 3}$ in $50 \%$ yield. ${ }^{1} \mathrm{H}$ NMR $\left(300 \mathrm{MHz}, \mathrm{CDCl}_{3}\right) \delta 9.52(\mathrm{~s}, 2 \mathrm{H}), 6.74(\mathrm{~s}, 2 \mathrm{H}), 4.05(\mathrm{~m}, 4 \mathrm{H}), 3.82(\mathrm{~d}, J=13.5 \mathrm{~Hz}$, 2H), $3.71(\mathrm{~d}, J=13.5 \mathrm{~Hz}, 2 \mathrm{H}), 3.13(\mathrm{t}, J=6.6 \mathrm{~Hz}, 4 \mathrm{H}), 2.98(\mathrm{t}, J=6.3 \mathrm{~Hz}, 4 \mathrm{H}), 2.70(\mathrm{~m}$, 
4H), $2.35(\mathrm{~m}, 2 \mathrm{H}), 2.18(\mathrm{~m}, 2 \mathrm{H}), 1.70(\mathrm{~m}, 8 \mathrm{H}) .{ }^{13} \mathrm{C} \mathrm{NMR}\left(75 \mathrm{MHz}, \mathrm{CDCl}_{3}\right) \delta 152.0$, $136.5,124.3,119.0,58.6,56.4,56.2,29.4,29.2,27.2,23.4,23.3 .[\alpha]_{\mathrm{D}}^{25}=-42.8(\mathrm{c}=$ 0.995, THF) m.p. $186-188{ }^{\circ} \mathrm{C}$. HRMS calcd. for $\mathrm{C}_{28} \mathrm{H}_{36} \mathrm{~N}_{2} \mathrm{O}_{2} \mathrm{~S}_{2}+\mathrm{H}$ : 497.2291. Found for $\mathrm{MH}^{+}: 497.2294$.

\section{$(S)-14$}

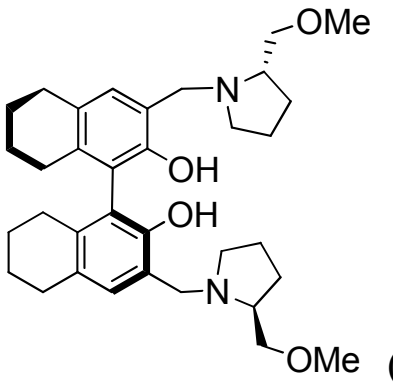

$(S)-3,3 '-\operatorname{bis}(((S)-2-($ methoxymethyl)pyrrolidin-1yl)methyl)-5,5',6,6',7,7',8,8'-octahydro-1, 1'-binaphthyl-2,2'-diol;

(1) Under nitrogen, $(S)$-2-(methoxymethyl)pyrrolidine (5.4 mL, $43.7 \mathrm{mmol})$, prepared according to Kipphardt's method and vacuum distillation through Vigreux column, ${ }^{14}$ was mixed with paraformaldehyde $(1.31 \mathrm{~g}, 43.7 \mathrm{mmol})$ at $0{ }^{\circ} \mathrm{C}$ for $1 \mathrm{~h}$. The mixture was then heated at $65^{\circ} \mathrm{C}$ for overnight, resulting in a thick yellowish solution. At room temperature, $(S)-\mathrm{H}_{8} \mathrm{BINOL}(650 \mathrm{mg}, 2.2 \mathrm{mmol})$ and dioxane $(10 \mathrm{~mL}$, degassed) were added and the reaction mixture was reheated at $65-70{ }^{\circ} \mathrm{C}$ for $18 \mathrm{~h}$. The reaction was shown to be complete by TLC and NMR. After the same work-up as in the preparation of $(S)$-3, a thick yellow oily residue was obtained. After repeated column chromatography on silica gel eluted with $\mathrm{CH}_{2} \mathrm{Cl}_{2} / \mathrm{MeOH}$, the NMR and HRMS spectra still showed impurities that could not be completely removed. ${ }^{1} \mathrm{H}$ NMR $(300 \mathrm{MHz}$, $\left.\mathrm{CDCl}_{3}\right) \delta 10.52(\mathrm{bs}, 2 \mathrm{H}), 6.71(\mathrm{~s}, 2 \mathrm{H}), 4.24(\mathrm{~d}, J=13.8 \mathrm{~Hz}, 2 \mathrm{H}), 3.64(\mathrm{~d}, J=13.8 \mathrm{~Hz}$, 2H), $3.46(\mathrm{~m}, 2 \mathrm{H}), 3.29(\mathrm{~s}, 6 \mathrm{H}), 3.11(\mathrm{~m}, 2 \mathrm{H}), 2.77(\mathrm{~m}, 6 \mathrm{H}), 2.49(\mathrm{~m}, 2 \mathrm{H}), 2.33(\mathrm{~m}, 2 \mathrm{H})$, $2.21(\mathrm{~m}, 2 \mathrm{H}), 1.97(\mathrm{~m}, 2 \mathrm{H}), 1.72(\mathrm{~m}, 16 \mathrm{H}) .{ }^{13} \mathrm{C} \mathrm{NMR}\left(75 \mathrm{MHz}, \mathrm{CDCl}_{3}\right) \delta 152.1,135.2$, $127.4,126.5,123.6,119.4,75.6,63.2,58.7,58.5,54.4,29.0,28.4,26.7,23.1,23.1,22.7$. 
$[\alpha]_{D}^{25}=-82.1(\mathrm{c}=1.13, \mathrm{THF})$. m.p. $68-80{ }^{\circ} \mathrm{C}$. HRMS calcd. for $\mathrm{C}_{46} \mathrm{H}_{68} \mathrm{~N}_{2} \mathrm{O}_{2}+\mathrm{H}$ :

549.3698. Found for $\mathrm{MH}^{+}:$549.3691. The mass spectrum gave an additional signal at 116.1073 corresponding to the starting $(S)$-2-(methoxymethyl)pyrrolidine $([\mathrm{MH}+]=$ 116.1075).

$(S)-15$

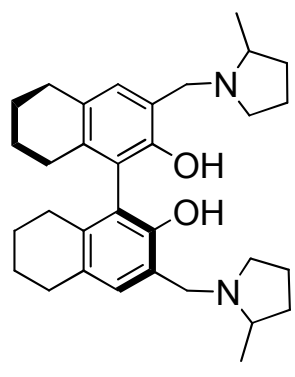

(1S)-3,3'-bis((2-methylpyrrolidin-1-yl)methyl)-5,5',6,6',7,7',8, ''octahydro-1,1'-binaphthyl-2,2'-diol;

(1) 2-Methylpyrrolidine was prepared from the commercially available 2-methyl-1pyrroline. 2-Methyl-1-pyrroline (5 mL, $53 \mathrm{mmol}$ ) was added to a mixed solvent of $\mathrm{MeOH}(120 \mathrm{~mL})$ and $\mathrm{H}_{2} \mathrm{O}(30 \mathrm{~mL})$ in a round bottom flask equipped with a stir bar. $\mathrm{NaBH}_{4}$ (64 mmol, 1.2 equiv) was then added in small quantities with vigorous stirring at room temperature. The mixture was allowed to stir at room temperature for $15 \mathrm{~h}$. TLC (eluted with 5:1 $\mathrm{CH}_{2} \mathrm{Cl}_{2} / \mathrm{MeOH}$ ) showed the complete consumption of the starting material. The reaction mixture was cooled with an ice bath and quenched with a slow addition of $2 \mathrm{M} \mathrm{HCl}$ until $\mathrm{pH}=1-3$. The solution was then stirred at room temperature for $1 \mathrm{~h}$ and adjusted to $\mathrm{pH}=13$ with $2 \mathrm{M} \mathrm{NaOH}$. $\mathrm{CH}_{2} \mathrm{Cl}_{2}(3 \times 100 \mathrm{~mL})$ was used for extraction and the combined organic layers were dried over $\mathrm{Na}_{2} \mathrm{SO}_{4}$, filtered and concentrated. The crude compound was then stirred with solid $\mathrm{KOH}$ pellets and dried over sodium metal under nitrogen at $40-50{ }^{\circ} \mathrm{C}$ for $12 \mathrm{~h}$. The subsequent distillation over a glass fractionating column gave 2-methylpyrrolidine. (2) Under nitrogen, 2methylpyrrolidine $(4.4 \mathrm{~mL}, 43.1 \mathrm{mmol})$ was added dropwise over $20 \mathrm{~min}$ to a 2 -necked 
round bottom flask containing paraformaldehyde $(43 \mathrm{mmol})$ and equipped with a stir bar, a condenser and a vacuum adaptor at $0{ }^{\circ} \mathrm{C}$. The resulting reaction mixture was heated at $60{ }^{\circ} \mathrm{C}$ for $7.5 \mathrm{~h}$. Then, $(S)-\mathrm{H}_{8} \mathrm{BINOL}(3 \mathrm{mmol})$ and dioxane $(20 \mathrm{~mL}$, degassed) were added at room temperature. The reaction mixture was reheated at $70{ }^{\circ} \mathrm{C}$ for $24 \mathrm{~h}$.

Following the workup as described fro (S)-12 (basic aqueous and aqueous extraction using ethyl acetate followed by recrystallization from ethanol), (S)-15 was obtained as a white solid in 57\% yield from two crops. ${ }^{1} \mathrm{H}$ NMR $\left(300 \mathrm{MHz}, \mathrm{CDCl}_{3}\right) \delta 10.98(\mathrm{~s}, 2 \mathrm{H})$, $6.70(\mathrm{~s}, 2 \mathrm{H}), 4.33(\mathrm{~m}, 1 \mathrm{H}), 4.12(\mathrm{~m}, 1 \mathrm{H}), 3.45(\mathrm{~m}, 1 \mathrm{H}), 3.21(\mathrm{~m}, 1 \mathrm{H}), 3.06(\mathrm{~m}, 2 \mathrm{H}), 2.75$ (m, 4H), $2.49(\mathrm{~m}, 3 \mathrm{H}), 2.25(\mathrm{~m}, 5 \mathrm{H}), 2.01(\mathrm{~m}, 2 \mathrm{H}), 1.61(\mathrm{~m}, 12 \mathrm{H}), 1.42(\mathrm{~m}, 2 \mathrm{H}), 1.16(\mathrm{~m}$, $6 \mathrm{H}) .{ }^{13} \mathrm{C}$ NMR $\left(75 \mathrm{MHz}, \mathrm{CDCl}_{3}\right) \delta 152.5,135.3,127.5,126.7,123.9,119.8,60.0,59.8$, 59.6, 57.0, 57.0, 56.9, 56.9, 53.8, 53.8, 32.8, 29.2, 26.8, 23.2, 23.2, 21.6, 21.6, 18.9, 18.8, 18.8, 18.7. This compound contains a mixture of diastereomers. See the NMR spectra in the appendix for more details. $[\alpha]_{\mathrm{D}}^{25}=-43.6\left(\mathrm{c}=0.735\right.$, THF). m.p. $162-166^{\circ} \mathrm{C}$. HRMS calcd. for $\mathrm{C}_{32} \mathrm{H}_{44} \mathrm{~N}_{2} \mathrm{O}_{2}+\mathrm{H}$ : 489.3476. Found for $\mathrm{MH}^{+}$: 489.3477 .

(S)-16 (1S)-3,3'-bis((octahydro-1H-indol-1-yl)methyl)5,5',6,6',7,7',8,8'-octahydro-1,1'-binaphthyl-2,2'-diol;

(1) Octahydro-1H-indole was prepared by adapting the method reported by Jessup. ${ }^{15}$ $\mathrm{Pd} / \mathrm{C}(10 \mathrm{~mol} \% \mathrm{Pd})$ was wetted with $50 \%$ water in a Parr reactor equipped with a stir bar. Indoline $(25,42$, or $84 \mathrm{mmol})$ and ethanol $(30$ or $100 \mathrm{~mL})$ were charged into the 
vessel. The vessel was closed and hydrogen gas was flushed through the mixture 3 times. Finally, the vessel was loaded with $\mathrm{H}_{2}\left(\sim 600\right.$ psi) and placed in a $100{ }^{\circ} \mathrm{C}$ bath. After 13 $\mathrm{h}$, the reactor was cooled to room temperature and TLC (ninhydrin stain) showed no starting material. The mixture was filtered through a packed celite pad and rinsed with chloroform and ethanol. The organics were concentrated, redissolved in $\mathrm{NaOH}(50 \mathrm{~mL})$, and extracted with chloroform. After it was dried over $\mathrm{Na}_{2} \mathrm{SO}_{4}$, the solution was filtered and concentrated. It was then vacuum distilled over molecular sieves ( $4 \AA$ ) at $40-60{ }^{\circ} \mathrm{C}$ to give octahydro-1H-indole. (2) Under nitrogen, octahydro- $1 \mathrm{H}$-indole (43.5 mmol) was mixed with paraformaldehyde $(43.5 \mathrm{mmol})$ in dioxane $(5 \mathrm{~mL}$, degassed $)$ and heated at 50 ${ }^{\circ} \mathrm{C}$ for $16 \mathrm{~h}$. Then, $(S)-\mathrm{H}_{8} \mathrm{BINOL}(2.4 \mathrm{mmol})$ and dioxane $(5 \mathrm{~mL}$, degassed $)$ were added at room temperature and reheated at $60-70{ }^{\circ} \mathrm{C}$ for $18 \mathrm{~h}$. After the same workup as described for $(S)-\mathbf{1 2}$, a residual oil was obtained which yielded impure crystals after evacuation. Recrystallization from ethanol (seeded with a small amount of the impure crystal) yielded pale yellow-whitish impure crystals. Upon column chromatography on silica gel eluted with hexanes/ethyl acetate (95:5 to 90:10), $(S)$-16 was obtained as a diastereomeric mixture in 70\% yield. ${ }^{1} \mathrm{H}$ NMR $\left(300 \mathrm{MHz}, \mathrm{CDCl}_{3}\right) \delta 10.30(\mathrm{bs}, 2 \mathrm{H}), 6.73$ (s, 2H), $4.27(\mathrm{~m}, 1 \mathrm{H}), 4.13(\mathrm{~d}, J=13.5 \mathrm{~Hz}, 1 \mathrm{H}), 3.45(\mathrm{~d}, J=13.5 \mathrm{~Hz}, 1 \mathrm{H}), 3.27(\mathrm{~m}, 2 \mathrm{H})$, $3.07(\mathrm{~m}, 2 \mathrm{H}), 2.73(\mathrm{bs}, 4 \mathrm{H}), 2.59-2.67(\mathrm{~m}, 2 \mathrm{H}), 2.35-2.51(\mathrm{~m}, 4 \mathrm{H}), 2.12(\mathrm{bs}, 2 \mathrm{H}), 1.22$ - 1.93 (m, 30H). ${ }^{13} \mathrm{C} \mathrm{NMR}\left(75 \mathrm{MHz}, \mathrm{CDCl}_{3}\right)$ 153.1, 152.9, 152.8, 135.7, 135.6, 128.1, $127.0,126.9,124.1,124.0,120.0,63.6,63.4,63.3,57.5,51.9,38.3,38.2,29.5,28.8,28.7$, $28.5,28.3,27.1,26.1,25.3,25.1,24.9,24.3,24.0,23.6,23.5,21.5,21.3,21.1$. This compound contains a mixture of diastereomers. See the NMR spectra in the appendix for 
more details. $[\alpha]_{\mathrm{D}}^{25}=-22.4(\mathrm{c}=1.14, \mathrm{THF})$. m.p. $122-128^{\circ} \mathrm{C}$. HRMS calcd. for $\mathrm{C}_{38} \mathrm{H}_{52} \mathrm{~N}_{2} \mathrm{O}_{2}+\mathrm{H}: 569.4102$. Found for $\mathrm{MH}^{+}: 569.4103$.

\section{$(S)-17$}

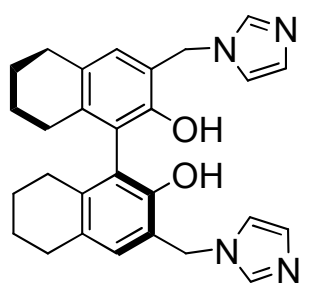

(S)-3,3'-bis((1H-imidazol-1-yl)methyl)-5, ', $, 6,6^{\prime}, 7,7^{\prime}, 8,8^{\prime}-$

octahydro-1,1'-binaphthyl-2,2'-diol;

(1) Under nitrogen, imidazole (11.33 g, $166.5 \mathrm{mmol})$ was added to an ice cold mixture of paraformaldehyde (5 g, $166.5 \mathrm{mmol})$ and 1,4-dioxane (45 $\mathrm{mL}$, degassed) in a 2-neck round-bottom flask equipped with a stir bar, a condenser and a vacuum adapter. The mixture was warmed to room temperature and stirred for $2 \mathrm{~h}$. It was then heated at $70{ }^{\circ} \mathrm{C}$ for $12 \mathrm{~h}$. After removal of dioxane under reduced pressure, imidazole methanol was obtained as a moist white solid. ${ }^{1} \mathrm{H}$ NMR $\left(300 \mathrm{MHz} \mathrm{CDCl}_{3}\right) \delta 5.41(\mathrm{~s}, 2 \mathrm{H}), 6.93(\mathrm{~s}, 1 \mathrm{H})$, $7.08(\mathrm{~s}, 1 \mathrm{H}), 7.32(\mathrm{~s}, 1 \mathrm{H}), 8.94(\mathrm{~s}, 1 \mathrm{H})$.

(2) Imidazole methanol (10 g, $102 \mathrm{mmol}, 30$ equiv), (S)- $\mathrm{H}_{8} \mathrm{BINOL}(1.0 \mathrm{~g}, 3.4 \mathrm{mmol})$, and 1,4-dioxane (6 mL, degassed) were combined in a screw cap-sealed vial. [NOTE: The vial and contents were placed under nitrogen and sealed. Electrical tape was placed around the vial to prevent potential evaporative loss and also as a precautionary safety measure.] The reaction mixture was heated at $135^{\circ} \mathrm{C}$ for $8 \mathrm{~h}$. [NOTE: The vial was placed behind a blast shield although no breakage of vial occurred.] Ethyl acetate was added to dilute the warm reaction mixture and the organic solution was washed with a saturated aqueous $\mathrm{NaHCO}_{3}$ solution $(3 \times 25 \mathrm{~mL})$ and water $(2 \times 25 \mathrm{~mL})$ [NOTE: It has been found that the reaction mixture can be difficult to handle after cooling to room temperature; to bypass this issue, caution is taken to handle the warm reaction mixture- 
still nonviscous—after $8 \mathrm{~h}$ reaction time]. After recyrstallization from ethanol, (S)-17 was obtained in $82 \%$ yield $(1.27 \mathrm{~g}) .{ }^{1} \mathrm{H}$ NMR $\left(300 \mathrm{MHz} \mathrm{CDCl}_{3}\right) \delta 7.38(\mathrm{~s}, 2 \mathrm{H}), 6.94(\mathrm{~s}$, 2H), $6.89(\mathrm{~s}, 2 \mathrm{H}), 6.76(\mathrm{~s}, 2 \mathrm{H}), 5.11(\mathrm{~d}, J=15.0 \mathrm{~Hz}, 2 \mathrm{H}), 5.00(\mathrm{~d}, J=14.7 \mathrm{~Hz}, 2 \mathrm{H}), 3.48$ (s, 2H), $2.67(\mathrm{~m}, 4 \mathrm{H}), 2.16(\mathrm{~m}, 4 \mathrm{H}), 1.68(\mathrm{~m}, 8 \mathrm{H}) .{ }^{13} \mathrm{C} \mathrm{NMR}\left(75 \mathrm{MHz} \mathrm{CDCl}_{3}\right) \delta$ 150.0, $137.5,136.9,130.1,129.6,128.3,121.0,120.7,119.3,45.1,29.2,27.1,22.9,22.8 .[\alpha]_{\mathrm{D}}{ }^{20}$ $=-36.4\left(\mathrm{c}=1.01, \mathrm{CHCl}_{3}\right)$. m.p. $248-250^{\circ} \mathrm{C}($ decomposition $)$. HRMS calcd. for $\mathrm{C}_{28} \mathrm{H}_{30} \mathrm{~N}_{4} \mathrm{O}_{2}+\mathrm{H}: 455.2447$; Found for $\mathrm{MH}^{+}: 455.2442$.

$(S)-18$

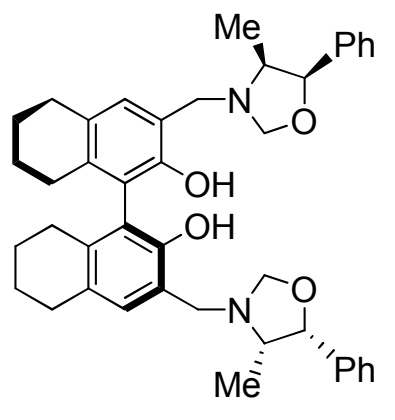

$(S)$-3-(((4R,5S)-4-methyl-5-phenyloxazolidin-3-

yl)methyl)-3'-(((4S,5R)-4-methyl-5-phenyloxazolidin-3-yl)methyl)-5,5',6,6',7,7',8,8'octahydro-1,1'-binaphthyl-2,2'-diol;

$(4 S, 5 R)$-4-methyl-5-phenyloxazolidine was prepared by stirring $(1 R, 2 S)$-(-)-norephedrine (6.05 g, $40 \mathrm{mmoL} ; 99 \%$, Aldrich) with paraformaldehyde (1.20 g, $40 \mathrm{mmoL})$ in degassed dioxane $(10 \mathrm{~mL})$ at $80{ }^{\circ} \mathrm{C}$ for $6 \mathrm{hrs}$ in a 2-neck round bottom flask equipped with stir bar, condenser, and vacuum adaptor. It was used directly (in situ) in the next step. This solution was cooled to room temperature and paraformaldehyde was added. The mixture was reheated to $80{ }^{\circ} \mathrm{C}$ and allowed to stir overnight (12 hrs). The solution was again cooled to room temperature and $(S)-\mathrm{H}_{8} \mathrm{BINOL}(2.4 \mathrm{~g}, 4 \mathrm{mmoL})$ along with another $10 \mathrm{~mL}$ degassed dioxane were added. The solution was returned to $80^{\circ} \mathrm{C}$ and heated for another $12 \mathrm{hrs}$. The reaction was complete at this time. After the usual workup (extraction in chloroform - washed with water and satd. sodium bicarbonate; 
dried with sodium sulfate, filtered, and concentrated) a residual viscous yellow oil is obtained. Upon evacuation of the oil, impure crystals appear. Recrystallization was attempted with hot ethanol. Upon cooling to room temperature (and further in an ice bath), pale yellowish-white crystals formed. NMR analysis identified the crystals as highly pure ((4S,5R)-4-methyl-5-phenyloxazolidin-3-yl)methanol, the aminomethanol starting reagent (formed in situ; an extremely small amount of desired ligand could be observed in the ${ }^{1} \mathrm{H}$ NMR, but only in the baseline of spectra). Thus, column chromatography was performed on the residual oil/crystalline mixture obtained from concentrating the mother liquor. After three columns (performed in repeat of one another; silica gel; hexanes:acetone (5-30 \%) eluent), another crystalline compound was obtained. NMR analysis of this proved to be almost pure ligand and recrystallization with hot ethanol yielded pure compound ( 2 crops, $40 \%$ yield). This technique shows a unique work up procedure whereby a first pass recrystallization can isolate the pure excess starting material making it possible to use again to prepare another batch of ligand.

Characterization of (4S,5R)-4-methyl-5-phenyloxazolidine: ${ }^{1} \mathrm{H}-\mathrm{NMR}\left(300 \mathrm{MHz}, \mathrm{CDCl}_{3}\right)$ $\delta 7.24$ to $7.33(\mathrm{~m}, 4 \mathrm{H}), 7.13$ to $7.16(\mathrm{~m}, 1 \mathrm{H}), 4.86$ to $4.92(\mathrm{~m}, 2 \mathrm{H}), 4.47$ to $4.49(\mathrm{~m}, 1 \mathrm{H})$, 3.43 to $3.50(\mathrm{~m}, 1 \mathrm{H}), 2.17(\mathrm{bs}, 1 \mathrm{H}), 0.74$ to $0.76(\mathrm{~m}, 3 \mathrm{H})$.

Characterization of ((4S,5R)-4-methyl-5-phenyloxazolidin-3-yl)methanol: ${ }^{1} \mathrm{H}-\mathrm{NMR}$ (300 $\left.\mathrm{MHz}, \mathrm{CDCl}_{3}\right) \delta 7.24$ to $7.36(\mathrm{~m}, 5 \mathrm{H}), 5.07(\mathrm{~m}, 1 \mathrm{H}), 4.91(\mathrm{~m}, 1 \mathrm{H}), 4.52(\mathrm{~m}, 1 \mathrm{H}), 3.62(\mathrm{~s}$, $1 \mathrm{H}), 3.43$ to $3.49(\mathrm{~m}, 1 \mathrm{H}), 0.68$ to $0.70(\mathrm{~d}, 3 \mathrm{H})$.

Characterization of $(S)-18:{ }^{1} \mathrm{H}-\mathrm{NMR}\left(300 \mathrm{MHz}, \mathrm{CDCl}_{3}\right) \delta 9.69$ (bs, 2H), 7.21 to $7.32(\mathrm{~m}$, $10 \mathrm{H}), 6.79(\mathrm{~s}, 2 \mathrm{H}), 5.22(\mathrm{~d}, J=6.7 \mathrm{~Hz}, 2 \mathrm{H}), 4.79(\mathrm{~d}, J=4.6 \mathrm{~Hz}, 2 \mathrm{H}), 4.36(\mathrm{~d}, J=4.6 \mathrm{~Hz}$, 
2H), $4.21(\mathrm{~d}, J=13.4 \mathrm{~Hz}, 2 \mathrm{H}), 3.74(\mathrm{~d}, J=13.5 \mathrm{~Hz}, 2 \mathrm{H}), 3.33(\mathrm{p}, J=6.6 \mathrm{~Hz}, 2 \mathrm{H}), 2.75$ (m, $4 \mathrm{H}), 2.16$ to $2.23(\mathrm{~m}, 2 \mathrm{H}), 1.65$ to $1.78(\mathrm{~m}, 8 \mathrm{H}), 0.66(\mathrm{~d}, J=6.8 \mathrm{~Hz}, 6 \mathrm{H}) .{ }^{13} \mathrm{C}-\mathrm{NMR}$ (300 MHz, $\left.\mathrm{CDCl}_{3}\right)$ 151.8, 138.5, 136.2, 128.4, 128.1, 127.7, 127.4, 126.2, 124.2, 118.5, $85.5,80.6,61.4,56.4,29.2,27.0,23.1,15.0 .[\alpha]_{\mathrm{D}}{ }^{25}-124.8(\mathrm{c}=0.960$, THF). M.P. 95-99 ${ }^{\circ} \mathrm{C}$. HRMS calcd. for $\mathrm{C}_{42} \mathrm{H}_{48} \mathrm{~N}_{2} \mathrm{O}_{4}$ : 644.3614. $\left(\mathrm{MH}^{+}=645.3687\right)$. Found: 645.3687.

$(S)-21$

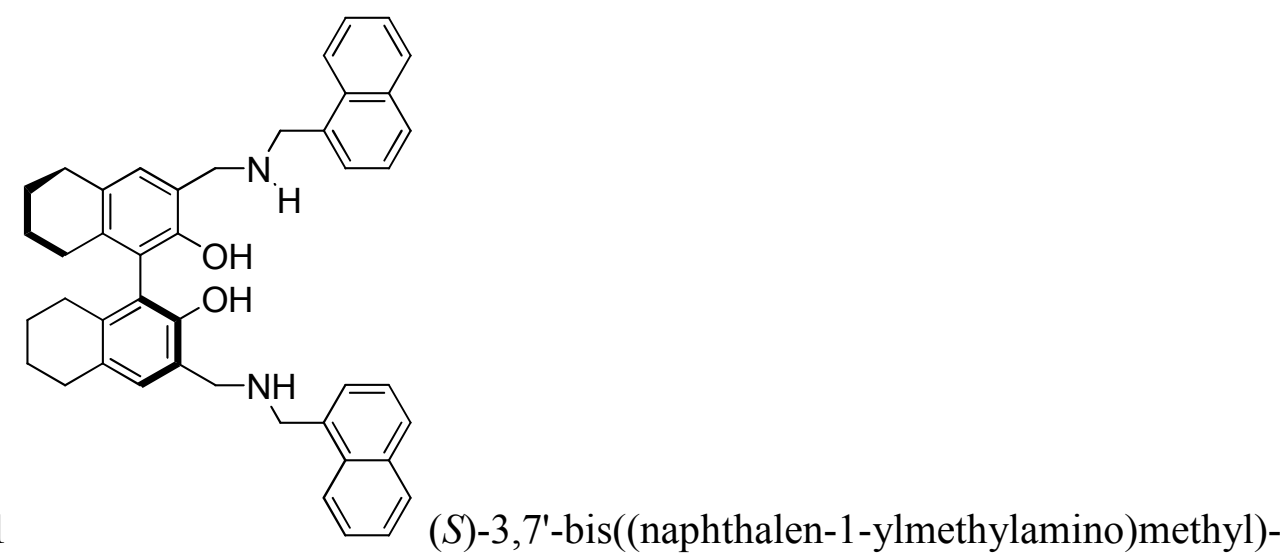
5,5',6,6',7,7',8,8'-octahydro-1,5'-binaphthyl-2,6'-diol;

(1) The phenolic groups of $(S)-\mathrm{H}_{8} \mathrm{BINOL}$ were first protected by treatment with $\mathrm{NaH}$ in $\mathrm{THF}$ at $0^{\circ} \mathrm{C}$ followed by addition of $\mathrm{MOMCl}$. The reaction mixture was warmed to room temperature and stirring was continued for another 3 to $4 \mathrm{hrs}$. The reaction was quenched after this time by the addition of water slowly into the mixture. The reaction was extracted with DCM ( 3 X $75 \mathrm{~mL})$, dried with sodium sulfate, filtered and concentrated. The crude mixture was purified using silica gel chromatography. The top (first) spot on TLC is identified as the diMOM- $(S)-\mathrm{H}_{8} \mathrm{BINOL}$ compound. The next (second) spot on TLC is the monoMOM- $(S)-\mathrm{H}_{8} \mathrm{BINOL}$ compound. The desired compound was obtained in $80 \%$ yield $((S)-\mathbf{1 9}$; with some amount obtained as mixed fractions with the monoMOM- $(S)-\mathrm{H}_{8} \mathrm{BINOL}$ that could be submitted to another column). 
(2) DiMOM- $(S)-\mathrm{H}_{8}$ BINOL was dissolved in THF. TMEDA (4eq, ) was added and the solution was cooled to $0^{\circ} \mathrm{C}$. A solution of $n$-buLi/hexanes was then slowly added into the reaction and allowed to stir for $4 \mathrm{hrs}$. At this time, the reaction was warmed to room temperature and stirred for $\sim 1 \mathrm{hr}$. Dry, distilled DMF was then charged into an ice-cooled solution and allowed to slowly warm to room temperature overnight. The mixture was quenched by the addition of water and then $1 \mathrm{~N} \mathrm{HCl}$. The reaction was extracted with DCM (3 X $75 \mathrm{~mL})$, dried with sodium sulfate, filtered and concentrated. The crude mixture was purified using silica gel chromatography. The top (first) spot on TLC is identified as the diformyl-diMOM- $(S)-\mathrm{H}_{8} \mathrm{BINOL}$ compound. The next (second) spot on TLC is the monoformyl-diMOM- $(S)-\mathrm{H}_{8} \mathrm{BINOL}$ compound. The desired compound was obtained in $70 \%$ yield (with some amount obtained as mixed fractions with the monoformyl-diMOM- $(S)-\mathrm{H}_{8} \mathrm{BINOL}$ that could be submitted to another column).

(3) The diformyldimom- $(S)-\mathrm{H}_{8} \mathrm{BINOL}$ was now deprotected. The pure compound was dissolved in a 1:1 solution of TFA in DCM $(10 \mathrm{~mL})$ and stirred overnight at room temperature. The unprotected diformyl- $\left.(S)-\mathrm{H}_{8} \mathrm{BINOL}(S)-\mathbf{2 0}\right)$ compound was obtained after typical workup (extraction in diethyl ether, dry with $\mathrm{MgSO}_{4}$, filter, concentrate and silica gel chromatography) in $>85 \%$ yield. ${ }^{1} \mathrm{H} \mathrm{NMR}\left(300 \mathrm{MHz}, \mathrm{CDCl}_{3}\right) \delta 10.96(\mathrm{~s}, 2 \mathrm{H})$, $9.88(\mathrm{~s}, 2 \mathrm{H}), 7.35(\mathrm{~s}, 2 \mathrm{H}), 2.83(\mathrm{~m}, 4 \mathrm{H}), 2.49(\mathrm{~m}, 2 \mathrm{H}), 2.22(\mathrm{~m}, 2 \mathrm{H}), 1.76(\mathrm{~m}, 8 \mathrm{H})$.

(4) (S)-3,3'-Diformyl-H ${ }_{8}$ BINOL (S)-20) (480 mg, $1.37 \mathrm{mmol}$ ) was dissolved in $\mathrm{CH}_{2} \mathrm{Cl}_{2}(30 \mathrm{~mL})$ and combined with naphthalen-1-yl methylamine (6.85 mmol, 5 equiv). The reaction mixture was stirred at room temperature for $4 \mathrm{~h}$ and was then concentration under vacuum. The residue was passed through a silica gel column eluted with 
hexanes/ethyl acetate (4-20\%) to give the corresponding Schiff base (818 mg, 1.37 mmol).

(5) The Schiff base was dissolved in ethanol (absolute, $50 \mathrm{~mL}$ ) and cooled down to 0 ${ }^{\circ} \mathrm{C} . \mathrm{NaBH}_{4}$ (4 equiv) was added in small portions, and the solution was then stirred at room temperature for $2 \mathrm{~h}$ to complete the reaction. The product mixture was cooled to 0 ${ }^{\circ} \mathrm{C}$ to which was added $\sim 1.2 \mathrm{~N} \mathrm{HCl}(20 \mathrm{~mL})$ portionwise to quench the reaction. Water $(20 \mathrm{~mL})$ was added and it was stirred for about $2 \mathrm{~h}$ at room temperature. The solution was then basified to $\mathrm{pH} \sim 8-9$. Extraction with $\mathrm{CH}_{2} \mathrm{Cl}_{2}(3 \times 50 \mathrm{~mL})$ followed by evaporation gave an oily yellow solid. Column chromatography purification of the product on silica gel gave $(S)$-21 in $80 \%$ yield as whitish to slight yellow crystals. The compound could be further purified by recrystallization from ethanol which gave $30 \%$ recovered yield from 2 crops. ${ }^{1} \mathrm{H} \mathrm{NMR}\left(300 \mathrm{MHz}, \mathrm{CDCl}_{3}\right) \delta 10.30(\mathrm{bs}, 2 \mathrm{H}), 8.02(\mathrm{~d}, J=$ $8.7 \mathrm{~Hz}, 3 \mathrm{H}), 7.86(\mathrm{~m}, 2 \mathrm{H}), 7.78$ (d, J=7.5 Hz, 3H), 7.45 (m, 10H), 6.79 (s, 2H), 4.27 (bs, 4H), $4.14(\mathrm{~d}, J=13.5 \mathrm{~Hz}, 1 \mathrm{H}), 4.03(\mathrm{~d}, J=13.5 \mathrm{~Hz}, 1 \mathrm{H}), 2.74(\mathrm{~m}, 6 \mathrm{H}), 2.44(\mathrm{~m}, 4 \mathrm{H})$, $2.19(\mathrm{~m}, 4 \mathrm{H}), 1.73(\mathrm{~m}, 12 \mathrm{H}) .{ }^{13} \mathrm{C} \mathrm{NMR}\left(75 \mathrm{MHz}, \mathrm{CDCl}_{3}\right) \delta 152.5,135.9,134.4,133.3$, $131.5,128.7,128.4,128.1,127.4,126.7,126.4,125.7,125.3,124.2,123.1,119.6,52.6$, 50.2, 29.3, 27.0, 23.3, 23.2. $[\alpha]_{\mathrm{D}}^{25}=-33.4(\mathrm{c}=0.52$, THF $)$ m.p. $112-116^{\circ} \mathrm{C} . \mathrm{HRMS}$ calcd. for $\mathrm{C}_{46} \mathrm{H}_{68} \mathrm{~N}_{2} \mathrm{O}_{2}+\mathrm{H}: 633.3476$. Found for $\mathrm{MH}^{+}$: 633.3471 .

Successful reactions (unable to isolate pure ligand): It is important to point out the following ligand syntheses because of the steric issue discovered in the systematic preparation of this class of compounds. At this time, the breadth of aminomethanols capable of reacting with $\mathrm{H}_{8} \mathrm{BINOL}$ is large. However, a difficulty in purification has 
been identified that hampers the efficient and expedient preparation and use of these ligands. The following ligands were successfully prepared (according to ${ }^{1} \mathrm{H}$ NMR of crude and work up mixtures of the reaction) but were unable to be isolated as pure compounds and thus were not used in catalytic screens: (a) $(S)-3,3$ 'bis((dioctylamino)methyl)-5,5',6,6',7,7',8,8'-octahydro-1,1'-binaphthyl-2,2'-diol; (b) (S)3,3'-bis((2-phenylpyrrolidin-1-yl)methyl)-5,5',6,6',7,7',8,8'-octahydro-1,1'-binaphthyl2,2'-diol; (c) (S)-3,3'-bis((dibenzylamino)methyl)-5,5',6,6',7,7',8,8'-octahydro-1,1'binaphthyl-2,2'-diol. The aminomethanols were made according to the same protocol described for other compounds (mixed with paraformaldehyde and heated in dioxane, typically overnight). Following this step, again the typical reaction protocol was done whereby $(S)-\mathrm{H}_{8} \mathrm{BINOL}$ was added with dioxane and reheated for some time. After completion (TLC and ${ }^{1} \mathrm{H}$ NMR), the reaction was worked up and attempted to be purified.<smiles>CCCCCCCCCCCCI</smiles>
dioctylaminomethanol was prepared using the same procedure described (1:1 reaction of paraformaldehyde and dioctylamine stirred at 55-80 ${ }^{\circ} \mathrm{C} 12$ hours in dioxane). When 8 equivalents of dioctylaminomethanol were reacted with $(S)-\mathrm{H}_{8} \mathrm{BINOL}$, the reaction was not complete after 24 hours heating at $80^{\circ} \mathrm{C}$. TLC and crude ${ }^{1} \mathrm{H}$ NMR indicated the starting material was consumed after 40 hours. The reaction was repeated using 30 equivalents of dioctylaminomethanol. This reaction was completed in 16 hours at $80^{\circ} \mathrm{C}$. Numerous extractions, silica gel and alumina gel column chromatography attempts, and recrystallizations were done to the crude mixture but were fruitless in yielding the pure 3,3'-disubstituted amino alcohol ligand. 
(b.)
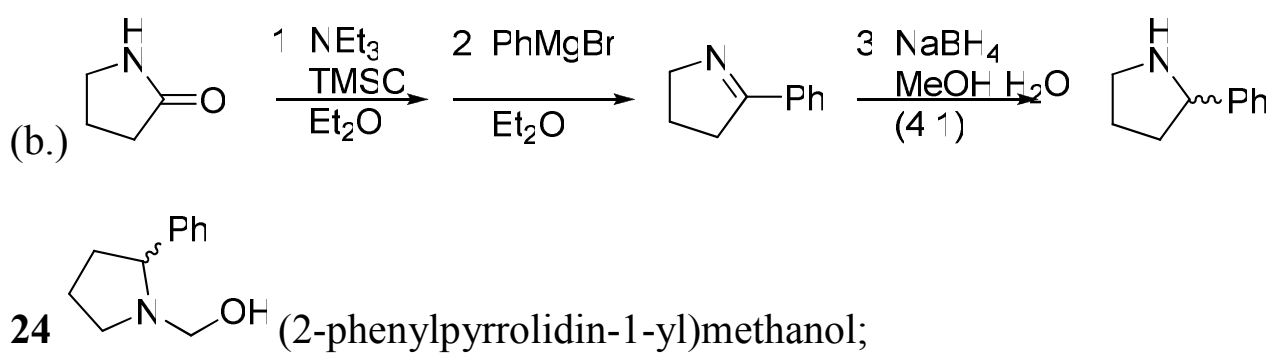

2-methylpyrrolidine was prepared from 2-pyrrolidinone according to the reaction scheme shown above. [REF: 2006, 128(7), 2224-2225]. (2-phenylpyrrolidin-1-yl)methanol was prepared using the same procedure described (1:1 reaction of paraformaldehyde and 2methylpyrrolidine stirred at $55-80{ }^{\circ} \mathrm{C} 12$ hours in dioxane) (2-methylpyrrolidine was distilled from solid $\mathrm{KOH}$ prior to reaction). ${ }^{1} \mathrm{H}-\mathrm{NMR}\left(300 \mathrm{MHz}, \mathrm{CDCl}_{3}\right) \delta 7.17$ (br-s, $1 \mathrm{H}), 3.71(\mathrm{dd}, J=34.5,7.6 \mathrm{~Hz}, 2 \mathrm{H}), 1.49(\mathrm{~m}, 1 \mathrm{H}), 1.31(\mathrm{~m}, 1 \mathrm{H}), 1.30(\mathrm{~d}, J=6.5 \mathrm{~Hz}$, 1H), $1.03(\mathrm{~d}, J=5.4 \mathrm{~Hz}, 3 \mathrm{H}) .20$ equivalents of 2-methylpyrrolidinyl methanol was formed in 5 hours at $65-70{ }^{\circ} \mathrm{C}$ and reacted to form the disubstituted- $\mathrm{H}_{8} \mathrm{BINOL}$ compound in 12 hours at $60-65^{\circ} \mathrm{C}$. The ligand could not be isolated from the crude mixture.

(c.) 25

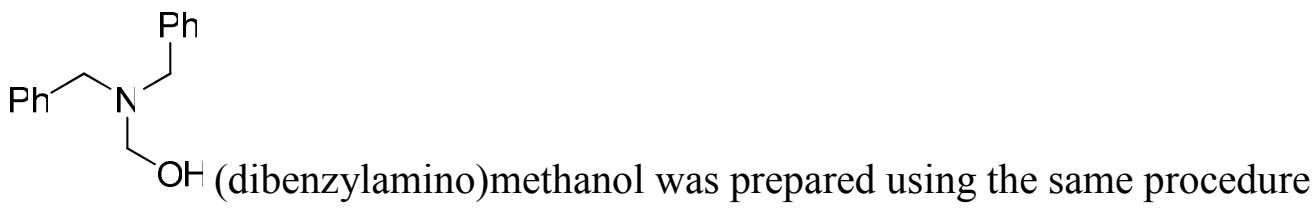
described $\left(1: 1\right.$ reaction of paraformaldehyde and dibenzylamine, stirred at $50{ }^{\circ} \mathrm{C} 14$ hours in dioxane). ${ }^{1} \mathrm{H}-\mathrm{NMR}\left(300 \mathrm{MHz}, \mathrm{CDCl}_{3}\right) \delta 7.47(\mathrm{~m}, 10 \mathrm{H}), 3.83(\mathrm{~s}, 4 \mathrm{H}), 3.32(\mathrm{~s}, 1 \mathrm{H})$. $(S)-\mathrm{H}_{8} \mathrm{BINOL}$ was stirred with either 20 equivalents of (dibenzylamino)methanol for 2 days or with 60 equivalents (dibenzylamino)methanol for 24 hours and heated at 90-100 ${ }^{\circ} \mathrm{C}$ to consume the starting material. After the typical workup (ethyl acetate extraction and wash with saturated sodium bicarbonate and water) and recrystallization from 
ethanol, pure (dibenzylamino)methanol was isolated. Further recrystallization attempts and column chromatography could not afford pure materials.

Unsuccessful reactions (failed ligand preparations):

(a.) 26

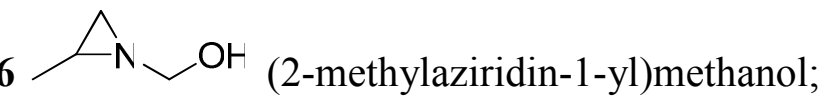

2-methylaziridine (90\%, technical grade) was converted into 2-methylaziridinyl methanol ${ }^{1} \mathrm{H}-\mathrm{NMR}\left(300 \mathrm{MHz}, \mathrm{CDCl}_{3}\right) \delta 7.17(\mathrm{br}-\mathrm{s}, 1 \mathrm{H}), 3.71(\mathrm{dd}, J=34.5,7.6 \mathrm{~Hz}, 2 \mathrm{H}), 1.49(\mathrm{~m}$, 1H), $1.31(\mathrm{~m}, 1 \mathrm{H}), 1.30(\mathrm{~d}, J=6.5 \mathrm{~Hz}, 1 \mathrm{H}), 1.03(\mathrm{~d}, J=5.4 \mathrm{~Hz}, 3 \mathrm{H})$.

(b.) 27<smiles>O=C1OCCN1CO</smiles>
3-(hydroxymethyl)oxazolidin-2-one was prepared using the same procedure described (1:1 reaction of paraformaldehyde and 2-oxazolidinone stirred at 75$80{ }^{\circ} \mathrm{C} 7.5$ hours in dioxane). ${ }^{1} \mathrm{H}-\mathrm{NMR}\left(300 \mathrm{MHz}, \mathrm{CDCl}_{3}\right) \delta 4.76(\mathrm{~m}, 2 \mathrm{H}), 4.32(\mathrm{~m}, 2 \mathrm{H})$, $4.72(\mathrm{~m}, 2 \mathrm{H}), 3.65$ (br-s, 1H). 15 equivalents of the aminomethanol was stirred with $(S)$ $\mathrm{H}_{8} \mathrm{BINOL}$ at $95{ }^{\circ} \mathrm{C}$ for 16 hours but did not react at all. No reaction was observed after the solution was refluxed for 24 hours. A separate preparation of 3(hydroxymethyl)oxazolidin-2-one was done in $1 \mathrm{~mL}$ dioxane and was then added to a reaction vial with $(S)-\mathrm{H}_{8} \mathrm{BINOL}$. The vial was sealed under nitrogen and heated at 120 ${ }^{\circ} \mathrm{C}$ for 10 hours. Again, no reaction was observed.

(c.) 2,2,6,6-tetramethylpiperidinyl methanol did not react with $(S)-\mathrm{H}_{8} \mathrm{BINOL}$ in refluxing dioxane over multiple days.

(d.) An impure mixture was prepared in an attempt to synthesize $N$-(hydroxymethyl)-4methylbenzenesulfonamide. This was likely a mixture of 
<smiles>Cc1ccc(S(=O)(=O)NCO)cc1</smiles>

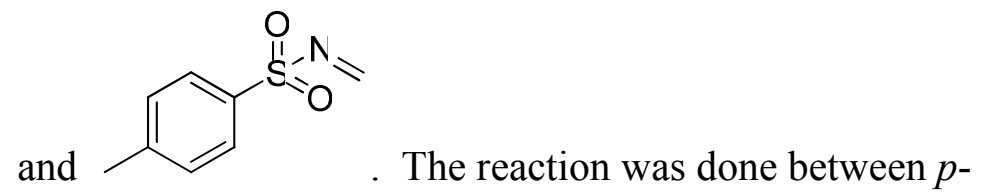

toluenesulfonamide and paraformaldehyde following the scheme to prepare $N$ tosylaldimines (see chapter 6 ). The mixture was added in excess with $(S)-\mathrm{H}_{8} \mathrm{BINOL}$ in dioxane but did not react at reflux over 24 hours. The sealed tube (vial) reaction was attempted $\left(135^{\circ} \mathrm{C}, 16\right.$ hours $)$ but again no reaction occurred. The reaction between a pure $N$-tosylaldimine — prepared from 4-chlorobenzaldehyde (see chapter 6) — was also attempted with $(S)-\mathrm{H}_{8} \mathrm{BINOL}$ in refluxing dichloromethane. No reaction was observed even after the addition of catalytic $p$-toluenesulfonic acid.

\section{Other Ligand Syntheses and Characterization:}

(S)-22<smiles>O=C(O)c1cc2c(cc1O)CCC2</smiles><smiles></smiles>

(S)-2,2'-dihydroxy-5, 5',6,6',7,7',8,8'-octahydro-1,1'-binaphthyl-3-

carboxylic acid;

${ }^{1} \mathrm{H}-\mathrm{NMR}\left(300 \mathrm{MHz}, \mathrm{CDCl}_{3}\right) \delta 10.31$ (br-s, 1H), $7.73(\mathrm{~s}, 1 \mathrm{H}), 7.04(\mathrm{~d}, J=8.2 \mathrm{~Hz}, 1 \mathrm{H})$, $6.80(\mathrm{~d}, J=8.3 \mathrm{~Hz}), 1 \mathrm{H}), 2.77(\mathrm{~m}, 4 \mathrm{H}), 2.24(\mathrm{~m}, 4 \mathrm{H}), 1.73(\mathrm{~m}, 8 \mathrm{H})$. 


\section{e. References:}

1. For reviews on BINOL-based compounds in asymmetric catalysis, see: (a) Chen, Y.; Yekta, S.; Yudin, A. Chem. Rev. 2003, 103, 3155-3211. (b) Kocovsky, P.; Vyskocil, S.; Smrcina, M. Chem. Rev. 2003, 103, 3213-3245. (c) Brunel, J. M. Chem. Rev. 2005, 105, 857-897. (d) Shibasaki, M.; Matsunaga, S. Chem. Soc. Rev. 2006, 35, 269-279. (e) Pu, L. Chem. Rev. 1998, 98, 2405-2494.

2. (a) Shibasaki, M.; Matsunaga, S. Chem. Soc. Rev. 2006, 35, 269-279. (b) Noyori, R.; Ohta, M.; Hsiao, Y.; Kitamura, M.; Ohta, T.; Takaya, H. J. J. Am. Chem. Soc. 1986, 108, 7117-7119. (c) Kitamura, M.; Tokunaga, M.; Noyori, R. J. Am. Chem. Soc. 1995, 117, 2931-2932.

3. (a) For a review on BINOL-AMs, see: Nájera, C.; Sansano, J. M.; Saá, J. M. Eur. J. Org. Chem. 2009, 2385-2400. For examples of 2-aminomethyl-substituted binaphthyl compounds, see (b) Bringmann, G.; Matthias Breuning, M. Tetrahedron: Asymmetry 1998, 9, 667-679. (c) Ko, D. -H.; Kim, K. H.; Ha, D. -C. Org. Lett. 2002, 4, 37593762.

4. (a) Richter, S. N.; Maggi, S.; Colloredo-Mels, S.; Palumbo, M.; Freccero, M. J. Am. Chem. Soc. 2004, 126, 13973-13979. (b) Colloredo-Mels, S.; Doria, F.; Verga, D.; Freccero, M. J. Org. Chem. 2006, 71, 3889-3895. (c) Doria, F.; Richter, S. N.; Nadai, M.; Colloredo-Mels, S.; Mella, M.; Palumbo, M.; Freccero, M. J. Med. Chem. 2007, 50, $6570-6579$.

5. For a review on $\mathrm{H}_{8} \mathrm{BINOL}$ derivatives, see: Au-Yeung, T. T.-L.; Chan, S.-S.; Chan, A. S. C. Adv. Synth. Catal. 2003, 345, 537-555. 
6. For detailed experimental studies on BINOL-titanoate complexes, see: (a) Balsells, J.; Davis, T. J.; Carroll, P.; Walsh, P. J. J. Am. Chem. Soc. 2002, 124, 10336-10348. (b) Davis, T. J.; Balsells, J.; Carroll, P.; Walsh, P. J. Org. Lett. 2001, 3 (5), 699-702. (c) Walsh, P. J. Acc. Chem. Res. 2003, 36, 739-749. For example of $\mathrm{H}_{8}$ BINOL-titanoate catalyst, see: Kim, J. G.; Camp, E. C.; Walsh, P. J. Org. Lett. 2006, 8, 4413-4416. 7. (a) Liu, L.; Pu, L. Tetrahedron 2004, 60, 7427-7430. (b) Qin, Y. -C.; Liu, L.; Pu, L. Org. Lett. 2005, 7, 2381-2383.

8. Ruan, J.; Lu, G.; Xu, L.; Li, Y.-M. ; Chan, A. S.C. Adv. Synth. Catal., 2008, 350, 7684.

9. (a) Turlington, M. ; DeBerardinis, A. M. ; Pu, L. Org. Lett. 2009, 11 (11), 2441-2444. (b) Yue, Y.; Turlington, M.; Yu, X.-Q.; Pu, L. J. Org. Chem. 2009, 74 (22), 8681-8689. 10. (a) Qin, Y.-C. ; Pu, L. Angew. Chem. Int. Ed. 2006, 45, 273-277. For related asymmetric catalytic reactions, see: (b) Huang, W.-S. ; Pu, L. J. Org. Chem. 1999, 64, 4222-4223 and (c) Huang, W.-S. ; Pu, L. Tetr.Lett. 200, 41, 145-149.

11. Turlington, M. ; Pu, L. Org. Synth. 2010, 87, 59-87.

12. DeBerardinis, A. M. ; Turlington, M. ; Ko, J. ; Sole, L. ; Pu, L. J. Org. Chem. 2010, $75,2836-2850$.

13. Pu, L. 1,1-Binaphthyl-based Chiral Materials : Our Journey; Imperial College Press: World Scientific Publishing, 2009.

14. (a) Soai, K.; Watanabe, M.; Koyano, M. Bull. Chem. Soc. Jpn. 1989, 62, 2124-2125.

(b) Oguni, N.; Omi, T. Tetrahedron Lett. 1984, 25, 2823-2824. (c) Soai, K.; Niwa, S. Chem. Rev. 1992, 92, 833-856. (d) Pu, L.; Yu, H.-B. Chem. Rev. 2001, 101, 757-824. (e) Bolm, C. Hermanns, N.; Hilderbrand, J. P.; Muniz, K. Angew. Chem. Int. Ed. 2000, 39, 
3465-3468. (f) Oppolzer, W.; Radinov, R. N. Tetrahedron 1991, 32, 5777-5780. (g) Pu, L. Tetrahedron 2003, 59, 9873-9886. (h) Anand, N. K.; Carreira, E. M. J. Am. Chem. Soc. 2001, 123, 9687-9688. (i) B0yall, D.; Frantz, D. E.; Carreira, E. M. Org. Lett. 2002, 4, 2605-2606.

15. (a) Vogl, E. M.; Groger, H.; Shibasaki, M. Angew. Chem. Int. Ed. 1999, 38, 15701577. (b) Qin, Y.-C.; Pu, L. Org. Lett. 2005, 7 (12), 2381-2383.

16. (a) Qin, Y.-C. ; Pu, L. Angew. Chem. Int. Ed. 2006, 45, 273-277. (b) Li, Z.; Pu, L. Org. Lett., 2004, 6 (6), 1065.

17. Qin, Y.-C.; Liu, L.; Sabat, M. ; Pu, L. Tetrahedron 2006, 62, 9335-9348.

18. Lindsey, A. S.; Jeskey, H. Chem. Rev. 1957, 57 (4), 583-620. 
Chapter 3: Functional Arylzinc Generation and Catalytic Asymmetric Additions to Aldehydes

a. Introduction

b. Generation and Catalytic Asymmetric Arylations to Aldehydes

c. Screening the $\mathrm{H}_{8}$ BINOL-AM Ligands for the Reaction of Methyl pIodobenzoate with Aldehydes

d. Screening the $\mathrm{H}_{8}$ BINOL-AM Ligands for the Reaction of m-Iodoanisole with Aldehydes

e. Screening the $\mathrm{H}_{8} \mathrm{BINOL-AM}$ Ligands for the Reaction of $\mathrm{m}$ Iodobenzonitrile with p-Methoxybenzaldehyde

f. Asymmetric Reaction of the Arylzinc Reagents Derived from 2Iodothiophene and 2-Bromothiophene Catalyzed by the $\mathrm{H}_{8}$ BINOL-AMs

g. Asymmetric Reaction of the in situ Generated Diphenylzinc from Iodobenzene Catalyzed by the $\mathrm{H}_{8}$ BINOL-AMs

h. Lignad Enantiomeric Purity Correlation Experiment, Absolute Configuration Assignment, and NMR study

i. Experimental and Characterization

j. References 


\section{a. Introduction}

The asymmetric arylzinc addition to aldehydes generates chiral diaryl and arylalkyl carbinols that are ubiquitous in organic molecules including those with biological activities. For example, diaryl carbinols and derivatives shown in Figure 3.1 have been found to be useful drug molecules with antihistamine, anticholergenic, analgesic, and other properties. ${ }^{1}$

Figure 3.1. Drug Molecules Made from Diaryl Carbinols.<smiles>Cc1ccc(C(OCCN(C)C)c2ccccc2)cc1</smiles>

$(R)$-neobenodine<smiles>Cc1ccccc1C(OCCN(C)C)c1ccccc1</smiles>

$(R)$-orphenadrine

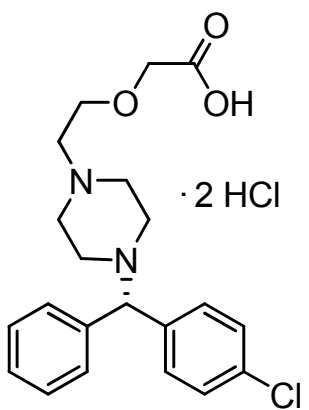

(S)-cetirizine<smiles>CN1CCC[C@H]1CCOC(=O)c1ccc(Cl)cc1</smiles><smiles>Cc1ccc([C@@H](OCCN(C)C)c2ccnn2C)cc1</smiles>

$(R)$-Cizolirtine<smiles>COc1ccc(C(Cc2ccncc2)c2ccccc2)cc1OC1CCCC1</smiles>

Although significant progress has been made on the asymmetric $\mathrm{Ph}_{2} \mathrm{Zn}$ addition to aldehydes, ${ }^{2}$ the study on the asymmetric reaction of other functional arylzincs with aldehydes had remained limited.,

A report by $\mathrm{Pu}$ and Huang in 1999 showed that good enantiocontrol was achieved for asymmetric phenylation of aldehydes by using bifunctional ligand $(R)$-33 (figure below). ${ }^{5}$ The asymmetric reaction is practically simple and direct, employing commercially 
available diphenylzinc and a catalytic amount of an chiral ligand. More recently, Qin and $\mathrm{Pu}$ found that the chiral 1,1'-binaphthyl compound $(S)$-2, prepared in one step from $(S)$ $\mathrm{H}_{8}$ BINOL (5,5',6,6',7,7',8,8' -octohydro-1,1'-bi-2-naphthol), was highly enantioselective for the reaction of diphenylzinc with aromatic, aliphatic, and $\alpha, \beta$-unsaturated aldehydes. ${ }^{6}$

Figure 3.2. Catalytic Asymmetric Diphenylzinc Additions and Ligands Employed<smiles>CCOc1ccc(OCC)c(-c2cc3ccccc3c(-c3c(O)c(-c4cc(OCC)ccc4OCC)cc4ccccc34)c2O)c1</smiles>

Huang and Pu, 1999

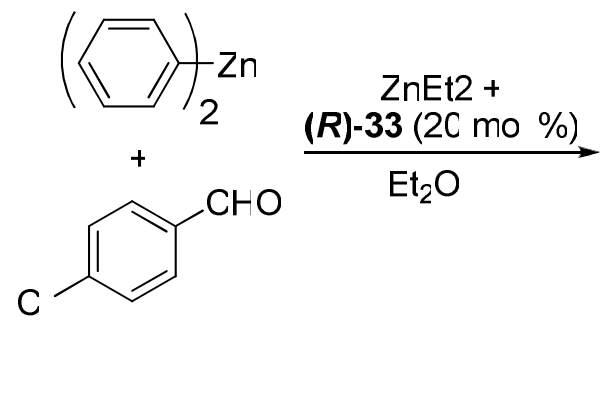<smiles>Cc1ccc(C(O)(O)c2ccccc2)cc1</smiles><smiles>Oc1c(CN2CCOCC2)cc2c(c1-c1c(O)c(CN3CCOCC3)cc3c1CCCC3)CCCC2</smiles>

(S)-2
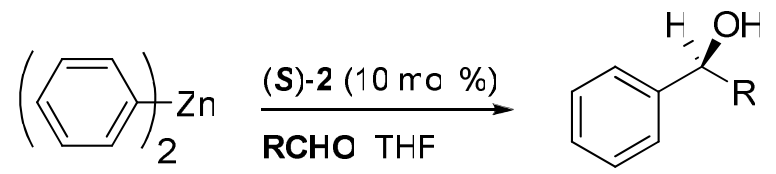

up to $\subseteq 8 \%$ ee

$\mathrm{R}=\mathrm{a} \mathrm{ky}$ ary

Again, the reaction followed the same straightforward protocol. It involved the premixing of ligand $(S)$-2 (10 mol\%) with diphenylzinc (1.2 equiv) in THF. After one hour, the aldehyde was added. Additions were complete in 6 to 12 hours yielding the chiral phenylmethanols in up to $97 \%$ yield and $98 \%$ ee.

The addition of organozinc reagents to aldehydes to synthesize secondary alcohols has become a useful method because of the high functional group tolerance of the organozinc reagents. Many highly enantioselective catalysts have also been 
developed for the asymmetric alkylzinc addition to aldehydes. ${ }^{7}$ Among the work reported for various organozinc reagents, the study of diarylzincs has mainly concentrated on diphenylzinc because only this diarylzinc reagent is readily available. Bolm ${ }^{8}$ and Dahmen ${ }^{9}$ reported the use of the pre-prepared arylboronic acids and arylboranes in combination with $\mathrm{Et}_{2} \mathrm{Zn}$ to generate various arylzincs for the catalytic asymmetric addition to aldehydes respectively. Since 2005, Walsh has studied the in situ conversion of aryl bromide to arylzincs by treatment with ${ }^{\mathrm{n}} \mathrm{BuLi}$ and $\mathrm{ZnCl}_{2}$ or EtZnCl and the subsequent asymmetric arylzinc addition to aldehydes. ${ }^{3 a, b}$ High enantioselectivity was achieved for a number of substrates. The reaction of aryl bromides with ${ }^{\mathrm{n}} \mathrm{BuLi}$ was done at low temperature. The preparation of arylzincs in this method uses an alkyllithium. Therefore, the method could potentially limit the type of functional groups on the resulting diarylzincs. The catalytic asymmetric additions of other nucleophilic aryl reagents to carbonyl compounds have also been reported. ${ }^{4}$

\section{b. Generation and Catalytic Asymmetric Arylations to Aldehydes}

Recently, Knochel reported a preparation of diarylzincs from the reaction of aryl iodides with a dialkylzinc under very mild conditions. ${ }^{10}$ The use of a dialkylzinc in this method instead of an alkyllithium allows the preparation of a great variety of functional arylzinc reagents. We tested the reaction of aldehydes with a few functional arylzincs prepared in situ with this method, but only observed very low yields of the alcohol products. Scheme 3.1 shows the reaction of $m$-iodoanisole with $\mathrm{Et}_{2} \mathrm{Zn}$ under Knochel's conditions which presumably produced a diarylzinc complex. ${ }^{10,11}$ When this arylzinc was treated with cyclohexanecarboxaldehyde at room temperature, the corresponding alcohol was isolated in only $30 \%$ yield after $19 \mathrm{~h}$ (scheme 3.1 below). ${ }^{12}$ Therefore, these 
arylzincs have quite low nucleophilicity and require activation for their addition to aldehydes.

Scheme 3.1 Preparation of a Substituted Arylzinc and Its Addition to an Aldehyde.
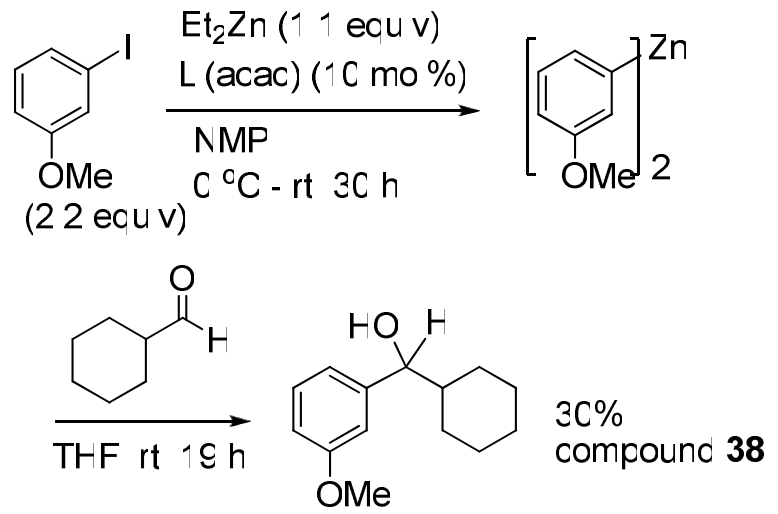

(S)-2 was tested in the reaction of the generated functional arylzincs with aldehydes. In the presence of $10 \mathrm{~mol} \%$ of $(S)$-2, the arylzinc generated in situ from $m$-iodoanisole reacted with cyclohexancarboxaldehyde to give the desired secondary alcohol not only in greatly increased yield (94\%) but also with very high enantioselectivity ( $>99 \%$ ee).

Thus, (S)-2 not only activated the nucleophilic arylzinc addition to the aldehyde but also demonstrated excellent stereocontrol in the addition. Scheme 3.2 below summarizes these initial findings.

Scheme 3.2 General Functional Arylation Protocol for the Asymmetric Catalysis of Enantioenriched Functional Aryl Alcohols

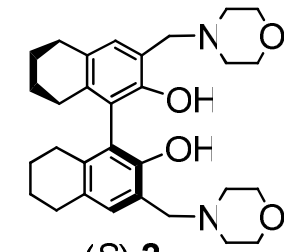

$(S)-2$

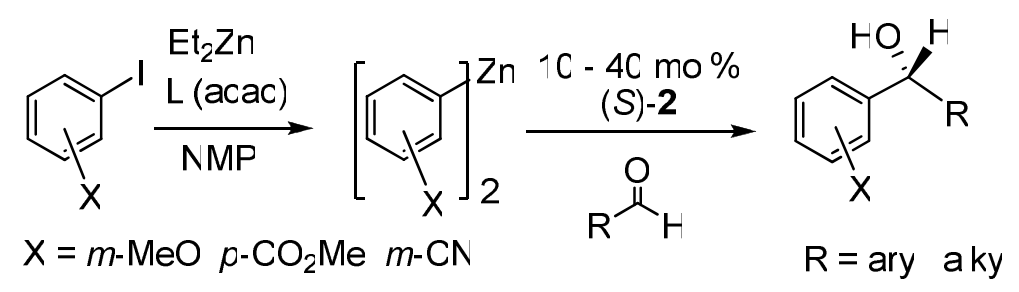

Table 3.1 shows the results of the arylzinc generated from $m$-iodoanisole and the catalyzed additions to aldehydes. 
Table 3.1 Addition of the Arylzinc Generated from $m$-Iodoanisole to Aldehydes in the Presence of $10 \mathrm{~mol} \%(S)-2$.

\begin{tabular}{|c|c|c|c|c|c|c|}
\hline Entry & Compound \# & Product & Time $(h)^{a}$ & Yield (\%) & ee $(\%)$ & Yield without $(S)-2$ \\
\hline 1 & 34 & & 7 & 93 & 91 & 56 \\
\hline 2 & 35 & & 11 & 95 & 91 & 43 \\
\hline 3 & 36 & & 10 & 85 & 90 & 41 \\
\hline 4 & 37 & & 8 & 93 & 83 & trace \\
\hline 5 & 38 & & 16 & 93 & $>99$ & 30 \\
\hline 6 & 39 & & 14 & 85 & 96 & 10 \\
\hline 7 & 40 & & 16 & 85 & 93 & 17 \\
\hline 8 & 41 & & 10 & $90^{\mathrm{b}}$ & $>99 ; 99$ & 25 \\
\hline
\end{tabular}

a. Third step. b. The combined yield of both diastereomers.

Table 3.1 summarizes the reaction of the in situ prepared $(m-\mathrm{MeOPh})_{2} \mathrm{Zn}$ with various aldehydes catalyzed by $(S)-2$. In the presence of $10 \mathrm{~mol} \%$ of $(S)-2$, the arylzinc 
additions to aromatic and aliphatic aldehydes are greatly activated. Without $(S)-\mathbf{2}$, the reactions are much slower with very low yields of the alcohol products. For example, almost no product was obtained for the arylzinc addition to $m$-nitrobenzaldehyde in the absence of (S)-2 (entry 4). However, using $(S)$-2 led to 93\% yield of the desired diarylcarbinol. In addition, high enantioselectivity ( 83 - >99\% ee) was achieved for the arylzinc addition to both aromatic and aliphatic aldehydes. In entry 8 , the addition to a chiral aldehyde generated both diastereomers in 1:1 ratio, each with over $99 \%$ ee.

Using a procedure similar to that described above, we conducted the reaction of benzaldehyde with the arylzinc generated in situ from methyl $p$-iodobenzoate and $\mathrm{Et}_{2} \mathrm{Zn}$. As shown in entry 1 of Table 3.2 , this gave only low yield (47\%) and ee $(67 \%)$ of the corresponding diarylcarbinol product. Increasing the time for the arylzinc formation step at room temperature increased the yield to $63 \%$ and the ee to $71 \%$ (entry 2). Using $\mathrm{Ph}_{2} \mathrm{Zn}$ or $\mathrm{Et}_{2} \mathrm{Zn}$ to prepare the zinc complex of $(S)-2$ as the catalyst increased the yield but decreased the ee (entries 3,4). Increasing the amount of $(S)-2$ to $20 \mathrm{~mol} \%$ did not improve the enantioselectivity (entry 5). Changing the solvent in the second step from THF to toluene or $\mathrm{Et}_{2} \mathrm{O}$ decreased the ee (entries 6,7). Using $\mathrm{CH}_{2} \mathrm{Cl}_{2}$ as the solvent in the second step significantly improved both the yield and ee (entry 8). Increasing the amount of $\mathrm{CH}_{2} \mathrm{Cl}_{2}$ further improved the enantioselectivity (entry 9). Finally, by using $20 \mathrm{~mol} \%$ of $(S)-2$ in $\mathrm{CH}_{2} \mathrm{Cl}_{2}$ at $0{ }^{\circ} \mathrm{C}$, up to $97 \%$ yield and $94 \%$ ee were obtained for this reaction (entry 11).

\section{Table 3.2 Conditions for the Reaction of the Arylzinc Generated from Methyl $p$ - Iodobenzoate with Benzaldehyde in the Presence of $(S)-2 .^{\text {a }}$}




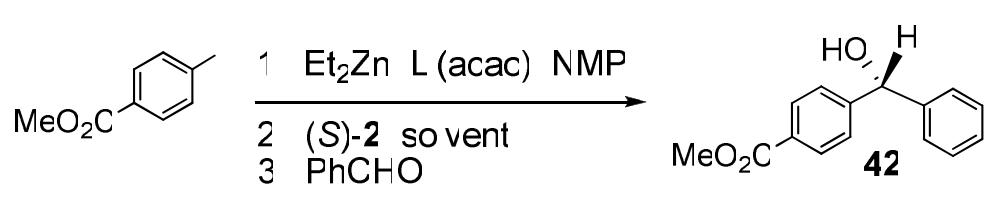

\begin{tabular}{|c|c|c|c|c|c|c|c|}
\hline Entry & $\begin{array}{c}\text { Time, step } \\
1 \text { (h) }\end{array}$ & $\begin{array}{c}(S)-1 \\
(\mathrm{~mol} \%)\end{array}$ & $\begin{array}{c}\text { Solvent } \\
\text { step } 2(\mathrm{~mL})\end{array}$ & $\begin{array}{c}\text { Step } 3 \\
\text { Temp }\left({ }^{\circ} \mathrm{C}\right)\end{array}$ & $\begin{array}{c}\text { Time, } \\
\text { step } 3 \text { (h) }\end{array}$ & $\begin{array}{l}\text { Isolated } \\
\text { yield (\%) }\end{array}$ & $e e(\%)^{b}$ \\
\hline $1^{\mathrm{c}}$ & 12 & 10 & THF (5) & rt & 27 & 47 & 67 \\
\hline $2^{\mathrm{d}}$ & 12 & 10 & THF (5) & $\mathrm{rt}$ & 27 & 63 & 71 \\
\hline $3^{\mathrm{e}}$ & 18 & 10 & THF (5) & $\mathrm{rt}$ & 22 & 75 & 54 \\
\hline $4^{f}$ & 16 & 10 & THF (5) & $\mathrm{rt}$ & 27 & 90 & 52 \\
\hline 5 & 18.5 & 20 & THF (5) & $\mathrm{rt}$ & 17.5 & 86 & 65 \\
\hline $6^{\mathrm{g}}$ & 21 & 10 & Toluene (5) & $\mathrm{rt}$ & 23 & quant. & 45 \\
\hline 7 & 21 & 10 & $\mathrm{Et}_{2} \mathrm{O}(5)$ & $\mathrm{rt}$ & 23 & 80 & 55 \\
\hline 8 & 18.5 & 10 & $\mathrm{CH}_{2} \mathrm{Cl}_{2}(5)$ & $\mathrm{rt}$ & 16 & 88 & 79 \\
\hline 9 & 12 & 10 & $\mathrm{CH}_{2} \mathrm{Cl}_{2}(10)$ & $\mathrm{rt}$ & 9 & 93 & 84 \\
\hline 10 & 17 & 20 & $\mathrm{CH}_{2} \mathrm{Cl}_{2}(5)$ & $\mathrm{rt}$ & 9 & 99 & 84 \\
\hline 11 & 18 & 20 & $\mathrm{CH}_{2} \mathrm{Cl}_{2}(20)$ & $\mathbf{0}$ & 17 & 97 & 94 \\
\hline
\end{tabular}

a. Unless otherwise indicated, the following conditions were employed: $2.0 \mathrm{mmol}$ methyl $p$-Iodobenzoate ( $2.2 \mathrm{eq}), 0.24 \mathrm{mmol} \mathrm{Li}(\mathrm{acac})(12 \mathrm{~mol} \%$, relative to the aryl iodide), $1.1 \mathrm{mmol} \mathrm{Et}_{2} \mathrm{Zn}$ (0.55 eq, relative to the aryl iodide), NMP (1.5 mL), and 0.91 mmol benzaldehyde (1.0 eq). Preparation of the arylzinc in the first step was conducted at $0{ }^{\circ} \mathrm{C}$. Upon addition of $(S)-2$ to the arylzinc solution, the reaction mixture was stirred for $1 \mathrm{~h}$ prior to addition of aldehyde. $\mathrm{b}$. Measured on Chiralpak HPLC AD column ( $2 \%$ IPA:98\% hexanes, $1 \mathrm{~mL} / \mathrm{min})$. c. Arylzinc was prepared at $0{ }^{\circ} \mathrm{C}$ for $6 \mathrm{~h}$ and then at $\mathrm{rt}$ for $6 \mathrm{~h}$. d. Arylzinc was prepared at $0{ }^{\circ} \mathrm{C}$ for $0.5 \mathrm{~h}$ and then at $\mathrm{rt}$ for $11.5 \mathrm{~h}$. e. $(S)-2$ was 
mixed with $\mathrm{Ph}_{2} \mathrm{Zn}$ (2 equiv versus the ligand) at $\mathrm{rt}$ for $1 \mathrm{~h}$ and then combined with benzaldehyde before addition to the arylzinc solution. f. (S)-2 was mixed with $\mathrm{Et}_{2} \mathrm{Zn}$ (2 equiv versus the ligand) at $\mathrm{rt}$ for $1 \mathrm{~h}$ and then combined with benzaldehyde before addition to the arylzinc solution. g. 3.2 eq aryl iodide was used.

The optimized conditions of entry 11 in Table 3.2 were applied to the reaction of various aldehydes with the arylzinc generated in situ from methyl $p$-iodobenzoate and $\mathrm{Et}_{2} \mathrm{Zn}$, and the results are summarized in Table 3.3. High yield and enantioselectivity were observed for a variety of aliphatic, aromatic and $\alpha, \beta$-unsaturated aldehydes. Using $(S)-\mathbf{2}$ has greatly activated the arylzinc addition with high stereocontrol. For example, without $(S)-\mathbf{2}$, the arylzinc generated from methyl $p$-iodobenzoate added minimally to cyclohexanecarboxaldehyde (4\% yield). In the presence of $20 \mathrm{~mol} \%(S)-2$, the desired product was isolated in $86 \%$ yield and $96 \%$ ee (entry 1 ).

Table 3.3 Addition of the Arylzinc Generated from Methyl p-Iodobenzoate to Aldehydes in the Presence of $20 \mathrm{~mol} \%(S)-2 .{ }^{a}$

\begin{tabular}{|c|c|c|c|c|c|c|}
\hline Entry & Compound \# & Product & Time $(h)^{\mathrm{a}}$ & ${ }^{\mathrm{a}}$ Yield (\%) & ee $(\%)$ & Yield without $(S)-1$ \\
\hline 1 & 43 & $\mathrm{MeO}_{2} \mathrm{C}^{-}$ & 16 & 86 & 96 & 4 \\
\hline 2 & 44 & $\mathrm{MeO}_{2} \mathrm{C}$ & 15 & 91 & 94 & 28 \\
\hline 3 & 45 & $\mathrm{MeO}_{2} \mathrm{C}$ & 13 & 84 & 92 & 37 \\
\hline 4 & 42 & 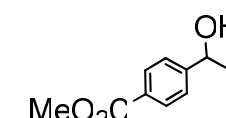 & 17 & 97 & 94 & -- \\
\hline
\end{tabular}


46

5

6

7

8

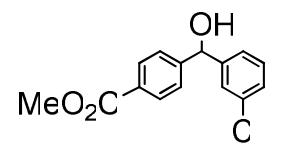

47

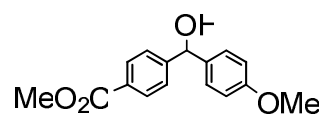

48

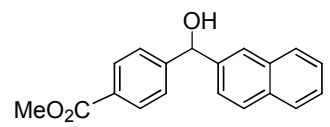

49

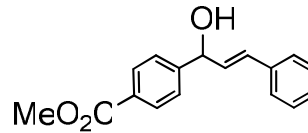

15

15

15

20
93

88

52

89

92

90

87

a. Third step.

An interesting byproduct was identified for the reaction taking place at room temperature. If the ligand exchange (step one: mixing of aryl iodide, $\mathrm{Et}_{2} \mathrm{Zn}$, and $\mathrm{Li}(\mathrm{acac})$ in NMP) was done at room temperature, the reaction became cloudier after about 30 to 60 minutes but never went into solution. This was observed for all other arylations.

However, when step one was done at $0{ }^{\circ} \mathrm{C}$, a homogeneous solution formed as expected and in agreement with the other arylation studies. It was determined that the biaryl product was rapidly being formed but only at room temperature (higher temperatures were not studied).

Biaryl Compound Generated From the Attempted Room Temperature Ligand Exchange Between Et $t_{2} Z n$ and Methyl-p-iodobenzoate in the Presence of Li(acac)<smiles>CC(=O)c1ccc(-c2ccc(C(C)=O)cc2)cc1</smiles> 
Various conditions were examined for this unique biaryl formation. No biaryl formation was observed when the aryl iodide and $\mathrm{Et}_{2} \mathrm{Zn}$ in $\mathrm{DCM}$ were mixed in the absence or in the presence of the $\operatorname{Li}(\mathrm{acac})$ additive. When the reagents were mixed in NMP (including Li(acac)), 35\% of the biaryl was isolated. Interestingly, 52\% was isolated when $\mathrm{Li}(\mathrm{acac})$ was absent from the NMP reaction. Each reaction that generated the biaryl appeared to reach completion within one hour as shown by TLC. This was perplexing as it also appeared that most of the biaryl compound formed appeared to crash out of the NMP solution. Perhaps this could be explained by a concentration dependence.

It is unknown through what process the biaryl compound is formed. Either a reductive elimination from the diarylzinc or the monoarylzinc displacement of another molecule of aryl iodide could occur. The reaction must take place at room temperature however as this pathway is shutdown at $0{ }^{\circ} \mathrm{C}$. The ester aryl iodide was the only substrate studied found to generate its biaryl byproduct. Therefore, it is not at this time anticipated that this could be a versatile method to prepare a series of biaryl compounds. Rather, this may well be a single example dependent solely on the substrate electronics. However, this should be further explored, for example, reactions done at elevated temperatures or in pressurized vessels at elevated temperatures, to study potential palladium-free couplings.

We also studied the reaction of benzaldehyde with the arylzinc generated from $m$ iodobenzonitrile in the presence of $(S)$-2. Table 3.4 summarizes the conditions for this reaction. It was found that THF was a better solvent than others such as $\mathrm{CH}_{2} \mathrm{Cl}_{2}$, toluene, and $\mathrm{Et}_{2} \mathrm{O}$ (entries 1-11). The optimized conditions involved the use of $40 \mathrm{~mol} \%(S)-2$ and THF at $0{ }^{\circ} \mathrm{C}$ which gave the product in $87 \%$ yield and $84 \%$ ee (entry 14 ). 
Table 3.4 Conditions for the Reaction of Arylzinc Generated from $m$ -

Iodobenzonitrile with Benzaldehyde in the Presence of $(S)-2 .^{a}$

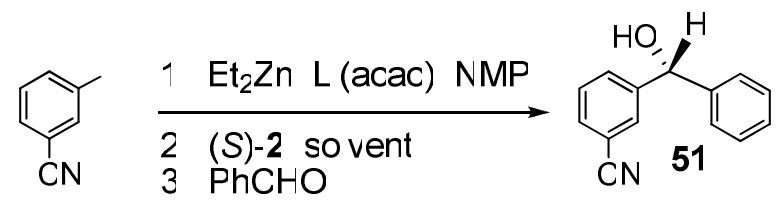

\begin{tabular}{|c|c|c|c|c|c|c|c|}
\hline Entry & $\begin{array}{c}\text { ArI } \\
\text { (equiv) }\end{array}$ & $\begin{array}{c}(\mathrm{S})-1 \\
(\mathrm{~mol} \%)\end{array}$ & $\begin{array}{c}\text { Solvent, } \\
\text { Step 2(mL) }\end{array}$ & $\begin{array}{c}\text { Temp } \\
\text { step } 3\left({ }^{\circ} \mathrm{C}\right)\end{array}$ & $\begin{array}{c}\text { Time, step } 3 \\
\text { (h) }\end{array}$ & $\begin{array}{c}\text { Isolated yield } \\
\text { (\%) }\end{array}$ & $e e(\%)^{b}$ \\
\hline $1^{\mathrm{c}}$ & 2.2 & 10 & THF (5) & $\mathrm{rt}$ & 30 & 77 & 66 \\
\hline $2^{\mathrm{c}, \mathrm{d}}$ & 2.2 & 10 & $\mathrm{CH}_{2} \mathrm{Cl}_{2}(5)$ & $\mathrm{rt}$ & 20 & 93 & 35 \\
\hline 3 & 2.2 & 10 & $\mathrm{CH}_{2} \mathrm{Cl}_{2}(5)$ & $\mathrm{rt}$ & 20 & 87 & 52 \\
\hline 4 & 2.2 & 10 & Toluene (5) & $\mathrm{rt}$ & 20 & 80 & 25 \\
\hline $5^{\mathrm{e}}$ & 2.2 & 10 & $\mathrm{Et}_{2} \mathrm{O}(5)$ & $\mathrm{rt}$ & 20 & 80 & 42 \\
\hline 6 & 2.2 & 20 & THF (20) & $\mathrm{rt}$ & 24 & 61 & 77 \\
\hline 7 & 2.6 & 20 & $\mathrm{CH}_{2} \mathrm{Cl}_{2}(10)$ & 0 & 22 & 65 & 52 \\
\hline 8 & 2.6 & 20 & THF (10) & 0 & 22 & 27 & 38 \\
\hline $9^{f}$ & 2.2 & 20 & THF (20) & $\mathrm{rt}$ & 24 & 70 & 71 \\
\hline $10^{\mathrm{f}}$ & 2.2 & 20 & $\mathrm{CH}_{2} \mathrm{Cl}_{2}(20)$ & $\mathrm{rt}$ & 24 & 40 & 73 \\
\hline $11^{\mathrm{f}, \mathrm{g}}$ & 3.2 & 20 & Toluene (20) & $\mathrm{rt}$ & 36 & 70 & 17 \\
\hline 12 & 2.2 & 20 & THF (20) & $11-13$ & 44 & 50 & 79 \\
\hline $13^{\mathrm{h}}$ & 3.2 & 40 & THF (25) & 0 & 36 & 60 & 88 \\
\hline
\end{tabular}




$\begin{array}{llllllll}14^{\mathrm{i}} & 3.2 & 40 & \text { THF }(25) & 0 & 48 & 87 & 84\end{array}$

a. Unless otherwise indicated, the following conditions were employed: $\operatorname{Li}(\mathrm{acac})$ (12 mol\% relative to aryl iodide), $\mathrm{Et}_{2} \mathrm{Zn}(0.55$ eq relative to aryl iodide $), \mathrm{NMP}(1.5 \mathrm{~mL})$, and $0.91 \mathrm{mmol}$ benzaldehyde $(1.0 \mathrm{eq})$. Arylzinc preparation proceeded at $0^{\circ} \mathrm{C}$ for $18 \mathrm{~h}$. $(S)$ 2 was added to the arylzinc solution and stirred for $1 \mathrm{~h}$ before the addition of benzaldehyde. b. Measured on Chiralpak HPLC AD column (solvent: isopropanol/hexanes). c. Arylzinc was prepared at $0^{\circ} \mathrm{C}$ for $17 \mathrm{~h} . \mathrm{d} .1 .1 \mathrm{mmol} \mathrm{m}-$ Iodobenzonitrile and $0.5 \mathrm{mmol}$ benzaldehyde were used. e. $(S)-2$ was sonicated in $\mathrm{Et}_{2} \mathrm{O}$ for 45 mins. f. (S)-2 was mixed with $\mathrm{Ph}_{2} \mathrm{Zn}$ (2 eq versus the ligand) at $\mathrm{rt}$ for $1 \mathrm{~h}$ and then combined with benzaldehyde before addition to the arylzinc solution. g. Arylzinc was prepared at $0{ }^{\circ} \mathrm{C}$ for $12 \mathrm{~h}$, warmed to $\mathrm{rt}$ and stirred $4 \mathrm{~h}$. h. Arylzinc was prepared at $0^{\circ} \mathrm{C}$ for $14 \mathrm{~h}$, warmed to $\mathrm{rt}$ and stirred $4 \mathrm{~h}$. i. Arylzinc was prepared at $0{ }^{\circ} \mathrm{C}$ for $2 \mathrm{~h}$, warmed to rt and stirred $34 \mathrm{~h}$.

The conditions in entry 14 of Table 3.4 were applied to the reactions of several aldehydes with the arylzinc generated in situ from $m$-iodobenzonitrile and $\mathrm{Et}_{2} \mathrm{Zn}$. As shown in Table 3.5, good yields and enantioselectivity are observed for the addition to several aromatic and aliphatic aldehydes.

Table 3.5 Addition of the Arylzinc Generated from $m$-Iodobenzonitrile to Aldehydes in the Presence of $40 \mathrm{~mol} \%(S)-2 .{ }^{a}$

\begin{tabular}{|c|c|c|c|}
\hline Compound \# & & $\mathbf{T}$ & Yield \\
\hline Entry & Product & (h) $)^{\mathbf{a}}$ & (\%) \\
\hline
\end{tabular}




25

a. Third step.

In summary of these initial screens, the nucleophilic reaction of functional arylzincs prepared in situ from aryl iodides and $\mathrm{Et}_{2} \mathrm{Zn}$ has been discovered to react with aldehydes through a significant activation by an easily available chiral ligand (S)-2. High yields and high enantioselectivity for the reaction of the arylzincs with a variety of aldehydes are obtained. The mild reaction conditions and the good functional group tolerance make this method synthetically useful.

\section{c. Screening the $H_{8} B I N O L-A M$ Ligands for the Reaction of Methyl p-Iodobenzoate with Aldehydes}

As shown in Scheme 3.3, an arylzinc species was generated in situ from the reaction of methyl $p$-iodobenzoate with $\mathrm{ZnEt}_{2}$ in the presence of $\mathrm{Li}(\mathrm{acac})$ and NMP. This reaction needed to be conducted at $0{ }^{\circ} \mathrm{C}$ since dimerization of the aryl iodide was observed at room temperature. After the formation of the arylzinc, the $\mathrm{H}_{8} \mathrm{BINOL-AM}$ compounds (20 mol\%) were added to catalyze the arylzinc addition to aldehydes in $\mathrm{CH}_{2} \mathrm{Cl}_{2}$ at $0{ }^{\circ} \mathrm{C}$. We have chosen to screen the $\mathrm{H}_{8} \mathrm{BINOL}-\mathrm{AM}$ compounds for the 
addition to $o$-methoxybenzaldehyde to generate the chiral diaryl carbinol $\mathbf{5 5}$, since the ortho-substituted benzaldehydes were found to be challenging substrates for the asymmetric arylzinc addition. The results for the formation of $\mathbf{5 5}$ in the presence of the $\mathrm{H}_{8}$ BINOL-AM ligands are summarized in Table 3.6.

Scheme 3.3 Asymmetric Reaction of Methyl p-Iodobenzoate with oMethoxybenzaldehyde Catalyzed by $\mathrm{H}_{8}$ BINOL-AM Ligands.

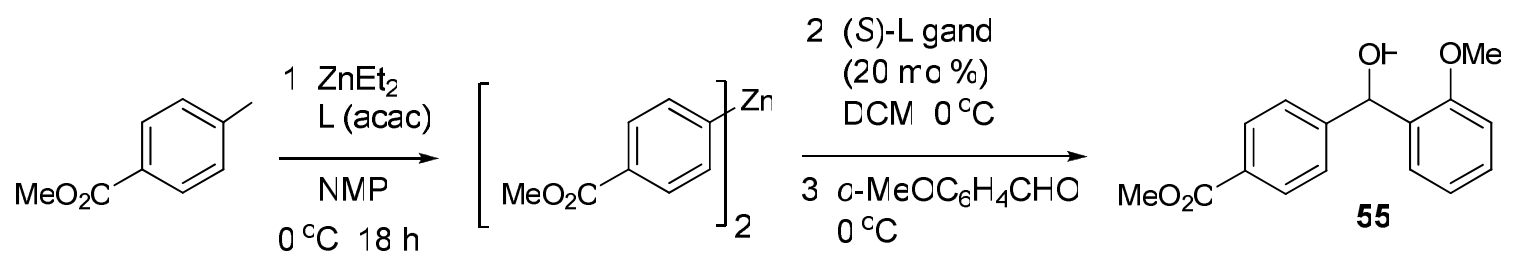

As shown in entry 1 of Table 3.6, $(S)-2$ catalyzed the arylzinc addition to $o$ methoxybenzaldehyde with $79 \%$ ee. This enantioselectivity is significantly lower than those we previously reported for the reactions of $p$ - or $m$-substituted aromatic aldehydes and aliphatic aldehydes catalyzed by $(S)$-2. Ligand $(S)$-10 in which the oxygen atom in the morpholinyl group of $(S)-2$ was replaced with a sulfur atom was tested and it showed the same enantioselectivity as $(S)-\mathbf{2}$ (entry 2). The oxygen and sulfur atoms in the cyclic amine substituents of ligands $(S)$-2 and $(S)$-10 did not interfere with the catalysis and they probably were not involved in the coordination with the Lewis acidic catalyst center. Using ligand $(S)-6$, in which the sterically much more bulky dicyclohexylamine was used in place of the morpholinyl groups of $(S)-2$, gave the racemic product (entry 3). The cyclohexyl rings in $(S)-6$ might have generated an overly crowded environment around the central chiral $\mathrm{H}_{8} \mathrm{BINOL}$ unit preventing the reaction from taking place there. Thus, no chiral induction could be provided by the $\mathrm{H}_{8} \mathrm{BINOL}$ unit of ligand $(S)-6$. When the 
less sterically crowded benzylmethylamine-based ligand $(S)-7$ was used, good enantioselectivity was observed (entry 4). As the steric congestion increased from ligands $(S)-\mathbf{7}$ to $(S)-8$ and $(S)-\mathbf{9}$, the enantioselectivity decreased correspondingly (entries $5,6)$. When the six member ring of the amine group of $(S)-2$ was replaced with the five member ring of the pyrrolidinyl-based ligand $(S)$-12, excellent enantioselectivity was achieved (entry 7). Thus, the reduced ring size of the amine substituent greatly enhanced the enantioselectivity. Incorporation of a sulfur atom into the five member ring of $(S)$-12 gave $(S)$-13 which maintained the high yield and enantioselectivity (entry 8 ). That is, the additional heteroatom in the aminocycle had no influence on the enantioselectivity, similar to that observed for $(S)-\mathbf{2}$ and $(S)$-10. Additional substituents on the fivemembered rings of $(S)$-12 decreased the enantioselectivity as shown by the use of ligands $(S)$-14 and $(S)$-16 (entries 9,10). Although $(S)$-16 contained a mixture of diastereomers, its enantioselectivity was still greater than $(S)$-14 that contained only one stereoisomer. The extra methoxy groups of $(S)$-14 might lead to chelate coordination of the Lewis acidic metal centers outside the chiral cavity of the $\mathrm{H}_{8} \mathrm{BINOL}$ unit, causing the dramatic reduction of the enantioselectivity versus the use of $(S)$-12. Alternatively, the opposite stereocenter on the 2-position of the pyrrolidine arm could be tested. 
Table 3.6 Reaction of Methyl $p$-iodobenzoate and $o$-methoxybenzaldehyde in the Presence of $\mathrm{ZnEt}_{2}$ and $\mathrm{H}_{8} \mathrm{BINOL-AMs}$ to Form 55. ${ }^{\mathrm{a}}$

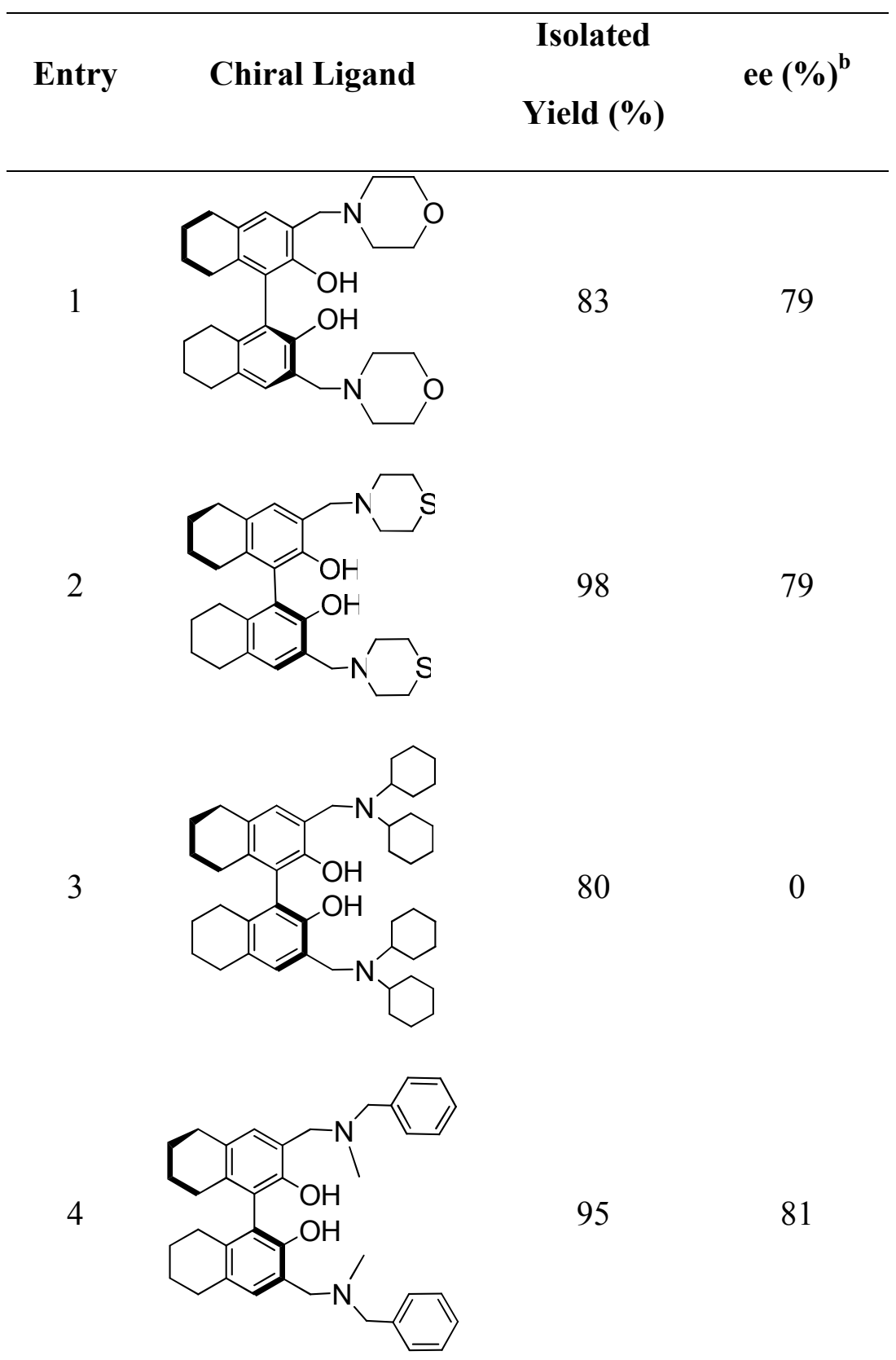


5

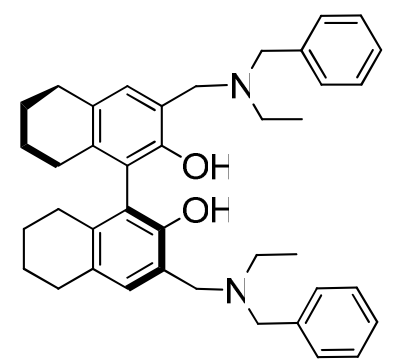

6

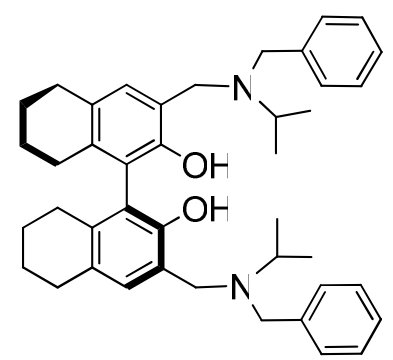

7

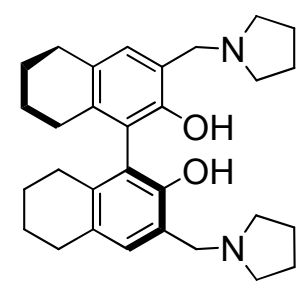

8<smiles>Oc1c(CN2CCSC2)cc2c(c1-c1c(O)c(CN3CCSC3)cc3c1CCCC3)CCCC2</smiles>

9

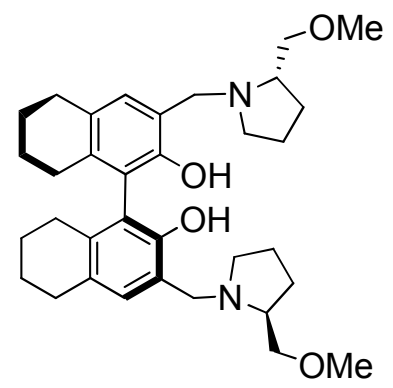


10

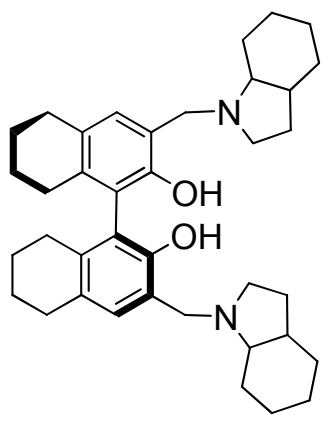

80

83

(a) Conditions: methyl $p$-iodobenzoate (2.2 equiv), Li(acac) (26 mol\%), $\mathrm{Et}_{2} \mathrm{Zn}(1.21$ equiv), NMP (1.5 mL), chiral ligand (20 mol\%), $\mathrm{CH}_{2} \mathrm{Cl}_{2}(20 \mathrm{~mL})$, aldehyde (1.0 equiv). Step 1: 18 h, $0{ }^{\circ}$ C. Step 2: 1 h, $0{ }^{\circ} \mathrm{C} ; 15$ min, rt. Step 3: 16 h, $0{ }^{\circ}$ C. (b) Determined by using HPLC-chiral column.

The use of the $\mathrm{H}_{8} \mathrm{BINOL-AM}$ compounds to catalyze the addition of the methyl $p$ iodobenzoate-derived arylzinc reagent to $o$-cholorobenzaldehyde to generate the chiral diarylcarbinol 56 was also investigated and the results are summarized in Table 3.7.<smiles>CC(=O)c1ccc(C(O)c2ccccc2C)cc1</smiles>

Ligands $(S)-\mathbf{2},(S)-\mathbf{1 0}$, and $(S)$-11 containing six member cyclic amine groups showed similarly low enantioselectivity (entries 1-3). The oxygen and sulfur atoms in the six member rings had little effect on the reaction. Changing the cyclic amines of ligands $(S)$ 2, $(S)$-10, and $(S)$-11 to the acyclic dialkyl amines ligands $(S)-\mathbf{3}$ and $(S)$-4 increased the enantioselectivity (entries 4,5). However, increasing the size of the alkyl groups from the primary alkyls of ligands $(S)-\mathbf{3}$ and $(S)$-4 to the secondary alkyl groups of ligands $(S)-\mathbf{5}$ diminished the enantioselectivity (entry 6). This is similar to that observed in the 
reaction of $o$-methoxybenzaldehyde shown in Table 3.6. The use of the benzylmethylamine-based ligand $(S)-7$ could not improve the enantioselectivity (entry 7). When the pyrrolidinyl-based $(S)-\mathbf{1 2}$ was used, it again exhibited significantly improved enantioselectivity over the other $\mathrm{H}_{8} \mathrm{BINOL}-\mathrm{AMs}$ (entry 8). Addition of $\mathrm{Ti}\left(\mathrm{O}^{\mathrm{i}} \mathrm{Pr}\right)_{4}$, another Lewis acid, reduced the enantioselectivity (entry 11). Using the substituted pyrrolidinyl ligand (S)-15 also reduced the enantioselectivity (entry 10).

When the imidazole-based ligand $(S)$-17 was used, very low enantioselectivity was observed (entry 11 ). The ${ }^{1} \mathrm{H}$ NMR spectrum of $(S)-\mathbf{1 7}$ shows the $\mathrm{OH}$ proton signal at $\delta 3.48$ which is much more upfield in comparison with those $(\delta 10-12)$ of all the other $\mathrm{H}_{8} \mathrm{BINOL}-\mathrm{AMs}$ prepared. This dramatic difference in the proton signals of the $\mathrm{OH}$ groups can be attributed to the lack of intramolecular hydrogen bonding between the $\mathrm{OH}$ groups of $(S)-\mathbf{1 7}$ and its imidazole nitrogens. The nitrogen in each of the imidazole rings connected to the 3-methylene group is not basic and the more basic nitrogen atom in the ring is pointing way from the chiral $\mathrm{H}_{8} \mathrm{BINOL}$ unit of $(S)-\mathbf{1 7}$, which makes it sterically incapable of forming an intramolecular hydrogen bond. Participation of the more basic nitrogen atom in the catalysis directing reaction away from the central chirality might have contributed to the diminished enantioselectivity. The results in Table 3.7 show that $o$-chlorobenzaldehyde is still a challenging substrate for this asymmetric arylzinc addition reaction. 
Table 3.7 Reaction of Methyl $p$-iodobenzoate and $o$-chlorobenzaldehyde in the Presence of $\mathrm{ZnEt}_{2}$ and $\mathrm{H}_{8} \mathrm{BINOL-AMs}$ to Form 56 . $^{\mathrm{a}}$

\begin{tabular}{lcc}
\hline Entry & Isolated & \\
& Ligand & ee $(\%)^{\text {b }}$
\end{tabular}

1

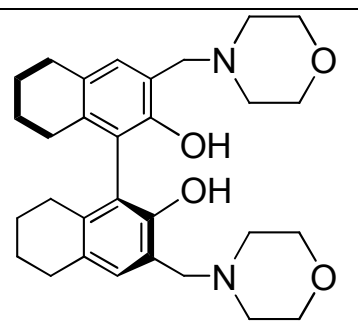

2<smiles>Oc1c(CN2CCCCC2)cc2c(c1-c1c(O)c(CN3CCSCC3)cc3c1CCCC3)CCCC2</smiles>

3

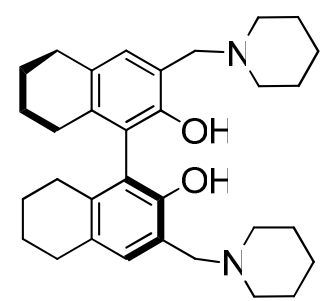

4

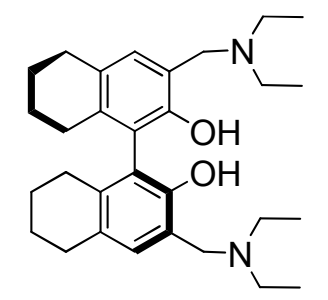

5

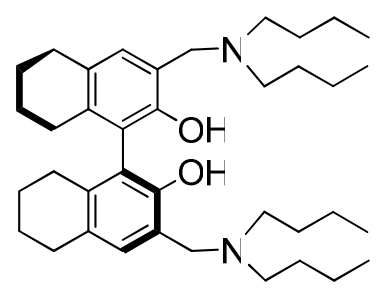


6

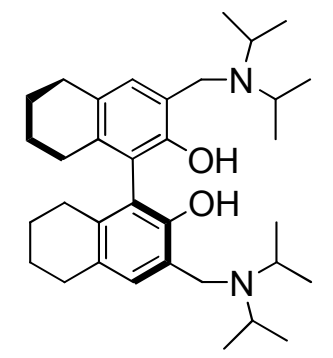

7

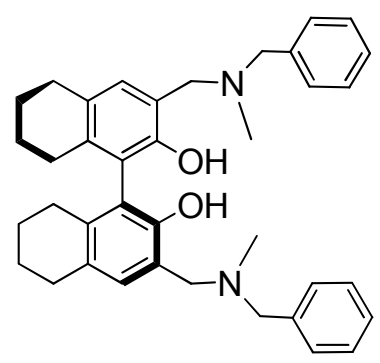

8

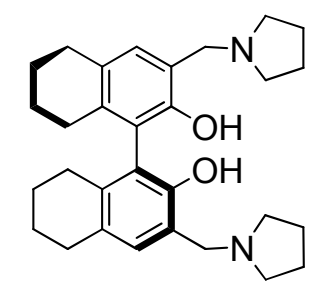

$9^{c}$

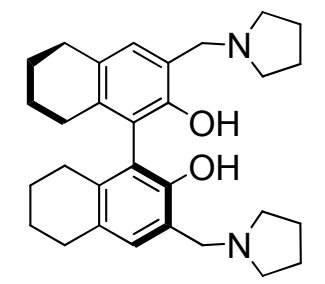

10

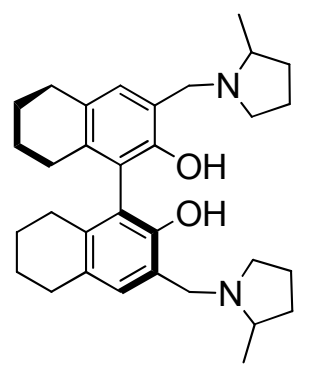

11<smiles>Oc1c(Cn2ccnc2)cc2c(c1-c1c(O)c(Cn3ccnc3)cc3c1CCCC3)CCCC2</smiles> 
(a) Following conditions were used unless otherwise noted: methyl $p$-iodobenzoate (2.2 equiv), Li(acac) (26 mol\%), Et 2 Zn (1.21 equiv), NMP (1.5 mL), chiral ligand (20 mol\%), $\mathrm{CH}_{2} \mathrm{Cl}_{2}(20 \mathrm{~mL})$, aldehyde (1.0 equiv), $0{ }^{\circ} \mathrm{C}$. Step 1: 18 h. Step 2: 1 h. Step 3: 12 h. (b) Determined by using HPLC-chiral column. (c) $\mathrm{Ti}\left(\mathrm{O}^{i} \mathrm{Pr}\right)_{4}(1.0$ equiv) was added after step 2 and was stirred from $1 \mathrm{~h}$ prior to the addition of the aldehyde.

The results in Tables 3.6 and 3.7 demonstrate that the pyrrodinyl-based compound (S)-12 forms a more enantioselective catalyst than (S)-2 and the other $\mathrm{H}_{8}$ BINOL-AM compounds in the asymmetric arylzinc addition to the ortho-substituted benzaldehydes. (S)-12 was used to catalyze the reaction of additional aldehyde substrates with the arylzinc derived from methyl $p$-iodobenzoate by using the conditions of entry 7 in Table 3.6. The use of $(S)-\mathbf{2}$ in these reactions was also compared with the use of $(S)-\mathbf{1 2}$ and the results are summarized in Table 3.8. For all the reactions, $(S)-\mathbf{1 2}$ exhibited significantly higher enantioselectivity than $(S)-2$. The enantioselectivity for the addition to 4-pyridinyl aldehyde was low for both ligands $(S)$-2 and $(S)$-12 which indicates a possible coordination of the pyridine nitrogen to the Lewis acidic catalyst to disturb the catalytic process (entries 3,6). 
Table 3.8 Comparison of Ligands $(S)-2$ and $(S)-12$ for the Asymmetric Reaction of Methyl $p$-iodobenzoate with Additional Aldehydes. ${ }^{a}$

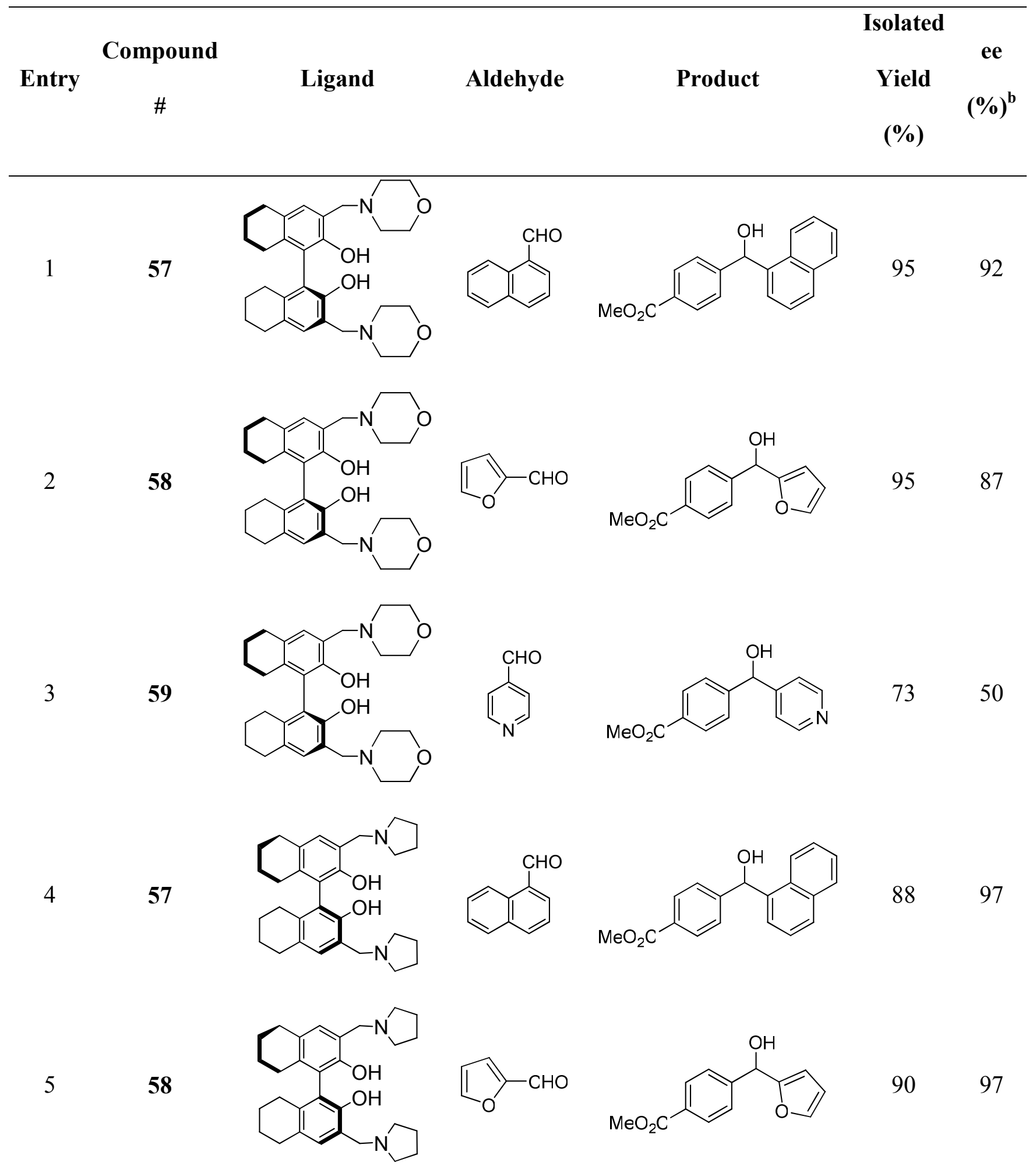


6 59

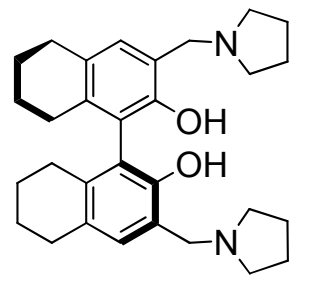<smiles>O=Cc1ccncc1</smiles><smiles>CC(=O)c1ccc(C(O)c2ccncc2)cc1</smiles>

(a) Conditions: methyl $p$-iodobenzoate (2.2 equiv), $\mathrm{Li}(\mathrm{acac})(26 \mathrm{~mol} \%), \mathrm{Et}_{2} \mathrm{Zn}(1.21$ equiv), NMP (1.5 mL), chiral ligand (20 mol\%), $\mathrm{CH}_{2} \mathrm{Cl}_{2}(20 \mathrm{~mL})$, aldehyde (1.0 equiv), 0 ${ }^{\circ}$ C. Step 1: 18 h. Step 2: 1 h. Step 3: 6-12 h. (b) Determined by using HPLC-chiral column.

\section{d. Screening the $H_{8} B I N O L-A M$ Ligands for the Reaction of m-Iodoanisole with}

\section{Aldehydes}

The asymmetric addition of the arylzinc reagent formed from $m$-iodoanisole to $o$ methoxybenzaldehyde in the presence of the $\mathrm{H}_{8} \mathrm{BINOL}-\mathrm{AM}$ compounds $(10 \mathrm{~mol} \%)$ was investigated to generate the chiral diaryl carbinol 60 (Scheme 3.9). As the results summarized in Table 3.9 show, increasing the steric bulkiness of the amine substituents from $(S)$-2 to $(S)-6$ led to a significant reduction in the enantioselectivity (entries 1,2). A small improvement was observed with the use of the benzylmethylamine-based $(S)-7$ (entry 3). As the steric congestion increased from $(S)-7$ to ligands $(S)-8$ and $(S)-\mathbf{9}$, the enantioselectivity diminished (entries 4,5). The pyrrolidinyl ligand (S)-12 exhibited enhanced enantioselectivity over the other compounds (entry 6). Decreasing the step 2 and step 3 temperature to $0{ }^{\circ} \mathrm{C}$ (entry 7) or increasing the amount of $(S)-12$ to $20 \mathrm{~mol} \%$ (entry 8) could not significantly improve the enantioselectivity. Incorporation of a sulfur atom into the pyrrolidinyl ring of $(S)-\mathbf{1 2}$ led to a small reduction in enantioselectivity (entry 9). Ligands $(S)-\mathbf{1 4}$ and (S)-16 containing additional substituents on the pyrrolidinyl rings gave reduced enantioselectivity (entries 10,11). The dramatic 
reduction of enantioselectivity from $(S)$-12 to $(S)$-14 was similar to that observed in entry 9 of Table 3.6. This could be attributed to the undesired participation of the methoxy groups of $(S)-\mathbf{1 4}$ in the coordination to the Lewis acidic metal centers.

Results from our functional arylation studies of aldehydes showed that the $\mathrm{H}_{8} \mathrm{BINOL-AM}$ compounds containing more sterically crowded tertiary amine substituents were generally less enantioselective than those containing sterically less crowded tertiary amine substituents. With the objective to compare the catalytic properties of these compounds with an even less bulky environment, compound $(S)-\mathbf{2 9}$, containing secondary amine groups at the 3,3'-positions, was tested. As shown in entry 12 of Table 3.9, compound $\mathbf{6 0}$ was formed in excellent yield but with decreased enantioselectivity of $68 \%$.

Scheme 3.4 Asymmetric Reaction of $m$-Iodoanisole with $o$-Methoxybenzaldehyde Catalyzed by $\mathrm{H}_{8}$ BINOL-AMs.

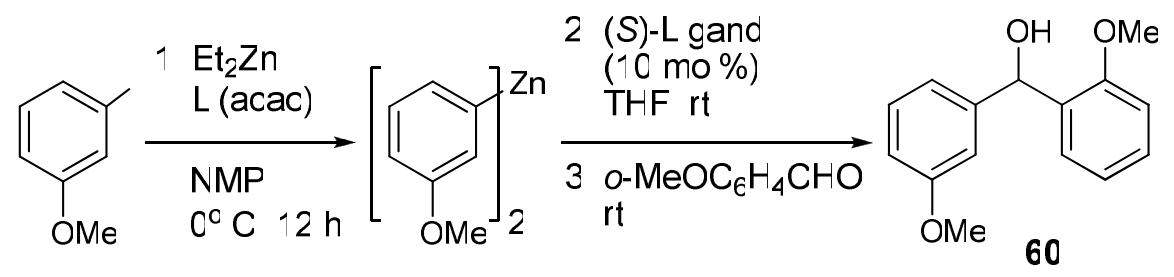


Table 3.9 Reaction of $m$-iodoanisole and $o$-methoxybenzaldehyde in the Presence of $\mathrm{ZnEt}_{2}$ and $\mathrm{H}_{8} \mathrm{BINOL-AMs}$ to Form 60 . $^{\mathrm{a}}$

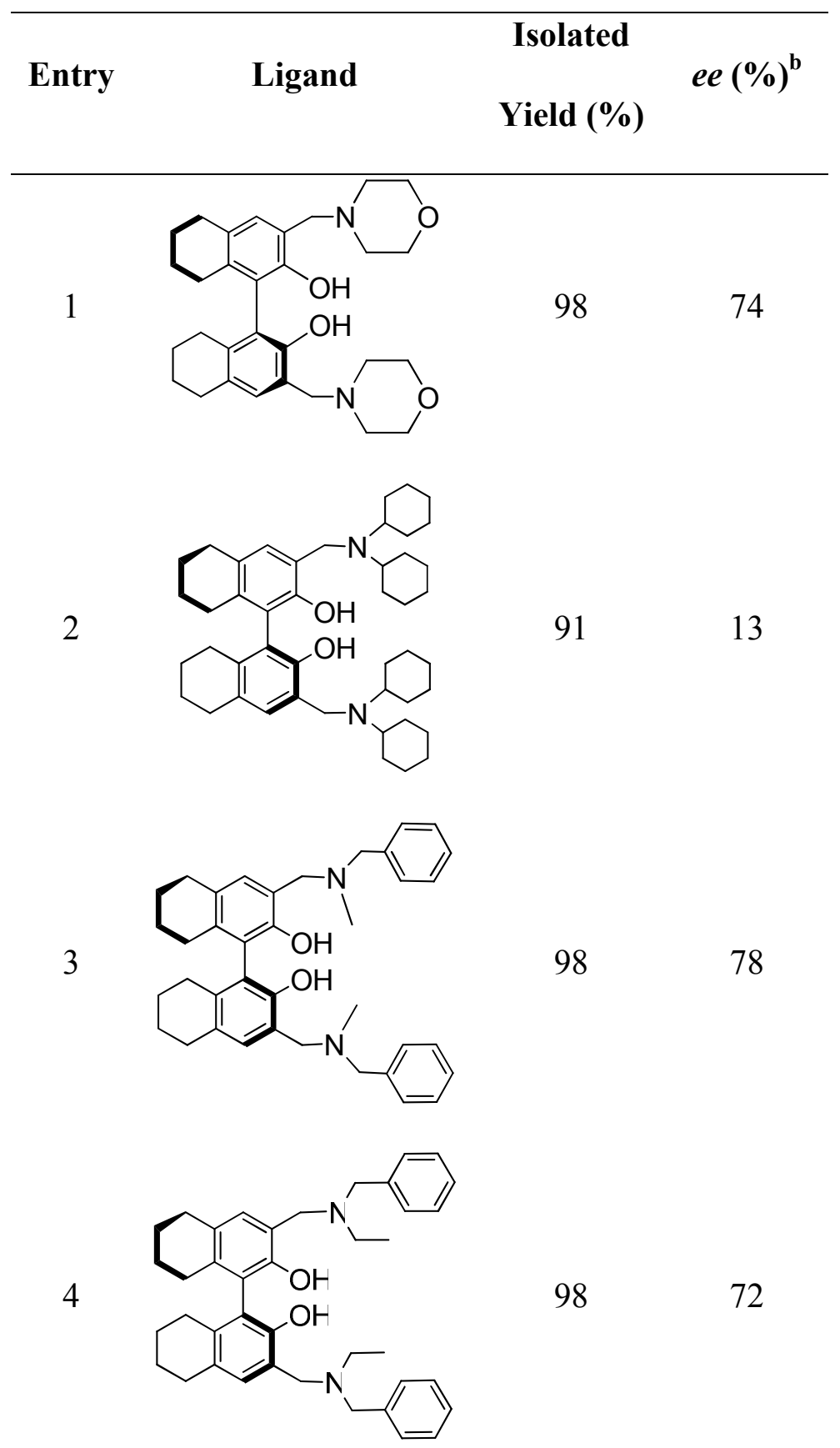




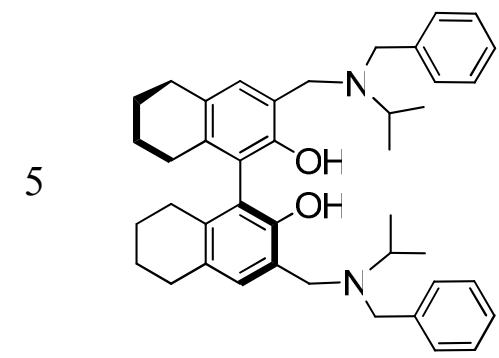

6

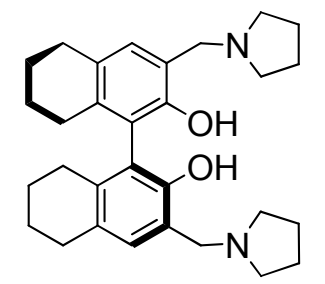

$7^{\mathrm{c}}$

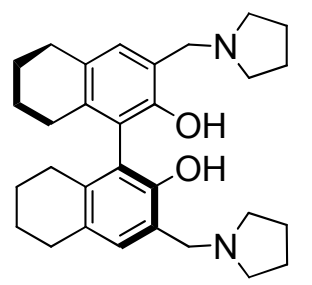

$8^{d}$<smiles>Oc1c(CN2CCCC2)cc2c(c1-c1c(O)c(CN3CCCC3)cc3c1CCCC3)CCCC2</smiles>

9<smiles>Oc1c(CN2CCSC2)cc2c(c1-c1c(O)c(CN3CCSC3)cc3c1CCCC3)CCCC2</smiles>

10

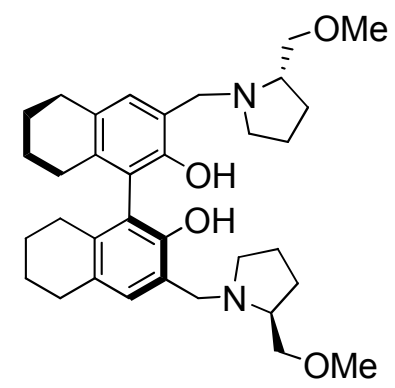




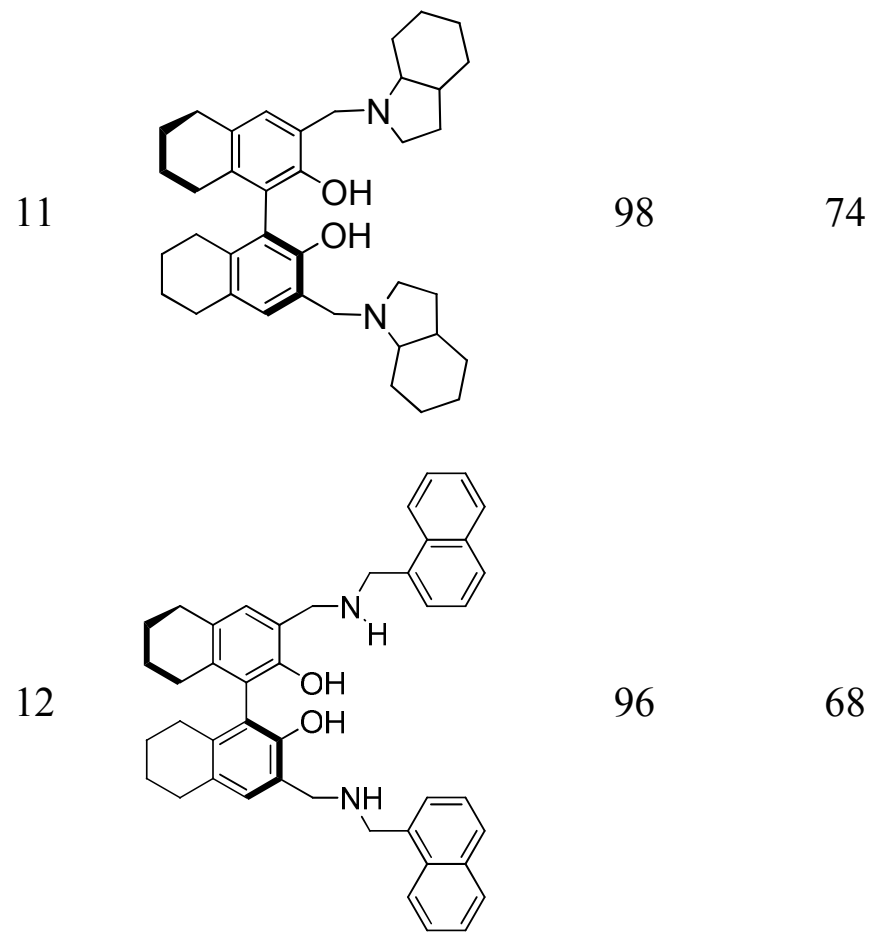

(a) Following conditions were used unless otherwise noted: $m$-iodoanisole (2.2 equiv), Li(acac) (26 mol\%), $\mathrm{Et}_{2} \mathrm{Zn}$ (1.21 equiv), NMP (1.5 mL), chiral ligand (10 mol\%), THF (5 $\mathrm{mL}$ ), aldehyde (1.0 equiv). Step 1: $12 \mathrm{~h}, 0{ }^{\circ} \mathrm{C}$. Step 2: $1 \mathrm{~h}, 0{ }^{\circ} \mathrm{C}$. Step 3: $12 \mathrm{~h}$, rt. (b) Determined by using HPLC-chiral column. (c) Step 3: 20 h, $0{ }^{\circ} \mathrm{C}$. (d) 20 mol \% (S)-12. Step 3: $20 \mathrm{~h}, 0{ }^{\circ} \mathrm{C}$.

In order to perform a comprehensive ligand search for this challenging anisylzinc addition, the following ligands (shown in Figure 3.3) were also tested.

Figure 3.3 3,3'-Bis(aryl)-(S)-H ${ }_{8}$ BINOL-Based Ligands That Show Excellent Catalytic Asymmetric Control for the Preparation of Aliphatic-Substituted Propargylic Alcohols. 

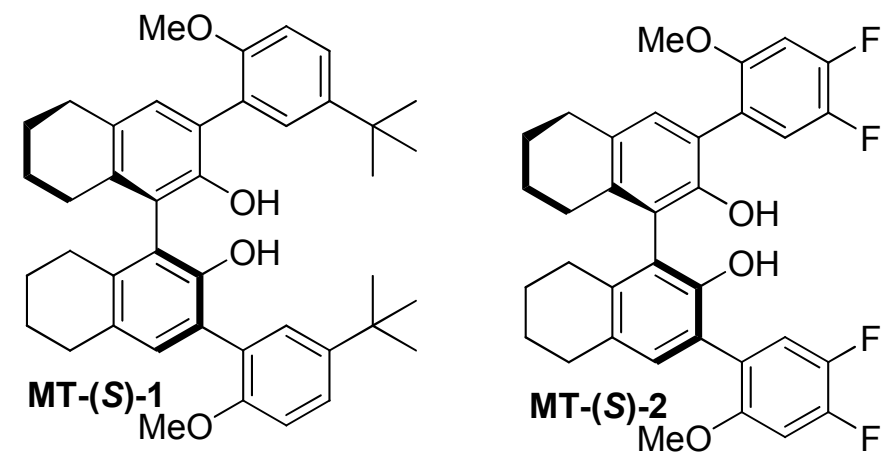

The BINOL-forms of these ligands had previously been used in our lab for asymmetric diphenylzinc additions. ${ }^{13}$ Recently, Turlington and Pu prepared a class of 3,3'-(bis)arylsubstituted $\mathrm{H}_{8} \mathrm{BINOL}$ ligands and reported their highly enantioselective functional alkynylzinc additions to aliphatic aldehydes in the presence of titanium tetraisopropoxide. Unfortunately, these ligands did not display good control in the functional arylations. MT-(S)-1 (10 mol\% ligand used, the same amount used in the other ligand screens) yielded the diaryl alcohol in 71\% yield and 31\% ee. MT-(S)-2 yielded 50\% alcohol in only $3 \%$ ee.

The three $\mathrm{H}_{8}$ BINOL-AM compounds $(S)-\mathbf{2},(S)-7$ and $(S)$-12 that showed better enantioselectivity as ligands in the above reaction were used to catalyze the addition of the $m$-iodoanisole-derived arylzinc to other ortho-substituted benzaldehydes and the results are summarized in Table 3.10. Among these three, $(S)$-12 gave better enantioselectivity for the reaction of $o$-chlorobenzaldehyde (entry 6); (S)-7 gave better enantioselectivity for the reaction of $o$-methylbenzaldehyde (entry 3) and $o$ bromobenzaldehyde (entry 9). Increasing the amount of $(S)-7$ from $10 \mathrm{~mol} \%$ to $20 \mathrm{~mol} \%$ and decreasing the step 2 and 3 temperature to $0{ }^{\circ} \mathrm{C}$ could not improve the enantioselectivity (entry 4). These results demonstrate that the asymmetric arylzinc addition to ortho-substituted benzaldehydes remains a challenging task and further 
exploration in this area is needed. Compound $(S)-\mathbf{2 9}$, containing the secondary amine groups, again demonstrated decreased enantioselectivity in the addition.

Table 3.10 Reaction of $m$-iodoanisole and additional ortho-substituted benzaldehydes in the presence of $\mathrm{ZnEt}_{2}$ and $\mathrm{H}_{8} \mathrm{BINOL-AMs.}{ }^{\mathrm{a}}$

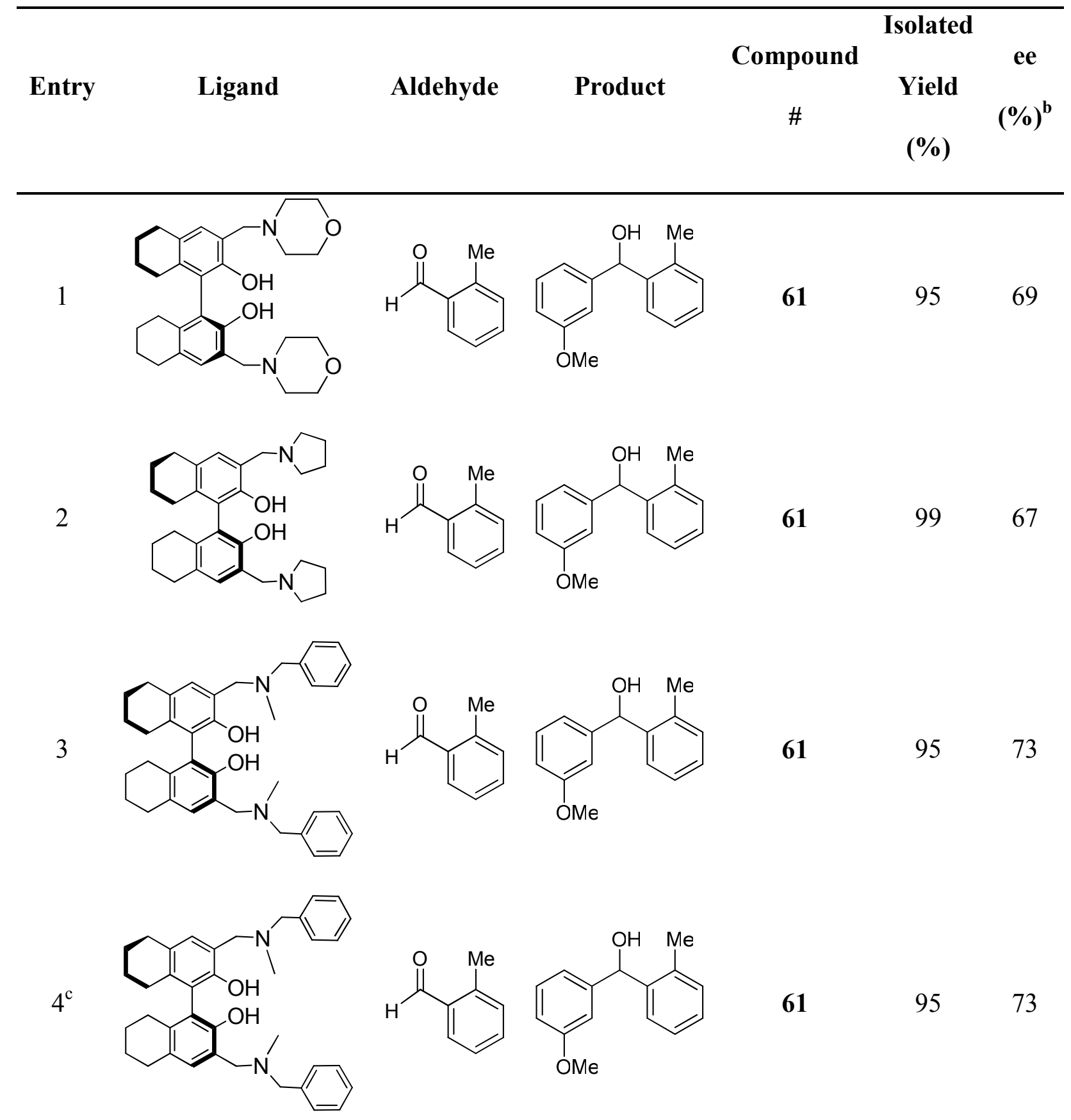


5<smiles>Oc1c(CN2CCOCC2)cc2c(c1-c1c(O)c(CN3CCOCC3)cc3c1CCCC3)CCCC2</smiles>

6<smiles>Oc1c(CN2CCCC2)cc2c(c1-c1c(O)c(CN3CCCC3)cc3c1CCCC3)CCCC2</smiles>

7<smiles>Fc1c(CNCc2cccc3ccccc23)cc2c(c1Cl)C(Cl)=C(CNCc1cccc3ccccc13)C(CNCc1cccc3ccccc13)C2</smiles><smiles>O=Cc1ccccc1Cl</smiles><smiles>COc1cccc(C(O)c2ccccc2C)c1</smiles>

62

91<smiles>O=Cc1ccccc1Cl</smiles><smiles>COc1cccc(C(O)c2ccccc2C)c1</smiles>

62

80

87<smiles>COc1cccc(C(O)c2ccccc2Br)c1</smiles>

63

63

63

8<smiles>Oc1c(CN2CCOCC2)cc2c(c1-c1c(O)c(CN3CCOCC3)cc3c1CCCC3)CCCC2</smiles><smiles>O=Cc1ccccc1Br</smiles><smiles>O=Cc1ccccc1Br</smiles><smiles>COc1cccc(C(O)c2ccccc2Br)c1</smiles>

10

92
93 55<smiles>O=Cc1ccccc1Br</smiles><smiles>COc1cccc(C(O)c2ccccc2Br)c1</smiles>

$97 \quad 51$<smiles>CN(Cc1ccccc1)Cc1cc2c(c(-c3c(O)c(CN(C)Cc4ccccc4)cc4c3CCCC4)c1O)CCCC2</smiles>
54 
(a) Following conditions were used unless otherwise noted: $m$-iodoanisole (2.2 equiv), Li(acac) (26 mol\%), Et 2 Zn (1.21 equiv), NMP (1.5 mL), chiral ligand (10 mol\%), THF (5 $\mathrm{mL}$ ), aldehyde (1.0 equiv). Step 1: $12 \mathrm{~h}, 0{ }^{\circ} \mathrm{C}$. Step 2: 1 h, $0{ }^{\circ} \mathrm{C}$. Step 3: 12-16 h, rt. (b) Determined by using HPLC-chiral column. (c) $20 \mathrm{~mol} \%(S)-7$. Step 3: $20 \mathrm{~h}, 0{ }^{\circ} \mathrm{C}$.

(S)-12 was further used to catalyze the reaction of the $m$-iodoanisole-derived arylzinc with other aldehydes and the results are summarized in Table 3.11. Despite the lower enantioselectivity for the addition to ortho-substituted benzaldehydes, $(S)-\mathbf{1 2}$ was highly enantioselective for the reaction of other aromatic and aliphatic aldehydes as shown in entries 1-4. For these substrates, the enantioselectivity from $(S)$-12 was comparable to that of $(S)-2$ previously shown. The reaction of the $m$-iodoanisole derived arylzinc with cyclohexanecarboxaldehyde in the presence of $(S)-\mathbf{2}$ was scaled up with the use of $29 \mathrm{mmol}$ of the aldehyde. The corresponding alcohol was afforded in $92 \%$ yield, $>99 \%$ ee and $>99 \%$ purity. ${ }^{12 b}$

$(S)-\mathbf{2}$ and $(S)$-12 were also used to catalyze the addition to heteroaromatic aldehydes. For the reaction of 2-furaldehyde, both showed high enantioselectivity (entries 5,6). However, lower ee's were observed for the reaction of 4pyridinecarboxaldehyde catalyzed by $(S)-\mathbf{2}$ and $(S)-\mathbf{1 2}$ (entries 7,8) similar to that observed in entries 3 and 6 of Table 3.8. The pyridine nitrogen atom of this aldehyde is likely interfering with the catalysis through coordination to the Lewis acidic metal center and potentially activating the symmetric addition or changing the catalyst structure. 
Table 3.11 Reaction of $m$-iodoanisole and Other Aldehydes in the Presence of $\mathrm{ZnEt}_{2}$ and $(S)-2$ and $(S)-12 .^{a}$

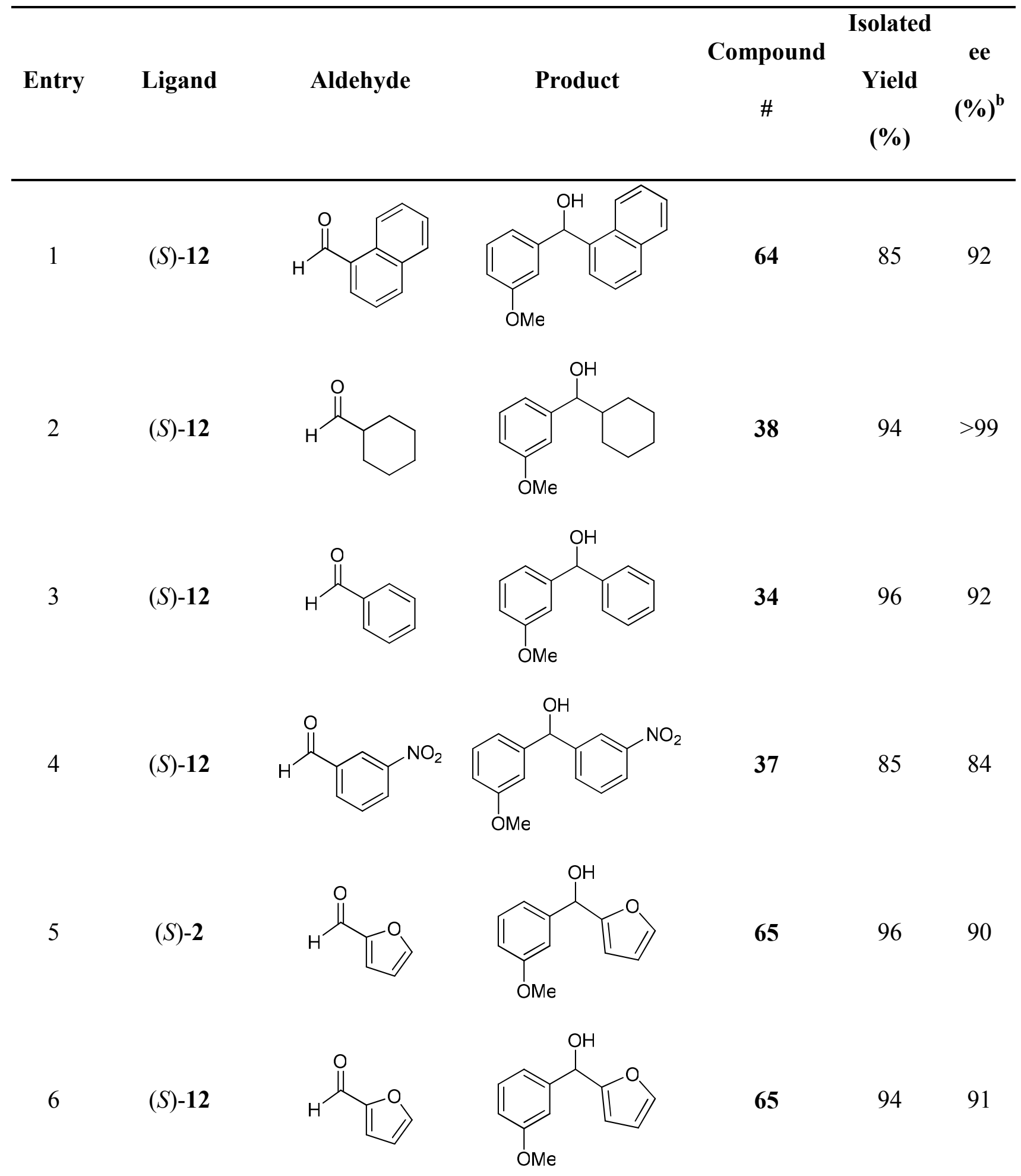


<smiles>O=Cc1ccncc1</smiles><smiles>COc1cccc(C(O)c2ccncc2)c1</smiles><smiles>O=Cc1ccncc1</smiles><smiles>COc1cccc(C(O)c2ccncc2)c1</smiles>

(a) Conditions: $m$-iodoanisole (2.2 equiv), $\mathrm{Li}(\mathrm{acac})(26 \mathrm{~mol} \%), \mathrm{Et}_{2} \mathrm{Zn}$ (1.21 equiv), NMP (1.5 mL), chiral ligand (10 mol\%), THF $(5 \mathrm{~mL})$, aldehyde (1.0 equiv). Step 1: $12 \mathrm{~h}, 0{ }^{\circ} \mathrm{C}$. Step 2: $1 \mathrm{~h}, 0{ }^{\circ} \mathrm{C}$. Step 3: 6-12 h, rt. (b) Determined by using HPLC-chiral column.

e. Screening the $H_{8} B I N O L-A M$ Ligands for the Reaction of m-Iodobenzonitrile with pMethoxybenzaldehyde

The experiments for the asymmetric arylzinc addition to aldehydes in the above sections show that $(S)-\mathbf{2},(S)-\mathbf{4},(S)-\mathbf{7}$ and $(S)$-12 have higher enantioselectivity than the other $\mathrm{H}_{8} \mathrm{BINOL}-\mathrm{AM}$ compounds used as chiral ligands. The ability of these four compounds to catalyze the reaction of $p$-methoxybenzaldehyde with the arylzinc reagent derived from $m$-iodobenzonitrile to give the chiral diaryl carbinol 52 (Scheme 3.5) was tested. As the results summarized in Table 3.12 show, $(S)-\mathbf{4},(S)-\mathbf{7}$ and $(S)-\mathbf{1 2}$ improved

the enantioselectivity previously reported for $(S)-2 .{ }^{12 a}$ The highest enantioselectivity was obtained with the use of (S)-7 (entry 3). In these reactions, $40 \mathrm{~mol} \%$ of the ligands was needed to achieve good yields and enantioselectivities.

\section{Scheme 3.5 The Asymmetric Reaction of $m$-Iodobenzonitrile with $p$ -} Methoxybenzaldehyde Catalyzed by the $\mathrm{H}_{8}$ BINOL-AM Ligands. 


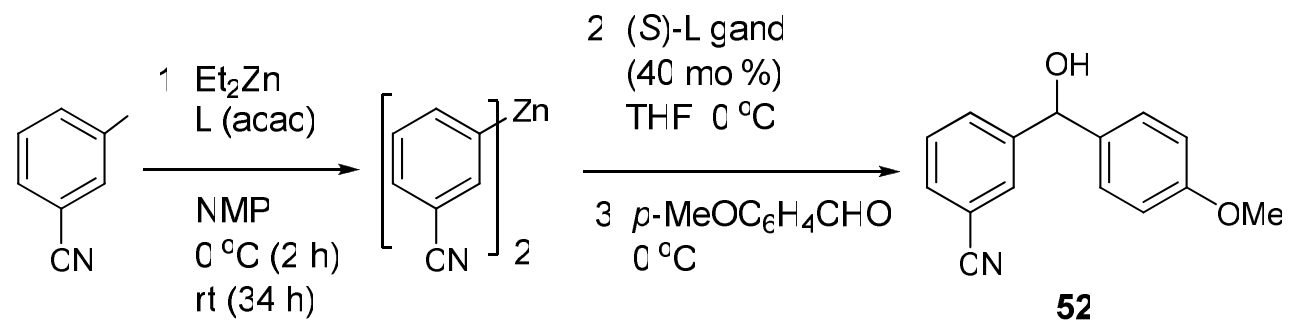

Table 3.12 Reaction of $m$-iodobenzonitrile and $p$-methoxybenzaldehyde in the Presence of $\mathrm{ZnEt}_{2}$ and $\mathrm{H}_{8}$ BINOL-AMs to Form 52.

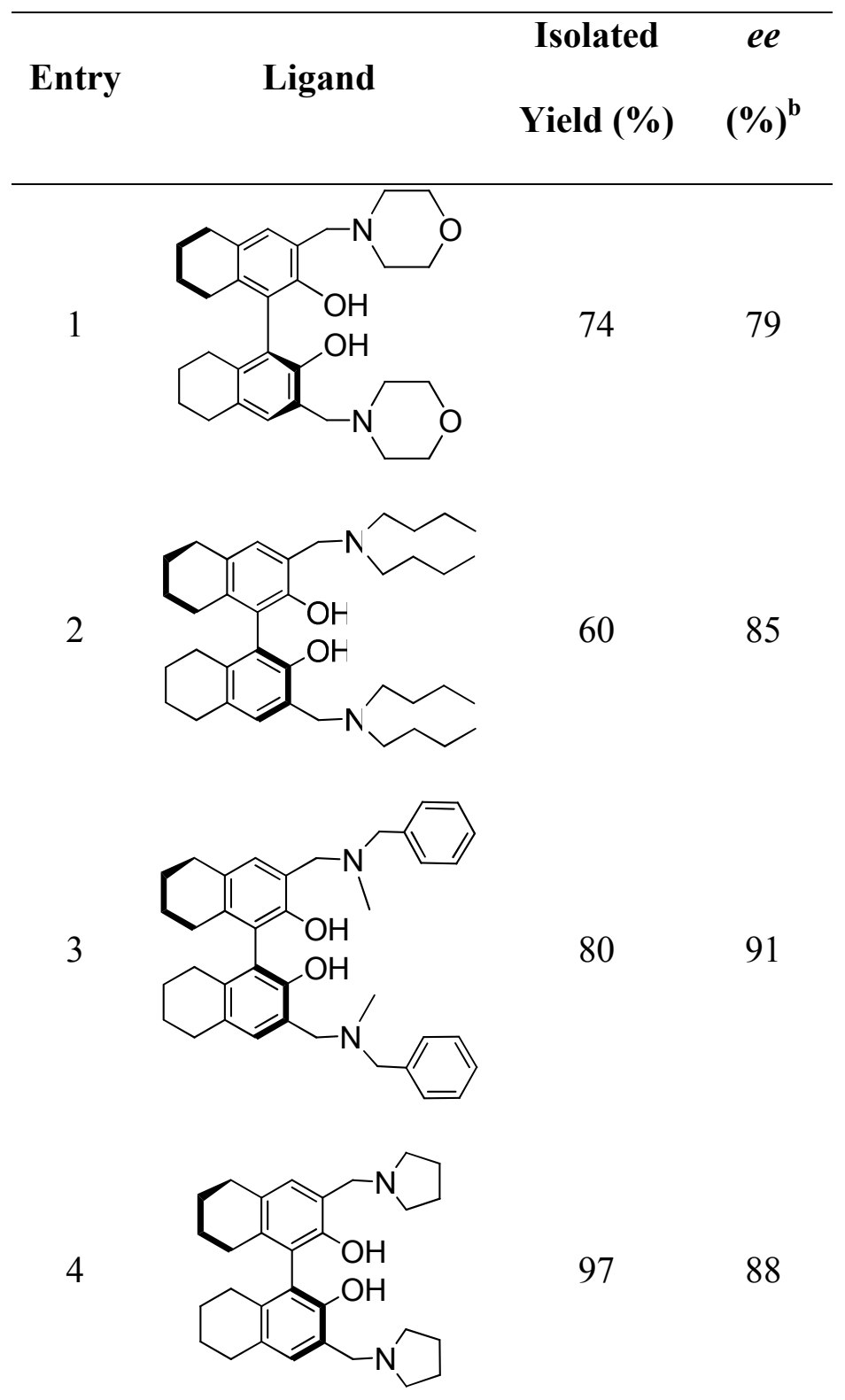


(a) Conditions: $m$-iodobenzonitrile (3.2 equiv), Li(acac) (37 $\left.\mathrm{mol}^{\%}\right), \mathrm{Et}_{2} \mathrm{Zn}$ (1.6 equiv), NMP (1.5 mL), chiral ligand (40 mol\%), THF (25 mL), p-methoxybenzaldehyde $(1.0$ equiv). Step 1: $2 \mathrm{~h}$ at $0{ }^{\circ} \mathrm{C}$, then $34 \mathrm{~h}$ at rt. Step 2: $1 \mathrm{~h}, 0{ }^{\circ} \mathrm{C}$. Step 3: $48 \mathrm{~h}, 0{ }^{\circ} \mathrm{C}$. (b) Determined by ${ }^{1} \mathrm{H}$ NMR spectroscopic analysis of the mandelic ester of $\mathbf{5 2}$ prepared from the reaction with $(R)-(-)-(\mathrm{O}-$ acetoxy $)$ mandelic acid in the presence of DCC and DMAP in $\mathrm{CH}_{2} \mathrm{Cl}_{2}$.

\section{f. Asymmetric Reaction of the Arylzinc Reagents Derived from 2-Iodothiophene and 2- Bromothiophene Catalyzed by the $\mathrm{H}_{8} B I N O L-A M s$}

We also explored the use of the $\mathrm{H}_{8}$ BINOL-AMs to promote the asymmetric reaction of thiophenyl halides with aldehydes. Scheme 3.6 shows the conversion of 2iodothiophene to a thiophenylzinc reagent using $\mathrm{ZnEt}_{2}, \mathrm{Li}(\mathrm{acac})$ and NMP and its subsequent asymmetric addition to aldehydes in THF in the presence of $10 \mathrm{~mol} \%$ of a chiral $\mathrm{H}_{8} \mathrm{BINOL}-\mathrm{AM}$. The entire process was conducted at room temperature. The results are summarized in Table 3.13. Entry 1 shows that $(S)-2$ is a good catalyst for the thiophenyl addition to benzaldehyde. When the thiophenylzinc formation time in step 1 was shortened from $12 \mathrm{~h}$ in entry 1 to $6 \mathrm{~h}$, the same result was obtained (entry 2 ). Entry 2 used the dried and distilled 2-iodothiophene and entry 1 used the reagent as received which did not affect the outcome of the experiment. Using the dibutylamine derivative $(S)-14$ gave a slightly increased ee (entry 3). Ligands $(S)-5$ and $(S)-6$ with increased size of the alkyl groups on the nitrogen atoms gave diminished ee's (entries 4,5). The benzylmethylamine derivative $(S)-\mathbf{7}$ gave enhanced enantioselectivity over both $(S)$-2 and $(S)-4$ (entry 6). Increasing the size of the methyl group of $(S)$-7 to the ethyl of $(S)-8$ and the isopropyl of $(S)-9$ reduced the enantioselectivity (entries 7,8 ). When the pyrrolidinyl 
(S)-12 was used, the highest enantioselectivity was achieved (entry 9). Reducing the amount of NMP used in step 1 did not cause significant change on the reaction (entry 10). The imidazole-based compound $(S)-\mathbf{1 7}$ could not carry out this reaction enantioselectivity (entry 11). The high enantioselectivity of $(S)$-12 for the reaction with benzaldehyde prompted us to examine its use for the reaction of aliphatic aldehydes. Good enantioselectivity was observed for the reaction of cyclohexanecarboxaldehyde and octyl aldehyde (entries 12,13). The four chiral ligands $(S)$-2, $(S)-\mathbf{4},(S)-\mathbf{7}$ and $(S)-\mathbf{1 2}$ were used to catalyze the thiophenylzinc addition to $o$-methoxybenzaldehyde. As the results in entries 14 - 17 show, the ortho-substituted benzaldehyde remains a challenging substrate for this reaction. The highest ee was 73\% obtained by using either $(S)-\mathbf{7}$ or $(S)-\mathbf{1 2}$ (entries 15,16).

Scheme 3.6 The Asymmetric Reaction of 2-Iodothiophene with Aldehydes Catalyzed by $\mathrm{H}_{8}$ BINOL-AMs.

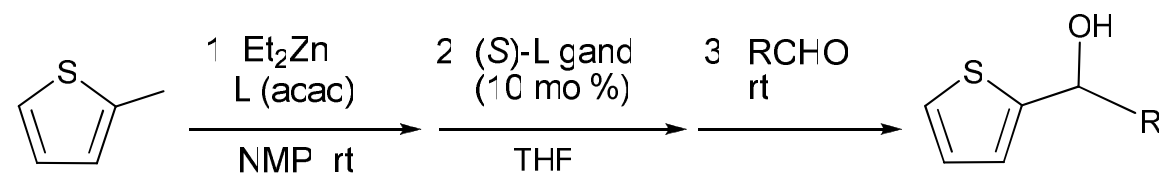

Table 3.13 Reaction of 2-iodothiophene With Aldehydes in the Presence of $\mathbf{Z n E t}_{2}$ and $\mathrm{H}_{8}$ BINOL-AMs. ${ }^{a}$

\begin{tabular}{|c|c|c|c|c|c|c|c|}
\hline Entry & Ligand & Aldehyde & Step 3 (h) & Product & $\begin{array}{c}\text { Compou } \\
\text { nd \# }\end{array}$ & $\begin{array}{c}\text { Isolated } \\
\text { Yield (\%) }\end{array}$ & $\begin{array}{c}e e \\
(\%)^{b}\end{array}$ \\
\hline $1^{\mathrm{c}}$ & & & 11 & & 67 & 95 & 84 \\
\hline
\end{tabular}


101
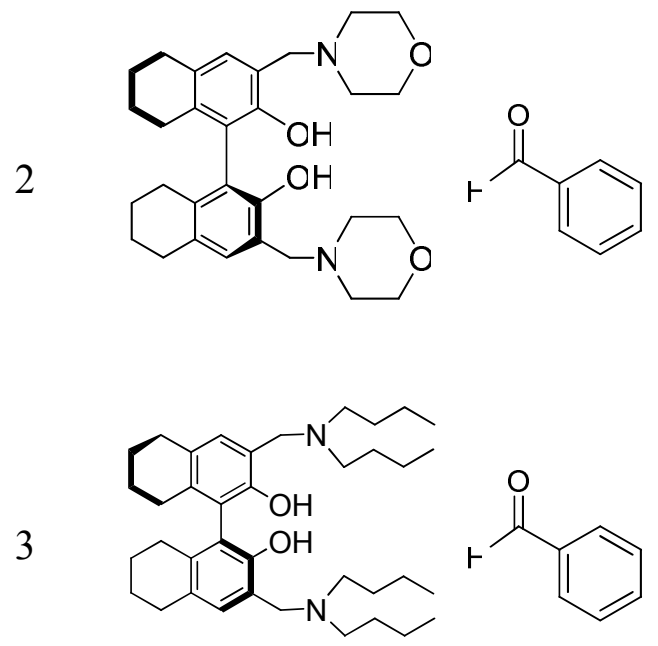

4
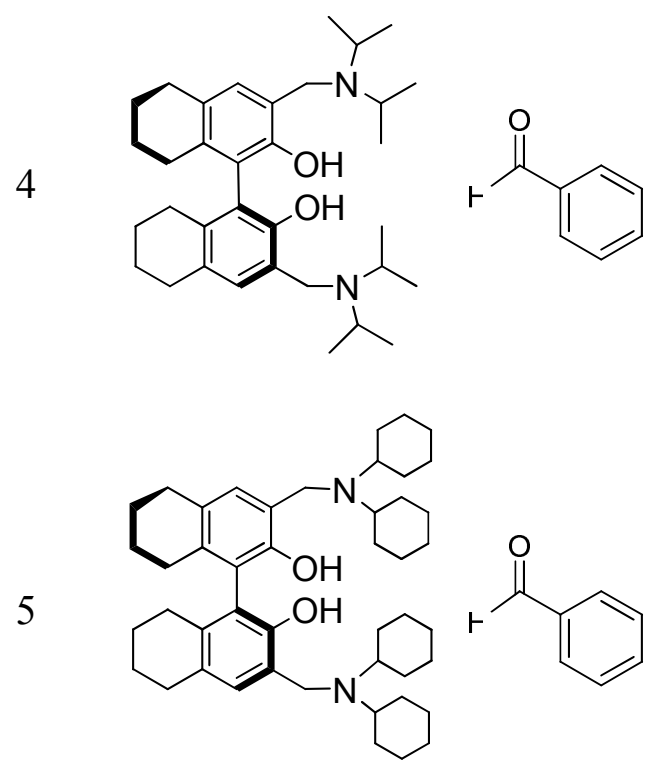

6

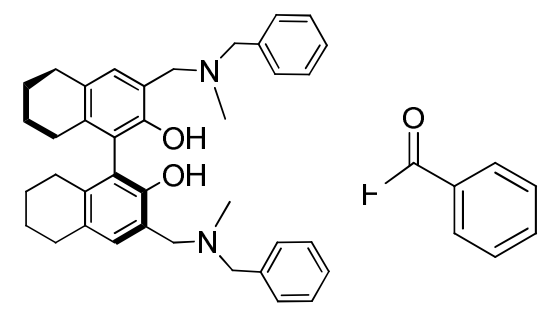

16

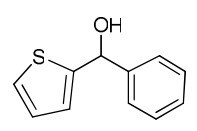

67

95

84

16

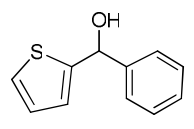

67

84

86

16<smiles>OC(c1ccccc1)c1cccs1</smiles>

67

57

5

16

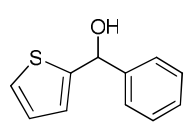

67

66

9

12<smiles>OC(c1ccccc1)c1cccs1</smiles>

67

91

89 
102
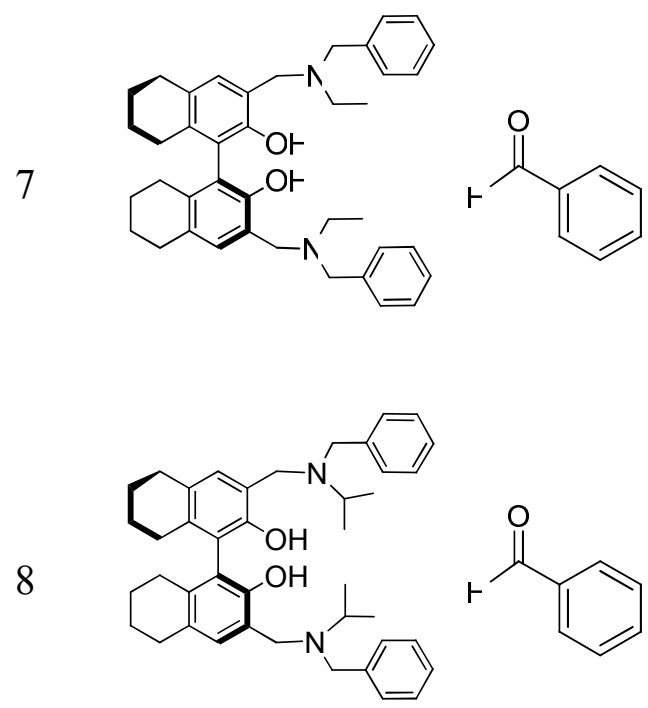

9

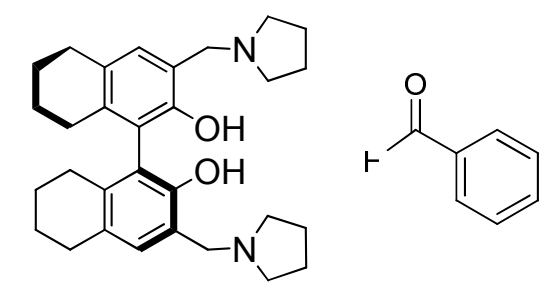

$10^{d}$
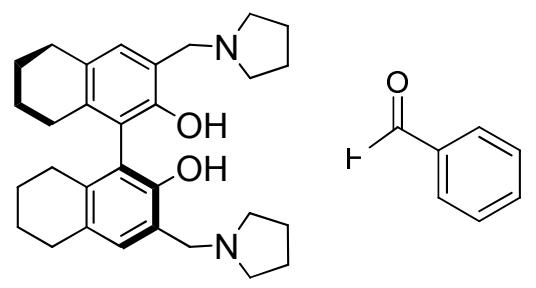

11

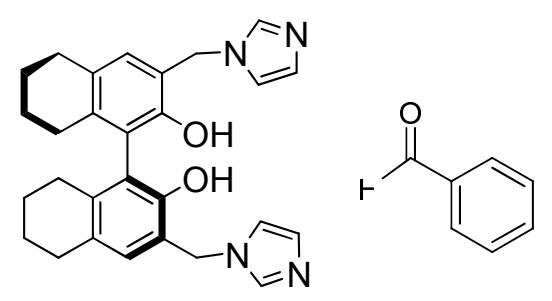

12

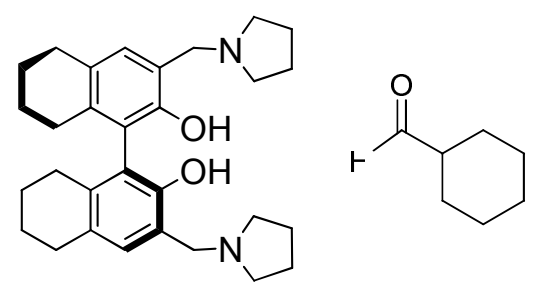

16

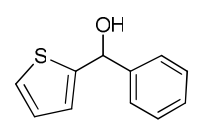

67

95

82

16

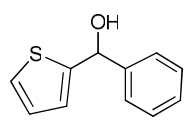

67

98

58

16

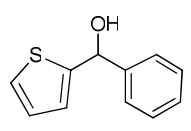

67

90

92

16

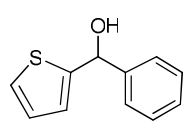

67

96

90

16<smiles>OC(c1ccccc1)c1cccs1</smiles>

67

81

2

14<smiles>CC(c1cccs1)C1CCCCC1</smiles>

68

94 
13<smiles>Oc1c(CN2CCCC2)cc2c(c1-c1c(O)c(CN3CCCC3)cc3c1CCCC3)CCCC2</smiles>

14<smiles>Oc1c2c(cc(CN3CCCCC3)c1-c1c(O)c(CN3CCCCCC3)cc3c1CCCC3)CCCC2</smiles>

15<smiles>CCCCN(CCCC)Cc1cc2c(c(-c3c(O)c(CN(CCCC)CCCC)cc4c3CCCC4)c1O)CCCC2</smiles>

16<smiles>CN(Cc1ccccc1)Cc1cc2c(c(O)c1O)CCCC2</smiles><smiles>C=C(F)c1ccccc1C(C)C</smiles>

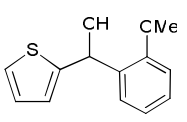

16

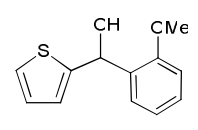

70

98

69

75 85

16<smiles></smiles>

70

98

64

16<smiles>CCC1CC=CC1C(C)c1cccs1</smiles>

70

98

66

16

70

92

73

(a) Following reaction conditions were used unless otherwise noted: 2-iodothiophene

(2.2 equiv, dried, distilled), $\mathrm{Li}(\mathrm{acac})$ (26 mol\%), $\mathrm{Et}_{2} \mathrm{Zn}$ (1.21 equiv), NMP (1.5 mL), chiral ligand (10 mol\%), $5 \mathrm{~mL}$ THF (5 mL), benzaldehyde (1.0 equiv), rt. Step 1: 6 h. Step 2: 1 h. Step 3. 12-16 h. (b) Determined by using HPLC-chiral column. (c) Undistilled 2-iodothiophene was used. (d) $0.75 \mathrm{~mL}$ NMP was used in step 1. 
The conditions for the reaction of 2-iodothiophene with benzaldehyde in the presence of $S$ )-12 were further explored in order to determine the effect of the solvent and additive on this reaction. These experiments are summarized in Table 3.14. As shown in entries 1-5, when the solvent was changed from THF to others, the enantioselectivity was significantly reduced. When the additive Li(acac) was replaced with 1,3bis(diphenylphosphine)propane, a small reduction in enantioselectivity was observed (entry 6). Removing both Li(acac) and NMP led to no thiophenyl addition product but only the $\mathrm{ZnEt}_{2}$ addition product (entry 7). This indicates that the thiophenylzinc was not generated under these conditions. In the presence of NMP but without Li(acac), high enantioselectivity and excellent yield were obtained (entry 8). That is, the additive $\mathrm{Li}(\mathrm{acac})$ that is necessary for the formation of other arylzinc reagents ${ }^{10,11}$ is not needed for the reaction of 2-iodothiophene. This gives a simplified reaction procedure.

Table 3.14 Varying the Conditions for the Reaction of 2-iodothiophene and Benzaldehyde in the Presence of $\mathrm{ZnEt}_{2}$ and $(S)-12$. $^{\mathrm{a}}$

\begin{tabular}{cccccc}
\hline Entry & Solvent & Additive & NMP & $\begin{array}{c}\text { Isolated } \\
\text { Yield (\%) }\end{array}$ & $\begin{array}{c}\text { ee } \\
(\%)\end{array}$ \\
\hline 1 & THF & Li(acac) $(26 \%)$ & $1.5 \mathrm{~mL}$ & 95 & 90 \\
2 & DCM & $\operatorname{Li}(\mathrm{acac})(26 \%)$ & $1.5 \mathrm{~mL}$ & 95 & 84 \\
3 & Toluene & $\operatorname{Li}(\mathrm{acac})(26 \%)$ & $1.5 \mathrm{~mL}$ & 91 & 82 \\
4 & Ether & $\operatorname{Li}(\mathrm{acac})(26 \%)$ & $1.5 \mathrm{~mL}$ & 92 & 78 \\
5 & Hexanes & $\operatorname{Li}(\mathrm{acac})(26 \%)$ & $1.5 \mathrm{~mL}$ & 91 & 75 \\
$6^{\mathrm{c}}$ & THF & $\left(\mathrm{Ph}_{2} \mathrm{PCH}_{2}\right)_{2} \mathrm{CH}_{2}(20 \%)$ & $1.5 \mathrm{~mL}$ & 92 & 86
\end{tabular}




$\begin{array}{cccccc}7^{\mathrm{d}} & \text { THF } & \text { None } & \text { None } & \text { None } & \text { n/a } \\ \mathbf{8}^{\mathbf{e}} & \text { THF } & \text { None } & \mathbf{1 . 5} \mathbf{~ m L} & 98 & 91 \\ \mathbf{9}^{\mathbf{f}} & \text { THF } & \text { None } & 1.5 \mathbf{m L} & \mathbf{9 8} & 91\end{array}$

(a) Following reaction conditions were used unless otherwise noted: 2-iodothiophene (2.2 equiv), an additive, $\mathrm{Et}_{2} \mathrm{Zn}$ (1.21 equiv), ligand (10 mol\%), NMP (1.5 mL), THF (5 $\mathrm{mL}$ ), benzaldehyde (1.0 equiv), rt. Step 1: 6 h. Step 2: 1 h. Step 3: 8 h. (b) Determined by using HPLC-chiral column. (c) Step 1: 16 h. (d) Step 1: THF (5 mL), no NMP, 16 h. Step 3: 16 h. The ethyl addition product was obtained in $90 \%$ yield. (e) Step 1: 12 h. (f) Step 1: $6 \mathrm{~h}$.

The thiophenylation was also tested using $10 \mathrm{~mol} \%$ of (S)-BINOL and $10 \mathrm{~mol} \%$ (S)$\mathrm{H}_{8} \mathrm{BINOL}$. The reaction with (S)-BINOL afforded 57\% alcohol in $10 \%$ ee and with (S)$\mathrm{H}_{8} \mathrm{BINOL}$ only a small amount of alcohol was formed (12\%) and with no selectivity. Aryl bromides were studied to investigate whether they could be used in place of aryl iodides for the asymmetric arylzinc addition to aldehydes. Most aryl bromides failed to react, for example, $m$-bromoanisole and methyl $p$-bromobenzoate did not react with $\mathrm{ZnEt}_{2}$ under the conditions used for the reaction of the aryl iodides even with extended reaction time and under refluxing. The excellent reactivity of 2-iodothiophene described here encouraged us to test the use of 2-bromothiophene for the reaction with benzaldehyde in the presence of $(S)-12$ and $\mathrm{ZnEt}_{2}$ to give diaryl carbinol 67 (see Scheme 3.7). We were pleased to find that the thiophenylzinc could be generated from 2bromothiophene to react with benzaldehyde in the presence of $(S)-\mathbf{1 2}$ with good enantioselectivity. The results are summarized in Table 3.15. The use of distilled 2- 
bromothiophene in entry 4 showed higher enantioselectivity than using undistilled 2bromothiophene (entries 1-3). This is the first example that an aryl bromide can be used to react with $\mathrm{ZnEt}_{2}$ to form a diarylzinc reagent. The product was obtained with slightly reduced enantioselectivity relative to the reaction using 2-iodothiophene. Unlike that found for 2-iodothiophene shown in entries 8 and 9 of Table 3.14, without Li(acac) the thiophenylzinc could not be generated from 2-bromothiophene and only ethyl addition product was observed in the presence of $(S)$-12. 2-Chlorothiophene did not react with $\mathrm{ZnEt}_{2}$ to form the arylzinc.

Scheme 3.7 Using 2-Bromothiophene for the Asymmetric Arylzinc Addition of Thiophene to Benzaldehyde in the Presence of $(S)-12$ and $\mathrm{ZnEt}_{2}$.

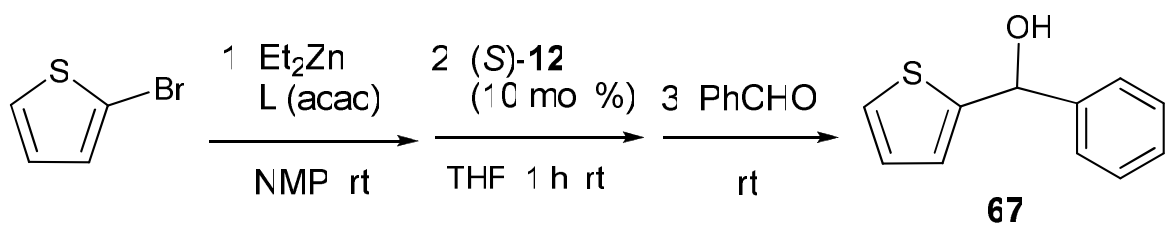

Table 3.15 The Asymmetric Reaction of 2-Bromothiophene with Benzaldehyde in the Presence of $(S)-12$ and $\mathrm{ZnEt}_{2}$ to Form 67.

\begin{tabular}{cccccc}
\hline Entry & $\begin{array}{c}\text { 2-Bromo- } \\
\text { thiophene }\end{array}$ & Step 1 (h) & Step 3 (h) & $\begin{array}{c}\text { Isolated } \\
\text { Yield (\%) }\end{array}$ & ee (\%) \\
\hline 1 & undistilled & 12 & 24 & 80 & 82 \\
2 & undistilled & 24 & 16 & 90 & 79 \\
3 & undistilled & 6 & 10.5 & 87 & 83 \\
4 & distilled & 6 & 10 & 98 & 86
\end{tabular}


(a) Conditions: 2-bromothiophene (2.2 equiv), Li(acac) (26 mol\%), $\mathrm{ZnEt}_{2}$ (1.21 equiv),

(S)-12 (10 mol\%), NMP (1.5 mL), THF (5 mL), benzaldehyde (1.0 equiv), rt. Step 2: 1

h. (b) Determined by using HPLC-chiral column.

Other aryl halides including 3-Bromothiophene, 2-bromoferrocene, 2bromothiazole, 2-chlorothiophene, and 3-bromofuran failed to undergo alkyl—halide exchange in the presence of $\mathrm{Et}_{2} \mathrm{Zn}, \mathrm{Li}(\mathrm{acac})$ and NMP at room temperature over various times. Typically, the ethyl addition to the aldehyde was observed.

2-Acetyl-5-iodothiophene was studied briefly. After the conditions used for 2iodothiophene had been applied to 2-acetyl-5-iodothiophene and reacted with benzaldehyde, a complex reaction mixture was obtained. The first fractions contained a mixture of both the unreacted iodothiophene substrate and the thiophene-based compound (indicative that iodide-zinc exchange had occurred). The next fraction was identified as a small amount of the addition product. This was a positive result as the ketone function has been a challenge in the asymmetric development of our catalytic systems. Unfortunately, only a small amount of the aryl addition compound $(\sim 20 \%$ yield; 71) was obtained and attempts to synthesize the racemic alcohol for analysis were unsuccessful.

Ligand $(S)$-18 was used to catalyze the functional arylations (3-iodoanisole, methyl p-iodobenzoate, and 2-iodothiphene) of 2-methoxybenzaldehyde. The results for are summarized in Table 3.16 below. 


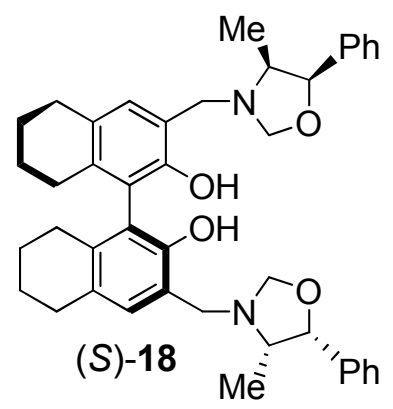

Table 3.16 Functional Arylations of 2-Methoxybenzaldehyde Catalyzed in the Presence of Ligand $(S)-18 .^{a}$

\begin{tabular}{lcc}
\hline Entry & Compound & ee (\%) \\
& & \\
\end{tabular}

a) The reaction conditions used were those found as optimal for the respective aryl iodide (ArI). b) ee measured by chiral HPLC

A note of interest in the enantioselective arylations obtained with $(S)-\mathbf{1 8}$. The relation of enantiocontrol followed a trend that could be qualitatively described as either good across the screened arylations or poor selectivity observed again across the board. What we note from the reactions catalyzed by $(S)-\mathbf{1 8}$, a "chiral-armed" ligand, is that this relation does not hold as it had for each of the other ligands studied. $(S)$-18 showed only an average enantiocontrol (69\% ee) (average relative to results obtained from other ligands) for the thiophenylation of 2-methoxybenzaldehyde. The alcohol from the 
reaction of methyl p-iodobenzoate to 2 -methoxybenzaldehyde was formed in $78 \%$ ee (whereas the two best results were obtained from other 5-membered cycles present on the amino-“arms": $(S)-\mathbf{1 2}$ and $(S)-\mathbf{1 3}$, as 93\% ee and 92\% ee, respectively). Finally, the alcohol from the addition between 3-iodoanisole and 2-methoxybenzaldehyde was afforded in $80 \%$ ee. This was actually the same as the best ligand previously identified $(S)$-12. The nature of this characteristic reactivity is likely due to the optically pure, chiral arms of $(S)-\mathbf{1 8}$.

\section{g. Asymmetric Reaction of the in situ Generated Diphenylzinc from Iodobenzene}

\section{Catalyzed by the $\mathrm{H}_{8}$ BINOL-AMs}

Qin and Pu previously reported the use of $(S)-2$ to catalyze the reaction of the commercially available $\mathrm{Ph}_{2} \mathrm{Zn}$ with aldehydes. ${ }^{5 \mathrm{~b}, \mathrm{c}}$ The diphenylzinc availability has proven to be an important factor in the development of this asymmetric methodology. There have been numerous reports in the past ten years on the asymmetric phenyladditions starting from diphenylzinc. ${ }^{2,5,7}$ A major drawback to these methods is the cost of diphenylzinc. While being commercially available, it remains expensive (as of November, 2010: 5 G diphenylzinc, 92\% purity, Aldrich $=\$ 461.00 ; 5$ G diphenylzinc, 98+\% purity, Alfa Aesar $=\$ 408.00 ; 5 \mathrm{G}$ diphenylzinc, 99\% purity, Strem Chemical, Inc. $=\$ 316.00)$. Furthermore, in most reports only a single phenyl group is utilized in the reactivity. The diminished reactivity of the resulting monophenylzinc compound (phenylzincalkoxide in the case where diphenylzinc is used in an addition reaction to a carbonyl compound) has hampered the efficiency of these protocols. This represents a challenge to diphenylzinc methodology as well as other organozinc reagents. After a 
single group on the zinc center from the organozinc is transferred, the resulting complex lacks either the nucleophilicity to transfer the second group (of ligand; phenyl in the case of diphenylzinc) or the zinc center has augmented its Lewis acidity to a nonreactive state. Both factors could potentially be responsible.

Iodobenzene was examined in these studies to identify an alternative strategy for the asymmetric phenylation of aldehydes. The addition of the in situ generated $\mathrm{Ph}_{2} \mathrm{Zn}$ from iodobenzene with $p$-methoxybenzaldehyde in the presence of $(S)-\mathbf{2}$ and $(S)-\mathbf{1 2}$ to form the diaryl carbinol $\mathbf{7 2}$ (Scheme 3.8) was studied. The results are summarized in Table 3.17. Using distilled iodobenzene led to significant enhancement of the enantioselectivity from entry 1 to entry 2 in the presence of $(S)-2$. The time for the in situ formation of $\mathrm{Ph}_{2} \mathrm{Zn}$ in the first step was found to strongly influence both the yield and ee of the reaction. Increasing the time in the first step from entry 2 to entry 3 reduced both the yield and ee, indicating a degradation of $\mathrm{Ph}_{2} \mathrm{Zn}$ over time. Changing the solvent from THF to $\mathrm{CH}_{2} \mathrm{Cl}_{2}$ diminished both the yield and ee (entry 4). The optimal reaction time for the first step was $3 \mathrm{~h}$ which led to the formation of $\mathbf{7 2}$ in good enantioselectivity and yield (entry 6). Under these conditions, replacing $(S)$-2 with $(S)$-12 enhanced both the yield and ee (entry 7). This demonstrates that in the presence of $(S)-\mathbf{1 2}$, iodobenzene could be used to replace $\mathrm{Ph}_{2} \mathrm{Zn}$ for the asymmetric $\mathrm{Ph}_{2} \mathrm{Zn}$ addition to aldehydes. When the commercially pure $\mathrm{Ph}_{2} \mathrm{Zn}$ was used for the addition to $p$-methoxybenzaldehyde in the presence of $(S)-\mathbf{2}$, the product was obtained with $91 \%$ ee and $91 \%$ yield. ${ }^{6}$ 
Scheme 3.8 Using Iodobenzene for the Asymmetric Phenylzinc Addition in the Presence of $\mathrm{H}_{8} \mathrm{BINOL-AMs.}$

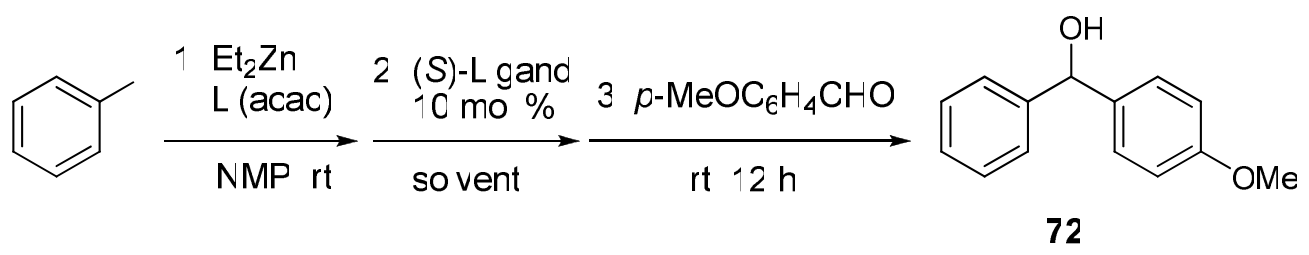

Table 3.17 The Asymmetric Reaction Using Iodobenzene and $p$ methoxybenzaldehyde in the Presence of $\mathrm{H}_{8}$ BINOL-AMs to Form 72.

\begin{tabular}{ccccc}
\hline Entry & Ligand & $\begin{array}{c}\text { Step 1 } \\
\text { (h) }\end{array}$ & $\begin{array}{c}\text { Isolated } \\
\text { Yield (\%) }\end{array}$ & $\boldsymbol{e e ~ ( \% )}$ \\
\hline $1^{\mathrm{c}}$ & $(S)-\mathbf{2}$ & 13 & 64 & 62 \\
2 & $(S)-\mathbf{2}$ & 13 & 77 & 85 \\
3 & $(S)-\mathbf{2}$ & 24 & 50 & 64 \\
$4^{\mathrm{d}}$ & $(S)-\mathbf{2}$ & 24 & 12 & 40 \\
5 & $(S)-\mathbf{2}$ & 6 & 56 & 82 \\
6 & $(S)-\mathbf{2}$ & 3 & 85 & 88 \\
7 & $(S)-\mathbf{1 2}$ & $\mathbf{3}$ & $\mathbf{9 8}$ & $\mathbf{9 3}$
\end{tabular}

(a) Following conditions were used unless otherwise noted: iodobenzene (2.2 equiv, freshly distilled), Li(acac) (26 mol\%), $\mathrm{Et}_{2} \mathrm{Zn}$ (1.21 equiv), NMP (1.5 mL), chiral ligand (10 mol\%), THF (5 mL), $p$-anisaldehyde (1.0 equiv, treated with $\mathrm{NaHCO}_{3}$, passed through alumina, degassed), rt, under nitrogen. Step 2: 1 h. Step 3: 12 h. (b) Determined by using HPLC-chiral column. (c) Undistilled iodobenzene was used. (d) $\mathrm{CH}_{2} \mathrm{Cl}_{2}$ was used in place of THF. 
When bromobenzene was attempted in the asymmetric phenylation of 4methoxybenzaldehyde, $95 \%$ yield of the ethyl addition product with $68 \%$ ee was isolated. The bromobenzene (dried and distilled) was stirred in NMP with $\mathrm{Et}_{2} \mathrm{Zn}$ and $\mathrm{Li}(\mathrm{acac})$ for 17 hours at room temperature before $(S)$-12 $(10 \mathrm{~mol} \%)$ and THF were added followed by the aldehyde.

The stoichiometry was tested in the following reaction. 1.21 equivalents iodobenzene was stirred with 1.21 equivalents $\mathrm{Et}_{2} \mathrm{Zn}$ in NMP for 3.5 hours at room temperature. (S)-2 and THF were then added and finally 4-methoxybenzaldehyde. We were surprised to find that only the ethyl addition product formed in about $50 \%$ yield and the starting material was not consumed over 2 days. This result was surprising because the 1:1 mixing of a functional aryl iodide and dialkylzinc had been reported to form a monoalkylarylzinc species by Knochel. ${ }^{10}$ Because we only slightly modified the exchange procedures and extended it to include iodobenzene, we anticipated this should behave in the same manner. It is unlikely that the monoalkylarylzinc formed because this species has been shown to preferentially deliver the aryl (phenyl) group to an aldehyde. ${ }^{14}$

A number of aryl iodides failed to react under these conditions. 2-Iodopyridine and 3-iodopyridine failed to yield alcohols even though this substrate had been reported by Knochel to react with diisopropylzinc. ${ }^{15}$ A protection and potential deactivation strategy was attempted for these substrates. A similar strategy had been previously reported in a number of synthetic protocols ${ }^{16}$ using heteroaromatics. Unfortunately, these were not successfully applied. When 3-iodopyridine was reacted with 1 equivalent of acetic anhydride in NMP for 1 hour, $\mathrm{Et}_{2} \mathrm{Zn}$ was added dropwise but resulted in a violent reaction. Presumably, the pyridine in the $N$-acyl form reacts with $\mathrm{Et}_{2} \mathrm{Zn}$ in NMP. When 
borontrifluoride etherate was attempted to protect the pyridine, no violent reaction was observed but again no addition product was formed. The triethylborane-(3-iodo)pyridine complex did not under alkyl—halide exchange either.

\section{h. Ligand Enantiomeric Purity Correlation Experiment, Absolute Configuration} Assignment, and NMR study

In order to gain more information about the asymmetric arylzinc addition to aldehydes in the presence of the $\mathrm{H}_{8} \mathrm{BINOL}-\mathrm{AM}$ compounds, the relationship between the enantiomeric purity of $(S)-\mathbf{2}$ and that of the product $\mathbf{3 8}$ from the reaction of $m$-iodoanisole with cyclohexanecarboxaldehyde was studied (Scheme 3.9). As shown in Figure 3.4, a linear relationship was obtained between the ee of $(S)-\mathbf{2}$ and the ee of $\mathbf{3 8}$. This indicates that the monomeric complex of $(S)-2$ rather than intermolecular aggregates are responsible for the catalysis. The observed linear relationship between the ee of $(S)$-2 and that of the arylzinc addition product is similar to that previously reported for the reaction of the commercially available pure $\mathrm{Ph}_{2} \mathrm{Zn}$ with aldehydes catalyzed by $(S)-2 .{ }^{6 \mathrm{~b}, \mathrm{c}}$

\section{Scheme 3.9 The Asymmetric Reaction of $m$-Iodoanisole With}

\section{Cyclohexanecarboxaldehyde Catalyzed by $(S)-2$.}

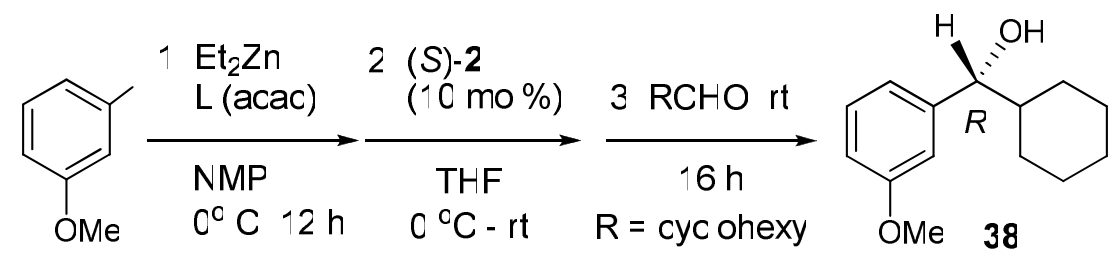

Figure 3.4 The Relationship of the Enantiomeric Purity of $(S)-2$ With that of the Corresponding Product 38. 


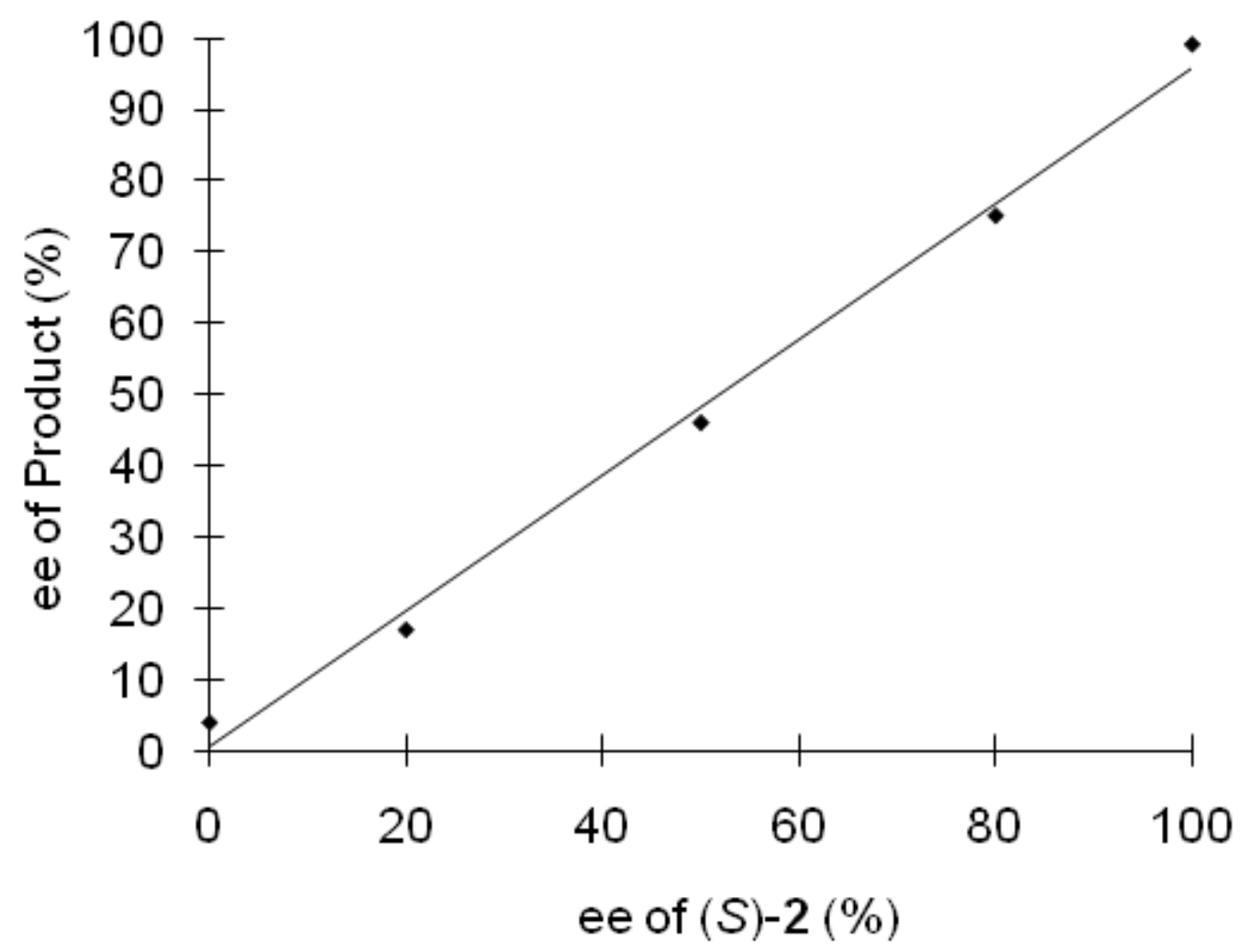

Absolute Configuration Determination:

The $(R)$ and $(S)$ - $\alpha$-methoxy- $\alpha$-phenylacetic (MPA) ester derivatives of $\mathbf{3 8}$ were prepared to determine its absolute configuration (Figure 3.5 below). ${ }^{17}$ The ${ }^{1} \mathrm{H}$ NMR analysis showed that in the (R)-MPA derivative of $\mathbf{3 8}$, the anisyl aromatic signals of $\mathbf{3 8}$ shifted upfield in comparison with those in the $(S)$-MPA derivative of $38 .^{12}$ This supports a $R$ configuration for $\mathbf{3 8}$ prepared by using $(S)$-2. Thus, the nucleophilic arylzinc should add to the re face of the aldehyde during the asymmetric arylation.

Figure 3.5 $(R)$ and $(S)$ - $\alpha$-methoxy- $\alpha$-phenylacetic (MPA) Ester Derivatives of 38 


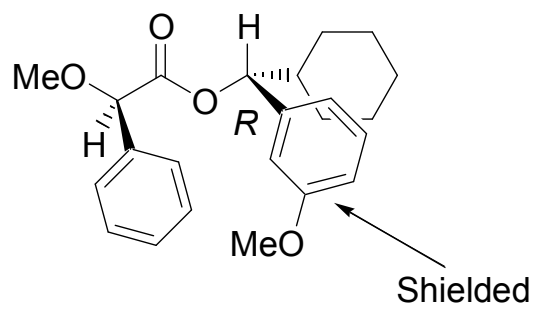

(R)-MPA derivative

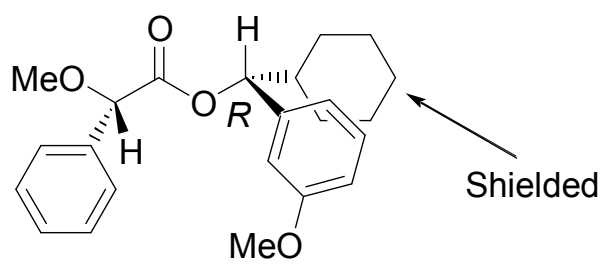

(S)-MPA derivative

\section{${ }^{1}$ H NMR Studies:}

We also conducted a NMR spectroscopic investigation for the reaction of the in situ generated arylzinc catalyzed by $(S)-\mathbf{2}$. Under nitrogen, a portion of the reaction solution (prepared at $0{ }^{\circ} \mathrm{C}$ for $18 \mathrm{~h}$ ) of methyl $p$-iodobenzoate $(0.067 \mathrm{mmol})$ with $\mathrm{ZnEt}_{2}(0.037$ mmol $)$ in NMP $(0.05 \mathrm{~mL}, 0.52 \mathrm{mmol})$ and $\mathrm{Li}(\mathrm{acac})(0.008 \mathrm{mmol})$ was added to $\mathrm{C}_{6} \mathrm{D}_{6}$, and the ${ }^{1} \mathrm{H}$ NMR spectrum of the solution showed signals at $\delta 8.34(\mathrm{~d}, \mathrm{~J}=8.1 \mathrm{~Hz}, 4 \mathrm{H}), 8.24$ $(\mathrm{d}, \mathrm{J}=7.8 \mathrm{~Hz}, 4 \mathrm{H}), 3.56(\mathrm{~s}, 6 \mathrm{H})$ corresponding to the desired diarylzinc $(p-$ $\left.\mathrm{MeO}_{2} \mathrm{CC}_{6} \mathrm{H}_{4}\right)_{2} \mathrm{Zn}$. The conversion of methyl $p$-iodobenzoate to $\left(p-\mathrm{MeO}_{2} \mathrm{CC}_{6} \mathrm{H}_{4}\right)_{2} \mathrm{Zn}$ was almost complete. When 1 equiv of the diarylzinc solution was added to a $\mathrm{C}_{6} \mathrm{D}_{6}$ solution of $(S)$-2, methyl benzoate was produced with a similar amount of unreacted $(S)-\mathbf{2}$ but no free $\left(p-\mathrm{MeO}_{2} \mathrm{CC}_{6} \mathrm{H}_{4}\right)_{2} \mathrm{Zn}$ observed. This indicates that one molecule of $(S)-2$ probably consumed more than one molecule of $\left(p-\mathrm{MeO}_{2} \mathrm{CC}_{6} \mathrm{H}_{4}\right)_{2} \mathrm{Zn}$. When 1.8 equiv of $(p$ $\left.\mathrm{MeO}_{2} \mathrm{CC}_{6} \mathrm{H}_{4}\right)_{2} \mathrm{Zn}$ was added, $(S)-2$ was completely consumed, but the structure of the resulting complex could not be established because of the complicated NMR signals. This is quite different from the reaction of $(S)-2$ with the commercially pure $\mathrm{Ph}_{2} \mathrm{Zn}$ which gave much better defined NMR signals. ${ }^{6 \mathrm{~b}}$ When $(S)-2$ was treated with 1.5 equiv of $\mathrm{Ph}_{2} \mathrm{Zn}$, the NMR spectrum showed the formation of a $2+3$ complex 73 (Figure 3.6). This complex collapsed upon reaction with excess $\mathrm{Ph}_{2} \mathrm{Zn}$ to form a $\mathrm{C}_{2}$-symmetric complex which might have a structure of either $\mathbf{7 3 a}$ or $\mathbf{7 3 b}$. This complex was found to be the 
catalytically active species for the arylzinc addition involving a possible transition state as shown. The much more complicated NMR spectrum obtained for the reaction of $(S)-2$ with the in situ generated $\left(p-\mathrm{MeO}_{2} \mathrm{CC}_{6} \mathrm{H}_{4}\right)_{2} \mathrm{Zn}$ could be partly attributed to the additional components such as NMP, $\mathrm{Li}(\mathrm{acac})$ and EtI present in this reaction system. When up to 5 equivalent of the $\left(p-\mathrm{MeO}_{2} \mathrm{CC}_{6} \mathrm{H}_{4}\right)_{2} \mathrm{Zn}$ solution was added to $(S)-\mathbf{2}$, the NMR spectrum still showed complicated signals for the ligand-zinc complex with no free ( $p$ $\left.\mathrm{MeO}_{2} \mathrm{CC}_{6} \mathrm{H}_{4}\right)_{2} \mathrm{Zn}$ present. Figure 3.6 shows the proposed intermediates based on the NMR study using $\mathrm{Ph}_{2} \mathrm{Zn}{ }^{6 b}$

Figure 3.6 Structures Formed Between the Reaction of (S)-2 and Various Equivalents of Arylzinc (below is Figure from a previous report and dissertation from Dr. Yingchuan Qin and $P u)^{6 b}$

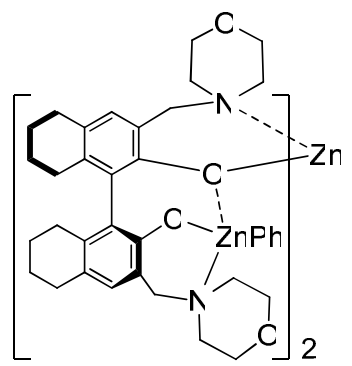

73

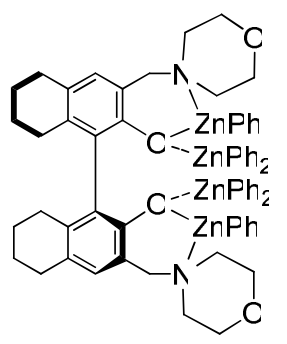

$73 a$

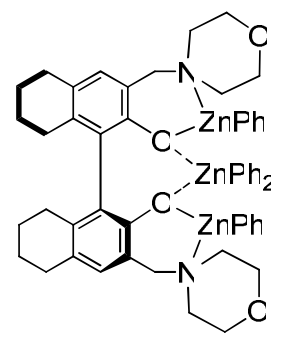

$73 b$

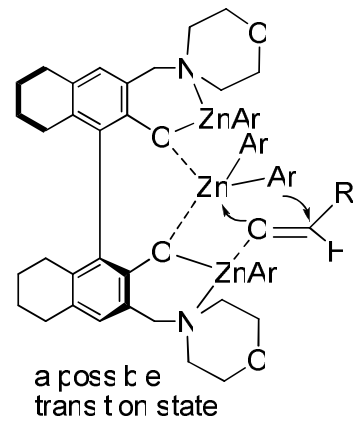

trans t on state

When the $\mathrm{H}_{8} \mathrm{BINOL}-\mathrm{AM}$ compounds are used for the arylzinc addition to aldehydes, the active catalysts are the zinc complexes generated from the reaction of the arylzincs with the chiral compounds. That is, for each arylzinc addition reaction, the catalyst is different because different arylzincs are used. On the basis of the reaction time described earlier, the following order was found for the relative activity of the reactions studied: $(\text { methyl } p \text {-benzoate })_{2}$ zinc $>(2 \text {-thiophenyl })_{\mathrm{n}}$ zinc $>(\text { phenyl })_{\mathrm{n}}$ zinc $>(m-$ anisyl $)_{2}$ zinc $>>(m \text {-benzonitrile })_{2}$ zinc. 
In summary of the $\mathrm{H}_{8} \mathrm{BINOL}-\mathrm{AM}$ catalytic screens, using the compounds as chiral ligands in the reaction of the in situ generated functional arylzincs from aryl iodides and $\mathrm{ZnEt}_{2}$ with a variety of aldehydes to produce chiral diaryl- and aryl, alkyl- carbinols, some general trends and observations were identified. The results of these studies show that the $\mathrm{H}_{8} \mathrm{BINOL}-\mathrm{AM}$ compounds with less sterically congested cyclic or acyclic tertiary amine substituents are more enantioselective than those with bulkier tertiary amine substituents. This strongly suggests that the ligands containing bulkier substituted amine groups distort the active catalyst structure, forming a sterically congested chiral cavity. Empirical data demonstrate that these structures do not provide asymmetric induction but do maintain activation of the nucleophilic arylzincs towards addition to aldehydes in most cases. The additions most likely occur outside the chiral cavity, possibly at the less crowded 3,3'-amino methyl and 4,4'-unsubstituted environment. A linear correlation was observed between the enantiomeric excess of the chiral ligand and that of the arylzinc addition product, suggesting a monomeric active catalytic species. The initial results for compound (S)-2 identified this ligand to generate a highly active and enantioselective catalyst for the asymmetric arylzinc addition to $p$ - and $m$-substituted aromatic aldehydes and aliphatic aldehydes. Results from the ligand screens showed that pyrrolidinyl- derivative $(S)$-12 was found in most cases to give enhanced enantioselectivity over (S)-2 and the other $\mathrm{H}_{8}$ BINOL-AM compounds, especially for the challenging ortho-substituted aromatic aldehydes. The benzylmethylamine-based compound (S)-7 also gave better enantioselectivity in several cases. A $\mathrm{H}_{8} \mathrm{BINOL-AM}$ containing 3,3'-bis-secondary-amine substituents $(S)$-29, prepared by a multi-step method, was used to catalyze the arylzinc addition to aldehydes but it showed lower 
enantioselectivity than the tertiary amine derivatives $(S)-\mathbf{2},(S)-\mathbf{7}$ and $(S)-\mathbf{1 2}$. The brief exploration using a chiral-“armed" ligand, $(S)$-18, showed an interesting finding. Whereas the generated catalyst from $(S)-\mathbf{1 8}$ showed good enantioselectivity for the arylzinc formed from 3-iodoanisole addition to 2-methoxybenzaldehyde (same ee as best result from screening of ligand family; $80 \%$ ee), other arylzinc additions were only average or below average. The trend for all other ligands screened, i.e. generally poor or generally good, was not observed for $(S)$-18. It was found for the first time that an aryl bromide, 2-bromothiophene, could be used to prepare a heteroarylzinc reagent by reaction with $\mathrm{ZnEt}_{2}$. The addition of this heteroarylzinc reagent to an aldehyde in the presence of $(S)$-12 proceeded with good enantioselectivity.

The functional arylzinc generations and catalyzed asymmetric additions to aldehydes represent an important development for this class of methodologies. Walsh showed a useful method to generate substituted arylzincs from aryl bromides, alkyllithiums, and $\mathrm{ZnCl}_{2}$ or EtZnCl. While these methods demonstrated that diarylzincs and arylalkylzincs (including heteroarylzincs), the use of alkyllithiums potentially limits the functional group compatibility of these protocols. Separately, a number of methods have described the generation of arylzincs from a variety of substituted aryl boronic acids (as well as other aryl substrates, see reference 4). As a number of substituted and functional group containing aryl boronic acids are commercially available, these methods also further expanded catalyzed asymmetric arylation methodology. However, typically excess diethylzinc was required (due to the presence of the acidic groups). 


\section{i. Experimental and Characterization}

\section{General Data and Instruments:}

The following instrumentation was used for the analysis of compounds: ${ }^{1} \mathrm{H}$ and ${ }^{13} \mathrm{C}$ NMR spectra were collected on Varian $300 \mathrm{MHz}$ and Burger $500 \mathrm{MHz}$. Optical rotation measurements were taken on a Jasco digital polarimeter P-2000. HPLC separations were performed on a Waters 600 pump and Waters 486 TUNABLE ABSORBANCE DETECTOR (254 nm) using one of the following chiral analytical columns: Daicel Chiralcel OD, OB-H and Chiralpak AD-H column. ee calculations were done based on the areas of peaks in chromatograms (corresponding racemic and chiral alcohol chromatograms).

All reactions were carried out under nitrogen. Unless otherwise noted, all chemicals were purchased from Aldrich Chemical Co. Diethylzinc (95\%) was purchased from Strem Chemicals, Inc. Toluene and THF were distilled over sodium and benzophenone under nitrogen. 1-Methyl-2-pyrrolidinone (NMP) was distilled over calcium hydride under reduced pressure. Dichloromethane and diethyl ether were dried by passing through activated alumina columns under nitrogen. Deuterated benzene was distilled over sodium. All solvents were stored over activated 4 Á molecular sieves. All liquid aldehydes were distilled prior to use. 3-Iodoanisole was distilled from activated molecular sieves and copper under reduced pressure with the careful exclusion of light. 4-methyl-iodobenzoate and 3-iodobenzonitrile (purchased from Aldrich Chemical Co. and TCI America) were dissolved in dry THF and evacuated to dryness prior to use. 2Iodothiophene and 2-bromothiophene were used as received or distilled in the same 
manner as 3-iodoanisole. High resolution mass spectral (HRMS) data were obtained from University of California, Riverside (UCR) Mass Spectrometry Facility or the University of Illinois (at Urbana-Champaign) Mass Spectrometry Laboratory. Some samples were spiked with ammonium acetate accounting for observation of $\left[\mathrm{MNH}_{4}{ }^{+}\right]$. $\left[\mathrm{MH}^{+}\right],[\mathrm{M}-\mathrm{H}]^{+}$, or $[\mathrm{M}-\mathrm{OH}]^{+}$ions were otherwise observed (ESI). These samples were dissolved in $\mathrm{MeOH}$ and injected into a $\mathrm{MeOH}$ stream leading to the instrument. ESI/APCI methods were used and analysis performed by Agilent LCTOF. (S)-17 was analyzed by ESI. 58 and 69 were analyzed by EI. Elemental analyses were obtained from Atlantic Microlab, Inc.

\section{a. General Procedure for the asymmetric reaction of 3-iodoanisole with aldehydes.}

Under nitrogen to a $10 \mathrm{~mL}$ round bottom flask (flame dried under vacuum), $\mathrm{Li}(\mathrm{acac})$ (24 $\mathrm{mg}, 0.22 \mathrm{mmol}, 0.24$ equiv), 3-iodoanisole ( $238 \mu \mathrm{L}, 2.0 \mathrm{mmol}, 2.2$ equiv), and NMP (1.5 $\mathrm{mL})$ were added sequentially. This mixture was cooled to $0{ }^{\circ} \mathrm{C}$ and $\mathrm{Et}_{2} \mathrm{Zn}(115 \mu \mathrm{L}, 1.1$ mmol, 1.20 equiv) was added dropwise. The mixture was stirred at $0{ }^{\circ} \mathrm{C}$ for $12 \mathrm{~h}$. A solution of a $\mathrm{H}_{8}$ BINOL-AM ( $0.091 \mathrm{mmol}, 0.1$ equiv) in THF $(5 \mathrm{~mL})$ was added. The resulting reaction mixture was stirred at $0{ }^{\circ} \mathrm{C}$ for $1 \mathrm{~h}$ and then warmed to room temperature. An aldehyde $(0.91 \mathrm{mmol})$ was added and the reaction was monitored by TLC. Upon completion, ammonium chloride ( $3 \mathrm{~mL}$, saturated, aq.) was added dropwise to quench the reaction. The resulting mixture was transferred into a separatory funnel and combined with additional ammonium chloride (30 mL, saturated, aq.). Diethyl ether was used to extract the mixture three times $(3 \times 60 \mathrm{~mL})$. The organic fractions were combined and washed with water $(2 \times 75 \mathrm{~mL})$. It was then dried over $\mathrm{Na}_{2} \mathrm{SO}_{4}$ and concentrated. The residue was purified by column chromatography on silica gel eluted 
with hexanes (or petroleum ether)/ethyl acetate ( $0-12 \%)$ to give the alcohol products as either an oil or solid.

\section{Characterization of 3-iodoanisole Addition Products.}

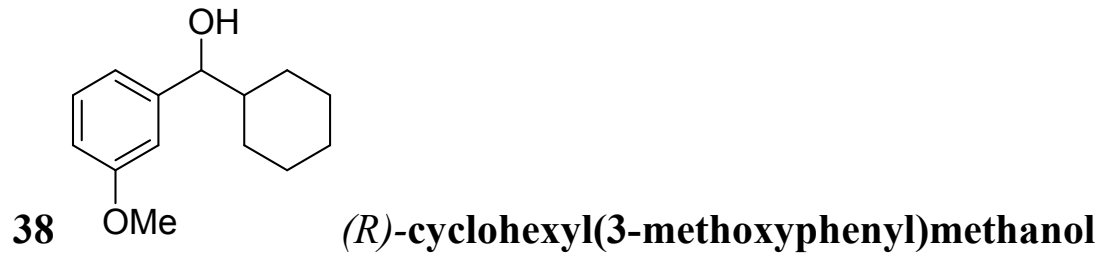

93\% yield, $>99 \%$ ee. ${ }^{1} \mathrm{H}$ NMR $\left(300 \mathrm{MHz}, \mathrm{CDCl}_{3}\right) \delta 7.23(\mathrm{~m}, 1 \mathrm{H}), 6.79$ to $6.87(\mathrm{~m}, 3 \mathrm{H})$, $4.30(\mathrm{dd}, J=2.6,7.2 \mathrm{~Hz}, 1 \mathrm{H}), 3.79(\mathrm{~s}, 3 \mathrm{H}), 2.08(\mathrm{~s}, 1 \mathrm{H}), 1.97(\mathrm{~d}, J=3.0 \mathrm{~Hz}, 1 \mathrm{H}), 1.56$ to $1.77(\mathrm{~m}, 4 \mathrm{H}), 1.37(\mathrm{~m}, 1 \mathrm{H}), 0.88$ to $1.26(\mathrm{~m}, 5 \mathrm{H}) .{ }^{13} \mathrm{C} \mathrm{NMR}\left(75 \mathrm{MHz}, \mathrm{CDCl}_{3}\right) \delta 159.3$. $145.3,129.0,118.9,112.6,112.0,79.1,55.0,44.7,29.2,28.7,26.3,26.0,25.9 .[\alpha]_{\mathrm{D}}{ }^{25}=$ $+18.5(\mathrm{c}=1.245, \mathrm{THF})>99 \%$ ee. HPLC: chiralcel OD column; solvent ratio: 95:5 hexanes:isopropanol, flow rate: $1 \mathrm{~mL} / \mathrm{min} . t_{\text {minor }}=13.6 \mathrm{~min}, t_{\text {major }}=18.1 \mathrm{~min}$. Anal. Calcd. for $\mathrm{C}_{14} \mathrm{H}_{20} \mathrm{O}_{2}: \mathrm{C}, 76.33 ; \mathrm{H}, 9.15$. Found: $\mathrm{C}, 76.23 ; \mathrm{H}, 9.26$. HRMS calcd. for $\left[\mathrm{C}_{15} \mathrm{H}_{16} \mathrm{O}_{2}+\mathrm{NH}_{4}\right]=238.1802$. Found for $\mathrm{MNH}_{4}^{+}: 238.1798$.

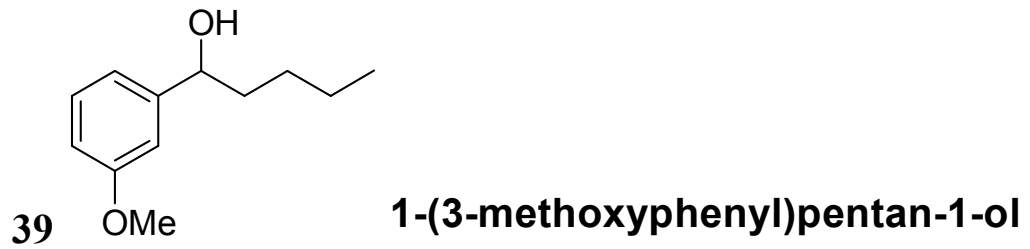

$85 \%$ yield, $96 \%$ ee. ${ }^{1} \mathrm{H}-\mathrm{NMR}\left(300 \mathrm{MHz}, \mathrm{CDCl}_{3}\right) \delta 7.22$ to $7.27(\mathrm{t}, 1 \mathrm{H}), 6.79$ to $6.91(\mathrm{~m}$, $3 \mathrm{H}), 4.57$ to $4.62(\mathrm{t}, 1 \mathrm{H}), 3.80(\mathrm{~s}, 3 \mathrm{H}), 2.25(\mathrm{~s}, 1 \mathrm{H}), 1.61$ to $1.81(2 \mathrm{H}), 1.18$ to $1.40(\mathrm{~m}$, 5H), 0.86 to 0.91 (t, 3H). ${ }^{13} \mathrm{C}-\mathrm{NMR}\left(300 \mathrm{MHz} \mathrm{CDCl}_{3}\right) \delta 159.5,146.6,129.2,118.1$, $112.7,111.2,74.4,55.0,38.6,27.8,22.5,13.9 .[\alpha]_{\mathrm{D}}^{25}=+28.8(\mathrm{c}=1.135$, THF) $96 \%$ ee HPLC: chiralcel OD-H column; solvent ratio: 99:1 hexanes:isopropanol, flow rate: 1 $\mathrm{mL} / \mathrm{min} . t_{\text {major }}=32.7$ min, $t_{\text {minor }}=37.9$ min. Anal. Calcd. for $\mathrm{C}_{12} \mathrm{H}_{18} \mathrm{O}_{2}: \mathrm{C}, 74.19 ; \mathrm{H}$, 
9.34. Found: $\mathrm{C}, 74.13 ; \mathrm{H}, 9.43$. HRMS calcd. for $\mathrm{C}_{12} \mathrm{H}_{18} \mathrm{O}_{2}: 194.1307$

$\left(\mathrm{MNH}_{4}{ }^{+}=212.1645\right)$. Found: 212.1641.

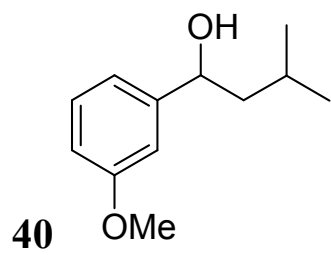

\section{1-(3-methoxyphenyl)-3-methylbutan-1-ol}

85\% yield, $93 \%$ ee. ${ }^{1} \mathrm{H}-\mathrm{NMR}\left(300 \mathrm{MHz}, \mathrm{CDCl}_{3}\right) \delta 7.21$ to $7.27(\mathrm{t}, 1 \mathrm{H}), 6.79$ to $6.91(\mathrm{~m}$, 3H), 4.66 to $4.70(\mathrm{t}, 1 \mathrm{H}), 3.79(\mathrm{~s}, 3 \mathrm{H}), 2.24(\mathrm{~s}, 1 \mathrm{H}), 1.63$ to $1.75(\mathrm{~m}, 2 \mathrm{H}), 1.42$ to $1.52(\mathrm{~m}$, 1H), 0.93 to 0.95 (d, 6H). ${ }^{13} \mathrm{C}-\mathrm{NMR}\left(300 \mathrm{MHz} \mathrm{CDCl}_{3}\right) \delta 159.5,146.9,129.3,118.1$, $112.7,111.2,72.5,55.0,48.1,24.6,23.0,22.1 .[\alpha]_{\mathrm{D}}^{25}=+37.0$ (c=1.13, THF) $93 \%$ ee . HPLC: chiralcel OD-H column; solvent ratio: 95:5 hexanes:isopropanol, flow rate: 1 $\mathrm{mL} / \mathrm{min} . t_{\text {minor }}=12.6 \mathrm{~min}, t_{\text {major }}=14.8$ min. Anal. Calcd. for $\mathrm{C}_{12} \mathrm{H}_{18} \mathrm{O}_{2}: \mathrm{C}, 74.19 ; \mathrm{H}$, 9.34. Found: $\mathrm{C}, 74.04 ; \mathrm{H}, 9.45$. HRMS calcd. for $\mathrm{C}_{12} \mathrm{H}_{18} \mathrm{O}_{2}: 194.1307$ $\left(\mathrm{MNH}_{4}{ }^{+}=216.1645\right)$. Found: 212.1640 .<smiles>CCC(C)C(O)c1cccc(OC)c1</smiles>

\section{1-(3-methoxyphenyl)-2-methylbutan-1-ol}

90\% yield, $>99 \%$ ee, $99 \%$ ee. ${ }^{1} \mathrm{H}-\mathrm{NMR}\left(300 \mathrm{MHz}, \mathrm{CDCl}_{3}\right) \delta 7.21$ to $7.26(\mathrm{t}, 2 \mathrm{H}), 6.78$ to $6.88(\mathrm{~m}, 6 \mathrm{H}), 4.46$ to $4.48(1 \mathrm{H}), 4.36$ to $4.39(1 \mathrm{H}), 3.80(\mathrm{~s}, 3 \mathrm{H}), 2.01$ to $2.06(\mathrm{~d}, 2 \mathrm{H}), 1.66$ to $1.76(\mathrm{~m}, 3 \mathrm{H}), 1.32$ to $1.45(\mathrm{~m}, 1 \mathrm{H}), 1.01$ to $1.23(\mathrm{~m}, 2 \mathrm{H}), 0.86$ to $0.94(\mathrm{~m}, 10 \mathrm{H}), 0.73$ to 0.75 (d, 3H). ${ }^{13} \mathrm{C}-\mathrm{NMR}\left(300 \mathrm{MHz} \mathrm{CDCl}_{3}\right) \delta 159.4,145.6,143.3,129.0,119.0,118.7$, 112.6, 112.4, 112.1, 111.8, 78.6, 77.8, 55.1, 41.8, 41.5, 25.8, 24.7, 15.0, 13.9, 11.6, 11.2. $[\alpha]_{\mathrm{D}}^{25}=+28.2(\mathrm{c}=0.98, \mathrm{THF})>99 \%$ ee, $99 \%$ ee . HPLC: chiralcel OD-H column; solvent ratio: 98:2 hexanes:isopropanol, flow rate: $1 \mathrm{~mL} / \mathrm{min} . \mathrm{R}_{\mathrm{t}}=\{20.0 \mathrm{~min}, 26.8 \mathrm{~min}\},\{22.4$ 
min, $32.6 \min \}$. Anal. Calcd. for $\mathrm{C}_{12} \mathrm{H}_{18} \mathrm{O}_{2}$ : C, 74.19; H, 9.34. Found: C, 73.97; H, 9.44. HRMS calcd. for $\mathrm{C}_{12} \mathrm{H}_{18} \mathrm{O}_{2}: 194.1307\left(\mathrm{MNH}_{4}{ }^{+}=212.1645\right)$. Found: 212.1639.

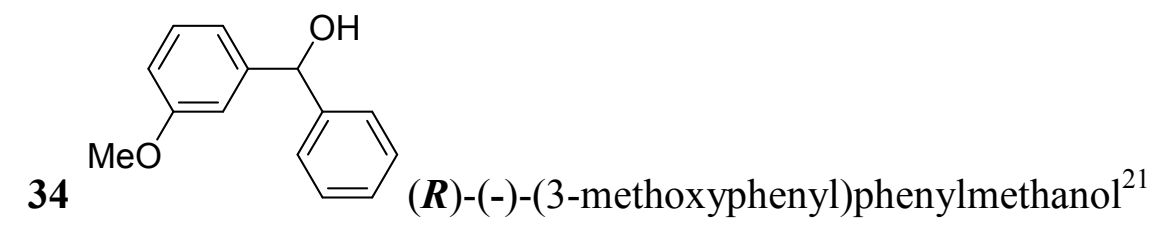

93\% yield, 91\% ee. ${ }^{1} \mathrm{H}-\mathrm{NMR}\left(300 \mathrm{MHz}, \mathrm{CDCl}_{3}\right) \delta$ 7.25 to $7.40(\mathrm{~m}, 6 \mathrm{H}), 6.94-6.97$ (m, 2H), 6.80 to $6.83(\mathrm{~m}, 1 \mathrm{H}), 5.78(\mathrm{~s}, 1 \mathrm{H}), 3.78(\mathrm{~s}, 3 \mathrm{H}), 2.51(\mathrm{~s}, 1 \mathrm{H}) .{ }^{13} \mathrm{C}-\mathrm{NMR}(300 \mathrm{MHz}$ $\left.\mathrm{CDCl}_{3}\right) \delta 159.5,145.3,143.5,129.4,128.4,127.5,126.4,118.8,112.8,111.9,76.0,55.1$. $[\alpha]_{\mathrm{D}}^{25}=-17.7$ (c=0.97, THF) 91\% ee . HPLC: chiralcel OD-H column; solvent ratio: 90:10 hexanes:isopropanol, flow rate: $1 \mathrm{~mL} / \mathrm{min} . t_{\text {minor }}=29.7 \mathrm{~min}, t_{\text {major }}=38.7 \mathrm{~min}$. Anal. Calcd. for $\mathrm{C}_{14} \mathrm{H}_{14} \mathrm{O}_{2}: \mathrm{C}, 74.48 ; \mathrm{H}, 6.59$. Found: $\mathrm{C}, 78.62 ; \mathrm{H}, 6.41$. HRMS calcd. for $\mathrm{C}_{14} \mathrm{H}_{14} \mathrm{O}_{2}: 214.0994\left(\mathrm{MNH}_{4}{ }^{+}=232.1338\right)$. Found: 197.0972, 232.1338 .

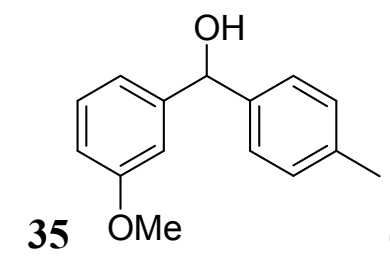

\section{(3-methoxyphenyl)(p-tolyl)methanol}

95\% yield, $91 \%$ ee. ${ }^{1} \mathrm{H}-\mathrm{NMR}\left(300 \mathrm{MHz}, \mathrm{CDCl}_{3}\right.$ ) $\delta 7.21$ to 7.27 (m, 3H), 7.12 to 7.15 (d, 2H), 6.93 to $6.96(\mathrm{~m}, 2 \mathrm{H}), 6.77$ to $6.81(\mathrm{ddd}, 1 \mathrm{H}), 5.78$ to $5.79(\mathrm{~d}, 1 \mathrm{H}), 3.79(\mathrm{~s}, 3 \mathrm{H}), 2.32$ (s, 3H), 2.14 to 2.15 (d, $1 \mathrm{H}) .{ }^{13} \mathrm{C}-\mathrm{NMR}\left(300 \mathrm{MHz} \mathrm{CDCl}_{3}\right) \delta 159.6,145.5,140.7,137.2$, $129.4,129.1,126.4,118.7,112.8,111.8,75.9,55.1,21.0 . \quad[\alpha]_{\mathrm{D}}^{25}=-23.3(\mathrm{c}=0.985, \mathrm{THF})$ 91\% ee. HPLC: chiralcel OD-H column; solvent ratio: 90:10 hexanes:isopropanol, flow rate: $1 \mathrm{~mL} / \mathrm{min} . t_{\text {minor }}=13.7 \mathrm{~min}, t_{\text {major }}=15.8 \mathrm{~min}$. Anal. Calcd. for $\mathrm{C}_{15} \mathrm{H}_{16} \mathrm{O}_{2}: \mathrm{C}, 78.92$; H, 7.06. Found: C, 78.82; H, 7.20. HRMS calcd. for $\mathrm{C}_{15} \mathrm{H}_{16} \mathrm{O}_{2}: 228.1150$ ([M$\mathrm{OH}]^{+}=211.1123$ ). Found: 211.1130. 


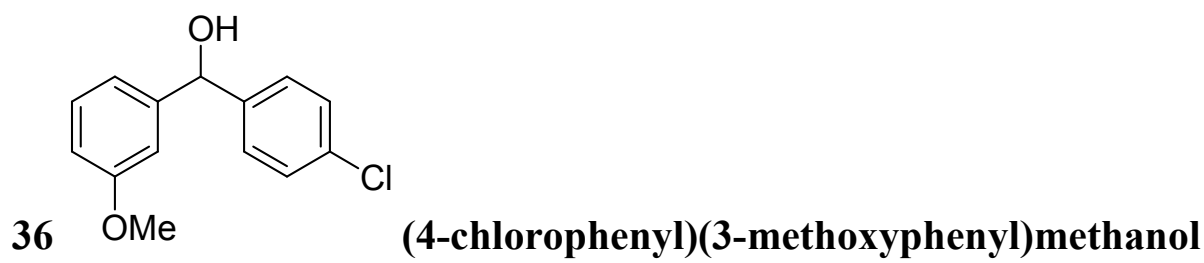

$85 \%$ yield, $90 \%$ ee. ${ }^{1} \mathrm{H}-\mathrm{NMR}\left(300 \mathrm{MHz}, \mathrm{CDCl}_{3}\right) \delta 7.23$ to $7.30(\mathrm{~m}, 5 \mathrm{H}), 6.90$ to $6.93(\mathrm{~m}$, $2 \mathrm{H}), 6.81$ to $6.83(\mathrm{~m}, 1 \mathrm{H}), 5.76$ to $5.77(\mathrm{~d}, 1 \mathrm{H}), 3.74(\mathrm{~s}, 3 \mathrm{H}), 2.26$ to $2.27(\mathrm{~d}, 1 \mathrm{H}) .{ }^{13} \mathrm{C}$ NMR $\left(300 \mathrm{MHz} \mathrm{CDCl}_{3}\right) \delta 159.6,144.9,141.9,133.1,129.5,128.4,127.7,118.7,112.9$, 112.0, 75.4, 55.2. $[\alpha]_{\mathrm{D}}{ }^{25}=+1.2(\mathrm{c}=1.03, \mathrm{THF}) 90 \%$ ee. HPLC: chiralcel OD-H column; solvent ratio: 90:10 hexanes:isopropanol, flow rate: $1 \mathrm{~mL} / \mathrm{min} . t_{\text {minor }}=15.1 \mathrm{~min}, t_{\text {major }}=$ 20.9 min. Anal. Calcd. for $\mathrm{C}_{14} \mathrm{H}_{13} \mathrm{ClO}_{2}$ : C, 67.61; H, 5.27. Found: C, 67.37; H, 5.30. HRMS calcd. for $\mathrm{C}_{15} \mathrm{H}_{16} \mathrm{O}_{2}: 248.0604\left(\mathrm{MNH}_{4}{ }^{+}=266.0942\right)$. Found: 266.0947.<smiles>COc1cccc(C(O)c2ccccc2OC)c1</smiles>

(2-methoxyphenyl)(3-methoxyphenyl)methanol 98\% yield, $80 \%$ ee. ${ }^{1} \mathrm{H}$ NMR $\left(300 \mathrm{MHz}, \mathrm{CDCl}_{3}\right) \delta 7.19$ to $7.29(\mathrm{~m}, 3 \mathrm{H}), 6.93(\mathrm{~m}, 4 \mathrm{H})$, $6.79(\mathrm{dd}, J=2.0,8.2 \mathrm{~Hz}, 1 \mathrm{H}), 6.03(\mathrm{~d}, J=5.5 \mathrm{~Hz}, 1 \mathrm{H}), 3.82(\mathrm{~s}, 3 \mathrm{H}), 3.79(\mathrm{~s}, 3 \mathrm{H}), 3.04$ $(\mathrm{d}, J=5.6 \mathrm{~Hz}, 1 \mathrm{H}), 2.14(\mathrm{~s}, 1 \mathrm{H}) .{ }^{13} \mathrm{C} \mathrm{NMR}\left(75 \mathrm{MHz}, \mathrm{CDCl}_{3}\right) \delta$ 159.4. 156.5, 144.9, $131.7,129.0,128.6,127.7,120.7,118.8,112.5,112.0,110.6,71.8,55.2,55.0 .[\alpha]_{\mathrm{D}}{ }^{25}=-$ $64.4(\mathrm{c}=0.965, \mathrm{THF})$. HPLC: chiralcel OD column; solvent ratio: 90:10 hexanes:isopropanol, flow rate: $1 \mathrm{~mL} / \mathrm{min} . t_{\text {minor }}=18.4 \mathrm{~min}, t_{\text {major }}=21.1 \mathrm{~min}$. HRMS calcd. for $\left[\mathrm{C}_{15} \mathrm{H}_{16} \mathrm{O}_{3}-\mathrm{H}\right]=243.1021$. Found for $[\mathrm{M}-\mathrm{H}]^{+}: 243.1016$.

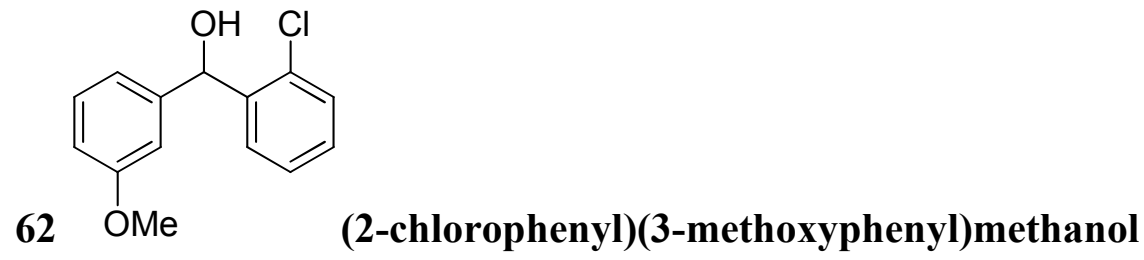


$91 \%$ yield, $58 \%$ ee. ${ }^{1} \mathrm{H}$ NMR $\left(300 \mathrm{MHz}, \mathrm{CDCl}_{3}\right) \delta 7.59(\mathrm{dd}, J=1.8,7.6 \mathrm{~Hz}, 1 \mathrm{H}), 7.19$ to $7.36(\mathrm{~m}, 4 \mathrm{H}), 6.96(\mathrm{~m}, 2 \mathrm{H}), 6.82(\mathrm{ddd}, J=1.0,2.5,8.2 \mathrm{~Hz}, 1 \mathrm{H}), 6.20(\mathrm{~s}, 1 \mathrm{H}), 3.78(\mathrm{~s}$, $3 \mathrm{H}), 2.39(\mathrm{~s}, 1 \mathrm{H}) .{ }^{13} \mathrm{C} \mathrm{NMR}\left(75 \mathrm{MHz}, \mathrm{CDCl}_{3}\right) \delta$ 159.4. 143.8, 140.7, 132.3, 129.3, $128.6,127.9,126.9,119.1,112.9,112.4,72.2,55.0 .[\alpha]_{\mathrm{D}}{ }^{25}=-37.4(\mathrm{c}=1.23, \mathrm{THF})$. HPLC: chiralcel OD column; solvent ratio: 90:10 hexanes:isopropanol, flow rate: 1 $\mathrm{mL} / \mathrm{min} . t_{\text {minor }}=11.1 \mathrm{~min}, t_{\text {major }}=16.9 \mathrm{~min}$. HRMS calcd. for $\left[\mathrm{C}_{14} \mathrm{H}_{13} \mathrm{ClO}_{2}-\mathrm{H}\right]=$ 247.0526. Found for $[\mathrm{M}-\mathrm{H}]^{+}: 247.0526$.<smiles>COc1cccc(C(O)c2cccc([N+](=O)[O-])c2)c1</smiles>

\section{(3-methoxyphenyl)(3-nitrophenyl)methanol}

93\% yield, $83 \%$ ee. ${ }^{1} \mathrm{H}-\mathrm{NMR}\left(300 \mathrm{MHz}, \mathrm{CDCl}_{3}\right.$ ) $\delta 8.26$ to $8.27(\mathrm{t}, 1 \mathrm{H}), 8.07$ to 8.10 (ddd, 1H), 7.68 to $7.70(\mathrm{~d}, 1 \mathrm{H}), 7.44$ to $7.50(\mathrm{t}, 1 \mathrm{H}), 7.24$ to $7.29(\mathrm{t}, 1 \mathrm{H}), 6.89$ to $6.93(\mathrm{~m}$, 2H), 6.80 to $6.84(\mathrm{ddd}, 1 \mathrm{H}), 5.84(\mathrm{~s}, 1 \mathrm{H}), 3.77(\mathrm{~s}, 3 \mathrm{H}), 2.76(\mathrm{bs}, 1 \mathrm{H}) .{ }^{13} \mathrm{C}-\mathrm{NMR}(300$ $\left.\mathrm{MHz} \mathrm{CDCl}_{3}\right) \delta 159.8,148.2,145.5,144.3,132.4,129.9,129.3,122.3,121.1,118.8$, 113.4, 112.2, 75.1, 55.2. $[\alpha]_{\mathrm{D}}{ }^{25}=+34.2(\mathrm{c}=0.6475$, THF) $83 \%$ ee . HPLC: chiralcel ODH column; solvent ratio: 90:10 hexanes:isopropanol, flow rate: $1 \mathrm{~mL} / \mathrm{min} . t_{\text {minor }}=24.8$ min, $t_{\text {major }}=36.5$ min. Anal. Calcd. for $\mathrm{C}_{14} \mathrm{H}_{13} \mathrm{NO}_{4}: \mathrm{C}, 64.86 ; \mathrm{H}, 5.05 ; \mathrm{N}, 5.40$. Found: C, 63.99; $\mathrm{H}, 5.21 ; \mathrm{N}, 5.13$. HRMS calcd. for $\mathrm{C}_{14} \mathrm{H}_{13} \mathrm{NO}_{4}: 259.0850\left(\mathrm{MNH}_{4}{ }^{+}=277.1138\right)$. Found: 277.1177.<smiles>COc1cccc(C(O)c2ccccc2C)c1</smiles>

(3-methoxyphenyl)(o-tolyl)methanol 
$97 \%$ yield, $67 \%$ ee. ${ }^{1} \mathrm{H}$ NMR $\left(300 \mathrm{MHz}, \mathrm{CDCl}_{3}\right) \delta 7.48(\mathrm{~m}, 1 \mathrm{H}), 7.12$ to $7.26(\mathrm{~m}, 4 \mathrm{H})$, $6.89(\mathrm{~m}, 2 \mathrm{H}), 6.80(\mathrm{~m}, 1 \mathrm{H}), 5.98(\mathrm{~s}, 1 \mathrm{H}), 3.77(\mathrm{~s}, 3 \mathrm{H}), 2.27(\mathrm{~s}, 3 \mathrm{H}), 2.14(\mathrm{~s}, 1 \mathrm{H}) .{ }^{13} \mathrm{C}$ NMR (75 MHz, $\left.\mathrm{CDCl}_{3}\right) \delta$ 159.6. 144.5, 141.2, 135.4, 130.5, 129.4, 127.5, 126.2, 126.1, 119.4, 112.8, 112.7, 73.2, 55.1, 19.3. $[\alpha]_{\mathrm{D}}^{25}=-19.1(\mathrm{c}=0.975$, THF). HPLC: chiralcel OD column; solvent ratio: 90:10 hexanes:isopropanol, flow rate: $1 \mathrm{~mL} / \mathrm{min} . t_{\text {minor }}=12.5$ min, $t_{\text {major }}=18.9$ min. HRMS calcd. for $\left[\mathrm{C}_{15} \mathrm{H}_{16} \mathrm{O}_{2}+\mathrm{H}\right]: 227.1072$. Found for $\mathrm{MH}^{+}$: 227.1068.<smiles>COc1cccc(C(O)c2ccccc2Br)c1</smiles>

\section{(2-bromophenyl)(3-methoxyphenyl)methanol}

97\% yield, 54\% ee. ${ }^{1} \mathrm{H}$ NMR (300 MHz, $\left.\mathrm{CDCl}_{3}\right) \delta 7.54(\mathrm{~m}, 2 \mathrm{H}), 7.33(\mathrm{~m}, 1 \mathrm{H}), 7.24(\mathrm{~m}$, 1H), $7.14(\mathrm{~m}, 1 \mathrm{H}), 6.97(\mathrm{~m}, 2 \mathrm{H}), 6.82(\mathrm{ddd}, J=1.0,2.5,8.2 \mathrm{~Hz}, 1 \mathrm{H}), 6.18(\mathrm{~d}, J=3.5 \mathrm{~Hz}$, 1H), $3.79(\mathrm{~s}, 3 \mathrm{H}), 2.37(\mathrm{~d}, J=3.8 \mathrm{~Hz}, 1 \mathrm{H}) .{ }^{13} \mathrm{C} \mathrm{NMR}\left(75 \mathrm{MHz}, \mathrm{CDCl}_{3}\right) \delta$ 159.6. 143.7, $142.3,132.8,129.5,129.1,128.5,127.7,122.8,119.2,113.0,112.6,74.6,55.2 .[\alpha]_{D}^{25}=-$ $44.7(\mathrm{c}=1.055, \mathrm{THF})$. HPLC: chiralcel OD column; solvent ratio: 90:10 hexanes:isopropanol, flow rate: $1 \mathrm{~mL} / \mathrm{min} . t_{\text {minor }}=11.9 \mathrm{~min}, t_{\text {major }}=21.1 \mathrm{~min}$. HRMS calcd. for $\left[\mathrm{C}_{14} \mathrm{H}_{13} \mathrm{BrO}_{2}-\mathrm{H}\right]=291.0021$. Found for $[\mathrm{M}-\mathrm{H}]^{+}: 291.0015$.<smiles>COc1cccc(C(O)c2ccco2)c1</smiles>

\section{furan-2-yl(3-methoxyphenyl)methanol}

94\% yield, 91\% ee. ${ }^{1} \mathrm{H}$ NMR $\left(300 \mathrm{MHz}, \mathrm{CDCl}_{3}\right) \delta 7.38(\mathrm{dd}, J=0.9,1.8 \mathrm{~Hz}, 1 \mathrm{H}), 7.28$ (m, 1H), $7.00(\mathrm{~m}, 2 \mathrm{H}), 6.85(\mathrm{~m}, 1 \mathrm{H}), 6.31(\mathrm{dd}, J=1.8,3.2 \mathrm{~Hz}, 1 \mathrm{H}), 6.13(\mathrm{dt}, J=0.7,3.2$ $\mathrm{Hz}, 1 \mathrm{H}), 5.77(\mathrm{~s}, 1 \mathrm{H}), 3.79(\mathrm{~s}, 3 \mathrm{H}), 2.68(\mathrm{~s}, 1 \mathrm{H}) .{ }^{13} \mathrm{C} \mathrm{NMR}\left(75 \mathrm{MHz}, \mathrm{CDCl}_{3}\right) \delta 159.5$, 
$155.7,142.4,142.3,129.4,118.8,113.5,111.9,110.1,107.3,69.8,55.1 .[\alpha]_{D}{ }^{25}=-23.9$ ( $c=0.54$, THF). HPLC: chiralcel OD column; solvent ratio: 90:10 hexanes:isopropanol, flow rate: $1 \mathrm{~mL} / \mathrm{min} . t_{\text {major }}=14.8 \mathrm{~min}, t_{\text {minor }}=16.4 \mathrm{~min}$. HRMS calcd. for $\left[\mathrm{C}_{12} \mathrm{H}_{12} \mathrm{O}_{3}-\mathrm{H}\right]$ $=203.0708$. Found for $[\mathrm{M}-\mathrm{H}]^{+}: 203.0706$.<smiles>COc1cccc(C(O)c2cccc3ccccc23)c1</smiles>

\section{(3-methoxyphenyl)(naphthalen-1-yl)methanol}

85\% yield, $92 \%$ ee. ${ }^{1} \mathrm{H}$ NMR ( $\left.300 \mathrm{MHz}, \mathrm{CDCl}_{3}\right) \delta 8.07(\mathrm{dd}, J=3.2,6.5 \mathrm{~Hz} 1 \mathrm{H}), 7.83$ (m, 2H), $7.62(\mathrm{~d}, J=7.0 \mathrm{~Hz}, 1 \mathrm{H}), 7.44(\mathrm{~m}, 3 \mathrm{H}), 7.25(\mathrm{t}, J=7.9 \mathrm{~Hz}, 1 \mathrm{H}), 6.98(\mathrm{~m}, 2 \mathrm{H})$, $6.81(\mathrm{~m}, 1 \mathrm{H}), 6.52(\mathrm{~d}, J=3.7 \mathrm{~Hz}, 1 \mathrm{H}), 3.76(\mathrm{~s}, 3 \mathrm{H}), 2.33(\mathrm{~d}, J=4.0 \mathrm{~Hz}, 1 \mathrm{H}) .{ }^{13} \mathrm{C} \mathrm{NMR}$ $\left(75 \mathrm{MHz}, \mathrm{CDCl}_{3}\right) \delta 159.7,144.7,138.6,133.9,130.6,129.5,128.7,128.5,126.1,125.5$, $125.3,124.6,123.9,119.3,112.9,112.7,73.5,55.1 .[\alpha]_{\mathrm{D}}^{25}=-77.5(\mathrm{c}=0.865$, THF $)$. HPLC: chiralpak AD-H column; solvent ratio: 90:10 hexanes:isopropanol, flow rate: 1 $\mathrm{mL} / \mathrm{min} . t_{\text {major }}=22.7 \mathrm{~min}, t_{\text {minor }}=36.3 \mathrm{~min}$. HRMS calcd. for $\left[\mathrm{C}_{18} \mathrm{H}_{16} \mathrm{O}_{2}-\mathrm{H}\right]=263.1072$. Found for $[\mathrm{M}-\mathrm{H}]^{+}: 263.1073$.<smiles>COc1cccc(C(O)c2ccncc2)c1</smiles>

\section{(3-methoxyphenyl)(pyridin-4-yl)methanol}

$86 \%$ yield, $70 \%$ ee. ${ }^{1} \mathrm{H}$ NMR $\left(300 \mathrm{MHz}, \mathrm{CDCl}_{3}\right) \delta 8.35(\mathrm{~d}, J=5.8 \mathrm{~Hz}, 2 \mathrm{H}), 7.29(\mathrm{~m}$, 2H), $7.23(\mathrm{~m}, 1 \mathrm{H}), 6.89(\mathrm{~m}, 2 \mathrm{H}), 6.80(\mathrm{~m}, 1 \mathrm{H}), 5.71(\mathrm{~s}, 1 \mathrm{H}), 4.75(\mathrm{bs}, 1 \mathrm{H}), 3.74(\mathrm{~s}, 3 \mathrm{H})$. ${ }^{13} \mathrm{C}-\mathrm{NMR}\left(75 \mathrm{MHz}, \mathrm{CDCl}_{3}\right) \delta 159.7,153.1,149.2,144.5,129.7,121.3,119.0,113.3$, 112.3, 74.5, 55.1. $[\alpha]_{\mathrm{D}}^{25}=35.2(\mathrm{c}=2.155,1 \mathrm{DCM}: 1 \mathrm{MeOH})$. HPLC: chiralcel OD column; solvent ratio: 90:10 hexanes:isopropanol, flow rate: $1 \mathrm{~mL} / \mathrm{min} . t_{\text {major }}=26.7 \mathrm{~min}$, 
$t_{\text {minor }}=39.9$ min. HRMS calcd. for $\left[\mathrm{C}_{13} \mathrm{H}_{13} \mathrm{NO}_{2}+\mathrm{H}\right]=216.1025$. Found for $\mathrm{MH}^{+}$:

216.1015.

b. General procedure for the asymmetric reaction of methyl 4-iodobenzoate with aldehydes.

Under nitrogen to a $25 \mathrm{~mL}$ round bottom flask (flame dried under vacuum), Li(acac) (24 $\mathrm{mg}, 0.22 \mathrm{mmol}, 0.24$ equiv), methyl 4-iodobenzoate (524 mg, $2.0 \mathrm{mmol}, 2.2$ equiv), and NMP $(1.5 \mathrm{~mL})$ were added sequentially. This mixture was cooled to $0{ }^{\circ} \mathrm{C}$ and $\mathrm{Et}_{2} \mathrm{Zn}(115$ $\mu \mathrm{L}, 1.1 \mathrm{mmol}, 1.20$ equiv) was added dropwise. The mixture was stirred at $0{ }^{\circ} \mathrm{C}$ for $18 \mathrm{~h}$. A solution of a $\mathrm{H}_{8} \mathrm{BINOL}-\mathrm{AM}\left(0.181 \mathrm{mmol}, 0.2\right.$ equiv) in $\mathrm{CH}_{2} \mathrm{Cl}_{2}(20 \mathrm{~mL})$ was added. The reaction mixture was stirred at $0{ }^{\circ} \mathrm{C}$ for $1 \mathrm{~h}$. The solution was warmed up to room temperature for $15 \mathrm{~min}$ and then cooled back to $0{ }^{\circ} \mathrm{C}$. An aldehyde $(0.91 \mathrm{mmol})$ was added and the reaction was monitored by TLC. Upon completion, ammonium chloride (3 $\mathrm{mL}$, saturated, aq.) was added dropwise to quench the reaction. The resulting mixture was transferred into a separatory funnel and combined with additional ammonium chloride (30 mL, saturated, aq.). Diethylether was used to extract the mixture three times $(3 \times 60 \mathrm{~mL})$. The organic fractions were combined and washed with water $(2 \times 75 \mathrm{~mL})$. It was then dried over $\mathrm{Na}_{2} \mathrm{SO}_{4}$ and concentrated. The residue was purified by column chromatography on silica gel eluted with hexanes (or petroleum ether)/ethyl acetate (0$12 \%)$ to give the alcohol products as either an oil or solid. .

\section{Characterization of methyl 4-iodobenzoate Addition Products.}<smiles>CC(=O)c1ccc(C(O)c2ccc(I)cc2)cc1</smiles>

\section{Methyl 4-(hydroxy(phenyl)methyl)benzoate}


97\% yield, 94\% ee. ${ }^{1} \mathrm{H}-\mathrm{NMR}\left(300 \mathrm{MHz}, \mathrm{CDCl}_{3}\right) \delta 7.96$ to $7.98(\mathrm{~d}, 2 \mathrm{H}), 7.43$ to 7.45 (d, 2H), 7.25 to $7.34(\mathrm{~m}, 5 \mathrm{H}), 5.84(\mathrm{~s}, 1 \mathrm{H}), 3.87(\mathrm{~s}, 3 \mathrm{H}), 2.73(\mathrm{~s}, 1 \mathrm{H}) .{ }^{13} \mathrm{C}-\mathrm{NMR}(300 \mathrm{MHz}$ $\left.\mathrm{CDCl}_{3}\right) \delta 166.9,148.7,143.2,129.6,129.0,128.5,127.8,126.5,126.2,75.7,52.0$.

$[\alpha]_{\mathrm{D}}{ }^{25}=-29.0(\mathrm{c}=0.77, \mathrm{THF})$ 94\% ee . HPLC: chiralpak AD column; solvent ratio: 98:2 hexanes:isopropanol, flow rate: $1 \mathrm{~mL} / \mathrm{min} . t_{\text {major }}=58.0 \mathrm{~min}, t_{\text {minor }}=71.6 \mathrm{~min}$. Anal. Calcd. for $\mathrm{C}_{15} \mathrm{H}_{14} \mathrm{O}_{3}$ : C, 74.36; H, 5.82. Found: C, 73.88; H, 5.98. HRMS calcd. for $\mathrm{C}_{15} \mathrm{H}_{14} \mathrm{O}_{3}: 242.0943\left(\mathrm{MNH}_{4}^{+}=260.1287\right)$. Found: 260.1297.

${ }^{\mathrm{MeO}_{2} \mathrm{C}}$

$86 \%$ yield, $96 \%$ ee. ${ }^{1} \mathrm{H}-\mathrm{NMR}\left(300 \mathrm{MHz}, \mathrm{CDCl}_{3}\right) \delta 7.98$ to $8.00(\mathrm{~d}, 2 \mathrm{H}), 7.34$ to 7.37 (d, $2 \mathrm{H}), 4.43$ to $4.46(\mathrm{~d}, 1 \mathrm{H}), 3.90(\mathrm{~s}, 3 \mathrm{H}), 1.87$ to $1.97(\mathrm{~m}, 2 \mathrm{H}), 1.58$ to $1.78(\mathrm{~m}, 4 \mathrm{H}), 1.36$ to $1.40(\mathrm{~d}, 1 \mathrm{H}), 0.89$ to $1.29(\mathrm{~m}, 5 \mathrm{H}) .{ }^{13} \mathrm{C}-\mathrm{NMR}\left(300 \mathrm{MHz} \mathrm{CDCl}_{3}\right) \delta 166.9,148.7,129.4$, $129.0,126.5,78.7,52.0,44.9,29.1,28.3,26.2,25.9,25.9 . \quad[\alpha]_{\mathrm{D}}{ }^{25}=+20.5(\mathrm{c}=0.815, \mathrm{THF})$ Anal. Calcd. for $\mathrm{C}_{15} \mathrm{H}_{14} \mathrm{O}_{3}$ : C, 72.55; H, 8.12. Found: C, 72.47; H, 8.19. HRMS calcd. for $\mathrm{C}_{15} \mathrm{H}_{14} \mathrm{O}_{3}: 248.1412\left(\mathrm{MNH}_{4}^{+}=266.1737\right)$. Found: $266.1742 .96 \%$ ee determined by preparation of acetyl derivative and chiral HPLC.<smiles>CC(=O)OC(c1ccc(C(C)=O)cc1)C1CCCCC1</smiles>

${ }^{1} \mathrm{H}-\mathrm{NMR}\left(300 \mathrm{MHz}, \mathrm{CDCl}_{3}\right) \delta 7.98$ to $8.02(\mathrm{~m}, 2 \mathrm{H}), 7.32$ to $7.35(\mathrm{~d}, 2 \mathrm{H}), 5.49$ to $5.41(\mathrm{~d}$, $1 \mathrm{H}), 3.90(\mathrm{~s}, 3 \mathrm{H}), 2.07(\mathrm{~s}, 3 \mathrm{H}), 1.64$ to $1.84(\mathrm{~m}, 4 \mathrm{H}), 0.87$ to $1.18(\mathrm{~m}, 6 \mathrm{H})$. HPLC: 
chiralpak AD column; solvent ratio: 98:2 hexanes:isopropanol, flow rate: $1.0 \mathrm{~mL} / \mathrm{min}$. $t_{\text {major }}=10.4 \mathrm{~min}, t_{\text {minor }}=13.2 \mathrm{~min}$.<smiles>COC(=O)c1ccc(C(O)CC(C)C)cc1</smiles>

91\% yield, 94\% ee. ${ }^{1} \mathrm{H}-\mathrm{NMR}\left(300 \mathrm{MHz}, \mathrm{CDCl}_{3}\right) \delta 7.91$ to $7.93(\mathrm{~d}, 2 \mathrm{H}), 7.32$ to 7.35 (d, $2 \mathrm{H}), 4.70$ to $4.75(\mathrm{q}, 1 \mathrm{H}), 3.85(\mathrm{~s}, 3 \mathrm{H}), 2.70(\mathrm{bs}, 1 \mathrm{H}), 1.61$ to $1.72(\mathrm{~m}, 2 \mathrm{H}), 1.37$ to 1.46 (m, $1 \mathrm{H}), 0.88$ to $0.90(\mathrm{~d}, 6 \mathrm{H}) .{ }^{13} \mathrm{C}-\mathrm{NMR}\left(300 \mathrm{MHz}_{\mathrm{CDCl}}\right) \delta 166.9,150.5,129.6,128.8$, 125.6, 72.0, 51.9, 48.2, 24.5, 23.0, 21.9. $[\alpha]_{\mathrm{D}}^{25}=+39.6(\mathrm{c}=0.77$, THF) $94 \%$ ee. HPLC: chiralcel OD-H column; solvent ratio: 98:2 hexanes:isopropanol, flow rate: $1 \mathrm{~mL} / \mathrm{min}$. $t_{\text {major }}=21.1 \mathrm{~min}, t_{\text {minor }}=26.5 \mathrm{~min}$. Anal. Calcd. for $\mathrm{C}_{13} \mathrm{H}_{18} \mathrm{O}_{3}: \mathrm{C}, 70.24 ; \mathrm{H}, 8.16$. Found: C, 70.06; H, 8.21. HRMS calcd. for $\mathrm{C}_{13} \mathrm{H}_{18} \mathrm{O}_{3}: 222.1256\left(\mathrm{MNH}_{4}{ }^{+}=240.1594\right)$. Found: 240.1591.

49

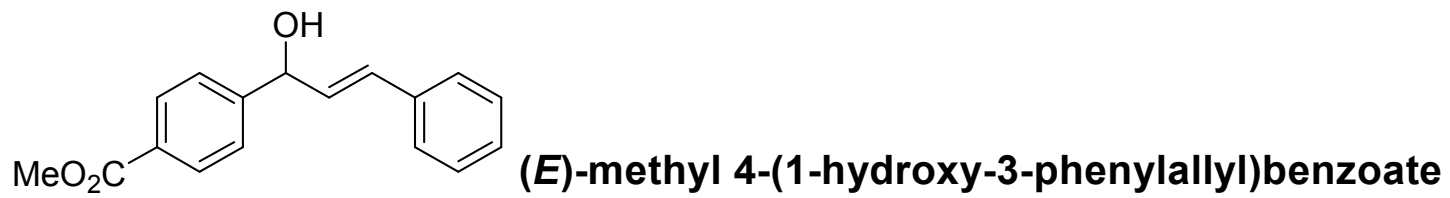
$90 \%$ yield, $87 \%$ ee. ${ }^{1} \mathrm{H}-\mathrm{NMR}\left(300 \mathrm{MHz}, \mathrm{CDCl}_{3}\right) \delta 7.99$ to $8.02(\mathrm{~d}, 2 \mathrm{H}), 7.46$ to $7.48(\mathrm{~d}$, 2H), 7.21 to $7.37(\mathrm{~m}, 5 \mathrm{H}), 6.63$ to $6.68(\mathrm{~d}, 1 \mathrm{H}), 6.28$ to $6.33(\mathrm{dd}, 1 \mathrm{H}), 5.38$ to $5.40(\mathrm{~d}$, 1H), 3.89 (s, 3H), 2.96 (bs, $1 \mathrm{H}) .{ }^{13} \mathrm{C}-\mathrm{NMR}\left(300 \mathrm{MHz} \mathrm{CDCl}_{3}\right) \delta 166.9,147.7,136.0$, $131.1,130.7,129.7,129.1,128.5,127.8,126.5,126.0,74.5,52.0 .[\alpha]_{\mathrm{D}}^{25}=+8.2(\mathrm{c}=1.075$, THF) 87\% ee. HPLC: chiralpak AD column; solvent ratio: 98:2 hexanes:isopropanol, flow rate: $1 \mathrm{~mL} / \mathrm{min} . t_{\text {minor }}=108.0 \mathrm{~min}, t_{\text {major }}=128.8 \mathrm{~min}$. Anal. Calcd. for $\mathrm{C}_{17} \mathrm{H}_{16} \mathrm{O}_{3}: \mathrm{C}$, 
76.10; H, 6.01. Found: C, 76.29; H, 6.00. HRMS calcd. for $\mathrm{C}_{17} \mathrm{H}_{16} \mathrm{O}_{3}: 268.1099$ ([M$\mathrm{OH}]^{+}=251.1070$ ). Found: 251.1072 .<smiles>CC(=O)c1ccc(C(O)c2cccc(Cl)c2)cc1</smiles>
93\% yield, $88 \%$ ee. ${ }^{1} \mathrm{H}-\mathrm{NMR}\left(300 \mathrm{MHz}, \mathrm{CDCl}_{3}\right) \delta 7.98$ to $8.019(\mathrm{~d}, 2 \mathrm{H}), 7.42$ to 7.45 (d, 2H), $7.36(\mathrm{~s}, 1 \mathrm{H}), 7.23$ to $7.27(\mathrm{~m}, 3 \mathrm{H}), 5.83$ to $5.84(\mathrm{~d}, 1 \mathrm{H}), 3.89(\mathrm{~s}, 3 \mathrm{H}), 2.52$ to 2.53 (d, 1H). ${ }^{13} \mathrm{C}-\mathrm{NMR}\left(300 \mathrm{MHz} \mathrm{CDCl}_{3}\right) \delta 166.9,148.1,145.1,134.2,129.6,129.0,127.6$, 126.4, 126.1, 124.5, 74.9, 52.0. $[\alpha]_{\mathrm{D}}^{25}=+8.7\left(\mathrm{c}=1.04\right.$, THF) Anal. Calcd. for $\mathrm{C}_{15} \mathrm{H}_{13} \mathrm{ClO}_{3}$ : C, 65.11; H, 4.74. Found: $\mathrm{C}, 65.17 ; \mathrm{H}, 4.77$. HRMS calcd. for $\mathrm{C}_{15} \mathrm{H}_{13} \mathrm{ClO}_{3}: 276.0553$ $\left(\mathrm{MNH}_{4}{ }^{+}=294.0896\right)$. Found: $294.0891 .88 \%$ ee determined by preparation of benzoylderivative and chiral HPLC.<smiles>CC(=O)c1ccc(C(OC(=O)c2ccccc2)c2cccc(Cl)c2)cc1</smiles>

${ }^{1} \mathrm{H}-\mathrm{NMR}\left(300 \mathrm{MHz}, \mathrm{CDCl}_{3}\right) \delta 8.12$ to $8.15(\mathrm{~m}, 2 \mathrm{H}), 8.03$ to $8.06(\mathrm{~m}, 2 \mathrm{H}), 7.58$ to 7.64 (m, 1H), 7.46 to $7.51(\mathrm{~m}, 4 \mathrm{H}), 7.40$ to $7.41(\mathrm{~m}, 1 \mathrm{H}), 7.30(\mathrm{~s}, 2 \mathrm{H}), 7.09(\mathrm{~s}, 1 \mathrm{H}), 3.91(\mathrm{~s}$, 3H). HPLC: chiralcel OD-H column; solvent ratio: 98:2 hexanes:isopropanol, flow rate: $0.5 \mathrm{~mL} / \mathrm{min} . t_{\text {major }}=51.3 \mathrm{~min}, t_{\text {minor }}=58.4 \mathrm{~min}$.

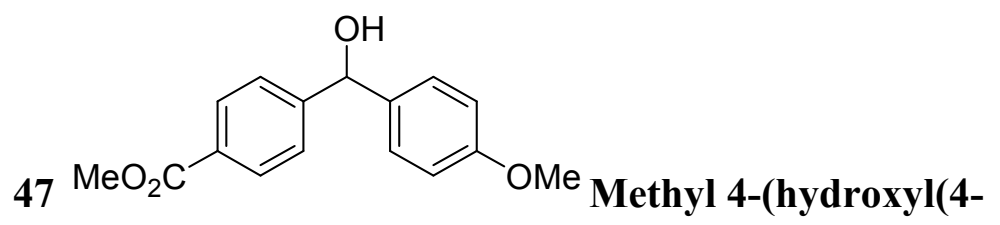
methoxyphenyl)methyl)benzoate 
$52 \%$ yield, $89 \%$ ee. ${ }^{1} \mathrm{H}-\mathrm{NMR}\left(300 \mathrm{MHz}, \mathrm{CDCl}_{3}\right) \delta 7.89$ to $7.92(\mathrm{~d}, 2 \mathrm{H}), 7.35$ to $7.38(\mathrm{~d}$, 2H), 7.15 to $7.18(2 \mathrm{H}), 6.76$ to $6.79(\mathrm{~d}, 2 \mathrm{H}), 5.75(\mathrm{~s}, 1 \mathrm{H}), 3.81(\mathrm{~s}, 3 \mathrm{H}), 3.70(\mathrm{~s}, 3 \mathrm{H}), 2.33$ to 2.34 (bs, $1 \mathrm{H}) .{ }^{13} \mathrm{C}-\mathrm{NMR}\left(300 \mathrm{MHz} \mathrm{CDCl}_{3}\right) \delta 166.9,159.1,148.9,135.5,129.6,128.8$, $127.9,126.1,113.9,75.3,55.1,52.0 .[\alpha]_{\mathrm{D}}^{25}=-42.3(\mathrm{c}=1.05, \mathrm{THF})$ Anal. Calcd. for $\mathrm{C}_{16} \mathrm{H}_{16} \mathrm{O}_{4}$ : C, 70.57; H, 5.92. Found: C, 70.50; H, 6.02. HRMS calcd. for $\mathrm{C}_{16} \mathrm{H}_{16} \mathrm{O}_{4}$ : 272.1409 $\left(\mathrm{MNH}_{4}^{+}=255.1016\right)$. Found: $255.1011 .89 \%$ ee determined by preparation of benzoyl-derivative and chiral HPLC.

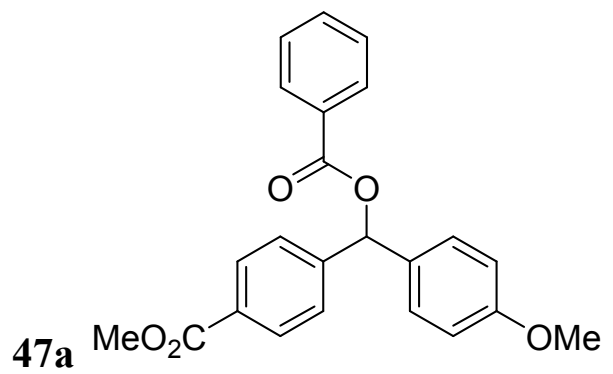

${ }^{1} \mathrm{H}-\mathrm{NMR}\left(300 \mathrm{MHz}, \mathrm{CDCl}_{3}\right) \delta 8.12$ to $8.15(\mathrm{~d}, 2 \mathrm{H}), 8.02$ to $8.04(\mathrm{~d}, 2 \mathrm{H}), 7.56$ to 7.61 (m, 1H), 7.46 to $7.51(\mathrm{~m}, 4 \mathrm{H}), 7.33$ to $7.36(\mathrm{~d}, 2 \mathrm{H}), 7.11(\mathrm{~s}, 1 \mathrm{H}), 6.87$ to $6.90(\mathrm{~d}, 2 \mathrm{H}), 3.90$ (s, 3H), 3.79 (s, 3H). HPLC: chiralpak AD column; solvent ratio: 95:5 hexanes:isopropanol, flow rate: $1.0 \mathrm{~mL} / \mathrm{min} . t_{\text {minor }}=33.2 \mathrm{~min}, t_{\text {major }}=43.0 \mathrm{~min}$.

$48 \mathrm{MeO}_{2} \mathrm{C}$

yl)methyl)benzoate

$89 \%$ yield, $92 \%$ ee. ${ }^{1} \mathrm{H}-\mathrm{NMR}\left(300 \mathrm{MHz}, \mathrm{CDCl}_{3}\right) \delta 7.98$ to $8.01(\mathrm{~d}, 2 \mathrm{H}), 7.78$ to $7.85(\mathrm{~m}$, 4H), 7.45 to $7.51(\mathrm{~m}, 4 \mathrm{H}), 7.38$ to $7.41(\mathrm{dd}, 1 \mathrm{H}), 6.02$ to $6.03(\mathrm{~d}, 1 \mathrm{H}), 3.89(\mathrm{~s}, 3 \mathrm{H}), 2.56$ to $2.57(\mathrm{~d}, 1 \mathrm{H}) .{ }^{13} \mathrm{C}-\mathrm{NMR}\left(300 \mathrm{MHz} \mathrm{CDCl}_{3}\right) \delta 166.9,148.0,140.4,133.0,132.8,129.6$, $129.0,128.4,127.9,127.6,126.3,126.2,126.0,125.2,124.5,75.8,52.0 . \quad[\alpha]_{\mathrm{D}}{ }^{25}=-51.6$ 
(c=1.00, THF) Anal. Calcd. for $\mathrm{C}_{19} \mathrm{H}_{16} \mathrm{O}_{3}: \mathrm{C}, 78.06 ; \mathrm{H}, 5.52$. Found: C, 77.79; H, 5.58. HRMS calcd. for $\mathrm{C}_{19} \mathrm{H}_{16} \mathrm{O}_{3}: 292.1099\left(\mathrm{MNH}_{4}{ }^{+}=310.1438\right)$. Found: $310.1432 .92 \%$ ee determined by preparation of benzoyl-derivative and chiral HPLC.<smiles>COC(=O)c1ccc(C(OC(=O)c2ccccc2)c2ccc3ccccc3c2)cc1</smiles>

${ }^{1} \mathrm{H}-\mathrm{NMR}\left(300 \mathrm{MHz}, \mathrm{CDCl}_{3}\right) \delta 8.16$ to 8.19 (m, 2H), 8.03 to 8.06 (m, 2H), 7.91 (bs, $\left.1 \mathrm{H}\right)$, 7.79 to $7.85(\mathrm{~m}, 3 \mathrm{H}), 7.55$ to $7.60(\mathrm{~m}, 3 \mathrm{H}), 7.46$ to $7.51(\mathrm{~m}, 5 \mathrm{H}), 7.31(\mathrm{~s}, 1 \mathrm{H}), 3.90(\mathrm{~s}$, 3H). HPLC: chiralpak AD column; solvent ratio: 95:5 hexanes:isopropanol, flow rate: $1.0 \mathrm{~mL} / \mathrm{min} . t_{\text {minor }}=37.7 \mathrm{~min}, t_{\text {major }}=48.1 \mathrm{~min}$.

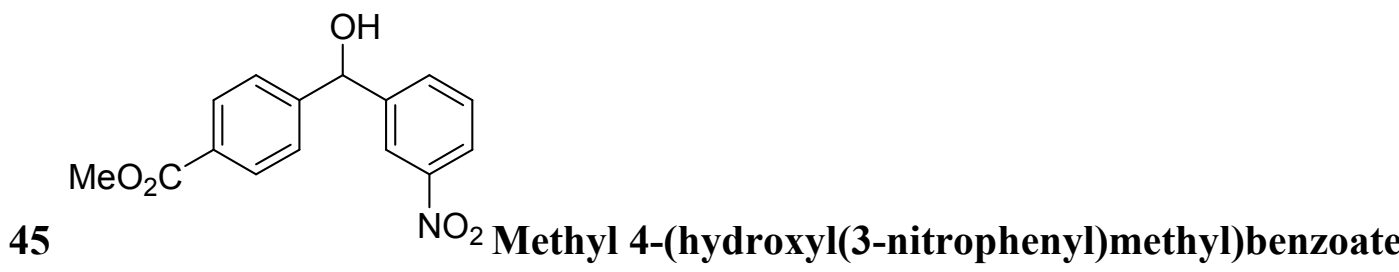
$84 \%$ yield, $92 \%$ ee. ${ }^{1} \mathrm{H}-\mathrm{NMR}\left(300 \mathrm{MHz}, \mathrm{CDCl}_{3}\right) \delta 8.26$ to $8.28(\mathrm{~m}, 1 \mathrm{H}), 8.10$ to 8.14 (ddd, $1 \mathrm{H}), 7.98$ to $8.02(\mathrm{~m}, 2 \mathrm{H}), 7.67$ to $7.70(\mathrm{~d}, 1 \mathrm{H}), 7.44$ to $7.53(\mathrm{~m}, 3 \mathrm{H}), 5.97(\mathrm{~s}, 1 \mathrm{H})$, $3.89(\mathrm{~s}, 3 \mathrm{H}), 2.74(\mathrm{bs}, 1 \mathrm{H}) .{ }^{13} \mathrm{C}-\mathrm{NMR}\left(300 \mathrm{MHz} \mathrm{CDCl}_{3}\right) \delta 175.8,166.6,147.4,145.1$, $132.4,130.1,129.5,126.4,122.7,121.3,74.9,52.2 .[\alpha]_{\mathrm{D}}^{25}=+21.0(\mathrm{c}=0.90, \mathrm{THF}) 92 \%$ ee. HPLC: chiralcel OD-H column; solvent ratio: 97:3 hexanes:isopropanol, flow rate: 1 $\mathrm{mL} / \mathrm{min} . t_{\text {major }}=103.3 \mathrm{~min}, t_{\text {minor }}=115.6 \mathrm{~min}$. Anal. Calcd. for $\mathrm{C}_{15} \mathrm{H}_{13} \mathrm{NO}_{5}: \mathrm{C}, 67.72 ; \mathrm{H}$, 4.56; N, 4.88. Found: C, 67.90; H, 4.62; N, 4.88. HRMS calcd. for $\mathrm{C}_{15} \mathrm{H}_{13} \mathrm{NO}_{5}$ : 287.0794 $\left(\mathrm{MNH}_{4}{ }^{+}=305.1132\right)$. Found: 305.1126 . 
<smiles>CC(=O)c1ccc(C(O)c2ccccc2C(C)C)cc1</smiles>

methyl 4-(hydroxy(2-methoxyphenyl)methyl)benzoate 90\% yield, 93\% ee. ${ }^{1} \mathrm{H}$ NMR $\left(300 \mathrm{MHz}, \mathrm{CDCl}_{3}\right) \delta 7.99(\mathrm{~m}, 2 \mathrm{H}), 7.46(\mathrm{~m}, 2 \mathrm{H}), 7.29(\mathrm{~m}$, 1H), 7.20 (m 1H), 6.94 (ddd, $J=4.6,9.3,12.1 \mathrm{~Hz}, 1 \mathrm{H}), 6.08(\mathrm{~d}, J=5.8 \mathrm{~Hz}, 1 \mathrm{H}), 3.90$, (s, 3H), $3.80(\mathrm{~s}, 3 \mathrm{H}), 3.09(\mathrm{~d}, J=5.8 \mathrm{~Hz}, 1 \mathrm{H}) .{ }^{13} \mathrm{C} \mathrm{NMR}\left(75 \mathrm{MHz}^{\mathrm{CDCl}} \mathrm{CD}_{3}\right) \delta 175.1,167.0$, $156.4,148.5,131.2,129.4,128.9,127.7,126.2,120.8,110.7,71.7,55.2,51.9 .[\alpha]_{\mathrm{D}}^{25}=-$ $97.8(\mathrm{c}=0.61, \mathrm{THF})$. HPLC: chiralcel OD column; solvent ratio: 90:10 hexanes:isopropanol, flow rate: $1 \mathrm{~mL} / \mathrm{min} . t_{\text {major }}=17.5 \mathrm{~min}, t_{\text {minor }}=27.7 \mathrm{~min}$. HRMS calcd. for $\left[\mathrm{C}_{16} \mathrm{H}_{16} \mathrm{O}_{4}-\mathrm{H}\right]=271.0971$. Found for $[\mathrm{M}-\mathrm{H}]^{+}: 271.0970$.

$56 \mathrm{MeO}_{2} \mathrm{C}$ 98\% yield, 79\% ee. ${ }^{1} \mathrm{H}$ NMR $\left(300 \mathrm{MHz}, \mathrm{CDCl}_{3}\right) \delta 7.93(\mathrm{~d}, J=8.4 \mathrm{~Hz}, 2 \mathrm{H}), 7.51(\mathrm{dd}, J=$ 1.7, $7.5 \mathrm{~Hz}, 1 \mathrm{H}), 7.42$ (d, $J=8.2 \mathrm{~Hz}, 2 \mathrm{H}), 7.15$ to $7.32(\mathrm{~m}, 3 \mathrm{H}), 6.21$ (bs, $1 \mathrm{H}), 3.85$ (s, 3H), $3.37(\mathrm{~d}, J=2.0 \mathrm{~Hz}, 1 \mathrm{H}) .{ }^{13} \mathrm{C} \mathrm{NMR}\left(75 \mathrm{MHz}, \mathrm{CDCl}_{3}\right) \delta 166.9,147.3,140.4,132.3$, $129.6,129.4,129.0,128.8,128.0,127.1,126.6,71.8,52.0 .[\alpha]_{\mathrm{D}}^{25}=-54.1(\mathrm{c}=1.285$, THF). HPLC: chiralcel OD column; solvent ratio: 90:10 hexanes:isopropanol, flow rate: $1 \mathrm{~mL} / \mathrm{min} . t_{\text {minor }}=13.4 \mathrm{~min}, t_{\text {major }}=21.9 \mathrm{~min} . \mathrm{HRMS}$ calcd. for $\left[\mathrm{C}_{15} \mathrm{H}_{13} \mathrm{ClO}_{3}+\mathrm{H}\right]=$ 277.0631. Found for $\mathrm{MH}^{+}: 277.0621$.

$57 \mathrm{MeO}_{2} \mathrm{C}$ methyl 4-(hydroxy(naphthalen-1-yl)methyl)benzoate $88 \%$ yield, 97\% ee. ${ }^{1} \mathrm{H}$ NMR $\left(300 \mathrm{MHz}, \mathrm{CDCl}_{3}\right) \delta 7.99(\mathrm{~m}, 3 \mathrm{H}), 7.84(\mathrm{~m}, 2 \mathrm{H}), 7.40$ to $7.53(\mathrm{~m}, 6 \mathrm{H}), 6.52(\mathrm{~d}, J=3.4 \mathrm{~Hz}, 1 \mathrm{H}), 3.87(\mathrm{~s}, 3 \mathrm{H}), 2.66(\mathrm{~d}, J=3.9 \mathrm{~Hz}, 1 \mathrm{H}) .{ }^{13} \mathrm{C} \mathrm{NMR}$ 
$\left(75 \mathrm{MHz}, \mathrm{CDCl}_{3}\right) \delta 166.9,148.1,138.2,133.2,130.5,129.5,128.9,128.7,126.6,126.1$, 125.6, 125.1, 125.0, 123.8, 73.1, 51.9. $[\alpha]_{\mathrm{D}}^{25}=-107.8(\mathrm{c}=1.065$, THF). HPLC:

chiralpak AD-H column; solvent ratio: 90:10 hexanes:isopropanol, flow rate: $1 \mathrm{~mL} / \mathrm{min}$. $t_{\text {major }}=22.8$ min, $t_{\text {minor }}=29.1$ min. HRMS calcd. for $\left[\mathrm{C}_{19} \mathrm{H}_{16} \mathrm{O}_{3}-\mathrm{OH}\right]=275.1078$. Found for $[\mathrm{M}-\mathrm{OH}]^{+}: 275.1095$.

$58 \mathrm{MeO}_{2} \mathrm{C}$ 90\% yield, 97\% ee. ${ }^{1} \mathrm{H}$ NMR (300 MHz, $\left.\mathrm{CDCl}_{3}\right) \delta 8.03(\mathrm{~m}, 1 \mathrm{H}), 7.50(\mathrm{~m}, 2 \mathrm{H}), 7.38(\mathrm{~m}$, 1H), $6.31(\mathrm{~m}, 1 \mathrm{H}), 6.10(\mathrm{~m}, 1 \mathrm{H}), 5.88(\mathrm{~d}, J=4.1 \mathrm{~Hz}, 1 \mathrm{H}), 3.91(\mathrm{~s}, 3 \mathrm{H}), 2.59(\mathrm{~d}, J=4.4$ $\mathrm{Hz}, 1 \mathrm{H}) .{ }^{13} \mathrm{C} \mathrm{NMR}\left(75 \mathrm{MHz}, \mathrm{CDCl}_{3}\right) \delta 166.8,155.2,145.8,142.6,129.6,126.4,110.2$, 107.6, 69.4, 52.0. $[\alpha]_{\mathrm{D}}^{25}=-24.0(\mathrm{c}=0.68, \mathrm{THF})$. HPLC: chiralcel OD column; solvent ratio: 90:10 hexanes:isopropanol, flow rate: $1 \mathrm{~mL} / \mathrm{min} . \quad t_{\text {minor }}=15.0 \mathrm{~min}, t_{\text {major }}=19.4$ min. HRMS calcd. for $\left[\mathrm{C}_{13} \mathrm{H}_{12} \mathrm{O}_{4}-\mathrm{OH}\right]=215.0714$. Found for $[\mathrm{M}-\mathrm{OH}]^{+}: 215.0720$.

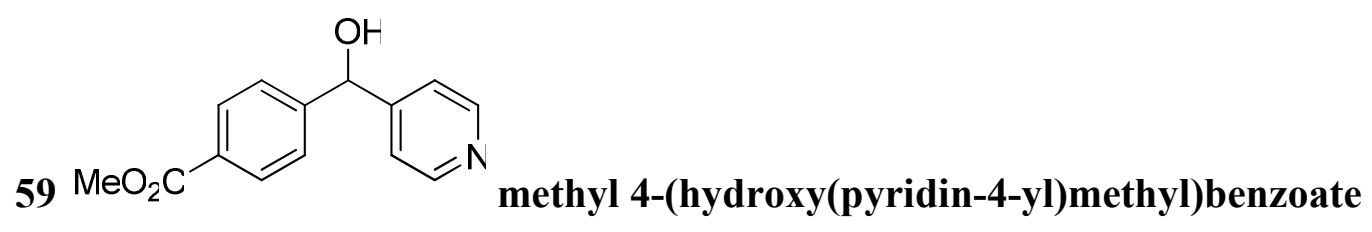
$75 \%$ yield, $76 \%$ ee. ${ }^{1} \mathrm{H}$ NMR $\left(300 \mathrm{MHz}, d_{6}\right.$-DMSO $) \delta 7.60(\mathrm{~d}, J=5.6 \mathrm{~Hz}, 1 \mathrm{H}), 7.03(\mathrm{~d}$, $J=8.1 \mathrm{~Hz}, 1 \mathrm{H}), 6.66(\mathrm{~d}, J=8.1 \mathrm{~Hz}, 1 \mathrm{H}), 6.50(\mathrm{~d}, J=5.5 \mathrm{~Hz}, 1 \mathrm{H}), 5.46(\mathrm{~s}, 1 \mathrm{H}), 4.92(\mathrm{~s}$, $1 \mathrm{H}), 3.92(\mathrm{~s}, 3 \mathrm{H}) .{ }^{13} \mathrm{C}$ NMR (75 MHz $d_{6}$-DMSO) $\delta 166.2,153.5,149.7,129.5,128.7$, 126.7, 121.4, 72.8, 52.3. $[\alpha]_{\mathrm{D}}^{25}=+28.3(\mathrm{c}=0.735,1 \mathrm{DCM}: 1 \mathrm{MeOH})$. HPLC: chiralpak AD-H column; solvent ratio: 90:10 hexanes:isopropanol, flow rate: $1 \mathrm{~mL} / \mathrm{min} . t_{\text {minor }}=$ $26.6 \mathrm{~min}, t_{\text {major }}=29.2 \mathrm{~min}$. HRMS calcd. for $\left[\mathrm{C}_{14} \mathrm{H}_{13} \mathrm{NO}_{3}+\mathrm{H}\right]=244.0974$. Found for $\mathrm{MH}^{+}: 244.0970$. 
$50 \mathrm{MeO}_{2} \mathrm{C}$

dimethyl biphenyl-4,4'-dicarboxylate

${ }^{1} \mathrm{H} \mathrm{NMR}\left(300 \mathrm{MHz}, \mathrm{CDCl}_{3}\right) \delta 8.13(\mathrm{~d}, J=8.3 \mathrm{~Hz}, 4 \mathrm{H}), 7.69(\mathrm{~d}, J=8.3 \mathrm{~Hz}, 4 \mathrm{H}), 3.94(\mathrm{~s}$,

6H). ${ }^{13} \mathrm{C}$ NMR $\left(75 \mathrm{MHz}, \mathrm{CDCl}_{3}\right) \delta 166.7,144.2,130.1,129.6,127.2,52.2$.

\section{c. General procedure for the asymmetric reaction of 3-iodobenzonitrile with}

\section{aldehydes.}

Under nitrogen to a $25 \mathrm{~mL}$ round bottom flask (flame dried under vacuum), Li(acac) (37 $\mathrm{mg}, 0.35 \mathrm{mmol}, 0.38$ equiv), 3 -iodobenzonitrile ( $663 \mathrm{mg}, 2.89 \mathrm{mmol}, 3.2$ equiv), and NMP $(1.5 \mathrm{~mL})$ were added sequentially. It was then cooled to $0{ }^{\circ} \mathrm{C}$ and $\mathrm{Et}_{2} \mathrm{Zn}(167 \mu \mathrm{L}$, $1.59 \mathrm{mmol}, 1.75$ equiv) was added dropwise. The resulting mixture was stirred at $0{ }^{\circ} \mathrm{C}$ for $2 \mathrm{~h}$. It was then warmed up to room temperature and stirred for $34 \mathrm{~h}$. A solution of a $\mathrm{H}_{8} \mathrm{BINOL}-\mathrm{AM}$ (178 mg, $0.362 \mathrm{mmol}, 0.4$ equiv) in THF ( $25 \mathrm{~mL}$ ) was added. It was stirred at room temperature for $2 \mathrm{~h}$. An aldehyde $(0.91 \mathrm{mmoL})$ was added and the reaction was monitored by TLC. Upon completion, ammonium chloride $(3 \mathrm{~mL}$, saturated, aq.) was added dropwise to quench the reaction. The resulting mixture was transferred into a separatory funnel and combined with additional ammonium chloride ( $30 \mathrm{~mL}$, saturated, aq.). Diethyl ether was used to extract the mixture three times $(3 \times 60$ $\mathrm{mL})$. The organic fractions were combined and washed with water $(2 \times 75 \mathrm{~mL})$. It was then dried over $\mathrm{Na}_{2} \mathrm{SO}_{4}$ and concentrated. The residue was purified by column chromatography on silica gel eluted with hexanes (or petroleum ether)/ethyl acetate ( 0 $12 \%)$ to give the alcohol products as either oil or solid.

\section{Characterization of 3- iodobenzonitrile Addition Products.}


51 CN

$87 \%$ yield, $84 \%$ ee. ${ }^{1} \mathrm{H}-\mathrm{NMR}\left(300 \mathrm{MHz}, \mathrm{CDCl}_{3}\right) \delta 7.71(\mathrm{~s}, 1 \mathrm{H}), 7.56$ to $7.63(\mathrm{~d}, 2 \mathrm{H})$,

7.31 to $7.45(\mathrm{~m}, 6 \mathrm{H}), 5.85(\mathrm{~s}, 1 \mathrm{H}), 2.31$ (bs, $1 \mathrm{H}) .{ }^{13} \mathrm{C}-\mathrm{NMR}\left(300 \mathrm{MHz} \mathrm{CDCl}_{3}\right) \delta$ 145.0, $142.7,131.0,130.8,129.9,129.1,128.8,128.2,126.5,118.7,112.3,75.2 .[\alpha]_{\mathrm{D}}^{25}=-44.5$ ( $c=1.065$, THF) Anal. Calcd. for $\mathrm{C}_{14} \mathrm{H}_{11} \mathrm{NO}$ : $\mathrm{C}, 80.36 ; \mathrm{H}, 5.30 ; \mathrm{N}, 6.69$. Found: $\mathrm{C}$, 80.19; $\mathrm{H}, 5.43 ; \mathrm{N}, 6.58$. HRMS calcd. for $\mathrm{C}_{14} \mathrm{H}_{11} \mathrm{NO}: 209.0841\left(\mathrm{MNH}_{4}{ }^{+}=227.1179\right)$. Found: $227.1176 .84 \%$ ee determined by preparation of benzoyl-derivative and chiral HPLC.<smiles>N#Cc1cccc(C(OC(=O)c2ccccc2)c2ccccc2)c1</smiles>

${ }^{1} \mathrm{H}-\mathrm{NMR}\left(300 \mathrm{MHz}, \mathrm{CDCl}_{3}\right) \delta 8.12$ to $8.18(\mathrm{~m}, 2 \mathrm{H}), 7.44$ to 7.33 (m, 4H), 7.34 to 7.41 (m, 4H), 7.15 (s, 1H). HPLC: chiralpak AD column; solvent ratio: 95:5 hexanes:isopropanol, flow rate: $1.0 \mathrm{~mL} / \mathrm{min} . t_{\text {minor }}=15.4 \mathrm{~min}, t_{\text {major }}=19.0 \mathrm{~min}$.

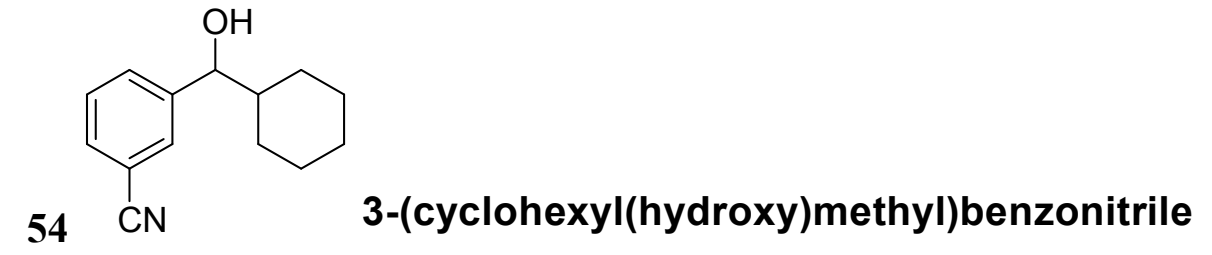

$77 \%$ yield, $98 \%$ ee. ${ }^{1} \mathrm{H}-\mathrm{NMR}\left(300 \mathrm{MHz}, \mathrm{CDCl}_{3}\right) \delta 7.36$ to $7.54(\mathrm{~m}, 4 \mathrm{H}), 4.36$ to $4.38(\mathrm{~d}$, 2H), $1.82(\mathrm{bs}, 1 \mathrm{H}), 1.50$ to $1.78(\mathrm{~m}, 5 \mathrm{H}), 1.33$ to $1.39(\mathrm{~m}, 2 \mathrm{H}), 0.92$ to $1.22(\mathrm{~m}, 6 \mathrm{H}) .{ }^{13} \mathrm{C}-$ 
$\operatorname{NMR}\left(300 \mathrm{MHz} \mathrm{CDCl}_{3}\right) \delta 144.9,131.0,130.6,130.0,128.7,118.8,111.7,77.8,44.7$, 30.1, 28.9, 28.0, 26.0, 25.8, 25.7. $[\alpha]_{\mathrm{D}}^{25}=+17.2(\mathrm{c}=1.12$, THF) Anal. Calcd. for $\mathrm{C}_{14} \mathrm{H}_{17} \mathrm{NO}$ : C, 78.10; H, 7.96; N, 6.51. Found: C, 77.96; H, 8.06; N, 6.39. HRMS calcd. for $\mathrm{C}_{14} \mathrm{H}_{17} \mathrm{NO}: 215.1310\left(\mathrm{MNH}_{4}{ }^{+}=233.1648\right)$. Found: $233.1643 .98 \%$ ee determined by preparing the $(R)-(-)-(\mathrm{O}-a c e t y l) m a n d e l i c$ acid derivative and comparing to racemic preparation peaks at $\delta 5.94$ and 5.99 .

$54 a$<smiles>CC(=O)OC(C(=O)OC(c1ccccc1)C1CCCCC1)c1cccc(C#N)c1</smiles>

Racemic ${ }^{1} \mathrm{H}$-NMR: $\left(300 \mathrm{MHz}, \mathrm{CDCl}_{3}\right) \delta 7.35$ to 7.57 (m, $\left.9 \mathrm{H}\right), 5.94$ to $5.99(1 \mathrm{H}), 5.44$ to $5.47(\mathrm{~m}, 1 \mathrm{H}), 2.17$ to $2.18(\mathrm{~s}, 3 \mathrm{H}), 0.65$ to $1.82(\mathrm{~m}, 11 \mathrm{H})$.

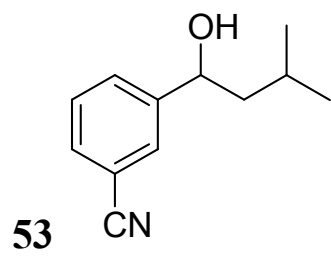

\section{3-(1-hydroxy-3-methylbutyl)benzonitrile}

$82 \%$ yield, $92 \%$ ee. ${ }^{1} \mathrm{H}-\mathrm{NMR}\left(300 \mathrm{MHz} \mathrm{CDCl}_{3}\right) \delta 7.41$ to $7.61(\mathrm{~m}, 4 \mathrm{H}), 4.72$ to $4.76(\mathrm{~m}$, $1 \mathrm{H}), 2.60(\mathrm{bs}, 1 \mathrm{H}), 1.63$ to $1.69(\mathrm{~m}, 2 \mathrm{H}), 1.40$ to $1.43(\mathrm{~m}, 1 \mathrm{H}), 0.92$ to $0.94(\mathrm{~d}, 6 \mathrm{H}) .{ }^{13} \mathrm{C}-$ NMR (300 MHz $\left.\mathrm{CDCl}_{3}\right) \delta 146.8,130.8,130.2,129.3,129.0,118.8,112.0,71.4,48.4$, 24.5, 23.0, 21.9. $[\alpha]_{\mathrm{D}}^{25}=+36.5\left(\mathrm{c}=1.065\right.$, THF) Anal. Calcd. for $\mathrm{C}_{12} \mathrm{H}_{15} \mathrm{NO}: \mathrm{C}, 76.16 ; \mathrm{H}$, 7.99; N, 7.40. Found: C, 75.99; H, 8.05; N, 7.31. HRMS calcd. for $\mathrm{C}_{12} \mathrm{H}_{15} \mathrm{NO}: 189.1154$ $\left(\mathrm{MNH}_{4}{ }^{+}=207.1492\right)$. Found: $207.1489 .92 \%$ ee determined by preparing the $(R)-(-)-(\mathrm{O}-$ acetyl)mandelic acid derivative and comparing to racemic preparation peaks at $\delta 5.96$ and 5.92 . 
<smiles>CC(=O)O[C@@H](C(=O)OC(CC(C)C)c1cccc(C#N)c1)c1ccccc1</smiles>

Racemic ${ }^{1} \mathrm{H}-\mathrm{NMR}:\left(300 \mathrm{MHz} \mathrm{CDCl}_{3}\right) \delta 7.35$ to $7.47(\mathrm{~m}, 8 \mathrm{H}), 7.18$ to $7.23(\mathrm{~m}, 1 \mathrm{H}), 7.06$ (m, $1 \mathrm{H}), 5.91$ to $5.95(1 \mathrm{H}), 2.18(\mathrm{~s}, 3 \mathrm{H}), 1.44$ to $1.88(\mathrm{~m}, 3 \mathrm{H}), 0.92$ to $0.96(\mathrm{~m}, 6 \mathrm{H})$.<smiles>COc1ccc(C(O)c2cccc(C#N)c2)cc1</smiles>

\section{3-(hydroxyl(4-methoxyphenyl)methyl)benzonitrile}

$80 \%$ yield, $91 \%$ ee. ${ }^{1} \mathrm{H}$ NMR $\left(300 \mathrm{MHz}, \mathrm{CDCl}_{3}\right) \delta 7.70(\mathrm{~s}, 1 \mathrm{H}), 7.56(\mathrm{~d}, J=7.5 \mathrm{~Hz}$, 1H), $7.48(\mathrm{~m}, 1 \mathrm{H}), 7.39(\mathrm{~d}, J=7.5 \mathrm{~Hz}, 1 \mathrm{H}), 7.20(\mathrm{~m}, 2 \mathrm{H}), 6.85(\mathrm{~m}, 2 \mathrm{H}), 5.81(\mathrm{~s}, 1 \mathrm{H})$, 3.80 (s, 3H), 2.23 (bs, 1H). ${ }^{13} \mathrm{C} \mathrm{NMR}\left(75 \mathrm{MHz}, \mathrm{CDCl}_{3}\right) \delta$ 159.1, 145.4, 135.0, 130.7, $129.7,128.9,127.8,118.7,113.9,111.9,74.5,55.1 .[\alpha]_{\mathrm{D}}^{25}=-58.0(\mathrm{c}=1.09$, THF $)$. Anal. Calcd. for $\mathrm{C}_{15} \mathrm{H}_{13} \mathrm{NO}_{2}$ : C, 75.30; H, 5.48; N, 5.85. Found: C, 75.12; H, 5.64; N, 5.76. HRMS calcd. for $\left[\mathrm{C}_{15} \mathrm{H}_{13} \mathrm{NO}_{2}+\mathrm{NH}_{4}\right]=257.1285$. Found for $\mathrm{MNH}_{4}{ }^{+}: 257.1281$. $80 \%$ ee determined by preparing the $(R)-(-)-(\mathrm{O}$-acetyl)mandelic acid derivative and comparing the ${ }^{1} \mathrm{H}$ NMR signals at $\delta 6.01$ and 6.03 with the racemic product.<smiles>COc1ccc(C(OC(=O)[C@@H](OC(C)=O)c2ccccc2)c2cccc(C#N)c2)cc1</smiles> 
Racemic ${ }^{1} \mathrm{H}-\mathrm{NMR}:\left(300 \mathrm{MHz}, \mathrm{CDCl}_{3}\right) \delta 7.25(\mathrm{~m}, 1 \mathrm{H}), 7.14(\mathrm{~m}, 2 \mathrm{H}), 7.07(\mathrm{~m}, 1 \mathrm{H}), 6.86$ (m, 2H), $6.78(\mathrm{~s}, 1 \mathrm{H}), 6.02(\mathrm{~m}, 1 \mathrm{H}), 3.79(\mathrm{~s}, 3 \mathrm{H}), 2.19(\mathrm{~s}, 3 \mathrm{H})$.

${ }^{1} \mathrm{H}$ NMR spectrum of the product SI-14 from the asymmetric reaction using $(S)-2.74 \%$ yield; $80 \%$ ee

${ }^{1} \mathrm{H}$ NMR spectrum of the product SI-14 from the asymmetric reaction using $(S)-\mathbf{1 2}: 97 \%$ yield, $88 \%$ ee.

${ }^{1}$ H NMR spectrum of the product SI-14 from the asymmetric reaction using $(S)-7: \quad 80 \%$ yield, $91 \%$ ee.

${ }^{1} \mathrm{H}$ NMR spectrum of the product SI-14 from the asymmetric reaction using $(S)-\mathbf{4}$ : $\sim 60 \%$ yield, $85 \%$ ee.

\section{d. General Procedure for the asymmetric reaction of 2-iodothiophene with}

\section{aldehydes.}

Under nitrogen to a $10 \mathrm{~mL}$ round bottom flask (flame dried under vacuum), Li(acac) (24 mg, 0.22 mmol, 0.24 equiv), 2-iodothiophene (221 $\mu \mathrm{L}, 2.0 \mathrm{mmol}, 2.2$ equiv), and NMP (1.5 mL) were added sequentially. $\mathrm{Et}_{2} \mathrm{Zn}(115 \mu \mathrm{L}, 1.1 \mathrm{mmol}, 1.20$ equiv) was added dropwise and was stirred at room temperature for 6 - 12 h. $\mathrm{A} \mathrm{H}_{8} \mathrm{BINOL}-\mathrm{AM}(0.091$ mmol, 0.1 equiv) and THF $(5 \mathrm{~mL})$ were added. After the reaction mixture was stirred for $1 \mathrm{~h}$, an aldehyde $(0.91 \mathrm{mmol})$ was added and the reaction was monitored by TLC. Upon completion, ammonium chloride ( $3 \mathrm{~mL}$, saturated, aq.) was added dropwise to quench the reaction. The resulting mixture was transferred into a separatory funnel and combined with additional ammonium chloride (30 $\mathrm{mL}$, saturated, aq.). Diethylether was used to extract the mixture three times $(3 \times 60 \mathrm{~mL})$. The organic fractions were combined and 
washed with water $(2 \times 75 \mathrm{~mL})$. The organic fraction was dried over $\mathrm{Na}_{2} \mathrm{SO}_{4}$, and concentrated. The residue was purified by column chromatography on silica gel eluted with hexanes (or petroleum ether)/ethyl acetate (1-8\%) to give the alcohol products as either oil or solid. .

\section{Characterization of 2-iodothiophene Addition Products.}

67

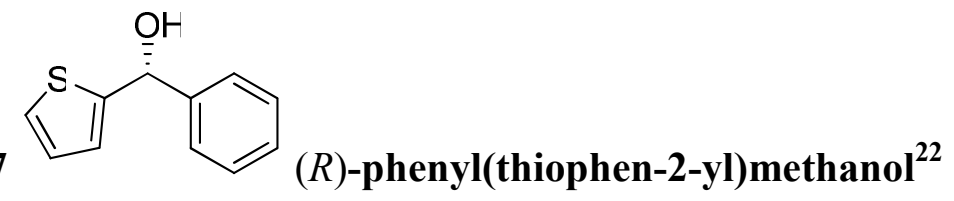

90\% yield, 92\% ee. ${ }^{1} \mathrm{H}$ NMR $\left(300 \mathrm{MHz}, \mathrm{CDCl}_{3}\right) \delta 7.47(\mathrm{~m}, 1 \mathrm{H}), 7.44(\mathrm{~m}, 1 \mathrm{H}), 7.30$ to $7.40(\mathrm{~m}, 3 \mathrm{H}), 7.27(\mathrm{dd}, J=1.3,5.1 \mathrm{~Hz}, 1 \mathrm{H}), 6.95(\mathrm{dd}, J=3.5,5.0 \mathrm{~Hz}, 1 \mathrm{H}), 6.88(\mathrm{~m}, 1 \mathrm{H})$, $6.05(\mathrm{~d}, J=3.9 \mathrm{~Hz}, 1 \mathrm{H}), 2.52(\mathrm{~d}, J=4.0 \mathrm{~Hz}, 1 \mathrm{H}) .{ }^{13} \mathrm{C} \mathrm{NMR}\left(75 \mathrm{MHz}, \mathrm{CDCl}_{3}\right) \delta 148.0$, $143.0,128.5,127.9,126.6,126.2,125.3,124.8,72.3 .[\alpha]_{\mathrm{D}}{ }^{25}=-19.1(\mathrm{c}=2.02, \mathrm{THF})$. HPLC: chiralcel OD column; solvent ratio: 95:5 hexanes:isopropanol, flow rate: 1 $\mathrm{mL} / \mathrm{min} . t_{\text {minor }}=19.1 \mathrm{~min}, t_{\text {major }}=20.5 \mathrm{~min}$.

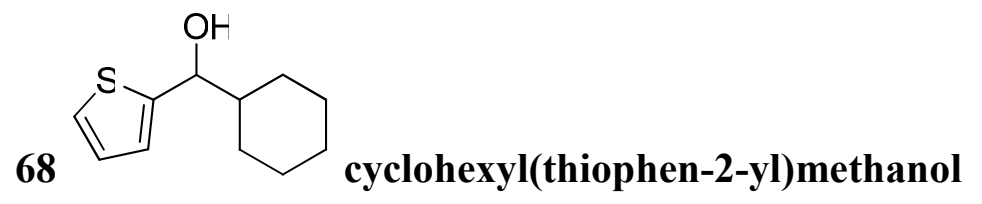

90\% yield, 94\% ee. ${ }^{1} \mathrm{H}$ NMR $\left(300 \mathrm{MHz}, \mathrm{CDCl}_{3}\right) \delta 7.24(\mathrm{~m}, 1 \mathrm{H}), 6.95(\mathrm{~m}, 2 \mathrm{H}), 4.63(\mathrm{dd}$, $J=3.6,7.3 \mathrm{~Hz}, 1 \mathrm{H}), 2.03(\mathrm{~m}, 1 \mathrm{H}), 1.98(\mathrm{~d}, J=3.7 \mathrm{~Hz}, 1 \mathrm{H}), 1.59$ to $1.71(\mathrm{~m}, 4 \mathrm{H}), 1.48$ (m, 1H), 0.89 to $1.32(\mathrm{~m}, 5 \mathrm{H}) .{ }^{13} \mathrm{C} \mathrm{NMR}\left(75 \mathrm{MHz}, \mathrm{CDCl}_{3}\right) \delta 147.6,126.2,124.2,124.1$, 74.9, 45.4, 29.1, 28.8, 26.2, 25.8, 25.7. $[\alpha]_{\mathrm{D}}{ }^{25}=+6.7(\mathrm{c}=0.90$, THF $)$. HPLC: chiralcel OD column; solvent ratio: 95:5 hexanes:isopropanol, flow rate: $1 \mathrm{~mL} / \mathrm{min}$. $t_{\text {minor }}=8.9$ min, $t_{\text {major }}=9.8$ min. HRMS calcd. for a. $)\left[\mathrm{C}_{11} \mathrm{H}_{16} \mathrm{OS}-\mathrm{H}\right]=195.0844$; b. $)\left[\mathrm{C}_{11} \mathrm{H}_{16} \mathrm{OS}-\right.$ $\mathrm{OH}]=179.0894$. Found for a.) $[\mathrm{M}-\mathrm{H}]^{+}:$195.0848; found for b.) $[\mathrm{M}-\mathrm{OH}]^{+}: 179.0880$. 


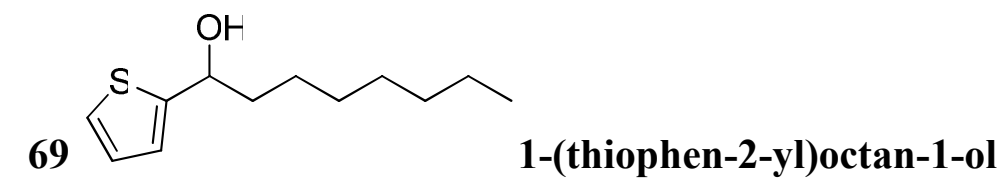

90\% yield, 92\% ee. ${ }^{1} \mathrm{H}$ NMR $\left(300 \mathrm{MHz}, \mathrm{CDCl}_{3}\right) \delta 7.23(\mathrm{~m}, 1 \mathrm{H}), 6.96(\mathrm{~d}, J=2.7 \mathrm{~Hz}$, 2H), $4.88(\mathrm{t}, J=6.7 \mathrm{~Hz}, 1 \mathrm{H}), 2.26(\mathrm{bs}, 1 \mathrm{H}), 1.75(\mathrm{~m}, 2 \mathrm{H}), 1.27$ to $1.48(\mathrm{~m}, 10 \mathrm{H}), 0.88(\mathrm{t}$, $J=6.6 \mathrm{~Hz}, 3 \mathrm{H}) .{ }^{13} \mathrm{C} \mathrm{NMR}\left(75 \mathrm{MHz}, \mathrm{CDCl}_{3}\right) \delta 148.9,126.4,124.3,123.5,70.2,39.2$, 29.2, 29.2, 25.7, 22.5, 14.0. $[\alpha]_{\mathrm{D}}^{25}=11.6(\mathrm{c}=0.805, \mathrm{THF})$. HPLC: chiralcel OB-H column; solvent ratio: 95:5 hexanes:isopropanol, flow rate: $1 \mathrm{~mL} / \mathrm{min} . t_{\text {minor }}=6.3 \mathrm{~min}$, $t_{\text {major }}=7.5 \mathrm{~min}$. HRMS calcd. for $\left[\mathrm{C}_{12} \mathrm{H}_{20} \mathrm{OS}-\mathrm{OH}\right]=195.1207$. Found for $[\mathrm{M}-\mathrm{OH}]^{+}$: 195.1206; ([M-H $]^{+}$was not observed).

70<smiles>COc1ccccc1C(O)c1cccs1</smiles>
$92 \%$ yield, $73 \%$ ee. ${ }^{1} \mathrm{H}$ NMR $\left(300 \mathrm{MHz}, \mathrm{CDCl}_{3}\right) \delta 7.27$ to $7.36(\mathrm{~m}, 2 \mathrm{H}), 7.23(\mathrm{dd}, J=$ 1.2, $5.1 \mathrm{~Hz}, 1 \mathrm{H}), 6.91$ to $7.01(\mathrm{~m}, 3 \mathrm{H}), 6.85(\mathrm{~m}, 1 \mathrm{H}), 6.21(\mathrm{~d}, J=6.7 \mathrm{~Hz}, 1 \mathrm{H}), 3.83(\mathrm{~s}$, 3H), $3.42(\mathrm{~d}, J=6.7 \mathrm{~Hz}, 1 \mathrm{H}) .{ }^{13} \mathrm{C} \mathrm{NMR}\left(75 \mathrm{MHz}, \mathrm{CDCl}_{3}\right) \delta 156.6,147.9,131.1,129.0$, $127.6,126.5,124.6,124.2,120.8,110.9,69.5 .55 .4 .[\alpha]_{\mathrm{D}}{ }^{25}=-18.1(\mathrm{c}=1.13, \mathrm{THF})$. HPLC: chiralpak AD-H column; solvent ratio: 92:8 hexanes:isopropanol, flow rate: 1 $\mathrm{mL} / \mathrm{min} . t_{\text {minor }}=37.8 \mathrm{~min}, t_{\text {major }}=40.5 \mathrm{~min} . \mathrm{HRMS}$ calcd. for a.) $\left[\mathrm{C}_{12} \mathrm{H}_{12} \mathrm{O}_{2} \mathrm{~S}-\mathrm{H}\right]=$ 219.0480; b.) $\left[\mathrm{C}_{12} \mathrm{H}_{12} \mathrm{O}_{2} \mathrm{~S}-\mathrm{OH}\right]=203.0531$. Found for a.) $[\mathrm{M}-\mathrm{H}]^{+}: 219.0481$; found for b.) $[\mathrm{M}-\mathrm{OH}]^{+}: 203.0514$.

71

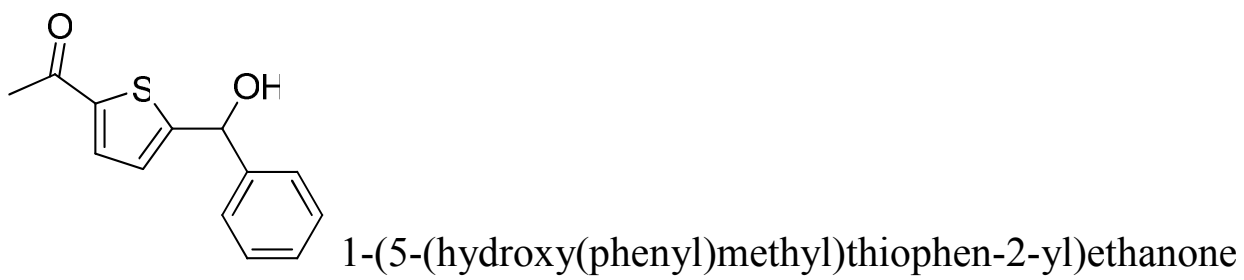


. ${ }^{1} \mathrm{H}$ NMR $\left(300 \mathrm{MHz}, \mathrm{CDCl}_{3}\right) \delta 7.54(\mathrm{~d}, J=3.9 \mathrm{~Hz}, 1 \mathrm{H}), 7.41(\mathrm{~m}, 5 \mathrm{H}), 6.91(\mathrm{~d}, J=3.9$

$\mathrm{Hz}, 1 \mathrm{H}), 6.03$ (s, 1H), 2.51 (s, 3H), 1.56 (br-s, 1H).

\section{General Procedure for the asymmetric reaction of 2-bromothiophene with aldehydes.}

Under nitrogen to a $10 \mathrm{~mL}$ round bottom flask (flame dried under vacuum), Li(acac) (24 mg, 0.22 mmol, 0.24 equiv), 2-iodothiophene ( $238 \mu \mathrm{L}, 2 \mathrm{mmol}, 2.2$ equiv), and NMP (1.5 mL) were added sequentially. $\mathrm{Et}_{2} \mathrm{Zn}(115 \mu \mathrm{L}, 1.1 \mathrm{mmol}, 1.20$ equiv $)$ was added dropwise and the mixture was stirred at room temperature for $6-12 \mathrm{~h}$. A solution of $(S)$ 12 (45 mg, $0.091 \mathrm{mmol}, 0.1$ equiv) in THF ( $5 \mathrm{~mL}$ ) was added, and the resulting mixture was stirred for $1 \mathrm{~h}$. An aldehyde $(0.91 \mathrm{mmoL})$ was added and the reaction was monitored by TLC. Upon completion, ammonium chloride ( $3 \mathrm{~mL}$, saturated, aq.) was added dropwise to quench the reaction. The resulting mixture was transferred into a separatory funnel and combined with additional ammonium chloride $(30 \mathrm{~mL}$, saturated, aq. $)$. Diethylether was used to extract the mixture three times $(3 \times 60 \mathrm{~mL})$. The organic fractions were combined and washed with water $(2 \times 75 \mathrm{~mL})$. It was then dried over $\mathrm{Na}_{2} \mathrm{SO}_{4}$, and concentrated. The residue was purified by column chromatography on silica gel eluted with hexanes (or petroleum ether)/ethyl acetate (1-8\%) to give the alcohol products as either oil or solid.

\section{e. General Procedure for the asymmetric reaction of iodobenzene with aldehydes.}

Under nitrogen to a $10 \mathrm{~mL}$ round bottom flask (flame dried under vacuum), Li(acac) (24 mg, $0.22 \mathrm{mmol}, 0.24$ equiv), iodobenzene ( $224 \mu \mathrm{L}, 2.0 \mathrm{mmol}, 2.2$ equiv), and NMP (1.5 
$\mathrm{mL})$ were added sequentially. $\mathrm{Et}_{2} \mathrm{Zn}(115 \mu \mathrm{L}, 1.1 \mathrm{mmol}, 1.20$ equiv) was added dropwise and the mixture was stirred at room temperature for $3 \mathrm{~h}$. A H $\mathrm{H}_{8} \mathrm{BINOL}-\mathrm{AM}(0.091 \mathrm{mmol}$, 0.1 equiv) and THF ( $5 \mathrm{~mL})$ were added and it was then stirred for $1 \mathrm{~h} . p$-Anisaldehyde ( $0.91 \mathrm{mmol})$ was added and the reaction was monitored by TLC. Upon completion, ammonium chloride ( $3 \mathrm{~mL}$, saturated, aq.) was added dropwise to quench the reaction. The resulting mixture was transferred into a separatory funnel and combined with additional ammonium chloride ( $30 \mathrm{~mL}$, saturated, aq.). Diethyl ether was used to extract the mixture three times $(3 \times 60 \mathrm{~mL})$. The organic fractions were combined and washed with water $(2 \times 75 \mathrm{~mL})$. It was then dried over $\mathrm{Na}_{2} \mathrm{SO}_{4}$, and concentrated. The residue was purified by column chromatography on silica gel eluted with hexanes (or petroleum ether)/ethyl acetate (1-8\%) to give the alcohol product as either oil or solid.

\section{Characterization of iodobenzene Addition Products.}

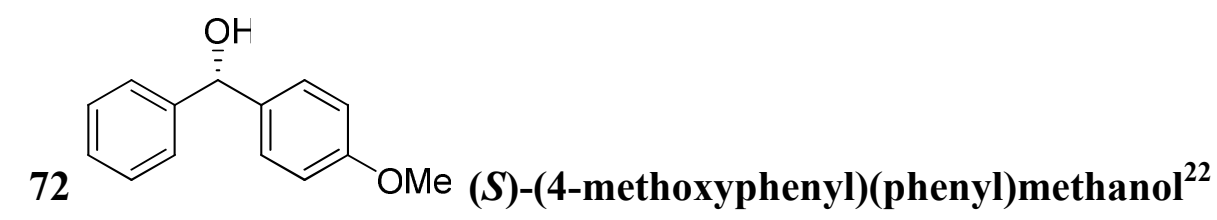

92\% yield, $93 \%$ ee. ${ }^{1} \mathrm{H}$ NMR $\left(300 \mathrm{MHz}, \mathrm{CDCl}_{3}\right) \delta 7.39(\mathrm{~m}, 4 \mathrm{H}), 7.32(\mathrm{~m}, 3 \mathrm{H}), 6.91(\mathrm{~d}, J$ $=8.6 \mathrm{~Hz}, 2 \mathrm{H}), 5.81(\mathrm{~s}, 1 \mathrm{H}), 3.82(\mathrm{~s}, 3 \mathrm{H}), 2.55(\mathrm{bs}, 1 \mathrm{H}) .{ }^{13} \mathrm{C} \mathrm{NMR}\left(75 \mathrm{MHz}, \mathrm{CDCl}_{3}\right) \delta$ $158.9,143.9,136.1,128.3,127.8,127.3,126.3,75.6,55.1 .[\alpha]_{\mathrm{D}}^{25}=-18.5(\mathrm{c}=0.88$, THF). HPLC: chiralpak AD-H column; solvent ratio: 92:8 hexanes:isopropanol, flow rate: $1 \mathrm{~mL} / \mathrm{min} . t_{\text {minor }}=40 \mathrm{~min}, t_{\text {major }}=42 \mathrm{~min}$.

\section{f. General procedure for the preparation of the racemic alcohols.}

The same procedure and conditions were used for the preparation of the 3-iodoanisole derived racemic carbinols as for the catalytic asymmetric additions with the exclusion of 
the chiral ligand. In the case where little to no product was observed, longer reaction times were allowed (see below for the exception of 3-nitrobenzaldehyde). The same procedure and conditions were also used for the preparation of the methyl 4-iodobenzoate derived racemic carbinols as for the catalytic asymmetric additions with the exclusion of the chiral ligand. Longer reaction times were allowed until a suitable amount of product was observed. For the preparation of (3-methoxyphenyl)(3-nitrophenyl)methanol and all 3-iodobenzonitrile derived racemic carbinols, 1 equiv $n$ - $\mathrm{BuLi}$ ( $2.5 \mathrm{M}$ solution in hexanes) was added to a THF solution of the appropriate aryl iodide at $-78^{\circ} \mathrm{C}$ under nitrogen. This solution was stirred for $30 \mathrm{~min}$ to $1 \mathrm{~h}$. An aldehyde was then added and the solution was warmed to room temperature. The solution was allowed to stir overnight and worked up accordingly: the reaction was quenched by dropwise addition of water $(3 \mathrm{~mL})$; the mixture was then extracted using $\mathrm{CH}_{2} \mathrm{Cl}_{2}(3 \times 35 \mathrm{~mL})$ from added $\mathrm{NH}_{4} \mathrm{Cl}$ (satd., aq., 30 $\mathrm{mL}$ ); after drying over sodium sulfate, filtering and concentrating, the crude racemic alcohols were purified by column chromatography.

It has been found that the racemic carbinols could also be formed in sufficient yields by treating the aryl iodide (or bromide) with $n$-BuLi as described for the 3-benzonitrile products. However, 2-iodothiophene, unlike 2-bromothiophene or thiophene, could not be used to react with $n$-BuLi to prepare the racemic carbinols.

\section{g. Preparation of Mandelic Esters.}

To a solution of an alcohol product (10-20 $\mathrm{mg}$ in $2-3 \mathrm{~mL} \mathrm{CH}_{2} \mathrm{Cl}_{2}$ ), DCC (2 equiv), DMAP (2 equiv), and ( $R$ )-(-)-(O-acetoxy)mandelic acid (2 equiv) were added sequentially. The conversion was complete in $20-30 \mathrm{~min}$ as monitored by TLC. The 
mixture was loaded onto a short plug of silica gel and eluted with $10 \%$ ethyl acetate in hexanes. The mandelic ester fractions were collected, concentrated and analyzed by ${ }^{1} \mathrm{H}$ NMR spectroscopy.

\section{h. Preparation of Acetyl-esters.}

To a solution of alcohol ( $10-20 \mathrm{mg}$ in 2 to $\left.3 \mathrm{~mL} \mathrm{CH}_{2} \mathrm{Cl}_{2}\right)$, pyridine (10 eq) and acetic anhydride (15 eq) were added sequentially. More reagents were added if necessary. Upon complete conversion the workup and analysis was identical to that described for mandelic esters.

\section{i. Preparation of Benzoyl-esters.}

To a solution of alcohol $\left(\sim 10-20 \mathrm{mg}\right.$ in 2 to $\left.3 \mathrm{~mL} \mathrm{CH}_{2} \mathrm{Cl}_{2}\right)$, triethylamine (15 eq) and benzoyl chloride (5 eq) were added sequentially. Upon complete conversion the reaction was quenched with $\mathrm{HCl}(\sim 5 \mathrm{~mL} 1 \mathrm{~N} \mathrm{HCl})$ and extracted with dichloromethane $(3 \mathrm{X} 20$ mL). The organics were then washed with $\mathrm{NaHCO}_{3}(2 \mathrm{X}$, satd., aq.). The organic fractions were dried over $\mathrm{Na}_{2} \mathrm{SO}_{4}$, concentrated and ran over short plug of silica gel and flashed using 10\% ethyl acetate in hexanes. The appropriate fractions were combined, concentrated and ${ }^{1} \mathrm{H}-\mathrm{NMR}$ analyzed. 


\section{j. References:}

1. (a) Astles, P. C.; Brown, T. J.; Halley, F.; Handscombe, C. M.; Harris, N. V.; Majid, T. N.; McCarthy, C.; McLay, I. M.; Morley, A.; Porter, B.; Roach, A. G.; Sargent, C.; Smith, C.; Walsh, R. J. A. J. Med. Chem. 2000, 43, 900. (b) Welch, W. M.; Kraska, A. R.; Sarges, R.; Coe, K. B. J. Med. Chem. 1984, 27, 1508. (c)

Nilvebrant, L.; Andersson, K.-E.; Gillberg, P.-G.; Stahl, M.; Sparf, B. Eur. J. Pharmacol. 1997, 327, 195. (d) Casy, A.F.; Drake, A.F.; Ganellin, C.R.; Mercer, A.D.; Upton, C. Chirality 1992, 4, 356-366. (e) Roth, F.E. Chemotherapia 1961, 3, 120-127. (f) Sperber, N.; Papa, D.; Schwenk, E.; Sherlock, M.; Fricano, R. J. Am. Chem. Soc., 1951, 73 (12), 5752-5759. (g) Jones, C.D.; Winter, M.A.; Hirsh, K.S.; Stam, N.; Taylor, H.M.; Holden, H.E.; Davenport, J.D.; Krumkalns, E.V.; Suhr, R.G. J. Med. Chem. 1990, 33, 416-429. (h) McCalmont, W. F.; Heady, T. N.; Patterson, J. R.; Lindenmuth, M. A.; Haverstick, D. M.; Gray, L. S.; Macdonald, T.

L. Bioorg. Med. Chem. Lett. 2004, 14 (14), 3691-3695. (i) Alexander, R. P.; Warrellow, G. J.; Eaton, M. A.; Boyd, E. C.; Head, J. C.; Porter, J. R.; Brown, J. A.; Reuberson, J. T.; Hutchinson, B.; Turner, P.; Boyce, B.; Barnes, D.; Mason, B.;

Cannel, A.; Taylor, R. J.; Zomaya, A.; Millican, A.; Leonard, J.; Morphy, R.; Wales, M.; Perry, M.; Allen, R. A.; Gozzard, N.; Hughes, B.; Higgs, G. Bioorg. Med. Chem. Lett. 2002, 12 (11), 1451-1456. (j) A.F. Casy, Antihistamine Drugs. In: D.F. Smith, Editor, Handbook of Stereoisomers, CRC Press, Boca Raton, Fl (1989), pp. 149-164. (k) Guay, D.; Hamel, P.; Blouin, M.; Brideau, C.; Chan, C. C.; Chauret, N.; Ducharme, Y.; Huang, Z.; Girard, M.; Jones, T. R.; Laliberté, F.; Masson, P.; McAuliffe, M.; Piechuta, H.; Silva, J.; Young, R. N.; Girard, Y. Bioorg. Med. Chem. 
Lett. 2002, 12 (11), 1457-1461. (1) Harms, A. F.; Hespe, W.; Nauta, W. T.; Rekker, R. F.; Timmerman, H.; de Vries, J. Diphenhydramine Derivatives: Through Manipulation Toward Design. In: E.J. Ariëns, Editor, Drug Design vol. 6, Academic Press, New York (1976), pp. 1-80. (m) Ariëns, E. J. A. General Introduction to the Fields of Drug Design. In: Ariëns, E. J. Editor, Drug Design vol. 1, Academic Press, New York (1971), pp. 1-270.

2. (a) Schmidt, F.; Stemmler, R. T.; Rudolph, J.; Bolm, C. Chem. Soc. Rev. 2006, 35, 454-470. (b) Dosa, P. I.; Ruble, J. C.; Fu, G. C. J. Org. Chem. 1997, 62, 444445. (c) Huang, W. -S.; Pu, L. J. Org. Chem. 1999, 64, 4222-4223. (d) Bolm, C.; Muñiz, K. Chem. Commun. 1999, 1295-1296.

3. (a) Salvi, L.; Kim, J. G.; Walsh, P. J. J. Am. Chem. Soc. 2009, 131, 12483-12493.

(b) Kim, J. G.; Walsh, P. J. Angew. Chem. Int. Ed. 2006, 45, 4175-4178. (c)

Dahmen, S.; Lormann, M. Org. Lett 2005, 7, 4597-4600. (d) Bolm, C.; Rudolph, J. J. Am. Chem. Soc. 2002, 124, 14850-14851.

4. From aryl boronates: (a) Wu, P.-Y.; Wu, H.-L.; Uang, B.-J. J. Org. Chem. 2006, 71, 833-835. (b) Lu, G.; Kwong, F. Y.; Ruan, J.-W.; Li, Y.-M.; Chan, A. S. C. Chem.Eur. J. 2006, 12, 4115-4120. (c) Wang, M.-C.; Wang, X.-D.; Ding, X.; Liu, Z.-K. Tetrahedron, 2008, 64 (11), 2559-2564. From aryl aluminums: (d) Shannon, J.; Bernier, D.; Rawson, D.; Woodward, S. Chem. Commun. 2007, 3945-3947. (e) Wu, K.-H.; Gau, H.-M. J. Am. Chem. Soc., 2006, 128, 14808-14809. (f) Chen, C.A.; Wu, K.-H.; Gau, H.-M. Angew. Chem. Int. Ed. 2007, 46, 5373-5376. (g) Wu, K.-H.; Chuang, D.-W.; Chen, C.-A; Gau, H.-M. Chem. Commun., 2008, 2343-2345. (h) Biradar, D. B.; Zhou, S.; Gau, H.-M. Org. Lett. 2009, 11, 3386-3389. (i) Zhou, 
S.; Wu, K.-H.; Chen, C.-A.; Gau, H.-M. J. Org. Chem. 2009, 74, 3500-3505. From aryl silanes: (j) Tomita, D.; Wada, R.; Kanai, M.; Shibasaki, M. J. Am. Chem. Soc. 2005, 127, 4138-4139. From aryl stannanes: (k) Oi, S.; Moro, M.; Inoue, Y. Chem. Commun. 1997, 1621-1622.

5. (a) Huang, W.-S. ; Pu, L. J. Org. Chem. 1999, 64, 4222-4223. (b) Huang, W.-S.; Hu, Q.-S. ; Pu, L. J. Org. Chem. 1999, 64, 7940-7956. (c) Huang, W.-S.; Hu, Q.-S. ; Pu, L. Tetrahedron Lett. 2000, 41 (2), 145-149.

6. (a) Liu, L.; Pu, L. Tetrahedron, 2004, 60, 7427-7430. (b) Qin, Y.-C.; Pu, L. Angew. Chem. Int. Ed. 2006, 118, 279-283. (c) Qin, Y.-C.; Liu, L.; Sabat, M.; Pu, L. Tetrahedron, 2006, 40, 9335-9348.

7. (a) Pu, L.; Yu, H. -B. Chem. Rev. 2001, 101, 757-824. (b) Dosa, P. I.; Ruble, J. C.; Fu, G. C. J. Org. Chem. 1997, 62, 444-445.

8. (a) Schmidt, F.; Stemmler, R. T.; Rudolph, J.; Bolm, C. Chem. Soc. Rev. 2006, 35, 454-470. (b) Bolm, C.; Muñiz, K. Chem. Commun. 1999, 1295-1296. (c) Bolm, C.; Rudolph, J. J. Am. Chem. Soc. 2002, 124, 14850-14851. (d) Bolm, C.; Hilderbrand, J. P.; Muñiz, K.; Hermanns, N. Angew. Chem. Int. Ed. 2001, 40, 3284.

9. Dahmen, S.; Lormann, M. Org. Lett 2005, 7, 4597-4600.

10. Kneisel, F. F.; Dochnahl, M.; Knochel, P. Angew. Chem. Int. Ed. 2004, 43, $1017-$ 1021.

11. DeBerardinis, A. M. ; Turlington, M. ; Ko, J. ; Sole, L. ; Pu, L. J. Org. Chem. 2010, $75,2836-2850$.

12. (a) DeBerardinis, A. M.; Turlington, M.; Pu, L. Org. Lett. 2008, 10, 2709-2713. (b)

DeBerardinis, A. M.; Turlington, M.; Pu, L. Organic Syntheses 2010, 87, 68-76. 
13. Turlington, M.; DeBerardinis, A. M.; Pu, L. Org. Lett. 2009, 11, 2441-2444.

14. (a) Bolm, C.; Hermanns, N.; Hilderbrand, J. P.; Muñiz, K. Angew. Chem. Int. Ed. 2000, 39, 3465-3467. (b) Schmidt, F.; Rudolph, J.; Bolm, C. Adv. Synth. Catal. 2007, 349, 703-708.

15. Gong, L.-Z.; Knochel, P. Synlett 2005, 2, 267-270.

16. Lutz, C.; Graf, C.-D.; Knochel, P. Tetrahedron 1998, 54, 10317-10328.

17. (a) Trost, B. M.; Belletire, J. L.; Goldleski, P. G.; McDougal, P. G.; Balkovec, J. M.; Baldwin, J. J.; Christy, M.; Ponticello, G.S.; Varga, S. L.; Springer, J. P. J. Org. Chem. 1986, 51, 2370. (b) Seco, J.; Quinoa, E.; Riguera, R. Chem. Rev. 2004, 104, $17-117$.

20. (a) Yamamoto, H. Lewis Acids in Organic Synthesis, Volumes 1 and 2. Wiley-VCH, 2000. (b) Yamamoto, H. Lewis Acids: A Practical Approach. Oxford University Press, USA; 2000.

21. Absolute configuration by literature comparison: (a) Kosaka, M.; Sugito, T.; Kasai, Y.; Kuwahara, S.; Watanabe, M.; Harada, N.; Job, G. E.; Shvet, A.; Pirkle, W. H. Chirality, 2003, 15, 324-328.

22. Absolute configuration by literature comparison: (a) Rudolph, J.; Schmidt, F.; Bolm, C. Adv. Syn. \& Catal. 2004, 346 (7), 867-872. (b) Kitano, Y.; Kusakabe, M.; Kobayashi, Y.; Sato, F. J. Org. Chem. 1989, 54 (4), 994-996.

23. Configuration and spectral comparison: (a) Huang, W.-S.; Pu, L. J. Org. Chem. 1999, 64 (12), 4222-4223. (b) Bolm, C.; Rudolph, J. J. Am. Chem. Soc. 2002, 124, 14850-14851. 
Chapter 4: Vinylzinc Generation and Catalytic Asymmetric Additions to Aldehydes
a. Introduction
b. Generation of Vinylzincs: Attempted Vinyl Iodides Reactions
c. Catalytic Asymmetric Vinylzinc Additions to Aldehydes
d. Experimental and Characterization

\section{a. Introduction}

In the past two decades, a tremendous amount of study has been conducted on using organozincs in asymmetric catalysis. ${ }^{1}$ Grignard reagents and organolithiums can be directly prepared from organohalides and are of great importance in organic synthesis. ${ }^{2}$ However, the high reactivity of these reagents makes it difficult to develop enantioselective catalysts for their nucleophilic addition to carbonyls to generate chiral alcohols. ${ }^{3}$ Organozincs are generally less reactive and more functional group tolerant than Grignard reagents and organolithiums. These characteristics have allowed the rapid development of enantioselective catalysts for the asymmetric organozinc addition to carbonyls. Among these studies, several highly enantioselective catalysts have been identified for the asymmetric vinylzinc addition to carbonyls to generate chiral allylic alcohols.

The direct preparation of enantioenriched allylic alcohols is an attractive area of research because these products are widely used intermediates in the syntheses of many natural products and biologically active compounds. ${ }^{4,5}$ Vinylzincs were prepared by using methods such as the hydrozicornation ${ }^{6}$ or hydroboration ${ }^{7}$ of alkynes followed by transmetalation, the use of vinyl boronic acids or esters, ${ }^{8}$ and the Ni-catalyzed $\mathrm{ZnMe}_{2}$ 
addition to alkynes. ${ }^{8}$ The hydrozirconation and hydroboration of terminal alkynes followed by treatment with alkylzincs have been shown to be very useful methods for the asymmetric addition to carbonyls but these methods also have limitations. For example, they have demonstrated poor reactivity towards the generation of non-terminal vinyl species and cannot be applied to make cycloalkenylzincs. Extensions of these pioneering methods have been reported. ${ }^{8,9}$ These methods have mainly been applied to terminal alkynes. Other reported methods start from an alkenyl-source or alkynyl-metal complex. Bolm $^{10}$ and Zhao ${ }^{11}$ et. al. have described procedures starting from alkenylboronic acids and alkenylboronic esters, respectively, but with limited success. Each protocol requires the transfer of the alkenyl-source to zinc forming the reactive alkenylzinc species. Preparation of vinylzincs directly from vinyl halides would avoid the above limitations but there was no report for the direct conversion of vinyl halides to vinylzincs ${ }^{12}$ for the catalytic asymmetric addition to carbonyls without using the less functional group tolerant $\mathrm{Mg}$ or Li reagents.

In a related area, Jamison developed a nickel-catalyzed coupling of alkynes and aldehydes for the highly regio- (>95:5) and enantioselective synthesis of allylic alcohols. ${ }^{13}$ Few procedures have been reported for the asymmetric addition of internal vinylmetallic reagents that form higher-substituted allylic alcohols. Methods using other alkyne-activation or reduction strategies have also been reported. ${ }^{14-16}$

In 2004, Knochel demonstrated that aryl iodides can be converted to arylzincs by using $\mathrm{Zn}^{\mathrm{i}} \mathrm{Pr}_{2},{ }^{17}$ but no report of this strategy appeared regarding its applicability to vinyl iodides. We examined the reactivity of vinyl iodides using the modified conditions found for the catalytic asymmetric arylations. ${ }^{18}$ This resulted in the discovery of a highly 
enantioselective catalyst for the reaction of vinyl iodides with aldehydes via the direct conversion of vinyl iodides to vinylzincs in the presence of $\mathrm{ZnEt}_{2}$. This method allows the synthesis of substituted and functionalized allylic alcohols with high enantiomeric purity under very mild conditions. These reactions can tolerate functional groups such as esters, halides, ethers and silylethers on the substrates.

\section{Scheme 4.1 General Results of the Vinylzinc Generation and Catalyzed Addition to} Enantioenriched Allylic Alcohols.

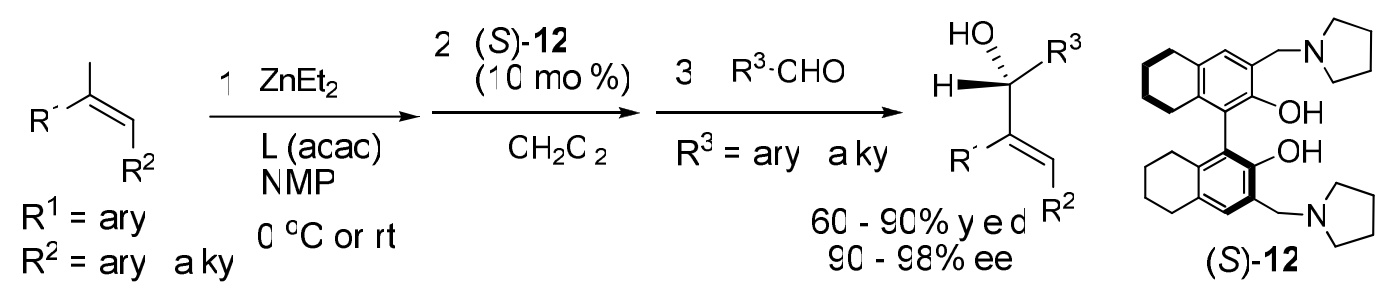

\section{b. Generation of Vinylzincs: Vinyl Iodides and Vinylzinc Preps}

Our initial attempts to generate simple vinylzincs focused on using aliphatic substituted, terminal vinyl iodides such as (E)-1-iodo-octene (VI-1). This substrate would represent an entry into a previously reported class of vinylzincs and other vinyl[M] reagents (where $[\mathrm{M}]$ is a metal). ${ }^{17 \mathrm{~b}}$ The vinylzinc could not be formed from this substrate under various conditions. The reaction was studied at $0{ }^{\circ} \mathrm{C}$ and room temperature, in 2:1 and 1:1 ratios of vinyl iodide to diethylzinc. Over a range of times, no vinyl addition product was observed either in the presence of ligand and aldehyde or only aldehyde (racemic synthesis). Ethyl addition was typically observed and isolated from column chromatography in these reactions along with starting material (vinyl iodide and aldehyde). For example, the initial experiments mixed (E)-1-iodo-octene (2.2 equiv), $\mathrm{Li}(\mathrm{acac})(26 \mathrm{~mol} \%)$, and $\mathrm{Et}_{2} \mathrm{Zn}$ (1.21 equiv) in NMP for 3 hours at room temperature. Subsequent catalyst formation with (S)-12 in THF and addition of benzaldehyde only led 
to ethyl addition to benzaldehyde overnight. When the vinylzinc generation attempt was allowed to stir at room temperature for 20 hours, the same result was observed. A number of vinyl iodides that were prepared for studies in the $\mathrm{Li}(\mathrm{acac})$ catalyzed reaction with diethylzinc failed to react. The following figure illustrates the vinyl iodides that were unsuccessful using these methods.

Figure 4.1 Unsuccessful Vinyl Iodides Attempted in the Li(acac) Catalyzed Reaction with Diethylzinc to Form Vinylzincs

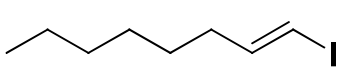

VI-1

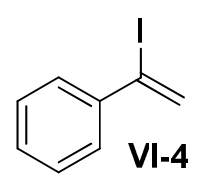

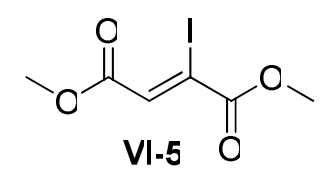

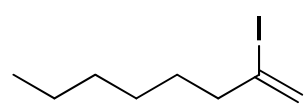

VI-2

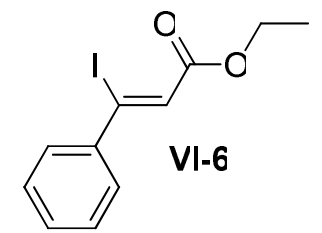

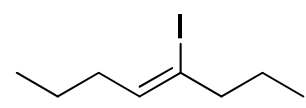

VI-3

A number of the vinyl iodides were prepared in a simple manner from the reaction of alkyne, sodium iodide, chlorotrimethylsilane, and a catalytic amount of water in acetonitrile at room temperature. ${ }^{19}$

In an attempt to expand the methodology of vinylzinc formation to vinyl bromides, similar to that found for 2-iodothiophene and 2-bromothiophene, reactions of $\alpha$-iodostyrene (VI-4) and $\alpha$-bromostyrene were planned. $\alpha$-Iodostyrene could be prepared but distillation failed. Under vacuum with minimal heating, the material rapidly polymerized (a dark reddish-brown material formed in a highly exothermic fashion). Reactions were run using the material obtained directly after workup, chromatography and evacuation (rotoevaporation followed by concentration on manifold) in the absence of light. Reactions failed in the presence or absence of ligand in the desired vinylation 
reaction. $\alpha$-Bromostyrene can be purchased in technical grade (95\%, Acros Organics). It was used as received, but the reaction yielded the ethyl addition product after mixing 2.2 equivalents $\alpha$-bromostyrene, 26 mol \% Li(acac), 1.21 equivalents $\mathrm{Et}_{2} \mathrm{Zn}$ in NMP (1.5 $\mathrm{mL}$ ) for 7 hours at room temperature. Bromo-triphenylethylene is a commercially available powder that was also unsuccessfully attempted.

Other substrates were attempted. We also screened non-terminal substrates citing the reactivity issues presented by the terminal vinyl iodide. The readily prepared (Z)-4iodo-4-octene (VI-3) was studied but also failed to yield allylic alcohols in the presence or absence of the chiral ligand. For example, when $(Z)$-4-iodo-4-octene was stirred at 0 ${ }^{\circ} \mathrm{C}$ with $\mathrm{Et}_{2} \mathrm{Zn}$ for 3 hours only ethyl addition product was isolated after introduction of benzaldehyde. After mixing the same equivalents for 5 hours at room temperature, only ethyl addition was observed again in the reaction mixture after 3 days (benzaldehyde was still present by TLC and ${ }^{1} \mathrm{H}$ NMR). The formation of the starting material, as well as recovery following no reaction, was checked and verified to be $Z$. Sterics could play a role in this case although no success has been achieved with a terminal or dialkylsubstituted vinyl iodide. 8 equiv (Z)-4-iodo-4-octene and 4 equiv Et $2 \mathrm{Zn}$ were tested but no vinylation was observed. This was also tested for the dimethyl 2-iodofumarate (VI-5) reaction but no reaction occurred.

Again, the search continued to find a suitable reagent for accessing the vinylzinc species. Iodostilbene (VI-8) was formed by the DIBAL-H reduction and iodinequenched reaction. ${ }^{20}$ When this substrate was reacted with benzaldehyde at room temperature, the anticipated allylic alcohol (79) was formed in good yields both in the presence and absence of ligand. However, the reproducibility of the reaction proved to 
be an issue. Upon review of the synthesis and ultimately making the observation of the vinyl iodide degradation (even when stored in a moisture- and oxygen-free atmosphere and in the dark), distillation was performed under vacuum. The stable vinyl iodide was collected at $120-140{ }^{\circ} \mathrm{C}(5 \mathrm{mmHg})$ and no trace of isomerization was observed $\left({ }^{1} \mathrm{H}\right.$ NMR). This solved the reproducibility issue. Thus, the first successful and reproducible generation of a vinylzinc was discovered and added to an aldehyde producing an allylic alcohol employing the $\mathrm{Li}(\mathrm{acac})$ catalyzed protocol. The vinylzinc was generated from commercially available diethylzinc (neat) and lithium acetylacetonate in $\mathrm{N}$ methylpyrrollidinone. A 2:1 ratio of diethylzinc to iodostilbene was mixed with a catalytic amount of $\operatorname{Li}(\mathrm{acac})(26 \mathrm{~mol} \%$ relative to the aldehyde) at room temperature for 5 hours to form the presumed (stilbene) ${ }_{2}$ zinc. Upon addition of $10 \mathrm{~mol} \%(S)-\mathbf{1 2}$ in dichloromethane, the chiral allylic alcohol (79) was afforded in $90 \%$ yield and $97 \%$ ee. This scheme is shown below.

It was interesting to observe the reaction performed in the absence of ligand. A high yield of the alcohol $(80 \%$; rac-79) was still formed under otherwise identical reaction conditions. We did not observe such a competitive background reaction in the arylations studies (and reported on in Chapter 3). Moving forward with the successful generation and reaction of a 1,2-diphenyl-substituted, internal vinyl iodide, we explored variations of this motif. Exchanging one phenyl group for an aliphatic group of varying length and containing functionality was operable. The vinyl iodides were first synthesized from an in situ generated zinc hydride/titanocene system ${ }^{21}$ followed by an iodine-quenched reaction. Again distillation of the vinyl iodide following workup and column chromatography was necessary to achieve reproducibility. Scheme 4.2 below 
introduces screened background reactions between the successfully generated vinylzinc species and aldehydes.

\section{Scheme 4.2 Reaction of Vinyl Iodides with Aldehydes in the Presence of $\mathbf{Z n E t}_{2}{ }^{\text {a,b }}$}

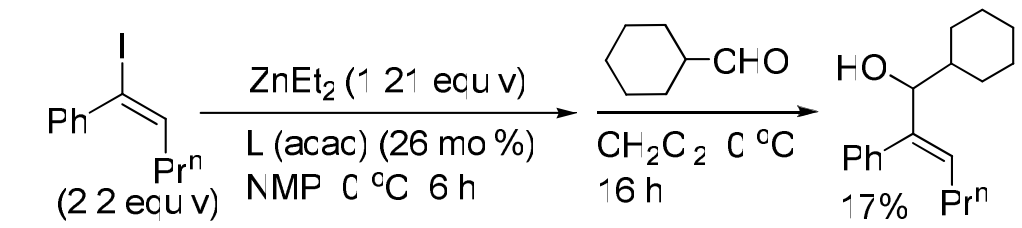

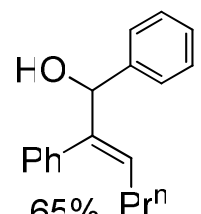

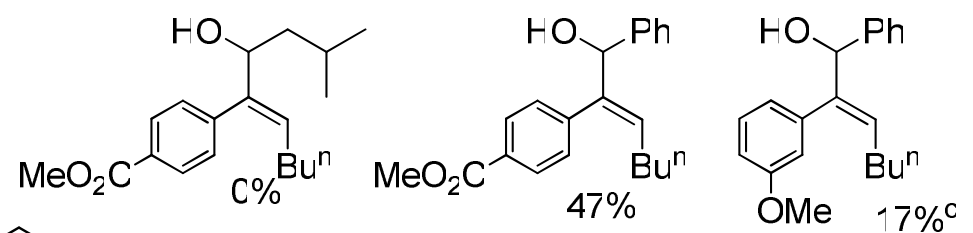<smiles>CCOC/C=C(\c1ccccc1)C(P)c1ccccc1</smiles>

(a) Methoc D n Exper mentas $w$ thout us ng the chra ganc

(b) Iso atec y e c

(c) $\mathrm{rt} \operatorname{Step} 18 \mathrm{~h}$

In general, low yields of the allylic alcohols were observed in the absence of a chiral ligand, except for the stilbenylzinc addition to benzaldehyde. We were disappointed to observe the same aldol pathway was operational when the vinylzinc was attempted to add to a ketone. The vinylzinc generated from iodostilbene was treated with 4'bromoacetophenone but only the aldol product was formed whether the ligand was present or absent.

It was again observed that the vinyl iodide that did not contain the geminal phenyl group (to the halide) failed to react in any of the conditions screened. It is interesting to note that the phenyl group could be displaying an electronic effect and must be present at the geminal carbon containing the iodide. The interaction of the pi electrons of the germinal benzene ring with the Lewis acidic $\mathrm{Zn}$ (II) center might play a role in facilitating 
the formation of the vinylzinc from the vinyl iodides. The zinc — halogen exchange fails in the absence of $\operatorname{Li}(\mathrm{acac})$.

(Z)-Ethyl 3-iodo-3-phenylacrylate (VI-6) was an interesting substrate. With the geminal phenyl group present, the corresponding vinylzinc could be generated and no substitution from the alkylzinc was observed. ${ }^{19}$ Reactivity of the iodo-acrylate was verified by ${ }^{1} \mathrm{H}$ NMR analysis of the crude mixture (after some time allowed for reaction between diethylzinc and iodo-acrylate). The starting vinyl iodide was consumed and after a typical quenching (saturated ammonium chloride) of the reaction and column chromatography, the acrylate (exchange iodine for proton; $\boldsymbol{d e}$-VI-6) was recovered. The nature of the vinylzinc could lead to the structure shown in the figure below.

Figure 4.2 Possible Chelation Complex Stabilizing (Phenylacrylate)Zinc Generated.

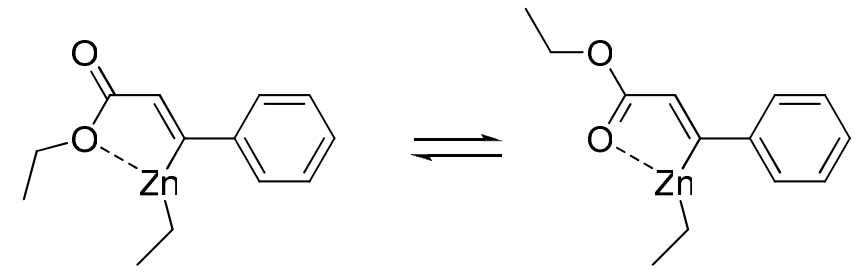

This was our hypothesis to address why no vinyl addition was observed in the presence of ligand and aldehyde even though the vinyl iodide reacted. In an attempt to override this stable cyclic intermediate, different amounts of titanium tetraisopropoxide were added (up to 5 equivalents relative to the aldehyde). This could potentially activate both the nucleophilic and electrophilic species in the reaction. The strategy could act in a twofold manner. One aim was to disrupt the vinylzinc substrate coordination cycle in the presence of titanium while the other aim is to further activate the aldehyde. However, still no addition reaction was observed and the de-iodinated acrylate was recovered. Interestingly, some product from the ethyl addition to the aldehyde was also isolated from 
the workup even though all of the vinyl iodide had been consumed (and theoretically reacted with the 0.55 relative equiv of diethylzinc). It is also possible that the divinylzinc species was generated in situ. This species may be even further stabilized by a bis(cyclic) intermediate that was only reactive under Brönsted acidic conditions (acidic quench).

Although the (diester)vinyl iodide (VI-5) was electronically and structural similar to that of the phenyl group, no vinylzinc formation was observed. Other substrates studied containing the geminal (phenyl)alkene motif failed to produce any allylic alcohol. The geminal iodo, trimethylsilyl-vinyl reagent (VI-7). This represents an important substrate because of the potential for further functionalization directly from the newly formed allylic alcohol. However, similar to other observed inactivity, when the halide is not attached to the same carbon as the phenyl group, exchange does not take place. $\alpha-$ Iodostyrene, discussed earlier, which would yield a disubstituted allylic alcohol containing a terminal vinyl group that could be further modified also failed.

The basis for the time differential required for the complete generation of the various vinylzinc species may be dependent on electronic and steric effects. Iodostilbene reacts at room temperature after 5 hours and appears to be relatively more stable than the other vinylzincs (at least at this temperature). The reactivity of the iodostilbene containing a di(phenyl)-substituted double bond shows vinylzinc formation and is somehow stabilized to degradation at room temperature. It should be noted that - as shown in the schemes above and explained further in detail below-all other methodologies to generate the vinylzincs in situ are performed at $0{ }^{\circ} \mathrm{C}$ for 3 to $6 \mathrm{hrs}$. Although the temperature was decreased, these vinyl iodides react at a rate faster or 
almost similar to iodostilbene at room temperature. ${ }^{22}$ Figure 4.3 shows vinyl iodide substrates that successfully generated vinylzincs and were found to react with aldehydes.

Figure 4.3 Vinyl Iodides that Successfully Generated Vinylzincs and Reacted with Aldehydes.
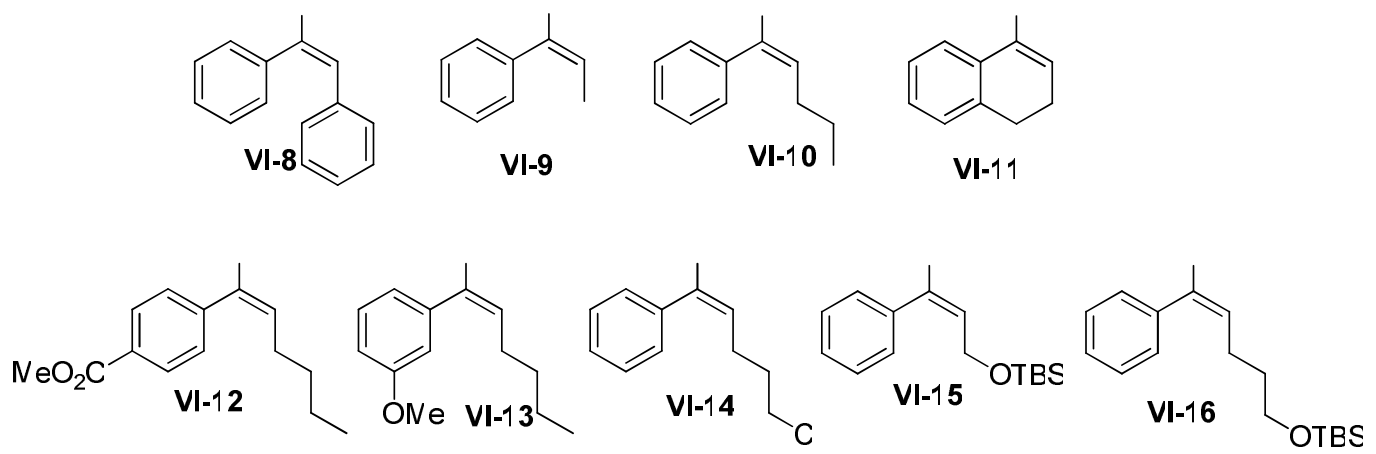

1-Iodo-1-phenyl propene (VI-9) readily reacted in these conditions to form the vinylzinc in 3 hours at $0{ }^{\circ} \mathrm{C}$. However, extending the aliphatic group required longer time. 1-Iodo-1-phenyl pentene (VI-10) was studied at 3, 4 and 5 hours at $0{ }^{\circ} \mathrm{C}$, but varying amount of ethyl addition was observed. 6 hours at $0{ }^{\circ} \mathrm{C}$ was required for complete consumption of the vinyl iodide. This procedure worked well with vinyl iodides containing an aliphatic portion ranging in functional group presence and from one carbon to four carbons in length. Furthermore, while the methodology tolerates the presence of functional groups on the phenyl ring, it is not clear what, if any, effect this aromatic substitution has on vinylzinc formation. An interesting study to be performed is the preparation and comparative reactivity study between the following vinyl iodides: 1iodo-1-(pentafluoro)phenyl propene and 1-iodo-1-(pentamethoxy)phenyl propene. This study would compare the electron-withdrawing and electron-donating effects of the phenyl substitution and provide insight into whether any such effect exists. This could be 
used to advance our current understanding of the vinylzinc formation that has been limited to the geminal phenyl substitution in the vinyl iodide.

The reaction of 1-iodo-3,4-dihydronaphthalene (VI-11) highlights the utility of this novel procedure. The reactivity screen show that the vinylzinc formed is unstable rapidly degrading over time. Yields of the allylic alcohol were consistently low when the vinylzinc formation was attempted using 2.2 to 4.4 equivalents of vinyl iodide at room temperature. The low yields persisted when these equivalents were applied at $0{ }^{\circ} \mathrm{C}$. Thus, 8.0 equivalents of 1 -iodo-3,4-dihydronaphthalene were mixed with 4.0 equivalents at $0{ }^{\circ} \mathrm{C}$ for only 3 hours. This gave better results. Good yields (61-90\%) and highly enantioselective reactions (91-96\% ee) were obtained. While these are not optimal conditions for this substrate, it represents a class of compounds that cannot be accessed using the common vinylzinc generating strategies reported to date, namely the Oppolozer and Wipf procedures ${ }^{6-9}$ that employ alkynes as the starting materials. Furthermore, terminal alkynes have been widely reported in these procedures. Few examples have been shown that utilize these strategies with non-terminal (internal) alkynes.

Explanations ${ }^{8,9}$ have focused on steric factors playing the major role in the diminished success for internal alkynes. The methodology developed as the basis of this dissertation chapter represents a significant advance in internal vinylzinc generation and subsequent asymmetric delivery for the preparation of enantioenriched allylic alcohols. In the next section, the results of this methodology are presented.

The reactivity of a mono(vinyl)zinc species was attempted. (E)-4-iodo-4-octene and 1-iodo-3,4-dihydronaphthalene were tested by mixing 1.2 equiv of the vinyl iodide with 1.2 equiv $\mathrm{Et}_{2} \mathrm{Zn}$ in NMP. Only the ethyl addition was the observed product when 
benzaldehyde was added (did not consume aldehyde over 3 days). This is interesting as we observe that a vinylzinc species is likely not generated in the absence of $\mathrm{Li}(\mathrm{acac})$. If the (ethyl)(vinyl)zinc was generated, we would anticipate the observation of vinyl addition over alkyl addition similar to that observed for a mixed ethyl(phenyl)zinc species. $^{23}$

\section{c. Catalytic Asymmetric Vinylations of Aldehydes}

The results for the asymmetric addition of the vinylzinc formed from $(E)$-iodostilbene to aldehydes are shown in Table 4.1 below.

Table 4.1 Catalytic Asymmetric Reaction of (E)-Iodostilbene with Aldehydes in the Presence of $\mathrm{ZnEt}_{2}$ and $(S)-12$. $^{\mathrm{a}}$

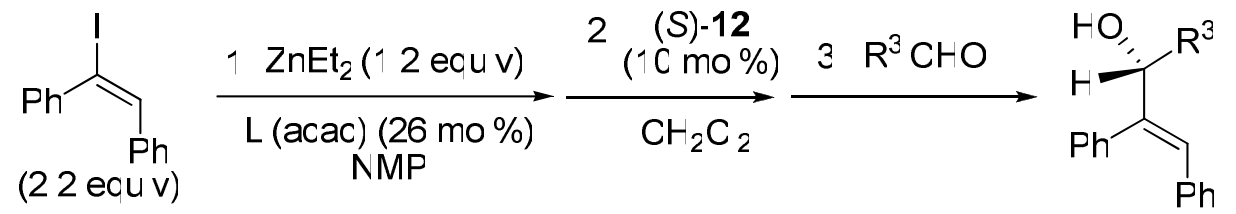

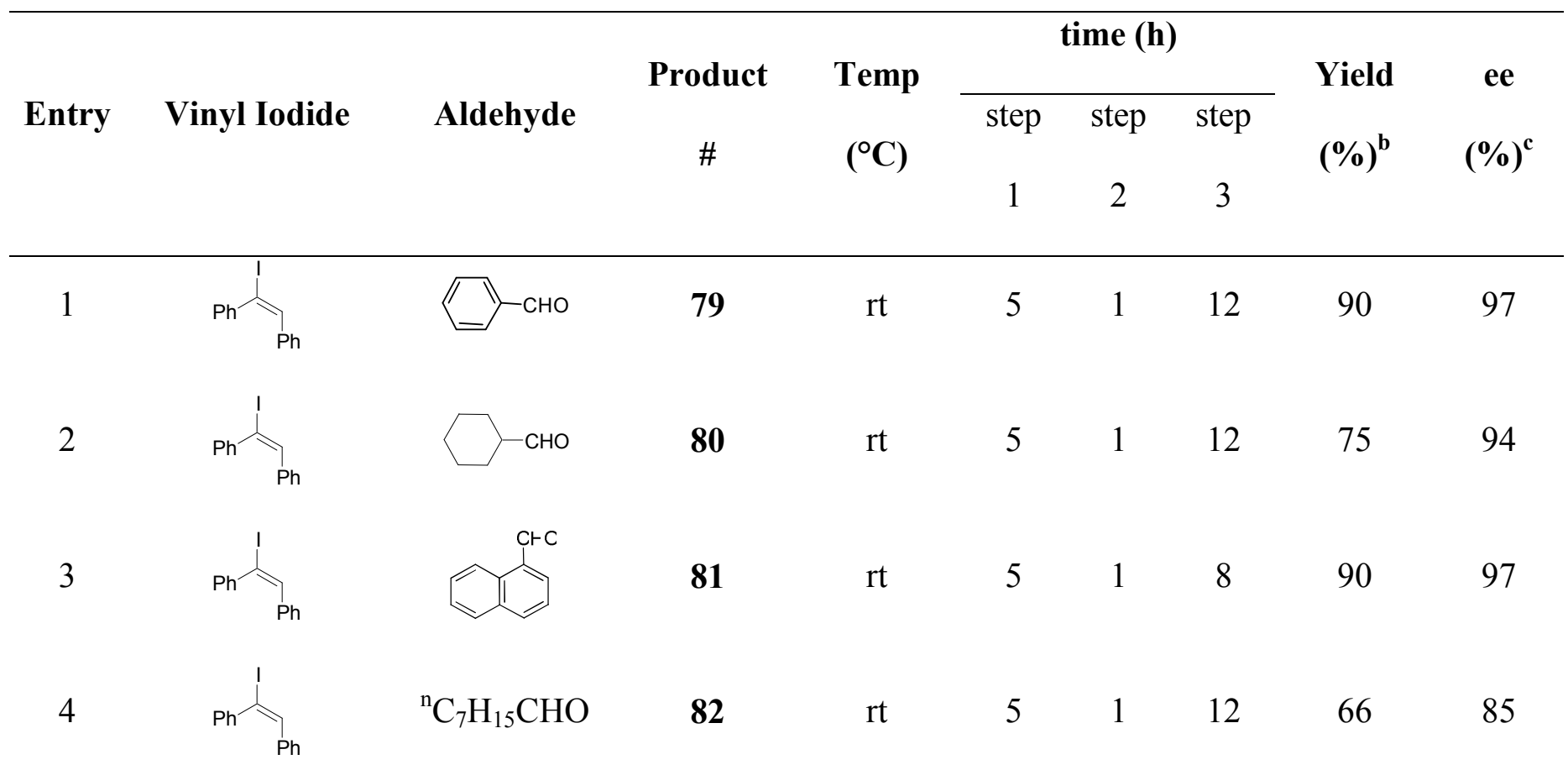


$\mathrm{rt}$

$5 \quad 1 \quad 12$

(a) Vinyl iodide (2.2 equiv), $\mathrm{Zn} \mathrm{Et}_{2},(1.2$ equiv), Li(acac) $(26 \mathrm{~mol} \%), \mathrm{NMP}(450 \mu \mathrm{L})$,

(S)-1 (10 mol\%), aldehyde (1.0 equiv) (b) Isolated yield. (c) Determined by chiral HPLC analysis.

High enantioselectivities were observed in both dichloromethane and tetrahydrofuran although higher yields were obtained in dichloromethane. This represents the only solvent-based experiment performed in the described asymmetric vinylations. The results from 1-iodo-1-phenyl-pentene and 1-iodo-1-phenyl-propene additions are listed in Table 4.2.

Table 4.2 Catalytic Asymmetric Reaction of 1-Iodo-1-phenyl-pentene and 1-Iodo-1phenyl-propene with Aldehydes in the Presence of $\mathrm{ZnEt}_{2}$ and (S)-12. ${ }^{\mathrm{a}}$

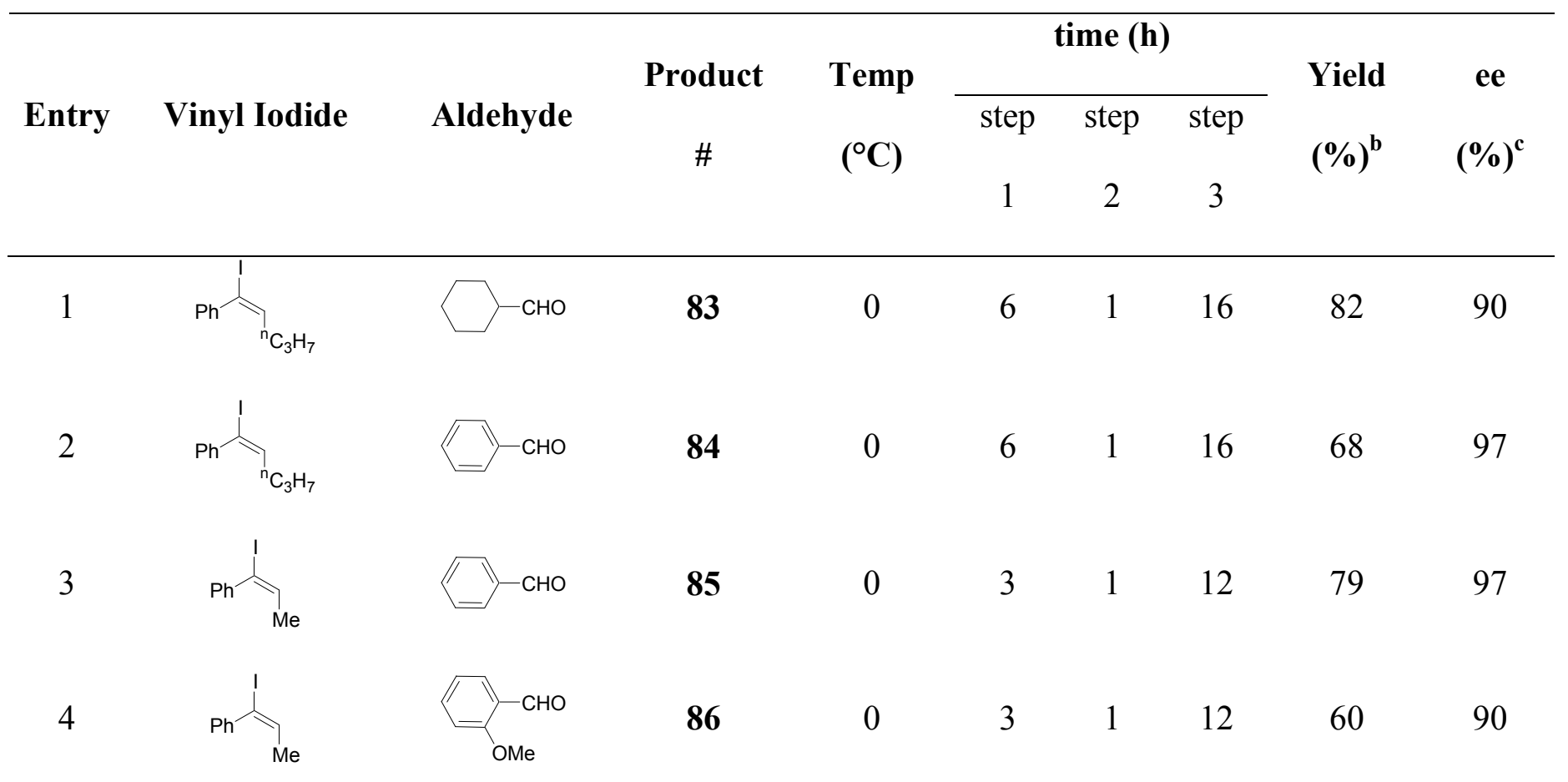


(a) Vinyl iodide (2.2 equiv), $\mathrm{Zn} \mathrm{Et}_{2},(1.2$ equiv), $\mathrm{Li}(\mathrm{acac})(26 \mathrm{~mol} \%), \mathrm{NMP}(1.0 \mathrm{~mL}$ in entries $1-6$ and $10-16 ; 450 \mu \mathrm{L}$ in entries 7-9), $(S)-1$ (10 mol\%), aldehyde (1.0 equiv). Reagents for entries 17 - 21: vinyl iodide (8.0 equiv), $\mathrm{ZnEt}_{2}$ (4.0 equiv), $\mathrm{Li}$ (acac) (50 mol\%), NMP (1.0 mL), (S)-1 (10 mol\%), aldehyde (1.0 equiv). (b) Isolated yield. (c) Determined by chiral HPLC analysis.

A comparison of the results obtained show excellent enantiocontrol for additions to aliphatic and aromatic aldehydes. The additions to benzaldehyde from each of the vinyl iodides yielded the alcohol in $97 \%$ ee showing no loss in catalytic control from the different sized vinyl groups. However, when comparing the additions to cyclohexanecarboxaldehyde, the values range from $97 \%$ ee (propenyl-zinc addition) to $90 \%$ ee (pentenyl-zinc addition) suggesting spatial hindrance from the catalyst. This would likely be a manifestation of the non-planar conformation of the aldehyde coordination to the catalytic center.

Table 4.3 shows the results from various functional vinyl iodides including ester (VI-12) and ether (VI-13) functions on the phenyl-group and chloro- (VI-14) and TBSprotected alcohol (VI-15, VI-16) substitution on the aliphatic chain. 
Table 4.3 Catalytic Asymmetric Reaction of Functional Vinyl Iodides with

Aldehydes in the Presence of $\mathrm{ZnEt}_{2}$ and $(S)-12$. $^{\mathrm{a}}$

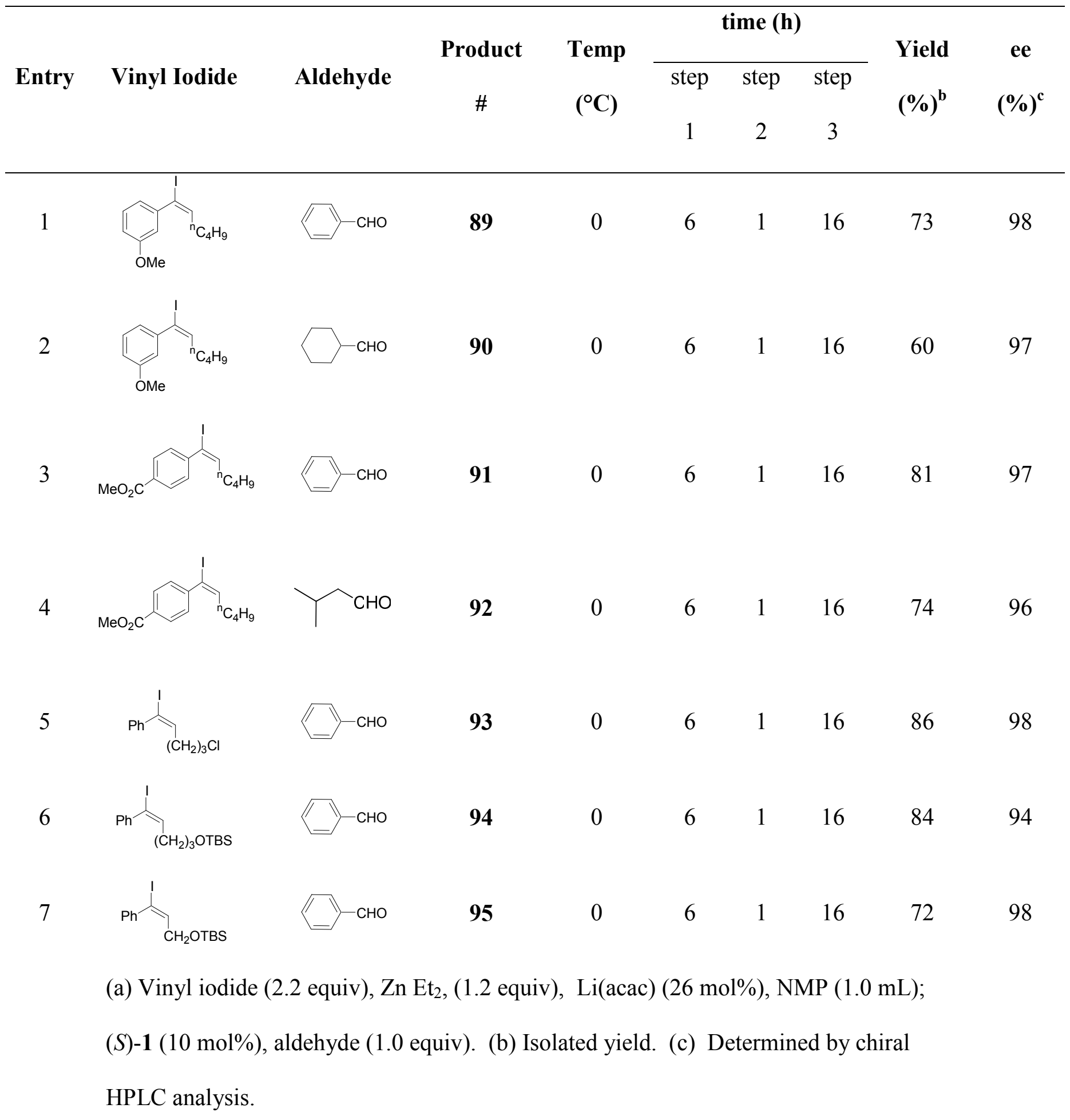


Good yields and high ee's were obtained for these allylic alcohols demonstrating the utility of the current method. The catalytic asymmetric protocols described have provided access to sterically demanding vinylzincs and the enantioselective synthesis of allylic alcohols. In particular, racemic compound $\mathbf{9 2}$ was not afforded by the common syntheses that had been attempted for the other allylic alcohol preparations. Scheme 4.3 shows the clean preparation of the racemic alcohol in high yield and demonstrates a potential reaction path that could be further studied for other asymmetric vinylations.

\section{Scheme 4.3 The Racemic Synthesis of Allylic Alcohol 92}
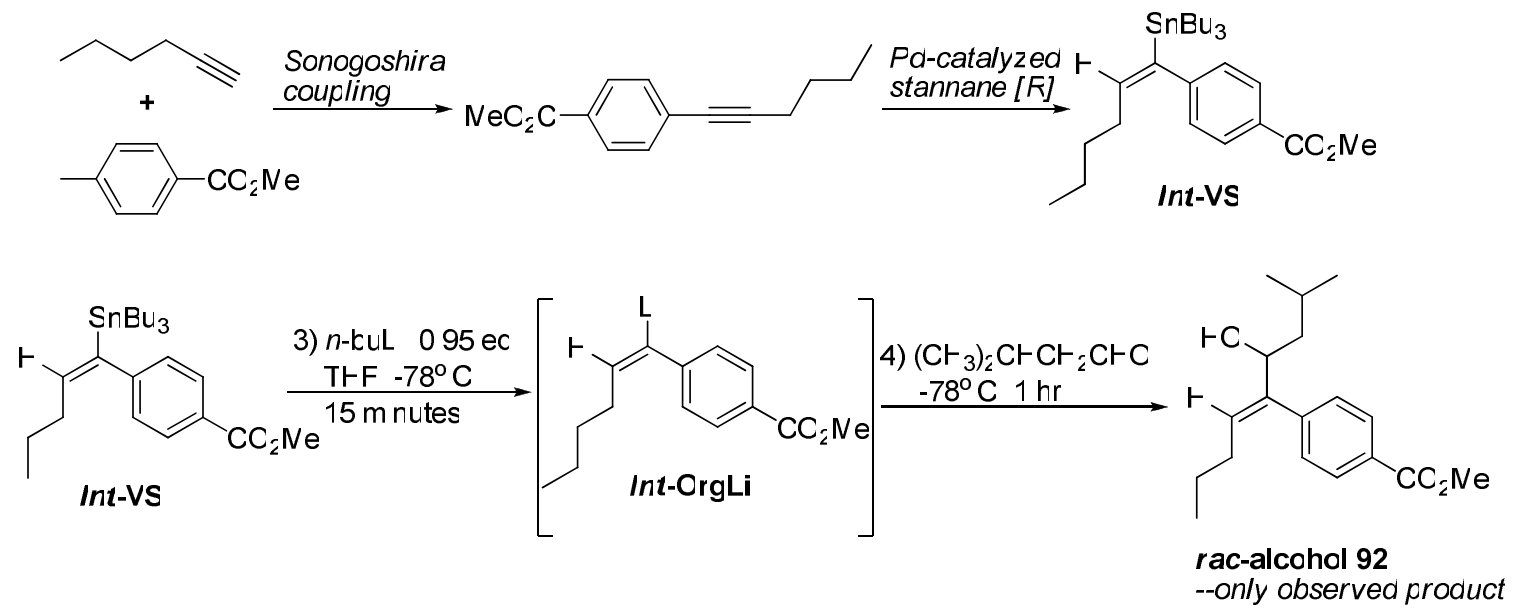

In the final table, Table 4.4 , of catalytic asymmetric vinylations to aldehydes developed by this procedure, the results from a cyclic vinyl iodide, 1-iodo-3,4dihydronaphthalene, are listed. 
Table 4.4 Catalytic Asymmetric Reaction of 1-Iodo-3,4-dihydronaphthalene, a Cyclic Vinyl Iodide, with Aldehydes in the Presence of $\mathrm{ZnEt}_{2}$ and $(S)-12 .{ }^{\mathrm{a}}$

\begin{tabular}{|c|c|c|c|c|c|c|c|c|c|}
\hline \multirow[b]{2}{*}{ Entry } & \multirow[b]{2}{*}{ Vinyl Iodide } & \multirow[b]{2}{*}{ Aldehyde } & \multirow{2}{*}{$\begin{array}{c}\text { Product } \\
\text { \# }\end{array}$} & \multirow{2}{*}{$\begin{array}{l}\text { Temp } \\
\left({ }^{\circ} \mathrm{C}\right)\end{array}$} & \multicolumn{3}{|c|}{ time (h) } & \multirow{2}{*}{$\begin{array}{l}\text { Yield } \\
(\%)^{b}\end{array}$} & \multirow{2}{*}{$\begin{array}{l}\text { ee } \\
(\%)^{\mathrm{c}}\end{array}$} \\
\hline & & & & & $\begin{array}{c}\text { step } \\
1\end{array}$ & $\begin{array}{c}\text { step } \\
2\end{array}$ & $\begin{array}{c}\text { step } \\
3\end{array}$ & & \\
\hline 1 & & $\mathrm{CHO}$ & 96 & 0 & 3 & 1 & 12 & 88 & 93 \\
\hline 2 & & & 97 & 0 & 3 & 1 & 12 & 79 & 96 \\
\hline 3 & & & 98 & 0 & 3 & 1 & 12 & 90 & 91 \\
\hline 4 & & & 99 & 0 & 3 & 1 & 12 & 84 & 96 \\
\hline 5 & & $\mathrm{CrO}$ & 100 & 0 & 3 & 1 & 12 & 61 & 91 \\
\hline & $\begin{array}{l}\text { (a) Vinyl iodid } \\
\text { (10 } \mathrm{mol} \% \text { ), alc }\end{array}$ & de (1.0 equi & $\begin{array}{l}\text { 2 (4.0 equi } \\
\text { (b) Isolate }\end{array}$ & $\begin{array}{l}\text { Li(acac) } \\
\text { ield. (c) }\end{array}$ & $0 \mathrm{~mol}$ & , NN & chiral & $\begin{array}{l}\text { ), }(S)-1 \\
\text { PLC }\end{array}$ & \\
\hline
\end{tabular}

The room temperature reaction of this substrate could only afford about $10 \%$ of the allylic alcohol but with $88 \%$ ee. Decreasing the reaction temperature did not solve the low yield issue although good enantioselectivities were maintained. When the reaction was performed at $-30^{\circ} \mathrm{C}$, about $20 \%$ product was obtained with an ee of $94 \%$. To increase the yield, 8.0 equivalents of the vinyl iodide and 4.0 equivalents of diethylzinc were employed (increased from 2.2 equiv and 1.21 equiv, respectively, used for the other vinyl iodide substrates in this report). This would form approximately 4 equivalents of a divinylzinc species during the reaction. 
Initially, 1-iodo-3,4-dihydronaphthalene presented challenges in our developing asymmetric vinylation of aldehydes. This substrate represented an important vinyl iodide in our methodology as it is a substrate that cannot be prepared using the previously established methodology, such as Oppolozer or Wipf's procedures ${ }^{6-9}$ that operate on terminal alkynes (internal alkynes have been attempted with limited success), or Jamison's procedures that operate on disubstituted (internal) alkynes (when the substituent is the same, lower enantioselectivity is typically realized). Ultimately, the best conditions found for this substrate required the use of 8 equivalents of vinyl iodide with 4 equivalents of diethylzinc. The excess vinyl iodide is expected to form 4 equivalents of the divinylzinc species in situ which afforded good yields. High enantioselectivity was observed in the presence of only $10 \mathrm{~mol} \%(S)$-12. Employing only 2.2 equivalents 1 -iodo-3,4-dihydronaphthalene (1.21 equivalents diethylzinc) or 4.0 equivalents 1-iodo-3,4-dihydronaphthalene (with 2.2 equivalents diethylzinc and 4.0 equivalents $\mathrm{Et}_{2} \mathrm{Zn}$ ) and adjusting the reaction conditions (time of step 1-ligand exchange; temperature of reaction) could not increase the yield but did maintain a high degree of enantiocontrol. The following table summarizes these findings. 
Table 4.5 Conditions Examined for the Generation of a Cyclic Vinylzinc From 1-

Iodo-3,4-dihydronaphthalene and Catalytic Asymmetric Additions to Benzaldehyde in the Presence of $\mathrm{ZnEt}_{2}$ and $(S)-12$.

\begin{tabular}{|c|c|c|c|c|c|c|}
\hline \multirow[b]{2}{*}{ Entry } & \multirow{2}{*}{$\begin{array}{l}\text { Vinyl } \\
\text { Iodide } \\
\text { (equiv) }\end{array}$} & \multicolumn{3}{|c|}{ time (h) } & \multirow{2}{*}{$\begin{array}{l}\text { Yield } \\
(\%)^{b}\end{array}$} & \multirow{2}{*}{$\begin{array}{c}\text { ee } \\
(\%)^{\text {c }}\end{array}$} \\
\hline & & $\left({ }^{\circ} \mathrm{C}\right)$ & step 1 & step 2 & & \\
\hline 1 & 2.2 & $\mathrm{rt}$ & 2 & 1 & 30 & 88 \\
\hline 2 & 2.2 & -30 & 2 & 1 & 19 & 94 \\
\hline 3 & 2.2 & $\mathrm{rt}$ & 2.5 & 1 & $<5 \%$ & 90 \\
\hline 4 & 2.2 & $\mathrm{rt}$ & 2.5 & 1 & $<5 \%$ & 42 \\
\hline $5^{\mathrm{d}}$ & 4 & $\mathrm{rt}$ & 3 & 1 & 62 & 80 \\
\hline 6 & 4 & $\mathrm{rt}$ & 2 & 1 & 89 & 83 \\
\hline $7^{\mathrm{e}}$ & 4.4 & 0 & 2 & 1 & 40 & 84 \\
\hline $8^{\mathrm{e}}$ & 8.0 & 0 & 2 & 1 & 63 & 80 \\
\hline 9 & 8 & $\mathrm{rt}$ & 1 & 1 & 64 & 63 \\
\hline 10 & 8 & $\mathrm{rt}$ & 0.5 & 1 & 68 & 81 \\
\hline 11 & 8 & $\mathrm{rt}$ & 3 & 1 & 93 & 84 \\
\hline 12 & 8 & 0 & 2 & 1 & 88 & 92 \\
\hline
\end{tabular}


(a) $\mathrm{Zn} \mathrm{Et}_{2},(0.55$ equiv relative to vinyl iodide), Li(acac) $(26 \mathrm{~mol} \%)$, NMP (1.0 mL), $(S)$ -

12 (10 mol\%), aldehyde (1.0 equiv). (b) Isolated yield. (c) Determined by chiral HPLC analysis. d) 1:1 ratio (vinyl iodide to $\mathrm{Et}_{2} \mathrm{Zn}$ used). e) $12 \mathrm{~mol} \% \mathrm{Li}(\mathrm{acac})$ used

When 8 eq 1-iodo-3,4-dihydronaphthalene and 4.4 eq $\mathrm{Et}_{2} \mathrm{Zn}$ are stirred for 1 hour at room temp., $64 \%$ yield and $63 \%$ ee was obtained. The reaction between 8.0 eq. 1 iodo-3,4-dihydronaphthalene and 4.4 eq $\mathrm{Et}_{2} \mathrm{Zn}$ mixed for 30 minutes at room temperature resulted in $68 \%$ yield and $81 \%$ ee. When 8 eq 1-iodo-3,4-dihydronaphthalene and 4.4 eq $\mathrm{Et}_{2} \mathrm{Zn}$ are stirred for 3 hours at room temp., $93 \%$ yield and $84 \%$ ee was obtained. The reaction between 4 eq. 1-iodo-3,4-dihydronaphthalene and 4 eq $\mathrm{Et}_{2} \mathrm{Zn}$ at room temperature for 3 hours afforded the allylic alcohol in $89 \%$ yield and $83 \%$ ee. The stoichiometry of the vinyl iodide and $\mathrm{Et}_{2} \mathrm{Zn}$ could generate a mixed zinc species (ethyl vinylzinc) as shown in the scheme below and demonstrates the reactivity difference relative to a presumed divinylzinc.

Scheme 4.4 1:1 Effect of the Vinyl Iodide to $\mathrm{Et}_{2} \mathrm{Zn}$ Stoichiometry on the Vinylzinc Generation and Catalyzed Addition to Benzaldehyde.

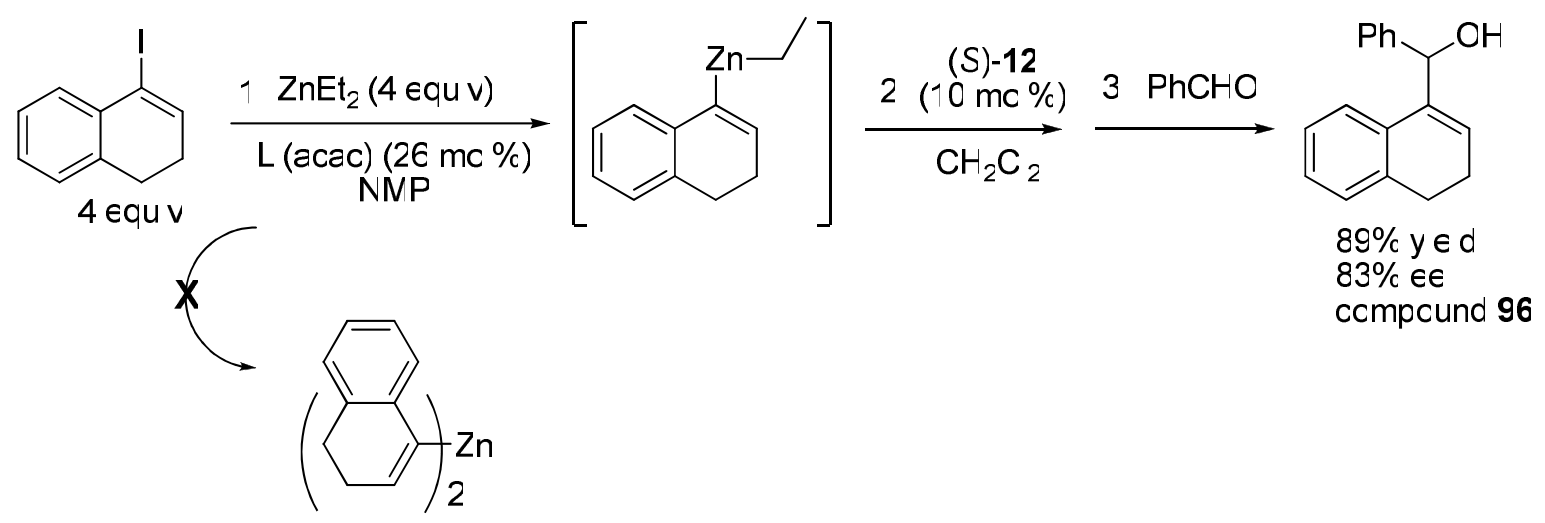


If only 2 hours were allowed for this reaction ( 4 eq 1-iodo-3,4-dihydronaphthalene and 4 eq $\mathrm{Et}_{2} \mathrm{Zn}$ at room temp), the isolated yield of product decreased to $62 \%$ and the ee was $80 \%$.

When 8 eq 1-iodo-3,4-dihydronaphthalene and 4.4 eq $\mathrm{Et}_{2} \mathrm{Zn}$ are stirred for 2 hours at $0{ }^{\circ} \mathrm{C}$ (with $26 \% \mathrm{Li}(\mathrm{acac})$ ), the alcohol was isolated in $88 \%$ yield and $92 \%$ ee (the reaction mixture was brought to room temperature after addition of benzaldehyde). Mixing either 4.4 eq 1-iodo-3,4-dihydronaphthalene and 2.42 eq $\mathrm{Et}_{2} \mathrm{Zn}$ or 8.0 eq 1-iodo3,4-dihydronaphthalene and 4.4 eq $\mathrm{Et}_{2} \mathrm{Zn}$ for 2 hours at $0{ }^{\circ} \mathrm{C}$ (both reactions used $12 \mathrm{~mol}$ $\% \mathrm{Li}(\mathrm{acac})$, half the amount used in the above reaction) resulted in alcohol yields of 40 and $63 \%$, respectively with diminished ee's (again, the reaction mixture was brought to room temperature after addition of benzaldehyde).

2 eq 1-iodo-3,4-dihydronaphthalene and 1.21 eq $\mathrm{Et}_{2} \mathrm{Zn}$ stirred at room temperature for 2 hours afforded the allylic alcohol in 30\% yield and $88 \%$ ee. The same reaction was run at $-30^{\circ} \mathrm{C}$. When this temperature was maintained throughout the reaction, $19 \%$ of the product was isolated with $94 \%$ ee. Room temperature reactions were ran at 2.5 hours and 5 hours for step 1 . Both reactions afforded $>5 \%$ product. The 2.5 hour step 1 reaction afforded the alcohol in $90 \%$ ee and in sharp contrast, the 5 hour step 1 reaction gave only $42 \%$ ee.

These reactions illustrate some resemblance to the issues presented by an arylations substrate we studied. Step 1 reaction times were searched for when methyl 4iodobenzoate reacted with $\mathrm{Et}_{2} \mathrm{Zn}$ to form enough diarylzinc species to afford good yields and ee's of the addition product to benzaldehyde at room temperature. No such time was found and instead we identified that a diaryl "coupled" product would quickly form, 
isolated in $>50 \%$ yield when step 1 time was only 30 minutes. Similarly, no such time could increase the yield of the allylic alcohol from the addition of 1-iodo-3,4dihydronaphthalene to benzaldehye at room temperature. Acceptable yields were only obtained with the use of multiple equivalents of the in situ generated vinylzinc from 1iodo-3,4-dihydronaphthalene. While good ee's were maintained, it was clear that a significant increase in ee was possible at colder temperatures. As such, to increase the yield and bypass a very sluggish reaction, 8 equivalents 1-iodo-3,4-dihydronaphthalene and 4.4 eq diethylzinc were mixed for 3 hours at $0{ }^{\circ} \mathrm{C}$. The reaction temperature was maintained at $0{ }^{\circ} \mathrm{C}$ with the subsequent additions of ligand, solvent, and aldehyde.

An attempt to prepare the vinylzinc from 1-iodo-3,4-dihydronaphthalene and $n$ butyllithium similar to Walsh's published procedures on the asymmetric arylation from aryl bromides ${ }^{24}$ was made. A solution of 1-iodo-3,4-dihydronaphthalene $(0.316 \mathrm{mmoL})$ in THF $(5.0 \mathrm{~mL})$ was cooled to $-78{ }^{\circ} \mathrm{C}$ under a nitrogen atmosphere. $n$-Butyllithium (0.275 mmoL, hexanes solution) was added and stirred 10 minutes. Next, zinc bromide $(0.149 \mathrm{mmoL})$ was introduced and the mixture was stirred for one hour. After this time, (S)-12 (10 mol \%) was added, stirred 20 minutes and followed by addition of benzaldehyde ( 1 equivalent). The reaction was maintained at $-78{ }^{\circ} \mathrm{C}$. While product was observed on TLC, the reaction stalled and was quenched at this temperature. Less than $20 \%$ of the racemic product was isolated. However, when n-butyllithium $(0.5 \mathrm{mmoL})$ was added to a $0{ }^{\circ} \mathrm{C}$ cooled solution of 1 -iodo-3,4-dihydronaphthalene $(0.5 \mathrm{mmoL})$ in THF, stirred for 30 minutes and then charged with benzaldehyde ( $0.5 \mathrm{mmoL}), 46 \%$ of the alcohol was isolated after stirring the reaction at room temperature overnight. 
Integral to the success of Walsh et. al. protocols ${ }^{24}$ was the use of a chelating additive that selectively bound salts (lithium salts) formed in the reaction and effectively diminished the background reaction. NMP may act as such a potential chelator. It is clear that this strategy could be further pursued in search of viable asymmetric methods that can operate on vinyl halides with commonly used synthetic reagents.

The configuration of the product has been assigned to be $R$ as determined by the preparation and NMR analysis of the $(R)$ - and $(S)$ - $\alpha$-methoxy- $\alpha$-phenylacetic (MPA) esters of the alcohol product. ${ }^{25}$ The reaction illustrating this determination was performed according to the Scheme 4.5.

Scheme 4.5 The Absolute Configuration Determination of Alcohol 94.
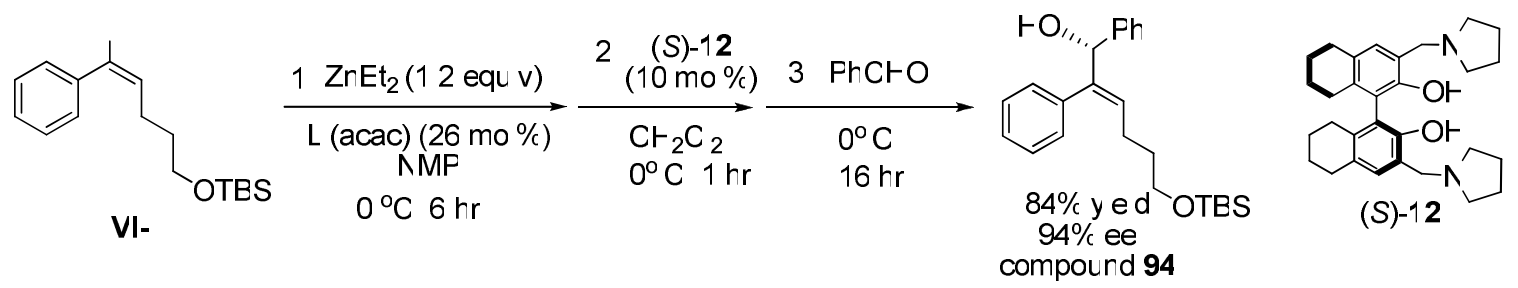

$(S)-12$<smiles>CC(C)(C)C(=CCCCC(O)c1ccccc1)c1ccccc1</smiles>

94
A

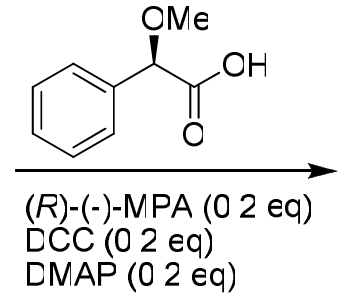

B

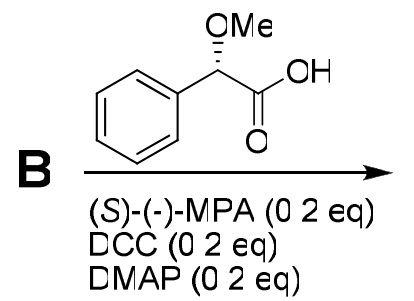

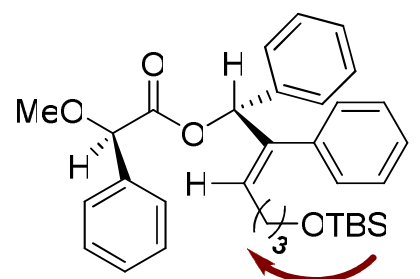

$94 a$

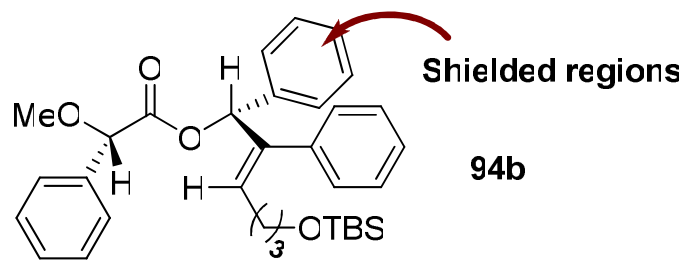


Although our understanding of the formation process and reactivity's of this diverse set of vinyl iodides is incomplete, the first method reporting the facile generation of a series of vinylzincs from an alkylzinc and vinyl iodides has been developed. The good functional group tolerance, extension to include bulky protecting groups, and mild conditions employed highlight the utility of this methodology. The range of internal vinyl iodides emphasizes the general steric compatibility and activity of the catalytic systems. The one-pot novel preparation of a series of sterically demanding non-terminal vinylzinc reagents in situ followed by their enantioselective addition to aromatic and aliphatic aldehydes resulted in the direct formation of enantioenriched, trisubstituted allylic alcohols ${ }^{26}$ with preservation of the starting stereochemistry.

These entries into the catalyzed asymmetric synthesis of allylic alcohols add a new dimension of the utilization of vinyl iodides in synthetic chemistry. Vinyl iodides and diethylzinc were mixed to form vinylzincs and then activated towards reaction with aldehydes, preparing tri-substituted allylic alcohols. The extension of this methodology to include more sterically demanding, novel substrates and products highlights the importance and potential impact of the methodology in synthetic chemistry. The established procedures for vinylzinc generation have been accomplished from terminal alkynes and reducing agents, hydroboration (Oppolozer's method) or hydrozirconation (Wipf's method), followed by transmetalation and subsequent asymmetric reaction. No reports extend these methods to general use for identically substituted, internal alkynes or non-identically substituted alkynes (where regioselectivity issues arise). Jamison and Krische have described regioselective in situ reductive methods from non-identically substituted alkynes to generate a vinylmetal species which can be asymmetrically 
delivered to a carbonyl in the presence of chiral ligands. The regioselectivity in these reports favor formation of the alkenyl—metal bond on the alkyl-substituted carbon (from the initial disubstituted alkyne, e.g. 1-phenyl-propyne). These procedures expanded the synthesis of chiral allylic alcohols to include more substituted. The extension of our methodology to generate internal vinylzincs demonstrated that the in situ generated nucleophile could afford a distinct class of vinylmetals (in our methods, specifically vinylzincs) from those reported by Jamison and Krische. Subsequent addition to aldehydes afforded enantio-enriched allylic alcohols containing the stereocenter on the carbon geminal with the aryl-substituent. Therefore, our protocols reported access to a new class of disubstituted vinylzincs from vinyl iodides and diethylzinc and the catalyzed asymmetric synthesis of trisubstituted allylic alcohols. A notable extension demonstrated by our vinylzinc generation and asymmetric methodology was the reaction of 1-iodo-3,4dihydronaphthalene. This species cannot be accessed from an alkyne and thus none of the discussed strategies could generate a nucleophile in this class of compounds. This represents an important extension and potential advancement in the asymmetric catalysis of allylic alcohols.

\section{c. Experimental and Characterization:}

Preparation of vinyl iodide, VI-10

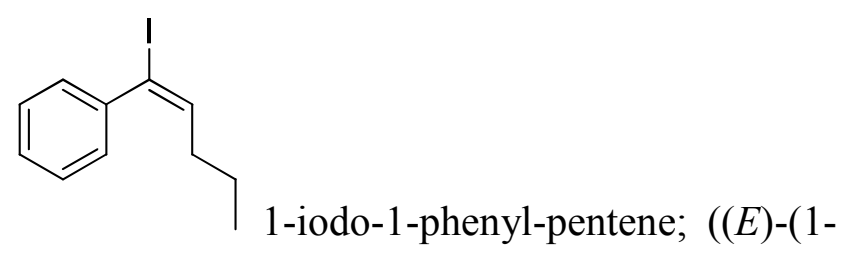

iodopent-1-enyl)benzene) ${ }^{21}$

The procedure from vinyl iodide used in Entries 3-6 was used to make this vinyl iodide.

${ }^{1} \mathrm{H}$ NMR spectral data matches that reported in the literature. Distillation was done as 
described for vinyl iodide used in Entries 7-9 (105-115 $\mathrm{C} ; 5 \mathrm{mmHg})$. As noted in the reference, the regioselectivity for this substrate (1-phenyl pentyne) was reduced relative to the reaction of 1-phenyl propyne.

General Procedure for vinylations from VI-10: Method D (used for the vinyl iodides in Entries 1-2, 10-16): A vinyl iodide (1 mmol, 2.2 equiv) was mixed with Li(acac) (0.119 mmol, $12.6 \mathrm{mg}, 26 \mathrm{~mol} \%)$ and NMP (1.0 mL) which was then cooled to $0{ }^{\circ} \mathrm{C}$. Diethylzinc $(0.55 \mathrm{mmol}, 58 \mu \mathrm{L}, 1.21$ equiv) was added dropwise to the mixture and stirred for $6 \mathrm{~h}$. At this time, $(S)-\mathbf{1}(0.0455 \mathrm{mmol}, 21 \mathrm{mg}, 10 \mathrm{~mol} \%)$ was dissolved in $\operatorname{DCM}(5.0 \mathrm{~mL})$ and then added to the reaction via canula transfer. The resulting mixture was stirred for $1 \mathrm{~h}$. An aldehyde $(0.455 \mathrm{mmol})$ was added and stirred until the reaction was complete as shown by TLC. The workup and purification were the same as described in Method A.

83

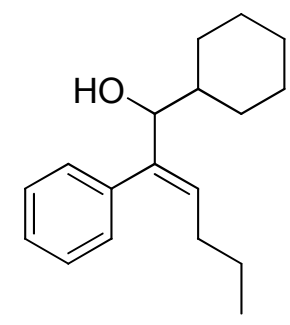

(E)-1-cyclohexyl-2-phenylhex-2-en-1-ol

$82 \%$ yield, 90\% ee. Method D was used. ${ }^{1} \mathrm{H}$ NMR $\left(300 \mathrm{MHz}, \mathrm{CDCl}_{3}\right) \delta 7.30(\mathrm{~m}, 3 \mathrm{H})$, $7.15(\mathrm{~m}, 2 \mathrm{H}), 5.63(\mathrm{t}, J=7.3 \mathrm{~Hz}, 1 \mathrm{H}), 3.99$ (br-s, $1 \mathrm{H}), 1.89(\mathrm{~m}, 3 \mathrm{H}), 1.65(\mathrm{~m}, 4 \mathrm{H}), 1.50$ (bs, 1H), $1.35(\mathrm{~m}, 2 \mathrm{H}), 1.05(\mathrm{~m}, 6 \mathrm{H}), 0.84$ (br-t, $J=7.5 \mathrm{~Hz}, 3 \mathrm{H}) .{ }^{13} \mathrm{C} \mathrm{NMR}(75 \mathrm{MHz}$ $\left.\mathrm{CDCl}_{3}\right) \delta 141.9,138.5,129.8,129.2,127.9,126.7,81.6,40.7,30.5,30.1,29.6,27.7,26.4$ 26.0, 25.9, 22.9, 13.8. $[\alpha]_{\mathrm{D}}^{25}=-16.4(\mathrm{c}=0.45, \mathrm{THF}) 90 \%$ ee . HPLC: chiralcel OD column; solvent ratio: 98:2 hexanes:isopropanol, flow rate: $1 \mathrm{~mL} / \mathrm{min} . t_{\text {minor }}=5.5 \mathrm{~min}$, $t_{\text {major }}=6.6$ min. $(254 \mathrm{~nm})$ HRMS calcd. for $\mathrm{C}_{18} \mathrm{H}_{26} \mathrm{ONa}: 281.1881[\mathrm{M}+\mathrm{Na}]^{+}$. Found: 281.1876. 


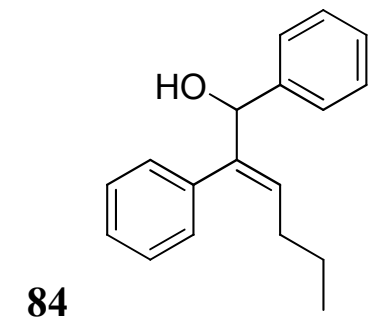

(E)-1,2-diphenylhex-2-en-1-ol

$68 \%$ yield, $97 \%$ ee. Method D was used. ${ }^{1} \mathrm{H}$ NMR $\left(300 \mathrm{MHz}, \mathrm{CDCl}_{3}\right) \delta 7.23(\mathrm{~m}, 8 \mathrm{H})$, $6.91(\mathrm{~m}, 2 \mathrm{H}), 5.85(\mathrm{dt}, J=0.9,7.4 \mathrm{~Hz}, 1 \mathrm{H}), 5.42(\mathrm{~d}, J=3.6 \mathrm{~Hz}, 1 \mathrm{H}), 2.01(\mathrm{~d}, J=2.1 \mathrm{~Hz}$, 1H), $1.89(\mathrm{~m}, 2 \mathrm{H}), 1.37(\mathrm{~m}, 2 \mathrm{H}), 0.84(\mathrm{t}, J=7.4 \mathrm{~Hz}, 3 \mathrm{H}) .{ }^{13} \mathrm{C} \mathrm{NMR}\left(75 \mathrm{MHz} \mathrm{CDCl}_{3}\right) \delta$ $142.9,142.1,137.9,129.3,128.8,127.9,127.6,127.1,126.6,126.5,78.3,30.4,22.7$, 13.6. $[\alpha]_{\mathrm{D}}^{25}=-24.7$ ( $\mathrm{c}=0.49$, THF) $97 \%$ ee . HPLC: chiralcel OD column; solvent ratio: 98:2 hexanes:isopropanol, flow rate: $1 \mathrm{~mL} / \mathrm{min} . t_{\text {minor }}=10.7 \mathrm{~min}, t_{\text {major }}=14.1 \mathrm{~min} .(254$ nm) HRMS calcd. for $\mathrm{C}_{18} \mathrm{H}_{20} \mathrm{ONa}$ : 275.1412 [M+Na] $]^{+}$. Found: 275.1414.

General Procedure for vinylations from VI-9: Method B: The vinyl iodide (1 $\mathrm{mmoL}$, $244.1 \mathrm{mg}, 2.2$ equiv) was mixed with $\mathrm{Li}(\mathrm{acac})(0.119 \mathrm{mmoL}, 12.6 \mathrm{mg}, 26 \mathrm{~mol} \%)$ and NMP $(1.0 \mathrm{~mL})$ which was then cooled to $0{ }^{\circ} \mathrm{C}$. Diethylzinc $(0.55 \mathrm{mmoL}, 58 \mu \mathrm{L}, 1.21$ equiv) was added dropwise to the mixture and stirred for $3 \mathrm{~h}$. At this time, $(S)-\mathbf{1}(0.0455$ mmol, $21 \mathrm{mg}, 10 \mathrm{~mol} \%)$ was dissolved in DCM $(5.0 \mathrm{~mL})$ and then added to the reaction via canula transfer. The resulting mixture was stirred for $1 \mathrm{~h}$. An aldehyde $(0.455 \mathrm{mmol})$ was then added and stirred until the reaction was complete as shown by TLC. The workup and purification were the same as described in Method A.

Preparation of vinyl iodide, VI-9<smiles>C/C=C(/I)c1ccccc1</smiles>
1-iodo-1-phenyl-propene; $((E)-(1-$ iodoprop-1-enyl)benzene) ${ }^{21}$ 
$\mathrm{ZnI}_{2}$ (7.2 mmoL, $2.3 \mathrm{~g}, 1.44$ equiv) was dissolved in THF $(10 \mathrm{~mL}) . \mathrm{LiH}(15.8 \mathrm{mmoL}$, $126 \mathrm{mg}, 3.16 \mathrm{eq}$ ) was added and the mixture was stirred at room temperature for $3 \mathrm{~h}$. At this time the mixture was cooled to $0{ }^{\circ} \mathrm{C}$ and 1 -phenyl-propyne $(5 \mathrm{mmoL}, 581 \mathrm{mg}, 1.0$ equiv) and titanocene $\left(\mathrm{Cp}_{2} \mathrm{TiCl}_{2} ; 0.715 \mathrm{mmoL}, 178 \mathrm{mg}, 0.143\right.$ equiv) were added sequentially. The mixture was stirred at $0{ }^{\circ} \mathrm{C}$ for $1 \mathrm{~h}$ and then warmed to room temperature for 3 to $5 \mathrm{~h}$ until reaction was complete as shown by TLC. The reaction mixture was then cooled to $-78^{\circ} \mathrm{C}$ and a solution of iodine in THF was added. The mixture was warmed to room temperature and after $30 \mathrm{~min}$ hexanes was added. The mixture was filtered over celite and washed with $\mathrm{NaHCO}_{3}$ and $\mathrm{Na}_{2} \mathrm{SO}_{3}$ (satd., aq.). The organics were dried over $\mathrm{MgSO}_{4}$, filtered, concentrated and purified over silica gel flash chromatography eluted with hexanes. The ${ }^{1} \mathrm{H}$ NMR spectral data match those reported in the literature. The vinyl iodide was distilled as described for vinyl iodide used in Entries 7-9 $\left(60-70{ }^{\circ} \mathrm{C} ; 5 \mathrm{mmHg}\right)$.

\section{Characterization of vinylations from VI-9 Addition Products:}<smiles>C/C=C(\c1ccccc1)C(O)c1ccccc1</smiles>

\section{(E)-1,2-diphenylbut-2-en-1-ol}

79\% yield, 97\% ee. Method B was used. ${ }^{1} \mathrm{H}$ NMR $\left(300 \mathrm{MHz}, \mathrm{CDCl}_{3}\right) \delta 7.25(\mathrm{~m}, 8 \mathrm{H})$, $6.96(\mathrm{~m}, 2 \mathrm{H}), 5.93(\mathrm{dq}, J=1.1,6.9 \mathrm{~Hz}, 1 \mathrm{H}), 5.45(\mathrm{br}-\mathrm{s}, 1 \mathrm{H}), 1.99(\mathrm{~d}, J=3.9 \mathrm{~Hz}, 1 \mathrm{H})$, $1.58(\mathrm{dd}, J=0.9,6.9 \mathrm{~Hz}, 3 \mathrm{H}) .{ }^{13} \mathrm{C} \mathrm{NMR}\left(75 \mathrm{MHz} \mathrm{CDCl}_{3}\right) \delta 143.8,142.1,137.7,129.3$, $128.1,127.9,127.3,126.8,126.6,123.6,78.4,14.3 . \quad[\alpha]_{\mathrm{D}}^{25}=-29.0(\mathrm{c}=0.50, \mathrm{THF}) 97 \%$ ee. HPLC: chiralcel OD column; solvent ratio: 95:5 hexanes:isopropanol, flow rate: 1 
$\mathrm{mL} /$ min. $t_{\text {minor }}=11.1 \mathrm{~min}, t_{\text {major }}=13.2 \mathrm{~min} .(232 \mathrm{~nm})$ HRMS calcd. for $\mathrm{C}_{16} \mathrm{H}_{16} \mathrm{ONa}$ : $247.1099[\mathrm{M}+\mathrm{Na}]^{+}$. Found: 247.1096.<smiles>C/C=C(\c1ccccc1)C(O)c1ccccc1OC</smiles>

\section{(E)-1-(2-methoxyphenyl)-2-phenylbut-2-en-1-ol}

$60 \%$ yield, $90 \%$ ee. Method B was used. ${ }^{1} \mathrm{H}$ NMR $\left(300 \mathrm{MHz}, \mathrm{CDCl}_{3}\right) \delta 7.25(\mathrm{~m}, 5 \mathrm{H})$, $7.08(\mathrm{~m}, 2 \mathrm{H}), 6.91(\mathrm{~m}, 1 \mathrm{H}), 6.83(\mathrm{~d}, J=8.1 \mathrm{~Hz}, 1 \mathrm{H}), 5.81(\mathrm{dq}, J=0.9,6.8 \mathrm{~Hz}, 1 \mathrm{H}), 5.71$ (br-s, 1H), 3.73 (s, 3H), 2.77 (br-s, 1H), 1.57 (dd, $J=1.0,6.9 \mathrm{~Hz}, 3 \mathrm{H}) .{ }^{13} \mathrm{C}$ NMR (75 $\left.\mathrm{MHz} \mathrm{CDCl}_{3}\right) \delta 156.7,143.1,138.4,130.3,129.2,128.3,127.9,127.7,126.5,122.9$, 120.4, 110.5, 73.9, 55.3, 14.4. $[\alpha]_{\mathrm{D}}^{25}=-38.7$ (c=0.425, THF) 90\% ee . HPLC: chiralcel AD-H column; solvent ratio: 98:2 hexanes:isopropanol, flow rate: $1 \mathrm{~mL} / \mathrm{min} . t_{\text {minor }}=$ 42.0 min, $t_{\text {major }}=37.5$ min. $(254 \mathrm{~nm})$ HRMS calcd. for $\mathrm{C}_{21} \mathrm{H}_{24} \mathrm{ONa}: 277.1204[\mathrm{M}+\mathrm{Na}]^{+}$. Found: 277.1197.

87<smiles>CC=C(c1ccccc1)C(O)C1CCCCC1</smiles>

(E)-1-cyclohexyl-2-phenylbut-2-en-1-ol

84\% yield, 97\% ee. Method B was used. ${ }^{1} \mathrm{H}$ NMR $\left(300 \mathrm{MHz}, \mathrm{CDCl}_{3}\right) \delta 7.35(\mathrm{~m}, 3 \mathrm{H})$, $7.21(\mathrm{~m}, 2 \mathrm{H}), 5.78(\mathrm{q}, J=6.9 \mathrm{~Hz}, 1 \mathrm{H}), 4.03(\mathrm{~m}, 1 \mathrm{H}), 1.91(\mathrm{~d}, J=12.4 \mathrm{~Hz}, 1 \mathrm{H}), 1.70(\mathrm{~m}$, 4H), $1.59(\mathrm{~m}, 3 \mathrm{H}), 1.55(\mathrm{~m}, 1 \mathrm{H}), 1.14(\mathrm{~m}, 6 \mathrm{H}) .{ }^{13} \mathrm{C} \mathrm{NMR}\left(75 \mathrm{MHz} \mathrm{CDCl}_{3}\right) \delta$ 142.9, $138.3,129.2,128.0,126.7,123.9,81.7,40.8,30.1,27.8,26.4,26.0,25.9,14.2 .[\alpha]_{\mathrm{D}}^{25}=-$ 1.3 (c=0.695, THF) 97\% ee . HPLC: chiralcel AD-H column; solvent ratio: 98:2 hexanes:isopropanol, flow rate: $1 \mathrm{~mL} / \mathrm{min} . t_{\text {minor }}=13.5 \mathrm{~min}, t_{\text {major }}=11.6 \mathrm{~min} .(254 \mathrm{~nm})$ HRMS calcd. for $\mathrm{C}_{16} \mathrm{H}_{22} \mathrm{ONa}: 253.1568[\mathrm{M}+\mathrm{Na}]^{+}$. Found: 253.1563 . 


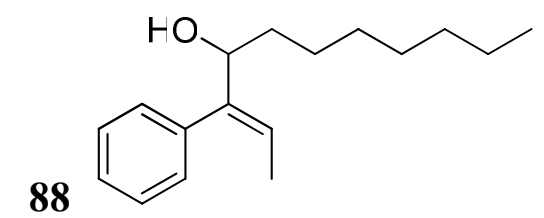

\section{(E)-3-phenylundec-2-en-4-ol}

68\% yield, 90\% ee. Method B was used. ${ }^{1} \mathrm{H}$ NMR $\left(300 \mathrm{MHz}, \mathrm{CDCl}_{3}\right) \delta 7.31(\mathrm{~m}, 3 \mathrm{H})$, $7.16(\mathrm{~m}, 2 \mathrm{H}), 5.79$ (q, $J=6.8 \mathrm{~Hz}, 1 \mathrm{H}), 4.28$ (br-s, 1H), 1.59 (br-s, 1H), $1.54(\mathrm{~m}, 3 \mathrm{H})$, $1.34(\mathrm{~m}, 12 \mathrm{H}), 0.86(\mathrm{t}, J=6.6 \mathrm{~Hz}, 3 \mathrm{H}) .{ }^{13} \mathrm{C} \mathrm{NMR}\left(75 \mathrm{MHz} \mathrm{CDCl}_{3}\right) \delta 144.4,138.1$, $129.2,128.0,126.8,122.8,35.6,31.7,29.4,29.2,25.7,22.6,14.2,14.0$. NOTE: the internal allylic carbon (chiral) was not observed in the ${ }^{13} \mathrm{C} N \mathrm{NM}$; it is presumed to be hiding under the solvent signals (possibly at $76.9 \mathrm{ppm}) .[\alpha]_{\mathrm{D}}^{25}=-11.5(\mathrm{c}=0.45, \mathrm{THF})$ 90\% ee . HPLC: chiralcel AD-H column; solvent ratio: 98:2 hexanes:isopropanol, flow rate: $1 \mathrm{~mL} / \mathrm{min} . t_{\text {minor }}=10.5 \mathrm{~min}, t_{\text {major }}=11.5 \mathrm{~min} .(242 \mathrm{~nm})$ HRMS calcd for $\mathrm{C}_{17} \mathrm{H}_{26} \mathrm{ONa}: 269.1881[\mathrm{M}+\mathrm{Na}]^{+}$. Found: 269.1888.

\section{Preparation of vinyl iodide, VI-8}

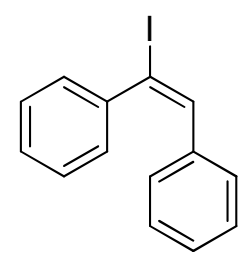

$E$-Iodostilbene; ((E)-(1-iodoethene-

\section{1,2-diyl)dibenzene) ${ }^{20}$}

A slightly modified procedure: To a solution of diphenylacetylene $(8.4 \mathrm{mmol}, 1.5 \mathrm{~g}, 1.0$ eq) in hexanes $(\sim 1 \mathrm{M})$ was added dropwise (slowly) of diisobutylaluminum hydride (DIBAL-H, 1.0 $\mathrm{M}$ in hexanes; $10.9 \mathrm{mmol}, 1.3$ equiv) at room temperature. After the reaction was stirred for $1 \mathrm{~h}$, it was warmed to $55{ }^{\circ} \mathrm{C}$ for $18 \mathrm{~h}$. The reaction mixture was then cooled to $-78^{\circ} \mathrm{C}$, and an iodine solution in THF $(12.88 \mathrm{mmol}, 3.3 \mathrm{~g} ; 60 \mathrm{~mL})$ was added. This mixture was warmed to $0{ }^{\circ} \mathrm{C}$ and stirred overnight. The contents were then transferred into an $500 \mathrm{~mL}$ Erlenmeyer flask and water was slowly added $(30 \mathrm{~mL})$ with vigorous stirring followed by $1.2 \mathrm{~N} \mathrm{HCl}(30 \mathrm{~mL})$. The organics were then extracted with 
$\mathrm{Et}_{2} \mathrm{O}(2 \times 100 \mathrm{~mL})$. The organics were combined and washed with water $(1 \mathrm{x} 75 \mathrm{~mL})$ and $\mathrm{Na}_{2} \mathrm{SO}_{3}$ (satd., aq. 2 × $75 \mathrm{~mL}$ ). The vinyl iodide was obtained in $85 \%$ yield after purification with silica gel flash chromatography (hexanes as eluent; fraction 1 collected). Typically, the vinyl iodide needed to be washed again with $\mathrm{Na}_{2} \mathrm{SO}_{3}$ (from ether or DCM) to remove the light pink color (leaching iodine). It was then concentrated and distilled from $\mathrm{Al}_{2} \mathrm{O}_{3}$ onto fresh copper pieces under vacuum $\left(125-135{ }^{\circ} \mathrm{C} ; 5 \mathrm{mmHg}\right)$. The ${ }^{1} \mathrm{H}$ NMR spectral data match those reported in the literature. NOTES: distillations attempted without the use of column chromatography failed likely due to residual aluminum salts in the crude. The addition of water into the formed vinyl iodide (crude reaction mixture) is exothermic as a portion of DIBAL-H (and alkyl aluminum) remains. The addition was done dropwise, with caution, and vigorous stirring.

General Procedure for vinylations from VI-8: Method A: The vinyl iodide (0.6 mmol, $184 \mathrm{mg}, 2.2$ equiv) was mixed with Li(acac) (0.071 mmol, $7.5 \mathrm{mg}, 26 \mathrm{~mol} \%)$ and NMP $(450 \mu \mathrm{L})$. Diethylzinc was added dropwise to the mixture and stirred for $5 \mathrm{~h}$. At this time, $(S)-\mathbf{1}(0.0273 \mathrm{mmol}, 12.6 \mathrm{mg}, 10 \mathrm{~mol} \%)$ and DCM $(1.5 \mathrm{~mL})$ were added to the reaction and stirred for $1 \mathrm{~h}$. An aldehyde ( $0.273 \mathrm{mmol}, 1.0$ equiv) was added and stirred until the reaction was complete as shown by TLC. Workup: The reaction was quenched with the addition of $\mathrm{NH}_{4} \mathrm{Cl}$ (satd., aq.; slow addition of $1 \mathrm{~mL}$; total $\sim 30 \mathrm{~mL}$ ). The aqueous layer was extracted with $\mathrm{Et}_{2} \mathrm{O}(3 \times 75 \mathrm{~mL})$. The organics were combined and washed with water $(1-2 \times 20 \mathrm{~mL})$. The organic solution was dried with $\mathrm{MgSO}_{4}$, filtered, and then concentrated. The residue was purified by flash column chromatography on 
silica gel eluted with hexanes and ethyl acetate (1 to $10 \%$ ) to give the chiral allylic alcohol product.

79

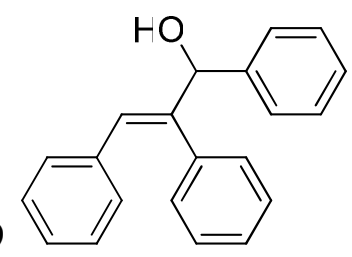

(E)-1,2,3-triphenylprop-2-en-1-ol ${ }^{32}$

90\% yield, 97\% ee. Method A was used. ${ }^{1} \mathrm{H}$ NMR $\left(300 \mathrm{MHz}, \mathrm{CDCl}_{3}\right) \delta 7.33(\mathrm{~m}, 5 \mathrm{H})$, $7.24(\mathrm{~m}, 3 \mathrm{H}), 7.10(\mathrm{~m}, 3 \mathrm{H}), 6.97(\mathrm{~m}, 4 \mathrm{H}), 6.89(\mathrm{~s}, 1 \mathrm{H}), 5.56(\mathrm{~s}, 1 \mathrm{H}), 2.28(\mathrm{br}-\mathrm{s}, 1 \mathrm{H}) .{ }^{13} \mathrm{C}$ $\operatorname{NMR}\left(75 \mathrm{MHz} \mathrm{CDCl}_{3}\right) \delta 143.8,141.5,137.9,136.2,129.3,129.2,128.4,128.2,127.8$ $127.5,127.2,127.0,126.7,126.7,79.0 .[\alpha]_{\mathrm{D}}^{25}=-49.4(\mathrm{c}=0.47, \mathrm{THF}) 97 \%$ ee . HPLC: chiralcel OD column; solvent ratio: 95:5 hexanes:isopropanol, flow rate: $1 \mathrm{~mL} / \mathrm{min}$. $t_{\text {minor }}$ $=13.7 \mathrm{~min}, t_{\text {major }}=17.9 \min (254 \mathrm{~nm}) . \mathrm{HRMS}$ calcd. for $\mathrm{C}_{21} \mathrm{H}_{18} \mathrm{ONa}: 309.1255$ $[\mathrm{M}+\mathrm{Na}]^{+}$. Found: 309.1252 .

80

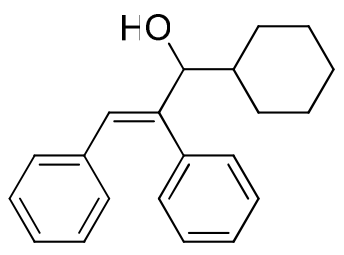

\section{(E)-1-cyclohexyl-2,3-diphenylprop-2-en-1-ol}

$75 \%$ yield, $94 \%$ ee. Method A was used. ${ }^{1} \mathrm{H}$ NMR $\left(300 \mathrm{MHz}, \mathrm{CDCl}_{3}\right) \delta 7.37$ (m, 3H), $7.24(\mathrm{~m}, 2 \mathrm{H}), 7.13(\mathrm{~m}, 3 \mathrm{H}), 6.96(\mathrm{~m}, 2 \mathrm{H}), 6.65(\mathrm{~s}, 1 \mathrm{H}), 4.24(\mathrm{~d}, J=3.9 \mathrm{~Hz}, 1 \mathrm{H}), 1.98(\mathrm{~m}$, 1H), $1.72(\mathrm{~m}, 5 \mathrm{H}), 1.39$ (br-m, 1H), $1.18(\mathrm{~m}, 5 \mathrm{H}) .{ }^{13} \mathrm{C} \mathrm{NMR}\left(75 \mathrm{MHz} \mathrm{CDCl}_{3}\right) \delta 143.4$, $138.5,136.5,129.2,128.6,127.9,127.8,127.2,126.5,82.0,40.5,30.2,27.4,26.4,26.0$,

25.9. $[\alpha]_{\mathrm{D}}^{25}=-48.9(\mathrm{c}=0.35$, THF) $94 \%$ ee HPLC: chiralcel AD-H column; solvent ratio: 98:2 hexanes:isopropanol, flow rate: $1 \mathrm{~mL} / \mathrm{min} . t_{\text {minor }}=20.8 \mathrm{~min}, t_{\text {major }}=23.0 \mathrm{~min}(254$ nm). HRMS calcd. for $\mathrm{C}_{21} \mathrm{H}_{24} \mathrm{ONa}: 315.1725[\mathrm{M}+\mathrm{Na}]^{+}$. Found: 315.1728 . 


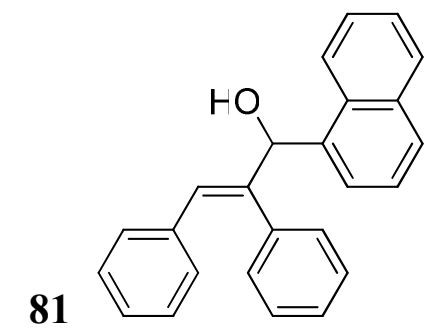

\section{(E)-1-(naphthalen-1-yl)-2,3-diphenylprop-2-en-1-ol}

94\% yield, 96\% ee. Method A was used. ${ }^{1} \mathrm{H}$ NMR $\left(300 \mathrm{MHz}, \mathrm{CDCl}_{3}\right) \delta 8.26(\mathrm{~m}, 1 \mathrm{H})$, $7.92(\mathrm{~m}, 1 \mathrm{H}), 7.85(\mathrm{~d}, J=8.2 \mathrm{~Hz}, 1 \mathrm{H}), 7.69(\mathrm{~d}, J=6.9 \mathrm{~Hz}, 1 \mathrm{H}), 7.52(\mathrm{~m}, 3 \mathrm{H}), 7.28(\mathrm{~m}$, 3H), $7.13(\mathrm{~m}, 4 \mathrm{H}), 7.00(\mathrm{~m}, 2 \mathrm{H}), 6.89(\mathrm{~s}, 1 \mathrm{H}), 6.33(\mathrm{~d}, J=3.3 \mathrm{~Hz}, 1 \mathrm{H}), 2.51(\mathrm{~d}, J=4.0$ $\mathrm{Hz}, 1 \mathrm{H}) .{ }^{13} \mathrm{C} \mathrm{NMR}\left(75 \mathrm{MHz} \mathrm{CDCl}_{3}\right) \delta 143.3,138.6,136.8,136.3,133.7,131.1,129.2$, $129.1,128.7,128.4,127.8,127.2,126.8,126.0,125.4,125.1,125.0,123.6,100.6,76.0$. $[\alpha]_{\mathrm{D}}^{25}=-74.7(\mathrm{c}=0.51, \mathrm{THF}) 96 \%$ ee . HPLC: chiralcel OD column; solvent ratio: $90: 10$ hexanes:isopropanol, flow rate: $1 \mathrm{~mL} / \mathrm{min} . t_{\text {minor }}=25.9 \mathrm{~min}, t_{\text {major }}=14.2 \mathrm{~min} .(254 \mathrm{~nm})$ HRMS calcd. for $\mathrm{C}_{25} \mathrm{H}_{20} \mathrm{ONa}$ : $359.1412[\mathrm{M}+\mathrm{Na}]^{+}$. Found: 359.1415.

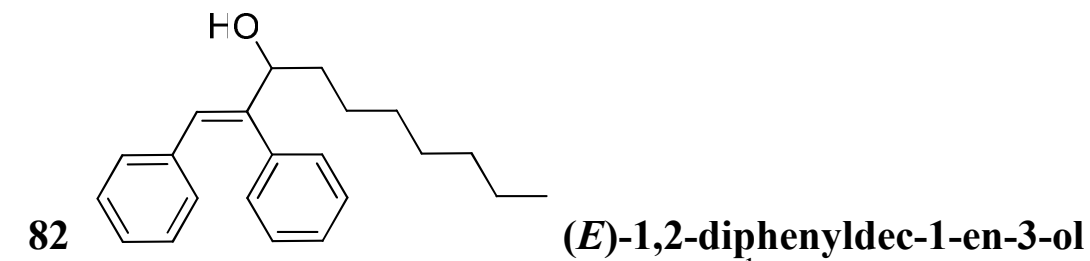

$66 \%$ yield, $85 \%$ ee. Method A was used. ${ }^{1} \mathrm{H}-\mathrm{NMR}\left(300 \mathrm{MHz}, \mathrm{CDCl}_{3}\right) \delta 7.30$ to 7.37 (m, 3H), 7.16 to $7.20(\mathrm{~m}, 2 \mathrm{H}), 7.06$ to $7.11(\mathrm{~m}, 3 \mathrm{H}), 6.91-6.94(\mathrm{~m}, 2 \mathrm{H}), 6.65(\mathrm{~s}, 1 \mathrm{H}), 4.45$ $(\mathrm{t}, J=5.4 \mathrm{~Hz}, 1 \mathrm{H}), 1.76(\mathrm{bs}, 1 \mathrm{H}), 1.25$ to $1.53(\mathrm{~m}, 12 \mathrm{H}), 0.87(\mathrm{t}, J=6.7 \mathrm{~Hz}, 3 \mathrm{H}) .{ }^{13} \mathrm{C}-$ NMR $\left(75 \mathrm{MHz} \mathrm{CDCl}_{3}\right) \delta 144.9,138.4,136.5,129.2,129.1,128.6,127.8,127.3,126.7$, $126.6,76.1,35.4,31.7,31.5,29.4,29.2,25.6,22.6,14.0 .[\alpha]_{\mathrm{D}}^{25}=-63.9(\mathrm{c}=0.405, \mathrm{THF})$ 85\% ee . HPLC: chiralcel OD column; solvent ratio: 95:5 hexanes:isopropanol, flow rate: $1 \mathrm{~mL} / \mathrm{min} . t_{\text {minor }}=10.9 \mathrm{~min}, t_{\text {major }}=12.4 \mathrm{~min}$. HRMS calcd. for $\mathrm{C}_{21} \mathrm{H}_{24} \mathrm{ONa}$ : 331.2038 [M+Na $]^{+}$. Found: 331.2045. 
NOTE: It was observed that this compound readily decomposes. The accurate HRMS measurement was obtained only after overnighting the freshly prepared sample for analysis (typical analyses involve about 2-3 days shipping prior to analysis). The acetateprotected and the methyl ether protected derivatives of the compound were prepared and HRMS were collected. As expected, these derivatives appeared to be more stable than the parent alcohol and accurate HRMS measurements were found. The results are presented here: (1) acetate protected alcohol; calcd. for $\mathrm{C}_{24} \mathrm{H}_{30} \mathrm{O}_{2} \mathrm{Na}: 373.2143[\mathrm{M}+\mathrm{Na}]^{+}$. Found: 373.2146. (2) methyl protected alcohol; calcd. for $\mathrm{C}_{23} \mathrm{H}_{30} \mathrm{ONa}$ : 345.2194 $[\mathrm{M}+\mathrm{Na}]^{+}$. Found: 345.2199 .

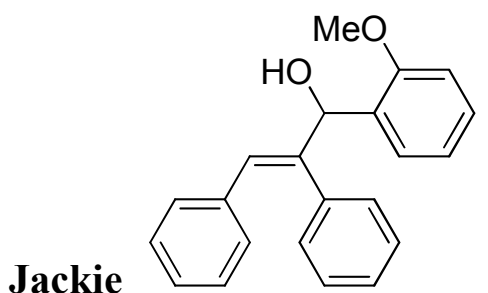

Jackie

(E)-1-(2-methoxyphenyl)-2,3-diphenylprop-2-en-1-ol $78 \%$ yield, $82 \%$ ee. ${ }^{1} \mathrm{H}-\mathrm{NMR}\left(300 \mathrm{MHz}, \mathrm{CDCl}_{3}\right) \delta 7.30(\mathrm{dd}, J=7.6,1.7 \mathrm{~Hz}, 1 \mathrm{H}), 7.21$ to $7.27(\mathrm{~m}, 4 \mathrm{H}), 7.04$ to $7.09(\mathrm{~m}, 5 \mathrm{H}), 6.89-6.96(\mathrm{~m}, 3 \mathrm{H}), 6.85(\mathrm{~d}, J=8.2 \mathrm{~Hz}, 1 \mathrm{H}), 6.77$ (s, $1 \mathrm{H}), 5.83(\mathrm{~d}, J=5.9 \mathrm{~Hz}, 1 \mathrm{H}), 3.75(\mathrm{~s}, 3 \mathrm{H}), 2.91(\mathrm{~d}, J=6.1 \mathrm{~Hz}, 1 \mathrm{H}) .{ }^{13} \mathrm{C}-\mathrm{NMR}(75 \mathrm{MHz}$ $\left.\mathrm{CDCl}_{3}\right) \delta 156.9,143.5,138.9,136.7,129.7,129.2,129.1,128.6,128.2,128.1,127.7$, $126.7,126.5,120.5,110.6,74.8,55.3 .[\alpha]_{\mathrm{D}}^{25}=-62.0(\mathrm{c}=0.50, \mathrm{THF}) 82 \%$ ee. HPLC: chiralcel OD column; solvent ratio: 90:10 hexanes:isopropanol, flow rate: $1 \mathrm{~mL} / \mathrm{min}$. $t_{\text {minor }}=29.4 \mathrm{~min}, t_{\text {major }}=23.5 \mathrm{~min} .(290 \mathrm{~nm})$ HRMS calcd. for $\mathrm{C}_{22} \mathrm{H}_{20} \mathrm{O}_{2} \mathrm{Na}$ : $339.1361[\mathrm{M}+\mathrm{Na}]^{+}$. Found: 339.1355 .

\section{Preparation of vinyl iodide, VI-11}<smiles>IC1=CCCc2ccccc21</smiles>
(1-iodo-3,4-dihydronaphthalene $)^{33}$ 
Fresh LDA $(5.5 \mathrm{mmol}, 771 \mu \mathrm{L}, 1.1 \mathrm{eq})$ was prepared in THF $(10 \mathrm{~mL})$ by adding $(n-$ butyllithium/hexanes dropwise to diisopropylamine (DIPA) (1.0 equiv $n$-butyllithium relative to DIPA, $5.5 \mathrm{mmol}$ ) at $-78^{\circ} \mathrm{C}$. It was then added slowly into a solution of $\alpha$ tetralone $(5 \mathrm{mmoL}, 665 \mu \mathrm{L}, 1.0 \mathrm{eq})$ in $\mathrm{THF}(20 \mathrm{~mL})$ at $-78{ }^{\circ} \mathrm{C}$. After stirring at this temperature for one $\mathrm{h}$, diethylchlorophosphate was charged into the reaction to trap the enolate. After $30 \mathrm{~min}$ the reaction mixture was warmed to $0{ }^{\circ} \mathrm{C}$, and stirred for $1 \mathrm{~h}$. The reaction was shown to be complete by TLC. Water was added dropwise to quench the reaction. Extraction of the crude reaction with $\mathrm{Et}_{2} \mathrm{O}(2 \times 100 \mathrm{~mL})$ was followed by drying with $\mathrm{MgSO}_{4}$. After filtration and concentration, the residue was purified by silica gel flash chromatography eluted with hexanes:ethyl acetate (3\% to $12 \%$ ethyl acetate) to give the product in $98 \%$ yield.

The vinyl phosphate $(5 \mathrm{mmoL}, 1.41 \mathrm{~g}, 1.0 \mathrm{eq})$ was dissolved in DCM $(10 \mathrm{~mL})$. Iodotrimethylsilane (15 mmoL, $2.1 \mathrm{~mL}, 3.0 \mathrm{eq})$ was added slowly into the solution while stirring. TLC showed the reaction was complete within $15 \mathrm{~min}$. Ice was added cautiously and DCM (2 x $75 \mathrm{~mL})$ was used to extract. After dried with $\mathrm{Na}_{2} \mathrm{SO}_{4}$, filtering, the solution was filtered and concentrated. The residue was purified by silica gel flash chromatography eluted with hexanes to give the crude vinyl iodide in $96 \%$ yield. The compound was distilled as described for the vinyl iodide used in Entries 7-9 (5 mmHg, 90-100 $\left.{ }^{\circ} \mathrm{C}\right) . \quad{ }^{1} \mathrm{H}$ NMR $\left(300 \mathrm{MHz}, \mathrm{CDCl}_{3}\right) \delta 7.47(\mathrm{~d}, J=7.5 \mathrm{~Hz}, 1 \mathrm{H}), 7.23(\mathrm{~m}, 2 \mathrm{H}), 7.05$ $(\mathrm{d}, J=7.1 \mathrm{~Hz}, 1 \mathrm{H}), 6.86(\mathrm{t}, J=4.6 \mathrm{~Hz}, 1 \mathrm{H}), 2.87(\mathrm{t}, J=8.0 \mathrm{~Hz}, 2 \mathrm{H}), 2.38(\mathrm{~m}, 2 \mathrm{H}) .{ }^{13} \mathrm{C}$ NMR $\left(75 \mathrm{MHz} \mathrm{CDCl}_{3}\right) \delta 139.9,135.6,134.2,130.6,128.1,127.1,126.8,97.9,27.7$, 27.0. 
General Procedure for vinylations from VI-11: Method C The vinyl iodide (1.82 mmol, $466 \mathrm{mg}, 8.0$ equiv) was mixed with $\mathrm{Li}(\mathrm{acac})(0.235 \mathrm{mmol}, 25 \mathrm{mg}, 50 \mathrm{~mol} \%)$ and NMP $(1.0 \mathrm{~mL})$ which was then cooled to $0{ }^{\circ} \mathrm{C}$. Diethylzinc $(1.0 \mathrm{mmol}, 105 \mu \mathrm{L}, 4.0$ equiv) was added dropwise to the mixture and stirred for $3 \mathrm{~h}$. At this time, $(S)-\mathbf{1}(0.023$ mmol, $10.6 \mathrm{mg}, 10 \mathrm{~mol} \%)$ was dissolved in DCM $(5.0 \mathrm{~mL})$ and then added to the reaction via canula transfer. The resulting mixture was stirred for one h. An aldehyde $(0.23 \mathrm{mmol})$ was added and the solution was stirred until reaction was complete as shown by TLC. The workup and purification were the same as described in Method A.

\section{Characterization of vinylations from VI-11 Addition Products:}<smiles>OC(c1ccccc1)c1cccc2ccccc12</smiles>

\section{(3,4-dihydronaphthalen-1-yl)(phenyl)methanol}

88\% yield, $93 \%$ ee. Method $\mathbf{C}$ was used. ${ }^{1} \mathrm{H}$ NMR $\left(300 \mathrm{MHz}, \mathrm{CDCl}_{3}\right) \delta 7.46(\mathrm{~m}, 2 \mathrm{H})$, $7.33(\mathrm{~m}, 3 \mathrm{H}), 7.25(\mathrm{~m}, 1 \mathrm{H}), 7.12(\mathrm{~m}, 3 \mathrm{H}), 6.16(\mathrm{~m}, 1 \mathrm{H}), 5.78(\mathrm{~s}, 1 \mathrm{H}), 2.80(\mathrm{t}, J=8.0 \mathrm{~Hz}$, 2H), 2.36 (m, 2H), 2.16 (br-s, 1H). ${ }^{13} \mathrm{C}$ NMR $\left(75 \mathrm{MHz} \mathrm{CDCl}_{3}\right) \delta$ 142.3, 138.2, 136.6, $132.9,128.3,128.3,127.6,127.5,127.3,126.9,126.7,126.1,125.8,123.5,73.9,28.0$, 22.9. $[\alpha]_{\mathrm{D}}^{25}=+11.8(\mathrm{c}=0.16$, THF) $93 \%$ ee. HPLC: chiralcel OD column; solvent ratio: 95:5 hexanes:isopropanol, flow rate: $1 \mathrm{~mL} / \mathrm{min} . t_{\text {minor }}=19.1 \mathrm{~min}, t_{\text {major }}=23.8 \mathrm{~min} .(254$ nm) HRMS calcd. for $\mathrm{C}_{17} \mathrm{H}_{16} \mathrm{ONa}$ : $259.1111[\mathrm{M}+\mathrm{Na}]^{+}$. Found: 259.1099 . 


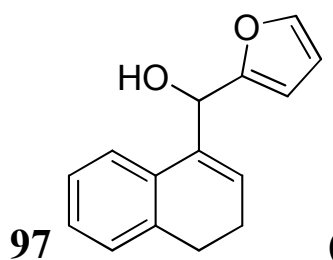

\section{(3,4-dihydronaphthalen-1-yl)(furan-2-yl)methanol}

$79 \%$ yield, $96 \%$ ee. Method $\mathbf{C}$ was used. ${ }^{1} \mathrm{H}$ NMR $\left(300 \mathrm{MHz}, \mathrm{CDCl}_{3}\right) \delta 7.40(\mathrm{~m}, 1 \mathrm{H})$, $7.21(\mathrm{~m}, 1 \mathrm{H}), 7.13(\mathrm{~m}, 3 \mathrm{H}), 6.31(\mathrm{~m}, 1 \mathrm{H}), 6.26(\mathrm{~m}, 1 \mathrm{H}), 6.23(\mathrm{~m}, 1 \mathrm{H}), 5.80(\mathrm{~d}, J=4.4$

$\mathrm{Hz}, 1 \mathrm{H}), 2.79(\mathrm{t}, J=8.0 \mathrm{~Hz}, 1 \mathrm{H}), 2.36,(\mathrm{~m}, 2 \mathrm{H}), 2.18,(\mathrm{~d}, J=4.9 \mathrm{~Hz}, 1 \mathrm{H}) .{ }^{13} \mathrm{C}$ NMR $(75$ $\left.\mathrm{MHz} \mathrm{CDCl}_{3}\right) \delta 155.2,142.2,136.4,136.1,132.8,127.6,127.0,126.9,126.2,123.0$, $110.3,107.5,67.7,28.0,22.9 .[\alpha]_{\mathrm{D}}^{25}=-13.6(\mathrm{c}=0.09, \mathrm{THF}) 96 \%$ ee. HPLC: chiralcel OD column; solvent ratio: 95:5 hexanes:isopropanol, flow rate: $1 \mathrm{~mL} / \mathrm{min} . t_{\text {minor }}=10.1 \mathrm{~min}$, $t_{\text {major }}=12.7$ min. $(280 \mathrm{~nm})$ HRMS calcd. for $\mathrm{C}_{15} \mathrm{H}_{14} \mathrm{O}_{2} \mathrm{Na}: 249.0891[\mathrm{M}+\mathrm{Na}]^{+}$. Found: 249.0886 .<smiles>OC(C1=CCCc2ccccc21)c1cccc2ccccc12</smiles>

(3,4-dihydronaphthalen-1-yl)(naphthalen-1-yl)methanol

90\% yield, $91 \%$ ee. Method $\mathbf{C}$ was used. ${ }^{1} \mathrm{H}$ NMR $\left(300 \mathrm{MHz}, \mathrm{CDCl}_{3}\right) \delta 8.06(\mathrm{~m}, 1 \mathrm{H})$, $7.89(\mathrm{~m}, 1 \mathrm{H}), 7.82(\mathrm{~d}, J=8.2 \mathrm{~Hz}, 1 \mathrm{H}), 7.68(\mathrm{~d}, J=7.1 \mathrm{~Hz}, 1 \mathrm{H}), 7.48(\mathrm{~m}, 3 \mathrm{H}), 7.31$ (m, 1H), $7.16(\mathrm{~m}, 3 \mathrm{H}), 6.55(\mathrm{~m}, 1 \mathrm{H}), 6.00(\mathrm{~m}, 1 \mathrm{H}), 2.80(\mathrm{t}, J=8.0 \mathrm{~Hz}, 2 \mathrm{H}), 2.31(\mathrm{~m}, 2 \mathrm{H})$, $2.11(\mathrm{~d}, J=5.2 \mathrm{~Hz}, 1 \mathrm{H}) .{ }^{13} \mathrm{C} \mathrm{NMR}\left(75 \mathrm{MHz} \mathrm{CDCl}_{3}\right) \delta 138.0,137.7,136.5,133.7,133.4$, 131.0, 128.6, 128.3, 128.0, 127.6, 126.9, 126.4, 126.1, 125.5, 125.3, 124.4, 123.6, 123.0, 69.5, 27.9, 22.9. $[\alpha]_{\mathrm{D}}^{25}=-33.6(\mathrm{c}=0.225$, THF) $91 \%$ ee . HPLC: chiralcel OD column; solvent ratio: 90:10 hexanes:isopropanol, flow rate: $1 \mathrm{~mL} / \mathrm{min} . t_{\text {minor }}=24.7 \mathrm{~min}, t_{\text {major }}=$ 14.9 min. $(254 \mathrm{~nm})$ HRMS calcd. for $\mathrm{C}_{21} \mathrm{H}_{18} \mathrm{ONa}: 309.1255[\mathrm{M}+\mathrm{Na}]^{+}$. Found: 309.1262 . 


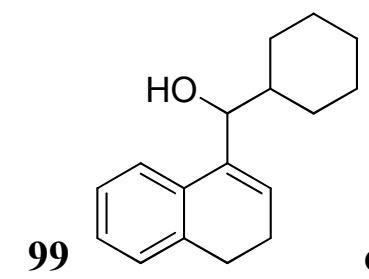

\section{cyclohexyl(3,4-dihydronaphthalen-1-yl)methanol}

84\% yield, $96 \%$ ee. Method C was used. ${ }^{1} \mathrm{H}$ NMR $\left(300 \mathrm{MHz}, \mathrm{CDCl}_{3}\right) \delta 7.48(\mathrm{~d}, J=6.9$ $\mathrm{Hz}, 1 \mathrm{H}), 7.16(\mathrm{~m}, 3 \mathrm{H}), 6.10(\mathrm{t}, J=4.6 \mathrm{~Hz}, 1 \mathrm{H}), 4.38(\mathrm{dd}, J=2.1,6.5 \mathrm{~Hz}, 1 \mathrm{H}), 2.73(\mathrm{t}, J=$ $7.9 \mathrm{~Hz}, 2 \mathrm{H}), 2.28(\mathrm{~m}, 2 \mathrm{H}), 1.99(\mathrm{~m}, 1 \mathrm{H}), 1.70(\mathrm{~m}, 5 \mathrm{H}), 1.55(\mathrm{~m}, 1 \mathrm{H}), 1.13(\mathrm{~m}, 5 \mathrm{H}) .{ }^{13} \mathrm{C}$ NMR (75 $\left.\mathrm{MHz} \mathrm{CDCl}_{3}\right) \delta 138.0,136.8,133.4,127.6,126.6,126.2,126.1,123.4,77.8$, $41.5,30.2,28.4,28.1,26.4,26.2,25.9,22.8 .[\alpha]_{\mathrm{D}}^{25}=27.0(\mathrm{c}=0.35, \mathrm{THF}) 96 \%$ ee. HPLC: chiralcel AD-H column; solvent ratio: 98:2 hexanes:isopropanol, flow rate: 1 $\mathrm{mL} / \mathrm{min} . t_{\text {minor }}=17.2 \mathrm{~min}, t_{\text {major }}=20.0 \mathrm{~min} .(254 \mathrm{~nm}) \mathrm{HRMS}$ calcd. for $\mathrm{C}_{17} \mathrm{H}_{22} \mathrm{ONa}$ : 265.1568 [M+Na $]^{+}$. Found: 265.1568.

100<smiles>CC(C)CC(O)C1=CCCc2ccccc21</smiles>

\section{1-(3,4-dihydronaphthalen-1-yl)-3-methylbutan-1-ol}

$61 \%$ yield, $91 \%$ ee. Method $\mathbf{C}$ was used. ${ }^{1} \mathrm{H}$ NMR $\left(300 \mathrm{MHz}, \mathrm{CDCl}_{3}\right) \delta 7.40(\mathrm{~d}, J=7.2$ $\mathrm{Hz}, 1 \mathrm{H}), 7.18(\mathrm{~m}, 3 \mathrm{H}), 6.18(\mathrm{t}, J=4.6 \mathrm{~Hz}, 1 \mathrm{H}), 4.77(\mathrm{~m}, 1 \mathrm{H}), 2.73(\mathrm{t}, J=8.0 \mathrm{~Hz}, 2 \mathrm{H})$, $2.27(\mathrm{~m}, 2 \mathrm{H}), 1.87(\mathrm{~m}, 1 \mathrm{H}), 1.58(\mathrm{~m}, 3 \mathrm{H}), 1.00(\mathrm{~d}, J=6.6 \mathrm{~Hz}, 3 \mathrm{H}), 0.95(\mathrm{~d}, J=6.6 \mathrm{~Hz}$, 3H). ${ }^{13} \mathrm{C} \mathrm{NMR}\left(75 \mathrm{MHz} \mathrm{CDCl}_{3}\right) \delta 139.8,136.9,133.3,127.7,126.7,126.2,124.4$, $122.8,70.0,45.6,29.6,28.2,25.0,23.4,22.7,21.9 .[\alpha]_{\mathrm{D}}^{25}=+62.8(\mathrm{c}=0.46, \mathrm{THF}) 91 \%$ ee. HPLC: chiralcel OD column; solvent ratio: 98:2 hexanes:isopropanol, flow rate: 1 $\mathrm{mL} / \mathrm{min} . t_{\text {minor }}=8.99 \mathrm{~min}, t_{\text {major }}=11.26 \mathrm{~min} .(254 \mathrm{~nm}) \mathrm{HRMS}$ calcd. for $\mathrm{C}_{15} \mathrm{H}_{20} \mathrm{ONa}$ : 239.1412 [M+Na $]^{+}$. Found: 239.1414. 
NOTE: The addition products from alpha-tetranyl vinyl iodide were observed to decompose rapidly (sometimes overnight, i.e. when collecting NMR spectral data). Our attempt to study this instability led us to protect the free alcohol to form the acetate (1 eq. DMAP, 1 eq. $\mathrm{Ac}_{2} \mathrm{O}$ in DCM; room temperature reaction for $\sim 10-15$ minutes). ${ }^{1} \mathrm{H}$ NMR and ${ }^{13} \mathrm{C}$ NMR were collected over 3 days. The acetate protected Entry 21, Table 1 was more stable than the free alcohol as evidenced by NMR (below) and TLC.<smiles>CC(=O)OC(CC(C)C)C1=CCCc2ccccc21</smiles>

${ }^{1} \mathrm{H}$ NMR $\left(300 \mathrm{MHz}, \mathrm{CDCl}_{3}\right) \delta 7.45(\mathrm{~d}, J=7.5 \mathrm{~Hz}, 1 \mathrm{H}), 7.21(\mathrm{~m}, 3 \mathrm{H}), 6.16(\mathrm{t}, J=4.6 \mathrm{~Hz}$, 1H), $5.90(\mathrm{~m}, 1 \mathrm{H}), 2.76(\mathrm{t}, J=4.6 \mathrm{~Hz}, 2 \mathrm{H}), 2.31(\mathrm{~m}, 2 \mathrm{H}), 2.12(\mathrm{~s}, 3 \mathrm{H}), 1.71(\mathrm{~m}, 3 \mathrm{H}), 0.97$ $(\mathrm{m}, 6 \mathrm{H}) .{ }^{13} \mathrm{C} \mathrm{NMR}\left(75 \mathrm{MHz} \mathrm{CDCl}_{3}\right) \delta 170.3,136.8,136.2,132.8,127.7,126.8,126.6$, $126.3,123.1,72.9,43.2,29.6,28.1,25.0,22.9,22.7,22.1,21.3$.

\section{Preparation of functional vinyl iodides, VI-12 to VI-16 and Characterization of}

\section{Their Addtions:}

Preparation of vinyl iodide, VI-13

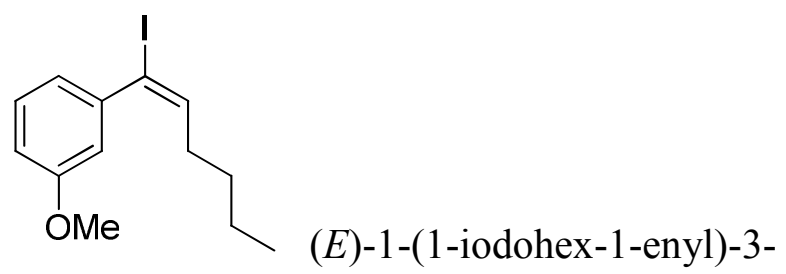
methoxybenzene ${ }^{34}$ 3-Iodo-methoxybenzene was coupled with 1-hexyne under Sonogashira conditions reported. (Aryl alkynes were isolated in yields $>90 \%$ ). 
The method from the vinyl iodide used in Entries 3-6 was applied to the aryl alkyne (10 mmoL scale). After flash chromatography, the vinyl iodide was isolated in 59\% yield and was distilled as described for vinyl iodide used in Entries 7-9 (5 mmHg, $145-160^{\circ} \mathrm{C}$; vapor $\left.80-100^{\circ} \mathrm{C}\right)$. NOTES: the yields were lower and the selectivity of this procedure was reduced (as seen for previous vinyl iodide used in Entries 1-2). We explored other procedures to prepare the following vinyl iodides. ${ }^{1} \mathrm{H}$ NMR $\left(300 \mathrm{MHz}, \mathrm{CDCl}_{3}\right) \delta 7.23$ (m, 1H), $6.85(\mathrm{~m}, 1 \mathrm{H}), 6.79(\mathrm{~m}, 2 \mathrm{H}), 6.46(\mathrm{t}, J=7.7 \mathrm{~Hz}, 1 \mathrm{H}), 3.81(\mathrm{~s}, 3 \mathrm{H}), 2.00(\mathrm{~m}, 2 \mathrm{H})$, $1.30(\mathrm{~m}, 4 \mathrm{H}), 0.83(\mathrm{t}, J=7.1 \mathrm{~Hz}, 3 \mathrm{H}) .{ }^{13} \mathrm{C} \mathrm{NMR}\left(75 \mathrm{MHz}, \mathrm{CDCl}_{3}\right) \delta 159.0,143.7,143.0$ 129.0, 121.0, 114.1, 113.5, 94.0, 55.2, 31.9, 31.2, 22.0, 13.8. HRMS calcd. for $\mathrm{C}_{13} \mathrm{H}_{17} \mathrm{OI}$ : 316.0325 $\left(\mathrm{M}^{+}\right)$. Found: 316.0328 .

89

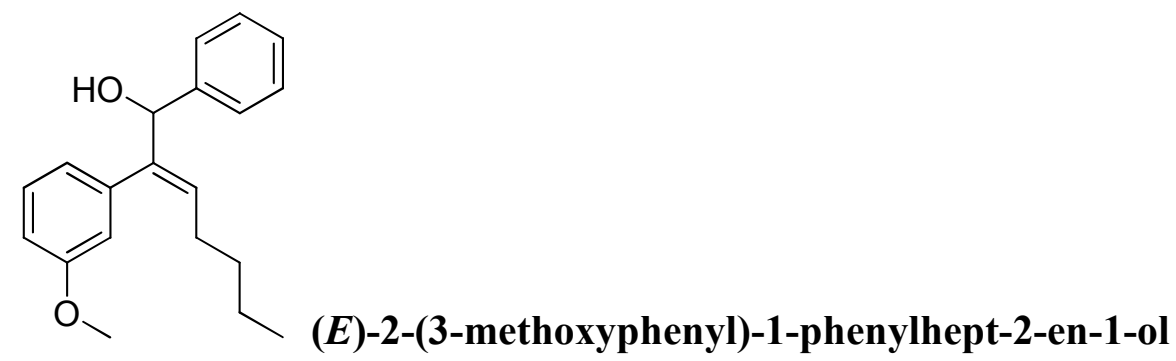

73\% yield, 98\% ee. Method D was used. ${ }^{1} \mathrm{H}$ NMR $\left(300 \mathrm{MHz}, \mathrm{CDCl}_{3}\right) \delta 7.27(\mathrm{~m}, 5 \mathrm{H})$, $7.15(\mathrm{~m}, 1 \mathrm{H}), 6.76(\mathrm{dd}, J=2.6,8.3 \mathrm{~Hz}, 1 \mathrm{H}), 6.53(\mathrm{~d}, J=7.5 \mathrm{~Hz}, 1 \mathrm{H}), 6.42(\mathrm{~m}, 1 \mathrm{H}), 5.83$ (t, $J=7.4 \mathrm{~Hz}, 1 \mathrm{H}), 5.41(\mathrm{~d}, J=3.8 \mathrm{~Hz}, 1 \mathrm{H}), 3.67(\mathrm{~s}, 3 \mathrm{H}), 1.99(\mathrm{~d}, J=5.4 \mathrm{~Hz}, 1 \mathrm{H}), 1.93$ $(\mathrm{m}, 2 \mathrm{H}), 1.28(\mathrm{~m}, 4 \mathrm{H}), 0.83(\mathrm{t}, J=7.1 \mathrm{~Hz}, 3 \mathrm{H}) .{ }^{13} \mathrm{C} \mathrm{NMR}\left(75 \mathrm{MHz} \mathrm{CDCl}_{3}\right) \delta 159.0$ $142.6,142.2,139.2,129.4,128.8,128.1,127.3,126.5,121.8,114.7,112.5,78.4,55.0$, 31.9, 28.3, 22.2, 13.9. $[\alpha]_{\mathrm{D}}^{25}=-20.6(\mathrm{c}=0.675$, THF) $98 \%$ ee . HPLC: chiralcel OD column; solvent ratio: 95:5 hexanes:isopropanol, flow rate: $1 \mathrm{~mL} / \mathrm{min} . t_{\text {minor }}=8.0 \mathrm{~min}$, $t_{\text {major }}=10.8$ min. $(254 \mathrm{~nm})$ HRMS calcd. for $\mathrm{C}_{20} \mathrm{H}_{24} \mathrm{O}_{2} \mathrm{Na}: 319.1674[\mathrm{M}+\mathrm{Na}]^{+}$. Found: 319.1672 . 


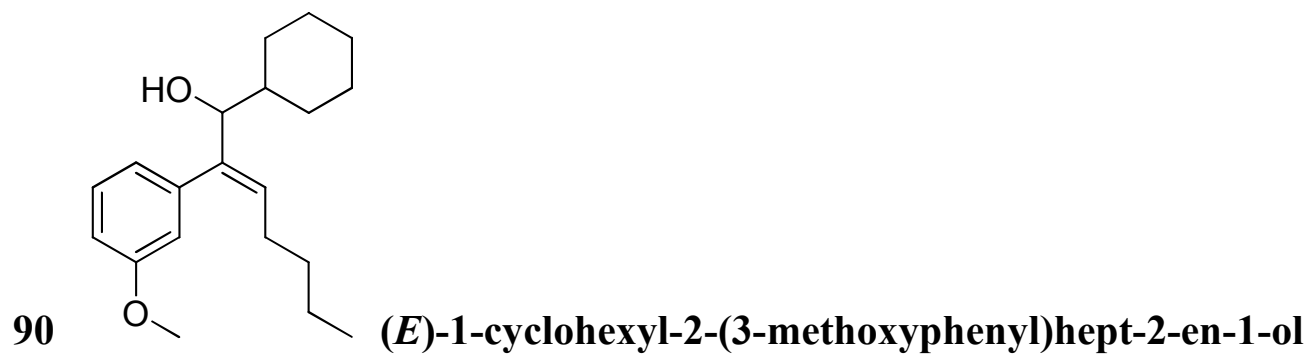

$60 \%$ yield, 97\% ee. Method D was used. ${ }^{1} \mathrm{H}$ NMR $\left(300 \mathrm{MHz}, \mathrm{CDCl}_{3}\right) \delta 7.28(\mathrm{~m}, 1 \mathrm{H})$, $6.84(\mathrm{~m}, 1 \mathrm{H}), 6.76(\mathrm{~m}, 1 \mathrm{H}), 6.73(\mathrm{~m}, 1 \mathrm{H}), 5.63(\mathrm{t}, J=7.4 \mathrm{~Hz}, 1 \mathrm{H}), 4.00(\mathrm{~m}, 1 \mathrm{H}), 3.83(\mathrm{~s}$, 3H), 1.93 (m, 2H), 1.85 (br-s, 1H), $1.73(\mathrm{~m}, 2 \mathrm{H}), 1.64(\mathrm{~m}, 3 \mathrm{H}), 1.51(\mathrm{~m}, 1 \mathrm{H}), 1.30(\mathrm{~m}$, 5H), $1.12(\mathrm{~m}, 5 \mathrm{H}), 0.85(\mathrm{t}, J=7.2 \mathrm{~Hz}, 3 \mathrm{H}) .{ }^{13} \mathrm{C} \mathrm{NMR}\left(75 \mathrm{MHz} \mathrm{CDCl}_{3}\right) \delta 159.1,141.5$ $140.0,129.9,128.9,121.7,115.0,111.9,81.5,55.1,40.7,32.0,30.2,28.2,27.7,26.4$, 26.0, 25.9, 22.3, 13.9. $[\alpha]_{\mathrm{D}}^{25}=-14.0(\mathrm{c}=0.515, \mathrm{THF}) 97 \%$ ee. HPLC: chiralcel OD column; solvent ratio: 98:2 hexanes:isopropanol, flow rate: $1 \mathrm{~mL} / \mathrm{min} . t_{\text {minor }}=5.4 \mathrm{~min}$, $t_{\text {major }}=6.4 \mathrm{~min} .(254 \mathrm{~nm})$ HRMS calcd. for $\mathrm{C}_{20} \mathrm{H}_{30} \mathrm{O}_{2} \mathrm{Na}: 325.2144[\mathrm{M}+\mathrm{Na}]^{+}$. Found: 325.2141 .

\section{Preparation of vinyl iodide, VI-12}

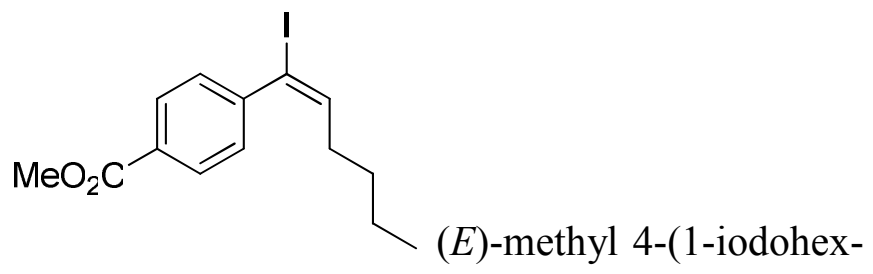

1-enyl)benzoate

Methyl-4-iodobenzoate was coupled with 1-hexyne. ${ }^{34,35}$

The aryl alkyne was subjected to the $\mathrm{Pd}$-catalyzed, $\mathrm{Bu}_{3} \mathrm{SnH}$ reduction and subsequent iodination (destannation) (conditions described in references below). 87\% yld (over 2 steps; vinylstannane and iodination). Distilled as described for vinyl iodide used in Entries 7-9 (5 mmHg, 190-200 $\mathrm{C}$; vapor $\left.\sim 100^{\circ} \mathrm{C}\right)$. NOTES: the method described for the preparation of vinyl iodide used in Entries 1-2 was attempted for the preparation of 
title compound. The main product was the ester-reduced alcohol and only a trace amount of alkyne reduction could be detected by NMR. When a 1:1 $\mathrm{LiH}$ and titanocene dichloride (stoichiometric relative to alkyne) was mixed together and added to a solution of the alkyne in THF at $0^{\circ} \mathrm{C} \rightarrow$ room temp., no reaction was observed. ${ }^{1} \mathrm{H}$ NMR (300 $\left.\mathrm{MHz}, \mathrm{CDCl}_{3}\right) \delta 7.98(\mathrm{~m}, 2 \mathrm{H}), 7.33(\mathrm{~m}, 2 \mathrm{H}), 6.52(\mathrm{t}, J=7.7 \mathrm{~Hz}, 1 \mathrm{H}), 3.91(\mathrm{~s}, 3 \mathrm{H}), 1.97$ (dd, $J=14.7,7.4 \mathrm{~Hz}, 2 \mathrm{H}), 1.30(\mathrm{~m}, 4 \mathrm{H}), 0.82(\mathrm{t}, J=7.1 \mathrm{~Hz}, 3 \mathrm{H}) .{ }^{13} \mathrm{C}$ NMR $(75 \mathrm{MHz}$, $\left.\mathrm{CDCl}_{3}\right) \delta 166.4,146.2,144.6,129.4,128.7,92.4,52.1,31.9,31.1,21.9,13.7$. HRMS calcd. for $\mathrm{C}_{14} \mathrm{H}_{17} \mathrm{O}_{2} \mathrm{I}: 344.0273\left(\mathrm{M}^{+}\right)$. Found: 344.0259 .

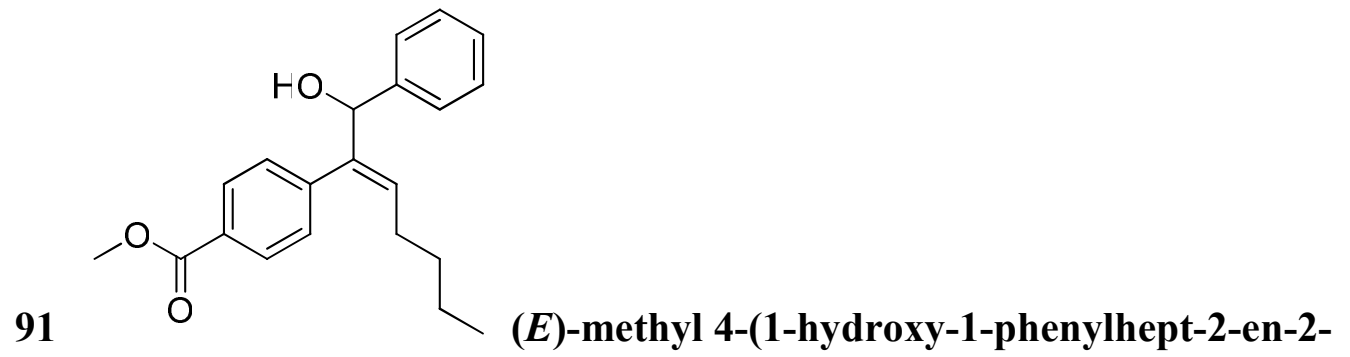

yl)benzoate

$81 \%$ yield, $97 \%$ ee. Method D was used. H NMR $\left(300 \mathrm{MHz}, \mathrm{CDCl}_{3}\right) \delta 7.89(\mathrm{~m}, 2 \mathrm{H})$, $7.24(\mathrm{~m}, 5 \mathrm{H}), 7.00(\mathrm{~m}, 2 \mathrm{H}), 5.92(\mathrm{t}, J=7.5 \mathrm{~Hz}, 1 \mathrm{H}), 5.44(\mathrm{~d}, J=2.9 \mathrm{~Hz}, 1 \mathrm{H}), 3.88(\mathrm{~s}$, 3H), 2.05 (br-s, 1H), 1.90 (m, 2H), 1.35 (m, 2H), $1.24(\mathrm{~m}, 2 \mathrm{H}), 0.82$ (t, $J=7.3 \mathrm{~Hz}, 3 \mathrm{H})$. ${ }^{13} \mathrm{C}$ NMR (75 $\left.\mathrm{MHz} \mathrm{CDCl}_{3}\right) \delta 167.0,143.1,142.1,141.7,130.0,129.5,129.1,128.5$, $128.2,127.5,126.5,78.3,52.0,31.7,28.2,22.2,13.8 . \quad[\alpha]_{\mathrm{D}}^{25}=-20.0(\mathrm{c}=0.41, \mathrm{THF}) 97 \%$ ee . HPLC: chiralcel OD column; solvent ratio: 98:2 hexanes:isopropanol, flow rate: 1 $\mathrm{mL} / \mathrm{min} . t_{\text {minor }}=25.0 \mathrm{~min}, t_{\text {major }}=29.6 \mathrm{~min} .(254 \mathrm{~nm})$ HRMS calcd. for $\mathrm{C}_{21} \mathrm{H}_{24} \mathrm{O}_{3} \mathrm{Na}: 347.1623[\mathrm{M}+\mathrm{Na}]^{+}$. Found: 347.1622 . 


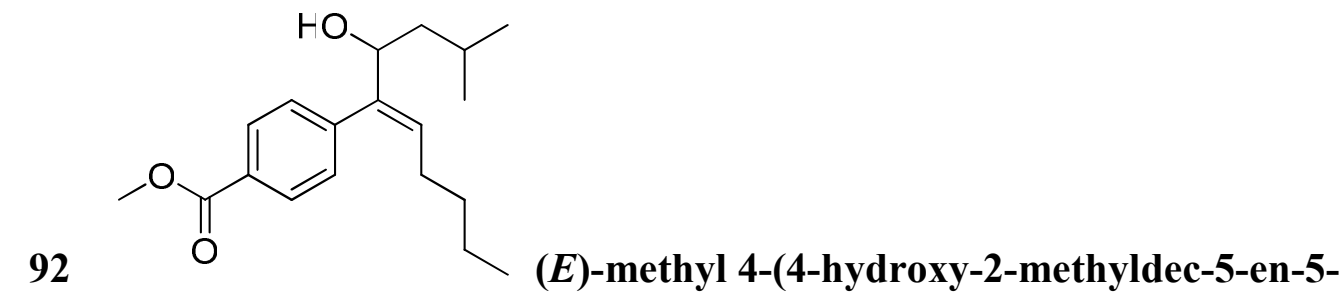

\section{yl)benzoate}

74\% yield, $96 \%$ ee. Method D was used. ${ }^{1} \mathrm{H}$ NMR $\left(300 \mathrm{MHz}, \mathrm{CDCl}_{3}\right) \delta 8.00(\mathrm{~d}, J=8.5$ $\mathrm{Hz}, 1 \mathrm{H}), 7.23(\mathrm{~d}, J=8.4 \mathrm{~Hz}, 1 \mathrm{H}), 5.73(\mathrm{t}, J=7.4 \mathrm{~Hz}, 1 \mathrm{H}), 4.36(\mathrm{~m}, 1 \mathrm{H}), 3.90(\mathrm{~s}, 3 \mathrm{H})$, $1.86(\mathrm{~m}, 2 \mathrm{H}), 1.76(\mathrm{br}-\mathrm{s}, 1 \mathrm{H}), 1.70(\mathrm{~m}, 1 \mathrm{H}), 1.29(\mathrm{~m}, 3 \mathrm{H}), 1.20(\mathrm{~m}, 3 \mathrm{H}), 0.85$ (d, J=6.6 $\mathrm{Hz}, 3 \mathrm{H}), 0.83(\mathrm{~d}, J=6.6 \mathrm{~Hz}, 3 \mathrm{H}), 0.79(\mathrm{t}, J=7.2 \mathrm{~Hz}, 3 \mathrm{H}) .{ }^{13} \mathrm{C} \mathrm{NMR}\left(75 \mathrm{MHz} \mathrm{CDCl}_{3}\right) \delta$ 167.0, 143.6, 143.0, 129.6, 129.3, 129.2, 128.5, 74.8, 52.0, 44.8, 31.7, 28.1, 24.6, 23.0, 22.1, 22.0, 13.8. $[\alpha]_{\mathrm{D}}{ }^{25}=-3.69(\mathrm{c}=0.355, \mathrm{THF}) 96 \%$ ee. HPLC: chiralcel OD column; solvent ratio: $98: 2$ hexanes:isopropanol, flow rate: $0.5 \mathrm{~mL} / \mathrm{min} . t_{\text {minor }}=17.1 \mathrm{~min}, t_{\text {major }}=$ 19.9 min. (232 nm) HRMS calcd. for $\mathrm{C}_{19} \mathrm{H}_{28} \mathrm{O}_{3} \mathrm{Na}: 327.1936[\mathrm{M}+\mathrm{Na}]^{+}$. Found: 327.1941.

\section{Preparation of vinyl iodide, VI-14}

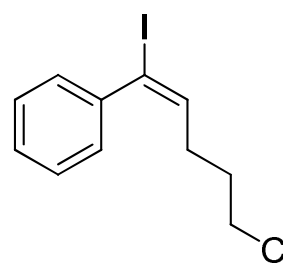

(E)-(5-chloro-1-iodopent-1enyl)benzene $e^{34,35}$

Iodobenzene was coupled with 5-chloro-1-pentyne.

The title vinyl iodide was prepared as described in the previous preparation (for vinyl iodide used in Entries 12-13). (77\% yield; over 2 steps) and distilled as described for vinyl iodide used in Entries 7-9 (5 mmHg, 145-160 ${ }^{\circ} \mathrm{C}$; vapor $\left.95^{\circ} \mathrm{C}\right) .{ }^{1} \mathrm{H} \mathrm{NMR}(300$ $\left.\mathrm{MHz}, \mathrm{CDCl}_{3}\right) \delta 7.30(\mathrm{~m}, 5 \mathrm{H}), 6.45(\mathrm{t}, J=7.6 \mathrm{~Hz}, 1 \mathrm{H}), 3.47(\mathrm{t}, J=6.6 \mathrm{~Hz}, 2 \mathrm{H}), 2.15(\mathrm{~m}$, 
2H), $1.83(\mathrm{~m}, 2 \mathrm{H}) .{ }^{13} \mathrm{C} \mathrm{NMR}\left(75 \mathrm{MHz}, \mathrm{CDCl}_{3}\right) \delta 141.3,141.2,128.4,128.1,128.0,96.1$, 43.8, 31.7, 29.2. HRMS calcd. for $\mathrm{C}_{11} \mathrm{H}_{12} \mathrm{ICl}: 305.9672\left(\mathrm{M}^{+}\right)$. Found: 305.9666.

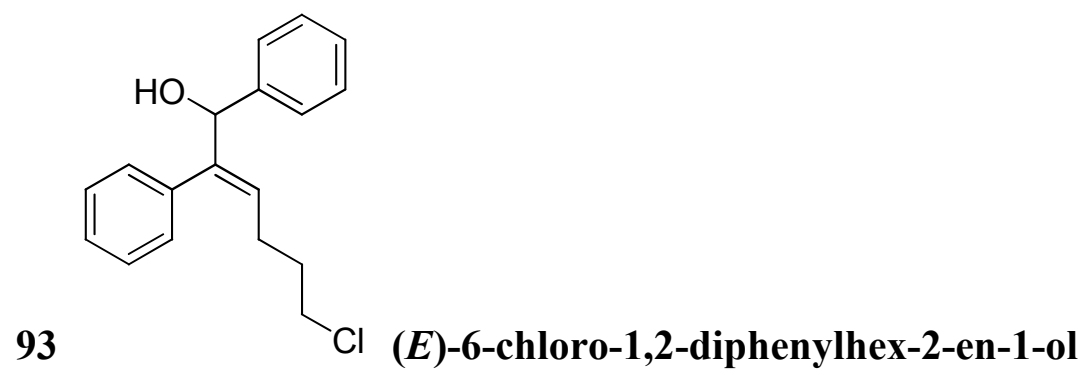

$86 \%$ yield, $98 \%$ ee. Method D was used. ${ }^{1} \mathrm{H}$ NMR $\left(300 \mathrm{MHz}, \mathrm{CDCl}_{3}\right) \delta 7.27(\mathrm{~m}, 8 \mathrm{H})$, $6.91(\mathrm{~m}, 2 \mathrm{H}), 5.85$ (t, $J=7.3 \mathrm{~Hz}, 1 \mathrm{H}), 5.41(\mathrm{~s}, 1 \mathrm{H}), 3.45$ (t, $J=6.7 \mathrm{~Hz}, 2 \mathrm{H}), 2.13$ (br-s, 1H), $2.08(\mathrm{~m}, 2 \mathrm{H}), 1.83(\mathrm{~m}, 2 \mathrm{H}) .{ }^{13} \mathrm{C} \mathrm{NMR}\left(75 \mathrm{MHz} \mathrm{CDCl}_{3}\right) \delta 144.3,141.8,137.5$, $129.2,128.1,127.9,127.4,127.0,126.7,126.5,78.2,44.3,32.5,25.9 .[\alpha]_{\mathrm{D}}^{25}=-26.1$ (c $=0.56$, THF) $98 \%$ ee . HPLC: chiralcel OD column; solvent ratio: $95: 5$ hexanes:isopropanol, flow rate: $1 \mathrm{~mL} / \mathrm{min} . t_{\text {minor }}=11.5 \mathrm{~min}, t_{\text {major }}=15.5 \mathrm{~min} .(254 \mathrm{~nm})$ HRMS calcd. for $\mathrm{C}_{18} \mathrm{H}_{19} \mathrm{ONaCl}$ : $309.1022[\mathrm{M}+\mathrm{Na}]^{+}$. Found: 309.1022 .

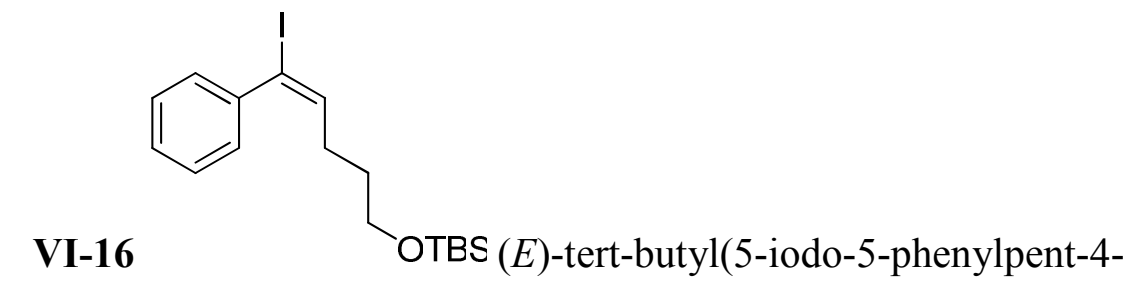

enyloxy)dimethylsilane $e^{34,35}$

5-phenyl-4-pentyn-1-ol was TBS protected as described in following substrate $(95 \%$ yield).

The title vinyl iodide was prepared as described for vinyl iodide used in Entries 12-13 (73\% yield; over 2 steps) and distilled as described for the vinyl iodide used in Entries 7$9\left(5 \mathrm{mmHg}, 190-200{ }^{\circ} \mathrm{C}\right.$; vapor $\left.100-120{ }^{\circ} \mathrm{C}\right) .{ }^{1} \mathrm{H}$ NMR $\left(300 \mathrm{MHz}, \mathrm{CDCl}_{3}\right) \delta 7.28(\mathrm{~m}$, $5 \mathrm{H}), 6.50(\mathrm{t}, J=7.7 \mathrm{~Hz}, 1 \mathrm{H}), 3.55(\mathrm{t}, J=6.3 \mathrm{~Hz}, 2 \mathrm{H}), 2.06(\mathrm{~m}, 2 \mathrm{H}), 1.57(\mathrm{~m}, 2 \mathrm{H}), 0.84$ 
(s, 9H), $0.00(\mathrm{~s}, 6 \mathrm{H}) .{ }^{13} \mathrm{C} \mathrm{NMR}\left(75 \mathrm{MHz}, \mathrm{CDCl}_{3}\right) \delta 143.0,141.6,128.6,128.0,127.9$, 94.9, 62.1, 32.2, 28.7, 25.8, 18.2, 5.3. HRMS calcd. for $\mathrm{C}_{17} \mathrm{H}_{27} \mathrm{IOSi}: 402.0876\left(\mathrm{M}^{+}\right)$; calcd. for $\mathrm{C}_{13} \mathrm{H}_{18} \mathrm{IOSi}$ : $345.0166\left[\mathrm{M}-\mathrm{C}_{4} \mathrm{H}_{9}\right]^{+}$. Found: 345.0172 .

94

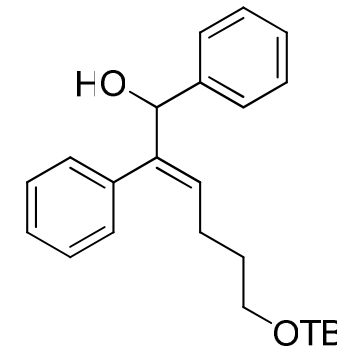

(E)-6-(tert-butyldimethylsilyloxy)-1,2-diphenylhex-2-en-1-

ol

84\% yield, 94\% ee. Method D was used. ${ }^{1} \mathrm{H}$ NMR $\left(300 \mathrm{MHz}, \mathrm{CDCl}_{3}\right) \delta 7.24(\mathrm{~m}, 8 \mathrm{H})$, $6.92(\mathrm{~m}, 2 \mathrm{H}), 5.87(\mathrm{t}, J=7.4 \mathrm{~Hz}, 1 \mathrm{H}), 5.43(\mathrm{~d}, J=4.1 \mathrm{~Hz}, 1 \mathrm{H}), 3.54(\mathrm{t}, J=6.6 \mathrm{~Hz}, 2 \mathrm{H})$, $2.07(\mathrm{~d}, J=4.3 \mathrm{~Hz}, 1 \mathrm{H}), 1.99(\mathrm{~m}, 2 \mathrm{H}), 1.58(\mathrm{~m}, 2 \mathrm{H}), 0.85(\mathrm{~s}, 9 \mathrm{H}), 0.00(\mathrm{~s}, 6 \mathrm{H}) .{ }^{13} \mathrm{C}$ $\operatorname{NMR}\left(75 \mathrm{MHz} \mathrm{CDCl}_{3}\right) \delta 143.2,142.1,137.7,129.2,128.6,128.0,127.8,127.3,126.8$, $126.5,78.4,62.6,32.9,25.9,24.9,18.2,-5.3 .[\alpha]_{\mathrm{D}}{ }^{25}=-17.0$ (c=0.525, THF) $94 \%$ ee . HPLC: chiralcel OD column; solvent ratio: 95:5 hexanes:isopropanol, flow rate: 1 $\mathrm{mL} / \mathrm{min} . t_{\text {minor }}=7.0$ min, $t_{\text {major }}=9.0 \mathrm{~min} .(254 \mathrm{~nm}) \mathrm{HRMS}$ calcd. for $\mathrm{C}_{24} \mathrm{H}_{34} \mathrm{O}_{2} \mathrm{NaSi}$ : 405.2226 [M+Na $]^{+}$. Found: 405.2226.

VI-15 3-phenyl-2-propyn-1-ol (3-phenyl propargylic alcohol) (23 mmoL, $3.04 \mathrm{~g}, 1.0 \mathrm{eq})$ was dissolved in DMF ( $45 \mathrm{~mL}$; dried over $4 \AA$ MS under nitrogen for $16 \mathrm{hrs}$ ) and was cooled to $0{ }^{\circ} \mathrm{C}$. Imidazole $(27.6 \mathrm{mmoL}, 4.16 \mathrm{~g}, 1.2$ equiv) was added portion wise and stirred for an additional $5 \mathrm{~min}$. Next, TBSCl was added to the reaction, warmed to room temperature and stirred for an additional $1 \mathrm{~h}$ before reaction was complete as shown by 
TLC. Water and dilute $\mathrm{HCl}(1.2 \mathrm{M})$ were added to the reaction, followed by $\mathrm{Et}_{2} \mathrm{O}(3 \mathrm{x}$ $100 \mathrm{~mL})$ extraction. The combined organics were then washed with water $(2 \mathrm{x} 30 \mathrm{~mL})$, dried with $\mathrm{MgSO}_{4}$, filtered, concentrated and purified over silica gel chromatography (hexanes:ethyl acetate; 1 to $3 \%$ ethyl acetate) to give the protected alkyne in $97 \%$ yield. The title vinyl iodide was prepared as described for the vinyl iodide used in Entries 12-13 (70\% yield; over 2 steps) and distilled as described in for the vinyl iodide used in Entries 7-9 (5 mmHg, $135-160{ }^{\circ} \mathrm{C}$; vapor $\left.\sim 70{ }^{\circ} \mathrm{C}\right) .{ }^{1} \mathrm{H} \mathrm{NMR}\left(300 \mathrm{MHz}, \mathrm{CDCl}_{3}\right) \delta 7.29(\mathrm{~m}, 5 \mathrm{H})$, $6.62(\mathrm{t}, J=6.7 \mathrm{~Hz}, 1 \mathrm{H}), 4.01(\mathrm{~d}, J=6.7 \mathrm{~Hz}, 2 \mathrm{H}), 0.85(\mathrm{~s}, 9 \mathrm{H}),-0.02(\mathrm{~s}, 6 \mathrm{H}) .{ }^{13} \mathrm{C} \mathrm{NMR}$ $\left(75 \mathrm{MHz}, \mathrm{CDCl}_{3}\right) \delta 142.2,141.0,128.5,128.4,128.0,97.6,61.7,25.8,18.2,5.2$. HRMS calcd. for $\mathrm{C}_{15} \mathrm{H}_{23} \mathrm{IOSi}$ : $374.0563\left(\mathrm{M}^{+}\right)$; calcd. for $\mathrm{C}_{11} \mathrm{H}_{14} \mathrm{IOSi}$ : $316.9867\left[\mathrm{M}-\mathrm{C}_{4} \mathrm{H}_{9}\right]^{+}$. Found: 316.9859 .

95<smiles>OCCOCCCCCCOC/C=C/C(O)c1ccccc1</smiles>

\section{(E)-4-(tert-butyldimethylsilyloxy)-1,2-diphenylbut-2-en-1-ol}

$72 \%$ yield, 98\% ee. Method D was used. ${ }^{1} \mathrm{H}$ NMR $\left(300 \mathrm{MHz}, \mathrm{CDCl}_{3}\right) \delta 7.28(\mathrm{~m}, 8 \mathrm{H})$, $6.96(\mathrm{~m}, 2 \mathrm{H}), 6.05(\mathrm{t}, J=6.3 \mathrm{~Hz}, 1 \mathrm{H}), 5.49(\mathrm{~s}, 1 \mathrm{H}), 4.12(\mathrm{~m}, 2 \mathrm{H}), 2.13(\mathrm{br}-\mathrm{s}, 1 \mathrm{H}), 0.89$ (s, 9H), $0.02(\mathrm{~s}, 6 \mathrm{H}) .{ }^{13} \mathrm{C}$ NMR $\left(75 \mathrm{MHz} \mathrm{CDCl}_{3}\right) \delta 141.5,137.0,129.0,128.2,128.1,127.9$, $127.5,127.3,126.7,77.9,60.6,25.9,18.2,-5.1 .[\alpha]_{\mathrm{D}}{ }^{25}=-28.1(\mathrm{c}=0.585, \mathrm{THF}) 98 \%$ ee . HPLC: chiralcel OD column; solvent ratio: 99:1 hexanes:isopropanol, flow rate: 0.5 $\mathrm{mL} / \mathrm{min} . t_{\text {minor }}=27.1 \mathrm{~min}, t_{\text {major }}=29.4 \mathrm{~min} .(254 \mathrm{~nm})$ HRMS calcd. for $\mathrm{C}_{22} \mathrm{H}_{30} \mathrm{O}_{2} \mathrm{NaSi}$ : $377.1913[\mathrm{M}+\mathrm{Na}]^{+}$. Found: 377.1908.

\section{General Procedures for the Preparation of the racemic alcohols:}


Method E. Typically, the racemic alcohols were prepared side by side with the asymmetric reactions for direct comparison of the background reaction. To conserve the vinyl iodide, the racemic reaction would sometimes be scaled down but the ratios of the substrates and the concentrations were maintained.

The background reaction was observed to vary widely among the vinylzinc species prepared. When it was extremely sluggish and only trace amounts of racemic alcohols were afforded, other methods were attempted.

Method F ${ }^{36}$ For the vinyl iodide used in Entries 17-21, the vinyl iodide was dissolved in THF and cooled to $-78{ }^{\circ} \mathrm{C}$. $n$-Butyllithium in hexanes ( 0.95 equiv) was added dropwise and stirred for 30-60 min. An aldehyde was introduced and the reaction was allowed to warm to room temperature. After the reaction produced good amounts of the alcohols as shown by TLC, it was quenched either within $2 \mathrm{~h}$ or after overnight. Application of this method to prepare the racemic alcohols from the vinyl iodide used in Entries 3-6 failed. In those experiments, it was found that the $(Z)$-isomer of the alcohol products were isolated-sometimes as a mixture and sometimes as the pure $(Z)$-isomer. We expect that after lithium-halogen exchange, the vinyllithium species could isomerize (at least partially) as reported in the literature especially at warmer temperatures. This was not observed in the halogen—zinc exchange.

Method G. The racemic alcohol for Entry 13, Table 1 was particularly difficult to prepare. There was no background reaction for the reaction of the vinyl iodide with the aldehyde in the presence of $\mathrm{ZnEt}_{2}$ without the chiral ligand. When the $n$-butyllithium method (Method F) was attempted at $-78^{\circ} \mathrm{C}$, the starting material reacted to form an 
inseparable and very complicated mixture as shown by TLC and NMR. This was observed even under dilute conditions and shorter reaction times. Instead we attempted to convert the vinylstannane (in THF) directly to the vinyllithium and study the reaction with the aldehyde. (see Scheme below). This method proved successful. After the vinylstannane (Int-VS; intermediate vinylstannane) was formed from the reaction of $\mathrm{Bu}_{3} \mathrm{SnH}$ with methyl 4-(hex-1-ynyl)benzoate (the alkyne from Sonogoshira coupled product between 1-hexyne and methyl-4-iodobenzoate; see references and scheme below for details) catalyzed by $\mathrm{Pd}\left(\mathrm{PPh}_{3}\right)_{4}$ in THF at room temperature for $1 \mathrm{~h}$, the reaction mixture was cooled to $-78{ }^{\circ} \mathrm{C}$. $n$-Butyllithium in hexanes ( 0.95 equiv) was added slowly and the mixture was stirred for 15 min (forming Int-OrgLi; intermediate organolithium). Isovaleraldehyde was then added and the mixture was stirred at $-78{ }^{\circ} \mathrm{C}$. After $1 \mathrm{~h}$, the reaction afforded the racemic alcohol.

Scheme: Method G, one pot reaction from alkyne to rac-alcohol 92.
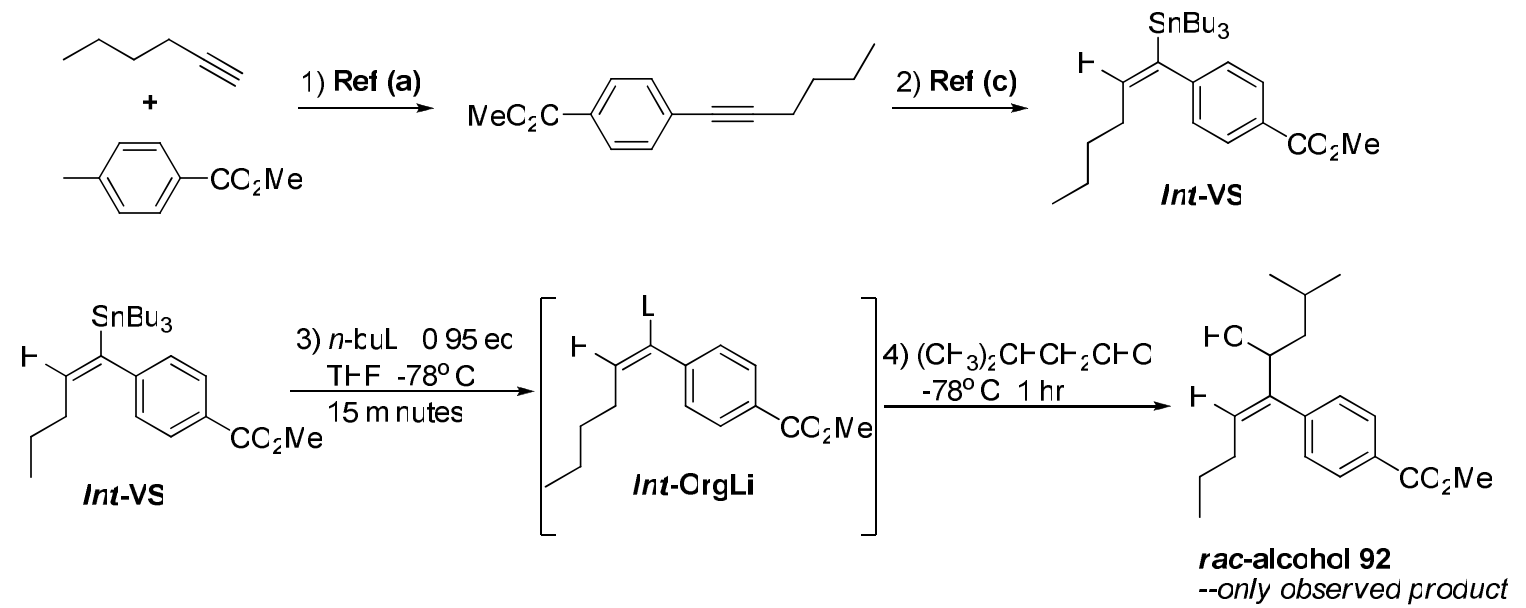

\section{Absolute Configuration Determination}

a. According to the published procedures, the alcohol $(0.054 \mathrm{mmoL}, 20 \mathrm{mg}, 1$ equiv.) was dissolved in DCM (2 mL). DCC (0.108 mmoL, $22 \mathrm{mg}, 2$ equiv), (+)- or (-)-MPA 
(0.108 mmoL, $18 \mathrm{mg}, 2$ equiv) and DMAP (0.108 mmoL, $13 \mathrm{mg}, 2$ equiv) were then added sequentially. The reaction was complete after $45 \mathrm{~min}$ as shown by TLC. The reaction was flashed through a short silica gel column eluted with $10 \%$ ethyl acetate in hexanes and the ester products were analyzed by NMR. The ${ }^{1} \mathrm{H}$ NMR analysis of the $(R)$ - and (S)-MPA esters (spectra below) provides the following stereochemical assignment: The chiral allylic alcohol produced in the presence of $(S)-\mathbf{1}$ has a $R$ configuration.

b. Analysis. The following ${ }^{1} \mathrm{H}$ NMR signals (reported in ppm; $300 \mathrm{MHz}$ ) shifted significantly upfield in the (R)-MPA ester (relative to both the starting chiral allylic alcohol and the $(S)$-MPA ester): (a) The aromatic signal at $\delta 6.92-6.95$ (the two ortho${ }^{1} \mathrm{H}$ of the starting vinyl iodide phenyl group) shifts to $6.72-6.75(\mathrm{~m}, 2 \mathrm{H})$; the signal in the $(S)$-MPA ester is at $\delta 6.91-6.96(\mathrm{~m}, 3 \mathrm{H}$. (note: this range includes an additional hydrogen). (b) The vinyl ${ }^{1} \mathrm{H}$ signal in the alcohol product resonates at $\delta 5.87(\mathrm{t}, 1 \mathrm{H})$. This signal shifts to $\delta 5.37(\mathrm{t}, 1 \mathrm{H})$ in the $(R)$-MPA ester and to $\delta 5.70(\mathrm{t}, 1 \mathrm{H})$ in the $(S)$ MPA ester. This signal is the most significant indication for the absolute configuration of the product. (c) The ${ }^{1} \mathrm{H}$ signal corresponding to the terminal methylene carbon (connected to the-OTBS group) is at $\square 3.54(\mathrm{t}, 2 \mathrm{H})$ in the alcohol. This signal shifts to $\delta$ $3.39(\mathrm{~m}, 2 \mathrm{H})$ ( note: the signal is hidden within the methoxy signal from the MPA) at $\delta$ $3.37(\mathrm{~s}, 3 \mathrm{H})$. The signal is at $\square 3.47(\mathrm{t}, 2 \mathrm{H})$ in the $(S)$-MPA ester. (d) In the aliphatic region, the other two methylene groups appear at $\delta 1.99(\mathrm{~m}, 2 \mathrm{H})$ and $1.59(\mathrm{~m}, 2 \mathrm{H})$ in the alcohol. The signals for these groups in the $(R)$-MPA ester appear at $\delta 1.77(\mathrm{~m}, 2 \mathrm{H})$ and $1.32(\mathrm{~m}, 2 \mathrm{H})$; in the $(S)$-MPA ester, they appear at $\delta 1.92(\mathrm{~m}, 2 \mathrm{H})$ and $1.48(\mathrm{~m}, 2 \mathrm{H})$. In the determination of the absolute configuration by the MPA derivatization protocol, the 
groups from the alcohol that are on the same side of the phenyl group of MPA as shown in the above scheme shift upfield. Therefore, the alcohol with the $R$ configuration matches the ${ }^{1} \mathrm{H}$ NMR data collected.

\section{g. Preparation and Characterization of Vinyl Iodides that Failed in Screened}

\section{Alkylzinc_-Vinyl Iodide Exchange Conditions}

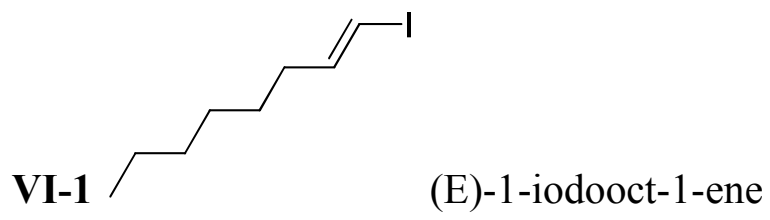

Prepared by reduction of 1-octyne with 1.0 M DIBAL-H solution in hexanes (1.0 equivalent) in DCM at room temperature for 16 hours. After this time, a solution of iodine (1.2 equivalents) in THF was slowly added. Upon completion, the dark red solution was cooled to $0{ }^{\circ} \mathrm{C}$ and quenched by the slow addition of water, followed by dilute $\mathrm{HCl}(0.1 \mathrm{~N} \mathrm{HCl})$. After normal workup (see other vinyl iodides), 55\% yield of the vinyl iodide was recovered pure by distillation $\left(\sim 90^{\circ} \mathrm{C}, 5 \mathrm{mmHg}\right.$; oil bath $\left.\sim 120^{\circ} \mathrm{C}\right)$. ${ }^{1} \mathrm{H}$ NMR $\left(300 \mathrm{MHz}, \mathrm{CDCl}_{3}\right) \delta 6.51(\mathrm{dt}, J=14.3,7.2 \mathrm{~Hz}, 1 \mathrm{H}), 5.96(\mathrm{dt}, J=14.3,1.3 \mathrm{~Hz}$, 1H), $2.04(\mathrm{~m}, 2 \mathrm{H}), 1.32(\mathrm{~m}, 8 \mathrm{H}), 0.87(\mathrm{t}, J=6.7 \mathrm{~Hz}, 3 \mathrm{H})$.

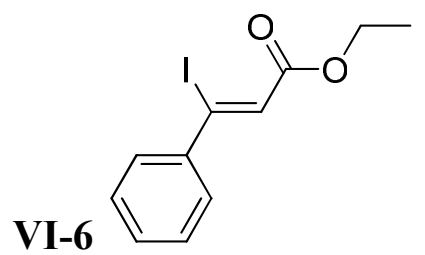

(Z)-ethyl 3-iodo-3-phenylacrylate

The title compound was formed by the following reaction scheme. A solution of phenylacetylene (19.6 mmoL) in THF was cooled to $-78^{\circ} \mathrm{C}$ and $n$-butyllithium $(1.05$ equiv) was added slowly. Upon completing the addition, the solution was stirred one hour, brought to room temperature and stirred 15 minutes. It was then cooled to $0{ }^{\circ} \mathrm{C}$ and 
ethylchloroformate (1.2 equiv) was added dropwise. The reaction was complete within 4 hours and was quenched by the slow addition of water. Extraction in DCM and flash silica chromatography afforded 50\% ethyl 3-phenylpropiolate. Ethyl 3-phenylpropiolate was then refluxed with sodium iodide (4 equiv) in acetic acid (16 equiv; glacial) for 4 hours. The resultant yellowish-brown mixture was extracted in DCM and washed about 5 times with water. After flash chromatography, the vinyl iodide was distilled pure (95$\left.100{ }^{\circ} \mathrm{C}, 5 \mathrm{mmHg}\right)$.

${ }^{1} \mathrm{H}$ NMR $\left(300 \mathrm{MHz}, \mathrm{CDCl}_{3}\right) \delta 7.53(\mathrm{~m}, 2 \mathrm{H}), 7.35(\mathrm{~m}, 3 \mathrm{H}), 6.63(\mathrm{~s}, 1 \mathrm{H}), 4.28(\mathrm{q}, J=7.1$ $\mathrm{Hz}, 2 \mathrm{H}), 1.34(\mathrm{t}, J=7.1 \mathrm{~Hz}, 3 \mathrm{H}) .{ }^{13} \mathrm{C} \mathrm{NMR}\left(75 \mathrm{MHz}, \mathrm{CDCl}_{3}\right) \delta 133.1,130.8,128.7$, $119.8,117.7,62.3,14.3$.

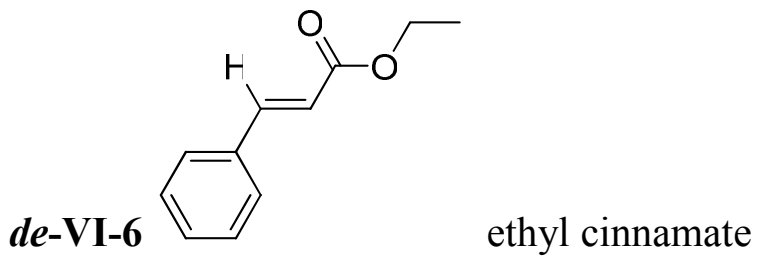

${ }^{1} \mathrm{H}$ NMR $\left(300 \mathrm{MHz}, \mathrm{CDCl}_{3}\right) \delta 7.69(\mathrm{~d}, J=16.0 \mathrm{~Hz}, 1 \mathrm{H}), 7.52(\mathrm{~m}, 2 \mathrm{H}), 7.38(\mathrm{~m}, 3 \mathrm{H})$, $6.44(\mathrm{~d}, J=16.0 \mathrm{~Hz}, 1 \mathrm{H}), 4.27$ (q, $J=7.1 \mathrm{~Hz}, 2 \mathrm{H}), 1.34$ (t, $J=7.1 \mathrm{~Hz}, 3 \mathrm{H})$. 


\section{References:}

1. (a) Soai, K.; Niwa, S. Chem. Rev. 1992, 92, 833. (b) Pu, L.; Yu, H. Chem. Rev. 2001, $101,757-824$.

2. A review on the asymmetric Grignard reagent and organolithium additions to carbonyls: (a) Luderer, M. R.; Bailey, W. F.; Luderer, M. R.; Fair, J. D.; Dancer, R. J.; Sommer, M. -B. Tetrahedron: Asymmetry 2009, 20, 981-998. (b) Roberts, J. T. In Handbook of Grignard Reagents; Silvermn, G. S.; Rakita, P. E., Eds.; Marcel Dekker: New York, 1996; pp 557-565.

3. Topics in Organometallic Chemistry: Organolithiums in Enantioselective Synthesis; Goldfuss, B. Hodgson, D. M., Eds.; Springer, 2003; pp 21-36. (b) Weber, B.; Seebach, D. Angew. Chem., Int. Ed. Engl. 1992, 31, 84-86. (c) Muramatsu, Y.; Harada, T. Angew. Chem., Int. Ed. 2008, 47, 1088-1090. (d) Da, C.-S.; Wang, J.-R.; Yin, X.-G.; Fan, X.-Y.; Liu, Y.; Yu, S.-L. Org. Lett. 2009, 11, 5578-5581. (e) Goldfuss, B. Synthesis 2005, 14, 2271-2280.

4. (a) Brückner, R. In Comprehensive Organic Synthesis; Trost, B. M., Ed.; Pergamon: New York, 1991; Vol. 6, Chapter 4.6, pp 873-908. (b) Hill, R. K. In Comprehensive Organic Synthesis; Trost, B. M., Ed.; Pergamon: New York, 1991; Vol. 5, Chapter 7.1, pp 785-826. (c) Wipf, P. In Comprehensive Organic Synthesis; Trost, B. M., Ed.; Pergamon: New York, 1991; Vol. 5, Chapter 7.1, pp 827-873. (d) Hoyveda, A. H.; Evans, D. A.; Fu, G. C. Chem. Rev., 1993, 93, 1307-1370.

5. (a) Barchi, J. J., Jr.; Moore, R. E.; Patterson, G. M. L. J. Am. Chem. Soc., 1984, 106, 8193-8197. (b) Bollag, D. M.; McQueney, P. A.; Zhu, J.; Hensens, O.; Koupal, L.; Liesch, J.; Goetz, M.; Lazarides, E.; Woods, C. M. Cancer Res., 1995, 55, 2325- 
2333. (c) Oka, M.; Iimura, S.; Tenmyo, O.; Sawada, Y.; Sugawara, M.; Ohkusa, N.; Yamamoto, H.; Kawano, K.; Hu, S.-L.; Fukagawa, Y.; Oki, T. J. Antibiot., 1993, 46, $367-373$.

6. (a) Wipf, P.; Ribe, S. J. Org. Chem. 1998, 63, 6454-6455. (b) Wipf, P.; Nunes, R. L. Tetrahedron 2004, 60, 1269-1279. (a) Wipf, P.; Xu, W. Tetrahedron Lett. 1994, 35, 5197-5200. (b) Wipf, P.; Ribe, S. J. Org. Chem. 1998, 63, 6454-6455. (c) Wipf, P.; Jayasuriya, N.; Ribe, S. Chirality 2003, 15, 208-212. For reviews on catalytic asymmetric vinylation of aldehydes, see: (d) Wipf, P.; Kendall, C. Chem.--Eur. J., 2002, $8,1778-1784$.

7. (a) Oppolzer, W.; Radinov, R. N. Helv. Chim. Acta 1992, 75, 170-173. (b) Chen, Y. K.; Lurain, A. E.; Walsh, P. J. J. Am. Chem. Soc. 2002, 124, 12225-12231. (c) Oppolzer, W.; Radinov, R. N. Tetrahedron Lett. 1988, 29, 5645-5648. (c) Oppolzer, W.; Radinov, R. N. J. Am. Chem. Soc. 1993, 115, 1593-1594. (d) Oppolzer, W.; Radinov, R. N.; El-Sayed, E. J. Org. Chem. 2001, 66, 4766-4770.

8. For an extension of Wipf's procedure, see: (a) Li, H.; Walsh, P. J. J. Am. Chem. Soc., 2005, 127, 8355-8361.

9. For extensions of Oppolzer's procedures, see: (a) Dahmen, S.; Bräse, S. Org. Lett., 2001, 3, 4119-4122. (b) Chen, Y. K.; Lurain, A. E.; Walsh, P. J. J. Am. Chem. Soc. 2002, 124, 12225-12231. (c) Lurain, A. E.; Walsh, P. J. J. Am. Chem. Soc. 2003, 125, 10677-10683. (d) Ji, J.-X.; Qiu, L.-Q.; Yip, C. W.; Chan, A. S. C. J. Org. Chem., 2003, 68, 1589-1590. (e) Ko, D.-H.; Kang, S.-W.; Kim, K.-H.; Chung, Y.; Ha, D.-C. Bull. Korean. Chem. Soc., 2004, 25, 35-36. (f) Sprout, C. M.; Richmond, M. L.; Seto, C. T. J. Org. Chem., 2004, 69, 6666-6673. (g) Chen, Y. K.; Walsh, P. J. 
J. Am. Chem. Soc, , 2004, 126, 3702-3703. (h) Jeon, S.-J.; Chen, Y. K.; Walsh, P. J. Org. Lett., 2005, 7, 1729-1732. (i) Sprout, C. M.; Richmond, M. L.; Seto, C. T. J. Org. Chem., 2005, 70, 7408-7417. (j) Kim, H.-Y.; Lurain, A. E.; Garcia-Garcia, P. ; Carroll, P. J. ; Walsh, P. J. J. Am. Chem. Soc., 2005, 127, 13138-13139. (j) Lauterwasser, F.; Gall, J.; Höfener, S.; Bräse, S. Adv. Synth. Catal., 2006, 348, 20682074. (1) Salvi, L.; Jeon, S.-J.; Fisher, E. L.; Carroll, P. J.; Walsh, P. J. J. Am. Chem. Soc., 2007, 129, 16119-16125. (k) Wu, H.-L.; Wu, P.-Y.; Uang, B.-J. J. Org. Chem., 2007, 72, 5935-5937.

10. Schmit, F.; Rudolph, J.; Bolm, C. Synthesis 2006, 3625-3630.

11. Chai, Z.; Liu, X.-Y.; Zhang, J.-K.; Zhao, G. Tetrahedron: Asymmetry 2007, 18, 724728.

12. A vinylzinc was prepared for the asymmetric addition to aldehydes by treating a vinyl halide with Li followed by $\mathrm{ZnBr}_{2}$ : (a) Shibata, T.; Nakatsui, K.; Soai, K. Inorg. Chim. Acta 1999, 296, 33-36. Knochel et. al. have described the generation of vinylzinc halides from zinc dust and a vinyl halide, but report the lack of reactivity with aldehydes and from transmetallation with copper in the presence of boron trifluride: (b) Knochel, P.; Rao, C. J. Tetrahedron 1993, 49, 29-48.

13. For regio- and stereoselective Ni-catalyzed reductive couplings of alkynes and aldehydes: (a) Huang, W.-S.; Chan, J.; Jamison, T. F. Org. Lett., 2000, 2, 4221-4223. For enantioselective reductive couplings of alkynes and aldehydes: (b) Miller, K. M.; Huang, W.-S.; Jamison, T. F. J. Am. Chem. Soc., 2003, 125, 3442-3443. (c) Colby, E. A.; Jamison, T. F. J. Org. Chem., 2003, 68, 156-166. (d) Van Dyke, A. R.; Miller, K. M.; Jamison, T. F. Org. Synth., 2007, 84, 111-119. (e) Yang, Y.; Zhu, S.-F.; 
Zhou, Q.-L. J. Am. Chem. Soc., 2008, 130, 14052-14053. For regio- and stereoselective Ru-catalyzed reductive couplings of alkynes, aldehydes and alcohols, see: (f) Patman, R. L.; Chaulagain, M.-R.; Williams, V. M.; Krische, M. J. J. Am. Chem. Soc., 2009, 131, 2066-2067. For a review of this subject, see: (g) Skucas, E.; Ngai, M.-Y.; Komanduri, V.; Krische, M. J. Acc. Chem. Res., 2007, 40, 1394-1401.

14. For the description of a titanium-alkyne complex asymmetric reaction with carbonyls, see: Takayanagi, Y.; Yamashita, K.; Yoshida, Y.; Sato, F. Chem. Commun., 1996, $1725-1726$.

15. For an example of asymmetric vinylaluminum additions to ketones, see: (a) Biradar, D.-B.; Gau, H.-M. Org. Lett., 2009, 11, 499-502.

16. For an example of asymmetric vinylation from vinylsilanes, see: Aikawa, K.; Hioki, Y.; Mikami, K. J. Am. Chem. Soc., 2009, 131, 13922-13923.

17. (a) Kneisel, F. F.; Dochnahl, M.; Knochel, P. Angew. Chem. Int. Ed. 2004, 43, 10171021. (b) Note: This protocol has not previously been applied to vinyl halides.

18. (a) DeBerardinis, A. M.; Turlington, M.; Ko, J.; Sole, L.; Pu, L. J. Org. Chem. 2010, 75, 2836-2850. (b) DeBerardinis, A. M.; Turlington, M.; Pu, L. Org. Lett., 2008, 10, 2709-2712. (c) DeBerardinis, A. M.; Turlington, M.; Pu, L. Org. Synth., 2010, 87, 68-76.

19. (a) Kamiya, N.; Chikami, Y.; Ishii, Y. Synlett., 1990, 11, 675. (b) Cesati III, R. R.; Dwyer, G.; Jones, R. C.; Hayes, M. P.; Yalamanchili, P. ; Casebier, D. S. Org. Lett., 2007, 9 (26), 5617-5620.

20. (a) Al-Hassan, M. I., Syn. Commun., 1986, 16 (3), 353-356. (b) Al-Hassan, M. I., Syn. Commun., 1987, 17 (15), 1787-1796. 
21. Gao, Y.; Harada, K.; Hata, T.; Urabe, H.; Sato, F. J. Org. Chem., 1995, 60, 290-291.

22. DeBerardinis, A. M.; Turlington, M.; Pu, L. Angew. Chem. Int. Ed., 2011, paper accepted.

23. (a) Bolm, C.; Hermanns, N.; Hilderbrand, J. P.; Muñiz, K. Angew. Chem. Int. Ed. 2000, 39, 3465-3467. (b) Schmidt, F.; Rudolph, J.; Bolm, C. Adv. Synth. Catal. 2007, 349, 703-708.

24. (a) Salvi, L.; Kim, J. G.; Walsh, P. J. J. Am. Chem. Soc. 2009, 131, 12483-12493.

(b) Kim, J. G.; Walsh, P. J. Angew. Chem. Int. Ed. 2006, 45, 4175-4178.

25. (a) Trost, B. M.; Belletire, J. L.; Goldleski, P. G.; McDougal, P. G.; Balkovec, J. M.; Baldwin, J. J.; Christy, M.; Ponticello, G.S.; Varga, S. L.; Springer, J. P. J. Org. Chem. 1986, 51, 2370. (b) Seco, J.; Quinoa, E.; Riguera, R. Chem. Rev. 2004, 104, $17-117$.

26. For the preparation of chiral $\alpha$-hydroxy ketones from chiral allylic alcohols, see Jamison et. al. in reference 9d. For the preparation of chiral acyl-protected acyloins from chiral allylic alcohols, see: Bogár, K.; Hoyos Vidal, P.; Alcántara León, A. R. ; Bäckvall, J.-E. Org. Lett., 2007, 9, 3401-3404.

27. Seebach, D.; Beck, A. K.; Heckel, A. Angew. Chem. Int. Ed. 2001, 40, 92-138.

28. Muramatsu, Y.; Harada, T. Angew. Chem., Int. Ed. 2008, 47, 1088-1090.

29. Roesch, K. R.; Larock, R. C. J. Org. Chem., 2001, 66 (2), 412-420

30. (a) Smith, N. D.; Mancuso, J.; Lautens, M. Chem. Rev., 2000, 100, 3257-3282. (b) Xu, G.; Loftus, T. L. ; Wargo, H. ; Turpin, J. A.; Buckheit, R. W.; Cushman, M. J. Org. Chem., 2001, 66 (18), 5958-5964. 
31. (a) Bailey, W. F.; Ovaska, T. V. J. Org. Chem. 1993, 115, 3080-3090. (b) Hunter, D. H.; Cram, D. J. J. Am. Chem. Soc., 1964, 86, 5478. (c) Miller, S. I.; Lee, W. G. J. Am. Chem. Soc., 1959, 81, 6313. (d) Curtin, D. Y.; Crump, J. W., J. Am. Chem. Soc., 1958, 80, 1922. (e) Drieding, A. S.; Pratt, R. J. J. Am. Chem. Soc., 1954, 76, 1902. (f) Braude, E. A.; Coles, J. A. J. Am. Chem. Soc., 1951, 73, 2078). 


\section{Chapter 5: Alkynylation of Carbonyls}

a. Introduction: Asymmetric Alkynylations and Organocatalysis

b. Studies on the Organocatalytic Methodology for Alkyne Additions to Aldehydes

c. Further Development of Catalytic Asymmetric Alkynylation of Aldehydes

d. Attempted Acetylene Additions using Calcium Carbide as Substrate

e. Experimental and Characterization

f. References

\section{a. Introduction}

Considerable research efforts were dedicated towards the development of an organocatalytic, asymmetric methodology for the functional alkyne addition to aldehydes. Recent progress in the $\mathrm{Pu}$ research group and reports in the literature ${ }^{1}$ led us to explore organocatalytic conditions. The progression towards metal-free asymmetric alkyne reactivity represents a significant advancement in the alkyne addition to carbonyls. $^{2}$ The advantages center on bypassing the requisite use of metals and metalbased reagents to generate nucleophilic alkynyl-species. Such methods would provide valuable, high-throughput asymmetric methodology to pharmaceutical development as well as providing versatility and simplicity in synthetic research. Our strategy was to employ existing asymmetric ligands as organocatalysts and screen or design novel catalysts to identify conditions that could direct the metal-free asymmetric alkyne additions to aldehydes. 
Terminal alkyne additions to aldehydes generate propargylic alcohols.

Propargylic alcohols have been recognized extensively as versatile functional precursors to complex organic molecules, in particular, natural products and pharmaceutical agents ${ }^{3}$ such as 5'-substituted tetronic acids, derivatives of which possess an array of valuable biological acitivites ${ }^{4}$. To date, asymmetric alkyne additions have been accomplished using stoichiometric and catalytic metallic-based reagents. The two general schemes employed in the asymmetric synthesis operate by either a direct route (one single step from starting materials) or an indirect route (three steps from starting materials). These two synthetic preparations are shown in the scheme below. ${ }^{5}$

\section{Scheme 5.1 Methods for the Asymmetric Synthesis of Functional Propargylic}

\section{Alcohols}

Route A:

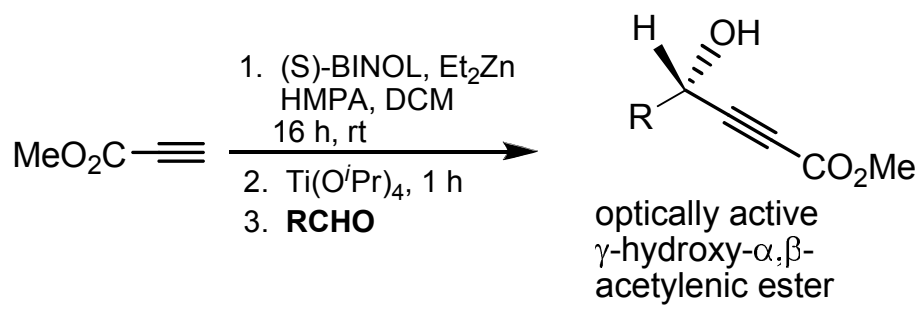

Route B:

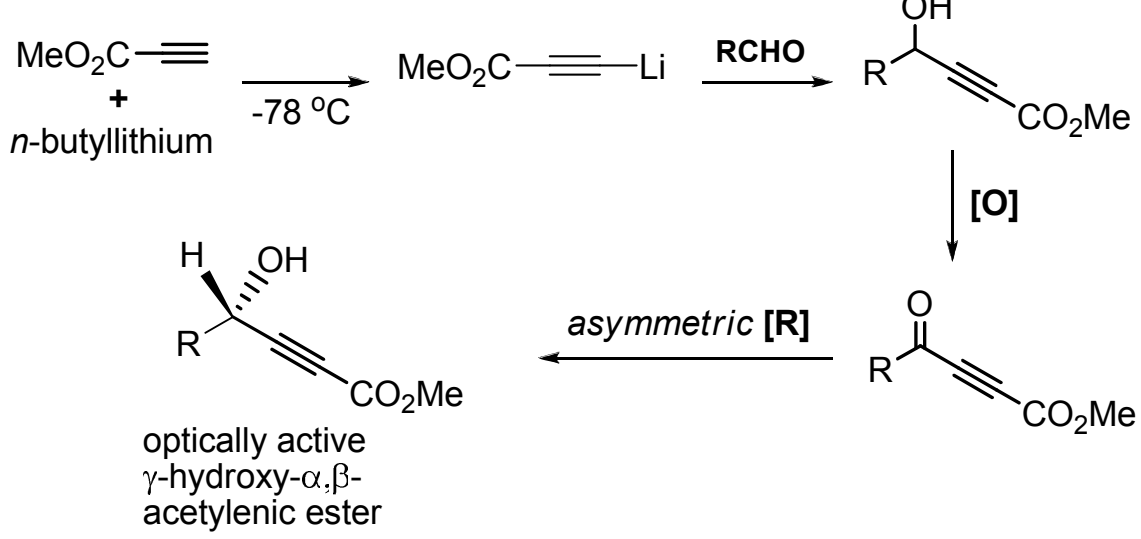


Route A illustrates the more efficient route to optically active propargylic alcohols. The procedure generates an active alkynyl nucleophile — as a metal acetylideand in the presence of chiral reagents, the addition to aldehydes can generate optically active alcohols. Numerous reports describe the general preparation of optically active propargyl alcohols. ${ }^{5}$ Optimal reaction conditions reported for this reactivity show practical limitations in the scope of reagents used, excess of reagents required, or the use of multiple metallic reagents. The potential synthetic applications of catalytic asymmetric systems are constrained by these factors. For example, "total" synthetic schemes, industrial-based chemical and pharmaceutical development mandates the efficient use of materials, which includes the cost of materials, atom economy, and also the configuration of the purification processes. Therefore, we set forth to identify catalytic asymmetric methodology for the generation of enantioenriched alcohols.

\section{b. Studies on the Organocatalytic Methodology for Alkyne Additions to Aldehydes}

The stimulus for designing such methodology is the production of pharmaceutical agents or optically pure chiral starting materials, which serve as templates upstream of the active drugs and other biologically active molecules. Because of the efficacious vs. deleterious relationship that can exist between enantiomers of a given drug, the optically pure preparation of these compounds is of great utility. Additionally, the inherent reaction system of organocatalysis represents the advantageous feature of bypassing the use of metals. In accordance with regulatory stipulations requiring low levels of metals, specialized separation techniques are employed in order to afford extremely pure compounds. Among the limited synthetic protocol that address cost-effective design by enhancing atom economy and also provide an environmentally conscious solution 
towards decreasing requisite purification and diminishing waste production, multicomponent domino processes have been identified ${ }^{1 \mathrm{a}, \mathrm{b} ; 6}$. An example is shown in the figure below. Illustrated are subsequent reactions occurring in one pot that lead to molecular complexity. ${ }^{7}$

\section{Figure 5.1 Example of a "Domino-Process" or Cascade Reaction}

Negishi et. al. "Deferred Carbonylative Esterification in the Pd-Catalyzed Cyclic

\section{Carbometalation-Carbonylation Cascade”}
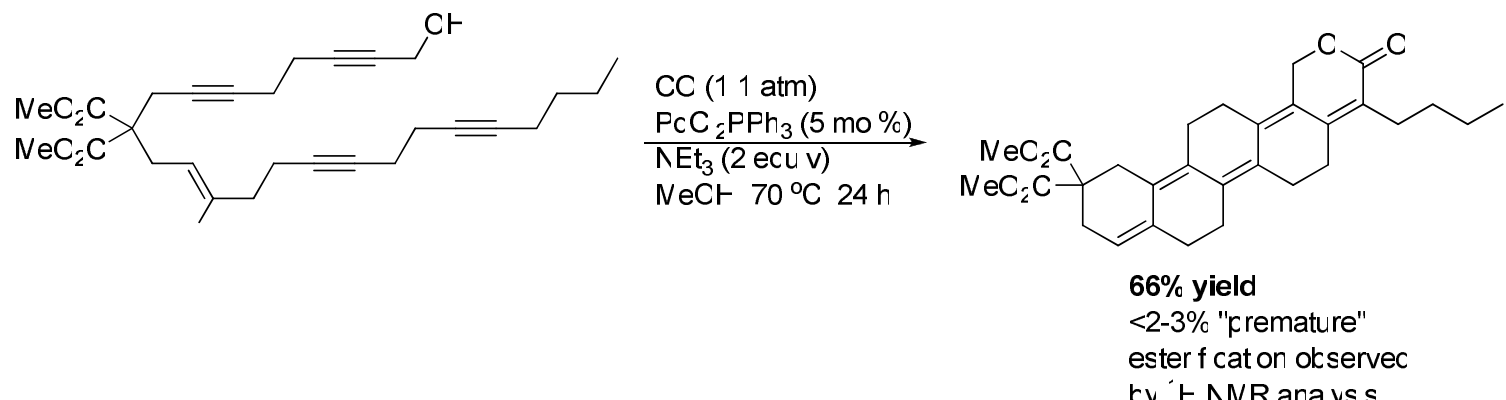

A number of chiral ligands have been identified as precursors to asymmetric acetylide additions to electrophilic species, including oxazoborolidines ${ }^{8}$, amino alcohols $^{5,9}$, pyridyl alcohols ${ }^{5}$, alkaloids ${ }^{5}$, and 1,1'-bi-2-naphthol (BINOL)-based systems. ${ }^{5}$ BINOL-derived systems have been the subject of much research. The Pu lab has studied the application of BINOL-based catalytic systems for various asymmetric reactions. BINOL is an axially chiral molecule that displays $\mathrm{C}_{2}$-symmetry perpendicular to the biaryl bond. Enantiomerically pure BINOL is inexpensive and can be obtained from a number of commercial sources. BINOL is stable to racemization at temperatures approaching $100^{\circ} \mathrm{C}$, and derivatives of BINOL, such as the readily prepared partially hydrogenated $\mathrm{H}_{8} \mathrm{BINOL}$, at still higher temperatures. Furthermore, derivatives of BINOL can be prepared with relative ease in good yield. ${ }^{10}$ This has been exemplified by 
the large number of BINOL-based applications appearing within the multifunctional catalytic approach. $^{11}$

The nucleophilic alkynyl species are prepared in situ and allowed to react in various organic solvents with aldehydes displaying a high degree of enantioselectivity in the presence of chiral ligands and metal species. Alkylzincs are readily available and have been shown to tolerate functionality on the alkyne, in generation of the acetylide, and aldehyde substrates to form propargylic alcohols. Systems describing the phenylacetylene additions to aldehydes based upon BINOL and derivatives were developed concomitantly by $\mathrm{Chan}$ and $\mathrm{Pu}^{5}$. The extensive progress of the BINOL-based catalytic asymmetric systems has been reported ${ }^{5}$. Further development of this reactivity demonstrated that using certain additives ${ }^{12}$ expanded the scope of the reactivity. Gao and $\mathrm{Pu}$ have shown the addition of HMPA to the initial solution of the reaction generated the acetylide at room temperature and subsequently affords propargylic alcohols in excellent enantioselectivity. The mild conditions accommodate functionality on the terminal alkyne substrate. The asymmetric addition of methyl propiolate to linear and aliphatic, aromatic, and $\alpha, \beta$-unsaturated aldehydes was successful. Further reactivity of these compounds has been studied. ${ }^{4,13}$ However, these systems all require the use of an additional metal reagent, i.e. titanium tetraisopropoxide, to achieve high enantioselectivities.

$\mathrm{Li}$ and $\mathrm{Pu}$ reported the preparation and asymmetric catalysis of BINOL-Salen ligands. ${ }^{1 \mathrm{~d}, 14}$ The multiple Lewis basic sites proved to be beneficial in asymmetric catalysis. Li discovered that this ligand catalyzed alkyne additions to aromatic aldehydes in the absence of additional Lewis acids to achieve high enantioselectivity (see Scheme 
5.2). The multifunctional approach allowed the elimination of the requisite use of the titanium additive while exhibiting excellent enantioselective control.

\section{Scheme 5.2 General Enantioselective Alkynylations Catalyzed by BINOL-Salen}

\section{Ligands}
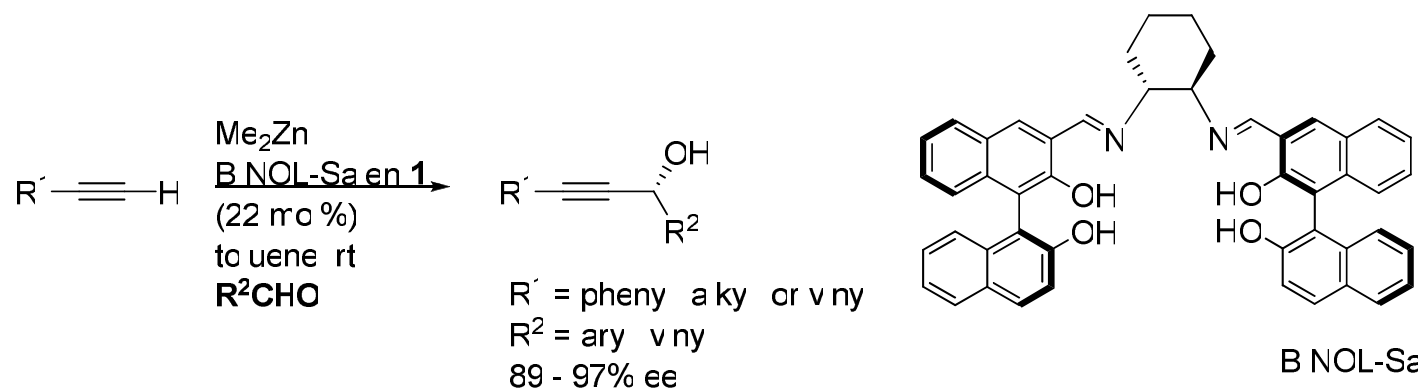

B NOL-Sa en 1
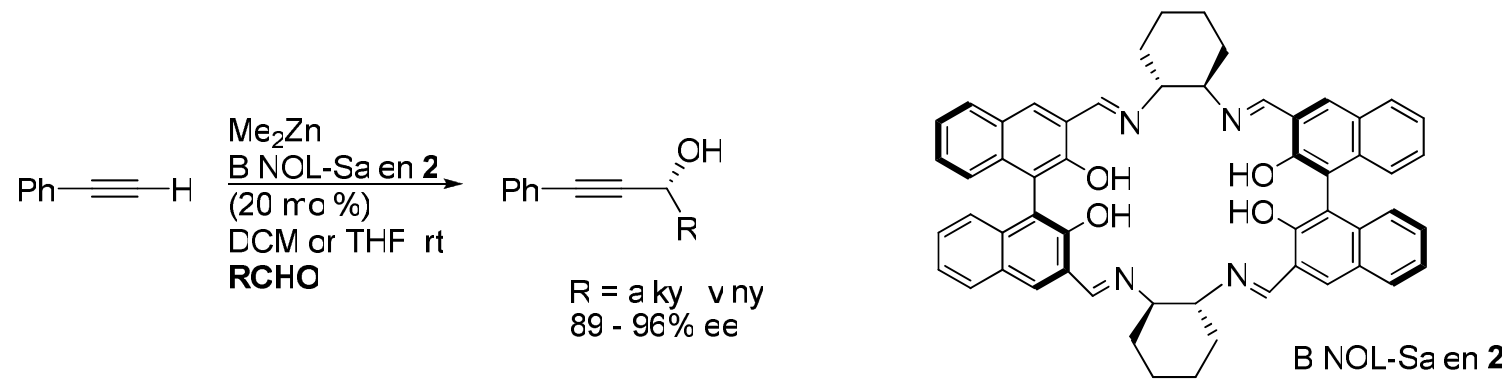

The Morita-Baylis-Hillman $(\mathrm{MBH})$ reaction has been identified as an efficient

pathway towards the generation of diverse and complex molecular frameworks. ${ }^{1 \mathrm{a}, \mathrm{b}, 7,18}$ It was recently found that $\mathrm{Et}_{3} \mathrm{~N}$ can catalyze the reaction of methyl propiolate with aldehydes to generate the corresponding propargylic vinyl ethers. A proposed mechanism of this process is shown in Scheme 5.3. This process indicates that the concept of metal-free, catalytic potential of BINOL derivatives for asymmetric alkyne additions to electrophiles was plausible. We have therefore undertaken the development of the organocatalytic asymmetric methodology for the alkyne addition to aldehydes. 


\section{Scheme 5.3 Proposed Mechanism for Synthesis of Enol-protected Propargylic}

Alcohol (EPPA).

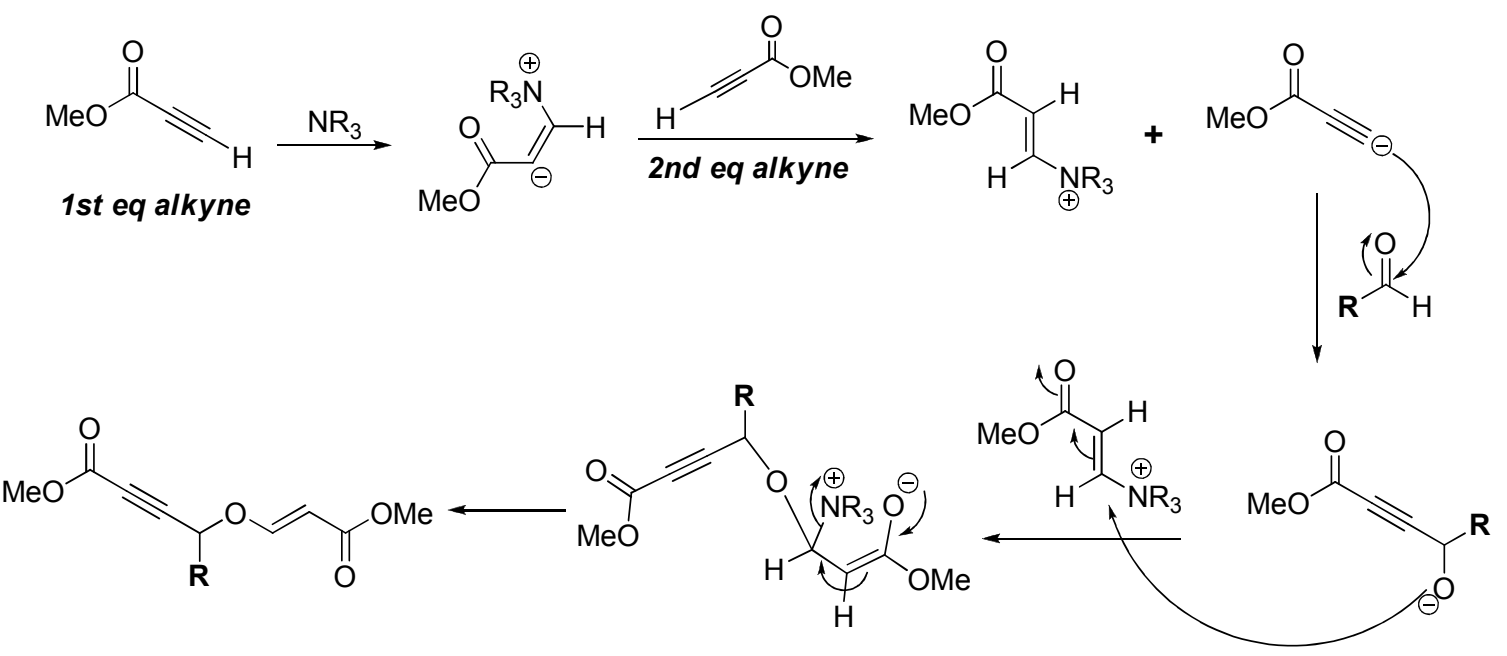

The overall equation for the $\mathrm{Et}_{3} \mathrm{~N}$-catalyzed alkyne addition is given below which involves two equivalents of alkyne and one equivalent of aldehyde.

$$
\underline{2} \mathrm{MeO}_{2} \mathrm{CC} \equiv \mathrm{C}-\mathrm{H}+1 \mathrm{RCHO} \underset{\text { solvent }}{\stackrel{\mathrm{NEt}_{3}}{\longrightarrow}} \quad 1 \text { EPPA }
$$

The fine-tuning of conditions was described, such as varying the solvent or nucleophile used, for the divergent synthesis of functional compounds from the same substrates in good yields. For example, enol-protected propargyl alcohols, 1,3-dioxolanes, and tetronic acids could be produced. It was found that the formation of enol-protected propargylic alcohols proceeds at $0{ }^{\circ} \mathrm{C}$ between 1.7 equiv of the propiolate and 1.0 equiv aldehyde, whereas 1,3-dioxolanes and tetronic acids were afforded in good yields when the equivalents are reversed ( 2 equiv aldehyde to 1 equiv methyl propiolate) and the temperature proceeds at $-78^{\circ} \mathrm{C}$. (The tetronic acids are generated after stirring mixture with concentrated $\mathrm{HCl}$ at $60^{\circ} \mathrm{C}$ ). The extension of this synthetic strategy to the general preparation of enantioenriched functional compounds would show tremendous potential for the expedient formation of chiral combinatorial libraries. Such high-throughput 
strategies available for the metal-free, organocatalytic asymmetric generation of medicinal compounds could serve an important role at the interface of chemistry and biology. ${ }^{16}$

Substoichiometric amounts of triethylamine were recently shown to generate the reactive (deprotonated) terminal alkyne from propiolates. As shown in Scheme 5.3, triethylamine was proposed to activate a molecule of the alkyne by a conjugate, nucleophilic addition to the alkynoate (i.e. methyl propiolate). This reactive species could deprotonate another alkyne molecule, affording the nucleophilic acetylide which can subsequently react with an electrophilic species (i.e. aldehyde). The major product formed was reportedly dependent upon the substrate stoichiometry and reaction temperature. Few successful asymmetric versions of Morita-Baylis-Hillman (MBH) and aza-MBH reactivity have been reported. Catalytic asymmetric systems employing chiral binaphthyls (e.g., BINOLs AND BINAPs) have shown some success in achieving asymmetry for traditional Morita-Baylis-Hillman reactivity and aza-MBH reactivity. As no description exists for catalytic asymmetric additions of conjugated alkyne species to aldehydes, ${ }^{17}$ we explored this reactivity. The number of asymmetric Morita-BaylisHillman reactions is limited in scope, focusing on the traditional activated alkenes and aldehydes or aldimines.

The reactivity of amino alcohol ligands prepared (see Chapter 2) and commercially available reagents or the application of several commercially available chiral reagents was examined. The bifunctional nature of such catalysts could plausibly lead to defined, selective transition states. In particular, the hydrogen bonding acceptor- 
donor abilities of the hydroxyl and amino functions could generate biased activationrecognition sites for the electrophilic substrates.

\section{Organocatalytic Alkyne Attempts:}

Amino alcohols $(S-\mathbf{2}, S-\mathbf{4}, S-\mathbf{7}, S-\mathbf{1 2})$ were studied for their catalytic ability in the alkynoate reaction. Disappointingly, no reaction was observed. Upon addition of triethylamine to these reaction mixtures, the reaction proceeded at room temperature only to afford the racemic enol-protected propargylic alcohol products along with side products. No selectivity was observed when reactions were done in the presence of the amino alcohol and triethylamine at $0{ }^{\circ} \mathrm{C}$.

$(1 R, 2 S)-N$-methylephedrine $(20 \mathrm{~mol} \%)$ was mixed with methyl propiolate $(1.1$ equiv) and isobutyraldehyde (1.0 equiv) in DMSO. After two days, the reaction yielded only a trace amount of propargyl alcohol and racemic enol-protected propargyl alcohol (108). When phenylacetylene was used, no reaction was observed after 6 days at room temperature. $(1 R, 2 S)-N$-methylephedrine (40 mol\%) was mixed with $\mathrm{LiOH}(38 \mathrm{~mol} \%)$ in DMSO. This was followed by the addition of phenylacetylene (1.0 equiv) and then isobutyraldehyde. A trace amount of alcohol (109) was observed on TLC after 6 days at room temperature that was unable to be isolated.

The reactions were attempted in acetonitrile and THF using $50 \mathrm{~mol} \%(1 R, 2 S)-N$ methylephedrine, 2.2 equiv methyl propiolate and 1 equiv isobutyraldehyde in attempts to observe some selectivity. The enol-protected alcohol forms with the starting material being consumed in 3 days at room temperature in both solvents. Unfortunately, no enantioselectivity was observed in either reaction. Again, only trace amounts of propargyl alcohol were detected by TLC. 
A secondary amine was tested in the alkynoate reaction. $30 \mathrm{~mol} \%(1 \mathrm{~S}, 2 \mathrm{~S})-$ pseudoephedrine was screened in DMSO and in DCM. Neither experiment produced reaction after 4 days or when heated. A mono-derived $\mathrm{H}_{8} \mathrm{BINOL}$ ligand, 3 morpholinylmethyl- $\mathrm{H}_{8} \mathrm{BINOL}(30 \mathrm{~mol} \%)$, was used in the same reaction. Experiments were run in DCM with the addition of HMPA (2 equiv) and separately in chloroform. Neither reaction proceeded even after refluxing for 2 days. ( \pm )-BINAM (1,1'binaphthamine) (50 mol\%), a primary diamine, was stirred in a 1:1 mixture of DMSO: THF with phenylacetylene and isobutyraldehyde for one week without the detection of product formation. After heating the mixture for one day, no change was observed. Separate solutions of (-)-cinchonidine (40 mol\%) and (8S, 9R)-(-)-benzylcinchonidium chloride (40 mol\%) were prepared in DMSO. Each ligand solution was added to a prepared solution containing 2.2 equiv. methyl propiolate and 1 equiv. isobutyraldehyde at room temperature. Only trace amounts of the enol-protected propargyl alcohol was observed from the (-)-cinchonidine reaction but the major products were an alkyne-“dimer"1a,b;5,15 (110; shown below) and the vinyl chloride (111). This species is likely formed by the nucleophilic displacement of a molecule of the nitrogenactivated alkyne by the alkynyl-ide generated in situ.

\section{Scheme 5.4 Proposed Propiolate Dimer Formation}




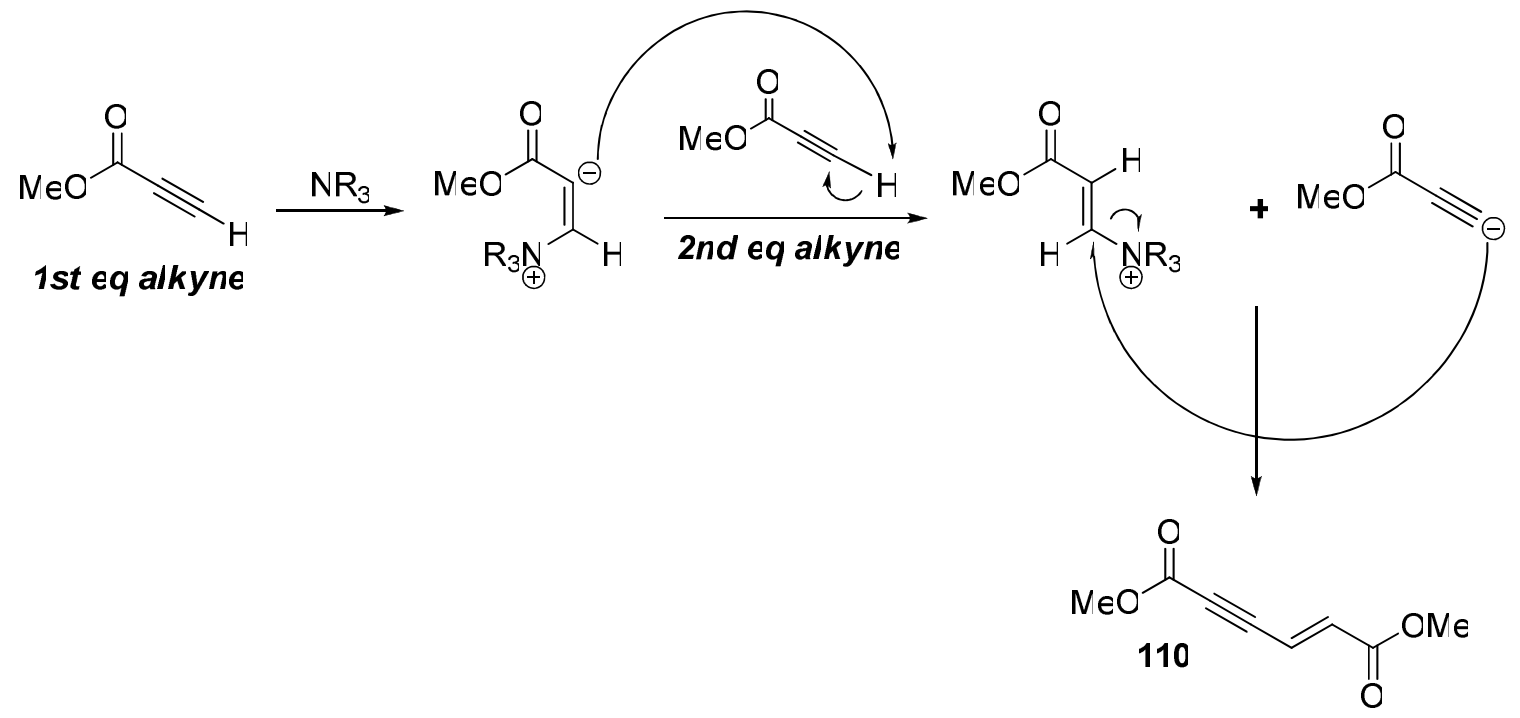

The vinyl chloride species was isolated in a fair yield from the (-)-cinchonidine reaction. A small amount of the enol-protected propargyl alcohol was isolated from the (8S, 9R)-()-benzyl-cinchonidium chloride catalyzed reaction but was racemic. The alkyne "dimer" (propiolate dimer) was the main product. When the equivalents were reversed in the (-)cinchonidine (40 mol\%) reaction (2.2 equivalents aldehyde and 1 equivalent alkyne), no enol-protected alcohol was observed and again only propiolate dimer and aldehyde were present after 3 days at room temperature in DMSO. When the (-)-cinchonidine (40 mol\%) catalysis was attempted in acetonitrile and in DCM at $0{ }^{\circ} \mathrm{C}$, the enol-protected propargyl alcohol was formed in good yields (2.2 equiv alkyne: 1.0 equiv aldehyde). In 5 hours at $0{ }^{\circ} \mathrm{C}$, the reactions were quenched and $48 \%$ of the product was isolated from the acetonitrile reaction and $68 \%$ yield from the DCM reaction. This reaction was repeated in DCM at $0{ }^{\circ} \mathrm{C}$ by mixing the ligand and aldehyde in the solvent and slowly adding the methyl propiolate into the solution. Slow addition of the alkyne was done in an attempt to control the amount available to the premixed combination of "neat" ligand (40 mol\%) 
and aldehyde with no other solvent. The enol-protected product was formed in lower yields from both reactions as the racemate.

When 2 mol\% (-)-cinchonidine was used for the reaction between methyl propiolate and isobutyraldehdye in DCM, only the alkyne dimer was formed. Triton B (benzyltrimethylammonium hydroxide) (10 mol\%; as a $40 \mathrm{~mol} \%$ solution in methanol) was used with $(S)$-BINOL $(10 \mathrm{~mol} \%)$ in the reaction with phenylacetylene (1.0 equiv) and isobutyraldehyde (1.2 equiv). No reaction occurred in DMSO. The same result was obtained when the reaction was attempted using $(S)-\mathrm{H}_{8} \mathrm{BINOL}$, no addition occurred.

$(S)-\mathrm{H}_{8} \mathrm{BINOL}(12 \mathrm{~mol} \%$ ) was dissolved in dry, oxygen-free THF and then the solvent was removed. It was redissolved with Triton B (10 mol\%) in DMSO). Phenylacetylene (1.0 equivalent) and isobutyraldehyde (1.2 equiv) were then added. A small amount of propargyl alcohol (109) was detected on TLC (after 20 days). After purification, it was determined to be racemic.

(1R,2S)-1-methoxy-N,N-dimethyl-1-phenylpropan-2-amine (28; $30 \mathrm{~mol} \%)$ was stirred with 2.5 equiv methyl propiolate and isobutyraldehyde (1 equiv) in a) DCM and b) acetonitrile. In these experiments, the ligand was added to a prepared solution of the alkyne and aldehyde. After 30 hours, $61 \%$ and $86 \%$ of the enol-protected propargyl alcohol 108 was isolated from the reactions in $\mathrm{DCM}$ and $\mathrm{CH}_{3} \mathrm{CN}$, respectively.

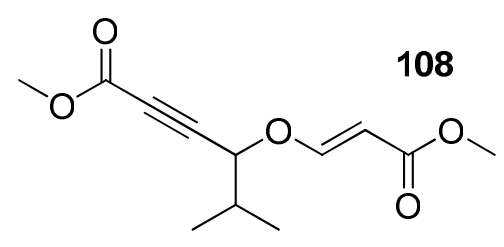

Both compounds were racemic. A white crystalline material was also isolated from the reaction mixture in a low yield. The compound was determined to be the terminal vinyl chloride (by ${ }^{1} \mathrm{H}$ NMR; from methyl propiolate; appeared on TLC below the enol- 
protected propargylic alcohol). The reaction workup included quenching with $1 \mathrm{~N} \mathrm{HCl}$ and the isolation of the vinyl chloride indicates that the complex initially formed by reaction of the tertiary amine and alkyne (forming a stable tetra-substituted amino complex) was still present in the reaction mixture.

This reaction was repeated using different $O$-protected derivatives of $(1 R, 2 S)-N$ methylephedrine but no selectivity was realized. The best yield $(60 \%)$ was obtained from (1R,2S)-N,N-dimethyl-1-phenyl-1-(trimethylsilyloxy)propan-2-amine (32). See table 5.1 for a summary of the ligand study.

Table 5.1 Enol-Protected Propargyl Alcohol 108 Synthesis Catalyzed by $O$ Protected, $N$-methylephedrines. ${ }^{\text {a }}$

Entry


5<smiles>CC([C@H](OC(=O)c1ccccc1)c1ccccc1)N(C)C</smiles><smiles>COC(c1ccccc1)C(C)C</smiles>

60

Reaction conditions: 2.5 equiv alkyne, 1 equiv aldehyde, $30 \mathrm{~mol} \%$ amine ligand. Unless otherwise noted, DCM used as solvent.

b) $\mathrm{CH}_{3} \mathrm{CN}$ used as solvent.

$(1 R, 2 S)-N$-methylephedrine (40 mol\%) was tested in DMSO using 1 equiv methyl propiolate and 1.2 equiv isobutyraldehyde. After 2 days at room temperature, the aldehyde was still present. Another equivalent of alkyne was added. After 24 hours, the enol-protected alcohol was the main compound but a complex mixture was observed. (-)-cinchonidine (40 mol\%) and (S)-3,3'-bis((benzylamino)methyl)-5, 5',6,6', 7, 7', 8, $8^{\prime}-$ octahydro-1,1'-binaphthyl-2,2'-diol (22 mol\%; a secondary amino alcohol) were also screened in the reaction of methyl propiolate and isobutyraldehyde in DMSO. The racemic product was obtained in low yield from (-)-cinchonidine. No reaction was observed using the secondary amino alcohol after 2 days at room temperature. $10 \mathrm{~mol} \%$ of triethylamine was added and the color change that immediately ensued was indication of the product formation. $(\boldsymbol{S})-4(36 \mathrm{~mol} \%)$ was screened in the formation of enolprotected alcohol. The reaction was slow with a small amount of product observed on TLC after 4 days. 
Recently, Tan et. al. had reported the isomerization of 3-alkynoates into chiral allenes (ee's up to $95 \%$ ) induced by the catalytic activity of a bicyclic guanidine. ${ }^{19} \mathrm{~A}$ number of reactions using the guanidine base as a potential organocatalyst in the alkynylation of aldehydes were examined. We were disappointed that the reaction between phenylacetylene (1.8 equivalents) and benzaldehyde failed in all of the cases. $N, N, N, N$-tetramethylguanidine (20 mol\% in acetonitrile or DCM; $80 \mathrm{~mol} \%$ in DMSO (wet)) did not generate any reaction. The reaction with methyl propiolate (1.8 equivalents), $80 \mathrm{~mol} \% \mathrm{~N}, N, N, N$-tetramethylguanidine and benzaldehyde failed in DCM, acetonitrile, or DMSO. Finally, 5 equivalents of $N, N, N, N$-tetramethylguanidine were mixed with phenylacetylene (1 equivalent) in DCM $(10 \mathrm{~mL})$. After benzaldehyde was added, the reaction was monitored by TLC. At 24 hours no reaction was observed. DMSO (5 mL; wet) was added and returned to reflux. The reaction was checked after 12, 24, 48, and 72 hours but no reaction took place.

\section{c. Further Development of Catalytic Asymmetric Alkynylation of Aldehydes}

In summary of our organocatalytic pursuits, all of the ligands screened failed to influence the enantioselectivity of the functional alkyne addition. Historically, MoritaBaylis-Hillman reactivity has suffered from extremely slow rates. Certain NMR tube reactions were monitored over week long periods, without evidence of aldehyde conversion. However, the successful catalysis by a commercially available chiral amino alcohol and its readily prepared derivatives was promising. Depending on the reaction conditions applied, two functional compounds were prepared and isolated in good yields:

1) the alkyne "dimer" and 2) the enol-protected propargylic alcohol. Both compounds 
have rich functionality and have been further studied by other members in Pu's lab. For example, Pu and Zhou have reported recently on the reactivity of this very propiolate dimer. $^{14 \mathrm{e}}$ The formation and isolation of other compounds such as the terminal vinyl chloride and propiolate dimer could be of potential synthetic interest.

The lack of selectivity requires a reconsideration of our research attempts in this area. When considering the proposed mechanism and the reactivity observed, we might revise the design of our organocatalyst to include multiple hydrogen bonding groups or domains. It has been established that a reactive alkynyl- and vinyl anion species are generated under the attempted reaction conditions. Further, it is clear that the presence of a simple alcohol (alkoxide following the assumed deprotonation from species generated above) or multiple phenolic groups (typically two in the case of BINOL ligands) do not display control in nucleophilic addition or electrophilic (carbonyl) activation. The reaction may occur locally to the chiral environment but does not proceed selectively. This can be stated confidently based on our results. A revised approach to ligand design may be taken from nature. Screens employing catalytic nucleobases or small polypeptides should be performed. These substrates contain multiple hydrogen-bonding functions that could potentially control the selectivity of the reaction. If the process showed selectivity, the design and synthesis of novel catalysts should be performed to investigate the optimal catalyst structure and electronics which may be variable depending on substrates, e.g. methyl vs. ethyl propiolate or propiolate vs. propionamide.

The limited success in our exploration for organocatalytic asymmetric alkynylation methods impelled us to revise our approach. We examined the use of alkaline bases to generate the nucleophilic alkynyl-species for the asymmetric alkyne 
addition to aldehydes. The experimental methods screened are described in the next section. Noteworthy to point out from our lengthy pursuit is that since the organocatalytic asymmetric project was ceased, a number of reports employing the bimetallic (alkylzincs and titanium alkoxides) have been published by the $\mathrm{Pu}$ laboratory. ${ }^{14 b, 20,21}$

$(S)$-BINOL and $(S)-\mathrm{H}_{8} \mathrm{BINOL}$ were tested in the asymmetric addition of phenylacetylene and methyl propiolate to aldehydes. The deprotonation of the terminal alkyne was attempted using a variety of bases and conditions. Lithium hydroxide (10 mol\%) was mixed with (S)-BINOL and (S)-H8BINOL (12 mol\%) in DMSO. Phenylacetylene (1.0 equiv) was added to the mixture followed by cyclohexanecarboxaldehyde (1.2 equiv). No reaction was observed in the (S)-BINOL reaction, but $8 \%$ of the propargyl alcohol (112) was isolated from the $(S)-\mathrm{H}_{8} \mathrm{BINOL}$ reaction after 18 hours.

$(S)-\mathrm{H}_{8} \mathrm{BINOL}$ (40 mol\%) was mixed with cesium hydroxide hydrate (38 mol\%) in DMSO followed by phenylacetylene and isobutyraldehyde. After $\sim 2.5$ days, $24 \%$ of the propargyl alcohol was isolated as the racemate. The reaction was also studied using $(S)$ BINOL and cesium hydroxide hydrate using the same conditions. After 4 days, 20\% yield of the alcohol was formed also as the racemate.

(S)-11 (20 mol\%) was mixed with LiOH (20 mol\%) in DMSO. The ligand was not readily soluble in the solvent and after stirring overnight (still insoluble), THF was added (3:1 ratio of DMSO:THF). This dissolved the contents and was followed by the addition of phenylacetylene and isobutyraldehyde. No reaction was observed after monitoring for 30 days. In another study, $(S)$-11 (20 mol\%) was reacted with 
phenylacetylene and isobutyraldehyde in 3:1 DMSO:THF. As expected, no reaction occurred. When $40 \mathrm{~mol} \%$ (-)-cinchonidine was mixed with phenylacetylene and isobutyraldehyde in DMSO, no reaction took place.

(S)-BINOL (50 mol\%) was mixed with $\mathrm{CaCO}_{3}(50 \mathrm{~mol} \%)$ in DMSO. 1 equiv of phenylacetylene and isobutyraldehyde were then added. The same amounts were also studied with $(S)-\mathrm{H}_{8} \mathrm{BINOL}$ and $\mathrm{CaCO}_{3}$. No reaction was observed after 3 days. An excess amount of $\mathrm{CaCO}_{3}$ was added but did not generate reaction. $30 \mathrm{~mol} \%$ each of water and $(S)-\mathrm{H}_{8} \mathrm{BINOL}$ were stirred together, followed by the addition of phenylacetylene and isobutyraldehyye. This attempted "neat" reaction did not yield the alcohol.

(S)-2 (50 mol\%) was converted to the mono-lithiated species at $-78^{\circ} \mathrm{C}$ in $\mathrm{THF}$. Benzaldehyde and methyl propiolate were then added sequentially. No reaction took place even after warming to room temperature. The reaction was attempted using octyl aldehyde but did not occur. No reaction was observed when the mono-lithiated $(1 R, 2 S)$ $N$-methylephedrine (50 mol\%) was used.

Potassium tert-butoxide was used in a number of reactions. In separate experiments, $48 \mathrm{~mol} \%$ of the alkoxide base was dissolved in a 1:1 DMSO:THF solvent with a) $50 \mathrm{~mol} \%(1 R, 2 S)-N$-methylephedrine, b) $50 \mathrm{~mol} \%(S)-\mathrm{H}_{8} \mathrm{BINOL}$, and c) 50 mol\% $(S)$-BINOL. Phenylacetylene (1.0 equiv) was added followed by isobutyraldehyde. The reaction using the ephedrine ligand showed only a trace amount of alcohol on TLC after 3 days even with a significant color change (clear to deeper amber/brown) was observed. The reactions with $(S)-\mathrm{H}_{8} \mathrm{BINOL}$ and $(S)$-BINOL afforded the propargyl alcohol in $44 \%$ and $87 \%$ yield, respectively. Again, we were disappointed 
to find no selectivity. The $(S)-\mathrm{H}_{8} \mathrm{BINOL}(50 \mathrm{~mol} \%)$ and $t$-BuOK (45 mol\%) catalyzed addition of phenylacetylene and isobutyraldehyde were tried in various solvents: a) THF:DMSO (4:1), b) DCM, c) toluene, and d) acetonitrile. Starting material was mainly present after 88 hours at room temperature, but the alcohol was detected in a), c), and d). From the THF:DMSO mixture, $15 \%$ alcohol was isolated. Approximately the same amounts, but impure compounds were afforded from the toluene and acetonitrile reactions. All three showed no selectivity. The reaction in DCM was monitored for 8 days with no indication of product formation.

When $33 \mathrm{~mol} \%$ of $(S)$-3 was stirred with phenylacetylene and isobutyraldehyde in 3:1 DMSO:THF for one week, no reaction occurred. To this solution, $25 \mathrm{~mol} \% t$-BuOK was added and instantly, the solution turned an amber color. The propargyl alcohol was present (via TLC). The mixture was stirred overnight and the alcohol was isolated in $85 \%$ yield. HPLC analysis identified the compound to be racemic.

1 equiv. $(S)-\mathrm{H}_{8} \mathrm{BINOL}$ was mixed with 2 equiv. $t$-BuOK in DMSO (after the ligand was dried in THF. After one hour, phenylacetlyene was added and then isobutyraldehyde. The experiment using 1 equiv. $(S)-\mathrm{H}_{8} \mathrm{BINOL}$ and 1 equiv. $t$-BuOK in DMSO was tested at the same time. The same yields (58 and 56\%) of the alcohol were isolated in racemic form after 22 hours.

The reaction of $t$ - $\mathrm{BuOK}$ ( $40 \mathrm{~mol} \%), 1$ equiv phenylacetylene, and 1.2 equiv. of isobutyraldehyde in DMSO was performed. After 18 hours at room temperature, $63 \%$ of the alcohol was formed. A solvent-free reaction was attempted between phenylacetylene and isobutyraldehyde in the presence of $40 \mathrm{~mol} \%$ each of $(S)-\mathrm{H}_{8} \mathrm{BINOL}$ and $t$-BuOK. The propargyl alcohol was formed but the alkyne was not consumed after 2 days at room 
temp. The alcohol was racemic. The same result was obtained from the reaction done in the presence of $40 \mathrm{~mol} \%(S)-\mathrm{BINOL}$. When the reaction was attempted in other organic solvents (DCM, THF, toluene, diethylether) using $(S)-\mathrm{H}_{8} \mathrm{BINOL}$ and $t$-BuOK, no homogeneous solution could be formed. No reaction occurred over 4 days. (-)cinchonidine and $t$-BuOK were stirred in THF:DMSO (1:5 ratio). Phenylacetylene and isobutyraldehyde were added. From the brown reaction that formed, $86 \%$ yield of the alcohol was isolated with $0 \%$ ee after almost 3 days at room temperature.

A report in 2007 by You et. al. highlighted an improved method for the catalytic asymmetric functional alkynylation of aldehydes. ${ }^{13 \mathrm{~b}}$ The method developed in the $\mathrm{Pu}$ laboratories required the use of 2 equivalents of HMPA, a toxic and potentially carcinogenic compound. ${ }^{13 a}$ The authors' work had centered on searching for a more efficient and less toxic additive for the process to address overall synthetic utility. (However, the yield and ee did not change when 1 equivalent HMPA vs. 2 equivalent HMPA were used in the reported Pu methodology: $88 \%$ yields and $82-83 \%$ ee; the ee was increased by the use of additional reagents, i.e. BINOL, alkyne, alkylzinc, and titanium tetraisopropoxide). The new method used only $5 \mathrm{~mol} \%$ of $N$-methylimidazole in place of the HMPA. It was found that this catalytic additive in combination with $10 \mathrm{~mol} \%$ BINOL and $25 \mathrm{~mol} \%$ titanium tetraisopropoxide was efficient at adding various alkynes to aromatic aldehydes. Also, the amount of alkyne was decreased to 2.4 equiv and $\mathrm{Et}_{2} \mathrm{Zn}$ to 2.0 equiv. (from 4 equiv each in the Pu method). Of particular interest to us were the following points: 1) no additions to aliphatic aldehydes were reported, which at the time still represented a limitation in the asymmetric alkynylation methodology $y^{20}$ and 2) methyl propiolate was reported in this methodology with only 2.1 equiv required to yield $68 \%$ of 
the propargyl alcohol from addition to benzaldehyde. However, this addition was the sole propiolate addition reported. The potential of this and modified versions of this protocol were explored for the alkynylation of carbonyls.

The reaction conditions reported for the methyl propiolate addition to benzaldehyde were slightly modified and studied for the reaction with octyl aldehyde (Scheme 5.5).

\section{Scheme 5.5 General Conditions Tested for the Catalyzed Asymmetric Methyl}

\section{Propiolate Addition to $n$-Octylaldehyde.}

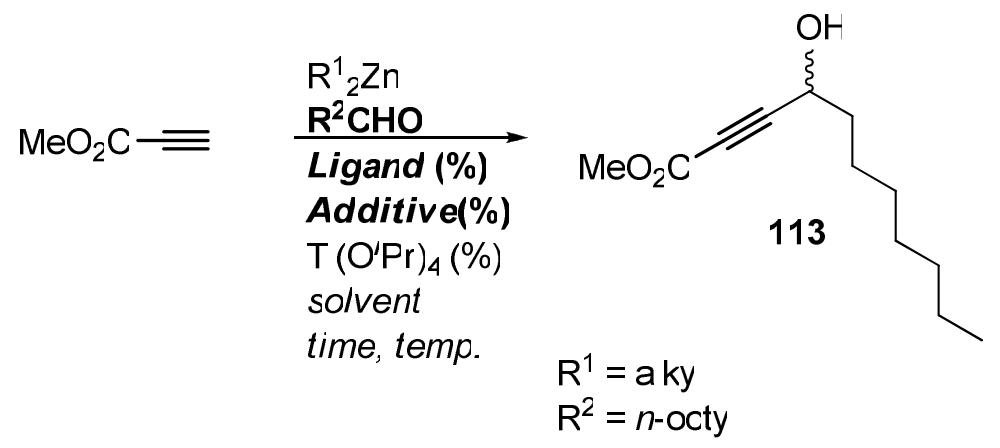

(S)-BINOL (10 mol\%) was dissolved in DCM. $N$-methylimidazole (5 mol\%; NMI), methyl propiolate (2.0 equivalents), and diethylzinc ( 2 equivalents) were then added sequentially at room temperature and stirred for 2 hours. After this time, titanium tetraisopropoxide (25 mol\%) was added and stirred one additional hour. Octyl aldehyde was then added to the reaction. After 16 hours reaction time, $69 \%$ yield of the alcohol was isolated. When the reaction was increased six-fold, close to $50 \%$ of the alcohol was isolated in the same time. However, when the reaction was performed in the absence of chiral ligand complex (no BINOL and no titanium tetraisopropoxide) and on a four-fold increased scale, $81 \%$ of the racemic alcohol was isolated. This reaction formed the alkynylzinc species for 8.5 hours at room temperature compared to the 2 hours used in 
our initial asymmetric experiments and 24 hours reported by You et. al. ${ }^{13 \mathrm{~b}}$ This is a notable racemic preparation of the propargyl alcohol because this represents a dramatic improvement over previously used techniques to prepare these samples. This method was further explored in the Pu laboratory and was reported in the literature. ${ }^{21 \mathrm{~b}}$ Typically, an alkyllithium has been used to generate the alkynyl-ide at low temperatures and then react with the addition of an aldehyde. ${ }^{22}$ This requires the precise addition of the pyrophoric alkyllithium reagent to bypass side reactions encountered such as displacement of the methoxy group (ester cleavage) and excess alkyllithium addition to the aldehyde. (NOTE: $n$-butyllithium was used by the authors of this published method for the preparation of racemic alcohols). The enantioselectivity of the alcohols prepared in the presence of $(S)$-BINOL was $75 \%$. Attempts were made to decrease the amounts of alkyne and alkylzinc required. 1.2 equivalents $\mathrm{Et}_{2} \mathrm{Zn}$ and 1.2 equivalents methyl propiolate were stirred at room temperature with NMI (5 mol\%) and $(S)$-BINOL (10 mol\%) in DCM for 12 hours. At this time, octyl aldehyde was added. After 20 hours a small amount of aldehyde was present. The reaction was quenched and afforded the propargyl alcohol in $69 \%$ yield and $65 \%$ ee. The same result was obtained when 2 equiv of alkyne and $\mathrm{Et}_{2} \mathrm{Zn}$ were used and stirred at room temperature for 2 hours.

The good yields and fair enantioselectivity of the process for the propiolate addition to octyl aldehyde were encouraging. Other base additives were studied to determine if varying the base structure could affect the enantioselectivity of the addition. Only three other bases ( $5 \mathrm{~mol} \%$ ) had been reportedly screened for the phenylacetylene addition to benzaldehyde: imidazole ( $83 \%$ yield, $87 \%$ ee), bisglyoxaline ( $78 \%$ yield, $87 \%$ ee), and benzimidazole ( $71 \%$ yield, $84 \%$ ee). The enantioselectivity in THF ( $79 \%$ 
ee), ether $(60 \%$ ee), or toluene $(76 \%$ ee) had also been decreased relative to the reaction in DCM similar to $\mathrm{Pu}$ et. al. findings for the BINOL-HMPA system.

As seen in Table 5.2, we also observed differences in the enantioselectivity when other base additives were employed in the BINOL-titanium catalyzed propiolate addition to octyl aldehyde.

Table 5.2 Screening of Base Additives for the BINOL-Ti Catalyzed Methyl Propiolate Addition to Octyl Aldehyde. ${ }^{a}$

\begin{tabular}{|c|c|c|}
\hline Entry & Base & ee $(\%)^{b}$ \\
\hline 1 & isoxazole & 76 \\
\hline 2 & thiazole & 73 \\
\hline 3 & 1,4-DMAP & 0 \\
\hline 4 & 1,2-bipyridine & 78 \\
\hline 5 & Thiophene & 80 \\
\hline 6 & $\begin{array}{c}N \text {-methylmorpholine } \\
(\mathrm{NMM})\end{array}$ & 70 \\
\hline 7 & $\begin{array}{c}N \text {-methylpyrrolidinone } \\
\text { (NMP) }\end{array}$ & 78 \\
\hline 8 & 1,2-bipyridine ${ }^{c}$ & 74 \\
\hline 9 & Pyridine & 74 \\
\hline 10 & Pyridine $^{\mathrm{d}}$ & 75 \\
\hline 11 & Pyridine $^{\mathrm{e}}$ & 65 \\
\hline 12 & Pyridine $^{\mathrm{f}}$ & 74 \\
\hline 13 & 2-picoline ${ }^{f}$ & 79 \\
\hline
\end{tabular}




$\begin{array}{ccc}14 & \text { 2,6-lutidine } & \text { f } \\ 15 & 2,6-\text { lutidine }^{\mathrm{g}} & 77 \\ 16^{\mathrm{h}, \mathrm{i}} & 2,6 \text {-lutidine } & 7 \\ 17 & \text { None; }(S)-7 & 25 \\ 18 & \text { None; }(S)-4 & 35\end{array}$

a) The following conditions were used unless otherwise noted. Step 1: 1.2 equiv methyl propiolate, 1.2 equiv $\mathrm{Et}_{2} \mathrm{Zn}, 0.1$ equiv (S)-BINOL, base ( $5 \mathrm{~mol} \%$ ) were stirred $2 \mathrm{~h}$ at room temp in DCM. Step 2: 0.25 equiv $\operatorname{Ti}\left(\mathrm{O}^{i} \operatorname{Pr}\right)_{4}$ were added and stirred $1 \mathrm{~h}$. Step 3: 1 equiv octyl aldehyde is introduced and reaction monitored (12 to $24 \mathrm{~h}$ ).

b) The ee was determined by preparation and NMR analysis of the (R)-Oacetylmandelate ester derivative from the propargyl alcohol.

c) Step 1: 2 equiv alkyne and $\mathrm{Et}_{2} \mathrm{Zn}, 10 \mathrm{~mol} \%$ base used; stirred for $2 \mathrm{~h}$ at room temp. Step 2: 0.5 equiv $\operatorname{Ti}\left(\mathrm{O}^{i} \operatorname{Pr}\right)_{4}$ used. The same yield of alcohol was isolated from this reaction as from Entry $4(\sim 50 \%)$.

d) Step 1: 2 equiv. alkyne, 2 eq $\mathrm{Et}_{2} \mathrm{Zn}$ at room temperature for $24 \mathrm{~h}$.

e) Step 1: 2 equiv. alkyne, 2 eq $\mathrm{Et}_{2} \mathrm{Zn}, 50 \mathrm{~mol} \%$ base at room temperature for $24 \mathrm{~h}$.

f) Step 1: 1.4 equiv. alkyne, $1.4 \mathrm{eq}_{2} \mathrm{Zn}$ at room temperature for $2 \mathrm{~h}$.

g) Step 1: 2 equiv alkyne, 2 eq $\mathrm{Et}_{2} \mathrm{Zn}$ at room temperature for $2 \mathrm{~h}$.

h) Step 1: 2 equiv alkyne, 2 eq $\mathrm{Et}_{2} \mathrm{Zn}$ at room temperature for $24 \mathrm{~h}$; Step 2: $(S)-\mathbf{2}(10$ mol\%) added and stirred $1 \mathrm{~h}$ (no $\mathrm{Ti}\left(\mathrm{O}^{i} \mathrm{Pr}\right)_{4}$ used); Step 3: octyl aldehyde added. 95\% yield. 
i) The reaction was repeated using $(S)-\mathbf{1 2}(10 \mathrm{~mol} \%)$ and resulted in $80 \%$ yield propargyl alcohol in $17 \%$ ee. When $(S)-4(10 \mathrm{~mol} \%)$ was used, $82 \%$ yield and $16 \%$ ee was obtained.

The asymmetric alkynylation was attempted in the absence of the base and titanium reagents, employing certain amino alcohol ligands in catalytic amounts (10 mol\%). The addition proceeds sluggishly. 1.2 equiv propiolate was stirred with 1.2 equiv $\mathrm{Et}_{2} \mathrm{Zn}$ and the ligand in diethylether at room temperature for 1 hour. The reaction was then cooled to $-20^{\circ} \mathrm{C}$ and octyl aldehyde (1.0 equiv) was added. The reaction proceeds sluggishly but propargyl alcohol was formed and after 2 days the reactions were quenched and analyzed. The following ee's were obtained: 1) (S)-2-68\%ee; 2) (S)-1254\%ee; 3) (S)-4-35\% ee; 4) (S)-7 - 25\% ee. These conditions had previously been reported in the addition of methyl propiolate to valeraldehyde. ${ }^{\text {le }}$ It is interesting to note that the catalyst formed in this series follows a different trend than that observed for the asymmetric arylations to aldehydes.

The reaction between methyl propiolate ( 1 equiv) and octyl aldehyde ( 0.9 equiv) was also tested in the presence of 1 equivalent of base (NMI and 1,2-bipyridine were used separately). After the base and alkyne were mixed at room temperature in DCM for one hour, the aldehyde was introduced. The major compound obtained was the enolprotected propargyl alcohol.

The observed enhanced nucleophilicity of the alkynylzinc species generated in the NMI-catalyzed reaction encouraged us to explore their addition to ketones. When the same ligand-free conditions ( 10 hours alkynylzinc formation) were applied to the reaction 
between methyl propiolate and acetophenone, very little reaction occurred after days at room temperature and refluxing in DCM. A small amount of self-aldol product was observed by ${ }^{1} \mathrm{H}$ NMR of the crude reaction.

Other ketone substrates were tested. 2 equiv methyl propiolate, 2 eq $\mathrm{Et}_{2} \mathrm{Zn}$, and 5 mol\% pyridine in DCM were combined and stirred for 15 hours at room temperature. Cyclohexanone and cyclopentanone (freshly distilled) were attempted as substrates for this reaction. The reactions were slow but alkyne addition was observed. $63 \%$ of methyl 3-(1-hydroxycyclohexyl)propiolate—addition to cyclohexanone (114)—was isolated after 6 days. The addition was studied again in DCM and in toluene. After 15 hours at room temperature for the alkynylzinc generation, cyclohexanone was added and the reactions were heated to reflux for 24 hours. $43 \%$ alcohol was isolated from the reaction in DCM and 55\% yield from toluene reaction. The reaction in benzene afforded $66 \%$ of the tertiary alcohol product after 3.5 hours at $80{ }^{\circ} \mathrm{C}$. When the reaction was repeated and allowed to stir beyond this time, a lesser amount of the product was observed and the crude reaction was more complex. Another experiment was performed where all the reagents were combined in benzene and were immediately heated to reflux. After 3.5 hours, $67 \%$ of the alcohol was isolated.

\section{Functional Racemic Tertiary Alcohols Prepared}
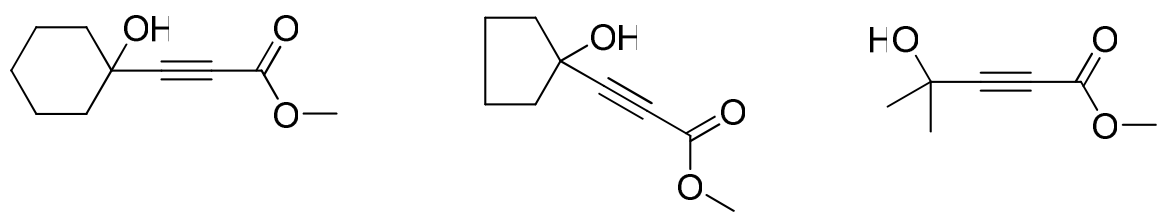

This procedure was repeated for cyclopentanone which had only shown complex mixtures and trace amounts (by TLC and crude ${ }^{1} \mathrm{H}$ NMR) of addition product in previous experiments. $25 \%$ of methyl 3-(1-hydroxycyclopentyl)propiolate (115) was isolated after 
the same time. The self-aldol product was also observed. When the conditions found for the reaction to cyclohexanone were attempted with acetone, acetophenone, and methyl pyruvate, unsatisfactory results were obtained. $30 \%$ alkyne addition to acetone was isolated (116). The reaction was not clean and aldol products were observed. No addition products were observed for the attempts using acetophenone or the $\alpha$-ketoester.

We briefly explored methodology for the asymmetric delivery of a linear aliphatic alkyne to aldehydes since not many examples appear in the literature. The addition of 1octyne to an $\sigma$-substituted aromatic aldehyde was studied. Previously, the phenylacetylene addition to 2-chlorobenzaldehyde was accomplished in the presence of $(S)-2\left(10\right.$ mol\%) using 4 eq alkyne and $\mathrm{Et}_{2} \mathrm{Zn}, 1$ eq titanium in THF. ${ }^{12}$ The alcohol was reportedly formed in $88 \%$ yield and $97 \%$ ee (see scheme below).

Scheme 5.6 Liu and Pu's Highly Enantioselective Phenylacetylene Addition to Aromatic Aldehydes Catalyzed by a [H8 BINOL-AM-Titanium] Complex.

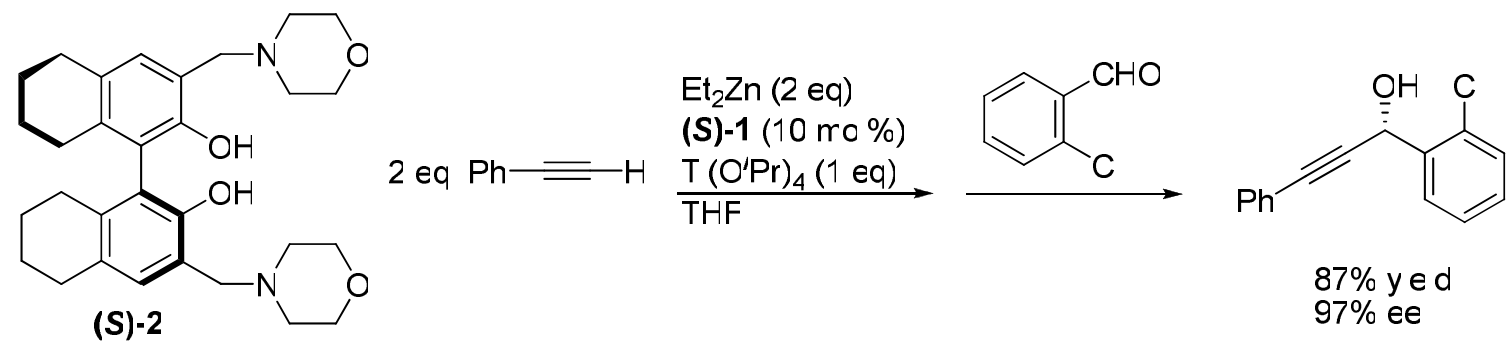

When the same conditions were used in the initial screen, about a 1:1 formation of ethyl- and alkyne- additions were observed (117 and 118, respectively). It is likely that the linear aliphatic alkyne is slightly less reactive towards the alkylzinc than phenylacetylene and more time is necessary (than 4 hours used) to allow formation of the alkynylzinc reagent at room temperature. Modified conditions were attempted for the 1octyne addition to 2-chlorobenzaldehyde. The results of the study are presented in Table 
5.3. Step 1 of the reaction, the formation of the alkynylzinc species, was allowed to proceed at room temperature for 14 hours. This resulted in over $90 \%$ yield of the propargyl alcohol with an ee of $78 \%$ (Entry 1, Table 5.3). We had discovered that orthosubstituted aromatic aldehydes presented a challenge in the asymmetric functional arylations. The linear aliphatic alkyne addition to 2-chlorobenzaldehyde was explored to address whether a good method could be found through a mimic of the introduced asymmetric phenylacetylene addition to the same substrate.

Table 5.3 Summary of Ligand and Condition Screening Results for the 1-Octyne Addition to Aldehydes. ${ }^{a}$

\begin{tabular}{|c|c|c|c|}
\hline Entry & Ligand & ee $(\%)^{b}$ & Yield \\
\hline 1 & $(S)-2$ & 78 & $>90$ \\
\hline $2^{c}$ & $(S)-2$ & 81 & 56 \\
\hline $3^{d}$ & $(S)-2$ & 71 & 40 \\
\hline $4^{\mathrm{e}}$ & $(S)-2$ & 82 & 32 \\
\hline 5 & $(S)-7$ & 70 & 98 \\
\hline $6^{\mathrm{f}}$ & $(S)-2$ & 77 & 90 \\
\hline $7^{\mathrm{f}}$ & $(S)-12$ & 77 & 93 \\
\hline 8 & $(S)-4$ & 60 & 91 \\
\hline 9 & $(S)-12$ & 82 & 88 \\
\hline $10^{\mathrm{g}}$ & $(S)-12$ & 83 & $>90$ \\
\hline $11^{\mathrm{h}}$ & $(S)-12$ & 69 & $>90$ \\
\hline $12^{\mathrm{i}}$ & $(S)-12$ & 72 & 88 \\
\hline 13 & $(S)-\mathbf{3}$ & 57 & 91 \\
\hline
\end{tabular}




$\begin{array}{llll}14^{\mathrm{j}} & (S)-\mathbf{9} & 6 & 86 \\ 15^{\mathrm{k}} & (S)-\mathbf{1 2} & 80 & >80 \\ 16^{\mathrm{l}} & (S)-\mathbf{1 2} & 72 & 70 \\ 17^{\mathrm{m}} & (S)-\mathbf{1 2} & 84 & 80 \\ \mathbf{1 8}^{\mathbf{n}} & (S)-\mathbf{1 2} & \mathbf{8 6} & >\mathbf{8 0} \\ 19^{\mathrm{o}} & (S)-\mathbf{1 2} & 74 & >80 \\ 20^{\mathrm{p}} & (S)-\mathbf{1 2} & 79 & 84 \\ 21^{\mathrm{q}} & (S)-\mathbf{1 2} & 82 & 85 \\ \mathbf{2 2} & (S)-\mathbf{1 2} & \mathbf{8 7} & \mathbf{9 5} \\ 23^{\mathrm{r}} & (S)-\mathbf{1 2} & 86 & 95 \\ 24^{\mathrm{t}} & (S)-\mathbf{1 2} & 36 & >95 \\ 25^{\mathrm{u}} & (S)-\mathbf{1 2} & 60 & 50 \\ 26^{\mathrm{v}} & (S)-\mathbf{1 2} & 93 & 45 \\ 27^{\mathrm{w}} & (S)-\mathbf{1 2} & 66 & 98\end{array}$

a) Unless otherwise noted, the following conditions were used. Step 1: 4 equiv. 1octyne, 4 equiv $\mathrm{Et}_{2} \mathrm{Zn}, 10 \mathrm{~mol} \%$ ligand were stirred at room temperature for 14 hours in 3 $\mathrm{mL}$ of THF (or other solvent). Step 2: 1.0 equiv $\operatorname{Ti}\left(\mathrm{O}^{i} \mathrm{Pr}\right)_{4}$ was added and stirred $1.5 \mathrm{~h}$. Step 3: 2-chlorobenzaldehyde (1.0 equiv) was added unless otherwise noted.

b) The ee was measured using a chiral HPLC (chiralcel OD column).

c) $\mathrm{Et}_{2} \mathrm{O}$ was used.

d) DCM was used.

e) Toluene was used.

f) $20 \mathrm{~mol} \%$ ligand was used. 
g) Concentration was decreased by one-half ( $6 \mathrm{~mL}$ THF).

h) Concentration was decreased by one-third ( $9 \mathrm{~mL} \mathrm{THF})$.

i) Aldehyde addition and reaction was done at $0{ }^{\circ} \mathrm{C}$.

j) The reaction was repeated twice with the same result.

k) 2 equiv alkyne and 2 equiv $\mathrm{Et}_{2} \mathrm{Zn}$ used.

1) 1.2 equiv alkyne and 2 equiv $\mathrm{Et}_{2} \mathrm{Zn}$ used.

m) 2 equiv alkyne, 2 equiv $\mathrm{Et}_{2} \mathrm{Zn}$, and $20 \mathrm{~mol} \%$ ligand used.

n) 2 equiv alkyne, 2 equiv $\mathrm{Et}_{2} \mathrm{Zn}, 10 \mathrm{~mol} \%$ ligand, and 0.5 equiv $\operatorname{Ti}\left(\mathrm{O}^{i} \mathrm{Pr}\right)_{4}$ used.

o) 2 equiv alkyne, 2 equiv $\mathrm{Et}_{2} \mathrm{Zn}, 10 \mathrm{~mol} \%$ ligand, and 0.25 equiv $\mathrm{Ti}\left(\mathrm{O}^{i} \mathrm{Pr}\right)_{4}$ used.

p) $1 \mathrm{~mL}$ THF was used.

q) 2 equiv alkyne, 2 equiv $\mathrm{Et}_{2} \mathrm{Zn}, 10 \mathrm{~mol} \%$ ligand, and 0.75 equiv $\left.\operatorname{Ti}^{i}\left(\mathrm{O}^{i}\right)_{4}\right)_{4}$ used.

r) 2 equiv alkyne, 2 equiv $\mathrm{Et}_{2} \mathrm{Zn}, 10 \mathrm{~mol} \%$ ligand, and 0.60 equiv $\mathrm{Ti}\left(\mathrm{O}^{i} \mathrm{Pr}\right)_{4}$ used.

s) 2 equiv alkyne, 2 equiv $\mathrm{Et}_{2} \mathrm{Zn}, 10 \mathrm{~mol} \%$ ligand, and 0.90 equiv $\mathrm{Ti}\left(\mathrm{O}^{i} \operatorname{Pr}\right)_{4}$ used.

t) 2 equiv alkyne, 2 equiv $\mathrm{Et}_{2} \mathrm{Zn}, 10 \mathrm{~mol} \%$ ligand, and no $\mathrm{Ti}\left(\mathrm{O}^{i} \mathrm{Pr}\right)_{4}$ was used.

u) 2 equiv alkyne, 2 equiv $\mathrm{Et}_{2} \mathrm{Zn}, 10 \mathrm{~mol} \%$ ligand, and 0.60 equiv $\mathrm{Ti}\left(\mathrm{O}^{i} \mathrm{Pr}\right)_{4}$ were used to react with 4-chlorobenzaldehyde.

v) 2 equiv alkyne, 2 equiv $\mathrm{Et}_{2} \mathrm{Zn}, 10 \mathrm{~mol} \%$ ligand, and 0.60 equiv $\operatorname{Ti}\left(\mathrm{O}^{i} \mathrm{Pr}\right)_{4}$ were used to react with 2-nitrobenzaldehyde.

w) 2 equiv alkyne, 2 equiv $\mathrm{Et}_{2} \mathrm{Zn}, 10 \mathrm{~mol} \%$ ligand, and 0.60 equiv $\operatorname{Ti}\left(\mathrm{O}^{i} \mathrm{Pr}\right)_{4}$ were used to react with benzaldehyde.

The reaction was attempted in diethyl ether, DCM, and in toluene (Entries 2, 3, 4). Although good enantioselectivities were still achieved and some were higher, the yields 
were diminished. Therefore, THF would appear to be the best option for alkynylzinc formation and asymmetric addition. When other ligands were studied, $(S)$-12 afforded the alcohol in a good yield and better ee $(82 \%)$. Thus, further studies used this ligand as we explored again the generality of the pyrrolidine-based binaphthol motif.

When the reaction was concentrated or diluted (by one-third), the ee was decreased. It was interesting to observe that the reaction yielded a significantly diminished product enantiomeric excess when the addition was done at $0{ }^{\circ} \mathrm{C}$. Further improvements were made by decreasing the amounts of alkyne and $\mathrm{Et}_{2} \mathrm{Zn}$ to 2 equiv each and altering the amount of $\operatorname{Ti}\left(\mathrm{O}^{i} \mathrm{Pr}\right)_{4}$ added. When the amount of addition reagents were further decreased to 1.2 equiv each, a drop in yield and ee was observed. Entry 22 shows the optimal result for this addition. The alcohol was isolated in $95 \%$ yield and $87 \%$ ee.

We were disappointed to realize the non-generality of the method. The conditions from Entry 22 were applied to study the 1-octyne addition to other aromatic aldehydes (Entries 25-27). Both the yields and enantioselectivities obtained varied widely. The best ee obtained was from the addition to 2-nitrobenzaldehyde $(93 \%$ ee; 119) although the yield was only moderate at $45 \%$. Additions to 4-chlorobenzaldehyde and benzaldehyde gave lower ee's: $60 \%$ ee $(50 \%$ yield; 120$)$ and 66\%ee (98\% yield; 121$)$, respectively. Aliphatic aldehydes were not screened using this method.

Recently, Du and Pu published a method describing asymmetric linear aliphatic alkyne additions to aldehydes catalyzed by an $(S)$-BINOL — titanium tetraisopropoxide complex. Three different alkyne substrates were shown to react with aliphatic aldehydes to afford the propargylic alcohols in $57-77 \%$ yield and $77-89 \%$ ee. $^{14 a}$ 
The key to this method was the further screening of nitrogen bases. It was discovered that dicyclohexylamine (5 mol\%) effectively generated the alkynylzinc species and afforded the best ee result in the addition of 1-hexyne to valeraldehyde (59\% yield, $84 \%$ ee). It is interesting to note that the ligand incorporating the dicyclohexylamine "arms" in the $\mathrm{H}_{8}$ BINOL-AM family prepared-(S)-6 (see chapter 3 for arylation studies) — demonstrated the poorest enantioselectivity among the family of compounds.

The methyl propiolate addition to aliphatic, aromatic, and $\alpha, \beta$-unsaturated aldehydes has been established by recent work in the Pu lab. ${ }^{13,14,20,21}$ The reaction proceeds to form propargylic alcohols in 60 to $>90 \%$ yields and 81 to $>95 \%$ ee. Propargyl acetate has been added to benzaldehyde to yield $89 \%$ of the alcohol in $90 \%$ ee. Attempts to react 3-butyne-2-one with benzaldehyde did not result in any isolated product. Studies using our established procedures for functional substrates (1) HMPA method and (2) BINOL-Salen ligand ${ }^{1 \mathrm{c}, 15}$ were unsuccessful as were the solvent screenings done. No reactivity was found for the synthesis of propargylic alcohols in $\mathrm{CH}_{2} \mathrm{Cl}_{2}$, benzene, THF, toluene, or diethylether. Thus, we have identified a limitation to the systems hereto developed for the asymmetric synthesis of functional propargylic alcohols.

The racemic preparation of propargyl acetate proceeded in the absence of ligand to yield the addition product to benzaldehyde in $65 \%$ yield. Otherwise, the same conditions were used: 4 equiv alkyne, 2.5 equiv $\mathrm{Et}_{2} \mathrm{Zn}, 2$ equiv HMPA, 1 equiv benzaldehyde in DCM. Only 4 hours was required to form the alkynylzinc at room temperature and the addition proceeds in the absence of both ligand and titanium 
tetraisopropoxide. However, when the reaction was attempted using 1 equiv of each reagent, no product was formed.

\section{d. Attempted Acetylene Additions using Calcium Carbide as Substrate}

Fitting with our approach to identify practical methodology based on commercially available reagents and inexpensive starting materials, we explored the use of calcium carbide as an acetylene source. Our objective was to evaluate conditions for the delivery of the acetylene group from the carbide to carbonyls. Calcium carbide is available in technical grade from Sigma-Aldrich in $\sim 80 \%$ grade $(500 \mathrm{G}, \$ 31.60 ; 2 \mathrm{KG}$, \$66.00; prices listed from November, 2010; impurities likely to include other metallic carbides, silicates, oxides, nitrides, sulfides, phosphides and free carbon) and carbide's

synthetic use has rarely been reported in the literature. ${ }^{23}$ Moreover, we aimed at studying an enantioselective process for the reaction.

We first screened simple protocols: 1) the mixing of carbide (1 equivalent) with 2-naphthaldehyde (1 equivalent) in THF; and 2) the mixing of carbide (1 equivalent), 2naphthaldehyde (1 equivalent), and $20 \mathrm{~mol} \%(S)-2$ in THF. After 2 days stirring the mixtures remained heterogeneous and no reaction was observed as only the starting aldehyde appeared on TLC. The activity of the reaction mixture was tested by quenching slowly. Upon dropwise addition of water into both mixtures, the reactive carbide was still observed to be active as violent bubbling resulted. Next, 1.4 equivalents of carbide were mixed with (S)-BINOL in THF overnight. 2-naphthaldehyde was added and the reaction was monitored. No reaction was observed. The symmetric addition in DCM was attempted using the same equivalents. The same result was obtained. After 24 hours 
at room temperature, both reactions were still heterogeneous and were heated to reflux for 16 hours. No reaction occurred and only starting material appeared on TLC. The carbide was still active after 3 days in the mixtures.

Next, a titanoate catalyst was formed by mixing a 1:1 ratio of $(S)$-BINOL and titanium tetraisopropoxide in DCM. The solution turns from a light yellow to a deep brownish-orange instantly at room temperature. After 30 minutes, the flask was evacuated to remove volatiles. The contents were redissolved in THF and carbide (1.4 equivalents) was added under nitrogen. After 10 minutes, 2-naphthaldehyde was added. The reaction was monitored over 64 hours at room temperature with only trace amounts of the reduction product observed. 5 equivalents of titanium tetraisopropoxide were added but did not result in reaction after another 2 days. The crude reaction ${ }^{1} \mathrm{H}$ NMR showed the presence of aldehyde and 2-naphthalenemethanol and this was confirmed by the addition of $\mathrm{D}_{2} \mathrm{O}$.

The BINOL-titanoate was prepared again and upon redissolving the catalyst (40 mol\%) in THF, 3 equivalents carbide and 2.0 equivalents of HMPA were added. The amount of titanium tetraisopropoxide was increased to 7 equivalents relative to aldehyde. This mixture was allowed to stir overnight and 2-naphthaldehyde was again introduced. After 3 weeks, only starting materials were present (no reduction product was observed). HMPA was used as solvent (23 equivalents) for an experiment. 2.5 equivalents carbide and 2-naphthaldehyde were stirred together for over 24 hours, no changes occurred. The crude reaction ${ }^{1} \mathrm{H}$ NMR showed only a trace amount of 2naphthalenemethanol other than starting material. 
A zinc-based (S)-BINOL was formed by reacting $80 \mathrm{~mol}^{2} \mathrm{Et}_{2} \mathrm{Zn}$ with $40 \mathrm{~mol} \%$ $(S)$-BINOL in THF for 30 minutes at room temperature. Calcium carbide (2 equivalents) was added and mixed for 2 hours followed by addition of 2-naphthaldehyde. No reaction took place after 27 hours. An excess of titanium tetraisopropoxide was added but did not result in reaction. The reaction stood at room temperature for 10 days. After this time, the reaction ${ }^{1} \mathrm{H}$ NMR showed 2-naphthalenemethanol only.

In attempts to boost the nucleophilicity—or availability—of the carbide which may be locked into a cage-like, highly restricted structure, 1 equivalent of absolute ethanol (nitrogen purged) was added to calcium carbide under nitrogen in THF at room temperature. After 30 minutes, 2-naphthaldehyde was added to a slightly cloudy but mainly heterogeneous mixture. After 4 days and only a trace amount of the reduced aldehyde observed on TLC, another equivalent of ethanol was added. The mixture got slightly cloudier and the reduction product increased over the course of one week reaction time. A better additive may have been acetic acid or a metallic bicarbonate, sulfate, or phosphate species (e.g. sodium bicarbonate) that would form stronger complexation to the calcium, not provided by ethoxide.

Another "activating" reaction was attempted by adding 1 equivalent $n$ butyllithium to calcium carbide at $-78^{\circ} \mathrm{C}$ in THF. This was stirred for one hour, brought to room temperature, and 2-naphthaldehyde was added. The cloudy solution instantly turned a deep yellow color. Within 5 minutes, the solution turned a darker yellow to red. TLC showed the consumption of aldehyde in $<6$ hours forming the reduction product. This reaction was repeated using benzaldehyde. The same reaction was observed and nearly quantitative benzyl alcohol was formed (TLC, ${ }^{1} \mathrm{H}$ NMR). 
This "activating" reaction was also attempted by adding 1 equivalent $n$ butyllithium to calcium carbide at room temperature in THF and preparing a separate solution of 2-naphthaldehyde was prepared in THF. The lithiated-calcium carbide was transferred to the aldehyde solution. Reduction of the aldehyde was the only species generated.

Another "activating" experiment was performed by mixing 2 equivalents TMEDA with the calcium carbide (4.5 equivalents) in THF. Two reactions were screened using benzaldehyde and octanal in THF. Benzaldehyde was again reduced completely, but a trace amount of ethynyl addition may have been observed in the octanal reaction. The crude NMR was complex. Attempted isolation of the new compound did not result in a pure compound $(\delta 4.15, \mathrm{~m} ; 2.37, \mathrm{~s})$. Octanal was present in a small amount and the major component was the expected octanol.

Attempting reactions closer to the recently reported synthetic use of calcium carbide, we looked at using a polar solvent. 4.0 equivalents calcium carbide was stirred in DMSO (dried and distilled; stored over $4 \AA$ molecular sieves). Again both benzaldehyde and octanal were used, but no reaction occurred.

We studied the potential to activate the calcium carbide using a transmetalation strategy. Reports were found that described the exchange of the metal of a carbide with other metals from a metallic chloride source, e.g. iron, cobalt, and nickel chlorides. ${ }^{24}$ The reaction takes place in acetonitrile at an elevated temperature (in the range of $75-120{ }^{\circ} \mathrm{C}$ ). We selected nickel chloride. Nickel chloride hexahydrate was first refluxed in thionyl chloride to generate the anhydrous salt. The salt was separated from the drying agent and evacuated overnight prior to being used (in a nitrogen atmosphere). 2 equivalents of 
anhydrous nickel chloride was stirred in acetonitrile (dried and distilled; stored over $4 \AA$ molecular sieves) for 18 hours. Calcium carbide (2.5 equivalents) was the added, stirred one hour and followed by the addition of an aldehyde. The reactions with benzaldehyde and octanal were attempted again. After the aldehyde was added, the mixtures were brought to reflux. No reaction was observed after 2 days.

\section{e. Experimental and Characterization}

The following describes the methods and products generated and isolated in alkyne additions to aldehydes (propargylic alcohols) and products from organocatalytic attempts (enol-protected propargyl alcohols).

\section{Preparation of asymmetric propargylic alcohols}

Under a nitrogen atmosphere to an oven-dried $50 \mathrm{~mL}$ round bottom flask equipped with stir bar (S)-BINOL (0.286g, $40 \mathrm{~mol} \%)$ was dissolved in $30 \mathrm{~mL}$ of dry methylene chloride. Alkyne (0.890 mL, $10 \mathrm{mmol})$, HMPA (0.870 mL, $5 \mathrm{mmol})$, and $\mathrm{ZnEt}_{2}(1.05 \mathrm{~mL}, 10 \mathrm{mmol})$ were added to this solution and stirred at room temperature for 16 hours. After briefly venting, $\mathrm{Ti}\left(\mathrm{O}^{\mathrm{i}} \mathrm{Pr}\right)_{4}(0.738 \mathrm{~mL}, 2.5 \mathrm{mmol})$ was added and allowed to stir for 1 hour. Aldehyde $(0.241 \mathrm{~mL}, 2.5 \mathrm{mmol})$ was then added to the flask. The reaction proceeds for four hours at room temperature. Saturated ammonium chloride was added to quench the reaction. This mixture was extracted with $\mathrm{CH}_{2} \mathrm{Cl}_{2}(3 \mathrm{X} 50 \mathrm{~mL})$, dried over $\mathrm{Na}_{2} \mathrm{SO}_{4}$, and concentrated. The resultant residue was passed through a silica gel column and eluted with $2-12 \%$ ethyl acetate in hexanes gradient. Enantiomeric excess was determined using chiral HPLC (Chiralcel OD column) or ${ }^{1} \mathrm{H}$ NMR by preparing mandelate esters of the propargylic alcohols. 


\section{Preparation of racemic propargylic alcohols:}

Method A: The racemic preparations of propargylic alcohols were done following the same conditions above except for the use of BINOL. When poor reactivity of the alkynylzinc species was observed, racemic BINOL was used. Otherwise, the two following methods were followed.

Method B: The racemic alcohols could be synthesized by treating an alkyne (1 equiv) solution in THF with 1 equiv of $n$-butyllithium at $-78^{\circ} \mathrm{C}$. The lithium acetylide was formed over 4 hours at this temperature and was then charged with the aldehyde (1 equiv). The cold bath was then removed and the reaction was allowed to warm to room temperature. Aldehyde consumption was typically observed within 2 hours. Side reactions were normally observed with this method when methyl propiolate was the alkyne. Butyl- displacement of the methyl ester was observed as well as butyl addition to the aldehyde (from unreacted $n$-butyllithium). The following method worked efficiently for alkynes tested.

Method C: $5 \mathrm{~mol} \%$ NMI was added into a DCM solution containing alkyne (1.2 to 2 equiv), diethylzinc (1.2 to 2 equiv; 1 equiv relative to alkyne), and $\operatorname{Ti}\left(\mathrm{O}^{i} \operatorname{Pr}\right)_{4}(25 \mathrm{~mol} \%)$. This solution was stirred 2 to 10 hours ( 2 hours for methyl propiolate or phenylactelyene, longer times were required for aliphatic alkynes). An aldehyde was then added and the reaction monitored over 12 to 24 hours at room temperature.

\section{Characterization:}

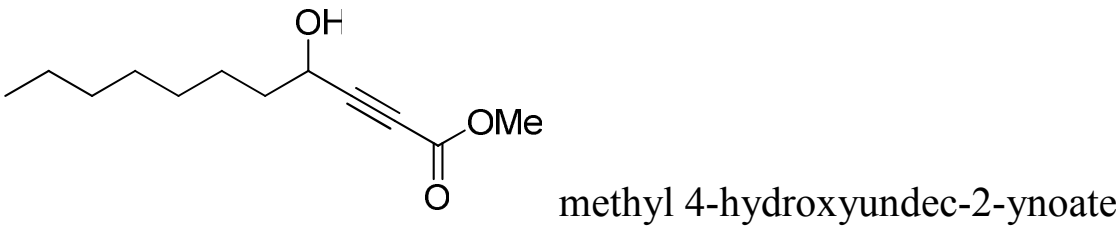

$76 \%$ yield. $81 \%$ ee (based on preparation and analysis of (R)-O-acetylmandelic ester derivative). 
${ }^{1} \mathrm{H}$ NMR (300MHz, $\left.\mathrm{CDCl}_{3}\right) \delta 4.49(\mathrm{~m}, 1 \mathrm{H}), 3.78(\mathrm{~s}, 3 \mathrm{H}), 1.88(\mathrm{~d}, J=5.9 \mathrm{~Hz}, 1 \mathrm{H}), 1.76(\mathrm{~m}, 2 \mathrm{H})$, $1.46(\mathrm{~m}, 2 \mathrm{H}), 1.29(\mathrm{~m}, 8 \mathrm{H}), 0.87(\mathrm{t}, J=6.4 \mathrm{~Hz}, 3 \mathrm{H}) .{ }^{13} \mathrm{C} \mathrm{NMR}\left(75 \mathrm{MHz}, \mathrm{CDCl}_{3}\right) \delta 153.8,133.0$, $124.1,86.7,76.7,67.4,52.7,13.2,11.9$.

108<smiles>COC(=O)C#CC(O/C=C/C(=O)OC)C(C)C</smiles>

(E)-methyl 4-(3-methoxy-3-oxoprop-1-enyloxy)-5-

methylhex-2-ynoate

${ }^{1} \mathrm{H}-\mathrm{NMR}\left(300 \mathrm{MHz}, \mathrm{CD}_{3} \mathrm{CN}\right) \delta 7.55(\mathrm{~d}, J=12.5 \mathrm{~Hz}, 1 \mathrm{H}), 5.37(\mathrm{~d}, J=12.5 \mathrm{~Hz}, 1 \mathrm{H}), 4.42(\mathrm{~d}, J=$ $5.8 \mathrm{~Hz}, 1 \mathrm{H}), 3.78(\mathrm{~s}, 3 \mathrm{H}), 3.70(\mathrm{~s}, 3 \mathrm{H}), 2.14(\mathrm{~m}, 1 \mathrm{H}), 1.06(\mathrm{~m}, 6 \mathrm{H})$.

\section{Methyl propiolate “dimer”:}

110<smiles>COC(=O)C#C/C=C/C(=O)OC</smiles>

(E)-dimethyl hex-2-en-4-ynedioate

${ }^{1} \mathrm{H}$ NMR $\left(300 \mathrm{MHz}, \mathrm{CDCl}_{3}\right) \delta 7.58(\mathrm{~d}, J=12.2 \mathrm{~Hz}, 1 \mathrm{H}), 5.66(\mathrm{~d}, J=12.2 \mathrm{~Hz}, 1 \mathrm{H}), 3.74$ $(\mathrm{s}, 3 \mathrm{H})$.

111 C (E)-methyl 3-chloroacrylate

${ }^{1} \mathrm{H}$ NMR $\left(300 \mathrm{MHz}, \mathrm{CDCl}_{3}\right) \delta 7.58(\mathrm{~d}, J=12.2 \mathrm{~Hz}, 1 \mathrm{H}), 5.66(\mathrm{~d}, J=12.2 \mathrm{~Hz}, 1 \mathrm{H}), 3.74$ $(\mathrm{s}, 3 \mathrm{H})$.

112

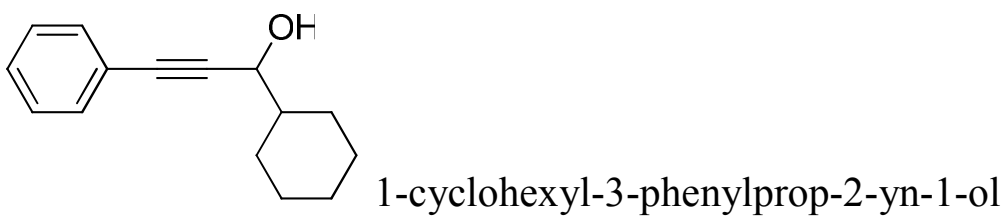

${ }^{1} \mathrm{H}$ NMR $\left(300 \mathrm{MHz}, \mathrm{CDCl}_{3}\right) \delta 7.43(\mathrm{~m}, 2 \mathrm{H}), 7.30(\mathrm{~m}, 3 \mathrm{H}), 4.38(\mathrm{t}, J=5.6 \mathrm{~Hz}, 1 \mathrm{H}), 1.92$ $(\mathrm{m}, 2 \mathrm{H}), 1.81(\mathrm{~m}, 3 \mathrm{H}), 1.66(\mathrm{~m}, 3 \mathrm{H}), 1.23(\mathrm{~m}, 4 \mathrm{H})$. 


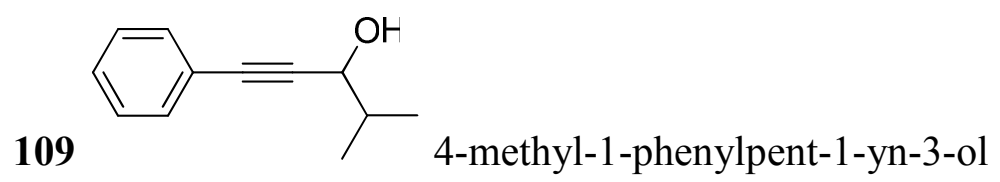

${ }^{1} \mathrm{H}$ - NMR (300MHz, $\left.\mathrm{CD}_{3} \mathrm{CN}\right) \delta 7.43(\mathrm{~m}, 2 \mathrm{H}), 7.31(\mathrm{~m}, 3 \mathrm{H}), 4.40(\mathrm{t}, J=5.6 \mathrm{~Hz}, 1 \mathrm{H}), 1.98(\mathrm{~m}$, $1 \mathrm{H}), 1.90(\mathrm{~d}, J=5.7 \mathrm{~Hz}, 1 \mathrm{H}), 1.07(\mathrm{t}, J=6.7 \mathrm{~Hz}, 6 \mathrm{H})$.

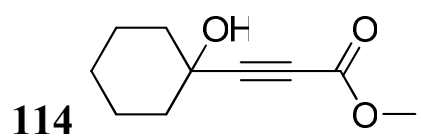

${ }^{1} \mathrm{H}$ NMR (300MHz, $\left.\mathrm{CDCl}_{3}\right) \delta 3.77$ (s, 3H), 2.24 (br-s, 1H), 1.95 (m, 2H), 1.61 (m, 8H).

${ }^{13} \mathrm{C} \mathrm{NMR}\left(75 \mathrm{MHz}, \mathrm{CDCl}_{3}\right) \delta 154.0,90.8,75.6,68.3,52.7,38.9,24.8,22.7$.

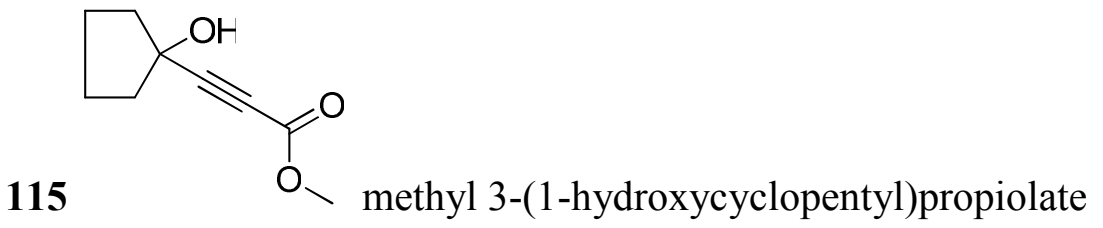

${ }^{1} \mathrm{H}$ NMR (300MHz, $\left.\mathrm{CDCl}_{3}\right) \delta 3.77$ (s, 3H), 2.07 (br-s, 1H), 1.99 (m, 4H), 1.81 (m, 4H).

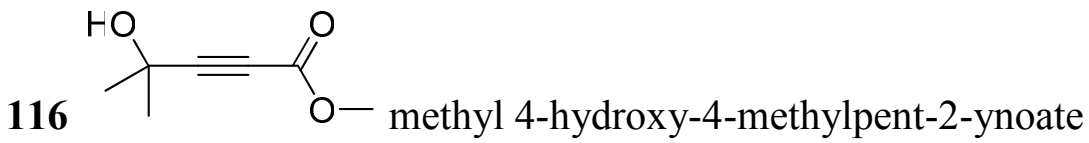

${ }^{1} \mathrm{H}$ NMR (300MHz, $\left.\mathrm{CDCl}_{3}\right) \delta 3.77$ (s, 3H), 2.27 (br-s, 1H), 1.56 (s, 6H).

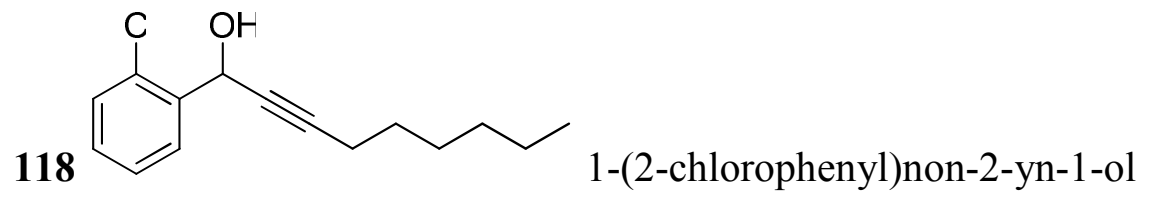

${ }^{1} \mathrm{H}$ NMR $\left(300 \mathrm{MHz}, \mathrm{CDCl}_{3}\right) \delta 7.77(\mathrm{~m}, 1 \mathrm{H}), 7.32(\mathrm{~m}, 3 \mathrm{H}), 5.81(\mathrm{~m}, 1 \mathrm{H}), 2.38(\mathrm{~d}, J=5.4$

Hz, 1H), $2.26(\mathrm{~m}, 2 \mathrm{H}), 1.54(\mathrm{~m}, 2 \mathrm{H}), 1.38(\mathrm{~m}, 2 \mathrm{H}), 1.29(\mathrm{~m}, 4 \mathrm{H}), 0.88(\mathrm{t}, J=6.8 \mathrm{~Hz}, 3 \mathrm{H})$.

${ }^{13} \mathrm{C}$ NMR $\left(75 \mathrm{MHz}, \mathrm{CDCl}_{3}\right) \delta 138.4,129.6,129.4,128.3,127.1,87.9,78.6,62.1,31.2$, 28.5, 28.4, 22.5, 18.7, 14.0. HPLC: chiralcel OD column; 98:2 hexanes:isopropanol, flow rate: $0.5 \mathrm{~mL} / \mathrm{min} . R T s=24,28 \mathrm{~min}$. 
1-(2-chlorophenyl)propan-1-ol

${ }^{1} \mathrm{H}$ NMR $\left(300 \mathrm{MHz}, \mathrm{CDCl}_{3}\right) \delta 7.54(\mathrm{~m}, 1 \mathrm{H}), 7.30(\mathrm{~m}, 2 \mathrm{H}), 7.19(\mathrm{~m}, 1 \mathrm{H}), 5.06(\mathrm{~m}, 1 \mathrm{H})$, 2.09 (br-s, 1H), 1.77 (m, 2H), 0.99 (t, $J=7.4 \mathrm{~Hz}, 3 \mathrm{H})$.

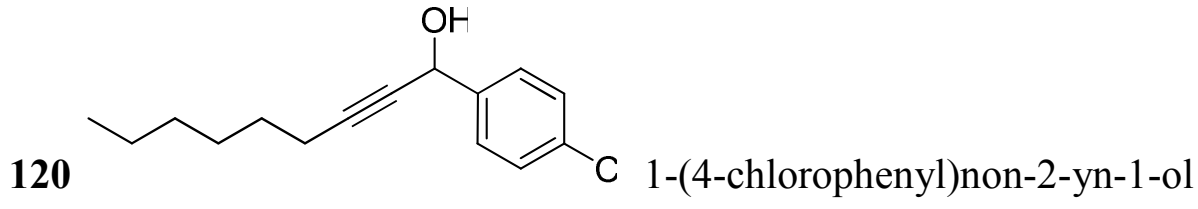

${ }^{1} \mathrm{H}$ NMR $\left(300 \mathrm{MHz}, \mathrm{CDCl}_{3}\right) \delta 7.48(\mathrm{~m}, 2 \mathrm{H}), 7.34(\mathrm{~m}, 2 \mathrm{H}), 5.43(\mathrm{~d}, J=6.0 \mathrm{~Hz}, 1 \mathrm{H}), 2.27$ (m, 2H), $2.09(\mathrm{~d}, J=6.0 \mathrm{~Hz}, 1 \mathrm{H}), 1.54(\mathrm{~m}, 2 \mathrm{H}), 1.39(\mathrm{~m}, 2 \mathrm{H}), 1.29(\mathrm{~m}, 4 \mathrm{H}), 0.89(\mathrm{t}, J=$ 6.7 Hz, 3H). HPLC: chiralpak AD-H column; solvent ratio: 95:5 hexanes:isopropanol, flow rate: $1 \mathrm{~mL} / \mathrm{min} . R T s=10.2,12.7 \mathrm{~min}$.

\section{1}

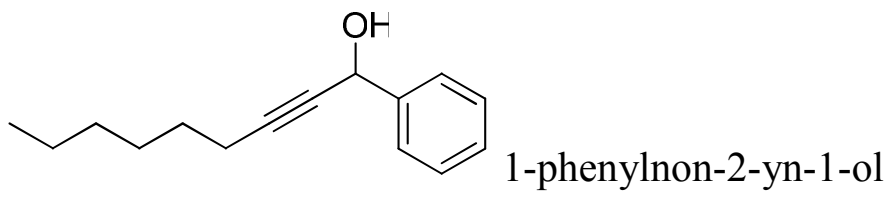

${ }^{1} \mathrm{H}$ NMR $\left(300 \mathrm{MHz}, \mathrm{CDCl}_{3}\right) \delta 7.55(\mathrm{~m}, 2 \mathrm{H}), 7.36(\mathrm{~m}, 3 \mathrm{H}), 5.46(\mathrm{~m}, 1 \mathrm{H}), 2.27(\mathrm{~m}, 2 \mathrm{H})$, $2.08(\mathrm{~d}, J=6.2 \mathrm{~Hz}, 1 \mathrm{H}), 1.55(\mathrm{~m}, 2 \mathrm{H}), 1.39(\mathrm{~m}, 2 \mathrm{H}), 1.28(\mathrm{~m}, 4 \mathrm{H}), 0.89$ (t, $J=6.8 \mathrm{~Hz}$, 3H). HPLC: chiralpak AD-H column; solvent ratio: 98:2 hexanes:isopropanol, flow rate: $1 \mathrm{~mL} / \mathrm{min} . R T s=16.7,20.2 \mathrm{~min}$.

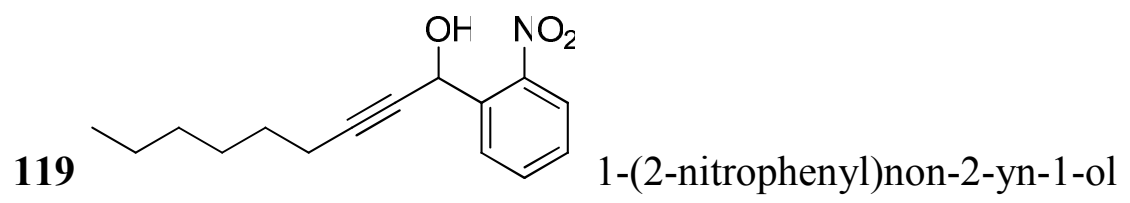

${ }^{1} \mathrm{H}$ NMR (300MHz, $\left.\mathrm{CDCl}_{3}\right) \delta 7.94(\mathrm{~m}, 2 \mathrm{H}), 7.66(\mathrm{~m}, 1 \mathrm{H}), 7.49(\mathrm{~m}, 1 \mathrm{H}), 5.96(\mathrm{~d}, J=1.9$ $\mathrm{Hz}, 1 \mathrm{H}), 3.06$ (br-s, 1H), $2.24(\mathrm{~m}, 2 \mathrm{H}), 1.50(\mathrm{~m}, 2 \mathrm{H}), 1.31(\mathrm{~m}, 6 \mathrm{H}), 0.88(\mathrm{t}, J=6.8 \mathrm{~Hz}$, 3H). HPLC: chiralpak AD-H column; solvent ratio: 95:5 hexanes:isopropanol, flow rate: $1 \mathrm{~mL} / \mathrm{min} . R T s=15.0,18.4 \mathrm{~min}$. 
The following experimentals describe the ligand preparations done for the exploration of organocatalytic alkynylations:

(a.) 28

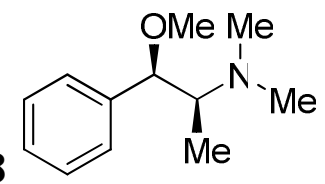

(1R,2S)-1-methoxy-N,N-dimethyl-1-phenylpropan-2-amine was prepared by stirring $(1 \mathrm{R}, 2 \mathrm{~S})-\mathrm{N}$-methylephedrine with potassium hydride (3 equivalents) in refluxing THF for 20 hours followed by the addition of iodomethane (1.1 equivalents) at $0{ }^{\circ} \mathrm{C}$. The suspension was warmed to room temperature and quenched by the slow addition of methanol with vigorous stirring of the mixture. $52 \%$ of the methyl ether-protected trialkylamine was isolated. ${ }^{1} \mathrm{H}-\mathrm{NMR}(300 \mathrm{MHz}, \mathrm{CDCl} 3) \delta 7.34(\mathrm{~m}, 2 \mathrm{H})$, $7.26(\mathrm{~m}, 3 \mathrm{H}), 4.38(\mathrm{~d}, J=3.5 \mathrm{~Hz}, 1 \mathrm{H}), 3.25(\mathrm{~s}, 3 \mathrm{H}), 2.63(\mathrm{~m}, 1 \mathrm{H}), 2.34(\mathrm{~m}, 6 \mathrm{H}), 0.99(\mathrm{~d}$, $J=6.8 \mathrm{~Hz}, 6 \mathrm{H})$.

(b.) 29<smiles>CC(=O)OC(C(=O)OC(c1ccccc1)[C@H](C)N(C)C)c1ccccc1</smiles>

(R)-((1R,2S)-2-(dimethylamino)-1-phenylpropyl) 2-acetoxy-2phenylacetate was prepared in an overall yield of $30 \%$ by the following procedure: $(R)$ $\alpha$-acetylmandelic acid was transformed into the acyl chloride by refluxing in thionyl chloride (15 equivalents) and benzene for 30 mins. The excess reagent and solvent were stripped off and the residue was quickly redissolved in dichloromethane (dried). To this solution, DMAP (5 mol\%) and pyridine (9 equivalents) were added and the reaction was heated to reflux for 12 hours. The coupled product between (1R,2S)- $N$-methylephedrine and $(R)$ - $\alpha$-acetylmandelic acid was recovered cleanly after silica gel flash chromatography. ${ }^{1} \mathrm{H}-\mathrm{NMR}(300 \mathrm{MHz}, \mathrm{CDCl} 3) \delta 7.51(\mathrm{~m}, 1 \mathrm{H}), 7.49(\mathrm{~m}, 1 \mathrm{H}), 7.38(\mathrm{~m}$, 
3H), $7.32(\mathrm{~m}, 2 \mathrm{H}), 7.26(\mathrm{~m}, 3 \mathrm{H}), 6.03(\mathrm{~s}, 1 \mathrm{H}), 5.89(\mathrm{~d}, J=4.5 \mathrm{~Hz}, 1 \mathrm{H}), 2.83(\mathrm{qd}, J=6.8$, $4.5 \mathrm{~Hz}, 1 \mathrm{H}), 2.16(\mathrm{~s}, 3 \mathrm{H}), 2.01(\mathrm{~s}, 6 \mathrm{H}), 0.80(\mathrm{~d}, J=6.8 \mathrm{~Hz}, 3 \mathrm{H})$.

(c.) 30<smiles>CC(=O)O[C@@H](c1ccccc1)[C@@H](C)N(C)C</smiles>

(1R,2S)-2-(dimethylamino)-1-phenylpropyl acetate was

prepared by treating $(1 \mathrm{R}, 2 \mathrm{~S})-N$-methylephedrine with 1 equivalent $n$-butyllithium at -78 ${ }^{\circ} \mathrm{C}$ in THF followed by the slow addition of acetyl chloride. $70 \%$ of the acetyl protected trialkylamine was isolated. ${ }^{1} \mathrm{H}-\mathrm{NMR}(300 \mathrm{MHz}, \mathrm{CDCl} 3) \delta 7.28(\mathrm{~m}, 5 \mathrm{H}), 5.94(\mathrm{~d}, J=5.1$ $\mathrm{Hz}, 1 \mathrm{H}), 2.86(\mathrm{qd}, J=6.7,5.2 \mathrm{~Hz}, 1 \mathrm{H}), 2.28(\mathrm{~s}, 6 \mathrm{H}), 2.10(\mathrm{~s}, 3 \mathrm{H}), 1.06(\mathrm{~d}, J=6.7 \mathrm{~Hz}$, $3 \mathrm{H})$.

(d.) 31<smiles>CC(C(OC(=O)c1ccccc1)c1ccccc1)N(C)C</smiles>

(1R,2S)-2-(dimethylamino)-1-phenylpropyl benzoate was prepared in the same manner described for the $O$-acetyl derivative by using benzoyl chloride. The compound was isolated in 95\% yield. ${ }^{1} \mathrm{H}-\mathrm{NMR}(300 \mathrm{MHz}, \mathrm{CDCl} 3) \delta 8.11$ $(\mathrm{m}, 2 \mathrm{H}), 7.58(\mathrm{~m}, 1 \mathrm{H}), 7.46(\mathrm{~m}, 2 \mathrm{H}), 7.30(\mathrm{~m}, 5 \mathrm{H}), 6.21(\mathrm{~d}, J=4.5 \mathrm{~Hz}, 1 \mathrm{H}), 3.03(\mathrm{~m}$, 1H), $2.35(\mathrm{~s}, 6 \mathrm{H}), 1.20(\mathrm{~d}, J=6.8 \mathrm{~Hz}, 3 \mathrm{H})$.

(e.) 32<smiles>C[O+]C(c1ccccc1)[C+](C)C</smiles>
2-amine was prepared in the same manner described for the $O$-acetyl derivative by using chlorotrimethylsilane. The compound was isolated in 47\% yield. 1H-NMR (300 MHz, $\mathrm{CDCl} 3) \delta 7.25(\mathrm{~m}, 5 \mathrm{H}), 4.82(\mathrm{~d}, J=4.4 \mathrm{~Hz}, 1 \mathrm{H}), 2.65(\mathrm{~m}, 1 \mathrm{H}), 2.29(\mathrm{~s}, 6 \mathrm{H}), 0.97(\mathrm{~d}, J=$ $6.7 \mathrm{~Hz}, 3 \mathrm{H}), 0.012(\mathrm{~s}, 9 \mathrm{H})$. 


\section{e. References:}

1. (a) de Armas, P.; Garcia-Tellado, F.; Marrero-Tellado, J. J.; Tejedor, D.; Maestro, M. A.; Gonzalez-Platas, J. Org. Lett. 2001, 3 (12), 1905. (b) Tejedor, D.; GarciaTellado, F.; Marrero-Tellado, J.; de Armas, P. Chem. Eur. J. 2003, 9, 3122. (c) Li, Z.; Pu, L. Org. Lett., 2004, 6 (6), 1065. (d) Li, Z.; Pu, L. J. Org. Chem., 2007, 72, 4340-4343. (e) Qin, Y.-C.; Liu, L.; Sabat, M. ; Pu, L. Tetrahedron 2006, 62, 93359348. (f) Qin, Y.-C.; Pu, L. Angew. Chem. Int. Ed. 2006, 118, 279-283.

2. Saito, S.; Yamamoto, H. Acc. Chem. Res. 2004, 37, 570-579.

3. (a) Trost, B. PNAS, 2004, 101, 5348. (b) Neurath, H. PNAS, 1999, 96 (20), 10962. (c) Thayer, A. Chem. \& Eng. News, 2005, 83 (36), 40-58. (d) Overman, L. E.; Bell, K. L. J. Am. Chem. Soc. 1981, 103, 1851. (e) Kuroda, S.; Katsuki, T.; Yamaguchi, M. Tetrahedron Lett. 1987, 803. (f) Herrmann, J. L.; Berger, M. H.; Schlessinger, R. H. J. Am. Chem. Soc. 1979, 101, 1544. For a review on the asymmetric synthesis of Active Pharmaceutical Ingredients (APIs), see: (g) Farina, V.; Reeves, J. T.; Senanayake, C. H.; Song, J. J. Chem. Rev. 2006, 106, 2734-2793.

4. (a) Rajaram, A., Pu, L. 2006, 8(10), 2019-2021. (b) Marshall, J. A.; Yu, R. H.; Perkins, J. F. 1995, 60, 5550. (c) Effenberger, F.; Syed, J. Tetrahedron: Asymmetry 1998, 9,817

5. (a) McDougal, N. T.; Schaus, S. E. J. Am. Chem. Soc. 2003, 125, 12094. (b) Matsui, K.; Takizawa, S.; Sasai, H. 2005, 127, 3680. (c) Pu, L.; Yu, H. Chem Rev. 2001, 101 (3), 757. (d) Pu, L. Tetrahedron, 2003, 59, 9873. (e) Pu, L. Chem. Rev. 1998, 98 (7), 2405. (f) Moore, D.; Pu, L. Org. Lett. 2002, 4, 1855. (g) Gao, G.; Moore, D.; Xie, R.; Pu, L. Org. Lett., 2002, 4 (23), 4143. (h) Lu, G.; Li, X.-S.; Chan, W. L.; Chan, A. S. 
C. J. Chem. Soc., Chem. Commun. 2002, 172. (i) Li, X.-S.; Lu, G.; Kwok, W. H.;

Chan, A. S. C. J. Am. Chem. Soc., 2002, 124, 12636. (j) Lu, G.; Li, X.-S.; Chen, G.;

Chan, W. L.; Chan, A. S. C. Tetrahedron: Asymmetry. 2003, 14, 449. (k) Gao, G.;

Wang, Q.; Yu, X-Q.; Xie, R-G.; Pu, L. Angew. Chem. Int. Ed. 2005, 45 (1), 122-125.

6. Sugihara, T.; Copéret, C.; Owczarczyk, Z.; Harring, L. S.; Negishi, E.-i. J. Am. Chem. Soc. 1994, $116(17)$, 7923-2924.

7. (a) Tejedor, D.; Gonzalez-Cruz, D.; Santos-Exposito, A.; Marrero-Tellado, J.; de Armas, P.; Garcia-Tellado, F. Chem. Eur. J. 2005, 11, 3502. (b) Tejedor, D.; LópezTosco, S. ; Cruz-Acosta, F.; Méndez,-Abt, G.; Garcia-Tellado, F.; Angew. Chem. Int. Ed. 2009, 48, 2090-2098.

8. Corey, E. J.; Cimprich, K. A. J. Am. Chem. Soc. 1994, 116, 3151.

9. Anand, N. K.; Carreira, E. M. J. Am. Chem. Soc. 2001, 123, 9687.

10. (a) Chen, Y.; Yekta, S.; Yudin, A. K. Chem. Rev. 2003, 103 (8), 3155. (b) Brunel, J. M. Chem. Rev. 2005, 105 (3), 857.

11. Shibasaki, M.; Sasai, H.; Arai, T. Angew. Chem. Int. Ed. 1997, 36, 1236.

12. (a) Liu, L.; Pu, L. Tetrahedron, 2004, 60, 7427-7430. (b) Qin, Y.; Liu, L.; Pu, L. 2005, 7 (12), 2381.

13. (a) Gao, G.; Xie, R.; Pu, L. PNAS, 2004, 101, 5417. (b) Yang, F.; Xi, P.; Yang, L. ; Lan, J. ; Xie, R. ; You, J. 2007, 72, 5457-5460.

14. (a) Du, Y.; Turlington, M; Zhou, X. ; Pu, L. Tetrahedron Lett. 2010, 51, 5024-5027.

(b) Zhou, L.-H. ; Yu, X.-Q. ; Pu, L. J. Org. Chem. 2009, 74, 2013-2017. (c) Zhou, L.H. ; Yu, X.-Q. ; Pu, L. Tetrahedron Lett. 2010, 51 (2), 425-427.

15. Li, Z. ; Liu, T.-D. ; Pu, L. J. Org. Chem. 2007, 72 (12), 4340-4343. 
16. Aragon, D. T.; Lopez, G. V.; Garcia-Tellado, F.; Marrero-Tellado, de Armas, P.; Terrero, D. J. Org. Chem. 2003, 68, 3365.

17. Trost, B.; Dake, G. J. Am. Chem. Soc. 1997, 119, 7595.

18. Aza-MBH reactivity involves the use of an imine, generally an aldimine (imine equivalent of an aldehyde), as the electrophilic substrate. Often, an $\mathrm{N}$-tosylated imine is used in the reaction. For a review, see: Masson, G.; Housseman, C.; Zhu, J. Angew. Chem. Int. Ed. 2007, 46, 4614-4628.

19. Liu, H. ; Leow, D.; Huang, K.-W.; Tan, C.-H. J. Am. Chem. Soc. 2009, 131, $7212-$ 7213.

20. (a) Turlington, M. ; Yue, Y.; Yu, X.-Q.; Pu, L. J. Org. Chem. 2010, 75 (20), 6941 6952. (b) Zhou, L.-H. ; Yu, X.-Q. ; Pu, L. J. Org. Chem.., 2009, 74, 2013-2017.

21. (a) Turlington, M.; DeBerardinis, A. M.; Pu, L. Org. Lett. 2009, 11, 2441-2444. (b) Yue, Y.; Yu, X.-Q.; Pu, L. Chem. Eur. J. 2009, 0000.

22. Midland, M. M.; Tramontano, A.; Cable, J. R. J. Org. Chem., 1980, 45, 28-29.

23. Zhang, W. ; Wu, H. ; Liu, Z. ; Zhong, P. ; Zhang, L. ; Huang, X. ; Cheng, J. Chem. Commun. 2006, 46, 4826-4828.

24. Nishi, N. ; Kosugi, K. U. S. Pat. Appl. Publ. 20050171370, 2005. 
Chapter 6: Additional Research Projects, Attempts and Discoveries

I. Attempted Asymmetric Additions

a. Catalytic Asymmetric Arylation of Ketones

b. Catalytic Asymmetric Arylation of Aldimines ( $N$-protected imines)

c. Extension of Arylzinc and Vinylzinc Generation Methodology to an Alkyl Iodide and Alkynyl Iodide: Catalytic Alkylation of Benzaldehyde and Catalytic Alkynylation of Cyclohexanecarboxaldehyde

d. Catalytic Asymmetric Allylations of Carbonyls

e. Catalytic Asymmetric Arene-Addition of Carbonyls

f. Attempted Synthesis of Chiral Allenes

g. Miscellaneous Reactivity:

i. 1,4-diol reactivity with methyl propiolate

ii. Catalytic Asymmetric Phenylation Attempts using Commerically Available Phenyl Reagents

iii. Attempted Vinylations Directly from Alkyne Reduction and Reaction with Aldehydes

iv. Catalytic Asymmetric Vinylation Attempts Using Vinyl Magnesium Bromide

II. Collaborative Work

a. Synthesis, Characterization and Reactivity of Chlorotris(triphenylphosphine)Iridium(I)

b. Experimental and Characterization

c. References 


\section{Attempted Asymmetric Additions}

\section{a. Catalytic Asymmetric Arylation of Ketones}

The identification of catalytic asymmetric methodology for the delivery of organozincs to ketones has been an intensive area of research. ${ }^{1}$ Methodology resulting in the asymmetric synthesis of tertiary alcohols has been rather elusive. The application of either the direct enantioselective addition of nucleophiles to aldehydes or the racemic synthesis of a secondary alcohol followed by oxidation and subsequent asymmetric reduction (i.e., Noyori BINAP-based hydrogenation) affords chiral secondary alcohols. Towards the preparation of chiral tertiary alcohols, such an alternate route is unavailable. Only a few studies have successfully applied asymmetric arylations to prochiral ketones. ${ }^{2}$

Our initial attempts—reactions between the arylzincs generated from 3iodoanisole and methyl-4-iodobenzoate and acetophenone under the optimal conditions found for additions to aldehydes — were disappointing. Only the aldol product (122) was formed (isolated in 34\% yield). The same result was obtained when the vinylzincs additions were attempted to this ketone. As a final attempt to study whether the organozinc generated in situ would be nucleophilic towards any ketone, a biaryl ketone (123) was prepared and tested. The use of this substrate would bypass the self-aldol pathway plaguing this reactivity, allowing us to determine if this arylation strategy could be operable on any level. (2-methoxyphenyl)(phenyl)methanol, previously synthesized, was readily converted to a ketone by reaction with base and stirring under aerobic conditions (see cited reference for our report using this strategy for general ketone synthesis). ${ }^{3}$ 
We were again disappointed by the lack of reactivity. No reaction was observed at room temperature over 14 hours. 1 equivalent of $\mathrm{MeOH}$ was added at this time, but another 24 hours showed only the ketone. 5 equivalents titanium tetraisopropoxide were added but failed again to facilitate reaction. From our previous studies, it is presumed that the organozinc degrades rapidly over time. (As such, the addition of methanol and finally titanium would not likely have an effect on the addition.) However, some level of addition would be expected if the pathway is workable. It appears that the substrate difference from aldehyde to ketone is high enough that addition completely fails. What is observed is the preference towards aldol reactivity in aliphatic ketones and no reactivity in a diaryl ketone screened using the current methodology. A tuning of the reaction conditions should be studied. For example, the amount of NMP required for the reaction to occur has not been fully elucidated. It is feasible that a smaller amount could be used. If NMP can be added as an additive (stoichiometric equivalents) or even a catalytic amount, perhaps the addition could proceed. Decreasing the polarity of the reaction medium may also decrease the hereto observed aldol preference.

The phenylzinc generated from iodobenzene reacted in the presence of $10 \mathrm{~mol} \%$ (S)-12 and 4'-bromoacetophenone to yield the self-aldol condensation product, 1,3-bis(4bromophenyl)-3-hydroxybutan-1-one (124). To form a potentially more active phenyl nucleophile in situ, after the phenylzinc was generated from iodobenzene and (S)-12 added, 1.0 equivalent of methanol (dried, distilled) was added and stirred 30 minutes. This reaction formed only aldol product as did the reaction in the absence of ligand again.

The racemic tertiary alcohol was prepared from the lithium—-halide exchange from iodobenze in $\mathrm{THF}$ at $0{ }^{\circ} \mathrm{C}$. After one hour, the ketone was added and the reaction 
was warmed to room temperature overnight. The phenyl-addition was the only product formed (125). The addition of titanium tetraisopropoxide (2 equivalents) or borontrifluoride (1.5 equivalents) after $(S)$-12 and prior to ketone addition still did not shut down the aldol pathway.

When a background (racemic) reaction was setup between diphenylzinc (2.0 equivalents) and this ketone, the aldol pathway was the only observed reactivity (over 3 days at room temperature). Another examination of the background reactivity was attempted by adding sequentially into dioxane (dried, distilled) diphenylzinc (4.0 equivalents), titanium tetraisopropoxide (2.0 equivalents), and ketone. Starting material was not consumed and the aldol product was formed.

The attempted thiophenylation of 4'-bromoacetophenone in THF, DCM, and 1,4dioxane yielded only the aldol product (reactions were done in the presence of $10 \mathrm{~mol} \%$ (S)-12). The only successful addition took place when the racemic product was synthesized from the reaction between lithiated-thiophene (from thiophene and $n$ butyllithium) followed by the addition of the ketone in THF (126).

With no successful ketone reactivity found using the developed arylation (or vinylation) methodologies, another route was tested. The zincate species had been proposed to operate by Knochel in the formation of the arylzincs when catalytic amounts of Li(acac) and some other salts are present. ${ }^{4}$ Others have studied zincate chemistry extensively. ${ }^{5}$ In particular to our objective, Ishihara et. al. have developed very useful synthetic methodologies based on reactive zincate species. ${ }^{6}$ Selective reactions using Grignard reagents were reported to afford tertiary compounds from additions to ketones 
and $N$-protected imines (over reduction byproducts). Examples of this methodology are shown in Scheme 6.1.

\section{Scheme 6.1 Example of Ishihara et. al. Selective Additions to Ketones From In Situ}

\section{Generated Zincate.}

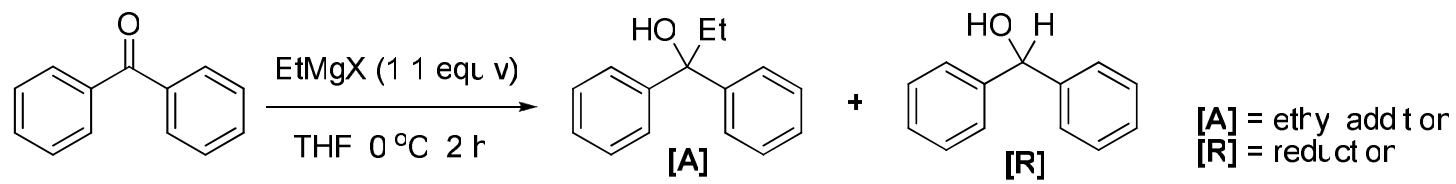
a) EtMgC
b) $\mathrm{EtMgEr}$
c) $\mathrm{EtMgC}+\mathrm{Et}_{2} \mathrm{Zr}$ (1 eqı v)
d) $\mathrm{EtMgC}+\mathrm{Et}_{2} \mathrm{Zr}(10 \mathrm{mo} \%)$
a) $25[\mathrm{~A}]: 71[\mathrm{R}]$
e) $\mathrm{EtMgC}+\mathrm{ZrC}_{2}(10 \mathrm{mo} \%)$
b) $20: 78$
c) $85: 6$
d) $84: 15$
e) $84: 15$

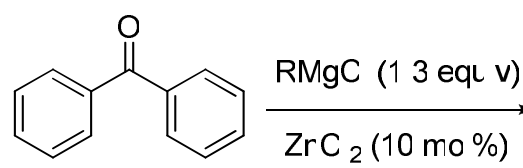
THF $0{ }^{\circ} \mathrm{C} 2 \mathrm{r}$
a) $\mathrm{R}=\mathrm{Me}$
b) $\mathrm{R}=i-\mathrm{Fr}$
c) $R=v r y$
d) $R=a y$
e) $R=E r$<smiles>CCC(O)(c1ccccc1)c1ccccc1</smiles>

a) $94[A]: 0$ [R]

b) $75: 10$

c) $96: 0$

d) $>99: 0$

e) $>99: 0$<smiles>OC(c1ccccc1)c1ccccc1</smiles>

[A] $=$ add $t$ or prodıct $[\mathrm{R}]=$ redı ct or

Result in the absence of $\mathrm{ZnCl}_{2}$ :

a) $91[A]: 0$ [R]

b) $62: 14$

c) $92: 0$

d) $>99: 0$

e) $90: 0$

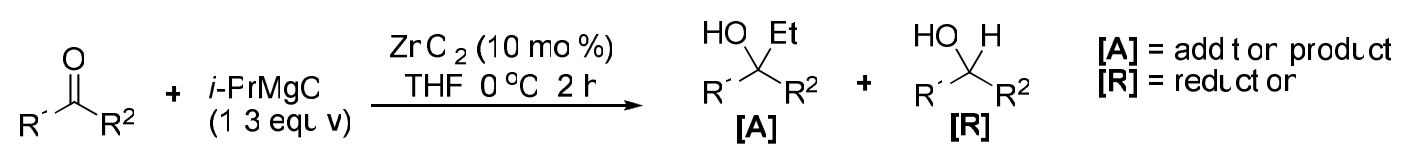
a) $\mathrm{R}^{\prime}=\mathrm{Fr} \mathrm{R}^{2}=\mathrm{Me}$
a) $85[\mathrm{~A}]: 0[\mathrm{R}]$
b) $R^{\prime}=\mathrm{Fr} R^{2}=\mathrm{Et}$
b) $95: 0$
c) $87: 12$
d) $80: 7$
e) $76: 0$
d) $R^{\prime}=4$-pyr dy $R^{2}=M e$
e) $R^{\prime}=1-r$ aprtry $R^{2}=M e$
a) 31 [A] : 11 [R]
b) $56: 38$
c) $38: 59$
d) $73: 11$
e) $33: 12$

Result in the absence of $\mathrm{ZnCl}_{2}$ :

The protocols vary in the formation of a zincate species, for example, either catalytic zinc chloride could be employed (typical reaction proceeds at $0{ }^{\circ} \mathrm{C}$ ) or the species can be generated by mixing a "nucleophile donor" to $\mathrm{R}_{2} \mathrm{Zn}$ (where $\mathrm{R}$ is alkyl, 
aryl). The nucleophilicity of these species has been demonstrated to be greatly enhanced in a similar fashion to Grignard and organolithium species.

The following racemic (background) reaction was performed. To a THF solution of diphenylzinc (2 equivalents), $\mathrm{PhMgBr} / \mathrm{Et}_{2} \mathrm{O}$ (at room temperature) was charged. After stirring one hour, 4'-bromoacetophenone was added. $65 \%$ of the phenyl-addition product (125) was isolated. When the reaction was carried out in the presence of $20 \mathrm{~mol} \%(S)-\mathbf{1 2}$ at $0{ }^{\circ} \mathrm{C}, 71 \%$ of the tertiary alcohol was isolated in $14 \%$ ee. This reaction was studied further. The reaction between diphenylzinc and 4'-bromoacetophenone in the presence of $20 \mathrm{~mol} \%(S)-12$ at room temperature formed $84 \%$ alcohol but in only $4 \%$ ee. When $\mathrm{PhMgBr} / \mathrm{THF}$ (2 equivalents) was stirred with $20 \mathrm{~mol} \%(S)-\mathbf{1 2}$ in THF at room temperature for 3 hours, followed by addition of 4'-bromoacetophenone, no addition product was observed. Only the aldol (124, major) and a small amount of reduction product were isolated.

The ligand amount was increased to $40 \mathrm{~mol} \%$ in the zincate reaction. 2 equivalents DPZ was mixed with $(S)-\mathbf{1 2}$ in THF. 1 equivalent of $\mathrm{PhMgBr} / \mathrm{THF}$ was then added. This mixture was stirred one hour at room temperature. The alcohol was isolated in $66 \%$ yield and $49 \%$ ee. This was a very promising result. We successfully applied the zincate methodology to generate good yields of a tertiary alcohol product and also showed some enantioselectivity (3:1). However, it appears that 1:1 ( $\%$ ligand to $\%$ ee product) relationship may exist and thus the reaction may not be catalytic. Nonetheless, the result was encouraging. The reaction was attempted using a commercially available phenyllithium solution ( 1.5 M solution in dibutylether) in place of the Grignard reagent but no reaction was observed. 
A solvent screen was performed using the following conditions: 2 equivalents $\mathrm{Ph}_{2} \mathrm{Zn}$ was mixed with $(S)-\mathbf{1 2}(40 \mathrm{~mol} \%)$ in solvent. Then, 1 equivalent of $\mathrm{PhMgBr} / \mathrm{THF}$ was added. This mixture was stirred one hour at room temperature prior to the ketone (4'-bromoacetophenone) addition. The alcohol was isolated from reactions in DCM, $\mathrm{Et}_{2} \mathrm{O}$, toluene, and a dioxane:THF (5:1) mixture. The only selectivity (17\% ee) was from the latter reaction in which the mixed system was required for a homogeneous reaction. When different Lewis acidic additives were screened to affect the reaction, only the aldol product was obtained. The screen was performed on reactions using 2 equivalents $\mathrm{Ph}_{2} \mathrm{Zn}$, $20 \mathrm{~mol} \%$ or $40 \mathrm{~mol} \%(S)-12,1.0$ equivalent $\mathrm{MgBr}_{2} \cdot \mathrm{OEt}_{2}$, and $20 \mathrm{~mol} \% \mathrm{Ti}\left(\mathrm{O}^{i} \mathrm{Pr}\right)_{4}$. All reactions were done in THF. After stirring $\mathrm{Ph}_{2} \mathrm{Zn}$ and the ligand for 30 minutes, the acid was added. This mixture was stirred 1.5 hours at room temperature followed by ketone addition.

The preference for delivering two potential nucleophiles present on the in situ prepared zincate was attempted. We also attempted to use diethylzinc in place of the zinc chloride reported by Ishihara. ${ }^{6}$ When 1.4 equivalents $\mathrm{PhMgBr}$ was added to $\mathrm{Et}_{2} \mathrm{Zn}$ (10 $\mathrm{mol} \%)$ in THF and reacted with 2-methoxybenzaldehyde (in the presence of $10 \mathrm{~mol} \%(S$ 12)), a highly complex mixture was formed including a small amount of addition product and more reduction product. When the reaction was done on 4'-bromoacetophenone, the racemic alcohol was selectively formed but in racemic form. $12 \%$ ee of the alcohol was obtained from the addition employing 2 equivalents $\mathrm{PhMgBr}$ and $20 \mathrm{~mol} \% \mathrm{Ph}_{2} \mathrm{Zn}$ in THF. $10 \mathrm{~mol} \%(S-\mathbf{1 2})$ was used again. When only 1.2 equivalents of the phenyl Grignard was employed, the alcohol was formed in $15 \%$ ee using $(S-\mathbf{1 2})$. We studied different ligands for the reaction. $10 \mathrm{~mol} \%(S-2)$ formed the alcohol in $18 \%$ ee and 10 
mol\% MT-(S)-1 afforded the alcohol in $6 \%$ ee. If $\mathrm{Ph}_{2} \mathrm{Zn}$ was replaced with $40 \mathrm{~mol} \%$ titanium tetraisopropoxide, $40 \mathrm{~mol} \%(S-12)$ and 1.2 equivalents $\mathrm{PhMgBr}$ in THF reacted to yield the racemic alcohol. The racemic alcohol was also obtained from the reactions in the presence of $40 \mathrm{~mol} \%$ of ephedrine, $40 \mathrm{~mol} \% \mathrm{~N}$-methylephedrine, and $40 \mathrm{~mol} \% 3$ morpholinomethyl-BINOL (a mono-substituted BINOL ligand). These reactions were attempted using 1 equivalent $\mathrm{PhMgBr}$ mixed with 2 equivalents $\mathrm{Ph}_{2} \mathrm{Zn}$.

The addition of the functional arylzincs to two $\alpha$-ketoester substrates was studied. Additions to these substrates would generate functional tertiary alcohols (containing an $\alpha$ ester group) and a number of asymmetric catalytic alkylation methods have been reported. $^{7}$ The optimal conditions were used to attempt the thiophenylation of ethyl benzoylformate and ethyl pyruvate (shown below).<smiles>CCOC(=O)C(=O)c1ccccc1</smiles>

No reaction occurred. The reaction between the anisylzinc and ethyl benzoylformate also failed at room temperature. Diphenylzinc prepared from iodobenzene and $\mathrm{Et}_{2} \mathrm{Zn}$ did not react at room temperature for 14 hours. 3 equivalents of titanium tetraisopropoxide were added but to no avail. The attempted (anisyl) ${ }_{2}$ zinc addition to ethyl pyruvate failed but the (p-methyl esterbenzoate) ${ }_{2}$ zinc proceeded to yield $20 \%$ product. No route was found to prepare the racemic alcohol. Decomposition was observed in the lithium-iodide exchange at $-78^{\circ} \mathrm{C}$ and there was no background reactivity between the in situ generated diarylzinc and ethyl pyruvate. Thus, the enantioselectivity was not determined.

\section{Experimental and Characterization:}


123 (2-methoxyphenyl)(3-methoxyphenyl) ketone<smiles>COc1cccc(C(O)c2ccccc2OC)c1</smiles>

To a solution of (2-methoxyphenyl)(phenyl)methanol in THF was added sodium hydride (1.6 equivalents, $\sim 60 \% \mathrm{NaH}$ mineral dispersion). The reaction mixture was allowed to stir at room temperature in a flask that was left open to the atmosphere. After 8 hours, the TLC showed the complete disappearance of the starting alcohol and a single new spot identified as the oxidation product. The ketone was isolated in $96 \%$ yield after workup and silica gel column chromatography (eluent: hexanes to $3 \%$ ethyl acetate in hexanes). The oxidation also took place when 2.0 equivalents of potassium tert-butoxide was used as the base in THF. The alcohol was consumed in less than 12 hours but only a small amount of the ketone was isolated. The reaction was attempted using potassium hydroxide and potassium carbonate (5 equivalents each) in methanol (dried over activated $\mathrm{CaSO}_{4}$ and stored over $4 \AA$ molecular sieves), but failed to react over 24 hours (only starting alcohol was observed on TLC).

${ }^{1} \mathrm{H}$ NMR $\left(300 \mathrm{MHz}, \mathrm{CDCl}_{3}\right) \delta 7.50(\mathrm{~m}, 2 \mathrm{H}), 7.36(\mathrm{~m}, 3 \mathrm{H}), 7.15(\mathrm{~m}, 1 \mathrm{H}), 7.05(\mathrm{~m}, 2 \mathrm{H})$, $3.88(\mathrm{~s}, 3 \mathrm{H}), 3.77$ (s, 3H).<smiles>CC(O)(c1ccc(Br)cc1)c1ccc(I)cc1</smiles>

${ }^{1} \mathrm{H}$ NMR (300 MHz, $\left.\mathrm{CDCl}_{3}\right) \delta 7.35$ (m, 9H), 2.16 (s, 1H), 1.93 (s, 3H). HPLC: chiralcel AD-H column; solvent ratio: 98:2 hexanes:isopropanol, flow rate: $1 \mathrm{~mL} / \mathrm{min} . R T s=18$, $20 \min (254 \mathrm{~nm})$. 
$124 \mathrm{Br}$

${ }^{1} \mathrm{H}$ NMR $\left(300 \mathrm{MHz}, \mathrm{CDCl}_{3}\right) \delta 7.75(\mathrm{~d}, J=8.6 \mathrm{~Hz}, 2 \mathrm{H}), 7.60(\mathrm{~d}, J=8.6 \mathrm{~Hz}, 2 \mathrm{H}), 7.43(\mathrm{~d}$, $J=8.6 \mathrm{~Hz}, 2 \mathrm{H}), 7.33(\mathrm{~d}, J=8.6 \mathrm{~Hz}, 2 \mathrm{H}), 4.71(\mathrm{~s}, 1 \mathrm{H}), 3.70(\mathrm{~d}, J=17.5 \mathrm{~Hz}, 1 \mathrm{H}), 3.28(\mathrm{~d}$, $J=17.5 \mathrm{~Hz}, 2 \mathrm{H}), 1.57(\mathrm{~s}, 3 \mathrm{H})$.

122

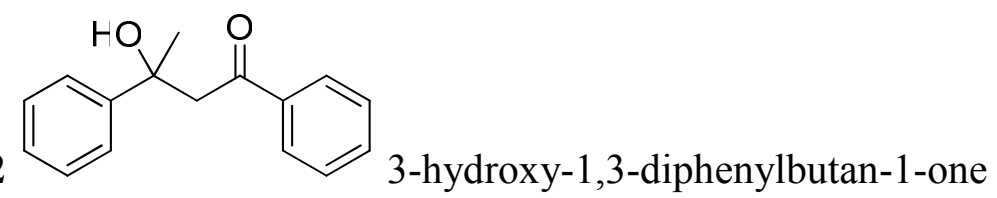

${ }^{1} \mathrm{H}$ NMR $\left(300 \mathrm{MHz}, \mathrm{CDCl}_{3}\right) \delta 7.29(\mathrm{~m}, 10 \mathrm{H}), 4.90(\mathrm{~m}, 1 \mathrm{H}), 3.04(\mathrm{~m}, 2 \mathrm{H}), 2.17$ (br-s, 1H). ${ }^{13} \mathrm{C} \mathrm{NMR}\left(77 \mathrm{MHz}, \mathrm{CDCl}_{3}\right) \delta 143.7,137.9,129.4,128.3,128.3,127.5,126.4$, 125.8, 75.2, 45.9. HPLC: chiralcel OD column; solvent ratio: 90:10 hexanes:isopropanol, flow rate: $1 \mathrm{~mL} / \mathrm{min} . R T s=12,16 \mathrm{~min}(292 \mathrm{~nm})$

$126 \mathrm{Br}$ ${ }^{1} \mathrm{H}$ NMR (300 MHz, $\left.\mathrm{CDCl}_{3}\right) \delta 7.49(\mathrm{~m}, 2 \mathrm{H}), 7.40(\mathrm{~m}, 2 \mathrm{H}), 7.28(\mathrm{~m}, 1 \mathrm{H}), 6.95(\mathrm{~m}, 2 \mathrm{H})$, $2.56(\mathrm{~m}, 1 \mathrm{H}), 2.02(\mathrm{~s}, 3 \mathrm{H})$.<smiles>COc1ccccc1C(O)c1ccccc1</smiles>

${ }^{1} \mathrm{H}$ NMR $\left(300 \mathrm{MHz}, \mathrm{CDCl}_{3}\right) \delta 7.32(\mathrm{~m}, 7 \mathrm{H}), 6.95(\mathrm{~m}, 1 \mathrm{H}), 6.90(\mathrm{~d}, J=8.2 \mathrm{~Hz}, 1 \mathrm{H}), 6.07$ $(\mathrm{d}, J=5.5 \mathrm{~Hz}, 1 \mathrm{H}), 3.81(\mathrm{~s}, 3 \mathrm{H}), 3.08(\mathrm{~d}, J=5.5 \mathrm{~Hz}, 1 \mathrm{H})$.

75<smiles>CCC(O)c1cccc(OC)c1</smiles> 
${ }^{1} \mathrm{H}$ NMR $\left(300 \mathrm{MHz}, \mathrm{CDCl}_{3}\right) \delta 7.30(\mathrm{~m}, 1 \mathrm{H}), 6.97(\mathrm{~m}, 2 \mathrm{H}), 6.87(\mathrm{~m}, 1 \mathrm{H}), 4.71(\mathrm{~s}, 2 \mathrm{H})$, 3.90 (br-s, 1H), 3.85 (s, 3H).

76<smiles>COc1cccc(CO)c1</smiles>

${ }^{1} \mathrm{H}$ NMR $\left(300 \mathrm{MHz}, \mathrm{CDCl}_{3}\right) \delta 7.30(\mathrm{~m}, 1 \mathrm{H}), 6.97(\mathrm{~m}, 2 \mathrm{H}), 6.87(\mathrm{~m}, 1 \mathrm{H}), 4.71(\mathrm{~s}, 2 \mathrm{H})$, 3.90 (br-s, 1H), $3.85(\mathrm{~s}, 3 \mathrm{H})$.<smiles>CCOC(=O)C(C)(O)c1ccc(C(C)=O)cc1</smiles>
methyl 4-(1-ethoxy-2-hydroxy-1-oxopropan-2-yl)benzoate ${ }^{1} \mathrm{H}$ NMR $\left(300 \mathrm{MHz}, \mathrm{CDCl}_{3}\right) \delta 8.00(\mathrm{~d}, J=8.5 \mathrm{~Hz}, 2 \mathrm{H}), 7.64(\mathrm{~d}, J=8.5 \mathrm{~Hz}, 2 \mathrm{H}), 4.22(\mathrm{~m}$, 2H), 3.92 (br-s, 1H), $3.90(\mathrm{~s}, 3 \mathrm{H}), 1.77$ (s, 3H), 1.24 (t, $J=7.1 \mathrm{~Hz}, 3 \mathrm{H})$.<smiles>CCC(O)c1ccc(OC)cc1</smiles>
${ }^{1} \mathrm{H}$ NMR $\left(300 \mathrm{MHz}, \mathrm{CDCl}_{3}\right) \delta 7.26(\mathrm{~m}, 2 \mathrm{H}), 6.88(\mathrm{~m}, 2 \mathrm{H}), 4.54(\mathrm{t}, J=6.1 \mathrm{~Hz}, 1 \mathrm{H}), 3.80$ (s, 3H), $1.76(\mathrm{~m}, 2 \mathrm{H}), 0.90(\mathrm{t}, J=7.4 \mathrm{~Hz}, 3 \mathrm{H})$.

\section{b. Catalytic Asymmetric Arylation of Aldimines ( $N$-protected imines)}

The importance of chiral arylmethines obtained from the asymmetric arylation of imines has also been studied. These compounds have been identified as potential pharmaceuticals with antioxidant, angiogenesis activity and other applications. ${ }^{7} \mathrm{~N}-$ tosylaldimines from benzaldehyde (128) and 4-chlorobenzaldehyde (129) were prepared according to literature procedures. Asymmetric functional arylzinc additions to $N$-tosyl protected aromatic imines were tested. The initial screens showed good reactivity but 
none of the reactions proceeded with any selectivity. As shown in the following figure, the arylzincs add to $N$-tosylaldimines comparably to the reaction with aldehydes.

Figure 6.1 Arylzinc Additions to $N$-Tosylaldimines.

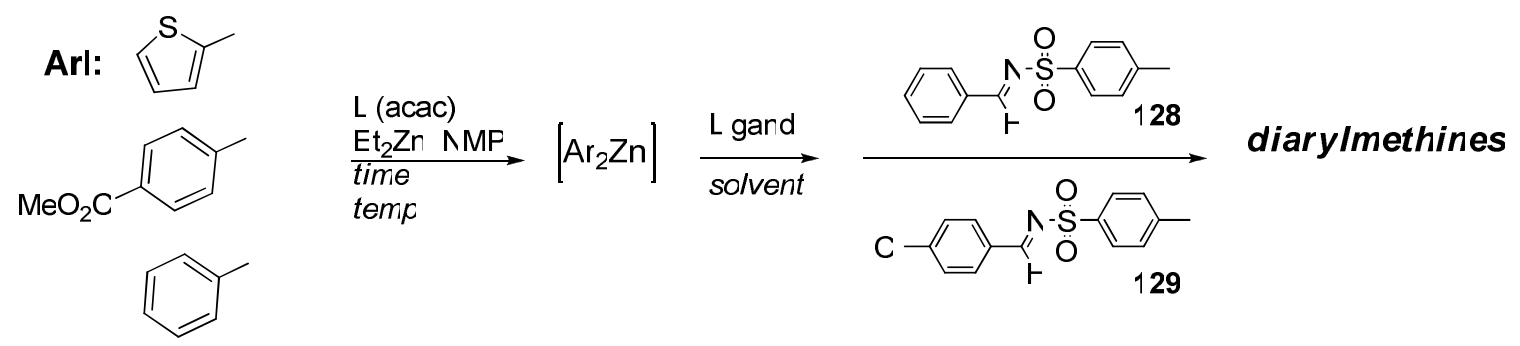

After 1.2 equivalents (relative to aldimine) diphenylzinc was mixed with $S$-12 (10 mol\%) in THF for one hour at room temperature, followed by $\mathbf{1 2 9}, 38 \%$ diaryl-substituted sulfonamide (130) was isolated as a racemate. The racemic reaction (no ligand present) was monitored and $55 \%$ of the diaryl-substituted sulfonamide was isolated. The diphenylzinc addition was also tested with $N$-tosylaldimine 128. 2.0 equivalents DPZ and the aldimine were added to a round bottom flask, charged with THF and stirred for 24 hours. $79 \%$ of the diphenyl-sulfonamide (131) was isolated.

We envisioned the design of a substrate-facilitated asymmetric addition. To accomplish this, we tested the thiophenylation of an $N$-tosylaldimine containing a Lewis basic group that could potentially assist in the aryl delivery, affording the asymmetric addition in the presence of an amino alcohol ligand. 2-methoxy-4-methyl-N(phenyl(thiophen-2-yl)methyl)benzenesulfonamide (132) was prepared under the same conditions used for the other $N$-tosylaldimines. Three reactions were tested using the electrophilic reagent. The racemic thiophenylation was accomplished from a lithiated thiophene. Two asymmetric experiments were done: 1) reaction using same conditions reported for the typical thiophenylation but exchanging the THF solvent for DCM to limit 
Lewis basic interference from the solvent (although the presence of NMP would potentially override this); and 2) reaction employing $50 \mathrm{~mol} \% \mathrm{Ti}\left(\mathrm{O}^{i} \mathrm{Pr}\right)_{4}(50 \mathrm{~mol} \%$ relative to aldimine; 5 times the amount of ligand used; DCM used as solvent). The latter reaction aimed at determining if the presence of the oxophilic titanium, a coordination complex between the metal atom and substrate, e.g. $O$-methoxy and an oxygen atom of the sulfonamide group could aid in the facial discrimination not realized for these substrates. This is depicted in the figure below (one "arm" of the disubstituted ligand has been left out for clarity).

Figure 6.2 Potential Substrate-Chelation Control in Asymmetric Thiophenylation of an $O$-methoxy, $N$-tosylaldimine.

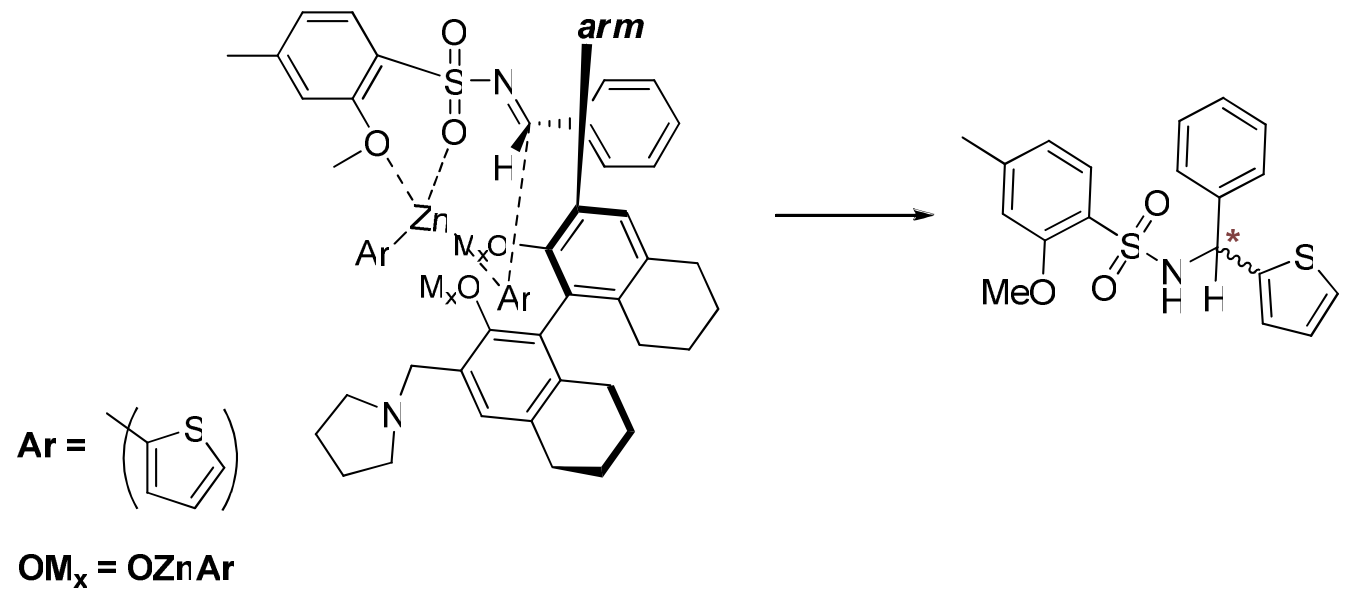

The racemic synthesis was accomplished from the lithium-halogen exchange between 2-bromothiophene and $n$-butyllithium at $-78{ }^{\circ} \mathrm{C}$. Upon addition of the 132, the reaction proceeded quickly and $\mathbf{1 3 2}$ was consumed as the reaction was warmed to room temperature. The reaction employing the typical thiophenylation conditions (using DCM as solvent) afforded $65 \%$ product (133) with no selectivity. When the titanium reagent was present, $58 \%$ product was isolated as the racemic diaryl-substituted sulfonamide again. 
With no enantioselectivity realized from our established catalytic asymmetric arylation methodology or in the presence of a Lewis acidic titanium reagent, we decided to further explore this latter strategy. A Lewis acid screen was therefore performed. The general scheme is shown below.

Scheme 6.2 Lewis Acid Study for the Asymmetric Thiophenylation of N-(4chlorobenzylidene)-4-methylbenzenesulfonamide.

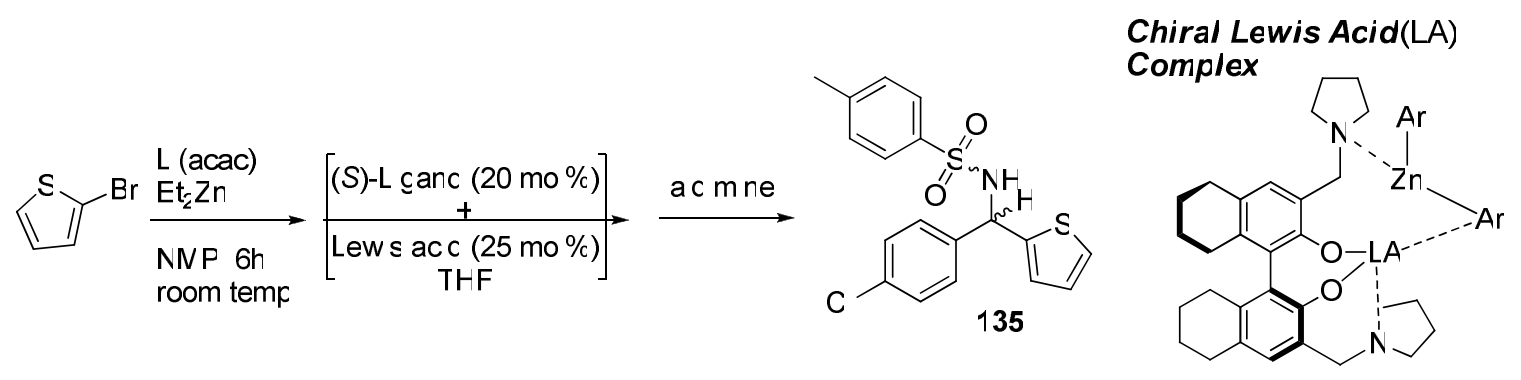

Table 6.1 below shows the results of these screens. It was found that in the presence of copper (I or II) salts, an increase in enantioselectivity was observed for the addition.

Table 6.1 Lewis Acid Screen for the Thiophenylzinc Addition to $\mathrm{N}$-(4chlorobenzylidene)-4-methylbenzenesulfonamide. ${ }^{a}$

\begin{tabular}{ccc}
\hline Entry & Lewis Acid & ee (\%) $)^{\mathbf{b}}$ \\
\hline 1 & None & 0 \\
2 & $\mathrm{AlMe}_{3}$ & 0 \\
3 & $\mathrm{Cu}(\mathrm{OTf})_{2}$ & 14 \\
4 & $\mathrm{CuI}$ & 32 \\
5 & $\mathrm{Co}(\mathrm{acac})_{3}$ & -- \\
6 & $\mathrm{InBr}_{3}$ & 4 \\
7 & $\mathrm{Sm}\left(\mathrm{O}^{\mathrm{i}} \mathrm{Pr}\right)_{3}$ & 0
\end{tabular}




$\begin{array}{ccc}8 & \mathrm{ZrCl}_{4} & 10 \\ 9 & \mathrm{RuCl}_{3} & -- \\ 10 & \mathrm{CeCl}_{3} \cdot \mathrm{H}_{2} \mathrm{O} & 0 \\ 11 & \mathrm{Y}\left(\mathrm{O}^{i} \mathrm{Pr}\right)_{3} & 0\end{array}$

a) Reaction conditions (the conditions used for the reaction of 2-bromothiophene were used here). Step 1: 2-bromothiophene (1.34 mmoL, 2.2 equiv), Li(acac) (0.16 mmoL, 26 mol\%), $\mathrm{Et}_{2} \mathrm{Zn}(0.738 \mathrm{mmoL}, 1.21$ equiv) and NMP (1 mL) are stirred at room temperature for 6 hours. Step 2: A solution of $(S)-\mathbf{1 2}(0.122 \mathrm{mmoL}, 20 \mathrm{~mol} \%)$ in THF $(5.0 \mathrm{~mL})$ and a Lewis acid $(0.16 \mathrm{mmoL}, 25 \mathrm{~mol} \%)$ was prepared (allowed to mix 5 hours at room temperature); the ligand - Lewis acid complex solution was transferred into the thiophenylzinc solution. Step 3: aldimine was added. Reaction was allowed to stand at room temperature for 12 hours.

b) ee measured by chiral HPLC (chiralcel OD column, $1 \mathrm{~mL} / \mathrm{min}, 90: 10$ hexanes:IPA, $R T S=15.0,20.3 \mathrm{~min})$. “--“ represents reaction where no aryl addition product was recovered.

A Lewis acid—ligand complex was initially formed in THF by mixing a 1.3:1.0 ratio of the Lewis acid and $(S)-\mathbf{1 2}$ at room temperature for 5 hours. This was then added into the formed diarylzinc generated from 2-bromothiophene. The mixture was stirred for another hour before the addition of $N$-tosylaldimine 129. Each reaction was stirred 12-16 hours at room temperature. There was an interesting finding in all the attempted arylations to the $N$-tosylaldimines. A varying amount of the ethyl addition product to the aldimine was typically observed, sometimes in a significant amount, affording an 
alkyl,aryl-substituted sulfonamide. However, the conditions employed for these additions have been found to have no reactive ethyl group present when in the presence of an aldehyde. We have verified the formation of iodoethane in NMR experiments performed (and also the consumption of diethylzinc). Iodoethane is formed from the Li(acac) catalyzed ligand exchange between the aryl iodide and diethylzinc. In a potential metathesis transition, the aryl-carbon—zinc bond could form simultaneously with the formation of the new alkyl-carbon — halide (ethyl iodide) bond. The presence of 2 equivalents of iodoethane could react with the $N$-tosylaldimine competitively with arylation. Theoretically this could occur if the nitrogen displaces the iodide forming an intermediate quaternary ammonium compound. This compound can rearrange to form the new carbon — carbon bond as shown in the figure below (NMR data for ethyl addition to compound 129 given in Experimental and Characterization below; 134).

Figure 6.3 Proposed Mechanism Leading to Formation of Ethyl Addition Product to $N$-tosylaldimine.<smiles>CCC(F)=NS(=O)(=O)c1ccc(C)cc1</smiles>

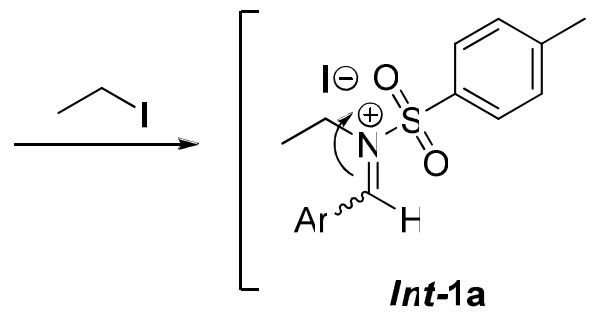<smiles>CCN([C@@H]([18O])Cl)S(=O)(=O)c1ccc(I)cc1</smiles>

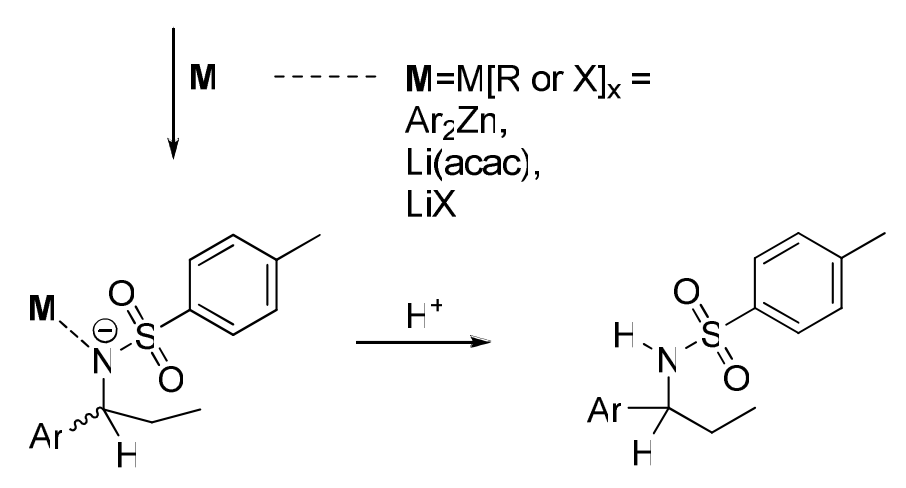


The benzylic cation represented in Int-1b is potentially further stabilized by the sulfonamide oxygen atoms. If this pathway exists, this could be the reason why the background reaction (uncatalyzed in the presence of amino alcohol ligand) proceeds and no selectivity is observed. It is possible that Int-1a could be activated towards aryl addition as well although this compound was not isolated (typical quench of reactions was done with a saturated ammonium chloride solution). One way to bypass this reactivity would be to study the additions to aldimines containing other $\mathrm{N}$-protection groups. Phospho- groups could display similar reactivity, but alkyl silanes would be chemically distinct with no coordinating potential. Literature reports have demonstrated that the group attached to the nitrogen significantly affects the addition and enantioselectivity governing asymmetric chiral methines synthesis. ${ }^{8}$

\section{Experimental and Characterization:}<smiles>Cc1ccc(S(=O)(=O)N=C(F)c2ccc([As])cc2)cc1</smiles>

(E)-N-benzylidene-4-methylbenzenesulfonamide

The title $N$-tosylaldimine was prepared according to the final procedure: in a $250 \mathrm{~mL}$ RBF equipped with a stir bar and Dean-stark water separator and condenser was loaded 6

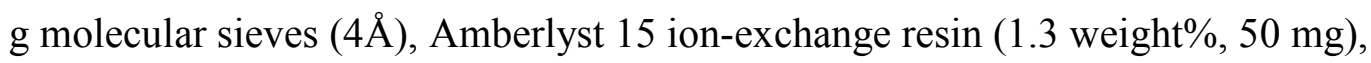
benzenesulfonamide (1.0 equiv, $40.55 \mathrm{mmoL}$ ), toluene $(75 \mathrm{~mL}$ ) and finally benzaldehyde (1.1 equiv, $5 \mathrm{~g}$ ) and a catalytic amount of p-toluenesulfonic acid ( $\sim 2 \mathrm{~mol} \%)$. The mixture was refluxed for 16 hours. At 10 hours reaction time, it appears that $0.6 \mathrm{~mL}$ water had collected in the Dean-stark water trap and thus reaction was close to completion. After 
cooling the mixture to room temperature, the crude contents were filtered over a pad of celite and washed with pentanes. Immediately following the evaporation of the reaction mixture, it was recrystallized using pentanes. 2 crops yielded $80 \%$ of the title compound. The compound was dissolved in dry, oxygen-free THF (in a clean, flame-dried RBF), stirred 8-12 hours, and evacuated to accomplish a moisture-free aldimine.

${ }^{1} \mathrm{H}$ NMR $\left(300 \mathrm{MHz}, \mathrm{CDCl}_{3}\right) \delta 9.03(\mathrm{~s}, 1 \mathrm{H}), 7.91(\mathrm{~m}, 4 \mathrm{H}), 7.61(\mathrm{~m}, 1 \mathrm{H}), 7.49(\mathrm{~m}, 2 \mathrm{H})$, $7.35(\mathrm{~d}, J=8.0 \mathrm{~Hz}, 2 \mathrm{H}), 2.43(\mathrm{~s}, 3 \mathrm{H})$.

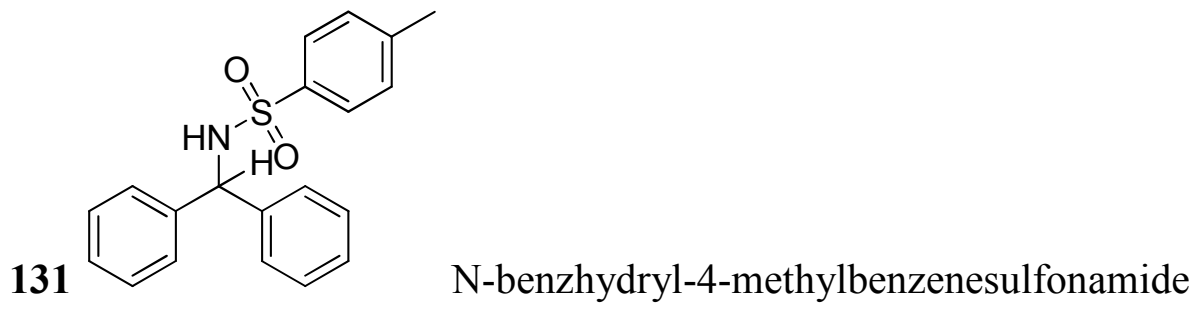
$79 \%$ yield. ${ }^{1} \mathrm{H}$ NMR $\left(300 \mathrm{MHz}, \mathrm{CDCl}_{3}\right) \delta 7.60(\mathrm{~d}, J=8.2 \mathrm{~Hz}, 2 \mathrm{H}), 7.21(\mathrm{~m}, 12 \mathrm{H}), 5.61$ $(\mathrm{d}, J=7.1 \mathrm{~Hz}, 1 \mathrm{H}), 5.20(\mathrm{~d}, J=6.9 \mathrm{~Hz}, 1 \mathrm{H}), 2.41(\mathrm{~s}, 3 \mathrm{H})$.

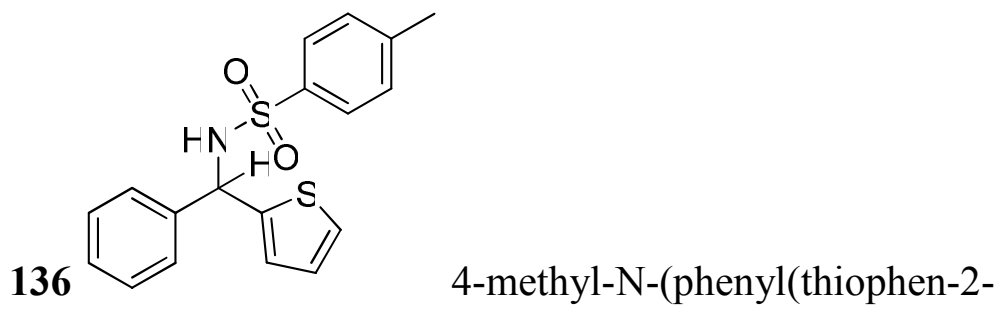

yl)methyl)benzenesulfonamide

${ }^{1} \mathrm{H}$ NMR (300 MHz, $\left.\mathrm{CDCl}_{3}\right) \delta 7.29(\mathrm{~m}, 10 \mathrm{H}), 4.90(\mathrm{~m}, 1 \mathrm{H}), 3.04(\mathrm{~m}, 2 \mathrm{H}), 2.17$ (br-s, 1H). ${ }^{13} \mathrm{C} \mathrm{NMR}\left(77 \mathrm{MHz}, \mathrm{CDCl}_{3}\right) \delta 143.7,137.9,129.4,128.3,128.3,127.5,126.4$, 125.8, 75.2, 45.9. HPLC: chiralcel OD column; solvent ratio: 90:10 hexanes:isopropanol, flow rate: $1 \mathrm{~mL} / \mathrm{min} . R T s=12,16 \mathrm{~min}$ 


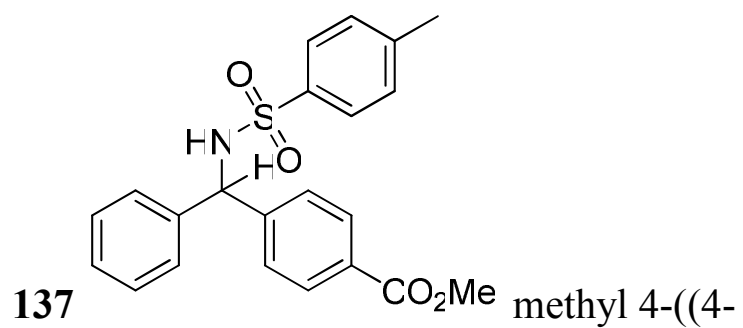

methylphenylsulfonamido)(phenyl)methyl)benzoate

${ }^{1} \mathrm{H}$ NMR $\left(300 \mathrm{MHz}, \mathrm{CDCl}_{3}\right) \delta 7.87(\mathrm{~d}, J=8.4 \mathrm{~Hz}, 2 \mathrm{H}), 7.56(\mathrm{~d}, J=8.3 \mathrm{~Hz}, 2 \mathrm{H}), 7.21(\mathrm{~m}$, 5H), $7.13(\mathrm{~d}, J=8.0 \mathrm{~Hz}, 2 \mathrm{H}), 7.03(\mathrm{~m}, 2 \mathrm{H}), 5.60$ (d, $J=7.2 \mathrm{~Hz}, 1 \mathrm{H}), 5.29$ (br-s, 1H), $3.88(\mathrm{~s}, 3 \mathrm{H}), 2.37(\mathrm{~s}, 3 \mathrm{H}) .{ }^{13} \mathrm{C} \mathrm{NMR}\left(77 \mathrm{MHz}, \mathrm{CDCl}_{3}\right) \delta 143.7,137.9,129.4,128.3$, 128.3, 127.5, 126.4, 125.8, 75.2, 45.9. HPLC: chiralcel OD column; solvent ratio: 90:10 hexanes:isopropanol, flow rate: $1 \mathrm{~mL} / \mathrm{min} . R T s=12,16 \mathrm{~min}$<smiles>Cc1ccc(/C(F)=N/S(=O)(=O)c2ccc(C)cc2)cc1</smiles>

(E)-N-(4-chlorobenzylidene)-4-

methylbenzenesulfonamide

The title compound was prepared using the same conditions as done for the benzaldehyde-based $\mathrm{N}$-tosylaldimine. $80 \%$ yield was recovered from the first crop of crystals (recrystallization done using pentanes).

${ }^{1} \mathrm{H}$ NMR $\left(300 \mathrm{MHz}, \mathrm{CDCl}_{3}\right) \delta 8.98(\mathrm{~s}, 1 \mathrm{H}), 7.86(\mathrm{~m}, 4 \mathrm{H}), 7.46(\mathrm{~d}, J=7.3 \mathrm{~Hz}, 2 \mathrm{H}), 7.34$ $(\mathrm{d}, J=7.7 \mathrm{~Hz}, 2 \mathrm{H}), 2.43(\mathrm{~s}, 3 \mathrm{H})$. 
130

methylbenzenesulfonamide

${ }^{1} \mathrm{H}$ NMR $\left(300 \mathrm{MHz}, \mathrm{CDCl}_{3}\right) \delta 7.55(\mathrm{~d}, J=8.3 \mathrm{~Hz}, 2 \mathrm{H}), 7.18(\mathrm{~m}, 7 \mathrm{H}), 7.04(\mathrm{~m}, 4 \mathrm{H}), 5.53$ $(\mathrm{d}, J=7.0 \mathrm{~Hz}, 1 \mathrm{H}), 5.17(\mathrm{~d}, J=6.3 \mathrm{~Hz}, 1 \mathrm{H}), 2.39(\mathrm{~s}, 3 \mathrm{H}) .{ }^{13} \mathrm{C} \mathrm{NMR}\left(77 \mathrm{MHz}, \mathrm{CDCl}_{3}\right) \delta$ 143.7, 137.9, 129.4, 128.3, 128.3, 127.5, 126.4, 125.8, 75.2, 45.9. HPLC: chiralcel OD column; solvent ratio: 90:10 hexanes:isopropanol, flow rate: $1 \mathrm{~mL} / \mathrm{min} . R T s=12,15.3$ $\min$<smiles>Cc1ccc(C(N)(NS(=O)(=O)c2ccc(C)cc2)c2ccccc2)cc1</smiles>
methylbenzenesulfonamide ${ }^{1} \mathrm{H}$ NMR $\left(300 \mathrm{MHz}, \mathrm{CDCl}_{3}\right) \delta 7.56(\mathrm{~d}, J=8.3 \mathrm{~Hz}, 2 \mathrm{H}), 7.17(\mathrm{~m}, 7 \mathrm{H}), 6.83(\mathrm{~m}, 1 \mathrm{H}), 6.64$ $(\mathrm{d}, J=3.5 \mathrm{~Hz}, 1 \mathrm{H}), 5.75(\mathrm{~d}, J=7.5 \mathrm{~Hz}, 1 \mathrm{H}), 5.43(\mathrm{~d}, J=7.5 \mathrm{~Hz}, 1 \mathrm{H}), 2.39(\mathrm{~s}, 3 \mathrm{H})$. HPLC: chiralcel OD column; solvent ratio: 90:10 hexanes:isopropanol, flow rate: 1 $\mathrm{mL} / \mathrm{min} . R T s=13,18 \mathrm{~min}$.<smiles>CCC(F)(NS(=O)(=O)c1ccc(C)cc1)c1ccc(C)cc1</smiles>

N-(1-(4-chlorophenyl)propyl)-4-

methylbenzenesulfonamide 
${ }^{1} \mathrm{H}$ NMR $\left(300 \mathrm{MHz}, \mathrm{CDCl}_{3}\right) \delta 7.56(\mathrm{~d}, J=8.3 \mathrm{~Hz}, 2 \mathrm{H}), 7.12(\mathrm{~m}, 4 \mathrm{H}), 6.98(\mathrm{~d}, J=8.4 \mathrm{~Hz}$, 2H), $5.70(\mathrm{~d}, J=7.5 \mathrm{~Hz}, 1 \mathrm{H}), 4.19(\mathrm{q}, J=7.3 \mathrm{~Hz}, 1 \mathrm{H}), 2.40(\mathrm{~s}, 3 \mathrm{H}), 1.74(\mathrm{~m}, 2 \mathrm{H}), 0.80(\mathrm{t}$, $J=7.4 \mathrm{~Hz}, 3 \mathrm{H}) .{ }^{13} \mathrm{C} \mathrm{NMR}\left(77 \mathrm{MHz}, \mathrm{CDCl}_{3}\right) \delta 143.4,139.5,137.7,133.2,129.8,129.2$, $128.9,128.6,128.3,128.0,127.6,126.9,59.5,30.7,21.7,10.7$.

132<smiles>COc1cc(I)ccc1S(=O)(=O)N=C(F)c1ccccc1</smiles>

N-benzylidene-2-methoxy-4-methylbenzenesulfonamide 2-methoxy-4-methylbenzenesulfonamide (95\%) was purchased from Matrix Scientific. The title compound was submitted to the same conditions used to prepare the benzaldehyde and 4-chlorobenzaldehyde based $N$-tosylaldimines. After evacuation of the crude reaction mixture, recrystallization from pentanes failed (oily residue). The crude NMR showed some excess benzaldehyde that was not evaporated. Flash column chromatography removed the excess aldehyde (fraction 1). The second fraction was the pure title compound ( $75 \%$ yield $)$.

${ }^{1} \mathrm{H}$ NMR $\left(300 \mathrm{MHz}, \mathrm{CDCl}_{3}\right) \delta 9.09(\mathrm{~s}, 1 \mathrm{H}), 7.93(\mathrm{~m}, 3 \mathrm{H}), 7.59(\mathrm{~m}, 1 \mathrm{H}), 7.47(\mathrm{~m}, 2 \mathrm{H})$, $6.90(\mathrm{~m}, 1 \mathrm{H}), 6.75(\mathrm{~s}, 1 \mathrm{H}), 3.77(\mathrm{~s}, 3 \mathrm{H}), 2.37(\mathrm{~s}, 3 \mathrm{H})$.

133<smiles>COc1cc(C)ccc1C(=O)NC(F)(c1ccccc1)c1cccs1</smiles>

2-methoxy-4-methyl-N-(phenyl(thiophen-2-

yl)methyl)benzenesulfonamide

${ }^{1} \mathrm{H}$ NMR $\left(300 \mathrm{MHz}, \mathrm{CDCl}_{3}\right) \delta 7.72(\mathrm{~d}, J=7.9 \mathrm{~Hz}, 1 \mathrm{H}), 7.18(\mathrm{~m}, 4 \mathrm{H}), 7.10(\mathrm{~m}, 2 \mathrm{H}), 6.81$ (m, 2H), $6.62(\mathrm{~d}, J=3.4 \mathrm{~Hz}, 1 \mathrm{H}), 6.49(\mathrm{br}-\mathrm{s}, 1 \mathrm{H}), 5.60(\mathrm{~s}, 1 \mathrm{H}$; hidden broadened singlet 
in signal, 1H), $3.58(\mathrm{~s}, 3 \mathrm{H}), 2.35(\mathrm{~s}, 3 \mathrm{H})$. HPLC: chiralcel OD column; solvent ratio: 95:5 hexanes:isopropanol, flow rate: $1 \mathrm{~mL} / \mathrm{min} . R T s=27,31 \mathrm{~min}$

\section{c. Extension of Arylzinc and Vinylzinc Generation Methodology to an Alkyl Iodide and Alkynyl Iodide: Catalytic Alkylation of Benzaldehyde and Catalytic}

\section{Alkynylation of Cyclohexanecarboxaldehyde}

During our work on developing conditions for the generation of functional arylzincs, phenylzinc, and vinylzincs and their catalytic asymmetric additions to aldehydes, methodology was explored to prepare other nucleophilic zinc reagents. Using the reported methods typically failed when attempting reaction with an aryl bromide in place of the aryl iodide. A significant discovery was identified when 2-bromothiophene reacted almost equally (yields and ee's of products formed) compared to 2-

iodothiophene. ${ }^{9}$ Notable in this finding and from further conditions explored was that no $\mathrm{Li}(\mathrm{acac})$ was required in the reaction of 2-iodothiophene while it was necessary for the reaction employing 2-bromothiophene. Conditions for 2-chlorothiophene were not found (the same methods used for the other thiophenes failed). Furthermore, 2-bromothiazole also failed to react.

While no vinyl bromide was found to react under the same conditions employed for the vinyl iodides, the search was not nearly exhaustive. At this point, the noteworthy finding from the vinyl iodide experiments has been the limitation: the presence of the geminal phenyl group (with the iodide) on the olefin is a requisite feature of substrates. A brief study was performed to examine if the aryl- and vinylzinc generating procedures could function on alkyl halides. 
A typical substrate for this chemistry is ethyl iodoacetate, used in the Reformatsky reaction. ${ }^{10}$ Recently, alkylzincs have been reported to react with this substrate and the functional alkylzinc has been applied to the asymmetric addition of carbonyls. ${ }^{11}$ While methods have been reported for the formation of alkylzincs from commercially available alkylzincs (diethylzinc and dimethylzinc), the methods employ excess alkylzinc and heat. When this reactivity is coupled in a two-step, one pot process, asymmetric additions to carbonyls have been shown but this requires that all excess alkylzinc be removed by evacuation. The removal of pyrrophoric reagents is certainly less than ideal. Limited preparations of benzylzinc reagents have previously reported from the reaction of an alkylzinc and benzyl halide. ${ }^{12}$ The reaction between toluenesulfinyl benzyl iodide and a strong base has been reported. In the presence of sodium hexamethyldisilyl amide at $-78^{\circ} \mathrm{C}$ in THF, the benzylic iodide shows no reactivity toward the base and generated mixtures of trisubstituted epoxides and the unsaturated toluenesulfinyl-ethylene compound when a carbonyl was added. This presented a good starting point into the potential for alkylzinc generation and reactivity.

Benzyl bromide was attempted but failed to show any reactivity. Benzyl iodide was synthesized from benzyl bromide and sodium iodide in acetone overnight in the dark (Finkelstein conditions). ${ }^{13}$ Quantitative benzyl iodide was formed. Benzyl iodide was flashed over silica gel and distilled with the careful exclusion of light under vacuum to yield a colorless to pale yellow liquid. It was stored in a nitrogen atmosphere at $-15{ }^{\circ} \mathrm{C}$ (solid at this temperature). It was discovered that benzyl iodide did react, forming a benzylzinc reagent in situ. The benzylzinc reagent added to benzaldehyde in the presence or absence of chiral ligand $(S)-\mathbf{1 2}$. When 6 hours was allowed for the benzylzinc 
formation at room temperature, a fair amount of the benzylic alcohol (138) was formed in the absence of ligand indicating moderate background reactivity. This reaction was repeated at $0{ }^{\circ} \mathrm{C}$ ( 6 hour benzylzinc formation) for the asymmetric reaction. Only the benzylic alcohol was observed. In the presence of $10 \mathrm{~mol} \%(S)-\mathbf{1 2}$, the alcohol was produced in very low ee $(\leq 10 \%)$. The first step conditions were varied and the results are summarized in the Table 6.2.

Table 6.2 Conditions Tested for the Generation of Benzylzinc and Its Reaction With Benzaldehyde in the Presence of Catalytic $(S)-12$.

\begin{tabular}{ccccc}
\hline Entry $^{\mathbf{a}, \mathbf{b}}$ & Step 1 time (h), temp & Step 2 solvent & Yield (\%) & ee (\%) \\
\hline 1 & 3, room temp & DCM & 90 & $<4$ \\
2 & $3,0^{\circ} \mathrm{C}$ & DCM & 90 & 10 \\
3 & 12, room temp & DCM & 93 & 0 \\
4 & $12,0^{\circ} \mathrm{C}$ & DCM & 91 & 0 \\
5 & 4, room temp & THF & -- & 6 \\
6 & 4, room temp & Toluene & -- & 0 \\
7 & 4, room temp & Hexanes:Ether & -- & 4 \\
8 & 4, room temp & Toluene:Hexanes & -- & 0
\end{tabular}

a) Reaction conditions for Entries 1 to 4. Step 1: $\mathrm{Li}(\mathrm{acac})$ (26 mol\%), $\mathrm{Et}_{2} \mathrm{Zn}$ (1.21 equiv) and NMP ( $1 \mathrm{~mL})$ are mixed with benzyl iodide ( 2.2 equiv; the time and temperature are indicated in the Table). Step 2: A solution of $(S)-12(10 \mathrm{~mol} \%)$ in DCM $(5.0 \mathrm{~mL})$ were 
added and stirred one hour. Step 3: benzaldehyde was added. Reaction was allowed to stand at room temperature for 12 hours at the temperature of Step 1.

b) Reaction conditions for Entries 5 to 8. Step 1: $\mathrm{Li}(\mathrm{acac})$ (26 mol\%), $\mathrm{Et}_{2} \mathrm{Zn}$ (2.2 equiv) and NMP (1 mL) are mixed with benzyl iodide (4 equiv; the time and temperature are indicated in the Table). Step 2: A solution of $(S)-12(10 \mathrm{~mol} \%)$ in solvent were added and stirred one hour; Entry 5-5.0 mL THF; Entry 6-5.0 mL toluene; Entry $7-5.0 \mathrm{~mL}$ hexanes, $4.0 \mathrm{~mL}$ diethylether; Entry $8-3.0 \mathrm{~mL}$ hexanes, 3.0 mL toluene. Step 3:

solutions were cooled to $0{ }^{\circ} \mathrm{C}$ and benzaldehyde was added. Reactions were kept at $0{ }^{\circ} \mathrm{C}$ for 12 hours.

c) ee measured by chiral HPLC (chiralcel OD column).

3 hours at room temperature was required to generate the active benzylzinc reagent. $90 \%$ product was isolated but in less than $4 \%$ ee with a small amount of ethyl addition. When benzyl iodide is mixed with diethylzinc and $\mathrm{Li}(\mathrm{acac})$ in NMP at $0{ }^{\circ} \mathrm{C}$ for 3 hours, a high yield of alcohol is again produced but with more ethyl addition observed. This suggests that both reactions done over 3 hours for step one- at room temperature or at $0{ }^{\circ} \mathrm{C}$ - showed incomplete generation of the benzylzinc reagent from diethylzinc. However, when the addition to benzaldehyde was also done at $0{ }^{\circ} \mathrm{C}$, the alcohol was obtained in $10 \%$ ee. Reactions were also attempted using 12 hours at room temperature and at $0{ }^{\circ} \mathrm{C}$ for step one. Both reactions afforded good yields of the benzyl alcohol, however no selectivity was observed for these alcohols.

The initial screening reactions suggest that the catalyst formed from either pure benzylzinc or a mixture of benzylethylzinc is not selective in the nucleophilic alkylation 
of benzaldehyde. The highest ee observed for the benzylzinc addition to benzaldehyde was only $10 \%$ afforded from a catalyst generated from the reaction between a mixed alkylzinc species and $(S)$-12. This indicates that the catalyst generated from the benzylzinc species and $(S)$-12 was less efficient relative to catalysts generated from arylzincs and vinylzincs.

Other than the necessary solvent screens to be performed, second stage screening should focus on the application of catalysts based on the chiral amino alcohol ligand and reaction with diethylzinc (since the best ee was obtained when ethyl was still present in an active addition form), dimethylzinc, diphenylzinc or from the functional arylzincs and vinylzincs previously shown to form highly active and enantioselective catalysts.

\section{Characterization:}<smiles>OC(Cc1ccccc1)c1ccccc1</smiles>

${ }^{1} \mathrm{H}$ NMR $\left(300 \mathrm{MHz}, \mathrm{CDCl}_{3}\right) \delta 7.29(\mathrm{~m}, 10 \mathrm{H}), 4.90(\mathrm{~m}, 1 \mathrm{H}), 3.04(\mathrm{~m}, 2 \mathrm{H}), 2.17$ (br-s, 1H). ${ }^{13} \mathrm{C} \mathrm{NMR}\left(75 \mathrm{MHz}, \mathrm{CDCl}_{3}\right) \delta 143.7,137.9,129.4,128.3,128.3,127.5,126.4$, 125.8, 75.2, 45.9. $[\alpha]_{\mathrm{D}}^{25}=-0.593(\mathrm{c}=0.55, \mathrm{THF}) 4 \%$ ee. HPLC: chiralcel OD column; solvent ratio: 95:5 hexanes:isopropanol, flow rate: $1 \mathrm{~mL} / \mathrm{min} . R T s=13.5,17.0 \mathrm{~min}(292$ nm) HRMS calcd. for $\mathrm{C}_{14} \mathrm{H}_{14} \mathrm{ONa}$ : $221.0942[\mathrm{M}+\mathrm{Na}]^{+}$. Found: 221.0945.

As a less practical but still interesting protocol, we studied the reaction of an alkynyl iodide with an alkylzinc to form an alkynylzinc and its reactivity with an aliphatic aldehyde. A number of systems have been reported for the direct use of 
terminal alkynes to form active alkynyl metals and their asymmetric additions to electrophiles. We wanted to test whether the alkynyl halide could be identified as a parallel route to the preparation of the synthetically useful propargylic alcohols. Linear aliphatic alkynes have presented a challenge application in catalytic asymmetric procedures. ${ }^{15}$ Our system required the synthesis of the starting substrate because no alkynyl iodides are commercially available. 1-octyne, a liner aliphatic alkyne, was converted to 1-iodo-1-octyne (139). After the compound was prepared and sufficiently cleaned (column chromatography and distillation), 1-iodo-1-octyne (2.2 equiv) was dissolved in NMP (0.75 mL) with Li(acac) $(26 \mathrm{~mol} \%)$. The mixture was stirred at room temperature and diethylzinc (1.21 equiv) was added. A racemic reaction was run sideby-side of the asymmetric reaction. It was mixed for $16 \mathrm{hrs}$ followed by the addition of (S)-12 (10 mol\%) and DCM (2.5 mL). After stirring one hour, cyclohexanecarboxaldehyde was added. The reaction was monitored by TLC and was complete in 10 hours. It was found that an active alkynylzinc was generated from the reaction between 1-iodo-1-octyne and diethylzinc. The subsequent reaction with cyclohexanecarboxaldehyde proceeded in the presence or absence of added $(S)-\mathbf{1 2}$.

The racemic reaction yielded $67 \%$ of the propargylic alcohol (140). When 10 mol\% $(S)-12$ was added to the reaction, 71\% alcohol was formed but without any considerable enantioselectivity (analyzed by comparison of optical rotation reported in the literature). It is interesting to note the difference in the reactivity observed for the alkynylzinc generated in these reactions. The racemic reaction proceeds to produce a good amount of alcohol. This is significantly different for other alkynylzinc reagents studied where the uncatalyzed, racemic (background) reaction is extremely sluggish or 
nonexistent. This could be attributed to either the polar medium or the nucleophilicity of a potential dialkynylzinc. Relevant studies again direct us to elucidating the role that NMP plays in the organozinc formation and reactivity with aldehydes. The search should also be expanded to include other alkynyl halides (e.g., bromides) as well as examining the readily prepared dihalo-alkene species typically used en route towards lithium acetylide species (Corey-Fuchs reaction). ${ }^{16}$

\section{Experimental and Characterization:}

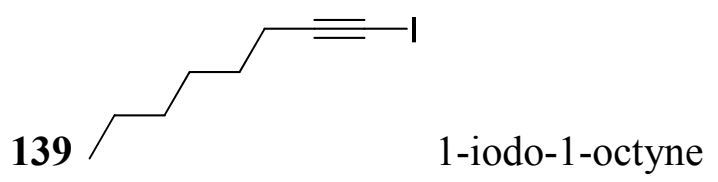

The alkynyl iodide was prepared from the reaction of 1-octyne with $n$-butyllithium in THF at $-40{ }^{\circ} \mathrm{C}$. After 120 minutes, iodine crystals were slowly added to the clear solution at the cold temperature. After 1.2 equivalents iodine had been delivered and the dark purle color persisted in the reaction flask, the cold bath was removed. The crude mixture containing the alkynyl iodide warmed to room temperature and was allowed to stand 1 hour before the cautious dropwise addition of water. After the typical iodide-prep workup, the 1-iodo-1-octyne was flashed over silica gel using hexanes and evacuated in the dark. The compound was verified by ${ }^{1} \mathrm{H}$ NMR and ${ }^{13} \mathrm{C}$ NMR.

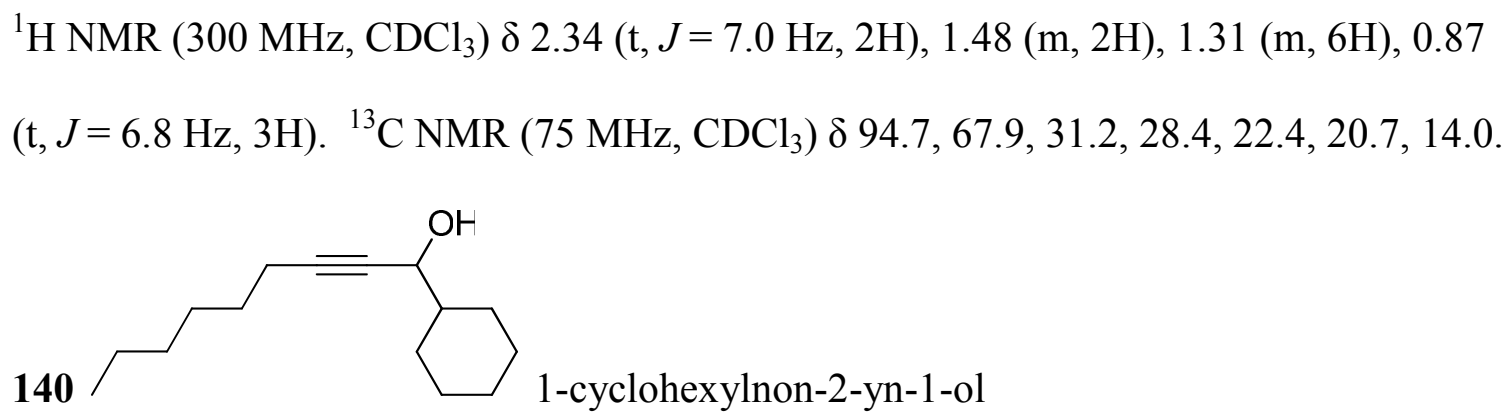

The compound was prepared according to the procedure described in the text. 
${ }^{1} \mathrm{H}$ NMR $\left(300 \mathrm{MHz}, \mathrm{CDCl}_{3}\right) \delta 4.12(\mathrm{~m}, 1 \mathrm{H}), 2.19(\mathrm{~m}, 2 \mathrm{H}), 1.79(\mathrm{~m}, 5 \mathrm{H}), 1.66(\mathrm{~m}, 1 \mathrm{H})$, $1.49(\mathrm{~m}, 3 \mathrm{H}), 1.25(\mathrm{~m}, 11 \mathrm{H}), 0.88(\mathrm{t}, J=6.8 \mathrm{~Hz}, 3 \mathrm{H})$.

\section{d. Catalytic Asymmetric Allylations of Carbonyls}

Asymmetric alkyl allylations (AAA) have been extensively studied. ${ }^{17}$ However, a considerable amount of work is being performed to identify novel and more efficient protocols. Recently, Ashfeld et. al. ${ }^{18}$ reported on the catalytic use of titanocene (bis(cyclopentadienyl)titanium(IV) dichloride) in the presence of allyl bromide and zinc dust (activated) to generate an allyliczinc species. They also demonstrated the nucleophilicity of the organozinc reagent by addition to carbonyl derivatives including aldehydes, ketones and an ester. Ashfeld also identified a limitation to the reactivity at cooler temperatures. For example, there was no generation of active allylic zinc at -40 ${ }^{\circ} \mathrm{C}$. A Lewis base phosphine additive screen was performed to study the activation at cold temperatures. $5 \mathrm{~mol} \%$ of triphenylphosphine, tricyclohexylphosphine, 1,3bis(diphenylphoshino)propane (dppp), 1,2-bis(diphenylphosphino)ethane (dppe), or racBINAP were successful. This reactivity was also applied to a benzylic bromide and terminal aliphatic bromide with both reactions employing a bidentate phosphine additive ( $5 \mathrm{~mol} \%$ dppe) and higher equivalents of titanocene.

The authors also described a single asymmetric example of this methodology. In the presence of $50 \mathrm{~mol} \%$ of a dilithiated diamine compound, the allylzinc generated by 2 mol $\%$ of titanocene added to benzaldehyde to produce the allylic alcohol in $28 \%$ yield and $68 \%$ ee. The reaction was done at $-40{ }^{\circ} \mathrm{C}$ and thus required a phosphine additive (15 mol \% dppe used). This is shown in Scheme 6.3. 


\section{Scheme 6.3 Titanocene Catalyzed Asymmetric Allylzinc Addition to Benzaldehyde} in the Presence of Substoichiometric Dilithiated Diamine.

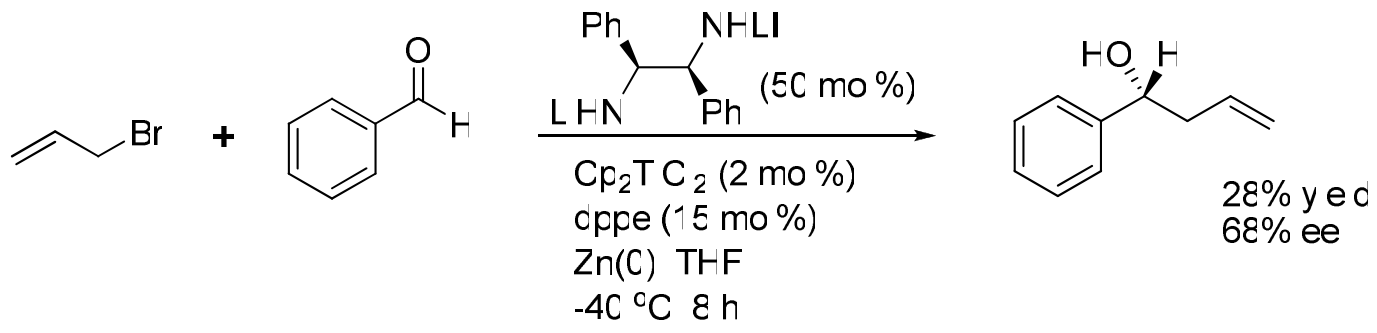

We explored the use of the some ligands to affect the asymmetric addition of the highly reactive allylzinc reagent to carbonyls. The single example by the authors illustrates that although the reaction conditions are synthetically practical, the asymmetric version may not be straightforward. The authors commented that neither a chiral titanocene nor phosphine gave selectivity in the reaction.

Our initial attempts were to repeat the reported reaction and simply add a catalytic amount of $(S)-\mathbf{1 2}$ (shown to be the most general ligand in our arylation studies) to study the selectivity of this process. Upon using zinc dust and titanocene directly as received (Sigma-Aldrich), the reaction failed to produce allylzinc determined by no addition product to benzaldehyde. The zinc dust was then washed with $\sim 1 \mathrm{M} \mathrm{HCl}$, followed by a superfluous amount of water. During both washings, clump formation occurred. They were transferred to a mortar and ground with a pestle back down into a dust. Next, acetone and then diethyl ether were washed over the zinc. As a final step, the zinc was ground very fine using the mortar and pestle and washed again with water, acetone, and then diethyl ether. Evacuation of the zinc dust overnight provided material that now was able to repeat the reactivity reported.

The first studies in the presence of catalytic $(S)-\mathbf{1 2}(10 \mathrm{~mol} \%)$ produced the allylic alcohol (141) in excellent yields $(>90 \%)$ but no ee. In related studies to the 
reported asymmetric example, dilithiated- $\mathrm{H}_{8} \mathrm{BINOL}$ complexes were formed by addition of 2 equivalents of $n$-butyllithium (hexanes solution; 2 equivalents relative to the ligand) and added to a solution of titanocene. This was mixed for 10 minutes at room temperature. Next, zinc was added followed by allyl bromide and benzaldehyde. Monitoring the reaction progress showed aldehyde consumption was complete by 15 minutes at room temperature. $(S)-\mathrm{H}_{8} \mathrm{BINOL}$ and $(S)-\mathbf{1 2}(20 \mathrm{~mol} \%$ each) were used in two separate experiments. The reactions both produced good yields ( $>90 \%)$ of the allylic alcohol. The reaction with the dilithiated $(S)-\mathrm{H}_{8} \mathrm{BINOLate} \mathrm{provided}<10 \%$ ee while the dilithiated $(S)$-12ate showed no selectivity. These reactions were complete at a rate consistent with the racemic reaction. Presumably, the allylzinc species is generated in the reaction mixture but was either unable to form an active catalyst or the catalyst formed did not compete with the background reaction. The background reaction may also be catalyzed by the presence of activating Lewis acids in the reaction mixture (i.e., titanium and zinc salts). Ashfeld et. al. provided some detailed studies suggesting that the zinc species acts independently of the titanium present in the reaction however. Plagued by the lack of selectivity, we attempted to prepare a catalyst known to control the asymmetric addition of other organozincs.

$20 \mathrm{~mol} \%$ of complex was formed by stirring $(S)-\mathbf{1 2}$ with two equivalents of diphenylzinc (relative to ligand) in THF. To this complex was added the [allylzinctitanocene] mixture portion-wise from a prepared stock solution. The stock solution was prepared by stirring titanocene $(1 \mathrm{~mol} \%)$, zinc, and allyl bromide in THF $(5.0 \mathrm{~mL})$ at room temperature. The resultant mixture was a yellowish, slightly cloudy mixture which concentration was approximated as $0.2 \mathrm{M}$. The first portion was added to the catalyst at 
room temperature and stirred 30 minutes. Next, benzaldehyde was introduced. Another portion (1 equivalent relative to ligand, maintaining an approximate 1:1 ratio of ligand/catalyst to allylzinc reagent) of allylzinc — titanocene was added each subsequent 30 minutes. After $4.25 \mathrm{~mL}$ of the stock solution was added ( $\sim 2$ equivalents of allylzinc reagent added), the reaction was complete. The alcohol was isolated in $97 \%$ yield with only $2.5 \%$ ee. This reaction was repeated using the dilithiated- $(S)-\mathbf{1 2}(20 \mathrm{~mol} \%)$. The racemic product was formed in good yield.

We attempted to study the reactivity of a directly formed titanoate. $20 \mathrm{~mol} \%$ of the dilithiated $(S)-\mathbf{1 2}$ was formed for 30 minutes at $0{ }^{\circ} \mathrm{C}$ to room temperature. 1 equivalent (relative to the ligand) of titanocene was added and stirred overnight. After this time, zinc and allyl bromide were added. Experiments were done at room temperature, $-30{ }^{\circ} \mathrm{C}$, and $-78^{\circ} \mathrm{C}$. The reaction at room temperature produced $<10 \%$ alcohol after 4 hours that was unable to be completely purified because of the complexity of the reaction. The reaction at $-30{ }^{\circ} \mathrm{C}$ formed $35 \%$ product in $16 \%$ ee and at $-78{ }^{\circ} \mathrm{C}$, $52 \%$ product was formed, also in $16 \%$ ee.

Finally, the reaction was attempted without the use of the catalytic titanium reagent. As discussed by Ashfeld et. al., the catalytic titanocene hastens the allylzinc formation considerably. At $-20{ }^{\circ} \mathrm{C}$, this catalyzed reaction proceeds to produce $79 \%$ of the 1,2-addition product to an enone in 20 minutes. At room temperature, the reaction affords $99 \%$ product in 5 minutes. The uncatalyzed reaction (no titanocene present when zinc dust and allyl bromide are mixed) fails to yield any alcohol over 48 hours at $-20{ }^{\circ} \mathrm{C}$. The uncatalyzed reaction between benzaldehyde and allyl bromide does reach full conversion when the reaction is run over 6 hours compared to 5-10 minutes when 
catalytic titanocene is present. Allyl iodide could replace allyl bromide. When this was done under the latter reaction conditions, $68 \%$ alcohol was formed in one hour.

Two reactions were studied. 1 equivalent each of zinc with allyl bromide was mixed in THF with $(S)$-12. After 1 hour, benzaldehyde was added. $60 \%$ of the racemate was isolated. When $(S)$-12 was reacted with diphenylzinc in THF, followed by the addition of 1 equivalent each of zinc with allyl bromide and then benzaldehyde, the alcohol was formed in $63 \%$ but with no selectivity.

It is clear that this protocol is challenging to develop an asymmetric variant. However, the synthetic practicality and reactivity scope demonstrated by the authors shows this pursuit worthwhile. Two strategies could be studied. The search for a selective quencher, or additive, could be found to control the active background reaction. A relevant discussion appears in the following section. It is clear that this reactivity must be modulated for an asymmetric catalyst to compete. This may lend itself well to what could be a second strategy. The slower, titanocene-free reaction seems more conducive to be controlled. This would likely narrow the range of reactive substrates. However, the appropriate asymmetric catalyst would override sluggish reactivity. Furthermore, the high reactivity and selectivity towards 1,2-addition in the case of ketones, enones, and esters should be studied. In each case, the allylation leads to tertiary-substituted alcohols which have been the focus of much research. There is evidence that the nucleophilicity of the allylzinc species in the titanocene catalyzed reaction would bypass the aldol pathway commonly observed for ketone substrates. The addition of the allylzinc reagent to a free phenolic aldehyde resulted in $97 \%$ allylic alcohol formation. 
When an allylzinc attempted to be generated from allyl iodide using the reported arylzinc and vinylzinc methodology, a highly exothermic reaction was observed upon the addition of diethylzinc at room temperature. It was expected that displacement could occur and upon searching the literature, studies were found that describe substitution reactions $\left(\mathrm{S}_{\mathrm{N}}{ }^{2}, \mathrm{~S}_{\mathrm{N}}{ }^{2}\right)$ of dialkylzincs and monoalkylzincs (copper(I) and nickel(II) catalyzed) in a polar medium (HMPA, DMF, TMEDA). ${ }^{19}$ This was tentatively confirmed by analyzing the crude reaction mixture (prior to quenching). The observation of the vinyl signals showed the consumption of allyl iodide and appearance of new peaks likely 1-pentene which was also cited as to why the closed reaction blew the stopple clear off prior to the completion of the $\mathrm{Et}_{2} \mathrm{Zn}$ addition. Thus, this substrate could be revisited for study if the amount of NMP were drastically decreased. Substituted allyl iodides were not tested.

\section{Characterization:}

141<smiles>C=CCC(O)c1ccccc1</smiles>

1-phenylbut-3-en-1-ol

${ }^{1} \mathrm{H}$ NMR $\left(300 \mathrm{MHz}, \mathrm{CDCl}_{3}\right) \delta 7.36(\mathrm{~d}, J=4.3 \mathrm{~Hz}, 4 \mathrm{H}), 7.29(\mathrm{~m}, 2 \mathrm{H}), 5.82(\mathrm{~m}, 1 \mathrm{H}), 5.17$

(m, 2H), $4.74(\mathrm{t}, J=5.3 \mathrm{~Hz}, 1 \mathrm{H}), 2.52(\mathrm{~m}, 2 \mathrm{H}), 2.06$ (br-s, 1H).

\section{e. Catalytic Asymmetric Arene-Addition of Carbonyls}

Previously, the method for functional organozinc generation developed by

Knochel has been discussed. ${ }^{20}$ During our research we identified slightly modified conditions (e.g. use of diethylzinc) to generate functional arylzincs, phenylzinc, and the extension to generate vinylzincs and benzylzinc. Knochel published a procedure 
describing the generation of arenylzincs from a 2,2,6,6-tetramethylpiperidine magnesium base (TMP-MgCl). ${ }^{20,21}$ For example, benzthiazole and coumarin were both reported to undergo reaction, forming di(arene)zinc reagents in situ as shown in the scheme 6.4.

Scheme 6.4 (TMP) $)_{2}$ Zinc Base Formation, Bis(Arene)Zinc Generation and Proposed Addition to Benzaldehyde.

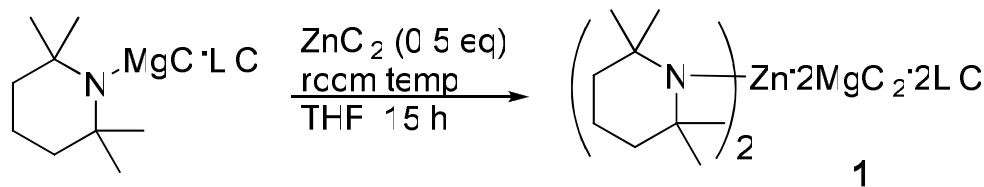<smiles>c1ccc2scnc2c1</smiles>

\section{$1(055 \in q)$} $\underset{20 \text { m nutes }}{\stackrel{\text { THF }}{\longrightarrow}}(\text { Arene })_{2}-\mathrm{Zn}$ $\mathrm{PhCHO}$<smiles>C=C1C=Cc2ccccc2C1</smiles>
chiral ligand<smiles>O[C@H](c1ccccc1)c1nc2ccccc2s1</smiles>

Arene examp $\in \mathrm{s}$<smiles>C=C1Cc2ccccc2C=C1[C@H](C)c1ccc(C)cc1</smiles>

The reported methodology was examined for the asymmetric preparation of alcohols from an arene source. According to Knochel's report, the first step generates a strong and selective zinc base which reacts with an arene to form an arenylzinc reagent in situ. This was accomplished according to the scheme above. Our strategy was to analyze the reaction in the presence of chiral ligands. We performed these studies using both benzthiazole and coumarin.

The bis(TMP)zinc base is formed by the room temperature mixing of anhydrous zinc chloride (1 equivalent; 99.999\%, Sigma-Aldrich) with the commercially available 2,2,6,6-tetramethylpiperidinylmagnesium chloride lithium chloride complex solution (TMPMgCl·LiCl) (1.9 equivalents; Sigma-Aldrich, available in 1.0 M THF/toluene solution). According to the procedure, the reagents are stirred 15 hours at room temperature. The initial purple colored $\mathrm{TMPMgCl} \cdot \mathrm{LiCl}$ solution turns greenish-blue and 
then a yellow, translucent solution with a small amount of insoluble zinc chloride remaining after 15 hours.

The reactions were first repeated following Knochel's method to obtain information on the background addition reaction to an aldehyde. Moreover, this reaction was not reported or discussed by Knochel, presumably because it was not tested. A solution of the arene in $\mathrm{THF}$ is stirred with the $\mathrm{TMP}_{2} \mathrm{Zn} \cdot 2 \mathrm{MgCl} \cdot 2 \mathrm{LiCl}(0.55$ equivalent relative to arene) for one hour. For both benzthiazole and coumarin, the reactions with benzaldehyde proceeded smoothly to yield the desired alcohol (142 and 143, respectively) in good amounts (yields not calculated; a single new spot appears on TLC corresponding to the newly prepared alcohol). The reactions were repeated for both arenes. After one hour affords the bis(arenyl)zinc in situ, $10 \mathrm{~mol} \%(S)-\mathbf{1 2}$ was added and stirred for 30 minutes. Benzaldehyde was added next. Again, excellent yields were obtained (the reaction was complete in 2.5 hours) but with no selectivity in the addition reaction. We were delighted to discover that the addition proceeds rapidly and to our knowledge, this is the first description of arenylzinc additions to aldehydes. Knochel et. al. reported on the additions of the arenylzincs to alkyl- acylchlorides, arylacylchlorides, and allyl bromides. For each of these reactions, however, a transmetallation strategy was used with the addition of stoichiometric $\mathrm{CuCN} \cdot 2 \mathrm{LiCl}$. The only direct addition reported was between the arenylzinc generated from benzthiazole and chloro-diphenylphosphine. This product was formed in $79 \%$ yield.

The asymmetric reactions were then screened in the presence of N, N, N', N'tetramethylethylenediamine (TMEDA), a bidentate chelator. 8.2 equivalents of TMEDA (relative to aldehyde) were added to the reaction flask after the arenylzinc had been 
formed and $(S)-\mathbf{1 2}(10 \mathrm{~mol} \%)$ was added. These reactions were also diluted with the addition of another $5.0 \mathrm{~mL}$ THF at the time of ligand addition. This amount of TMEDA was chosen because of the presence of 1.21 equivalents of $\mathrm{TMP}_{2} \mathrm{Zn} \cdot 2 \mathrm{MgCl} \cdot 2 \mathrm{LiCl}$ (relative to aldehyde) used in the reaction. After arenylzinc formation, an excess of 2.42 equivalents each of magnesium and lithium salts should be present in a potentially "naked" and deleterious forms to the asymmetric pathway. Thus, $\sim 4.8$ equivalents of excess Lewis acidic species are present and this was initially combated with 1.7 effective equivalents of TMEDA. The benzthiazole reaction with benzaldehyde formed $80 \%$ product with $0 \%$ ee. The coumarin reaction with benzaldehyde formed $65 \%$ product with $7 \%$ ee. When 20 equivalents TMEDA were used for the benzthiazole reaction, $64 \%$ yield alcohol was isolated again with no selectivity. When 20 equivalents TMEDA were used for the coumarin reaction, no reactivity was observed. This reaction was repeated a number of times using freshly prepared $\mathrm{TMP}_{2} \mathrm{Zn} \cdot 2 \mathrm{MgCl} \cdot 2 \mathrm{LiCl}$, freshly distilled benzaldehyde, and varying the amounts of TMEDA added. No additions were observed. Another variable would be the original solution THF/toluene of $\mathrm{TMPMgCl} \cdot \mathrm{LiCl}$. The reagent was stored in a nitrogen atmosphere. No change in this solution could be determined other than the lack of reactivity. The color was already purple upon arrival (purchase) but remained clear and no precipitation was observed. The authors indicate that a freshly titrated solution of $\mathrm{TMPMgCl} \cdot \mathrm{LiCl}$ was used to prepare the $\mathrm{TMP}_{2} \mathrm{Zn} \cdot 2 \mathrm{MgCl} \cdot 2 \mathrm{LiCl}$ solution. From this reaction, the $\mathrm{TMP}_{2} \mathrm{Zn} \cdot 2 \mathrm{MgCl} \cdot 2 \mathrm{LiCl}$ was also freshly titrated prior to use. It is possible therefore that the original $\mathrm{TMPMgCl} \cdot \mathrm{LiCl}$ solution may have degraded. Although organolithiums are commonly used and titration of these commercially available versatile reagents is required, the practicality of the 
$\mathrm{TMP}_{2} \mathrm{Zn}$-based active arene nucleophile generation is questionable. The reactions were only screened over the course of two weeks and reproducibility was not achieved (successful reactivity was realized within week one). The coumarin-based arenylzinc addition to benzaldehyde should be further studied with freshly prepared and purified metallic reagents. The benzthiazole arenation of 4'-bromoacetophenone was attempted. Disappointingly, the aldol pathway was the only reaction observed yet again.

One likely issue for the lack of selectivity was the presence of excess salts in the reaction. Use of additives, also termed selective chelators or inactivators, should be studied to determine whether the sufficient removal of the abundant "naked" Lewis acidity from the reaction mixture could be achieved to significantly reduce the background reaction. For example, Walsh et. $a l^{22}$. has studied the selective quenching of lithium salts in reports of asymmetric arylations. Use of bidentate amine additives effectively ceased this undesired pathway that leads to racemic product formation. Da et. $a l .{ }^{23}$ have shown the controlled reactivity of Grignard reagents by using a bis(dialkylamino)ether reagent as additive. Furthermore, as a mechanistic inquiry from our previous modifications leading to the generation of arylzinc, vinylzinc, and benzylzinc reagents, we would like to elucidate the role of NMP or some other polar solvent. In only one arylation (2-iodothiophene) was it found that the $\mathrm{Li}(\mathrm{acac})$ "activator" was not required. But for all the organozinc formations discovered by our efforts, NMP was necessary. In such a study designed to elucidate the role of NMP, it is plausible to suggest that a chelation effect, similar to that observed in the related reactivity above or widely reported in asymmetric enolate procedures (e.g. chiral auxiliary use), may be uncovered. 


\section{Experimental and Characterization:}

142

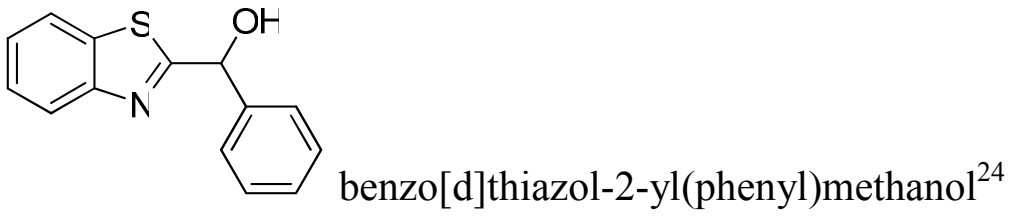

${ }^{1} \mathrm{H}$ NMR $\left(300 \mathrm{MHz}, \mathrm{CDCl}_{3}\right) \delta 7.99(\mathrm{~m}, 1 \mathrm{H}), 7.84(\mathrm{~m}, 1 \mathrm{H}), 7.53(\mathrm{~m}, 2 \mathrm{H}), 7.46(\mathrm{~m}, 1 \mathrm{H})$, $7.37(\mathrm{~m}, 4 \mathrm{H})$.

143

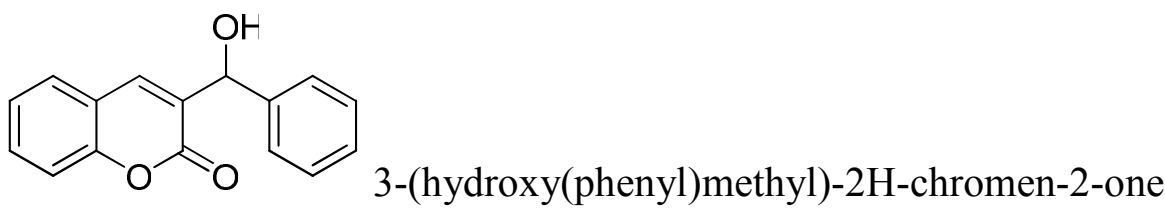

${ }^{1} \mathrm{H}$ NMR $\left(300 \mathrm{MHz}, \mathrm{CDCl}_{3}\right) \delta 7.64(\mathrm{~m}, 1 \mathrm{H}), 7.46(\mathrm{~m}, 4 \mathrm{H}), 7.32(\mathrm{~m}, 5 \mathrm{H}), 5.86(\mathrm{~d}, J=4.3$

$\mathrm{Hz}, 1 \mathrm{H}), 3.50(\mathrm{~d}, J=4.4 \mathrm{~Hz}, 1 \mathrm{H})$.

\section{f. Synthesis of Chiral Allenes}

Chiral allenes are important synthetic components in a number of reactions. ${ }^{25}$ Often prepared in situ, there are only a few reports that describe the preparation and isolation of chiral allenes.

Our goal was to study the transformation of chiral propargylic alcohols into chiral allenes. Recent progress in asymmetric alkynylation methodology has been made to include functional alkynes, e.g. the ester-containing alkyne, methyl propiolate. The challenge presented by such alkynes has been discussed previously (chapter 5). The synthetic utility of the propargylic products obtained from the reaction between methyl propiolate and an aldehyde is very promising. ${ }^{26}$ A number of experiments were attempted to screen whether allene products could be synthesized and potentially isolated from propargylic alcohols. 
Recently, the triarylphosphine-mediated reductive condensation of $\gamma$-acyloxy butynoates to form substituted furans in a sealed tube and heated to $110{ }^{\circ} \mathrm{C}$ was reported. ${ }^{27}$ Our studies concentrated on applying this methodology to alkynyl alcohols. Similar to the $\gamma$-acyloxy alkynoates, the reaction with the hydroxy-butynoates (products from propiolate additions to aldehydes) could proceed through an allene intermediate. Therefore, we aimed at determining if the reaction could be stopped at the allene and whether chirality-transfer could take place from propargylic alcohol to allene. This is illustrated below.

\section{Scheme 6.5 Proposed Allene Formation From a Propargylic Alcohol.}

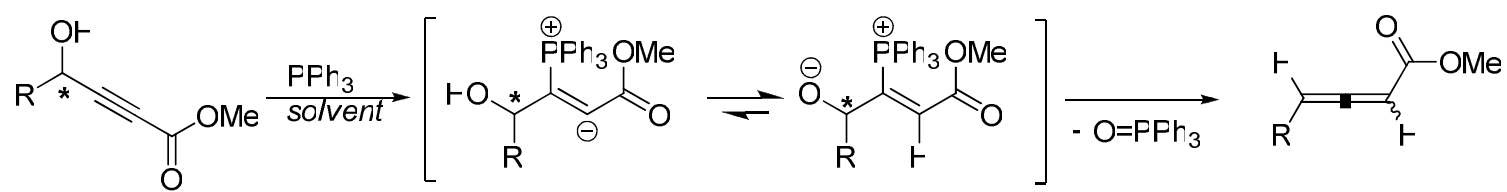

We first studied the reaction on racemic alcohols. A solution of methyl 4cyclohexyl-4-hydroxybut-2-ynoate (144, the propargyl alcohol shown below) in benzene (dried, distilled from sodium benzophenone) was prepared.<smiles>COC(=O)C#CC(O)C1CCCCC1</smiles>

1.2 equivalents of triphenylphosphine were added and the reaction was monitored at room temperature. After 3 hours, TLC shows the appearance of a new spot was observed that was UV active (on coated TLC plate) but did not react in polymolybdic acid (PMA) ethanol stain. The starting alcohol slowly disappeared from 3 to 6 to 20 hours, but was not completely consumed until 3 days at room temperature. While the TLC showed the presence of only one new spot, the crude NMR and isolation showed evidence of more 
than a single chemical species which may or may not have contained the allene. Signals in the aromatic region $(\delta 7.33 ; \mathrm{m})$ were assigned to two possibilities: 1$)$ that the phosphine could not be completely removed from the reaction or 2) complete oxidation of the cyclohexyl substituent. The signals further downfield in the ${ }^{1} \mathrm{H}$ NMR $(\delta 7.63 ; \mathrm{m})$ are likely from vinyl species, possibly the dehydrated, alkyne-reduction product. As evidenced by the reaction performed on an aryl-substituted propargyl alcohol (discussed below), it appeared the dehydrated compound was the only product formed. The aliphatic region contained signals at $\delta 2.21$ and 2.40 , indicating the presence of allylic protons. A single peak was observed for the methyl ester singlet at $\delta 3.73$. The vinyl region contained the following signals: $\delta 5.79(\mathrm{~d}, J=15.2 \mathrm{~Hz})$ and $5.94(\mathrm{~d}, J=11.5 \mathrm{~Hz})$. The complex spectrum was likely representative of a mixture of partially to completely oxidized methyl propargyl ester, including the phosphine-facilitated oxidation of the cyclohexyl ring. The formation of these products agrees with the TLC observation of a UV-active, PMA-ethanol stain unreactive species.

To bypass this reactivity, methyl 4-hydroxy-4-o-tolylbut-2-ynoate (146, the propargylic alcohol shown below) was submitted to the previously used reaction conditions.

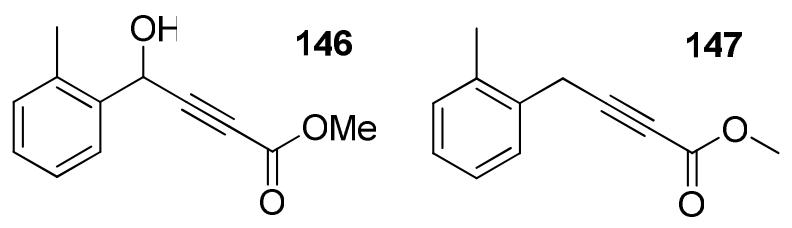

Interestingly, a reduction product was the sole compound formed (147). It was isolated in $50 \%$ yield. We attempted to use triphenylphosphite ( 0.9 equivalents) in place of the phosphine to modulate the nucleophilic activity of the base, but no reaction occurred 
(over 5 days at room temperature). No reaction occurred by using 1 equivalent trimethylphosphite either.

When tri(n-butyl)phosphine was used in the reaction of methyl 4-cyclohexyl-4hydroxybut-2-ynoate, the similar reaction process was observed. The reaction was stopped earlier than the reaction with triphenylphosphine with starting alcohol still present in the mixture. While the TLC showed the appearance of a single new compound, the crude ${ }^{1} \mathrm{H}$ NMR and isolated spot's ${ }^{1} \mathrm{H}$ NMR showed a complex mixture of oxidized chemical species. Notably, the vinyl- region and the methyl ester region showed multiple signals. We presume that we stopped the progression of the reaction leading to a completely oxidized compound.

Methyl 4-hydroxy-5-methylhept-5-en-2-ynoate (148, propargylic alcohol shown below) was reacted with triphenylphosphine in benzene.

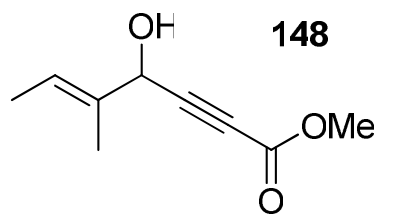

After two hours, two new spots appeared on TLC around the starting alcohol and one spot that was highly nonpolar. After 22 hours at room temperature, the alcohol was consumed. The initially observed compounds around the alcohol disappeared and only the UV active nonpolar species was present. The isolation of this species again provided an apparent mixture of oxidized products. Two methyl ester signals were observed and approximately 6 to 7 individual vinyl signals. This could be attributed to the reduction of the alkyne, dehydration of alcohol, and also the rearrangement of allylic methyl to form a completely conjugated species. The mixture could be an inseparable diastereomeric mixture that was observed. 
144 was subjected to reaction with tri(n-butyl)phosphine ( 1 eq). The reaction did not change from 2 hours to 8 or 24 hours. The major new compound was identified as (E)-methyl 4-cyclohexyl-4-hydroxybut-2-enoate (145). The reaction was repeated and it was found that the starting alcohol was consumed in one hour. Again the crude ${ }^{1} \mathrm{H}$ NMR and TLC showed the alkyne-reduction product only, but $<10 \%$ could be recovered. An NMR experiment was performed using 10 equivalents ethanol (absolute, nitrogenpurged), alcohol 144 and tri(n-butyl)phosphine (1 equivalent each) in deuterated benzene $\left(\mathrm{C}_{6} \mathrm{D}_{6}\right)$. After 16 hours, no starting material remained $\left({ }^{1} \mathrm{H} \mathrm{NMR}\right) . \quad 30 \%$ of the reducedalkyne was isolated (145). When the reaction was repeated in ethanol (as solvent), an approximate 1:1 mixture of starting material and alkyne-reduction product was found and no further reaction occurred after 6 days.

The final study pursued was the reaction of the alkynoate with a triphenylphosphine resin (swelling volume given as $6.5 \mathrm{~mL} / \mathrm{G}$ in DCM; phosphine substitution listed as $1.2 \mathrm{mmoL} / \mathrm{G})$. Methyl 4-hydroxyundec-2-ynoate (113) shown below) was used.

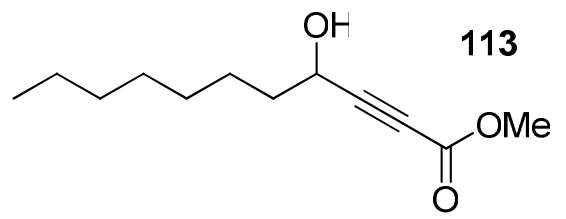

First, the amount of solvent (benzene) required to "wet" the resin was determined. $\sim 200$ to $250 \mu \mathrm{L}$ benzene wet the resin (53 $\mathrm{mg}$ in a one dram vial) forming a gel-like species. After 350 to $500 \mu \mathrm{L}$ solvent (total volume) was added to the resin, a nearly homogeneous solution was obtained. The solution became homogeneous upon standing. Next, the alcohol was added and stirred overnight. At 2 hours reaction time, an aliquot was removed, concentrated and chloroform was used to wash the crude residue over glass 
wool. An NMR of this showed an approximate $1:[\sim 0.5$ to 1$]$ ratio of the starting alcohol and similar reduction products observed in the other reactions. Two distinct methyl ester signals were in the spectrum at $\delta 3.79$ and 3.74. Vinyl signals at $\delta 6.15,5.79$ and 5.60 were present. The multiplet at $\delta 2.15$ may be indicative of allylic hydrogens present on both the allene and extended conjugate reduction species. The characteristic propargyl proton was identified at $\delta$ 4.49. This ratio did not change over days of mixing time.

When the reaction was repeated in ethanol, no reaction was observed likely due to insufficient wetting and thus mixing of the phosphine with the alcohol.

Unfortunately, the desired allenic compounds could not be generated. It is clear that the unprotected alcohol is reactive towards the species generated by the initial 1,4-phosphine addition to the alkynoate. It is proposed in the cited references that the acyl-protected alkynoates that following this initial addition, the resulting stabilized vinyl anion causes rearrangement with the acyl group and forms the 4-membered oxyphosphorous cycle. Taking into account this mechanism and our experimental findings, the free alcohol is probably displaying reaction with the same stabilized vinyl anion initially formed by deprotonation of the alcohol (intra- or intermolecularly), subsequent loss of the phosphine oxide species, and further reaction of the (potential allene) intermediate with phosphine or phosphine oxide to yield oxidation products.

\section{Characterization:}

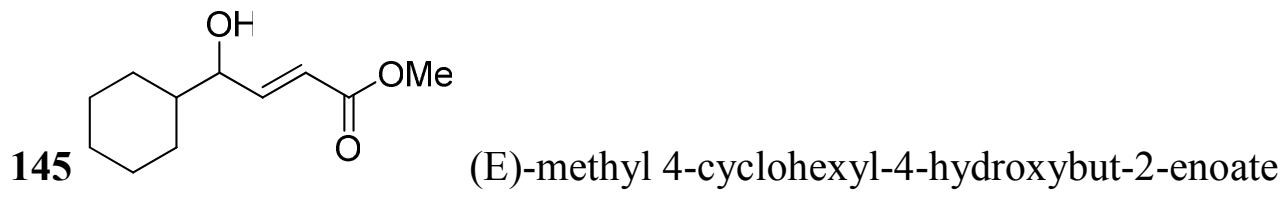
$90 \%$ ee (based on preparation and analysis of (R)-O-acetylmandelic ester derivative). 
${ }^{1} \mathrm{H}$ NMR $\left(300 \mathrm{MHz}, \mathrm{CDCl}_{3}\right) \delta 6.97(\mathrm{dd}, J=15.7,5.2 \mathrm{~Hz}, 1 \mathrm{H}), 6.04(\mathrm{dd}, J=15.7,1.7 \mathrm{~Hz}$, 1H), $4.09(\mathrm{~m}, 1 \mathrm{H}), 3.74(\mathrm{~s}, 3 \mathrm{H}), 1.71(\mathrm{~m}, 8 \mathrm{H}), 1.50(\mathrm{~m}, 4 \mathrm{H})$.

147<smiles>COC(=O)C#CCc1ccccc1C</smiles>
methyl 4-o-tolylbut-2-ynoate

${ }^{1} \mathrm{H}$ NMR $\left(300 \mathrm{MHz}, \mathrm{CDCl}_{3}\right) \delta 7.44(\mathrm{~d}, J=7.3 \mathrm{~Hz}, 1 \mathrm{H}), 7.23(\mathrm{~m}, 2 \mathrm{H}), 7.15(\mathrm{~m}, 1 \mathrm{H}), 3.82$ (s, 3H), $3.60(\mathrm{~s}, 2 \mathrm{H}), 2.47$ (s, 3H).

\section{g. Miscellaneous Reactivity:}

\section{i. 1,4-diol reactivity with methyl propiolate}

In our ongoing efforts to develop an organocatalytic method using the $\mathrm{BINOL} / \mathrm{H}_{8} \mathrm{BINOL}$ motif, an interesting reaction was discovered. When BINOL was mixed with methyl propiolate and 4-dimethylaminopyridine (4-DMAP) in DCM, both oxygens from the binaphthol (presumably as the alkoxide) add to the terminal position of the alkyne. This formal addition forms an acetal protection of the 1,4-diol (see (see 149). It is important to note that the first reaction attempted was done in the presence of an aldehyde. No incorporation of the aldehyde was observed either by the alkoxide or the presumed anion generated. After a literature search was done for a description of this reactivity, two references were identified. ${ }^{28}$ In the publications, the authors describe an intramolecular reaction between diols and alkyl propiolates. In particular, reactivity was described between the alcohol and a methoxycarbonyl alkyne (i.e. methyl propiolate, termed "mocdene") or tert-butylcarbonyl alkyne (i.e. tert-butyl propiolate, termed "bocdene") reactivity. However, the authors specify that the reactivity was not observed when attempted on a 1,4-diol (the substrate studied was 1,2-benzenedimethanol). For 
1,3- and 1,4-diols, cyclic acetals were not formed. Instead, mono- or bis-bocvinyl derivatives were generated. Thus, we have discovered a novel entry into this reactivity.

The initial finding was in a reaction attempted containing $N$-methylephedrine (20 mol\%), (S)-BINOL (50 mol\%), isovaleraldehyde (1 equivalent), and methyl propiolate (2 equivalents). The reagents were added in this order in DCM. No reaction was observed. When the equivalents were varied between the aldehyde ( 2 equivalents) and alkynoate (1 equivalent), $10 \%$ of the cyclic acetal was isolated. After the product was determined by NMR, the literature was found. Other than having found the application of the process to a 1,4-diol, it was also interesting to note that the amino alcohol likely facilitated the reaction. Notably, the authors discussed reactivity differences between the bases used. 4-DMAP facilitated the reaction faster than both triethylamine and $\mathrm{N}$ ethyldiisopropylamine and no reaction was observed in the absence of base (even in refluxing acetonitrile. Trimethylphosphine and tributylphosphine also facilitated the intramolecular reaction, but not in yields comparable to the amine bases $(50 \%$ maximum from phosphine bases). Thus, we studied the reaction using 4-DMAP and acetonitrile.

(S)-BINOL (1.0 equivalent) and 4-DMAP (1.5 equivalents) were dissolved in acetonitrile. Methyl propiolate (1.1 equivalents) were then charged into the reaction flask. After 15 minutes, the cyclic product was observed by TLC but in a small amount. The reaction was very sluggish. The cyclic product slowly formed and by 36 hours at room temperature, $(S)$-BINOL was still present although it appeared the product was in a greater amount (TLC). After workup and column chromatography, 50\% of the cycle (149) was isolated. When the amount of 4-DMAP was increased to 5.0 equivalents, the reaction was still sluggish. The reaction was allowed to stand 5 days, however close to 
the same yield (44\%) was isolated. The reaction was performed on $(S)-\mathrm{H}_{8} \mathrm{BINOL}$ (using 1.5 equivalents 4-DMAP). The cyclic adduct was observed but only in a small amount. The same issue was encountered when 10 equivalents 4-DMAP were employed in the $(S)-\mathrm{H}_{8} \mathrm{BINOL}$ reaction. $38 \%$ of the cyclic product was isolated from the reaction between $(S)$-BINOL and methyl propiolate in the presence of 50 equivalents 4-DMAP (heterogeneous mixture) in acetonitrile. The reaction was performed on $(R)-6,6^{\prime}-$ dibromo-BINOL. Using 10 equivalents 4-DMAP in acetonitrile, 44\% of the cyclic acetal (150) was formed after 24 hours at room temperature. The reaction was attempted between $(S)$-BINOL and $(S)-\mathrm{H}_{8}$ BINOL with propiolic acid but both failed to react.

To study if the newly formed 7-membered cyclic acetals behaved the same way the authors reported for the other intramolecular adducts, we tested the "deprotection" strategy. Up to 25 equivalents TFA in DCM were added to $(S)$-BINOL cycle 149 and no reaction was observed.

1,4-diol substrates have been identified that react with methyl propiolate (1.1 equivalent) in the presence of 4-DMAP to form up to 50\% yield of the 1,4-bis(ether). $(S)$-BINOL and 6,6'-dibromo-(R)-BINOL afforded the 7-membered cyclic adducts in up to $50 \%$ and $44 \%$ yields, respectively. It is possible that screening various bases, possibly in a catalytic amount, could be applied to boost the yields for the novel cycles.

\section{Characterization:}

149

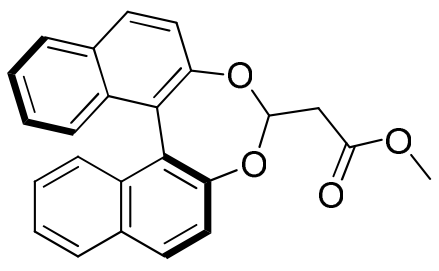

methyl 2-((11bS)-dinaphtho[2,1-d:1',2'-f][1,3]dioxepin-4-

yl)acetate 
${ }^{1} \mathrm{H}$ NMR $\left(300 \mathrm{MHz}, \mathrm{CDCl}_{3}\right) \delta 7.96(\mathrm{~m}, 4 \mathrm{H}), 7.46(\mathrm{~m}, 6 \mathrm{H}), 7.31(\mathrm{~m}, 2 \mathrm{H}), 6.20(\mathrm{t}, J=5.8$

$\mathrm{Hz}, 1 \mathrm{H}), 3.80(\mathrm{~s}, 3 \mathrm{H}), 2.94(\mathrm{~m}, 2 \mathrm{H})$.

150

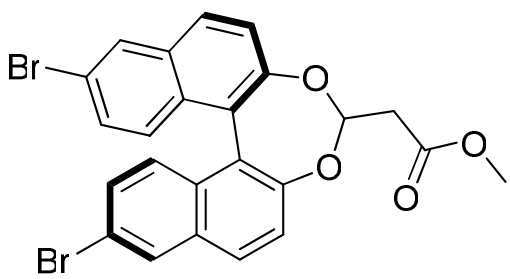

methyl 2-((11bR)-9,14-dibromodinaphtho[2,1-d:1',2'-

f][1,3]dioxepin-4-yl)acetate

${ }^{1} \mathrm{H}$ NMR (300 MHz, $\left.\mathrm{CDCl}_{3}\right) \delta 8.09(\mathrm{~m}, 2 \mathrm{H}), 7.88(\mathrm{~m}, 2 \mathrm{H}), 7.46(\mathrm{~m}, 2 \mathrm{H}), 7.38(\mathrm{~m}, 2 \mathrm{H})$,

$7.30(\mathrm{~m}, 2 \mathrm{H}), 6.20(\mathrm{t}, J=5.8 \mathrm{~Hz}, 1 \mathrm{H}), 3.80(\mathrm{~s}, 3 \mathrm{H}), 2.92(\mathrm{~m}, 2 \mathrm{H})$.

ii. Functional Alkyne Additions to Aldehydes

144<smiles>COC(=O)C#CC(O)C1CCCCC1</smiles>

methyl 4-cyclohexyl-4-hydroxybut-2-ynoate

95\% yield. $81 \%$ ee (based on preparation and analysis of (R)-O-acetylmandelic ester derivative).

${ }^{1} \mathrm{H}$ NMR $\left(300 \mathrm{MHz}, \mathrm{CDCl}_{3}\right) \delta 4.28(\mathrm{t}, J=6.1 \mathrm{~Hz}, 1 \mathrm{H}), 3.78(\mathrm{~s}, 3 \mathrm{H}), 1.89(\mathrm{~d}, J=6.1 \mathrm{~Hz}, 1 \mathrm{H})$, $1.80(\mathrm{~m}, 4 \mathrm{H}), 1.64(\mathrm{~m}, 2 \mathrm{H}), 1.15(\mathrm{~m}, 6 \mathrm{H})$. The reaction in diethylether gave the alcohol in $89 \%$ yield and $55 \%$ ee at room temperature. When done at $-20{ }^{\circ} \mathrm{C}$, the alcohol was isolated in $30 \%$ yield and $76 \%$ ee.

148

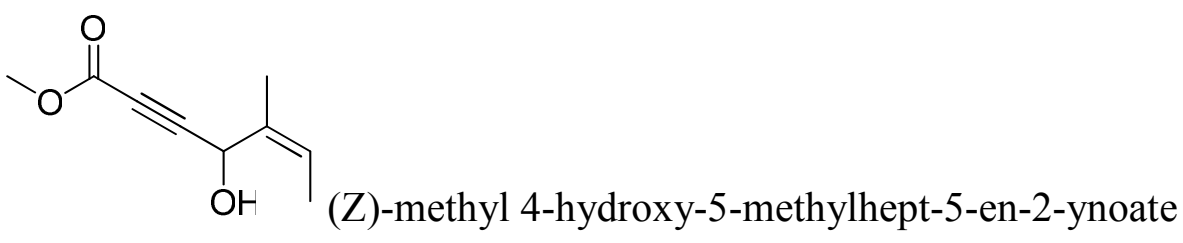

$62 \%$ yield. $90 \%$ ee (determined by preparation and analysis of (R)-O-acetylmandelic ester derivative. $[\alpha]_{\mathrm{D}}=-21.0\left(\mathrm{c}=1.015, \mathrm{CHCl}_{3}\right) .{ }^{1} \mathrm{H} \mathrm{NMR}\left(300 \mathrm{MHz}, \mathrm{CDCl}_{3}\right) \delta 5.73(\mathrm{~m}, 1 \mathrm{H}) 4.86(\mathrm{~s}$, 
1H), 3.78(s, 3H), $1.83(\mathrm{br}-\mathrm{s}, 1 \mathrm{H}), 1.76(\mathrm{~m}, 3 \mathrm{H}), 1.66(\mathrm{~m}, 3 \mathrm{H}) .{ }^{13} \mathrm{C} \mathrm{NMR}\left(75 \mathrm{MHz}, \mathrm{CDCl}_{3}\right) \delta$

$153.8,133.0,124.1,86.7,76.7,67.4,52.7,13.2,11.9$.

151<smiles>CC(=O)OCC#CC(O)c1ccccc1</smiles>

4-hydroxy-4-phenylbut-2-ynyl acetate

${ }^{1} \mathrm{H}$ NMR (300MHz, $\left.\mathrm{CDCl}_{3}\right) \delta 7.53(\mathrm{~m}, 2 \mathrm{H}), 7.37$ (m, 3H), 5.51 (m, 1H) $4.76(\mathrm{~s}, 2 \mathrm{H}), 2.16$ (br-s, $1 \mathrm{H}), 2.10(\mathrm{~s}, 3 \mathrm{H}) .58 \%$ yield. $90 \%$ ee. The racemic alcohol was prepared in $65 \%$ yield from the same reaction conditions without ligand. HPLC: chiralcel OD, $10 \% \mathrm{IPA}, 1 \mathrm{~mL} / \mathrm{min}, R T s: 17.0$, 20.2 mins. ${ }^{13} \mathrm{C}$ NMR $\left(75 \mathrm{MHz}, \mathrm{CDCl}_{3}\right) \delta 170.3,140.0,128.6,128.5,126.6,86.3,80.5,64.5$, $52.3,20.7$.

ii. Catalytic Asymmetric Phenylation Attempts Using Commercially Available Phenyl Reagents

We also studied the use of commercially available nucleophilic phenyl sources. Phenyl magnesium bromide is inexpensive (e.g. $100 \mathrm{~mL}$ of $1.0 \mathrm{M}$ solution in THF is $\$ 32.50$, Sigma Aldrich as of $12 / 2010$ ) and we sought to explore the potential phenyl source whether we could control the enantioselectivity of the addition reaction with carbonyls in the presence of a catalytic amount of an amino alcohol ligand.

The challenges facing the broad application of the reactive organomagnesium reagents in asymmetric synthesis have been discussed in previous chapters. We attempted to utilize the good reactivity of phenylmagnesium bromide to study the addition and enantiocontrol with aldehydes $(S)$-2 $(10 \mathrm{~mol} \%)$ was dissolved in THF. 1.2 equivalents $\mathrm{PhMgBr}(\sim 3 . \mathrm{M}$ in diethylether) was added and stirred one hour. The solution was then cooled to $-78{ }^{\circ} \mathrm{C}$ and 2-methoxybenzaldehyde was added slowly. The 
product (74) was readily formed in a good yield with little selectivity $(<7 \%$ ee). The same result was obtained when the reaction was done in toluene.

Next, the $\mathrm{PhMgBr}$ solution was stirred with $15 \mathrm{~mol} \%$ zinc chloride and $15 \mathrm{~mol} \%$ $(S)-2$ in THF for 12 hours at room temperature. The aldehyde was added to a $-78{ }^{\circ} \mathrm{C}$ cooled solution dropwise. Again, the alcohol was formed in only $6 \%$ ee. To test whether the catalyst could have degraded or decomposed over the 12 hour interval with the Grignard reagent and zinc chloride, the following experiment was done. $\mathrm{PhMgBr}$ and zinc chloride were mixed in THF for about 45 minutes. $(S)-2(10 \mathrm{~mol} \%)$ was then added and stirred at room temp. for 30 minutes. The solution was cooled to $-78{ }^{\circ} \mathrm{C}$ and the aldehyde was added over the course of 40 minutes. This resulted in a sluggish reaction. Starting material was present at 1.5 hours after all was added. The reaction was warmed up (below room temperature) and product formed. The aldehyde was allowed to react overnight and was consumed at room temperature. Again the alcohol was isolated in only $6 \%$ ee.

Next, the Grignard reagent was stirred with zinc chloride in a 1.2:1 ratio in THF for one hour, followed by addition of $(S)-2(10 \mathrm{~mol} \%)$. The catalyst was allowed to form overnight. To a $-78{ }^{\circ} \mathrm{C}$ cooled mixture, the aldehyde was added dropwise. Again, a very sluggish reaction was observed over the course of 4 hours. The reaction was warmed to 0 ${ }^{\circ} \mathrm{C}$ and stirred 12 hours. A small amount of aldehyde was present, but the reaction was quenched and alcohol was analyzed. Compound 74 was formed in $11 \%$ ee.

Our efforts turned towards the study of phenylzinc bromide which is also commercially available as a pre-prepared solution. This organometallic should be less reactive than its organomagnesium (and other organometals, such as organolithiums, 
organoaluminums) equivalent. Instead of exploring synthetic utility of the organometal through a deactivating control ${ }^{19}$, we opted to study the potential for activation through catalytic asymmetric phenylation using the phenylzinc bromide and amino alcohol ligands. As a vast number of organozincs are available in this form (RZnX, where $\mathrm{R}$ is alkyl or aryl group, and X is a halide), this methodology would have widespread potential in asymmetric catalytic additions.

To achieve activation of the mild $\mathrm{PhZnBr}$, we attempted mixing 2.2 equivalents $\mathrm{PhZnBr}$ (in THF) with 1.21 equivalents $\mathrm{Et}_{2} \mathrm{Zn}$ (0.55 equivalents relative to $\mathrm{PhZnBr}$ ) in the presence of $12 \mathrm{~mol} \% \mathrm{Li}(\mathrm{acac})$ in NMP. The reagents were stirred at room temperature for 16 hours. $10 \mathrm{~mol} \%(S)-2$ was then added to the solution and catalyst was formed for one hour. Next, 3-methoxybenzaldehyde was charged into the reaction flask. At 24 hours, only a small amount of starting material remained with two major new compounds observed on TLC. The compounds were not separated by column chromatography but the mixture was identified as a 1:1 ratio of phenyl-addition and ethyl-addition products ( $77 \%$ total). Chiral HPLC analysis resolved the compounds and showed no enantioselectivity for either the ethyl or phenyl addition products. The same result was obtained for a number of other experiments: 1) when the attempted exchange (step 1) was allowed to stand for 24 hours and 2) if $\operatorname{Li}(\mathrm{acac})$ was not added to affect the exchange and step 1 was allowed to stand 24 hours at room temperature. Both of these reactions yielded the same mixture of ethyl- and phenyl- additions with no enantioselectivity.

These conditions mirror previously determined conditions for successful arylations while incorporating the strategy reported by Bolm et. al. ${ }^{14}$ Bolm identified a 
system that took advantage of the existing equilibrium between diphenylzinc and $\mathrm{Et}_{2} \mathrm{Zn}$ in situ and discovered conditions that were both high yielding and more selective relative to pure diphenylzinc's use.

$\mathrm{PhZnBr}$ was mixed in the same fashion as the original experiment $(2.2$ equivalents $\mathrm{PhZnBr}$, 1.21 equivalents diethylzinc, $12 \mathrm{~mol} \% \mathrm{Li}(\mathrm{acac})$ in NMP at room temperature). After $(S)$-2 (10 mol\%) was added and stirred one hour, $30 \mathrm{~mol} \%$ methanol (dried, distilled) was added cautiously and stirred an additional one hour. This was followed by the addition of 3-methoxybenzaldehyde. Although more phenylation was observed in this reaction, ethyl addition (75) was still present. The phenyl addition (34) product was racemic.

At this point, the background (uncatalyzed) reaction between $\mathrm{PhZnBr}$ and 3methoxybenzaldehyde was studied. 1.1 equivalents $\mathrm{PhZnBr} / \mathrm{THF}$ solution reacted with 3 -methoxybenzaldehyde to yield only $28 \%$ of the alcohol after 30 hours at room temperature. With such a limited reactivity, we turned our efforts to find Lewis basic activators of the $\mathrm{PhZnBr}$ addition to aldehydes. While the Lewis acidic (for example, boron trihalides, titanium alkoxides or halides, alkylaluminums or aluminum halides) screen would likely increase the reactivity of the two substrates, this has been welldocumented. ${ }^{20}$ Thus, it was of greater interest to us to develop an alternative protocol. 2 equivalents of $\mathrm{PhZnBr}$ were mixed with $20 \mathrm{~mol} \%$ aminoethanol. After 5 minutes, the aldehyde was introduced. Interestingly, the major product formed was the aldehyde reduction product (3-methoxybenzyl alcohol; 76) with a small amount of phenyl addition formed. When $80 \mathrm{~mol} \%$ pyridine was used, only the phenyl-addition product appeared on TLC but the aldehyde was not consumed after 22 hours. If 5 or 10 
equivalents of $\mathrm{PhZnBr}$ were used, 3-methoxybenzaldehyde was consumed but the reaction took over 24 hours at room temperature.

We studied the potential activation by catalytic amounts of Lewis base to boost the reactivity of the functional diarylzinc generated from aryl iodides. The yields of the racemic alcohol from the 3-anisylzinc addition to benzaldehyde were improved when 20 mol $\%$ TMEDA or $20 \mathrm{~mol} \%$ pyridine were used. The product was isolated in $72 \%$ and $67 \%$ yield, respectively. When 20 mol\% HMPA was used, only $48 \%$ alcohol was formed. Comparatively, the background reaction (in the absence of any additive or ligand) afforded the alcohol in 56\% yield. This could be beneficial for the symmetric preparation of various aryl alcohols containing functionality not compatible with the typical organomagnesium or orgnolithium reagents.

\section{iii. Attempted Vinylations Directly from Alkyne Reduction and Reaction with}

\section{Aldehydes}

Practical vinylation methodology for the one pot reduction of alkynes and subsequent catalytic asymmetric addition to carbonyls was also further examined. We studied the reaction of an in situ generated vinylaluminum species. 1 equivalent of diisobutylaluminum hydride (DIBAL-H) reacts with 1 equivalent of an alkyne resulting in this substrate. The reduction proceeds rapidly at cold or at room temperature. Due to the limitations discovered in our vinylzinc methodology, we studied the asymmetric reactivity of 1-octenyl(diisobutyl)aluminum formed by the DIBAL-H reduction of 1octyne.

The first reaction ran was the DIBAL-H reduction of 1-octyne in hexanes. Following a literature procedure, the reagents ( 1.5 equiv each relative to benzaldehyde) 
were added together and heated to $50{ }^{\circ} \mathrm{C}$ for two hours. After cooling to room temperature, $(S)-\mathbf{1 2}(10 \mathrm{~mol} \%)$ was added and stirred for one hour before introducing benzaldehyde. The reaction was complete within 30 minutes and the allylic alcohol was the major product observed. It was isolated in 55\% yield but the reaction did not demonstrate any enantioselectivity. The reaction was carried out in the absence of ligand and the same result was obtained. Therefore, we observed this background (likely uncatalyzed) addition in the presence of $10 \mathrm{~mol} \%$ ligand in hexanes at room temperature. The vinylaluminum species was formed again in the same fashion. After $(S)-\mathbf{1 2}(10$ mol\%) was added with stirring, the solution was cooled to $-78{ }^{\circ} \mathrm{C}$ and benzaldehyde was added. Again, rapid consumption of the aldehyde was observed. Within 45 minutes, the racemic product was isolated in a higher yield relative to the room temperature reaction however. The reaction was studied again in the absence of ligand. Here, instead of using heat in step one, DIBAL-H and 1-octyne were stirred at room temperature for 10 hours. This afforded the alkyne reduction and a similar result was obtained. Benzaldehyde was consumed within one hour at $-78{ }^{\circ} \mathrm{C}$ and the reaction afforded $83 \%$ of the allylic alcohol (101).

The room temperature formation of the vinylaluminum species was studied in the following reactions. When $20 \mathrm{~mol} \%(S)$-BINOL in hexanes was added followed by benzaldehyde addition at $-78{ }^{\circ} \mathrm{C}, 75 \%$ of the racemic alcohol was formed. $20 \mathrm{~mol} \%(S)$ $\mathrm{H}_{8} \mathrm{BINOL}$ gave the same result. We studied the effects of solvent variations on the reaction. The vinylaluminum species was generated at room temperature in $\mathrm{CH}_{2} \mathrm{Cl}_{2}$ over 12 hours. In the absence or presence of a chiral ligand $\left(20 \mathrm{~mol} \%(S)-\mathrm{H}_{8} \mathrm{BINOL}\right)$, the reaction produces near quantitative allylic alcohol as a racemate. However, when THF 
was used as the solvent, the alcohol was produced with a slight ee of $9 \%$ using $20 \mathrm{~mol} \%$ $(S)-\mathrm{H}_{8} \mathrm{BINOL}$. When $20 \mathrm{~mol} \%(S)-\mathrm{H}_{8} \mathrm{BINOL}$ was used in a toluene solution, the reaction was complete in 15 minutes at $-78{ }^{\circ} \mathrm{C}$. The product was isolated in $85 \%$ yield and $0 \%$ ee. The background reaction was tested again in this toluene reaction and proceeded in same manner as the reaction with ligand present. Clearly, the vinylaluminum species - a dialkyl, mono-vinylaluminum species is very active even at cold temperatures. Again, we face the challenge of tempering the fast rate of the uncatalyzed addition.

It was noted that in the presence of $40 \mathrm{~mol} \%(\mathrm{~S})-\mathrm{H}_{8} \mathrm{BINOL}$ in THF, the addition did not proceed at $-78^{\circ} \mathrm{C}$. Instead, only the aldehyde reduction was observed, forming slowly at the cold temperature and when the reaction was brought to room temperature. We attempted to transmetallate the vinylaluminum species at $-78^{\circ} \mathrm{C}$ with the addition of 1.5 equivalents of $\mathrm{Et}_{2} \mathrm{Zn}$ ( 1 equiv relative to alkyne and DIBAL-H). After mixing one hour, solutions of $20 \mathrm{~mol} \%(S)-\mathrm{H}_{8} \mathrm{BINOL}$ and separately $20 \mathrm{~mol} \%(S)-\mathbf{1 2}$ in DCM were added and stirred an additional hour. Benzaldehyde was added at $-78{ }^{\circ} \mathrm{C}$. Both reactions produced the allylic alcohol in $80 \%$ yield without any enantioselectivity.

At this time, I was prepared to pursue the additions of the highly reactive vinylaluminum species and potentially a bulkier vinylaluminum species (generated from an internal alkyne) to the less reactive ketones. However, upon a literature search, the catalytic asymmetric version of this reaction had very recently been published by Gau et. $a l{ }^{31}$ The reaction is reportedly catalyzed by a BINOL-titanoate complex as shown in the figure below. 
Figure 6.4 Gau et. al. Enantioselective Terminal Vinyl Additions to Ketones From Vinylaluminums.

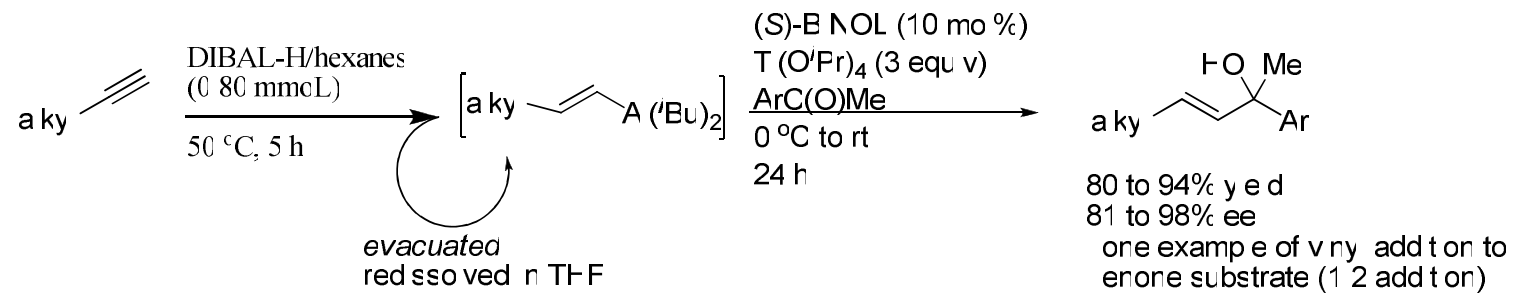

Two experiments were performed using a relatively milder alkyne-selective reducing agent for the potential direct functional vinylation from methyl propiolate. The hydrozirconation of methyl propiolate could be accomplished by mixing an equivalent amount of Schwartz's reagent (dicyclopentadienyl zirconium hydrochloride) and methyl propiolate each at room temperature in THF for 30 minutes. $^{32} 10 \mathrm{~mol} \%(S)-\mathbf{1 2}$ was added and stirred one hour followed by the addition of benzaldehyde. After 24 hours at room temperature, the aldehyde was not consumed but a complex mixture was observed by crude TLC. Due to the trace amounts of compound formed and complexity, no pure fractions could be isolated. A ${ }^{1} \mathrm{H}$ NMR taken of fractions 2 and 3 (below benzaldehyde; fraction 3 stained in PMA-ethanol) could be the (Z)-allylic alcohol (102) mixed with methyl acrylate. No such formation was observed in the absence of ligand even after 3 days at room temperature. Thus, no ee was measured.

\section{Characterization:}

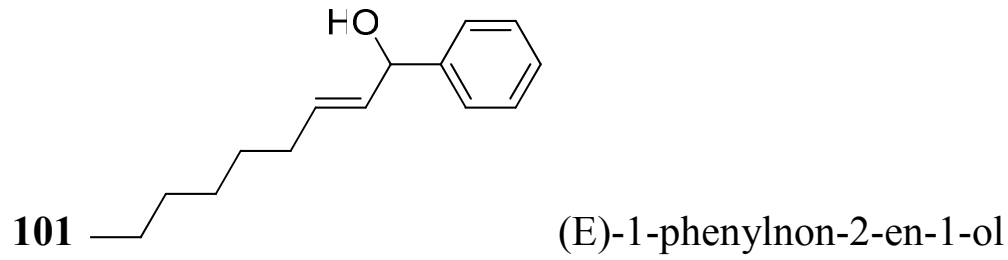

\footnotetext{
${ }^{1} \mathrm{H}$ NMR $\left(300 \mathrm{MHz}, \mathrm{CDCl}_{3}\right) \delta 7.32(\mathrm{~m}, 5 \mathrm{H}), 5.72(\mathrm{~m}, 2 \mathrm{H}), 5.17(\mathrm{dd}, J=6.4,2.9 \mathrm{~Hz}, 1 \mathrm{H})$, $2.05(\mathrm{~m}, 2 \mathrm{H}), 1.88(\mathrm{~d}, J=3.3 \mathrm{~Hz}, 1 \mathrm{H}), 1.31(\mathrm{~m}, 8 \mathrm{H}), 0.87(\mathrm{t}, J=6.7 \mathrm{~Hz}, 3 \mathrm{H}) .{ }^{13} \mathrm{C} \mathrm{NMR}$
} 
$\left(75 \mathrm{MHz} \mathrm{CDCl}_{3}\right) \delta 143.5,132.7,132.1,128.3,127.3,126.0,75.1,32.1,31.6,28.9,28.8$, 25.5, 14.0. HPLC: chiralcel OD column; solvent ratio: 97:3 hexanes:isopropanol, flow rate: $1 \mathrm{~mL} / \mathrm{min} . R T s=19,23 \mathrm{~min}$.<smiles>COC(=O)/C=C\C(O)c1ccccc1</smiles>

(Z)-methyl 4-hydroxy-4-phenylbut-2-enoate

${ }^{1} \mathrm{H}$ NMR $\left(300 \mathrm{MHz}, \mathrm{CDCl}_{3}\right) \delta 7.33(\mathrm{~m}, 5 \mathrm{H}), 6.48(\mathrm{~m}, 1 \mathrm{H}), 5.27(\mathrm{~d}, J=6.0 \mathrm{~Hz}, 1 \mathrm{H}), 3.87$ (s, 3H), $3.19(\mathrm{~d}, J=6.9 \mathrm{~Hz}, 1 \mathrm{H})$.<smiles>[Z]OC(=O)C=CCCCCCC</smiles>

${ }^{1} \mathrm{H}$ NMR $\left(300 \mathrm{MHz}, \mathrm{CDCl}_{3}\right) \delta 6.38,6.19,5.12,3.84$.

\section{iv. Catalytic Asymmetric Vinylation Attempts Using Vinyl Magnesium Bromide}

The use of a commercially available nucleophilic vinyl source was also studied. Vinyl magnesium bromide is inexpensive (e.g. $100 \mathrm{~mL}$ of $1.0 \mathrm{M}$ solution in THF is $\$ 33.10$, Sigma Aldrich as of $11 / 2010$ ) and we sought to explore the potential vinyl source whether we could control the enantioselectivity of the addition reaction with aldehydes in the presence of a catalytic amount of some amino alcohol ligands. We have presented the challenges facing the broad application of the very reactive organomagnesium reagents in asymmetric synthesis. ${ }^{2,3}$

We attempted to utilize the high reactivity of vinylmagnesium bromide (THF solution) to study addition and enantiocontrol with ketones. 1.4 equivalents of vinylmagnesium bromide are stirred with $10 \mathrm{~mol} \%$ of a $1.0 \mathrm{M}$ solution of zinc chloride (diethyl ether solution) for 2 hours. Next $(S)-2(10 \mathrm{~mol} \%)$ is added as a solution in THF 
and stirred at room temperature for 30 minutes. The mixture was cooled to $0^{\circ} \mathrm{C}$ and acetophenone was added dropwise over 20 minutes. A small amount of the ketone remained at 6 hours and the same was observed by TLC after 16 hours with one new main spot. ${ }^{1} \mathrm{H}$ NMR analysis of the crude mixture showed only a small amount of vinylation product (103) but mainly the aldol (104) reaction product. When 2.2 equivalents of the vinyl Grignard reagent was used with 0.5 equivalent of zinc chloride (diethyl ether solution) and 0.5 equivalents of ligand, the same result was obtained. The small amount of vinyl addition could not be isolated. Solid zinc chloride (as received, Sigma-Aldrich, $98+\%)$ was used in place of the salt solution. When both reactions (1.4 equivalents Grignard, $10 \mathrm{~mol} \%$ zinc chloride and ligand; 2.2 equivalents Grignard, 0.5 equivalents zinc chloride and ligand) were repeated with acetophenone, the same result was obtained.

We turned to study the reaction between the vinyl Grignard reagent and aldehydes. When the reaction performed with acetophenone was repeated with benzaldehyde at $-78^{\circ} \mathrm{C}$ in the presence of $10 \mathrm{~mol} \%$ ligand in THF, the reaction proceeded slowly. The $\mathrm{ZnCl}_{2}$ (10 mol \%; solid) was stirred with 1.4 equivalents vinylmagnesium bromide (diethyl ether solution) for 1 hour at room temp. Next a solution of ligand in THF was introduced and stirred for 3 hours. The resultant mixture contained some solids. $2 \mathrm{~mL}$ THF was added but this did not completely dissolve the reaction contents. The mixture was allowed to stir for another 10 hours before cooling to $-78^{\circ} \mathrm{C}$ and adding benzaldehyde dropwise over 40 minutes. Product was observed in 3 hours but the starting material was not consumed even after 7 hours. The reaction was brought to $0{ }^{\circ} \mathrm{C}$ and stirred overnight. The aldehyde had been consumed after stirring at 
$0{ }^{\circ} \mathrm{C}$. Difficulty in handling the product, 1-phenyl-2-propen-1-ol (105), was realized due to the compound volatility. Thus no accurate yields were determined (from the racemic preparation, only $32 \%$ product was isolated, although starting material was consumed with only the crude product observed on TLC and NMR). Further, benzyl alcohol produced by the Grignard-facilitated reduction of benzaldehyde, was observed as a byproduct, the amount varying from reaction to reaction. We decided to pursue the vinylation of 2-methoxybenzaldyde. The racemic vinylation resulted in $89 \%$ isolated yield of product ( 2 equivalents vinyl Grignard added slowly_over 40 minutes — to aldehyde solution in diethyl ether at $0{ }^{\circ} \mathrm{C}$; reaction time was $>2$ hours). Now, when the reaction initially ran with benzaldehyde was repeated using 2-methoxybenzaldehyde, $67 \%$ product (106) was isolated and in $14 \%$ enantiomeric excess. The following observations were made: the vinylmagnesium bromide solution (in THF, as received) has a slight brownish color that became darker when stirred with zinc chloride. After the ligand solution ( $2 \mathrm{~mL}$ diethyl ether did not dissolve the ligand completely and $2 \mathrm{~mL}$ THF were added) was added to this mixture, the solution color turned to a light brownishorange, suggesting the formation of a potential catalyst. No more changes were observed over the next one hour. Aldehyde was introduced at room temperature and stirred for 10 hours prior to being quenched.

The reaction was repeated with only THF used as the solvent dissolving the ligand (and transferring into vinylmagnesium and zinc salt mixture). Using $10 \mathrm{~mol} \%$ ligand at room temperature gave the addition product in high yield (73\%) but low ee $(12 \%)$. To increase the ee, we attempted to prepare a stoichiometric amount of a vinylzinc reagent. When a 1:1 ratio of vinylmagnesium bromide was stirred with zinc 
chloride at room temperature and $0{ }^{\circ} \mathrm{C}$ for 1 hour, followed by the addition of ligand in THF (stirred another hour) and 2-methoxybenzaldehyde, a more sluggish reaction was observed. Only vinyl addition was observed on TLC and after 20 hours the reaction was quenched although not complete. The product was found to be racemic. The reaction was then performed using a 2:1 vinyl Grignard reagent to zinc chloride ratio. Again a slower reaction was observed with the aldehyde consumed after 20 hours. The high yielding reaction afforded the racemic product again. Relatively small amounts of the reduction product (108) were observed (crude TLC) for these reactions.

Futher conditions were explored. The first reaction ran gave an interesting result. When zinc was absent in the reaction between vinylmagnesium bromide and 2methoxybenzaldehyde in the presence of $10 \mathrm{~mol} \%$ ligand at $-78^{\circ} \mathrm{C}$, the reaction was complete within 1.5 hours yielding the vinyl addition as the major product (along with some reduction product) in $10 \%$ ee. Thus it was found that the presence of zinc had a minimal or no effect on the reaction.

This reaction was repeated using toluene as the solvent. While precipitates were observed after mixing the ligand and vinyl reagent in only $2 \mathrm{~mL}$ solvent, when the total volume was increased to $20 \mathrm{~mL}$, little to no precipitation was observed. The mixture was stirred at $-78^{\circ} \mathrm{C}$ for 1 hour and the aldehyde was added slowly over 45 minutes. The reaction was quenched 45 minutes later and the product alcohol was isolated in good yield. The ee was measured to be $19 \%$. When the reaction was done in diethyl ether, almost $20 \%$ ee was obtained. This is an interesting reactivity as the active catalyst in these reactions affording $10-20 \%$ ee in different solvents is likely a binaphtholatemagnesium complex which has not previously been described by our lab. ${ }^{2 a}$ 
Modeled after Seebach's work with TADDOLs and titanium-based catalytic systems, we attempted to study the reaction of a vinyltitanoate with 2-

methoxybenzaldehyde. ${ }^{29} 1.0$ equivalent of titanium tetraisopropoxide $(99.9995 \%$ purity, Sigma-Aldrich) was mixed with $10 \mathrm{~mol} \%$ ligand in $3.0 \mathrm{~mL}$ THF for 15 hours at room temperature. After this time, the reaction was evacuated for a total of 8 hours to remove solvent and volatiles formed. The reaction flask contents (an oily mixture) were redissolved in 5.0 mL THF and 1.3 equivalents of the vinyl Grignard reagent was introduced. The reaction was cooled to $-78^{\circ} \mathrm{C}$ and 2-methoxybenzaldehyde was slowly added over 1 hour. The reaction showed no product formation after 4 hours and was warmed to room temp. After another 16 hours, only a trace amount of aldehyde but no product alcohol was observed. Upon quenching the reaction, no product appeared. The same result was observed when repeated in toluene.

The addition reaction using 1 equivalent ligand and aldehyde was studied. The ligand was mixed with 3.2 equivalents vinylmagnesium bromide in THF (using very slow, cautious addition of Grignard; addition done over 1 hour). Only a trace amount of product was observed on TLC however and was unable to be isolated for analysis.

The enantiocontrol of a previously studied catalyst was studied for the vinylation (alkyne and aryl additions to aldehydes). $10 \mathrm{~mol} \%(S)-\mathbf{2}$ was reacted with 2 equivalents of diethylzinc (relative to ligand) in THF. After stirring 18 hours at room temperature, the vinyl Grignard (1.0 equivalent) was added, stirred 30 minutes, and cooled to $-78{ }^{\circ} \mathrm{C}$. Aldehyde was added dropwise. The reaction was nearly complete in 4 hours and TLC showed the presence of addition product, a small amount of reduction product and starting material. The reaction was quenched and ee of alcohol was measured at $10 \%$. 
While our initial attempts failed to yield successful synthesis of allylic alcohols, we became encouraged by a number of recent reports in the literature. Harada et. al. published a method employing an aryl or alkyl Grignard reagent to titanium transmetalation strategy in methylene chloride. ${ }^{30}$ In the presence of a chiral ligand, the reaction of an aryl- or alkyltitanoate was effectively controlled with good yields and ee's. In another report, Ishihara et. al. published on the modified reactivity of an in situ prepared zincate (mixed substrate). ${ }^{31}$ Bolm has also published on the reactivity and successful application to asymmetric catalysis of related mixed zinc species. ${ }^{23} \mathrm{~A}$ few other vinylations were attempted based on these reports. The racemates were prepared again with a fresh bottle of vinylmagnesium bromide. Additions to both benzaldehyde (105) and 4'-bromoacetophenone (107) in THF at room temperature resulted in high yielding and clean reactions.

It was once again observed that the vinyltitatonate reaction failed. After mixing vinylmagnesium bromide $(0.6 \mathrm{mmoL})$ with titanium tetraisopropoxide $(1 \mathrm{mmoL})$ in DCM at $-78{ }^{\circ} \mathrm{C}$ for only 10 minutes, bispyrrolidine ligand $(S)-12(10 \mathrm{~mol} \%)$ was added. Benzaldehyde was added next but no reaction was observed.

The mixed zinc species generated from reaction between diethylzinc (1.2 equivalents) and vinylmagnesium bromide (1.1 equivalents) added to both benzaldehyde and 4'-bromoacetophenone in the presence of $10 \mathrm{~mol} \%$ of the bis(pyrrolidino)ligand. The secondary allylic alcohol was obtained in 33\% yield and $12 \%$ ee. The tertiary allylic alcohol product was afforded in $65 \%$ yield and $13 \%$ ee. Because the ketone vinylation resulted in a good yield and approximately a 1:1 ligand:ee relation, we studied increasing the ligand loading. When 1 equivalent of ligand was used (with 2.05 equivalents 
diethylzinc and 1.55 eqs vinylmagnesium bromide), $48 \%$ product was formed with $24 \%$ ee. When 0.5 equivalents of ligand was used (with 2.05 equivalents diethylzinc and 1.55 eqs vinylmagnesium bromide), $30 \%$ product was formed with $28 \%$ ee. This represents an important development in our laboratory. Good methods employing the amino alcohol ligands for asymmetric additions to ketones are limited. The reactivity of these zincate species demonstrate a preference towards 1,2-addition instead of the aldol reactivity commonly observed. Furthermore, this is the first identified asymmetric vinylation of a ketone in our laboratory. An asymmetric version employing zincate chemistry has resulted in the successful preparation of a tertiary allylic alcohol (addition to ketone) with up to $28 \%$ ee.

\section{Vinylmagnesium bromide (Grignard) addition products:}

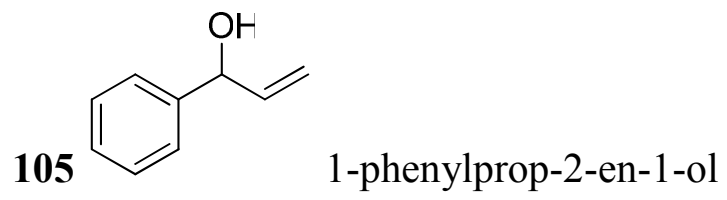

${ }^{1} \mathrm{H}$ NMR $\left(300 \mathrm{MHz}, \mathrm{CDCl}_{3}\right) \delta 7.34(\mathrm{~m}, 5 \mathrm{H}), 6.055(\mathrm{~m}, 1 \mathrm{H}), 5.35(\mathrm{~m}, 1 \mathrm{H}), 5.20(\mathrm{~m}, 2 \mathrm{H})$, $2.08(\mathrm{br}-\mathrm{s}, 1 \mathrm{H})$.<smiles>C=CC(O)c1ccccc1OC</smiles>

${ }^{1} \mathrm{H}$ NMR $\left(300 \mathrm{MHz}, \mathrm{CDCl}_{3}\right) \delta 7.27(\mathrm{~m}, 2 \mathrm{H}), 6.96(\mathrm{~m}, 1 \mathrm{H}), 6.90(\mathrm{~m}, 1 \mathrm{H}), 6.14(\mathrm{~m}, 1 \mathrm{H})$, $5.41(\mathrm{~m}, 1 \mathrm{H}), 5.31(\mathrm{~m}, 1 \mathrm{H}), 5.17(\mathrm{~m}, 1 \mathrm{H}), 3.86(\mathrm{~s}, 3 \mathrm{H}), 2.76(\mathrm{~d}, J=6.2 \mathrm{~Hz}, 1 \mathrm{H})$. HPLC: chiralcel OD column; solvent ratio: 98:2 hexanes:isopropanol, flow rate: $1 \mathrm{~mL} / \mathrm{min}$. 
$107 \mathrm{Br}$

${ }^{1} \mathrm{H}$ NMR $\left(300 \mathrm{MHz}, \mathrm{CDCl}_{3}\right) \delta 7.46(\mathrm{~d}, J=8.6 \mathrm{~Hz}, 2 \mathrm{H}), 7.34(\mathrm{~d}, J=8.7 \mathrm{~Hz}, 2 \mathrm{H}), 6.12$ $(\mathrm{dd}, J=17.3,10.6 \mathrm{~Hz}, 1 \mathrm{H}), 5.28(\mathrm{~d}, J=17.3 \mathrm{~Hz}, 1 \mathrm{H}), 5.16(\mathrm{dd}, J=10.6,0.8 \mathrm{~Hz}, 1 \mathrm{H})$, $1.92(\mathrm{~s}, 1 \mathrm{H}), 1.62(\mathrm{~s}, 3 \mathrm{H})$. HPLC: chiralcel OD column; solvent ratio: 98:2 hexanes:isopropanol, flow rate: $1 \mathrm{~mL} / \mathrm{min}$.

\section{Collaborative Work}

\section{a. Synthesis, Characterization and Reactivity of}

\section{Chlorotris(triphenylphosphine)Iridium(I)}

In a collaborative effort with Gary Shambat and Dr. John Bean in the computer and electrical engineering department at the University of Virginia, the preparation of an iridium(1) compound and its surface reactivity with silicon(111)-hydrogen terminated (or passivated) surfaces was studied. Broadly stated, this study was based in the chemical modification of microelectronic device platforms.

Surface components, or interfaces, within a series of microelectronic devices largely influence the overall performance of the system. In particular, the interfaces chemical and physical properties direct this performance. Novel approaches are required to achieve desired properties of these components since the clear objective is to drive the overall dimensions down. Research in this area will have an impact on the basic understanding of altering surface chemistry and the resulting surface properties and also on device engineering through chemical modification of the semiconductor surface.

When a molecule is chemisorbed or "assembled" onto a semi-conductive surface, the electronics can be modulated and possibly controlled. (Chemisorbtion is the process 
of chemically, or otherwise, covalently attaching substrates to a surface; i.e. the formation of chemical bonds between silicon and some element or molecule. Physisorbtion is the physical process of introducing substrates to a surface that are bound by other energetic means, for example, electrostatic or dipole-dipole interactions. Much research effort has focused on the attachment of organic molecules to silicon surfaces resulting in direct silicon—carbon bonds. The results of such surface engineering have been described in the literature. ${ }^{1}$

The chemical modification of a surface has been realized using a range of methods and studies have shown ranges from single monolayers to multiple layers attached onto the surface. ${ }^{2}$ For example, UV-induced radical reaction can take place between a passivated silicon surface and an alkyne or alkene vapor introduced in vacuo at some temperature. A mild method for conversion of the passivated silicon surface to an iodo-terminated silicon surface has been shown plausible and compatible with a typical substitution reaction with alcohols. While this method was shown to operate effectively for the in situ functionalization of an iodo-silicon surface to an alkoxide-silicon surface, it could also potentially represent a mild and efficient method to introduce organometallic reagents, such as organolithiums, organomagnesiums, or the functionally diverse organozincs directly onto the silicon surface.

Our goal was to study a new method of functionalization of the silicon surface. We synthesized chlorotris(triphenylphosphine)iridium(I) (152) using a slightly modified procedure $^{3}$ and studied the reactivity with passivated silicon(111) surfaces as shown in Scheme 6.6. 


\section{Scheme 6.6 Chemical Addition (Chemisorption) Reaction of Chloro}

tris(triphenylphosphine)Iridium(I) and Hydrogen-Terminated Silicon Surface.

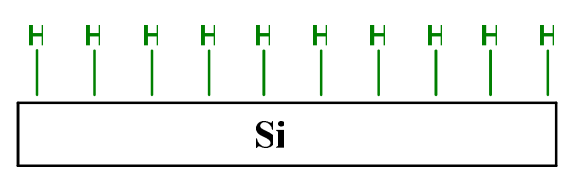

Silicon(111) passivated suyface rt. 2 hr
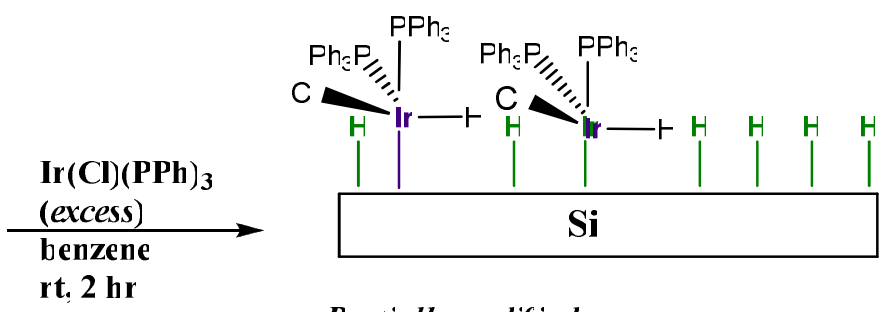

Pariially modif ied Silicon(111)--Iridium complexed sulf ace

Characterization of the reacted surfaces was performed using X-ray Photoelectron Spectroscopy (XPS) and Cyclic Voltammetry (CV).

A drawback to the system would most likely be the use of iridium which is a rather scarce and expensive metal. While this would likely prevent the practical utilization, moving from the bench to vast microelectronic device applications, the chemical modification of a passivated solid silicon surface using a mild, solution-based methodology previously shown to react with silanes ${ }^{5}$ has been established. The extension of the established methodology is potential access to study a range of functional variance from spatial to electronic considerations based simply on selection of the ligand set on the metal as well as variance in the attached metal.

\section{Experimental and Characterization:}

Synthesis of chlorotris(triphenylphosphine)iridium(I) (152)

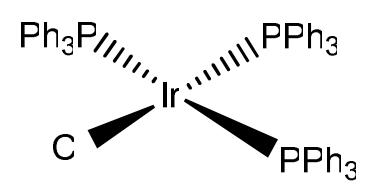

Reagent grade chloro-1,5-cyclooctadiene iridium(1) dimer (99\%) (250 mg) and triphenylphosphine $(1.24 \mathrm{~g})$ were dissolved in $30 \mathrm{~mL}$ heptanes (heptanes was distilled 
from calcium hydride under nitrogen and stored over $4 \AA$ molecular sieves; boiling point $98^{\circ} \mathrm{C}$ ). This orange mixture was then heated to reflux for 1 hour. After this time, the reaction was cooled to room temperature and a thick orange precipitate formed. This was the impure iridium complex. The complex was filtered and rinsed with heptanes in a nitrogen atmosphere. The complex was evacuated overnight and stored in a nitrogen atmosphere. NMR analysis confirmed the synthesis. ${ }^{31} \mathrm{P}$ NMR of the iridium complex using a $\mathrm{H}_{3} \mathrm{PO}_{4}$ standard in deuterated benzene ( $\mathrm{d}_{6}$-benzene was dried and distilled from sodium metal under nitrogen). This spectra shows a doublet around $24 \mathrm{ppm}$ and a triplet around $16.5 \mathrm{ppm}$ corresponding to the chemically inequivalent phosphorus atoms. ${ }^{1} \mathrm{H}$ NMR spectra shows complex signaling in the aromatic region.

Chemical addition reaction between the iridium complex and silicon surface: First, the silicon (wafers) were cleaned and passivated. The wafers were used soon after passivation (and drying) to minimize the oxide layer. Under nitrogen atmosphere, the hydrogen-terminated silicon wafer was immersed in benzene (about $2 \mathrm{~mL}$; benzene was dried and distilled from sodium/benzophenone and stored over $4 \AA$ molecular sieves) and about 5-10 mg of the iridium complex was added. The mixtures were allowed to stand for 2 hours. After this time, the wafers were dried about four times with benzene and evacuated overnight. Analysis was performed by Gary Shambat or other labs after this time. 


\section{References:}

\section{Part I:}

1. (a) Dosa, P. I.; Fu, G. C. J. Am. Chem. Soc. 1998, 120, 445-446. (b) Weber, B.;

Seebach, D. Angew. Chem. Int. Ed. 1992, 31, 84-86. Reviews of chiral tertiary alcohol synthesis: (c) Hatano, M.; Ishihara, K. Synthesis 2008, 11, 1647-1675. (d) Shibasaki, M.; Motomu, K. Chem. Rev. 2008, 108, 2853-2873.

2. reductive strategy from ketone to chiral 3o alcohols: For examples of asymmetric arylations of ketones, see: (a) Li, H. ; Garcia, C.; Walsh, P. J. PNAS 2004, 101, 54255427. (b) Anaya de Parrodi, C.; Walsh, P. J. Synlett 2004, 2417-2420. (c) Betancort, J. M. ; Garcia, C. ; Walsh, P. J. Synlett 2004, 749-760.

3. Zhou, L.-H. ; Yu, X.-Q. ; Pu, L. Tetrahedron Lett. 2010, 51 (3), 475-477.

4. Kneisel, F. F.; Dochnahl, M.; Knochel, P. Angew. Chem. Int. Ed. 2004, 43, $1017-$ 1021.

5. (a) Rijnberg, E.; Jastrzebski, J. T. B. H.; Boersma, J.; Kooijman, H.; Veldman, N.;

Spek, A. L.; van Koten, G. Organometallics 1997, 16 (11), 2239-2245. (b)

Westerhausen, M.; Wieneke, M.; Ponikwar, W.; Nöth, H.; Schwarz, W.

Organometallics 1998, 17 (7), 1438-1441. (c) Clegg, W.; Conway, B.; Hevia, E.;

McCall, M. D.; Russo, L.; Mulvey, R. E. J. Am. Chem. Soc. 2009, 131 (6), 2375-

2384. (d) Uchiyama, M.; Matsumoto, Y.; Nobuto, D.; Furuyama, T.; Yamaguchi, K.;

Morokuma, K. J. Am. Chem. Soc. 2006, 128 (27), 8748-8750. (e) Hevia, E.;

Kennedy, A. R.; Klett, J.; Livingstone, Z.; McCall, M. D. Dalton Trans. 2010, 520.

6. (a) Hatano, M.; Suzuki, S.; Ishihara, K. J. Am. Chem. Soc. 2006, 128, 9998-9999. (b)

Hatano, M.; Ishihara, K. Org. Lett. 2007, 9 (22), 4535-4538. (c) Hatano, M.; 
Ishihara, K. The Chem. Record 2008, 8, 143-155.

7. (a) DiMauro, E. F.; Kozlowski, M. C. Org. Lett. 2002, 4, 3781-3784. (b) DiMauro, E.

F.; Kozlowski, M. C. J. Am. Chem. Soc. 2002, 124, 12668-12669.

8. (a) Harrak, Y.; Romero, M.; Constans, P.; Pujol, M. D. Lett. In Org. Chem. 2006, 3, 29-34. (b) Waring, D. R.; Hallas, G. The Chemistry and Application of Drugs; Plenum: New York, 1990. (c) Van Duzer, J. H.; Michaelis, A. F.; Geiss, W. B.; Stafford, D. G.; Raker, J.; Yu, X. Y.; Siedlecki, J. M.; Yang, Y. PCT Int. Appl. 2005. CAN 143:133224. 8. (a) Trincado, M.; Ellman, J. A. Angew. Chem. Int. Ed. 2008, 47, 5623-5626. (b) Palomo, C.; Oiarbide, M.; Halder, R.; Laso, A.; López, R. Angew. Chem. Int. Ed. 2008, $45,117-120$.

9. DeBerardinis, A. M. ; Turlington, M. ; Ko, J. ; Sole, L. ; Pu, L. J. Org. Chem. 2010, $75,2836-2850$.

10. (a) Emmerson, D. P. G.; Hems, W. P.; Davis, B. G. Tetrahedron: Asymmetry 2005, 16, 213-221. (b) Orsini, F.; Sello, G.; Manzo, A. M.; Lucci, E. M. Tetrahedron: Asymmetry 2005, 16, 1913-1918. (c) Cozzi, P. G. Adv. Synth. Catal. 2006, 348, 20752079. (d) Ribeiro, C. M. R.; de Farias, F. M. C. Mini-Reviews in Organic Chemistry, 2006, 3, 1-10.

11. Fernández-Ibáñez, M. Á.; Maciá, B.; Minnaard, A. J. ; Feringa, B. L. Angew. Chem. Int. Ed., 2008, 47, 1317-1319.

12. (a) Hayashi, T.; Matsumoto, Y. Tetrahedron: Asymmetry 1991, 2 (7), 601-612. Example of benzyl iodide lack of reactivity toward strong base: (b) Arroyo, Y.; Meana, Á.; Sanz-Tejedor, A.; Ruano, J. L. G. Org. Lett., 2008, 10 (11), 2151-2154. Knochel has reported a Pd and Ni cross-coupling method using benzylic zinc 
bromides (the organozinc is prepared from the reaction between $\mathrm{Zn}$ foil and the benzyl bromide): (c) Piber, M.; Jensen A. E.; Rottländer, M.; Knochel, P. Org. Lett., 1999, 1 (9), 1323-1326. For other prepartions and use of alkylzincs, see: (d) Berk, S. C.;

Knochel, P.; Yeh, M. C. P. J. Org. Chem. 1988, 53, 5789-5791. (e) Zhu, L.; Wehmeyer, R. M.; Rieke, R. D. J. Org. Chem. 1991, 56, 1445-1453. (f) Tucker, C. E.; Knochel, P. J. Org. Chem. 1993, 58, 4781-4782. (g) Brieden, W.; Ostwald, R.; Knochel, P. Angew.

Chem. Int. Ed. 1993, 32(4), 582-584. (h) Rozema, M. J.; AchyuthaRao, S.; Knochel, P. J. Org. Chem. 1993, 57, 1956. (i) Knochel, P.; Rao, C. J. Tetrahedron 1993, 49, 29-48.

13. Hoang, C. T.; Bouillère, F.; Johannesen, S.; Zulauf, A.; Panel, C.; Pouilhès, A.; Gori, D.; Alezra, V.; Kouklovsky, C. J. Org. Chem. 2009, 74 (11), 4177-4187.

14. Hayashi, T.; Matsumoto, Y. Tetrahedron: Asymmetry 1991, 2 (7), 601-612.

15. Du, Y.; Turlington, M; Zhou, X. ; Pu, L. Tetrahedron Lett. 2010, 51, 5024-5027.

16. (a) Corey, E. J. ; Fuchs, P. L. Tetrahedron 1972, 13, 3769-3772. (b) Mori, M.; Tonogaki, K.; Kinoshita, A. Org. Synth. 2005, 81, 1. (c) Marshall, J. A.; Yanik, M. M.; Adams, N. D.; Ellis, K. C.; Chobanian, H. R. Org. Synth. 2005, 81, 157.

17. (a) Yasui, K.; Goto, Y.; Yajima, T.; Taniseki, Y.; Fugami, K.; Tanaka, A.; Tamaru, Y. Tetrahedron 1993, 34 (47), 7619-7622. (b) Zanoni, G.; Gladiali, S.; Marchetti, A.;

Piccinini, P. ; Tredici, I. ; Vidari, G. Angew. Chem., 2004, 116, 864-867. (c) Trost, B. M. J. Org.Chem. 2004, 69, 5813-5837.

18. Fleury, L. M.; Ashfeld, B. L. Org. Lett. 2009, 11 (24), 5670-5673.

19. (a) Sekiya, K.; Nakamura, E. Tetrahedron. Lett. 1988, 29 (40), 5155-5156. (b) Arai, M.; Kawasuji, T.; Nakamura, E. Chem. Lett. 1993, 357-360. 
20. (a) Wunderlich, S. H.; Knochel, P. Angew. Chem. Int. Ed. 2007, 46, 7685-7688. (b) Jeganmohan, M.; Knochel, P. Angew. Chem. Int. Ed. 2010, 49, 1-6.

21. (a) Eaton, P. E.; Lee, C.-H.; Xiong, Y. J. Org. Chem. 1989, 111, 8016-8018.

(b) Rohbogner, C. J.; Wunderlich, S. H.; Clososki, G. C.; Knochel, P. Eur. J. Org. Chem. 2009, 1781-1795. (c) Dong, Z.; Clososki, G. C.; Wunderlich, S. H.; Unsinn, A.; Li, J.; Knochel, P. Chem. Eur. J. 2009, 15, 457-468. (d) Clososki, G. C.; Rohbogner, C. J.; Knochel, P. Angew. Chem. Int. Ed. 2007, 46, 7681-7684.

22. (a) Da, C.-S.; Wang, J.-R.; Yin, X.-G.; Fan, X.-Y.; Liu, Y.; Yu, S.-L. Org. Lett. 2009, 11 (24), 5578-5581. (b) Muramatsu, Y.; Harada, T. Chem.-Eur. J. 2008, 14 (34), 1056010563. (c) Muramatsu, Y.; Kanehira, S. ; Tanigawa, M.; Miyawaki, Y.; Harada, T. Bull. Chem. Soc. Japan. 2010, 83 (1), 19-32.

23. (a) Salvi, L.; Kim, J. G.; Walsh, P. J. J. Am. Chem. Soc. 2009, 131, 12483-12493.

(b) Kim, J. G.; Walsh, P. J. Angew. Chem. Int. Ed. 2006, 45, 4175-4178.

24. Capriati, V.; Florio, S.; Ingrosso, G.; Granito, C.; Troisi, L. Eur. J. Org. Chem. 2002, 478-484.

25. Ogasawara, M. Tetrahedron: Asymmetry 2009, 20 (3), 259-271.

26. (a) Trost, B. M.; Weiss, A. H. Adv. Synth. Catal. 2009, 351, 963-983. (b) Tejedor, D.; López-Tosco, S. ; Cruz-Acosta, F.; Méndez,-Abt, G.; Garcia-Tellado, F.; Angew. Chem. Int. Ed. 2009, 48, 2090-2098. (c) Zhou, L.-H. ; Yu, X.-Q. ; Pu, L. J. Org. Chem. 2009, 74 (5), 2013-2017. (d) Yue, Y.; Yu, X.-Q.; Pu, L. Chem. Eur. J. 2009, 0000. (e) Rajaram, A. R. ; Pu, L. Org. Lett., 2006, 8 (10), 2019-2021. (f) Turlington, M. ; Yue, Y.; Yu, X.-Q.; Pu, L. J. Org. Chem. 2010, 75 (20), 6941-6952.

27. Jung, C.-K.; Wang, J.-C.; Krische, M. J. Am. Chem. Soc. 2004, 126, 4118-4119. 
28. (a) Ariza, X.; Costa, A. M.; Faja, M.; Pineda, O.; Vilarrasa, J. Org. Lett., 2000, 2 (18), 2809-2811. (b) Ariza, X.; Pineda, O.; Vilarrasa, J.; Shipps, Jr., G. W.; Ma, Y.; Dai, X. Org. Lett., 2001, 3 (9), 1399-1401.

29. (a) Da, C.-S.; Wang, J.-R.; Yin, X.-G.; Fan, X.-Y.; Liu, Y.; Yu, S.-L. Org. Lett. 2009, 11 (24), 5578-5581. (b) Muramatsu, Y.; Harada, T. Chem.-Eur. J. 2008, 14 (34), 1056010563. (c) Muramatsu, Y.; Kanehira, S. ; Tanigawa, M.; Miyawaki, Y.; Harada, T. Bull. Chem. Soc. Japan. 2010, 83 (1), 19-32.

30. (a) Bolm, C.; Hermanns, N.; Hilderbrand, J. P.; Muñiz, K. Angew. Chem. Int. Ed. 2000, 39, 3465-3467. (b) Schmidt, F.; Rudolph, J.; Bolm, C. Adv. Synth. Catal. 2007, 349, 703-708.

31. (a) Biradar, D. B.; Gau, H.-M. Org. Lett. 2009, 11 (3), 499-502. A similar system was reported for the enantioselective arylaluminum additions to ketones, catalyzed by an (R)H ${ }_{8}$ BINOL_titanium complex: (b) Zhou, S. Wu, K.-H.; Chen, C.-A.; Gau, H.-M. J. Org. Chem., 2007, 74, 3500-3505.

32. For examples of BINOL-based Zirconium complexes and their catalytic studies, see:

a) Casolari, S.; Cozzi, P. G.; Orioli, P.; Tagliavini, E.; Umani-Ronchi, A. Chem.

Commun., 1997, 2123-2124. b) Volk, T.; Korenaga, T.; Matsukawa, S.; Terada, M.;

Mikami, K. Chirality 1998, 10, 717-721. c) Kobayashi, S.; Ishitani, H.; Ueno, J. J. Am. Chem. Soc., 1998, 120, 431-432. d) Kurosu, M.; Lorca, M. Tetrahedron Lett., 2002, 43, 1765-1769. e) Ihori, Y.; Yamashita, Y.; Ishitani, H.; Kobayashi, S. J. Am. Chem. Soc., 2005, $127,15528-15535$.

33. A review on the asymmetric Grignard reagent and organolithium additions to carbonyls: (a) Luderer, M. R.; Bailey, W. F.; Luderer, M. R.; Fair, J. D.; Dancer, R. J.; 
Sommer, M. -B. Tetrahedron: Asymmetry 2009, 20, 981-998. (b) Roberts, J. T. In Handbook of Grignard Reagents; Silvermn, G. S.; Rakita, P. E., Eds.; Marcel Dekker: New York, 1996; pp 557-565.

34. Topics in Organometallic Chemistry: Organolithiums in Enantioselective Synthesis; Goldfuss, B. Hodgson, D. M., Eds.; Springer, 2003; pp 21-36. (b) Weber, B.; Seebach, D. Angew. Chem., Int. Ed. Engl. 1992, 31, 84-86. (c) Muramatsu, Y.; Harada, T. Angew. Chem., Int. Ed. 2008, 47, 1088-1090. (d) Da, C.-S.; Wang, J.-R.; Yin, X.-G.; Fan, X.-Y.; Liu, Y.; Yu, S.-L. Org. Lett. 2009, 11, 5578-5581. (e) Goldfuss, B. Synthesis 2005, 14, 2271-2280.

35. (a) Hatano, M.; Suzuki, S.; Ishihara, K. J. Am. Chem. Soc. 2006, 128, 9998-9999. (b) Hatano, M.; Ishihara, K. Org. Lett. 2007, 9 (22), 4535-4538. (c) Hatano, M.; Ishihara, K. The Chem. Record 2008, 8, 143-155.

36. (a) Banert, K.; Hagedorn, M.; Liedtke, C.; Melzer, A.; Schöffler, C. Eur. J. Org. Chem., 2000, 257-267. (b) Cotter, J.; Hogan, A.-M. L.; O’Shea, D. F. Org. Lett., 2007, 9 (8), 1493-1496. (c) Tamao, K.; Akita, M.; Maeda, K.; Kumada, M. J. Org. Chem., 1987, $52,1100-1106$.

37. (a) Calogeropoulou, T.; Hammond, G. B.; Wiemer, D. F. J. Org. Chem., 1987, 52 (19), 4185-4190. (b) Lee, K.; Wiemer, D. F. Tetrahedron Lett., 1993, 34 (15), 24332436.

38. Bolm, C.; Hermanns, N.; Hilderbrand, J. P.; Muñiz, K. Angew. Chem. Int. Ed. 2000, 39, 3465-3467.

\section{Part II:}


1. (a) He, T.; Ding, H.; Peor, N.; Lu, M.; Corley, D. A.; Chen, B.; Ofir, Y.; Gao, Y.; Yitzchaik, S.; Tour, J. M. J. Am. Chem. Soc. 2008, 130, 1699-1710. (b) Deutsch, D.;

Natan, A.; Yoram, S.; Kronik, L. J. Am. Chem. Soc. 2007, 129, 2989-2997. (c) Segev, L.;

Salomon, A.; Natan, A. ; Cahen, D.; Kronik, L.; Amy, F.; Chan, C. K.; Kahn, A. Phys. Rev. B 2006, 74, 165323-1: 165323-6.

2. Buriak, J. M. Chem. Rev. 2002, 102 (5), 1271-1308.

3. Bennett, M. A.; Milner, D. L. J. Am. Chem. Soc. 1969, 91, 6983-6994.

4. Shambat, G.; DeBerardinis, A.; Chen, B.; Tour, J.; Reinke, P.; Venton, J.; Pu, L.; Bean, J. Appl. Surf. Sci. 2009, 255, 8533-8538.

5. Bennett, M. A.; Charles, R.; Fraser, P. J. Aust. J. Chem. 1977, 30, 1201-1211. 
VII. Appendix

a. NMR spectrum of ligands synthesized and other compounds from Chapter 2

b. NMR spectrum of the arylation addition products and other compounds from Chapter 3

i. ${ }^{1}$ H NMR spectrum of mandelate derivatives for the determination of ee in the asymmetric addition of 3benzonitrile to aldehydes

ii. ${ }^{1}$ H NMR spectrum of $(R)-(+)-\alpha$-cyclohexyl-3-methoxybenzenmethanol: absolute configuration determination

iii. NMR spectrum of the NMR investigation of catalyst structure

c. NMR spectrum of the vinylation addition products and other compounds from Chapter 4

i. 2D ${ }^{1} \mathrm{H}$ NMR spectrum for determination of double-bond geometry

ii. 2D ${ }^{1} \mathrm{H}$ NMR spectra for determination of long-range ( 5 bond)

${ }^{1} \mathrm{H}-{ }^{1} \mathrm{H}$ coupling observed for vinylation addition products

iii. ${ }^{1}$ H NMR spectrum of $(R)-(-)-(E)-6$-(tert-butyldimethylsilyloxy)1,2-diphenylhex-2-en-1-ol: absolute configuration determination

d. NMR spectrum of the alkyne additions and other compounds from Chapter 5

e. NMR spectrum of compounds from Chapter 6

i. NMR spectra of the arylation additions to ketone products

ii. NMR spectra of the arylation addition to $\mathrm{N}$-tosylaldimine products

iii. NMR spectrum of the Arene Addition Products

iv. NMR spectrum of the Allyl Addition Products

v. NMR spectrum of Chlorotris(triphenylphosphine)Iridium(I) 

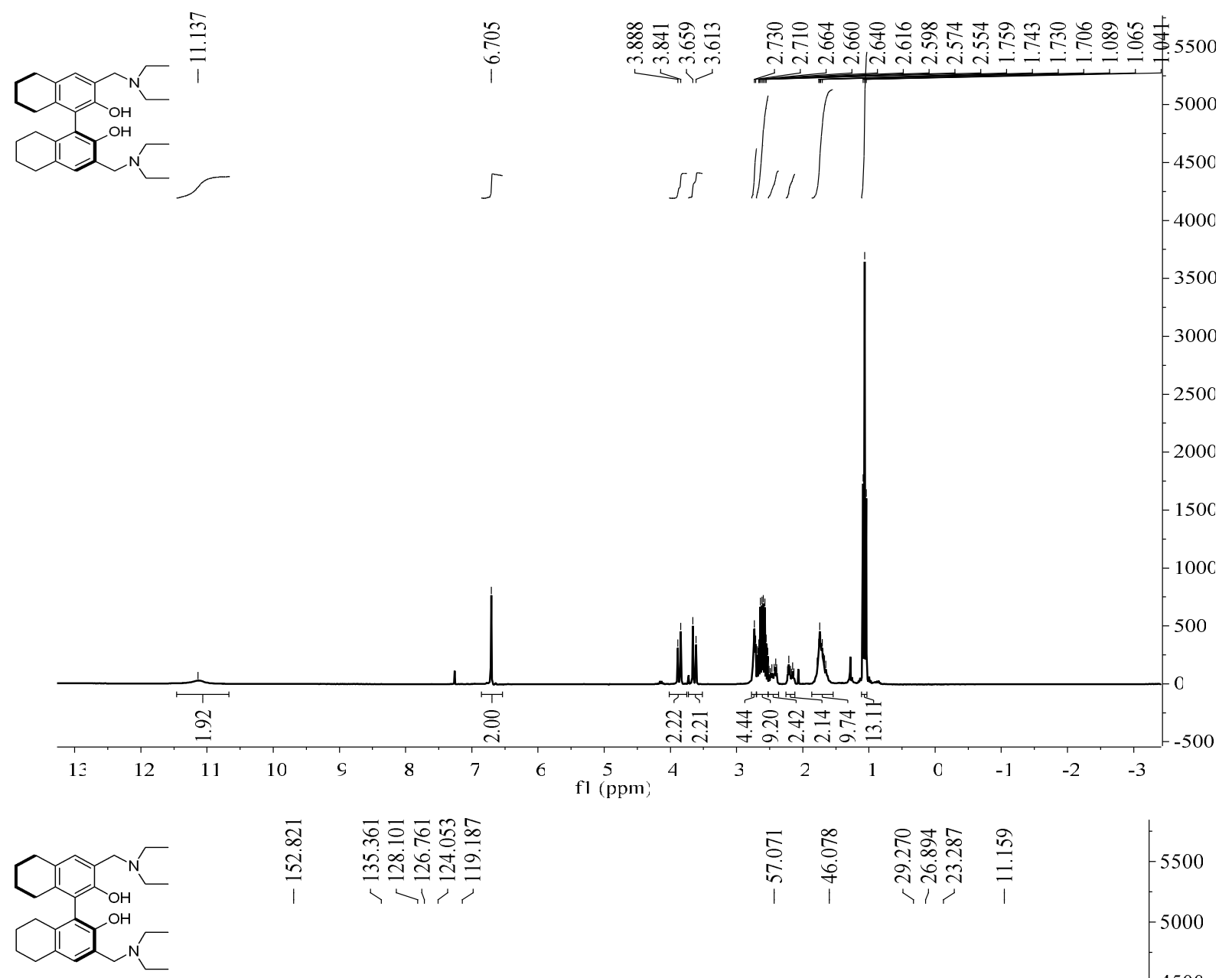

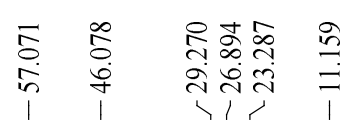

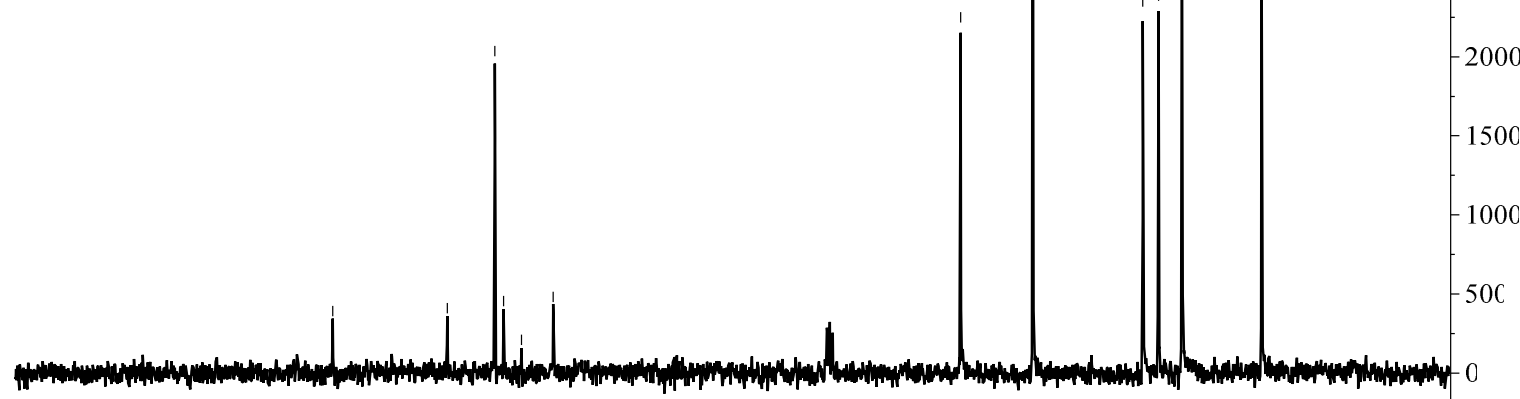



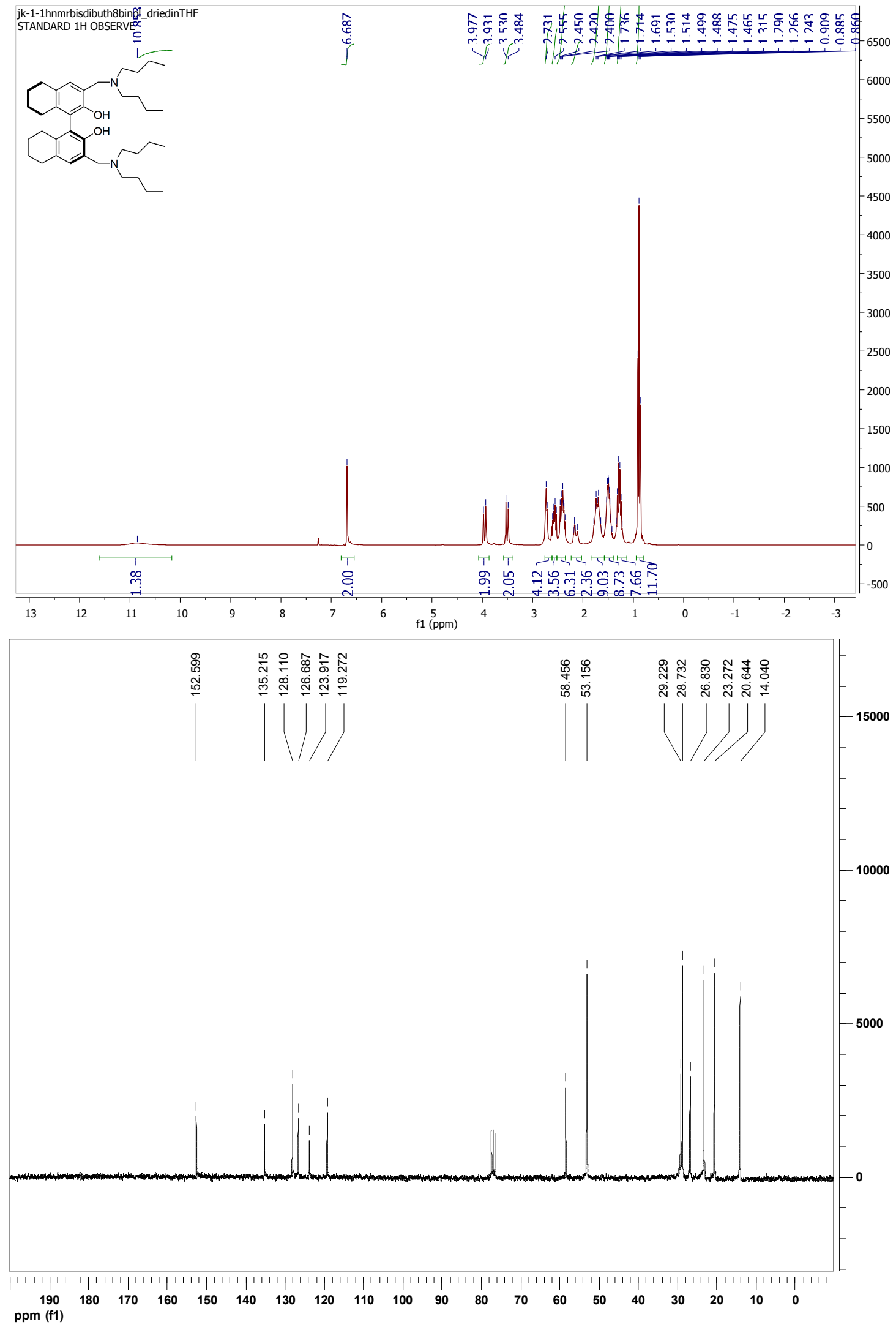


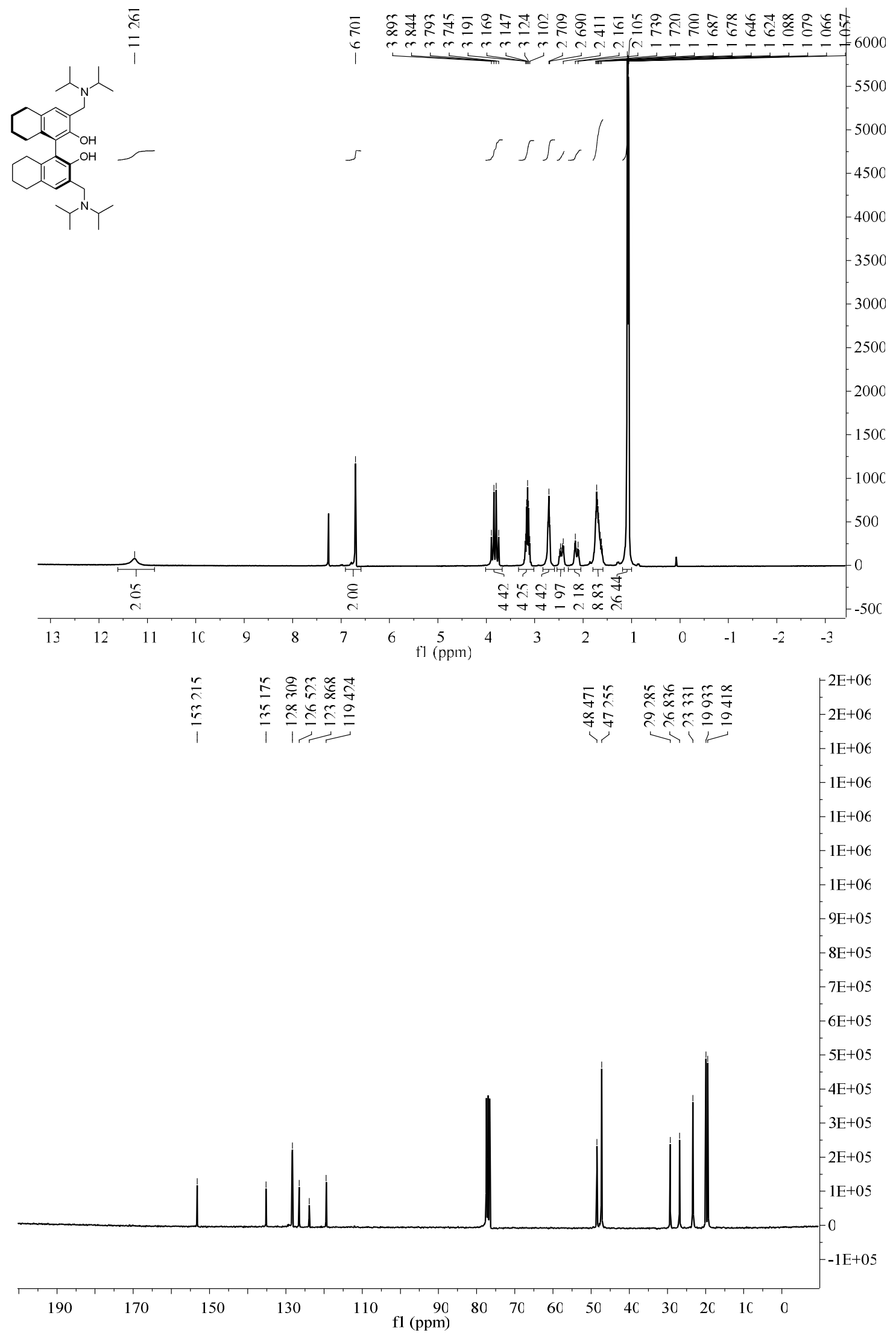




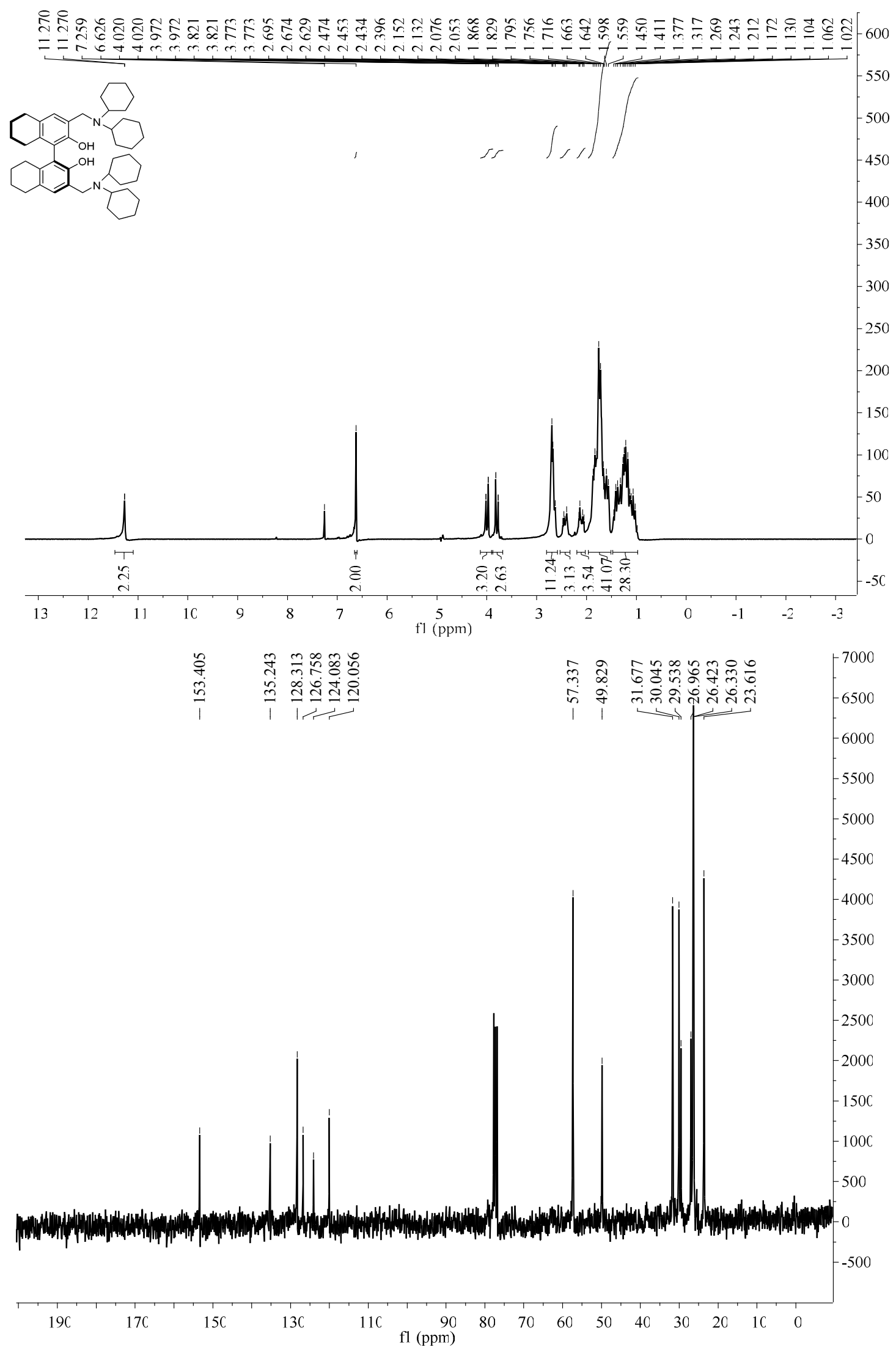




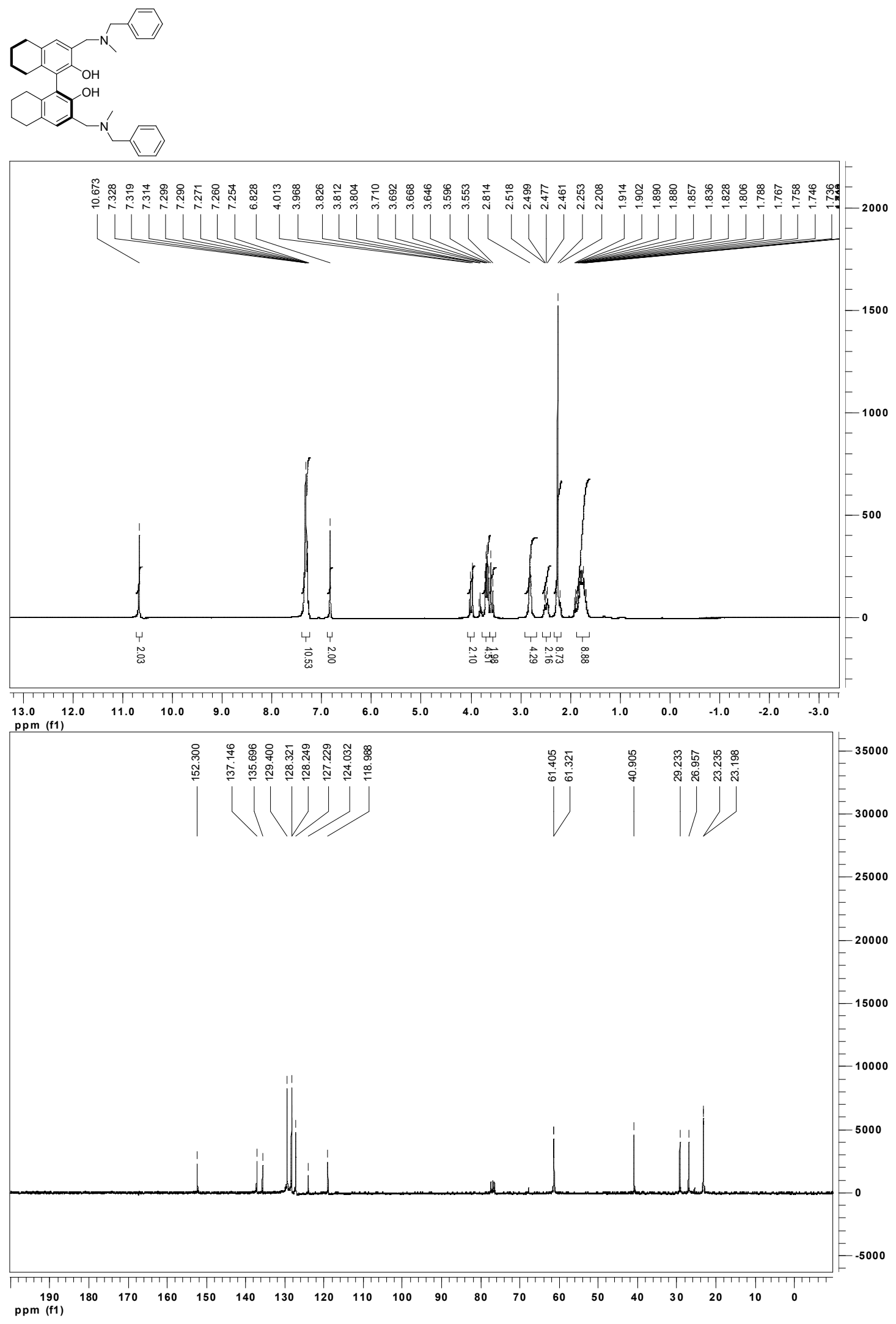



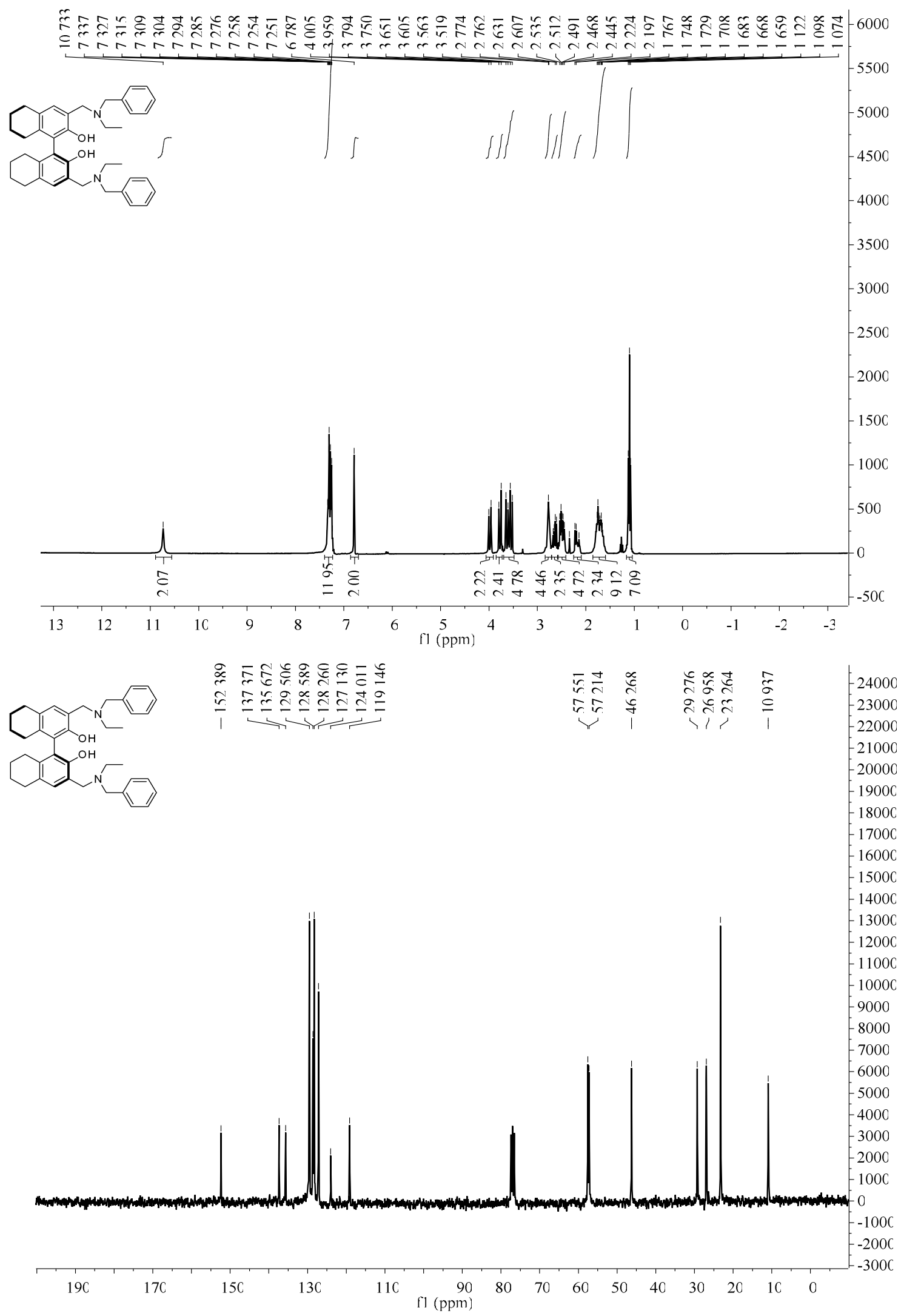


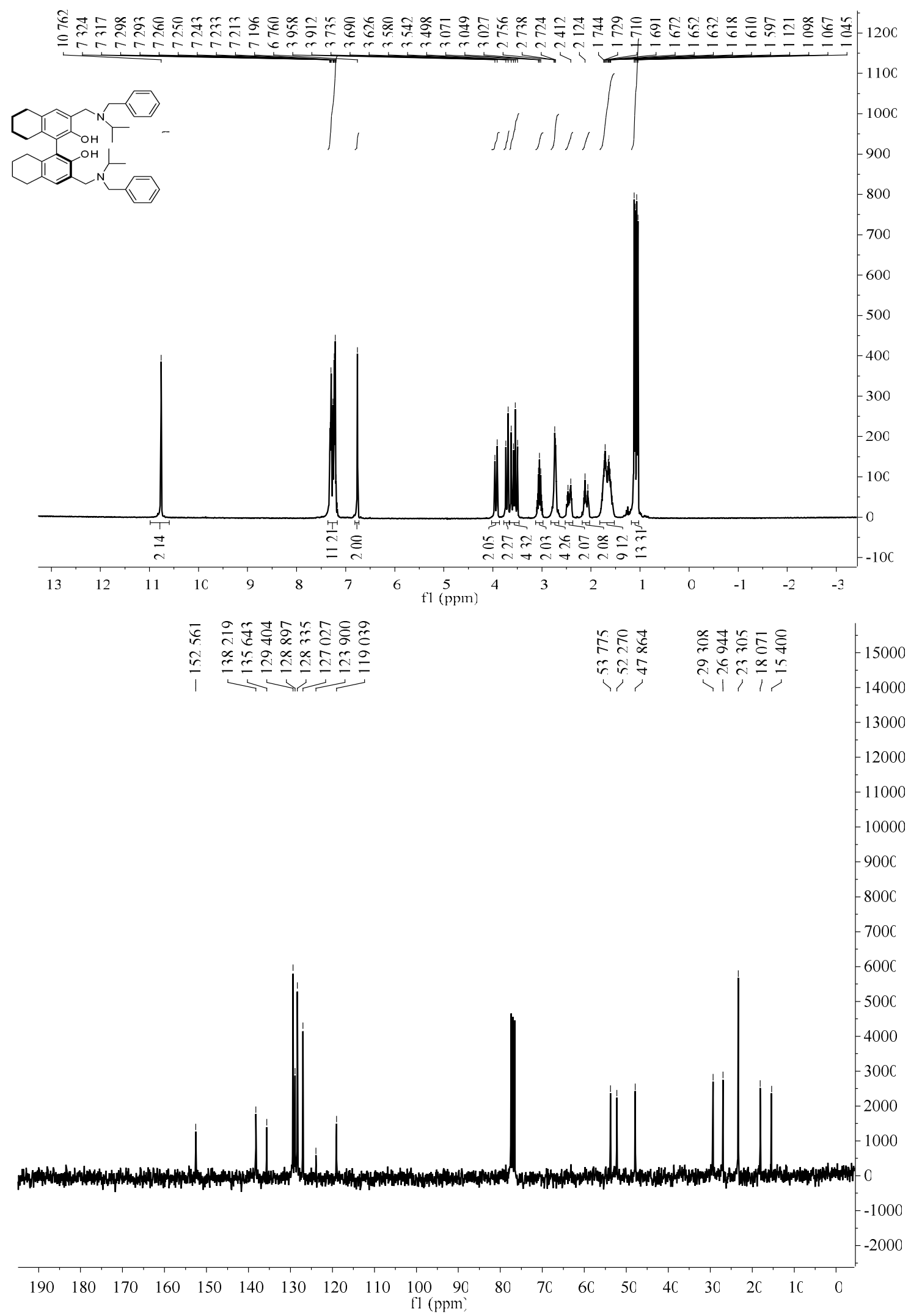




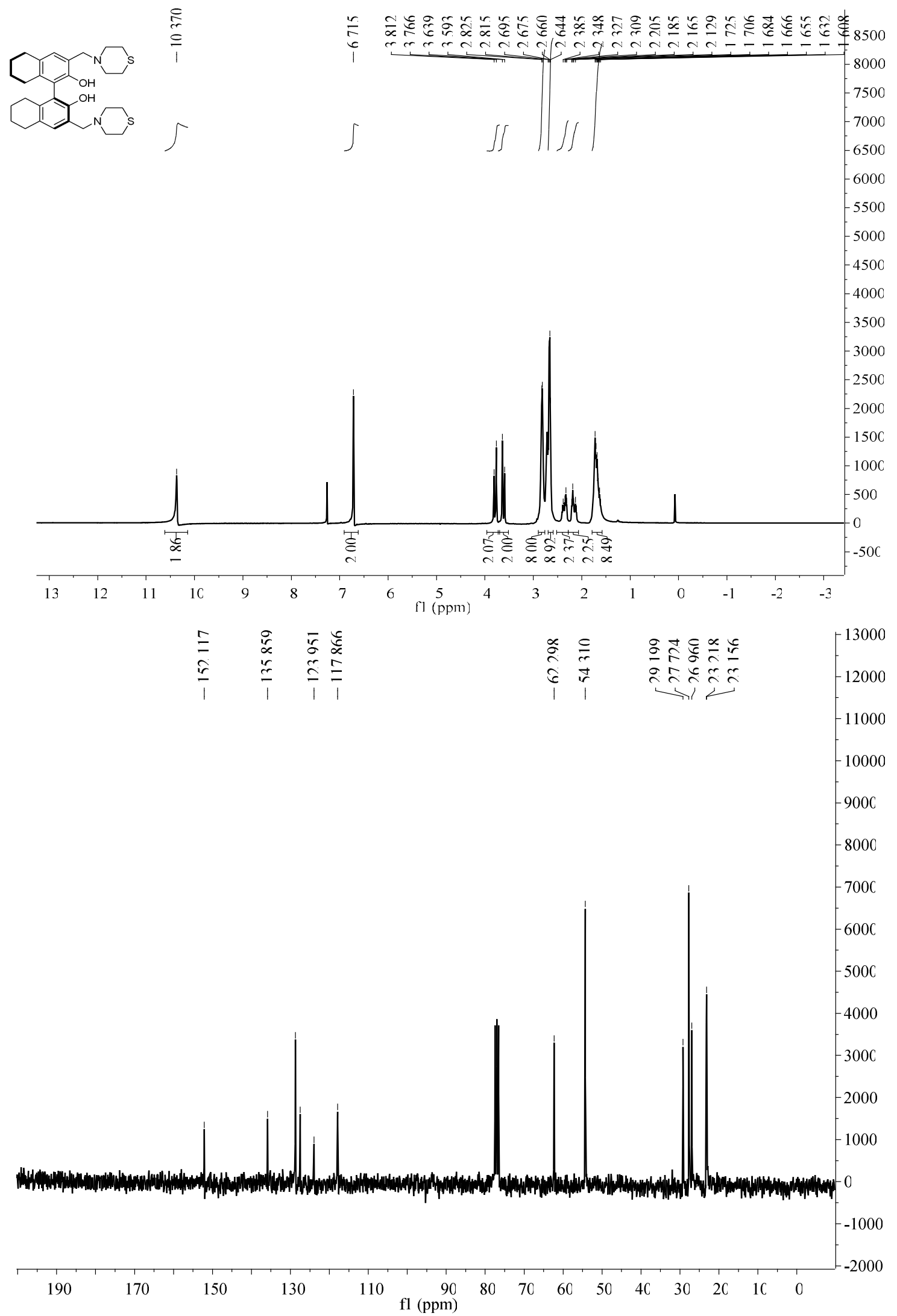




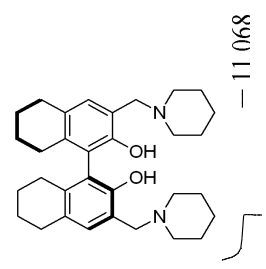

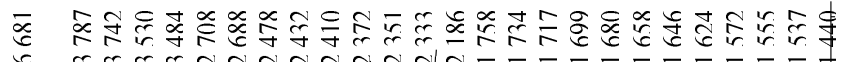
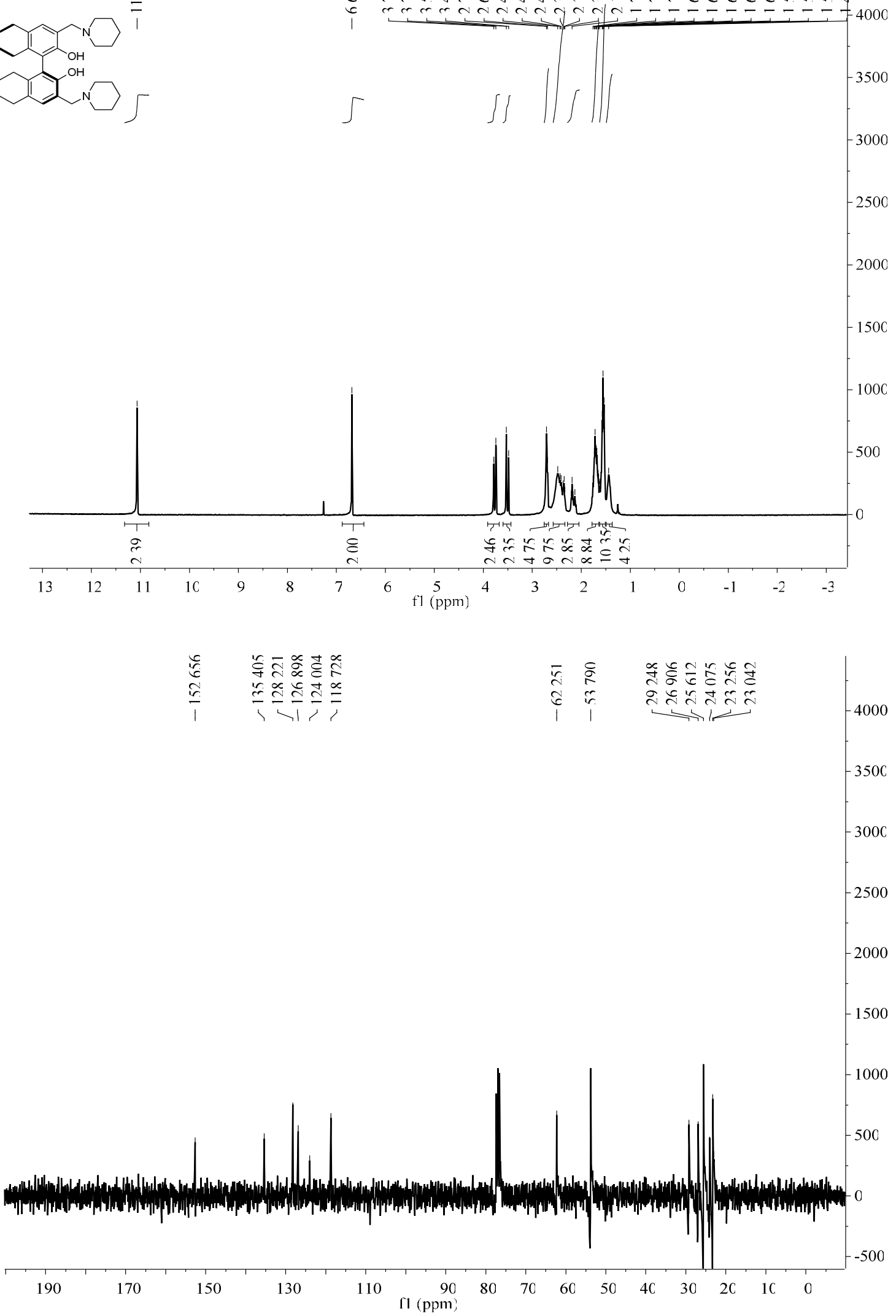


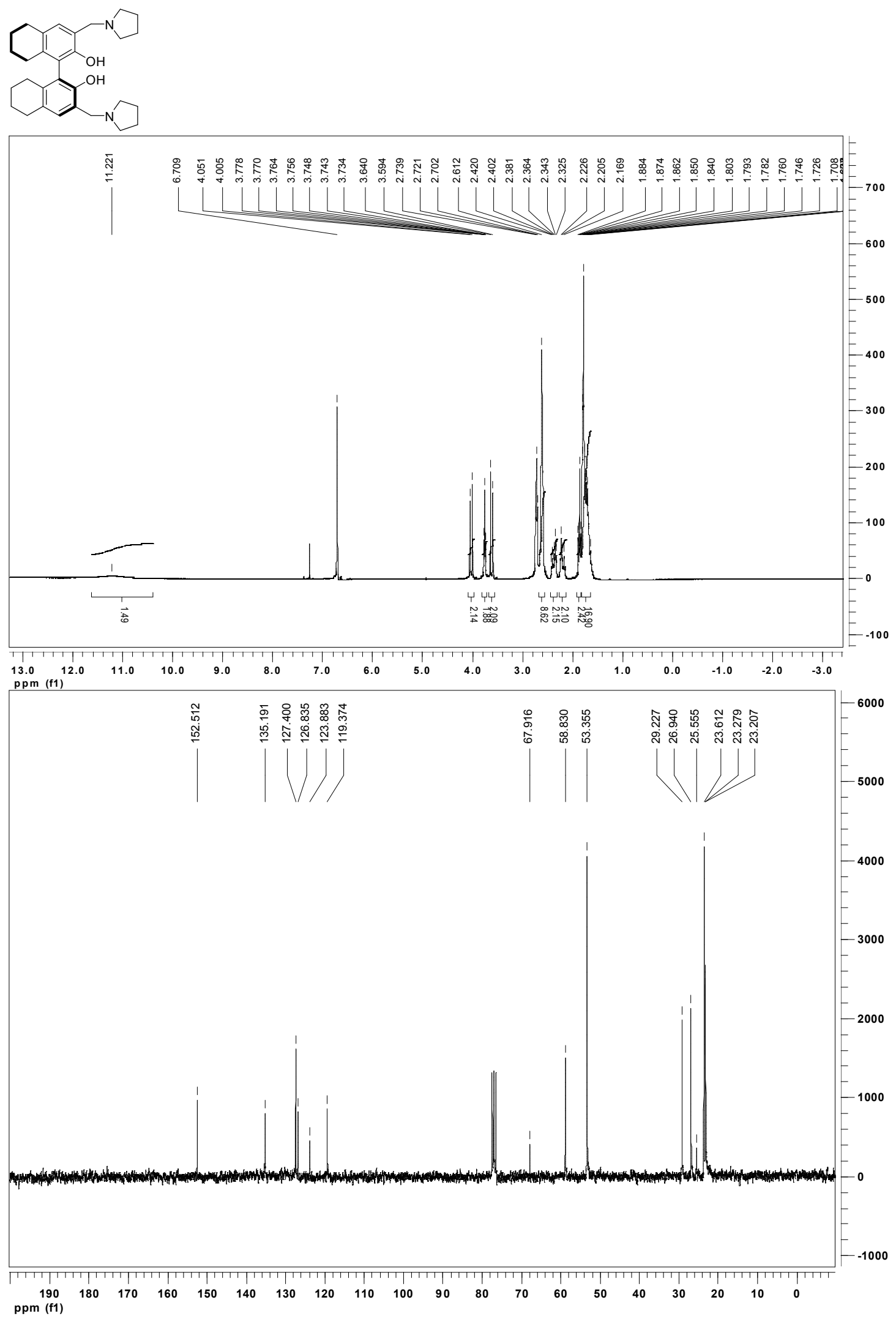




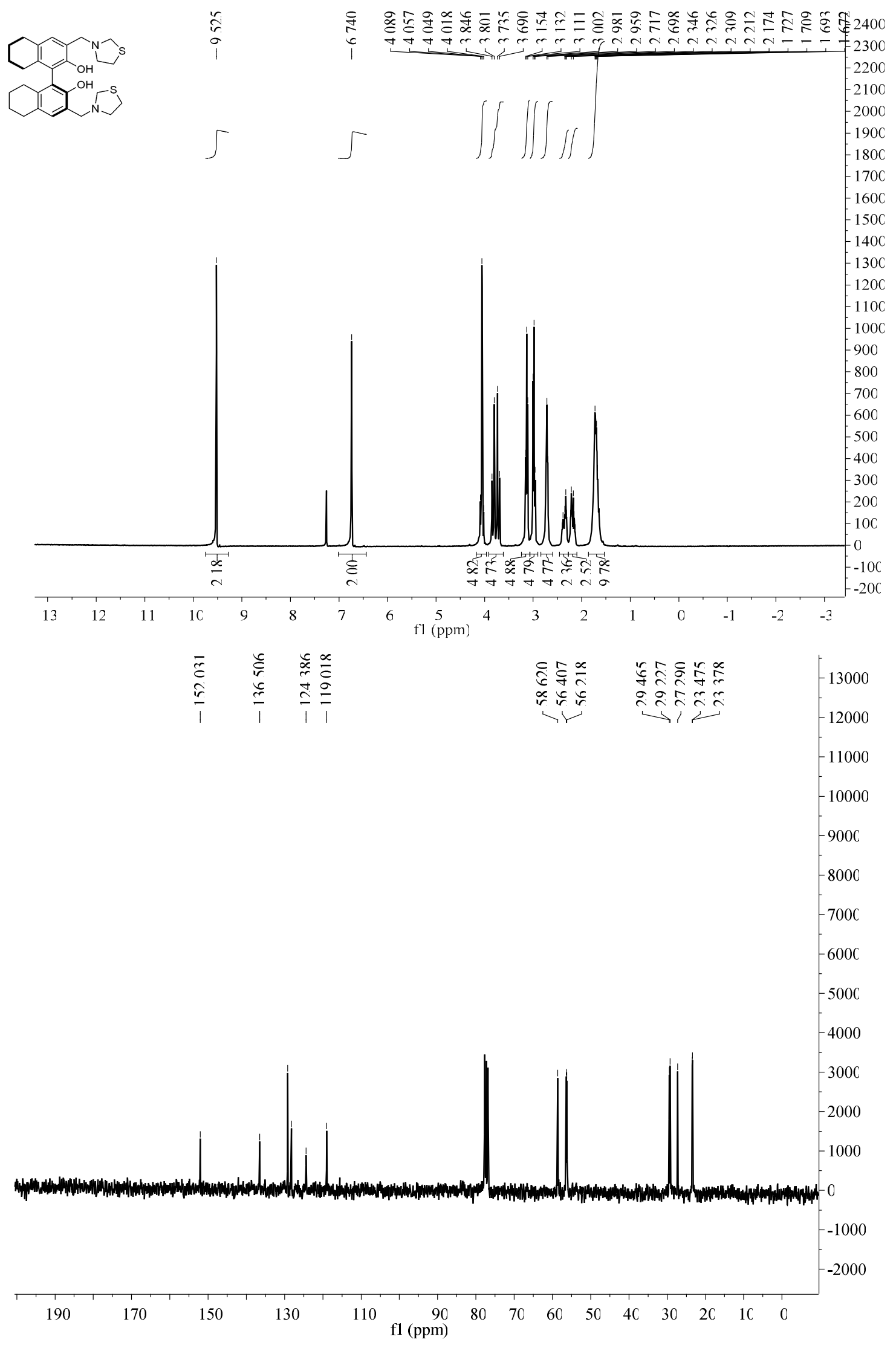




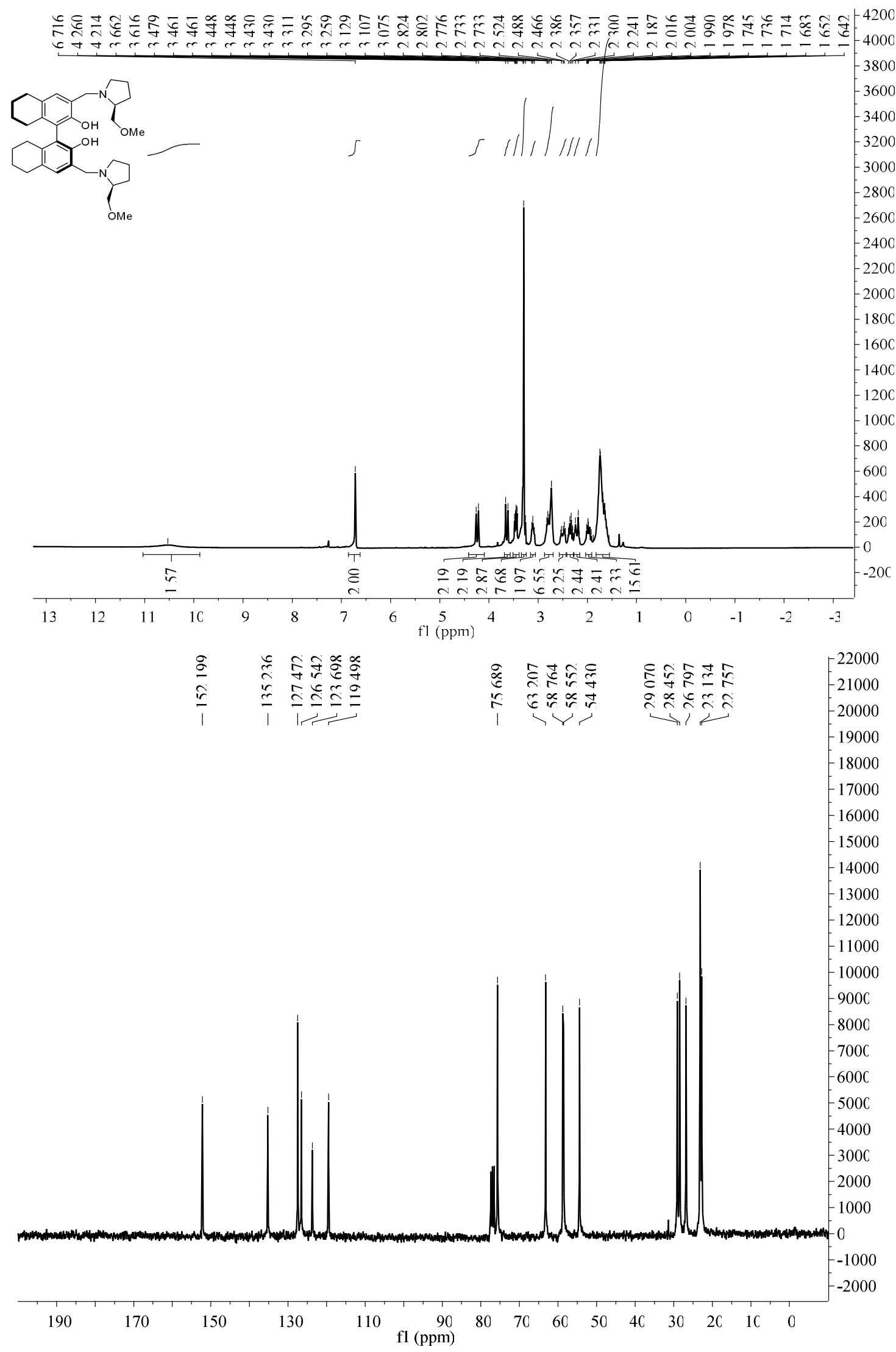




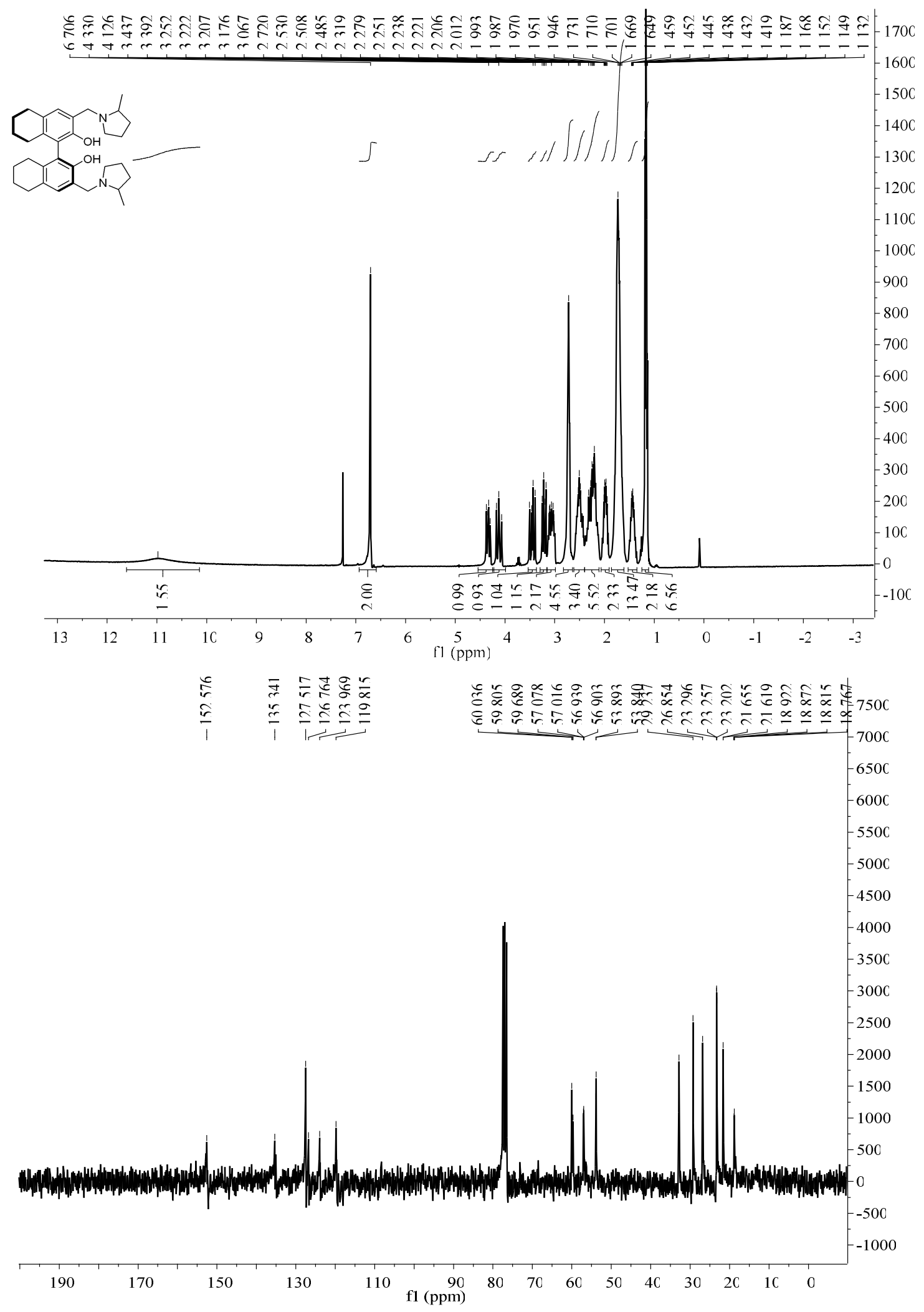



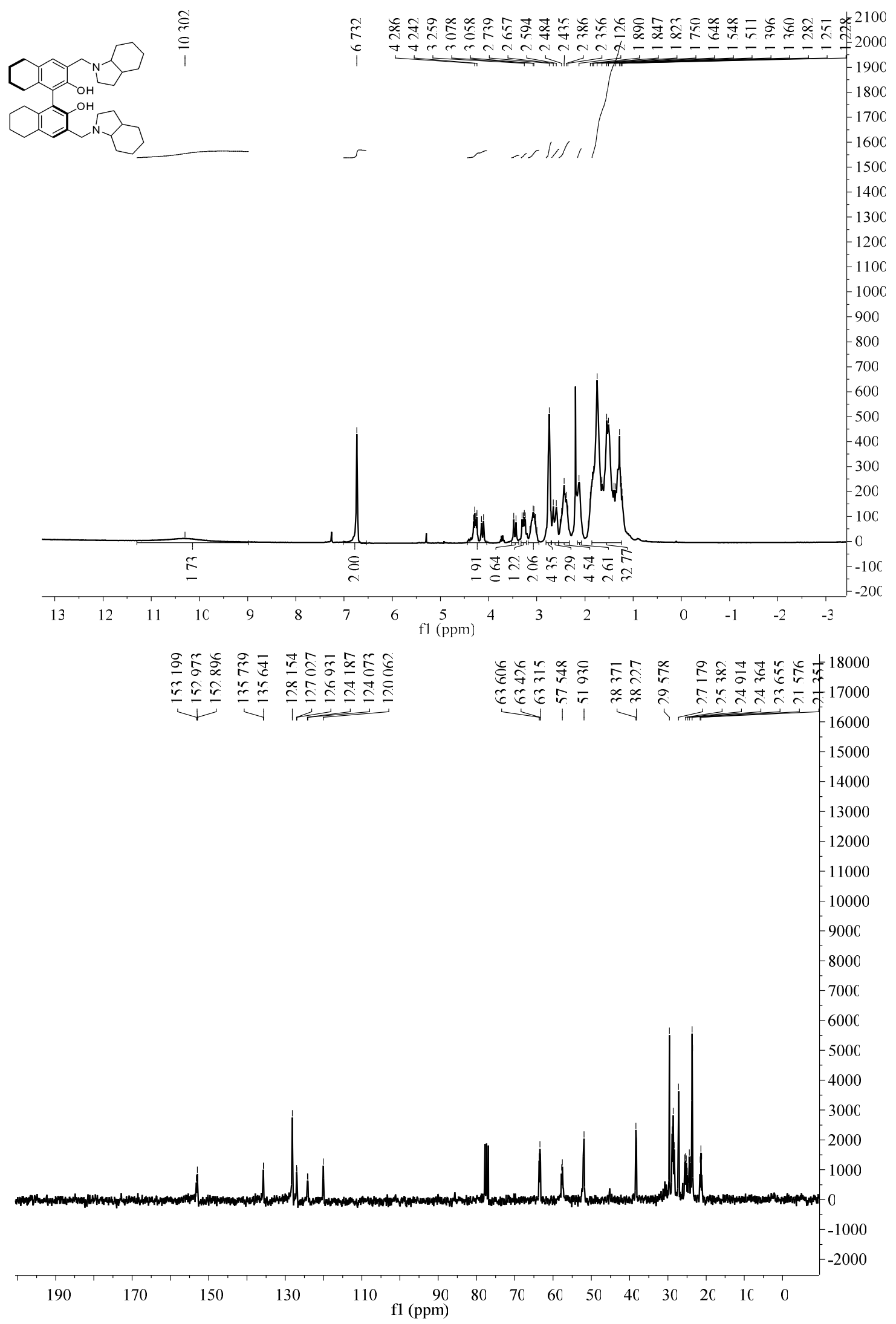


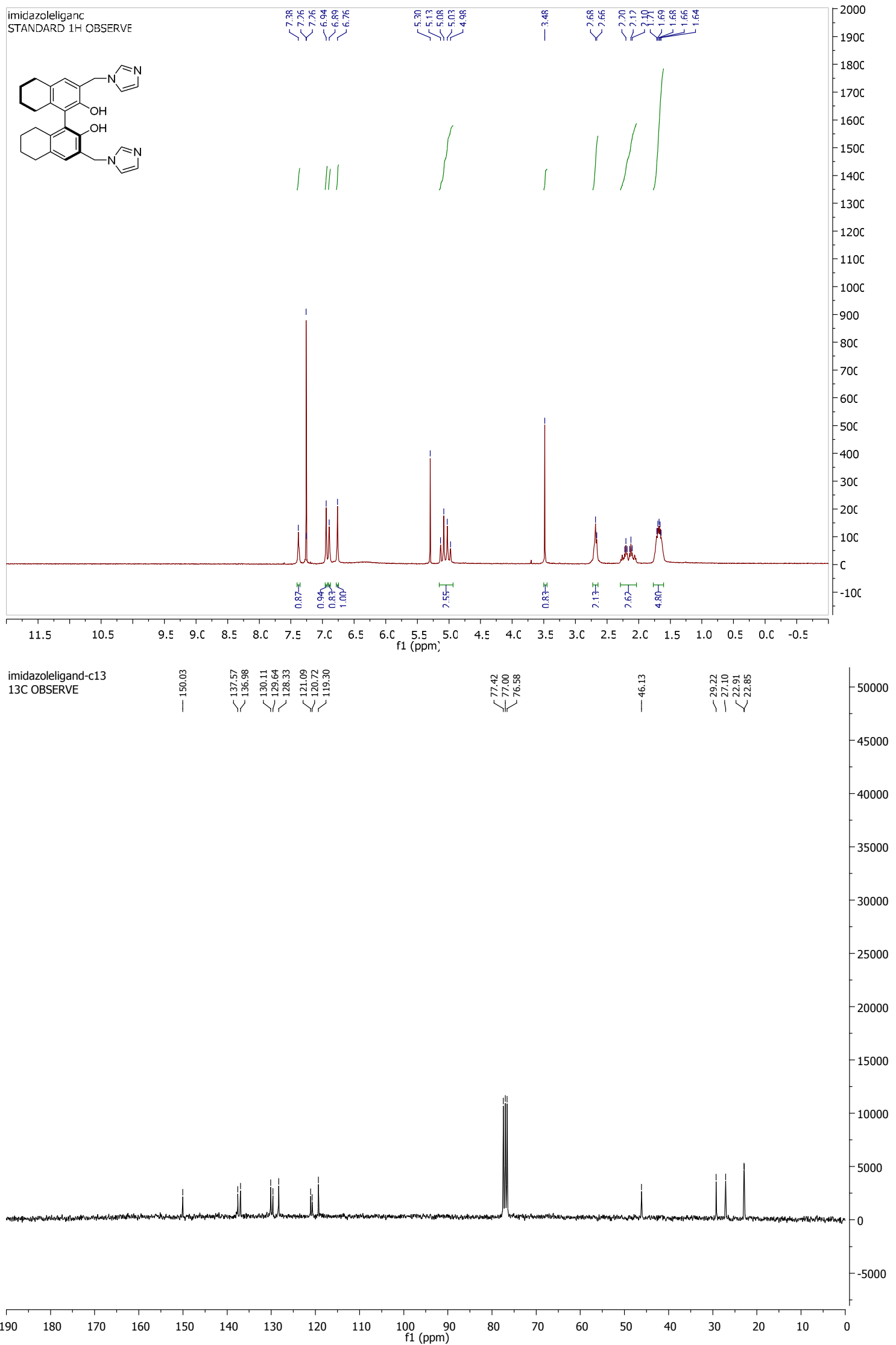




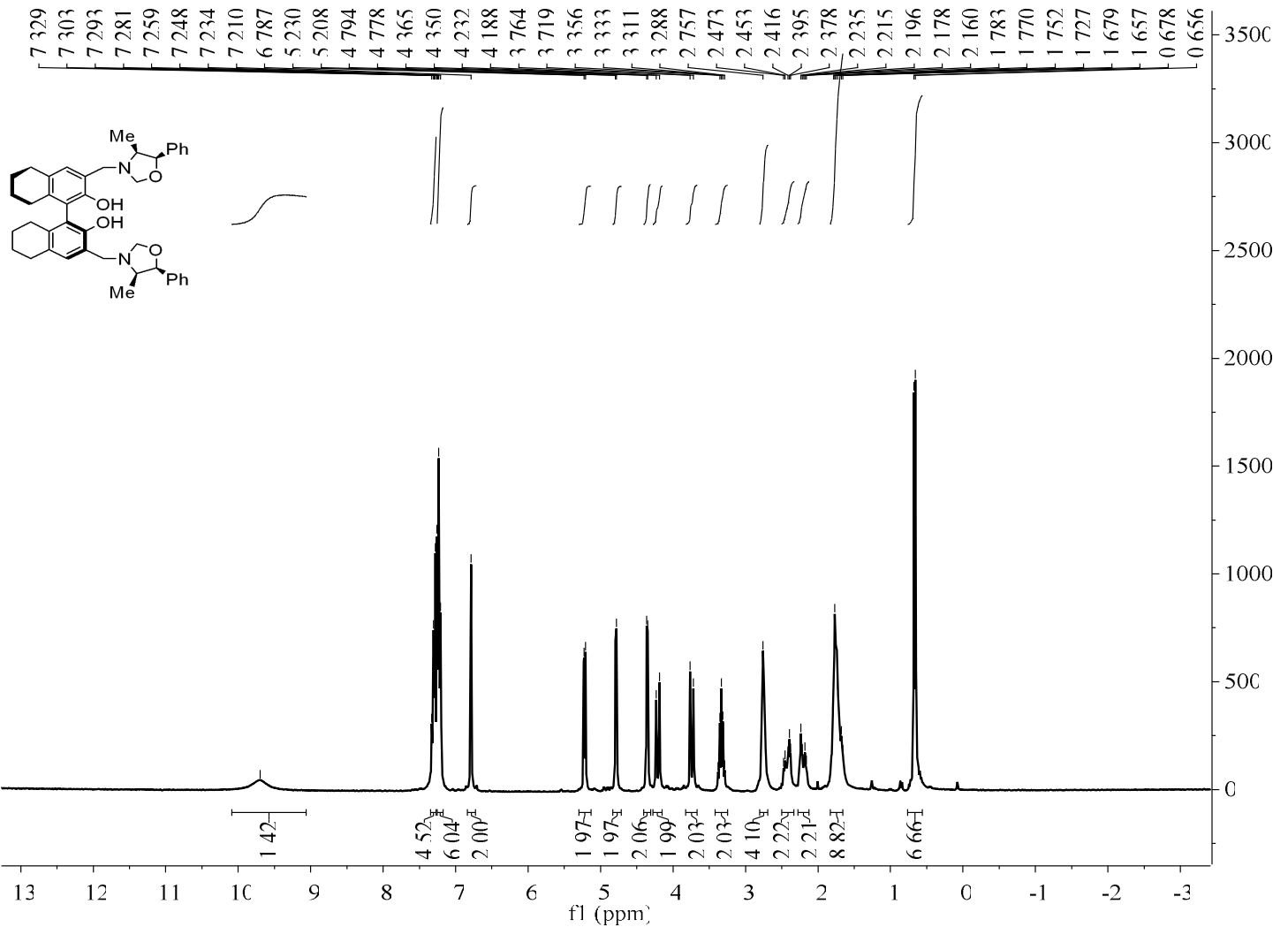

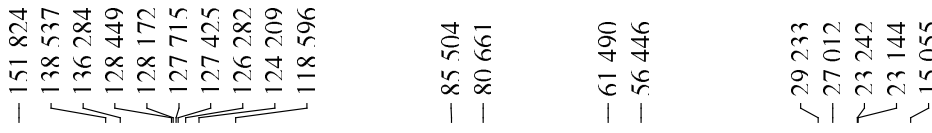

-2400
-2300
-2200
-2100
-2000
-1900
-1800
-1700
-1600
-1500
-1400
-1300
-1200
-1100
-1000
$-90 C$
-800
$-70 C$
$-60 C$
$-50 C$
$-40 C$
$-30 C$
$-20 C$
-100
-0
-100
-

190

170

150

130

110 I] (ppm) 


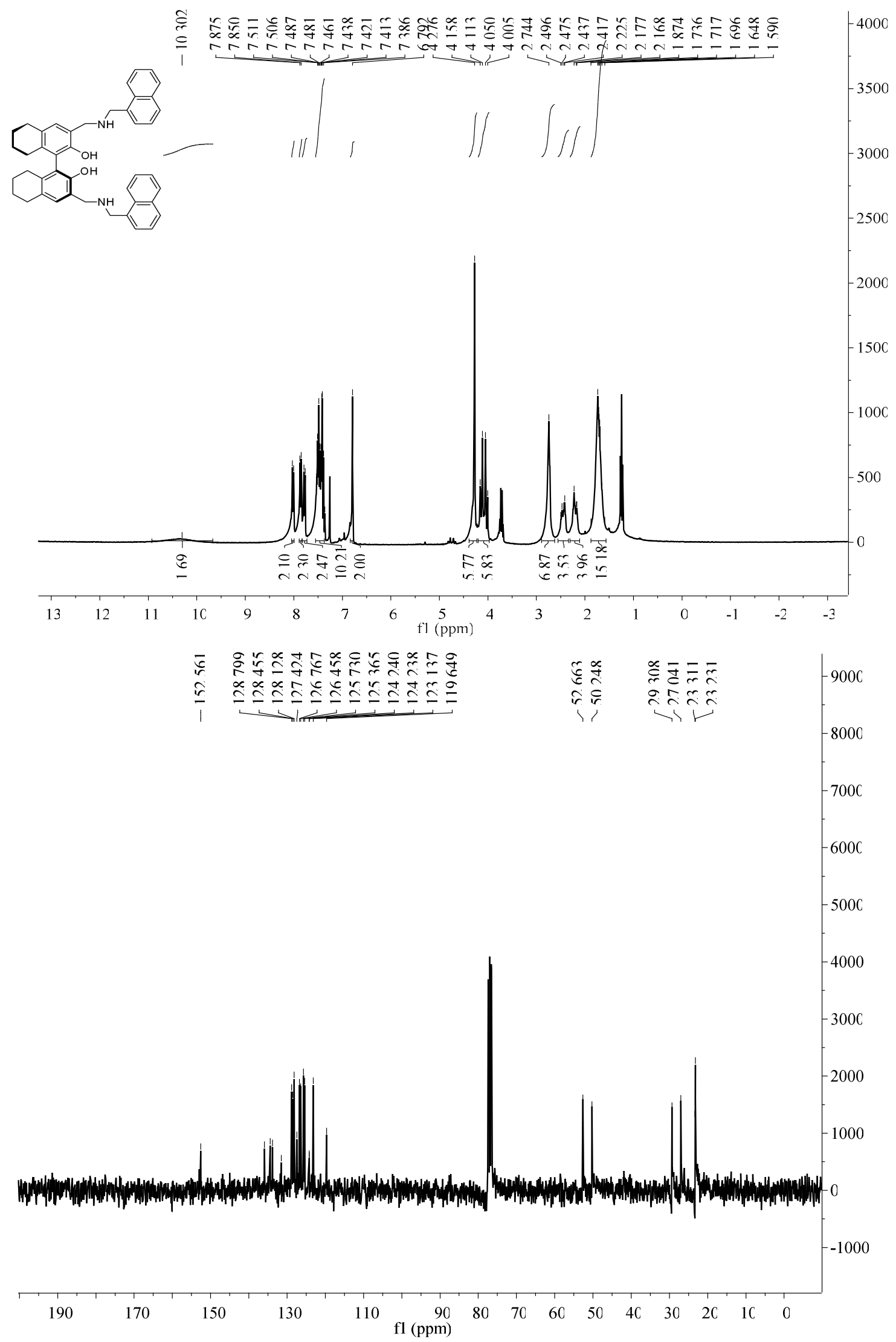



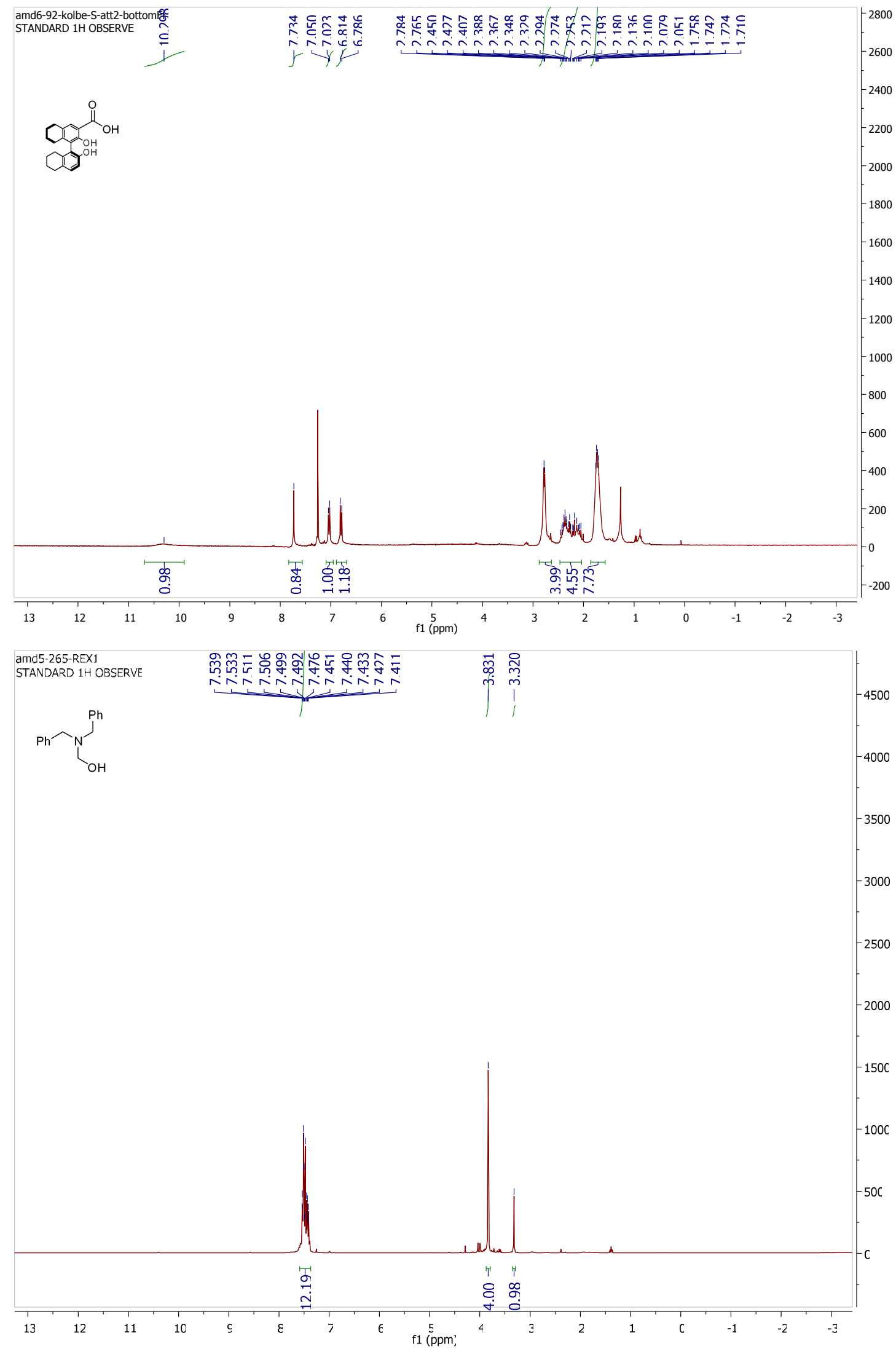

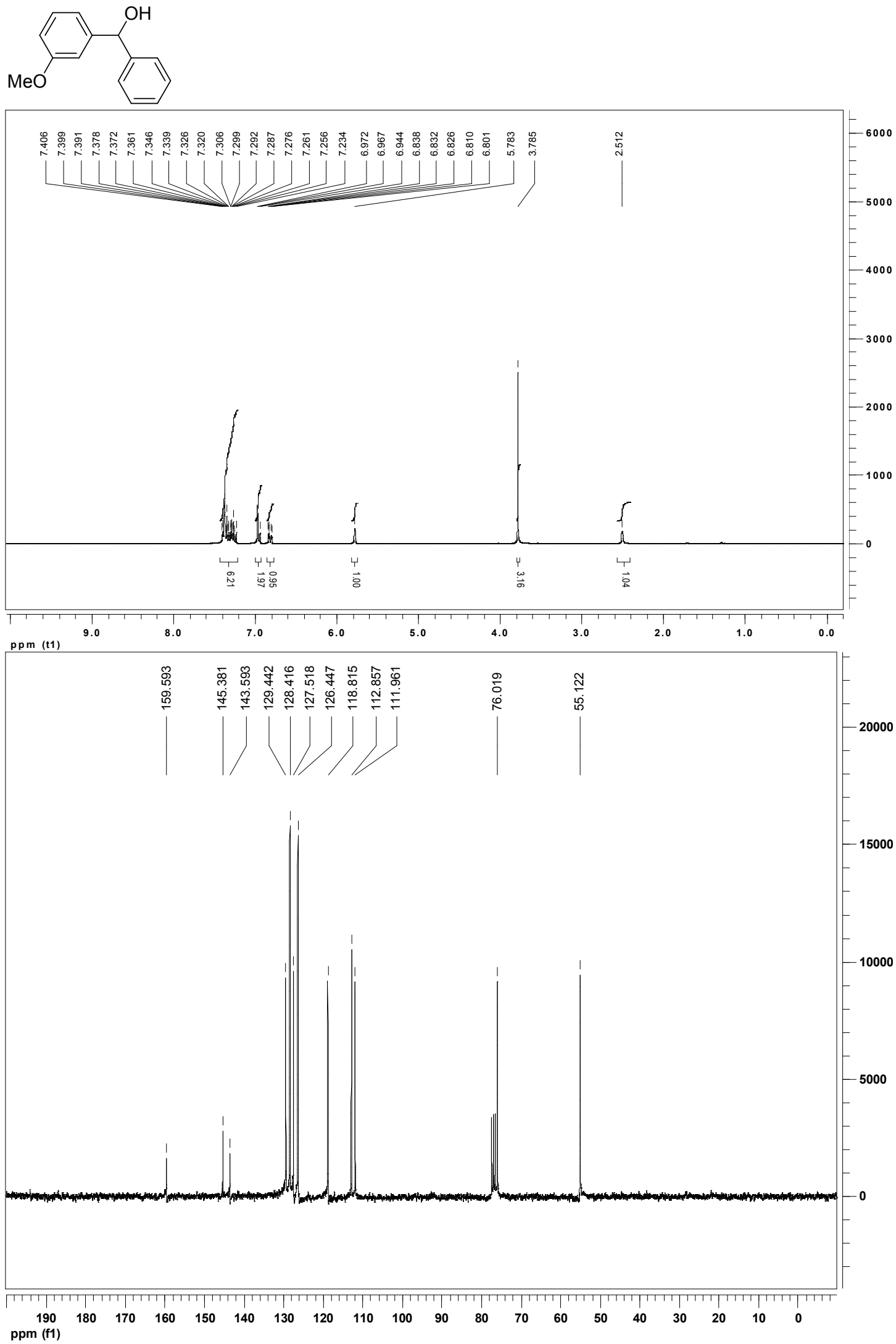


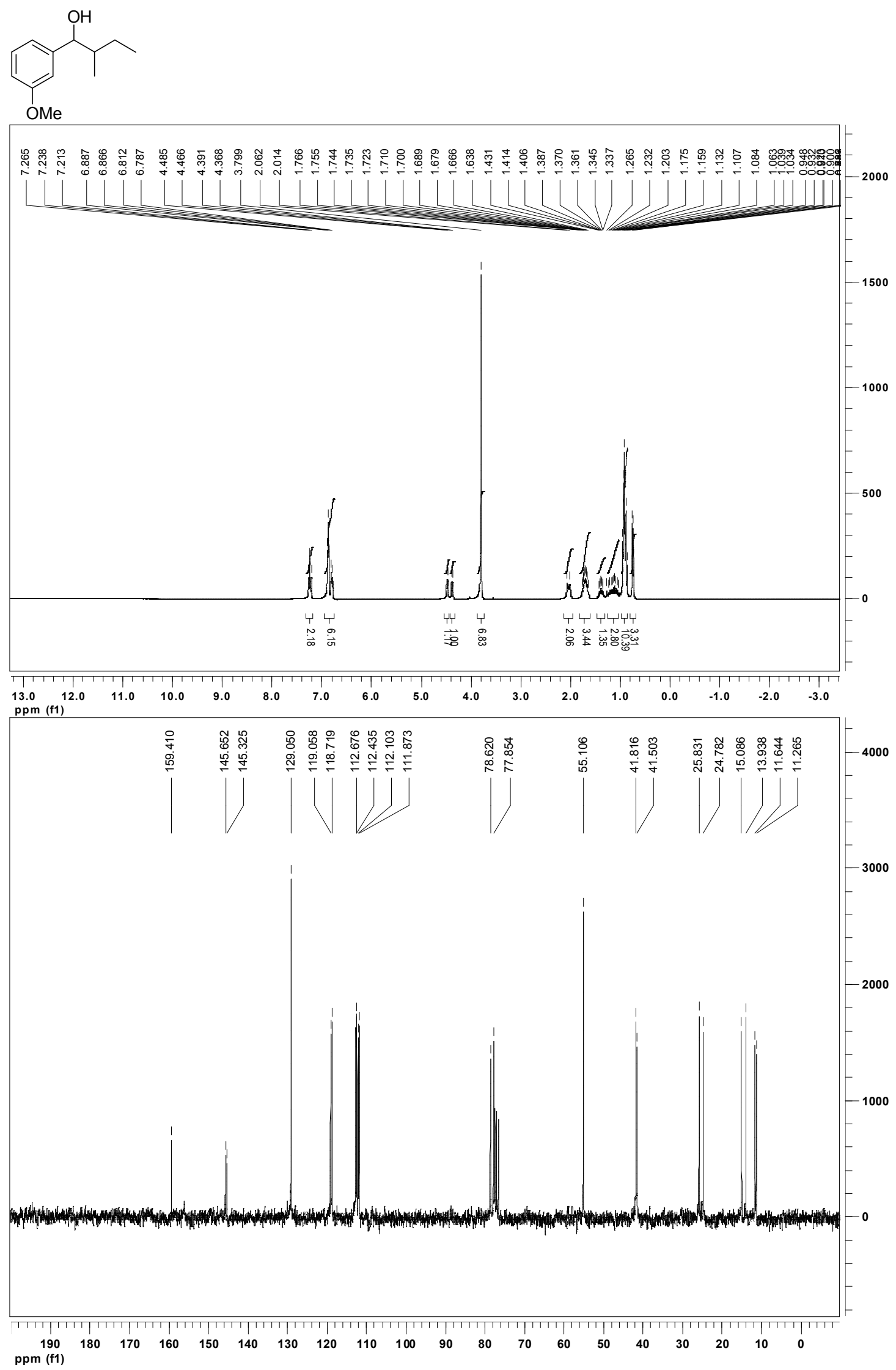



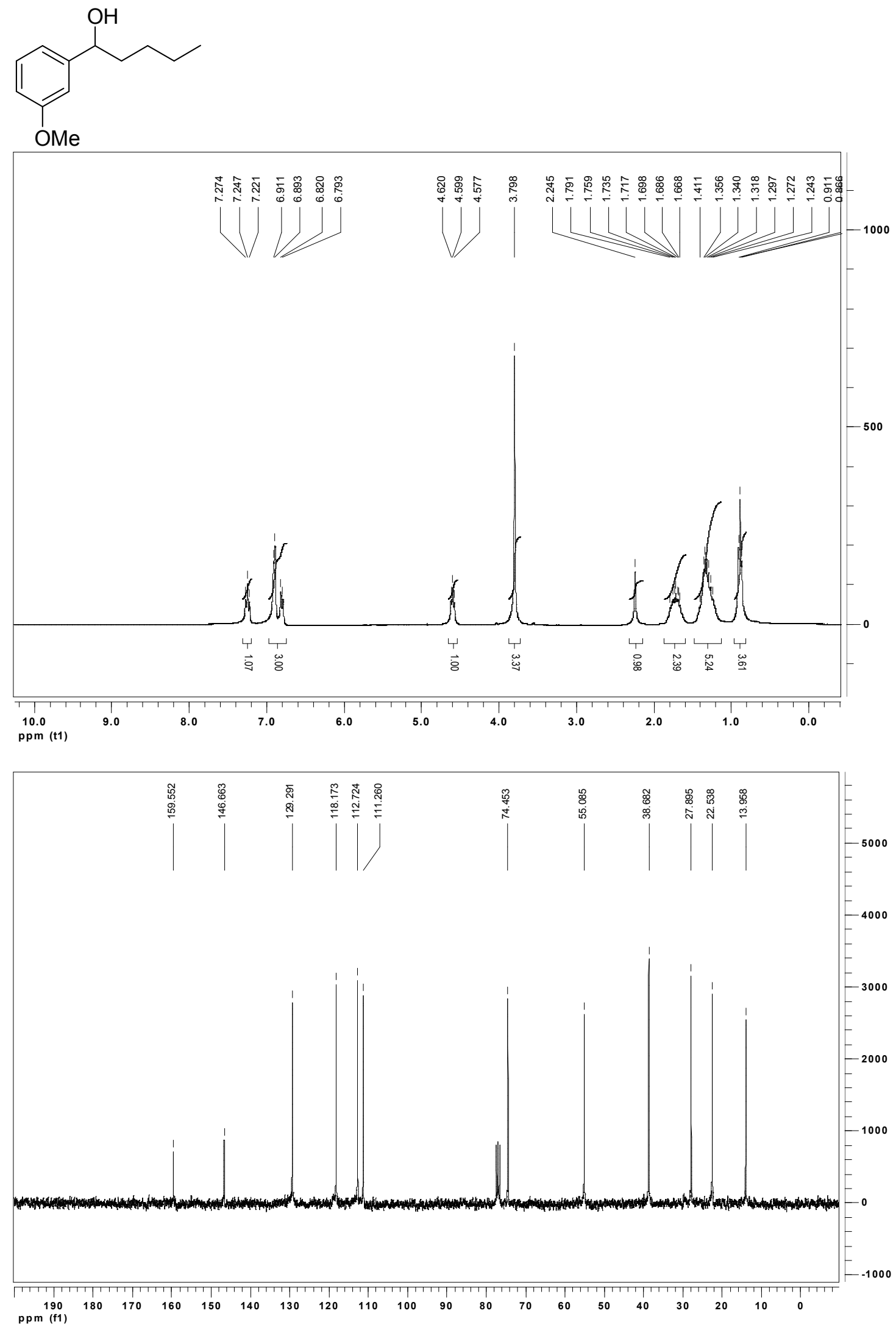
OMe

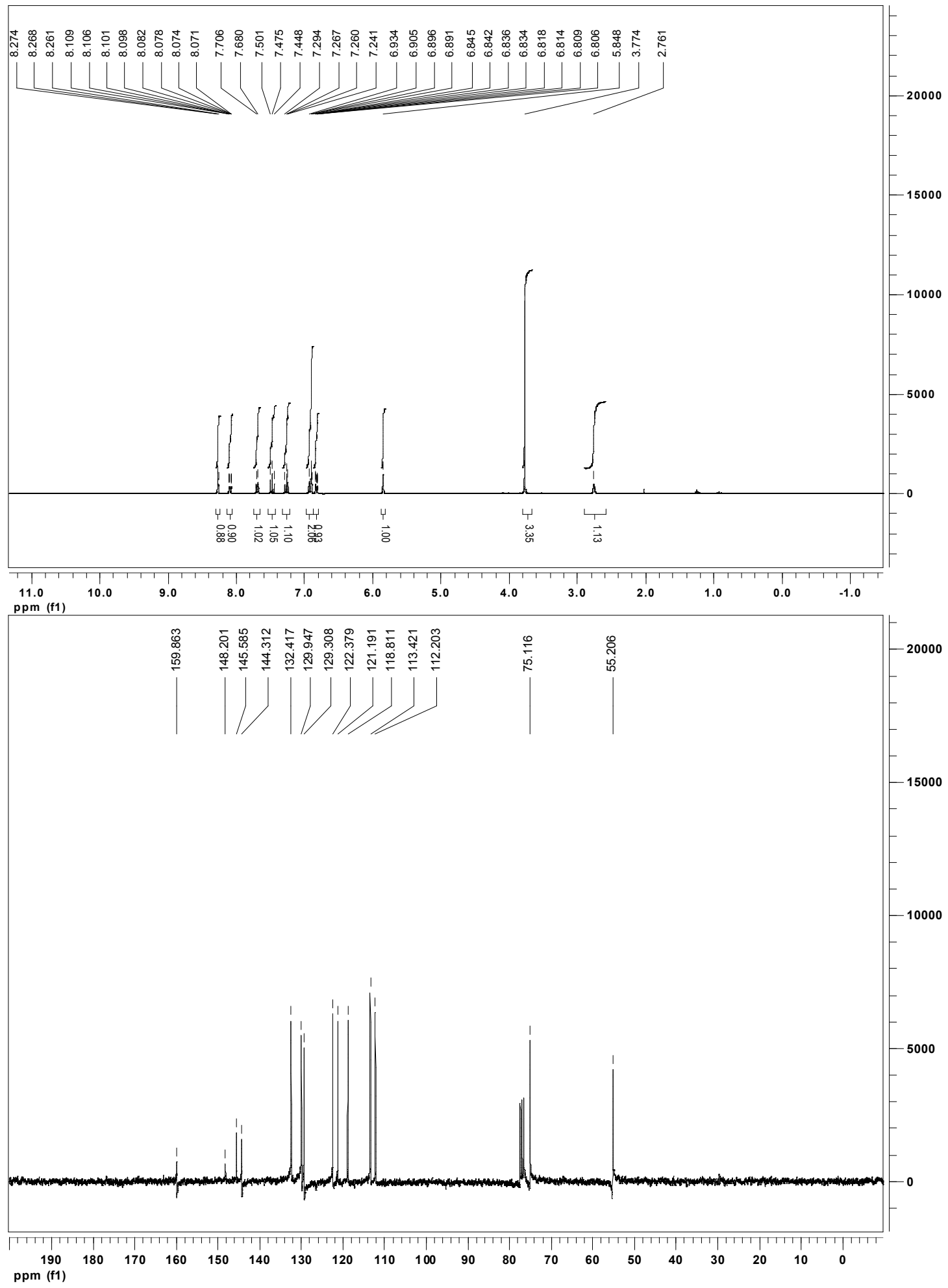




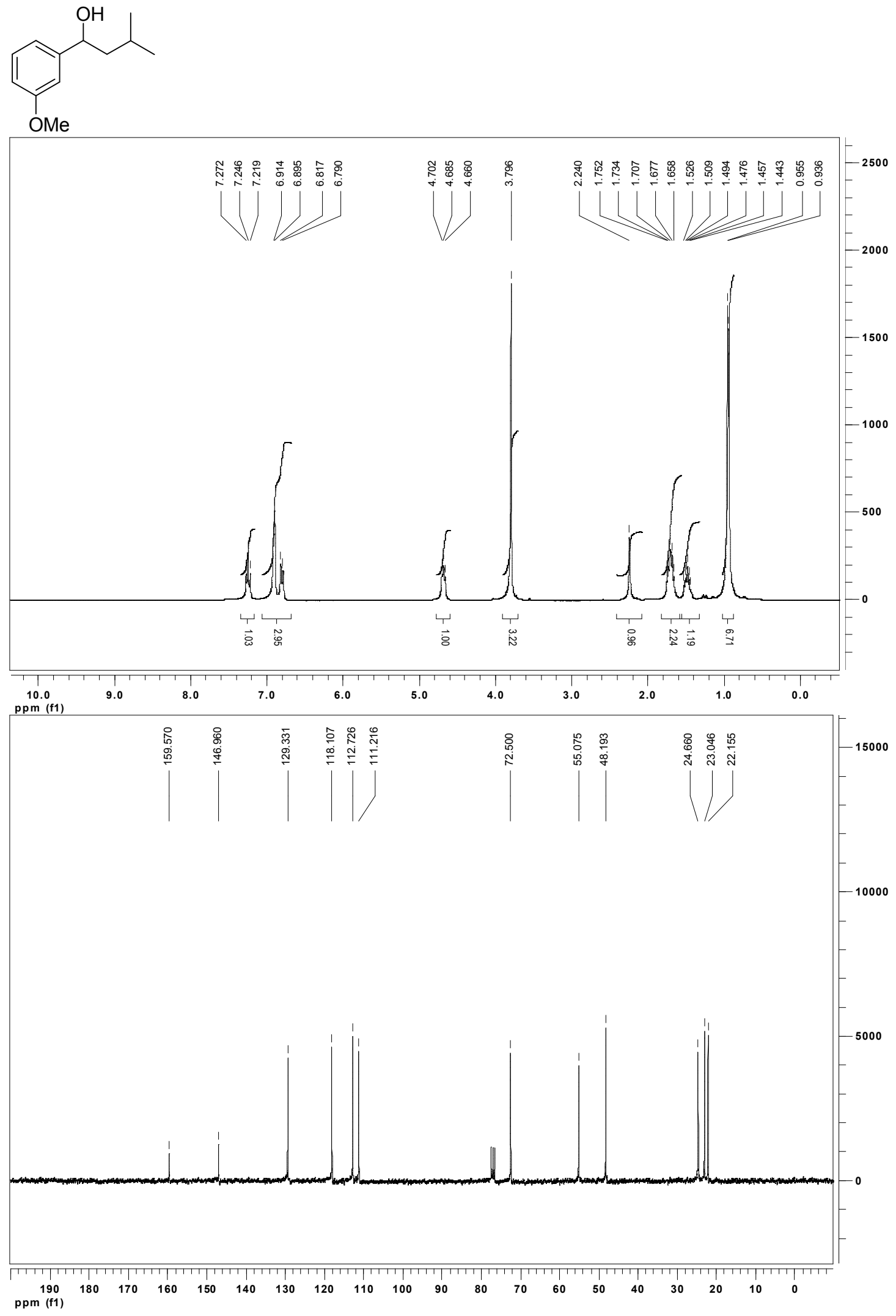




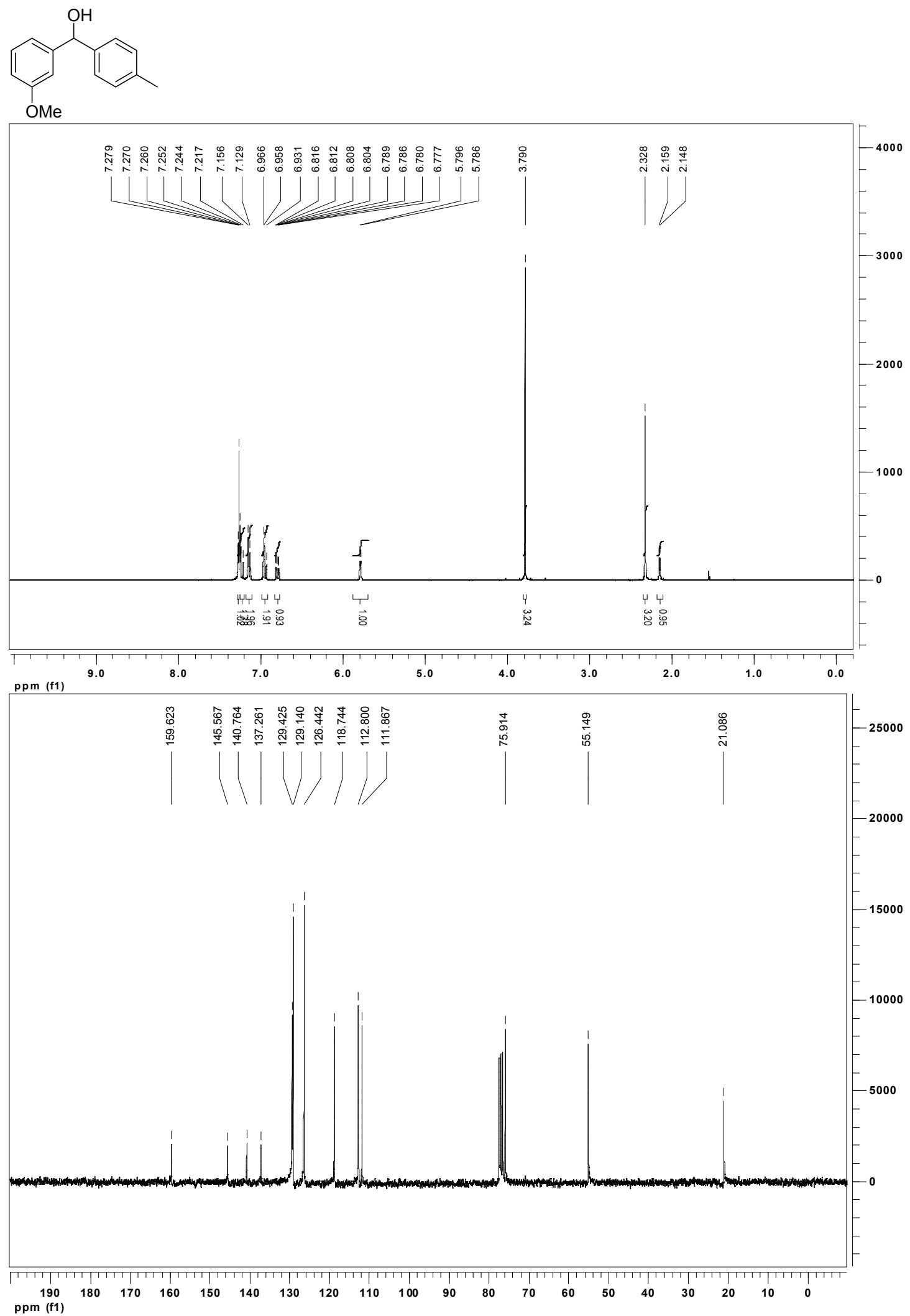



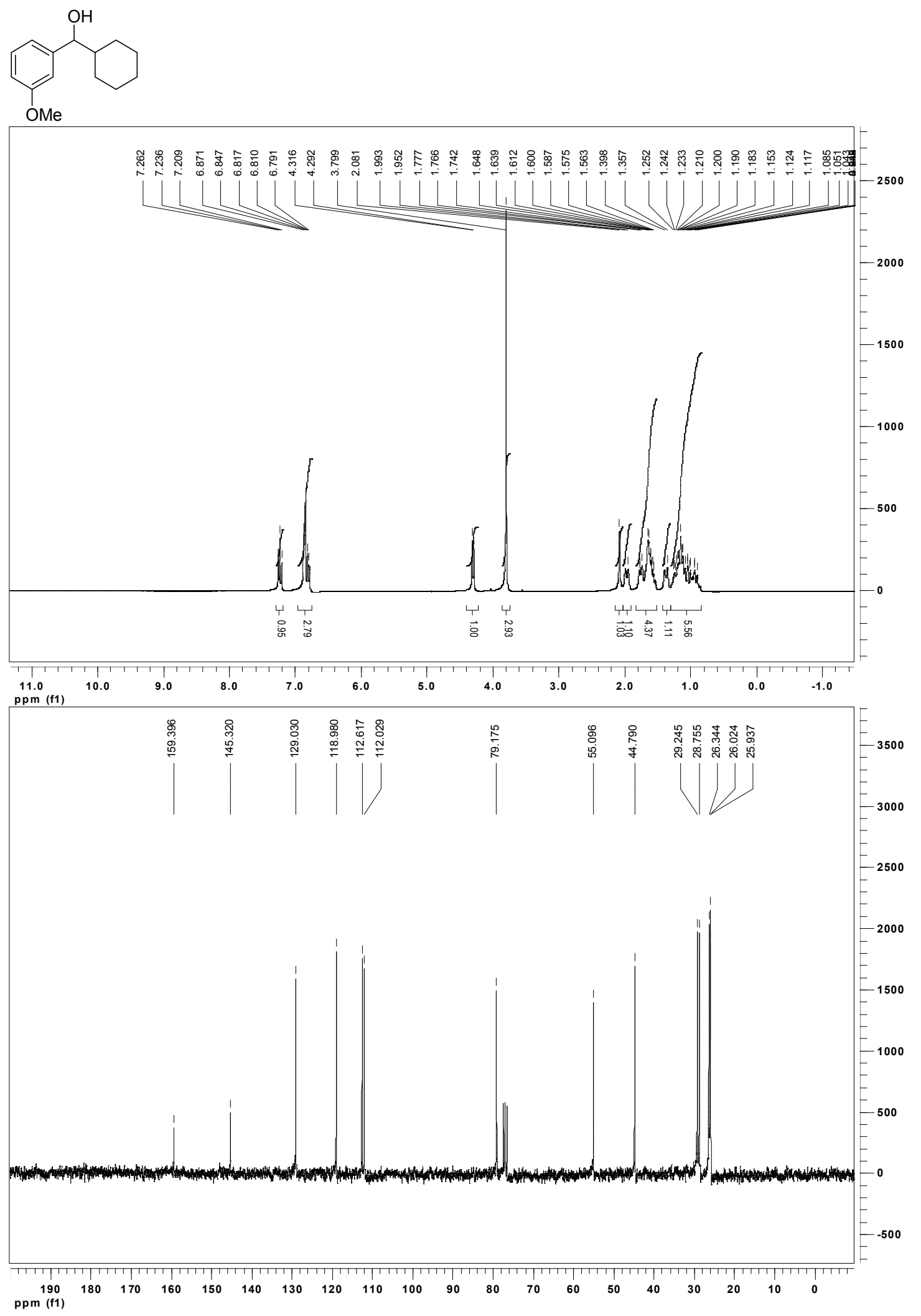


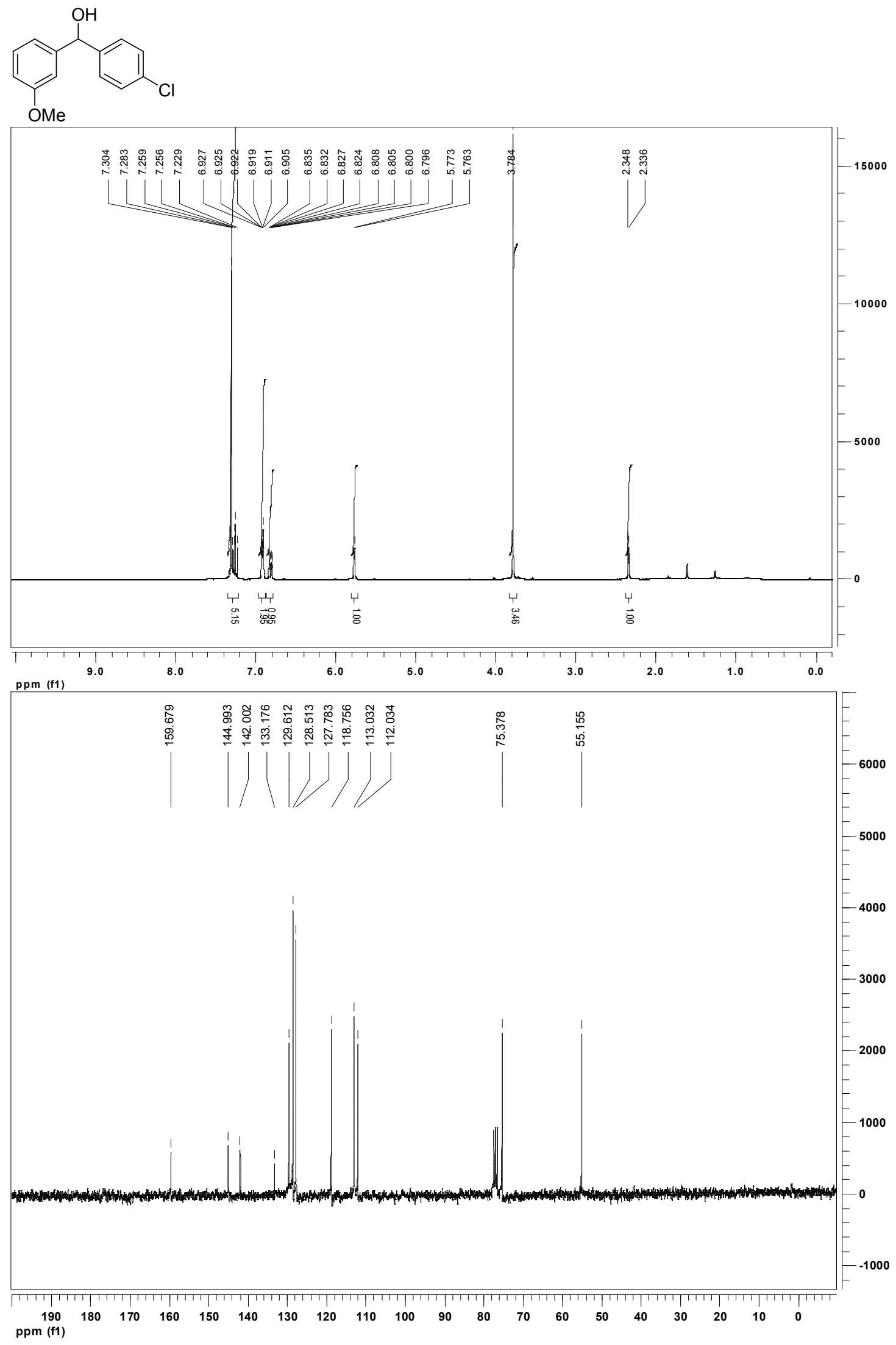




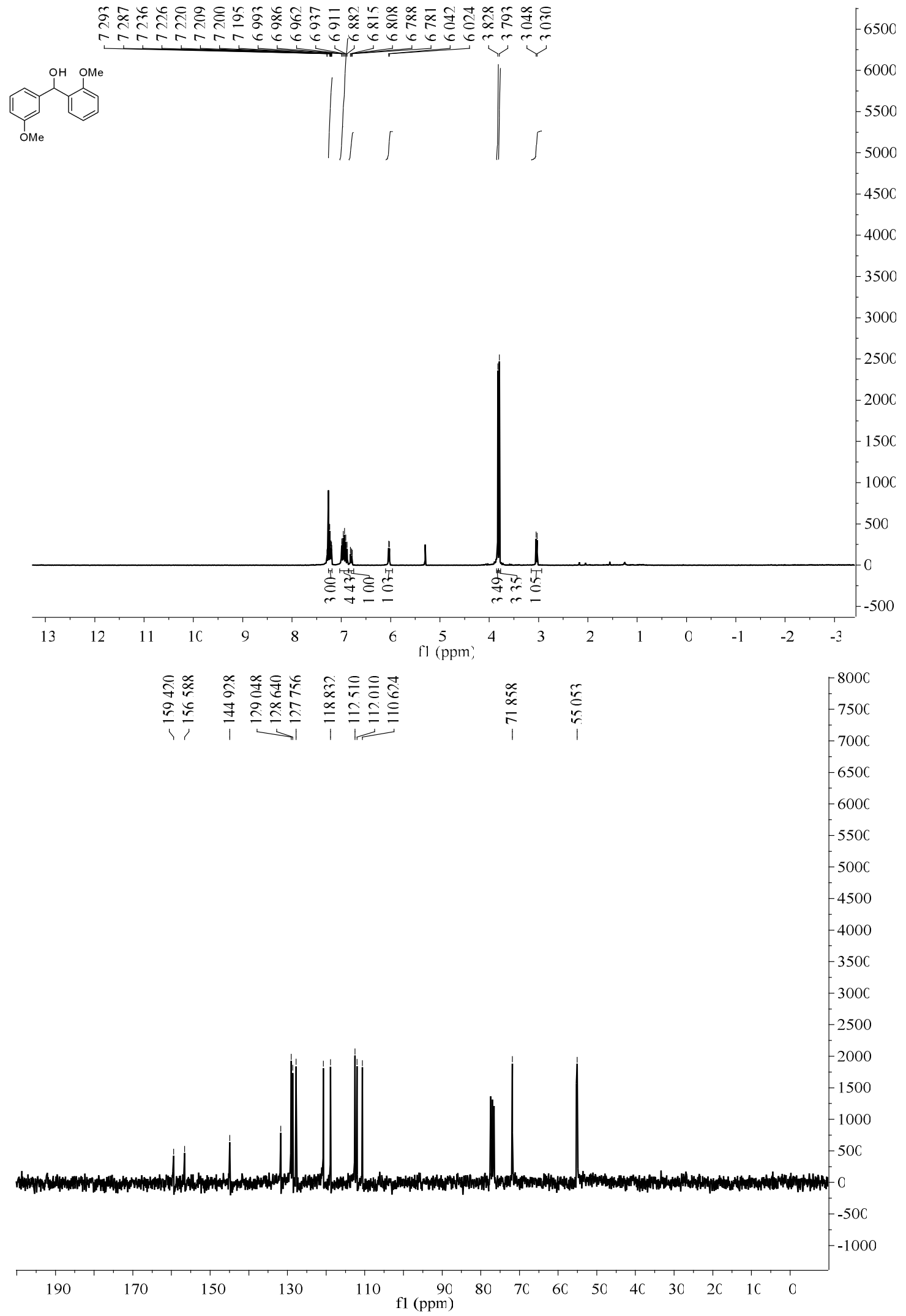




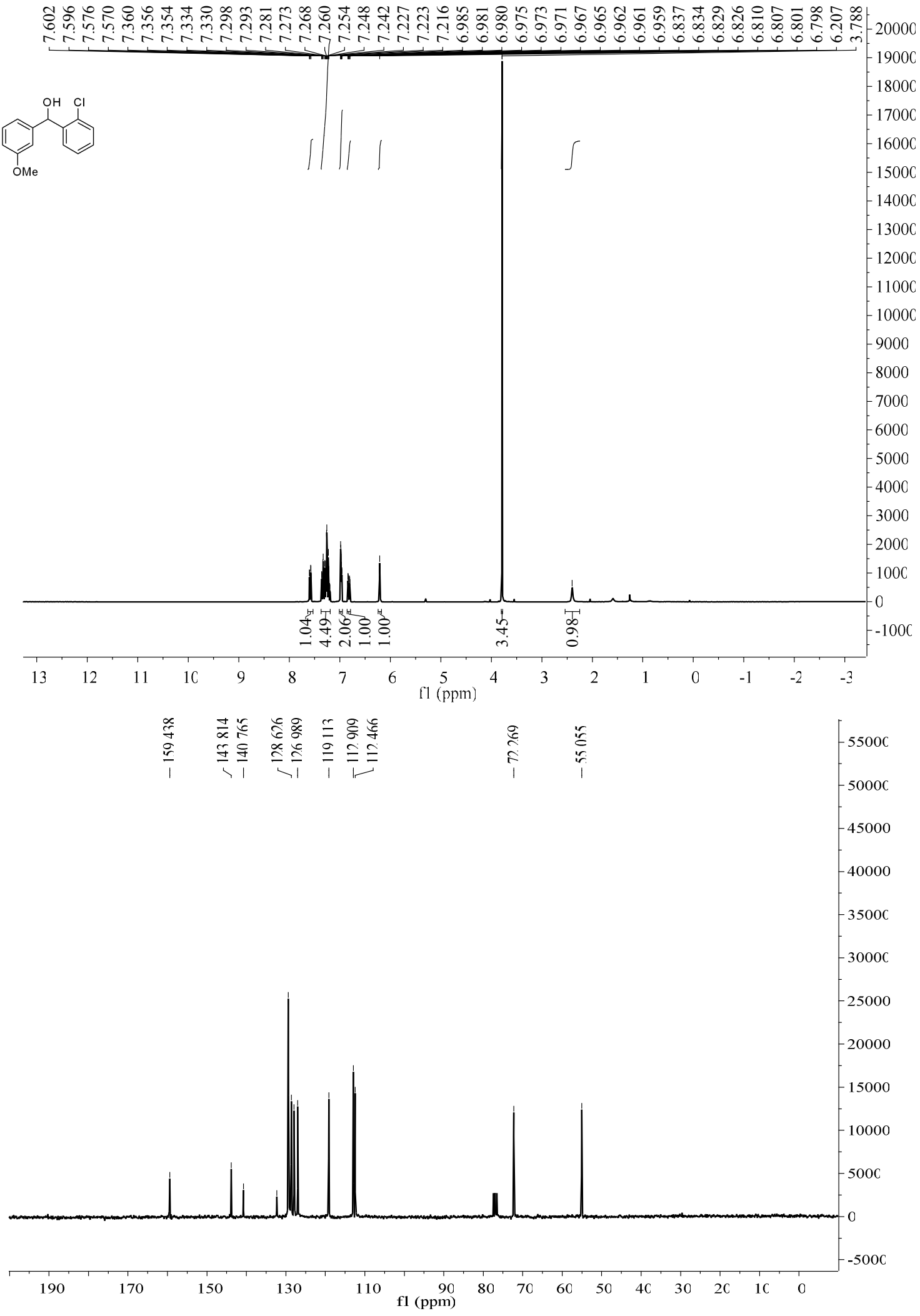




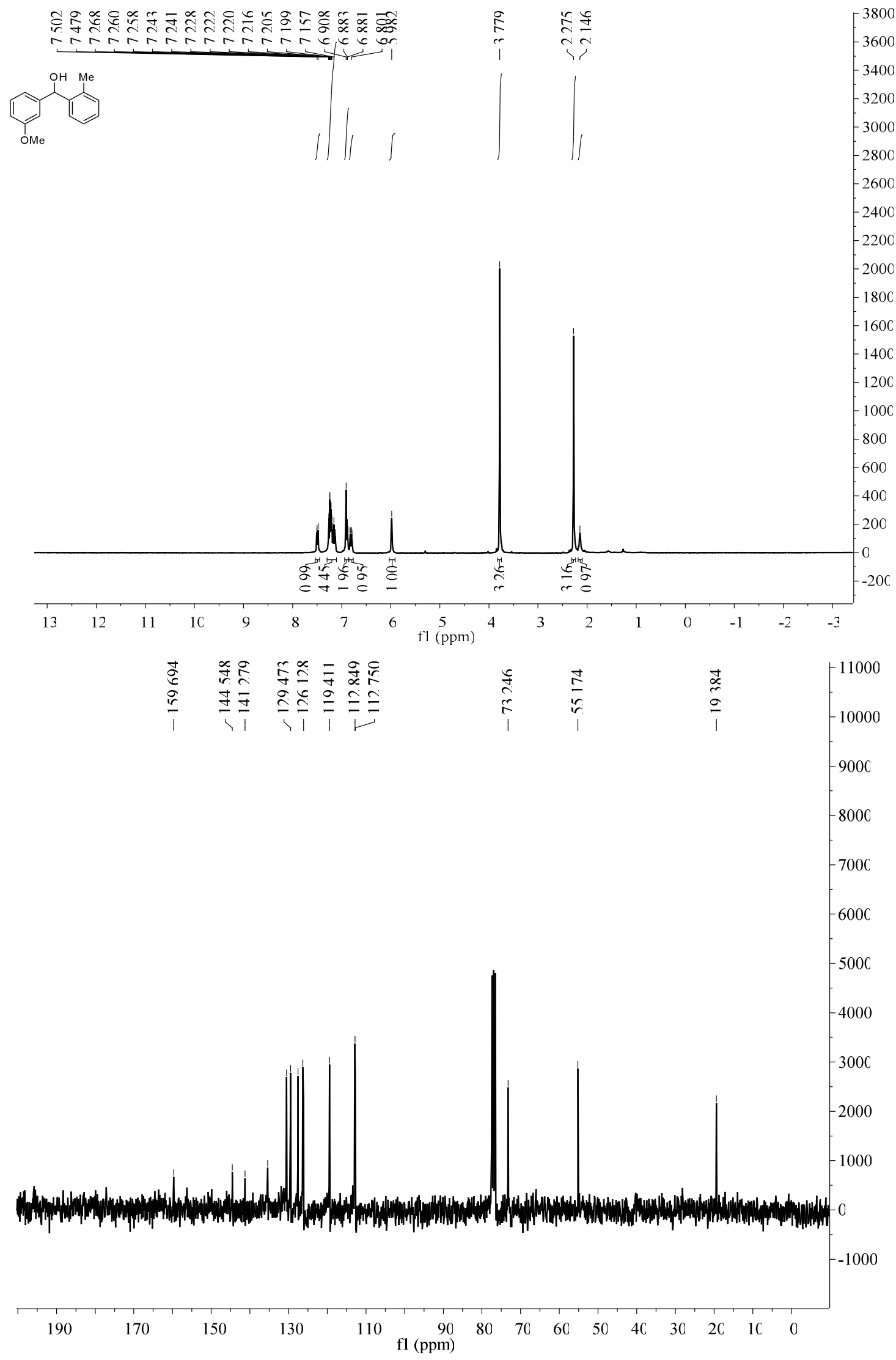




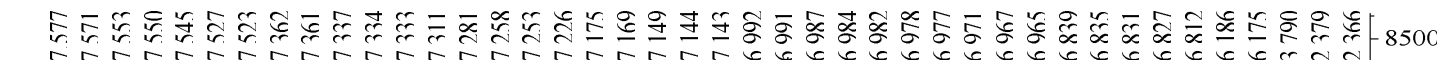

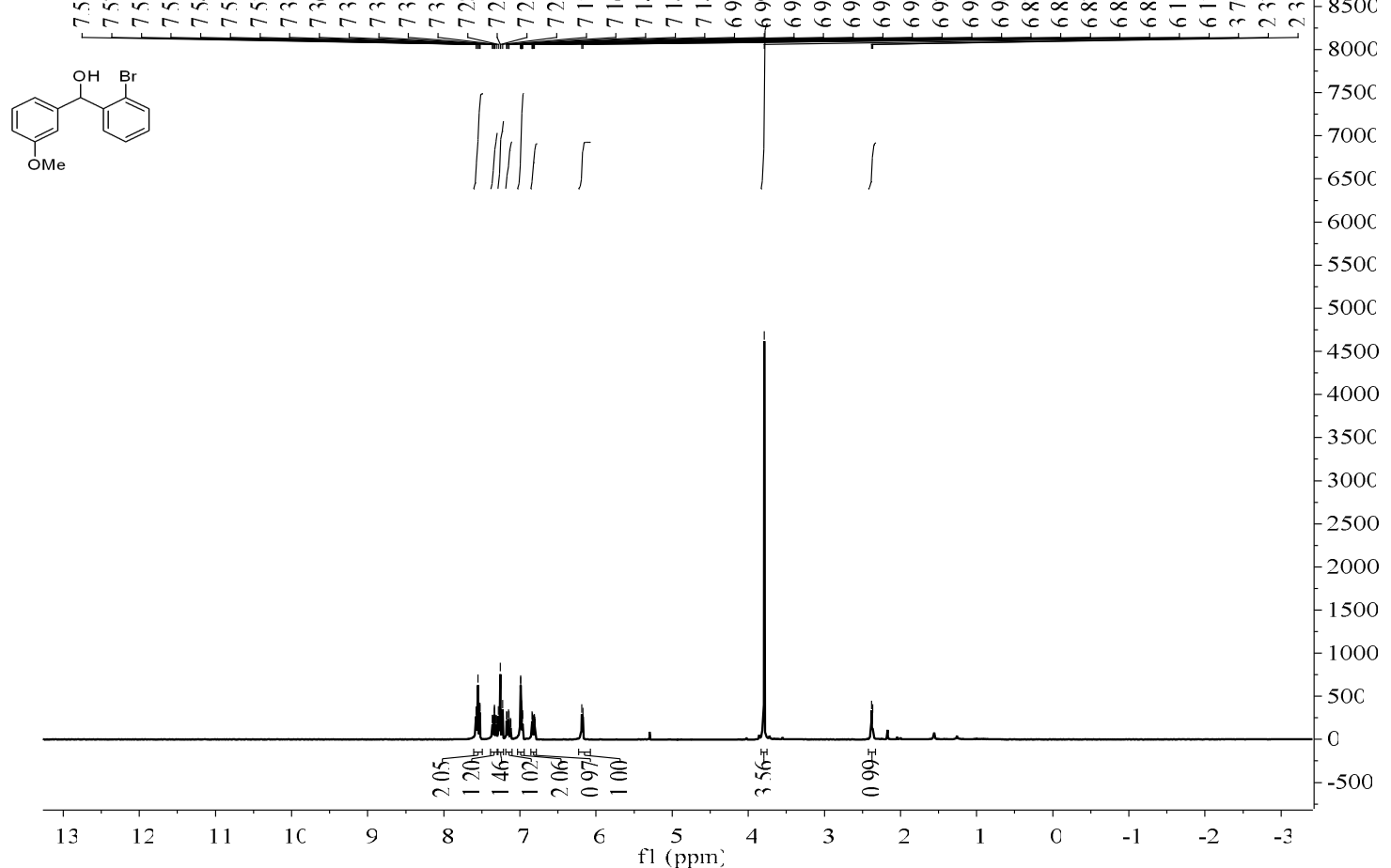

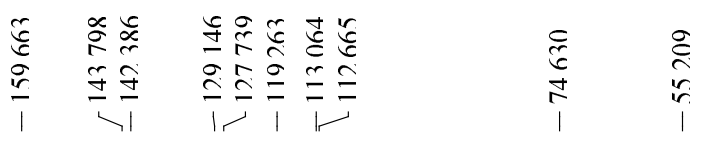

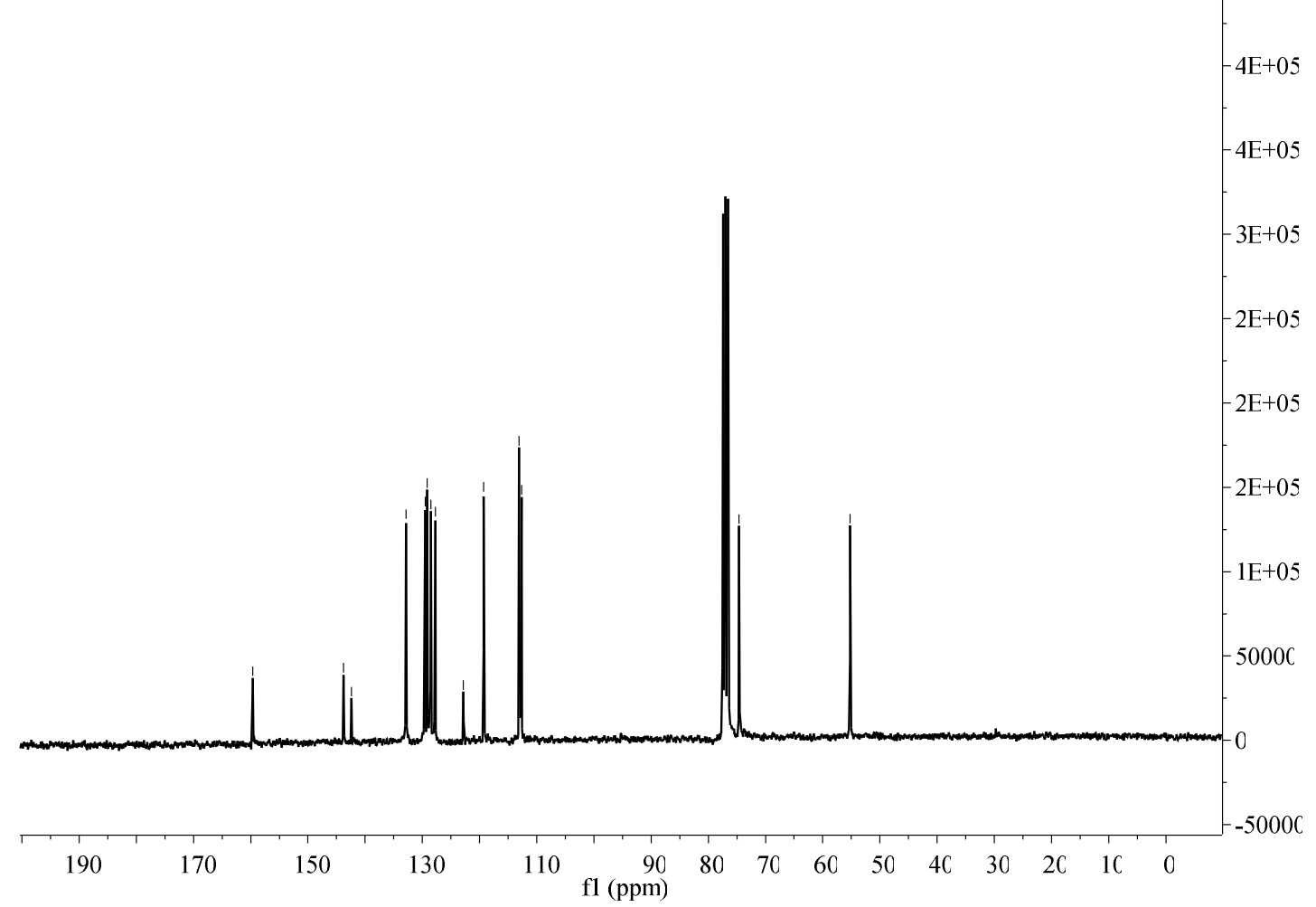




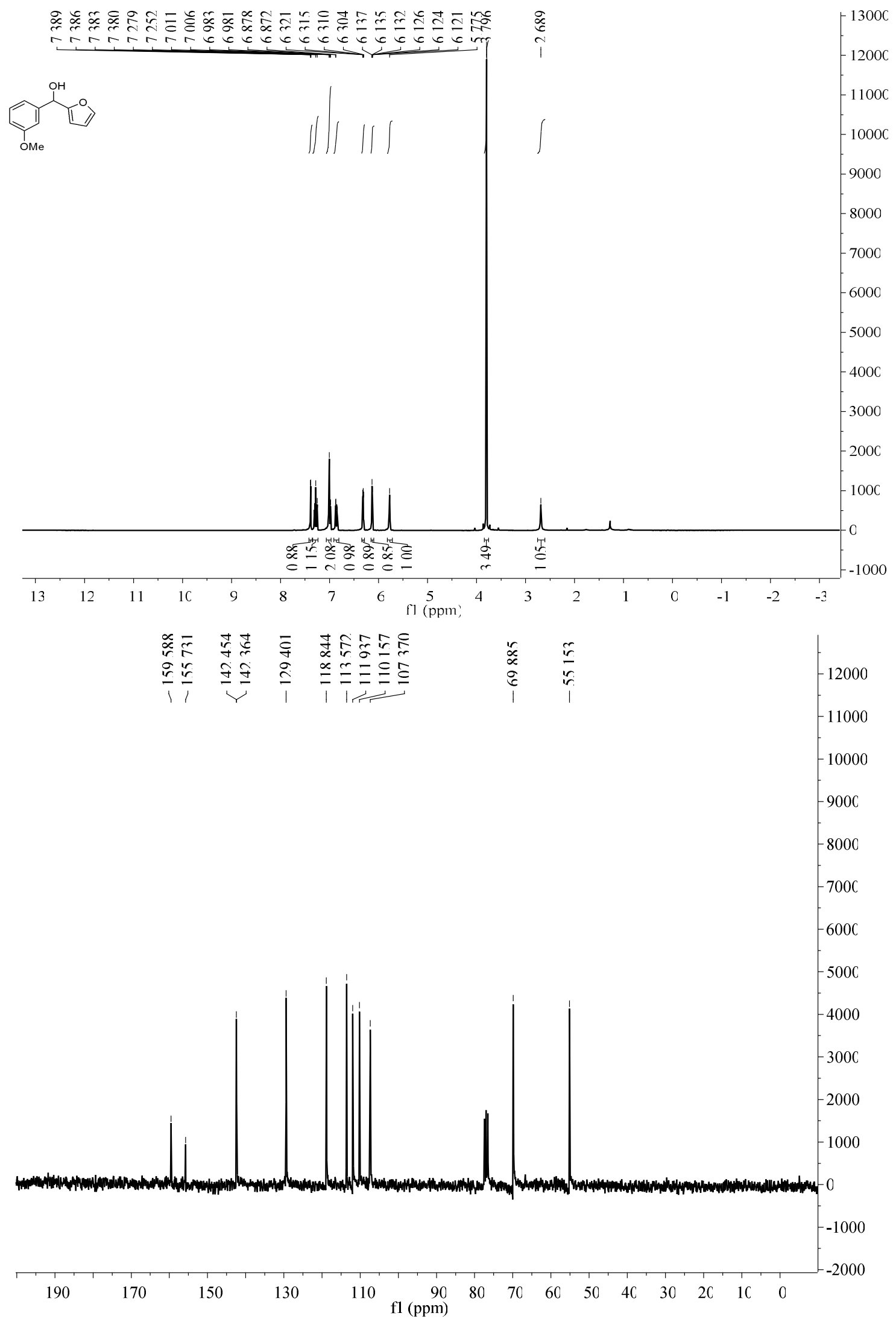




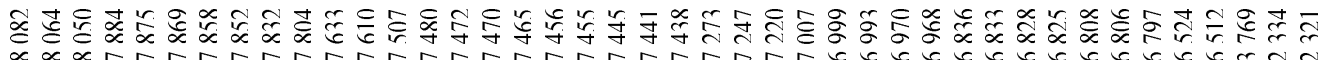
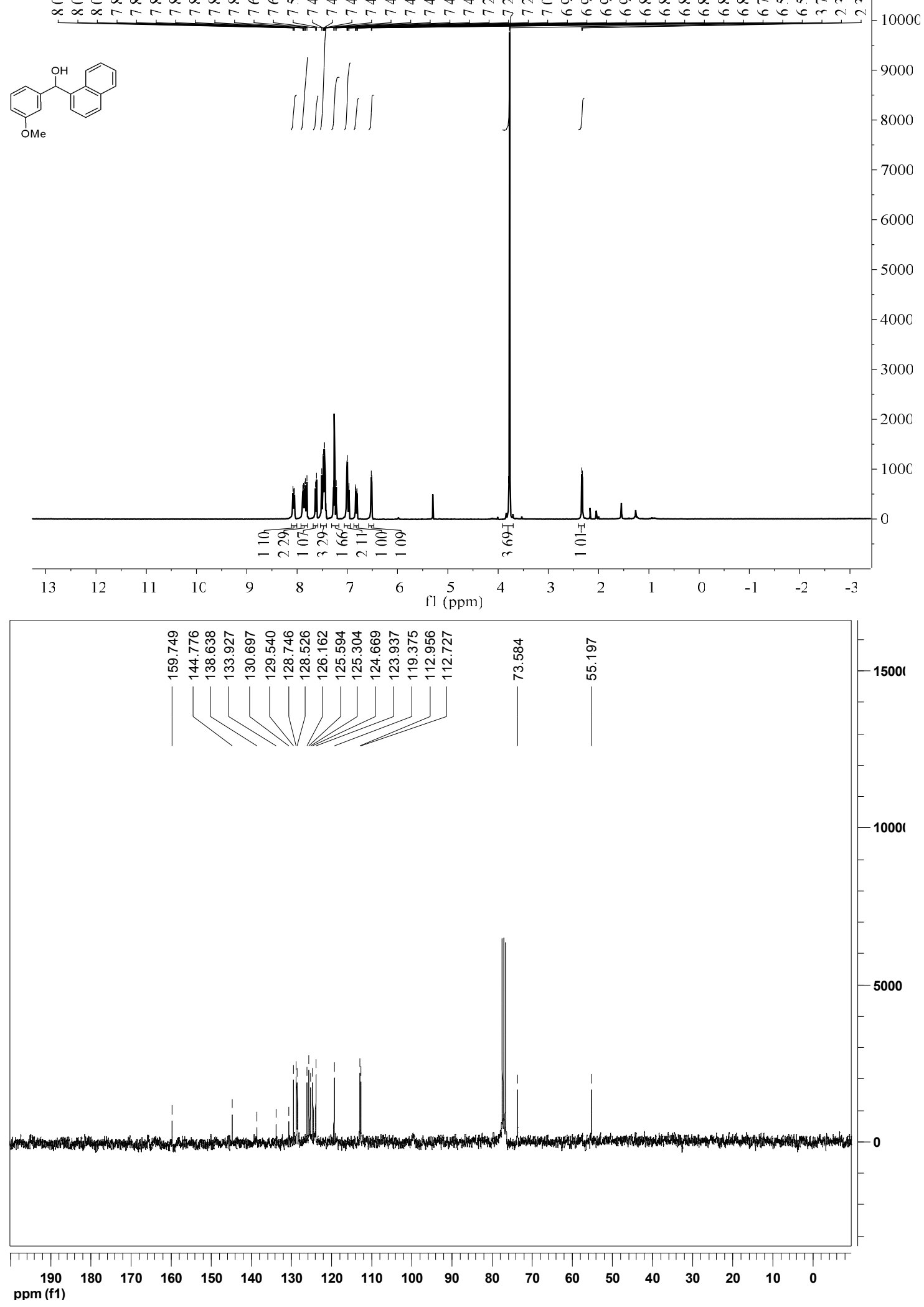

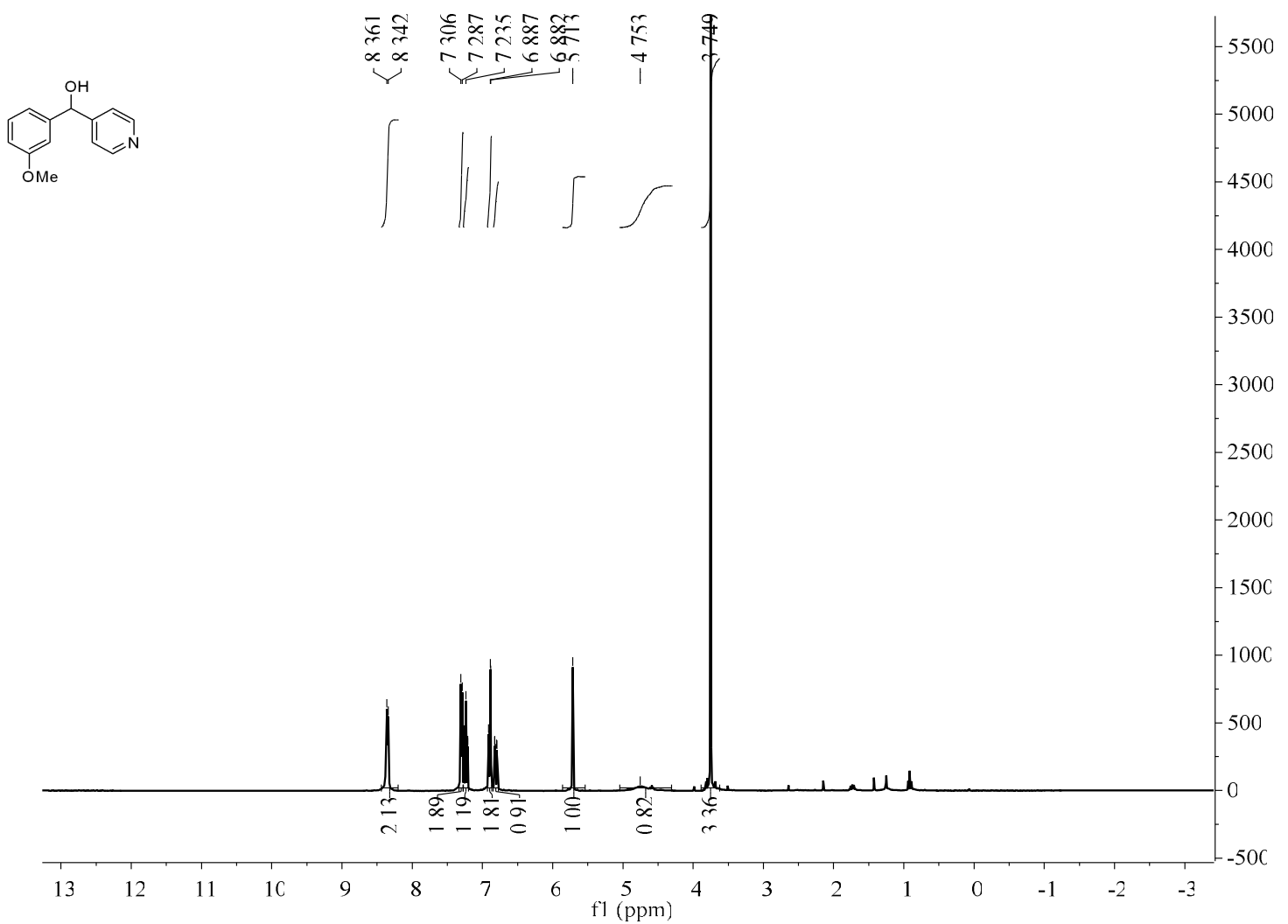

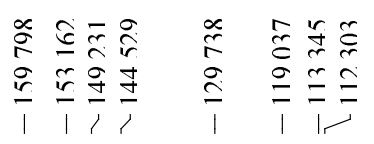

1
$\frac{1}{4}$
2

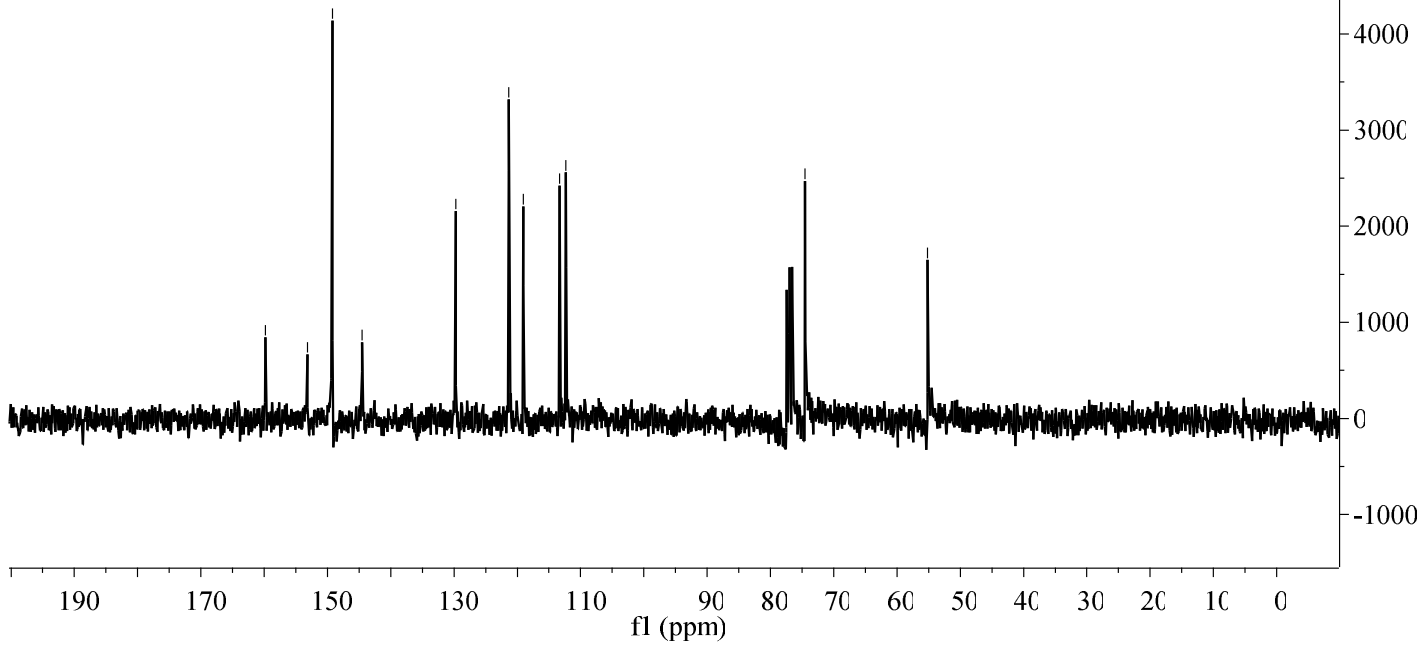


(neO
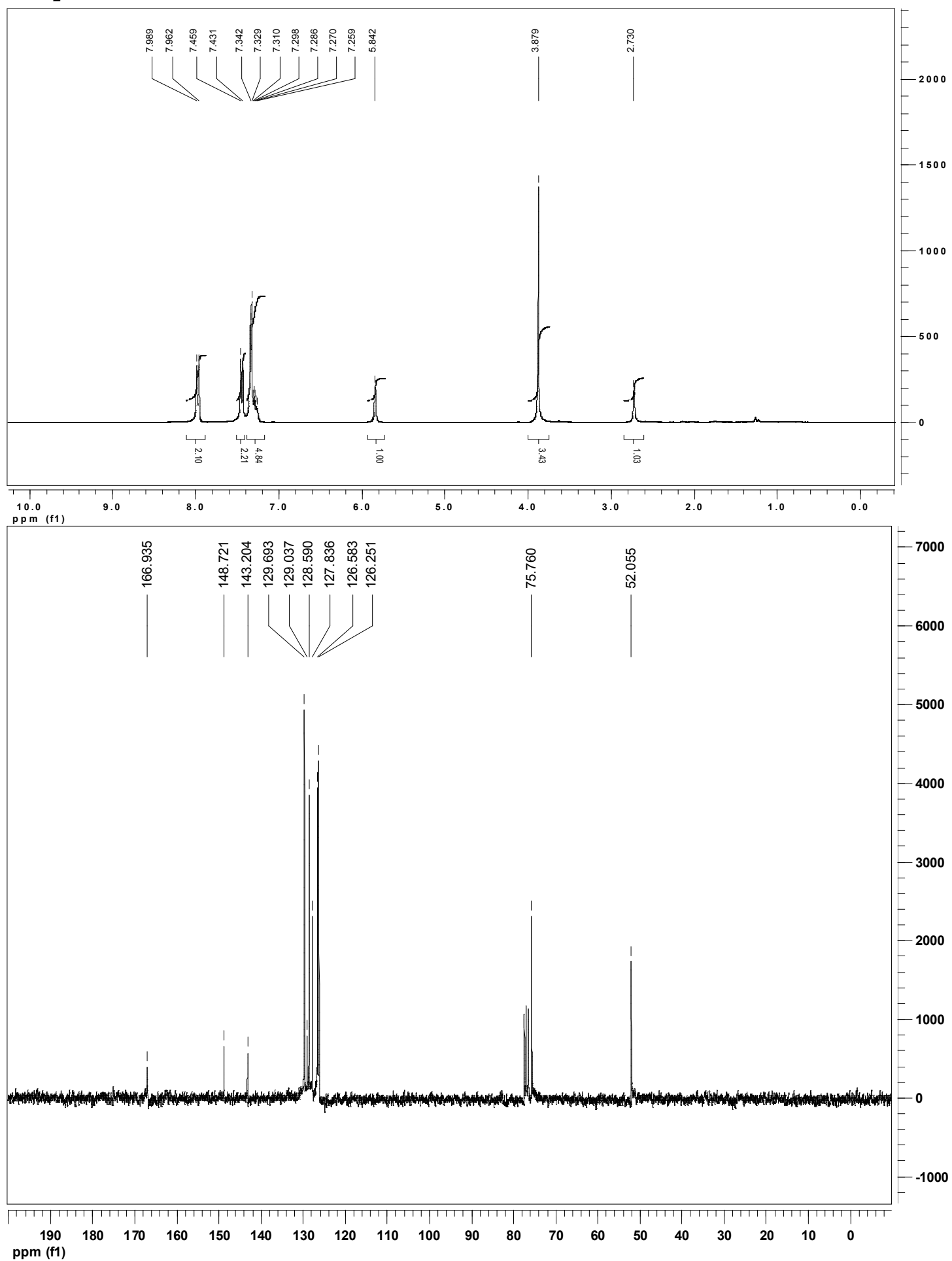


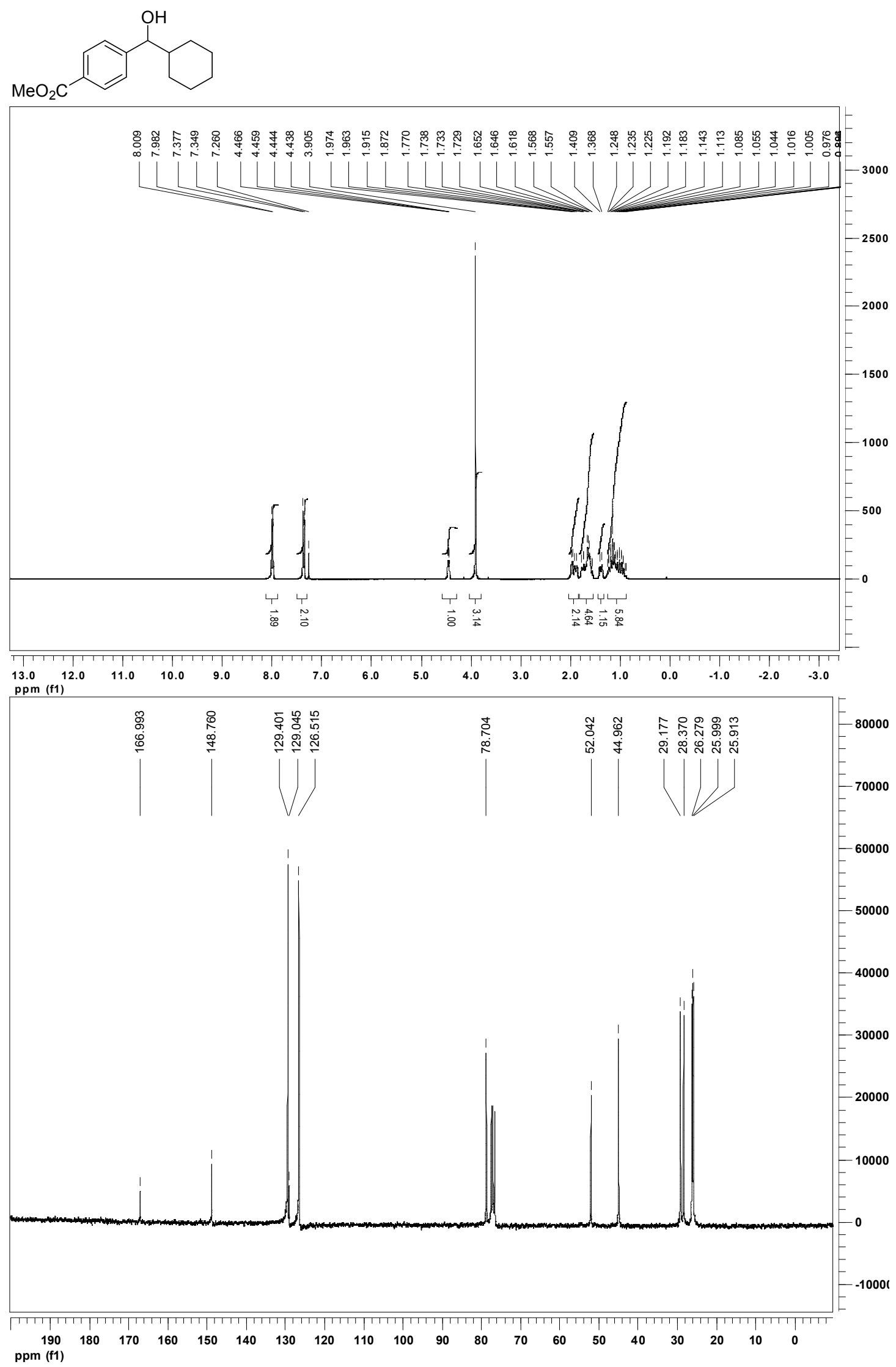




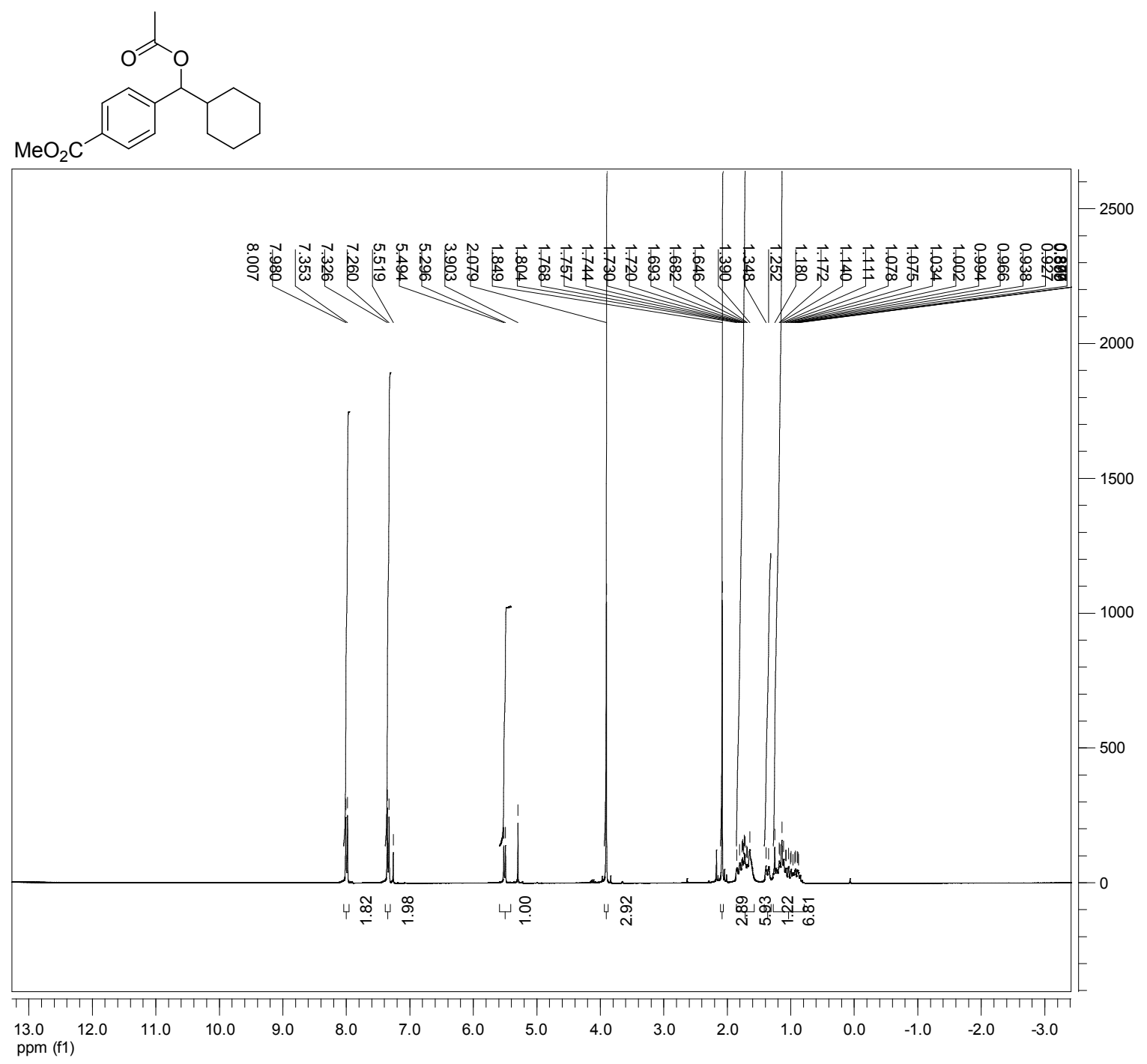


<smiles>CC(=O)c1ccc(C(O)CC(C)C)cc1</smiles>

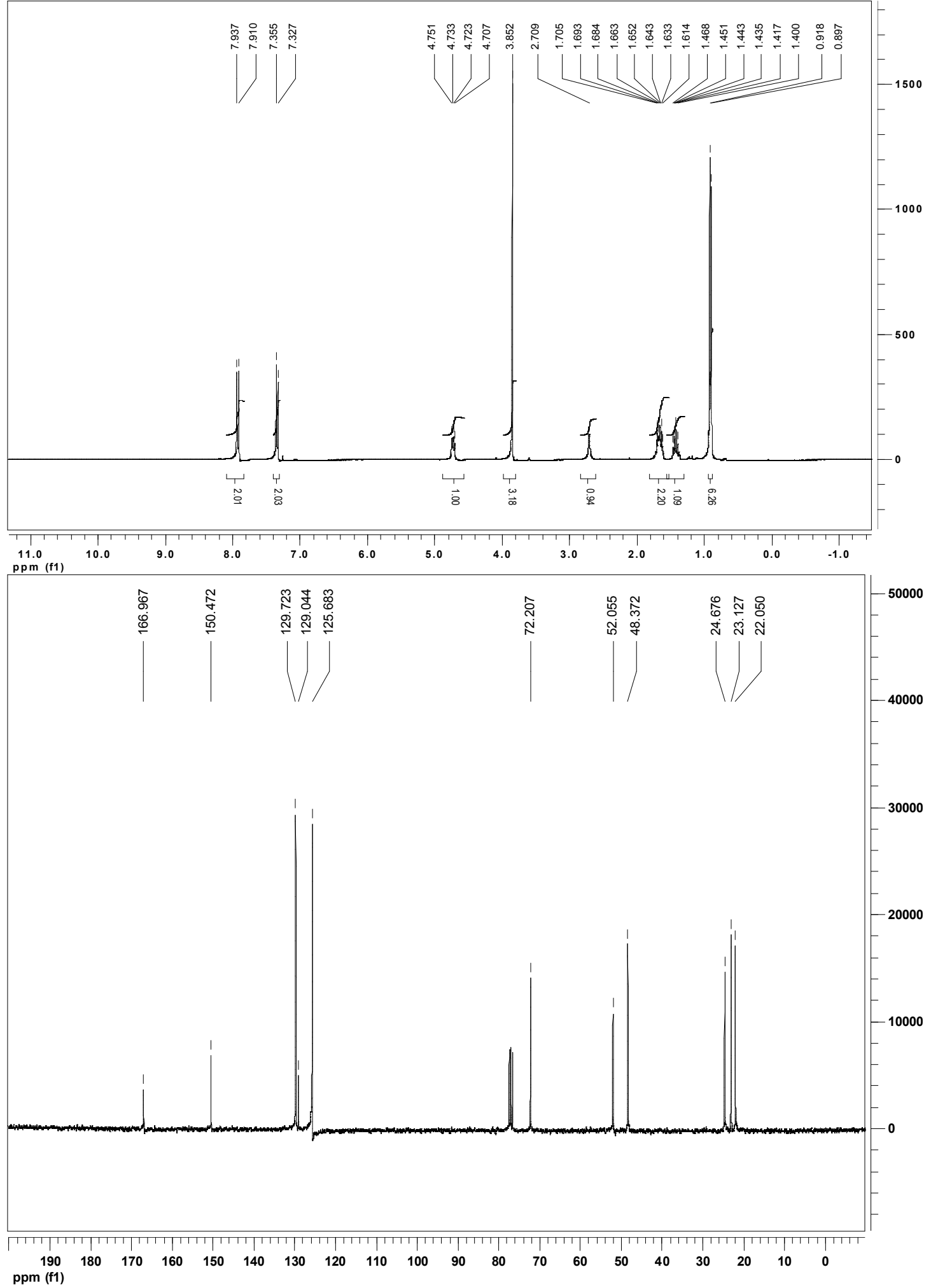


$\mathrm{MeO}_{2}$

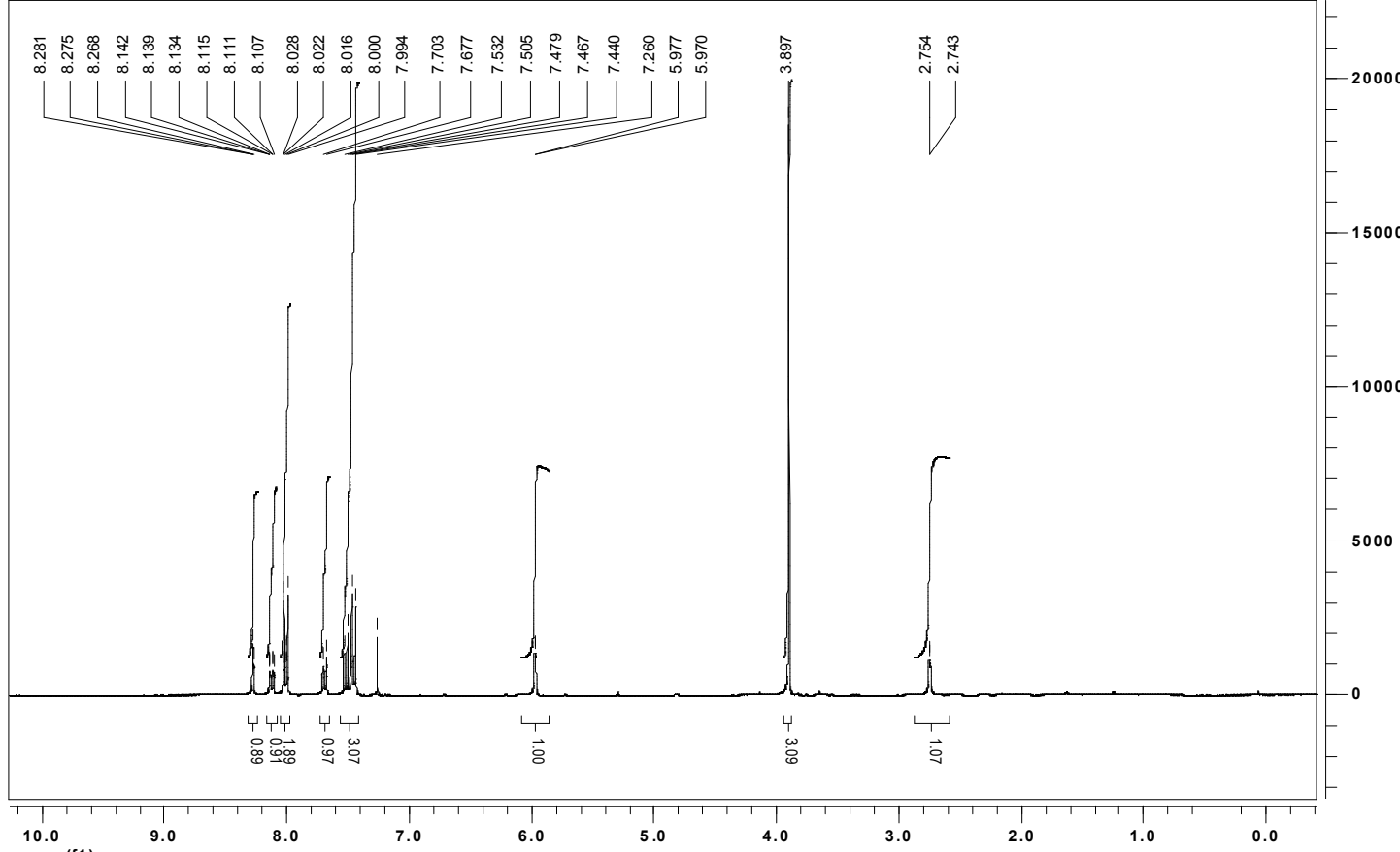

ppm (f1)
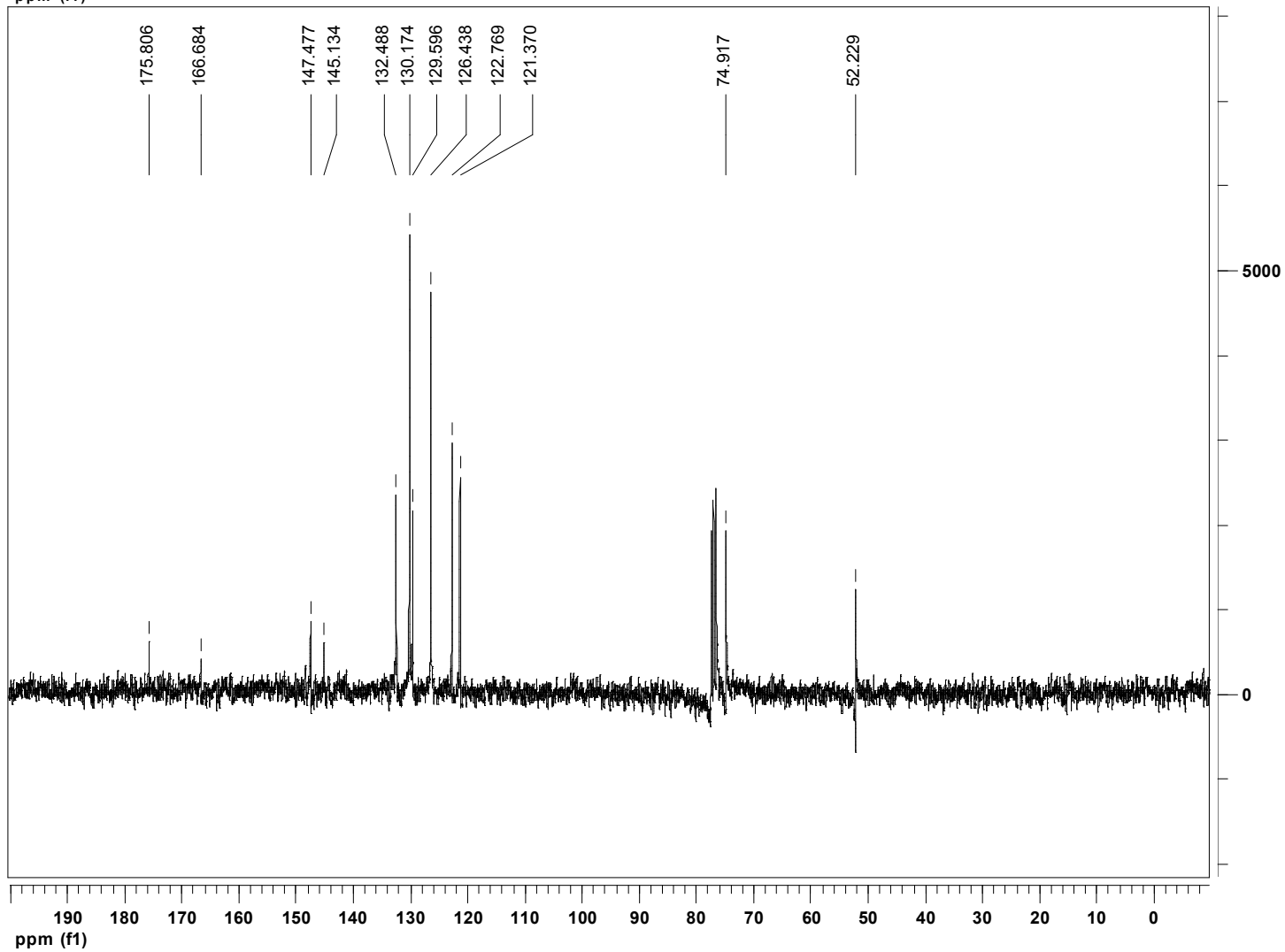
(neO

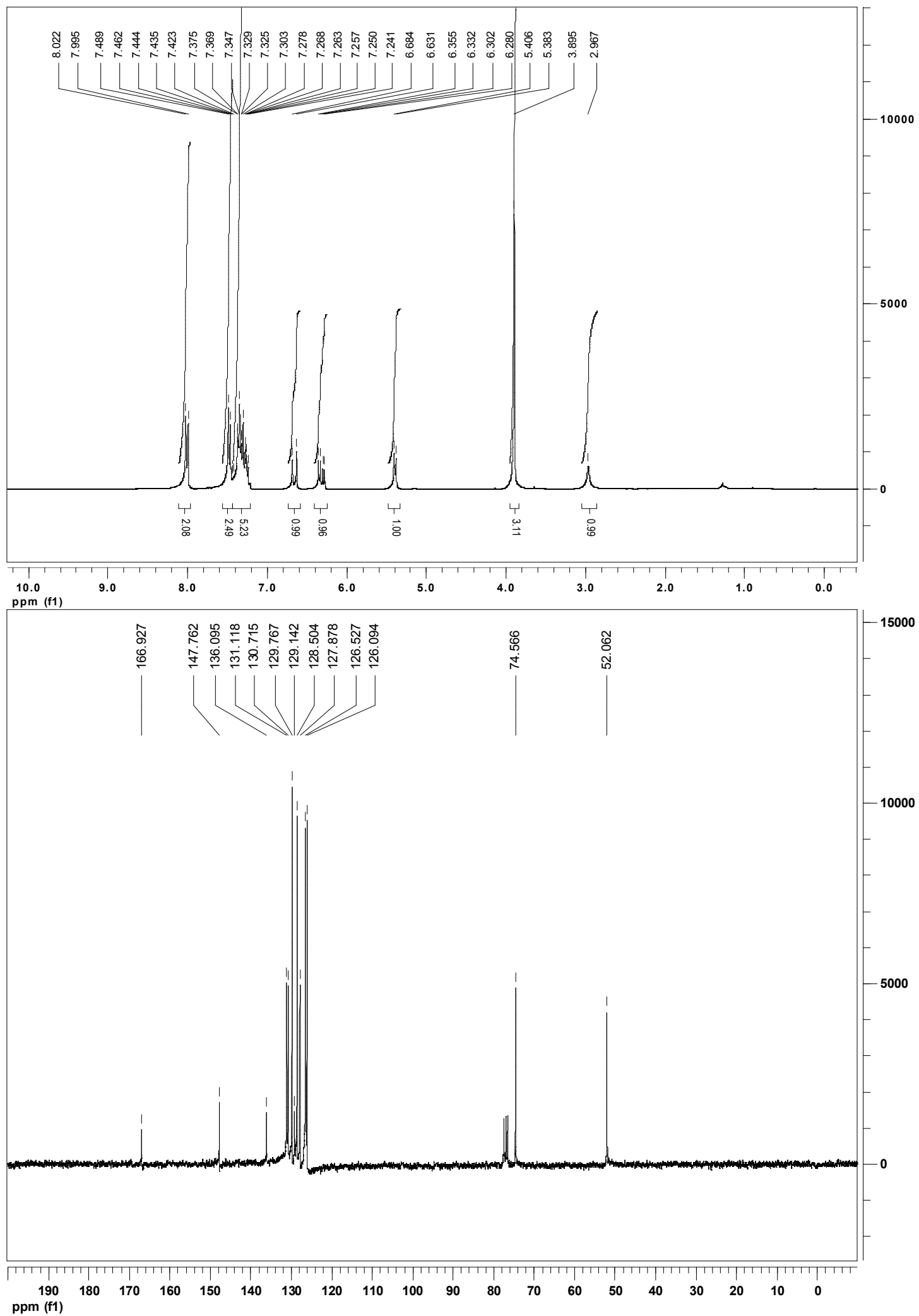




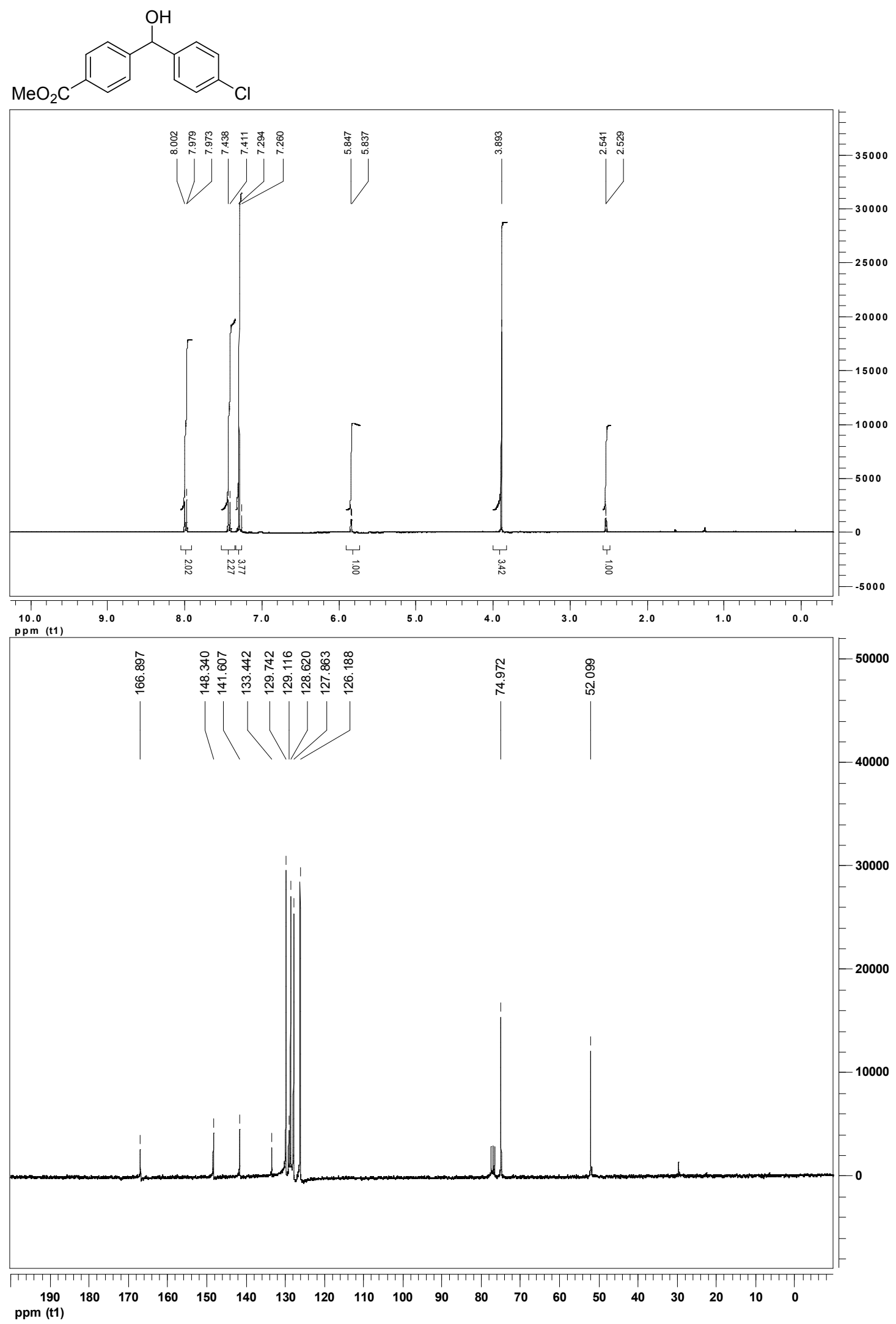




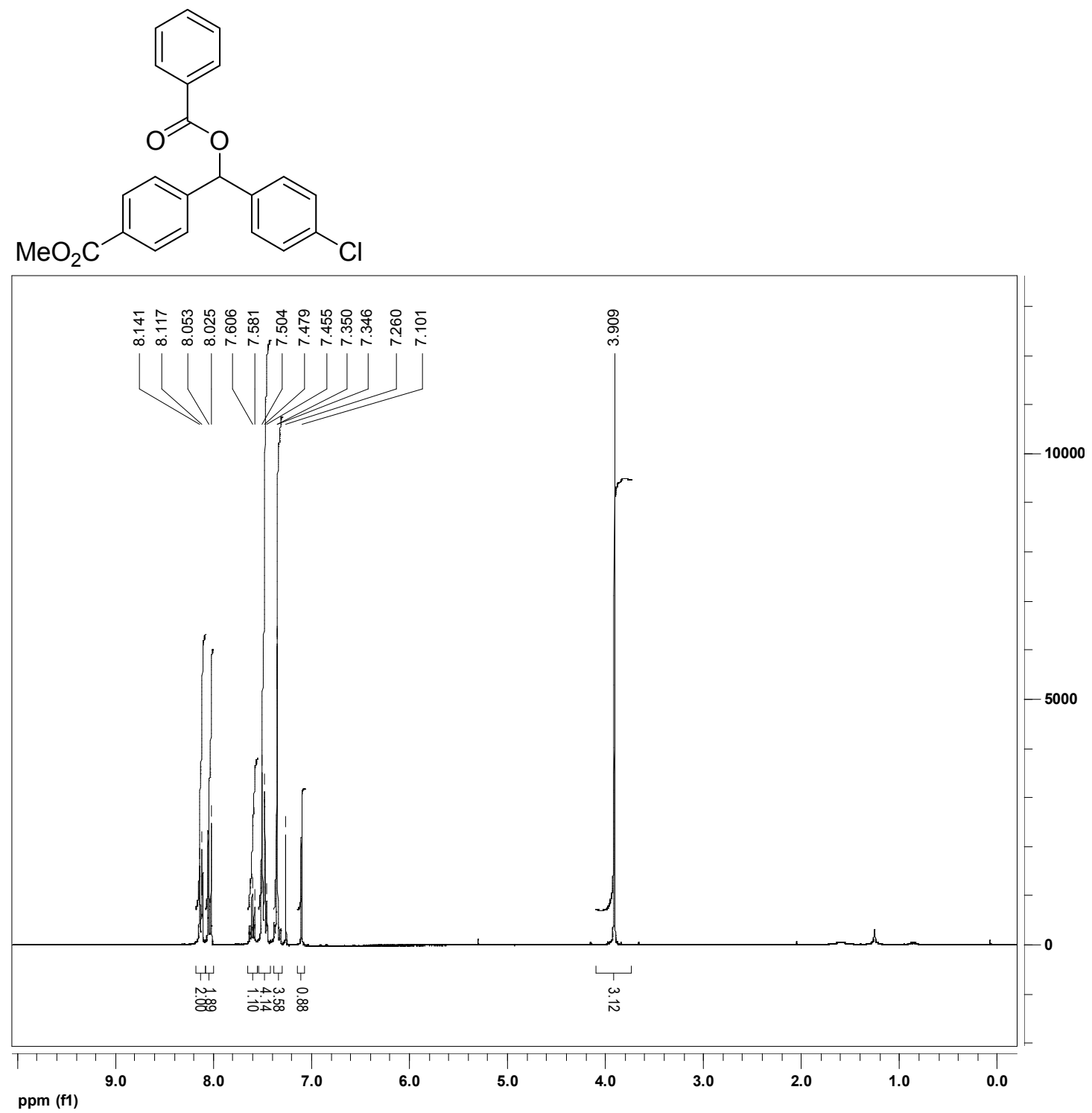


MeO

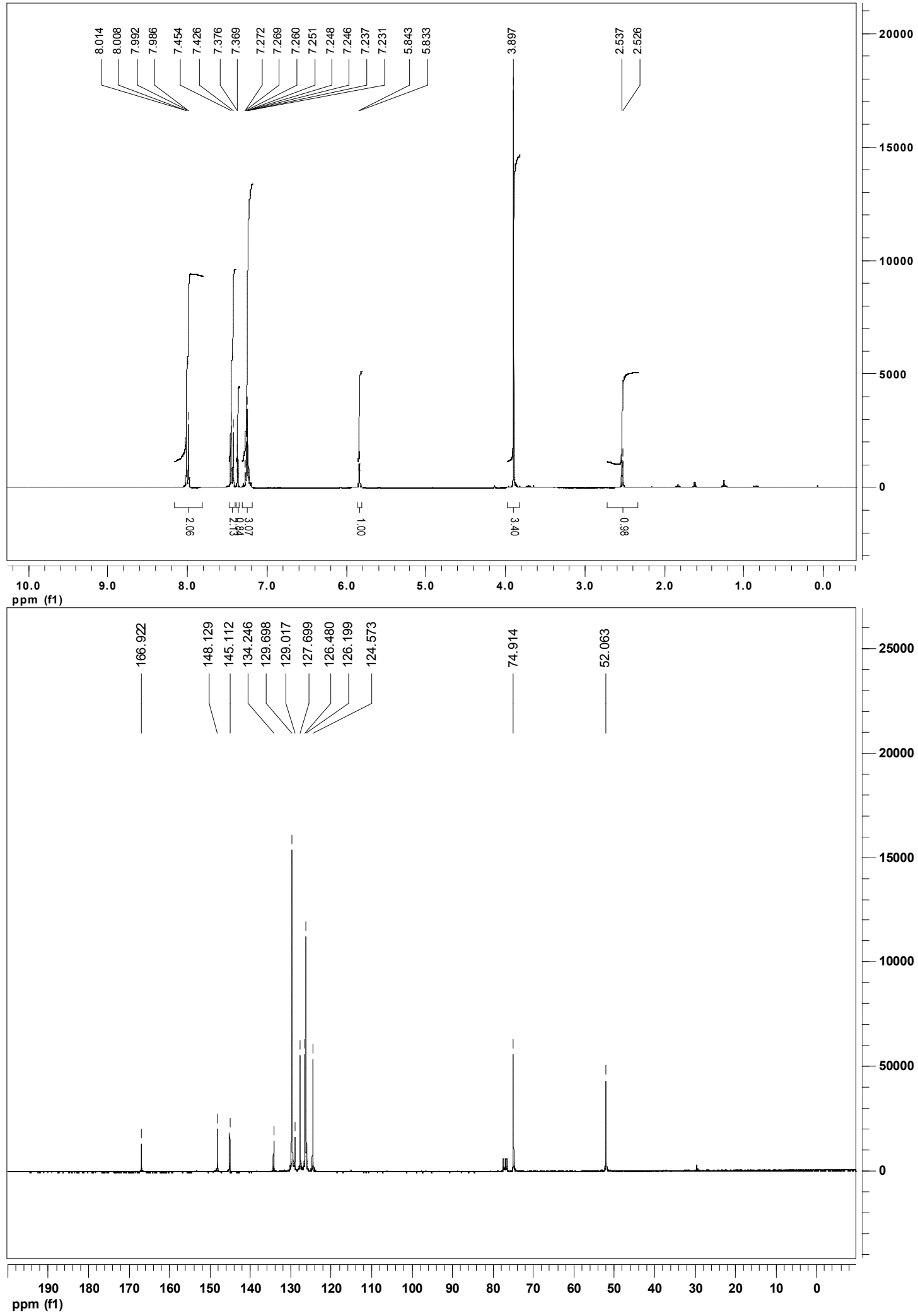




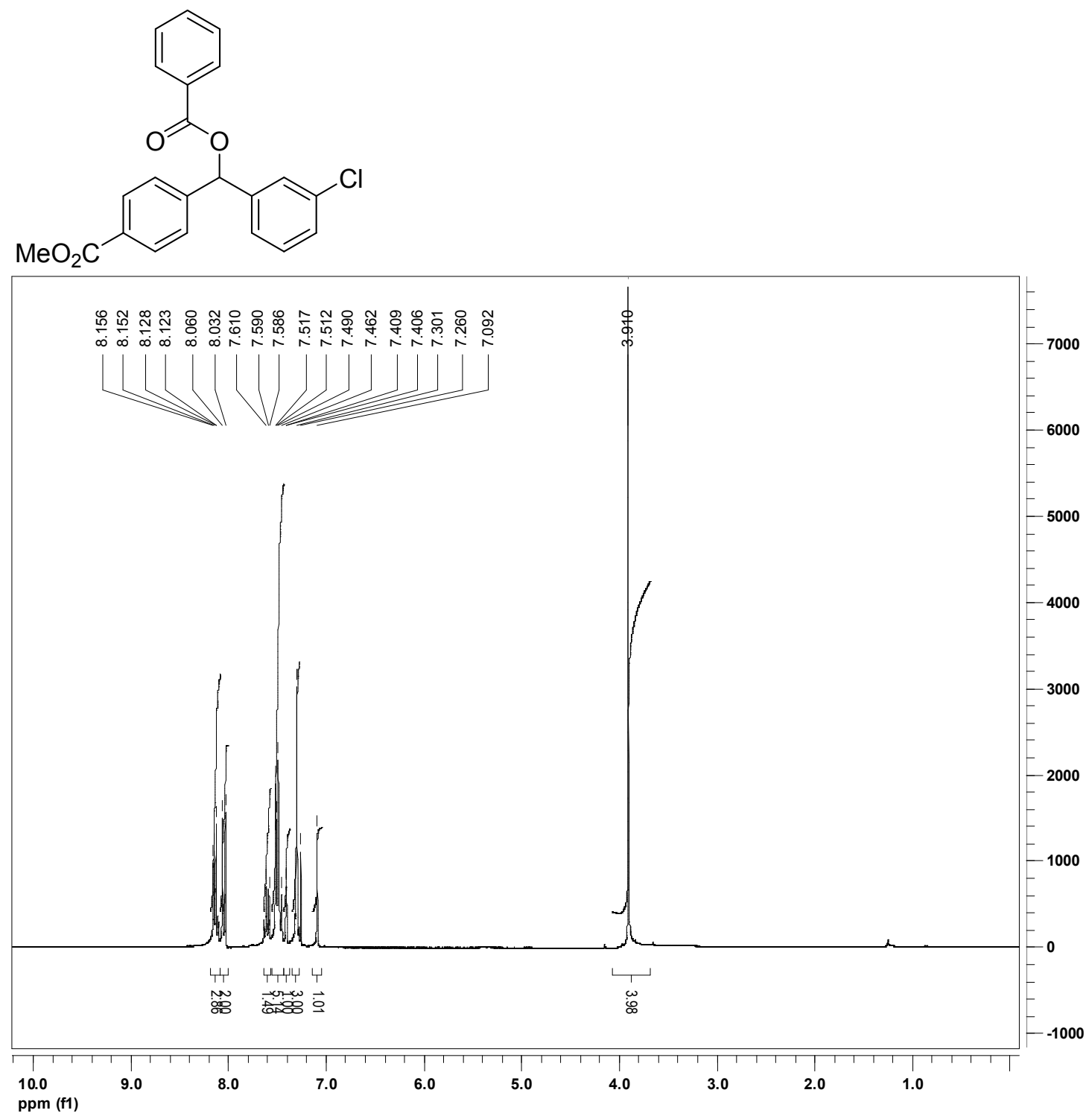



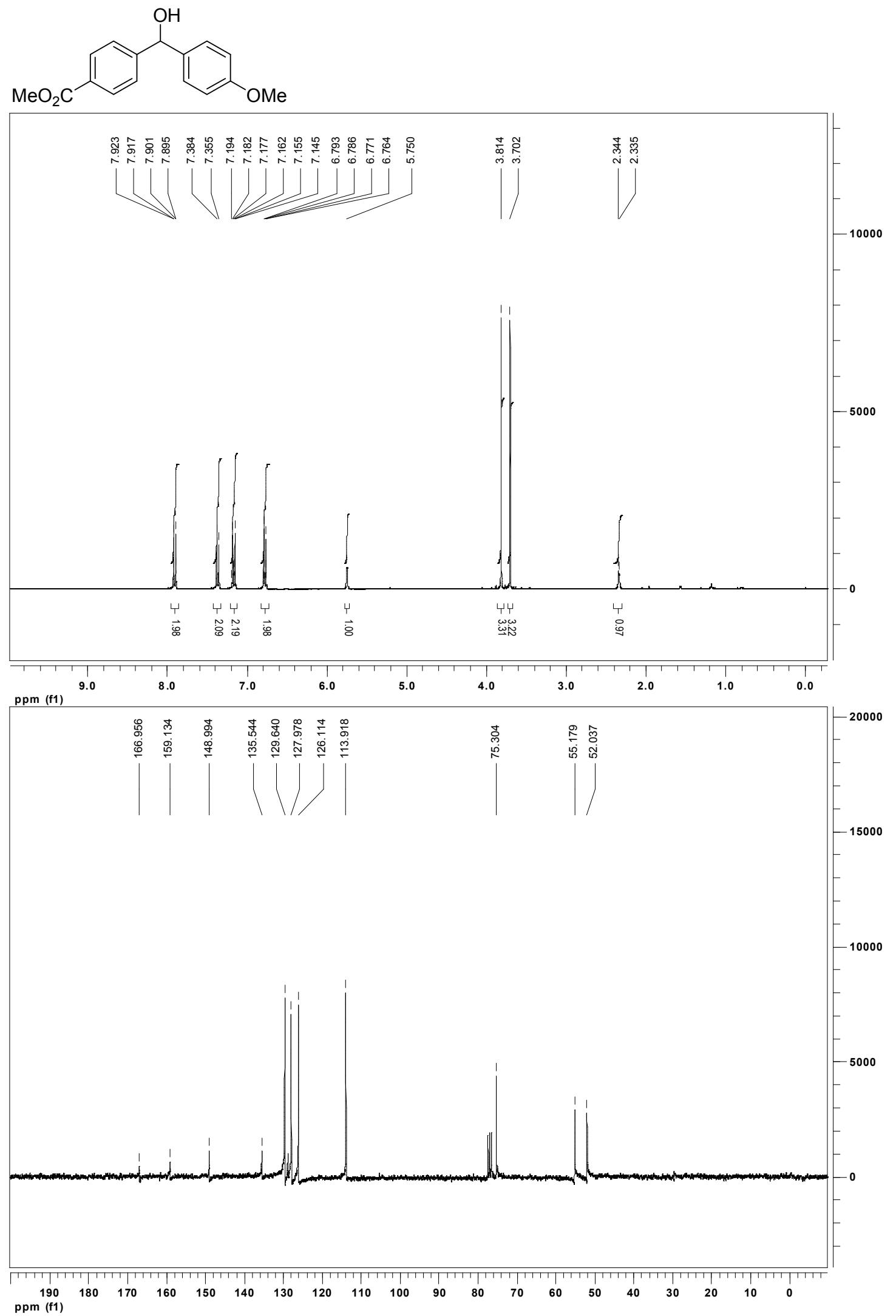


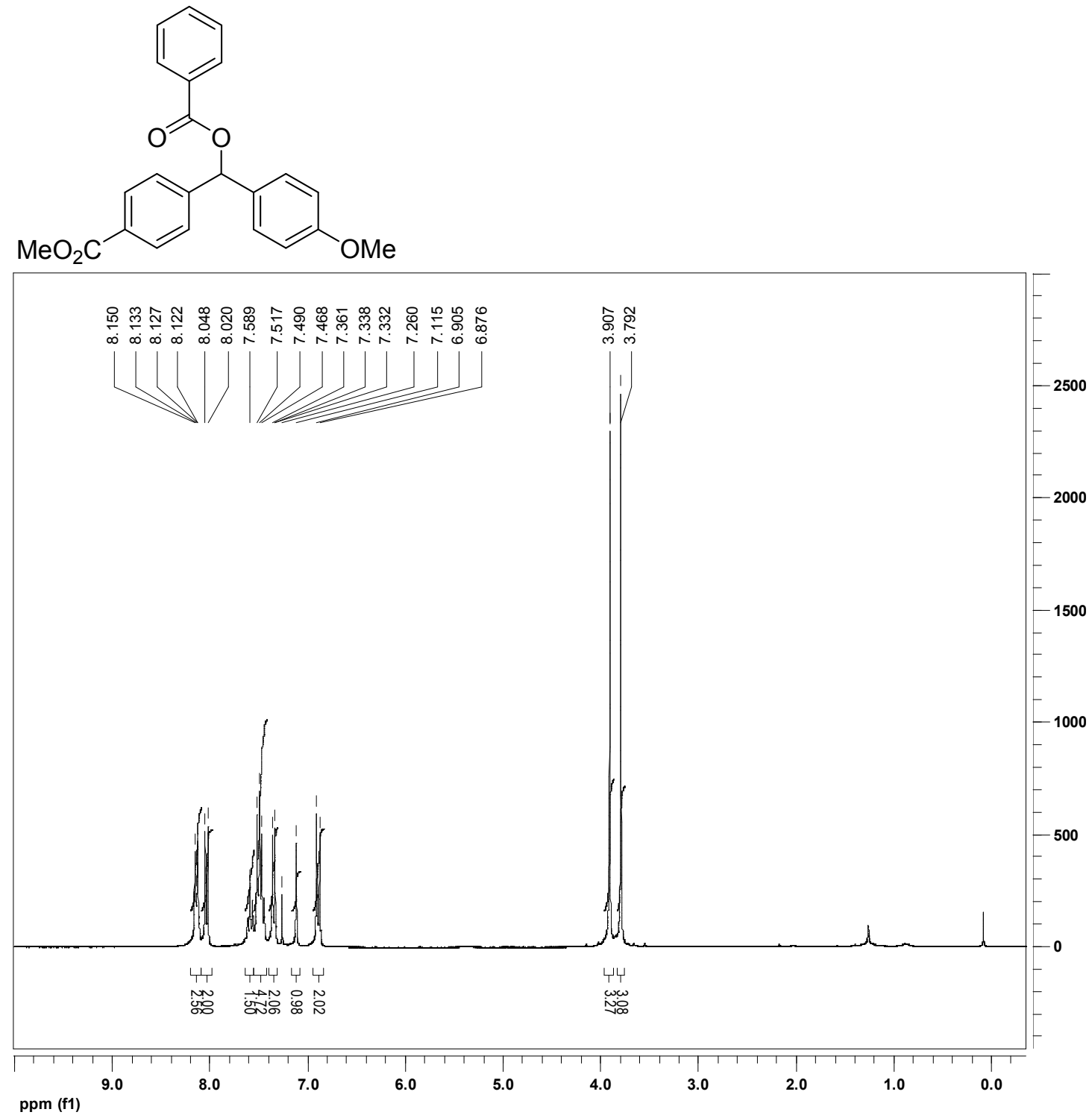


<smiles>CC(=O)c1ccc(C(O)c2ccc3ccccc3c2)cc1</smiles>

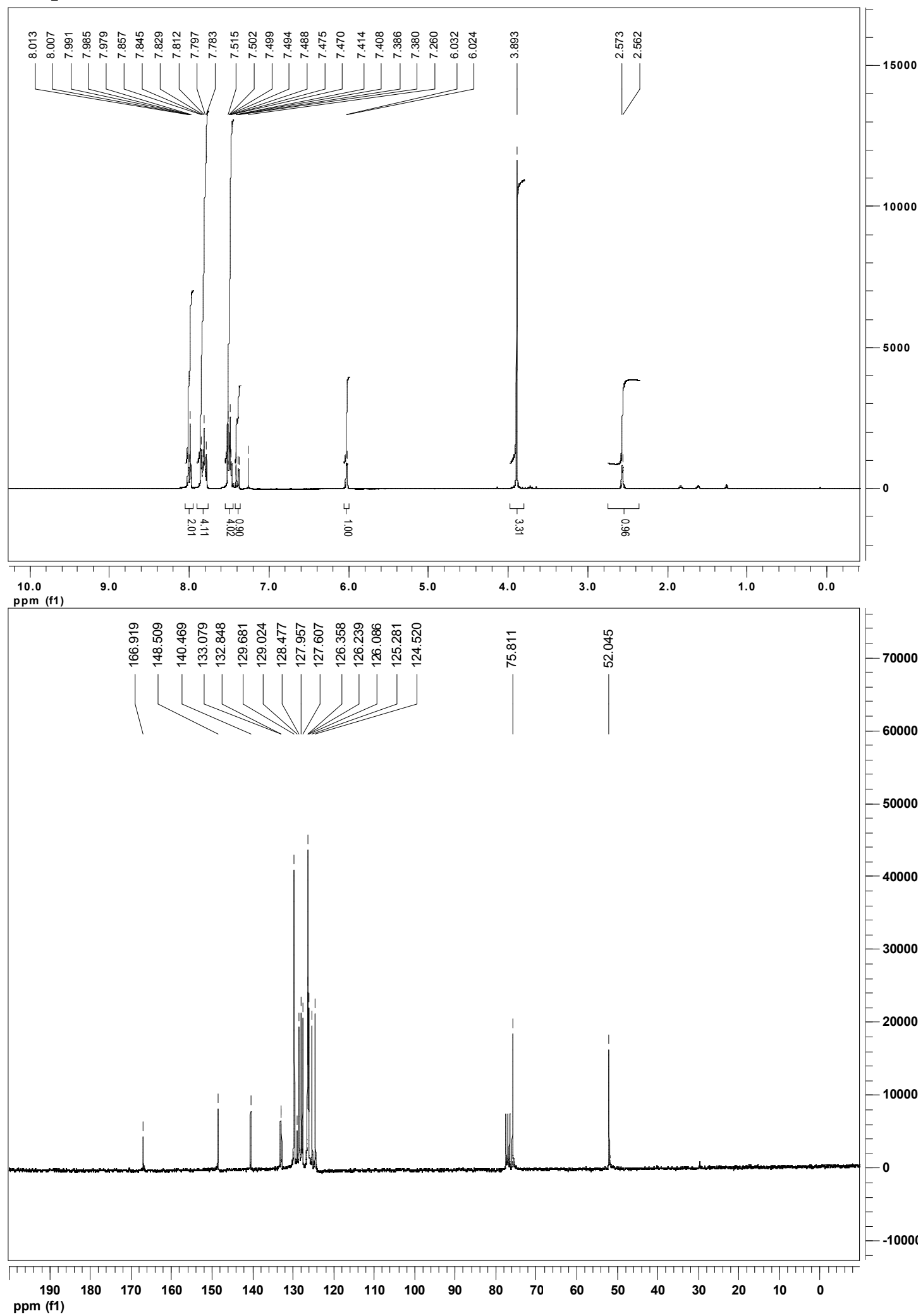




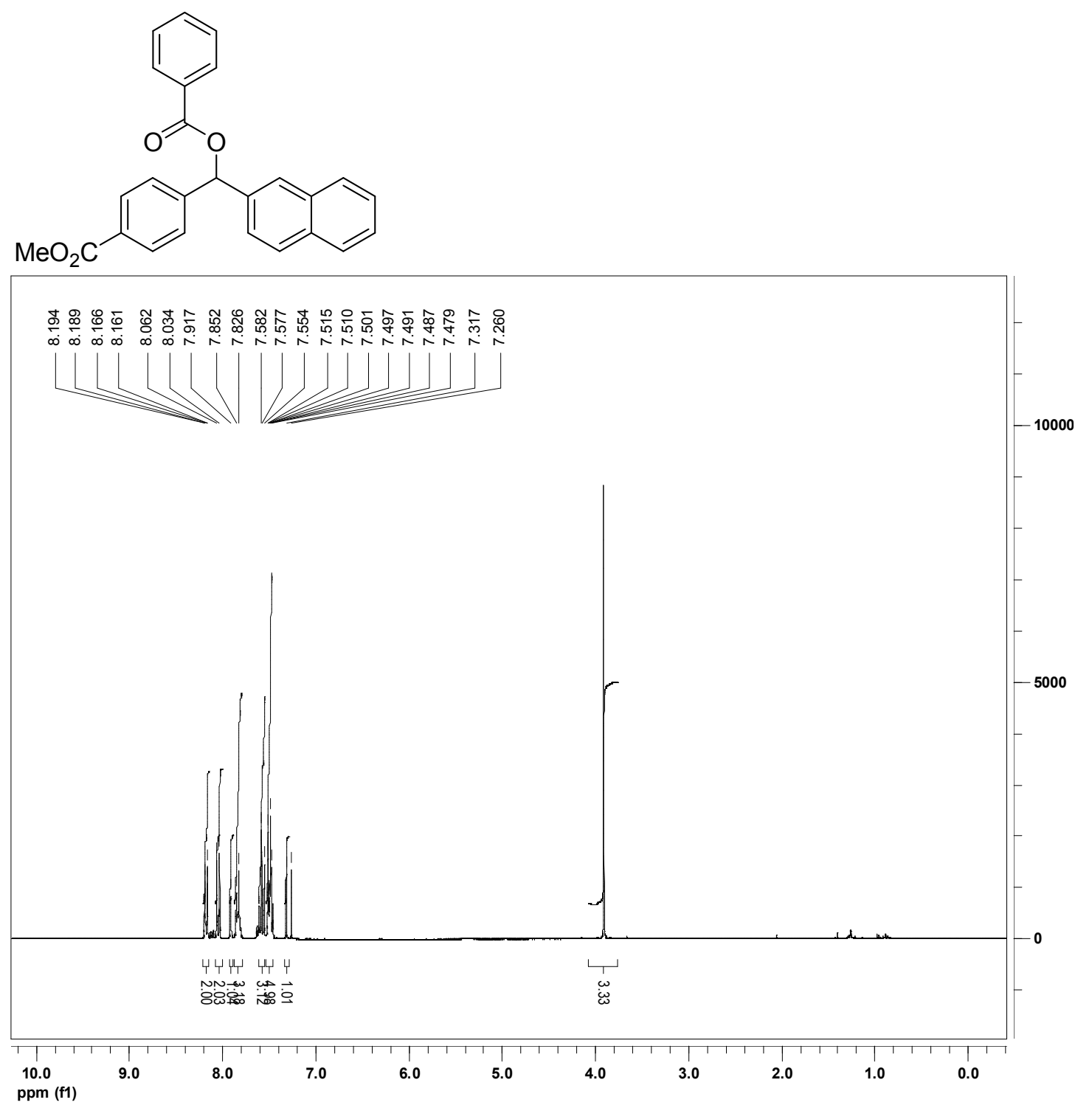




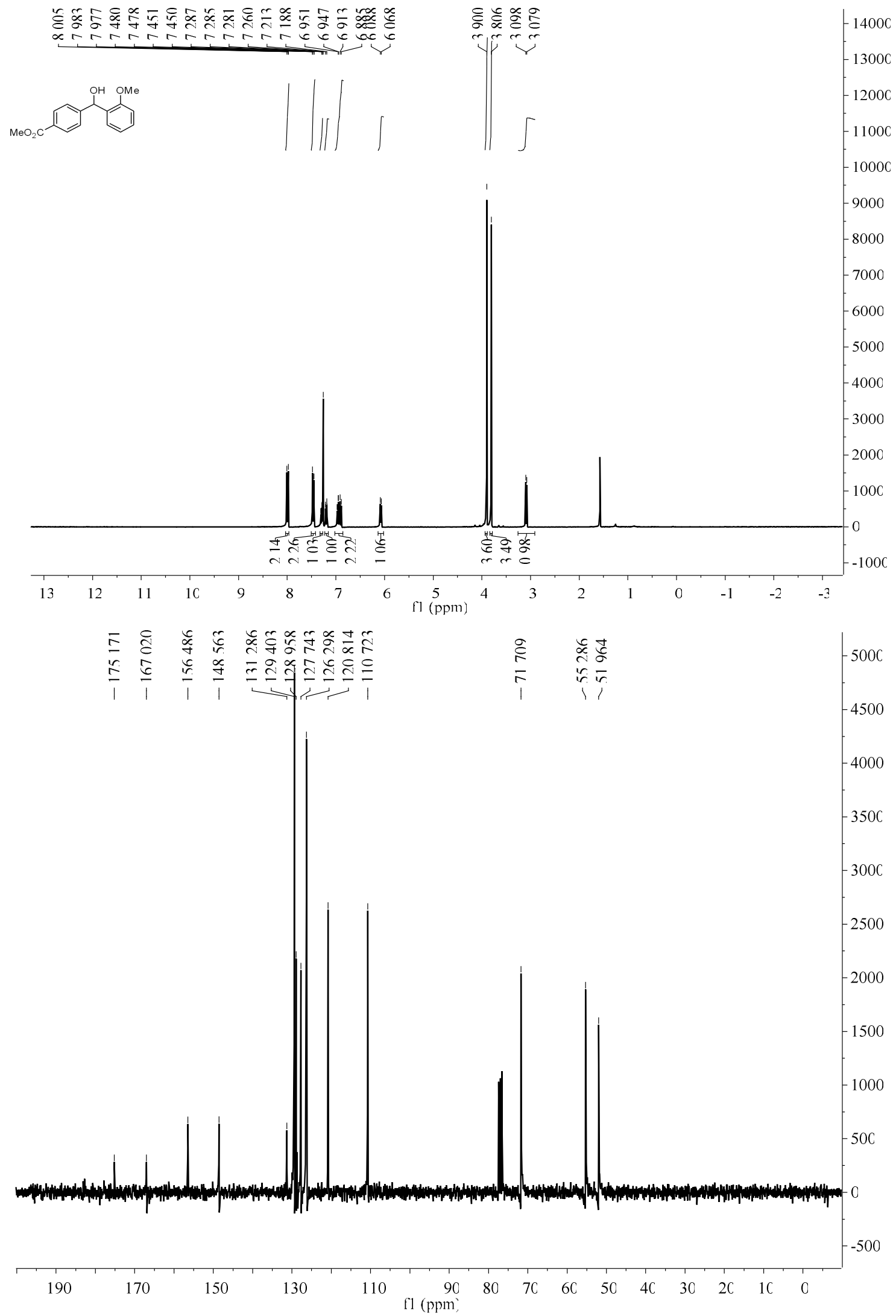




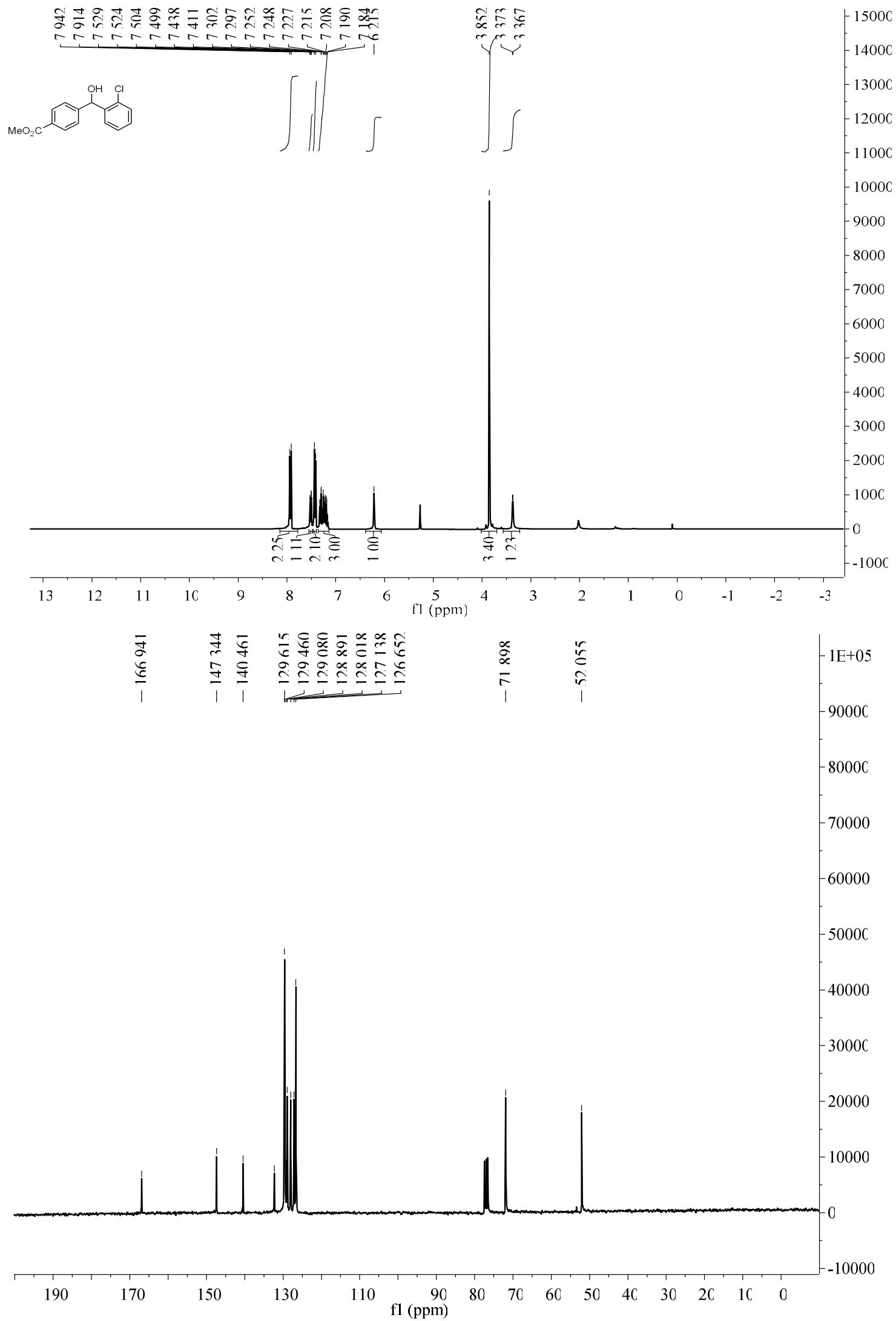




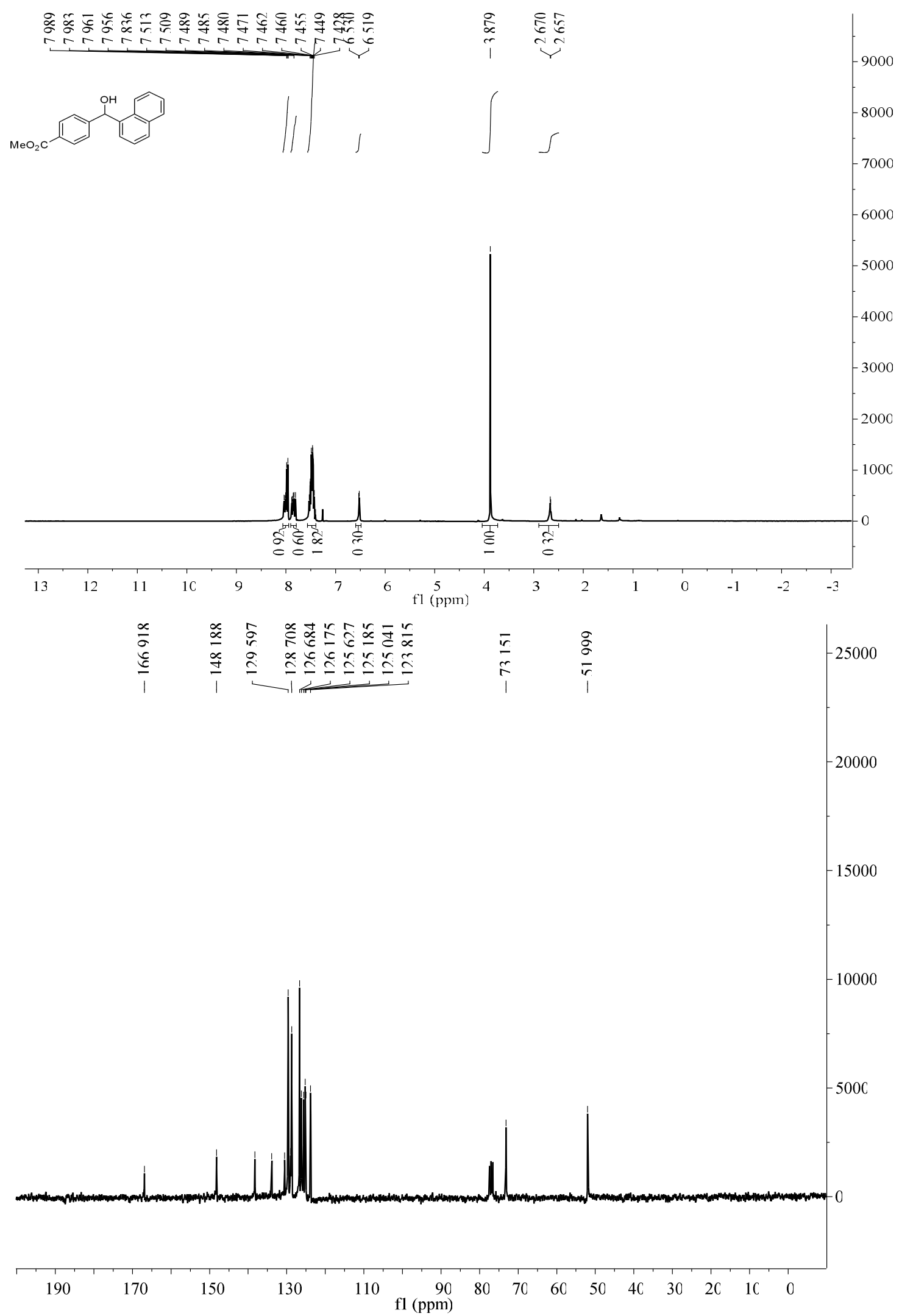




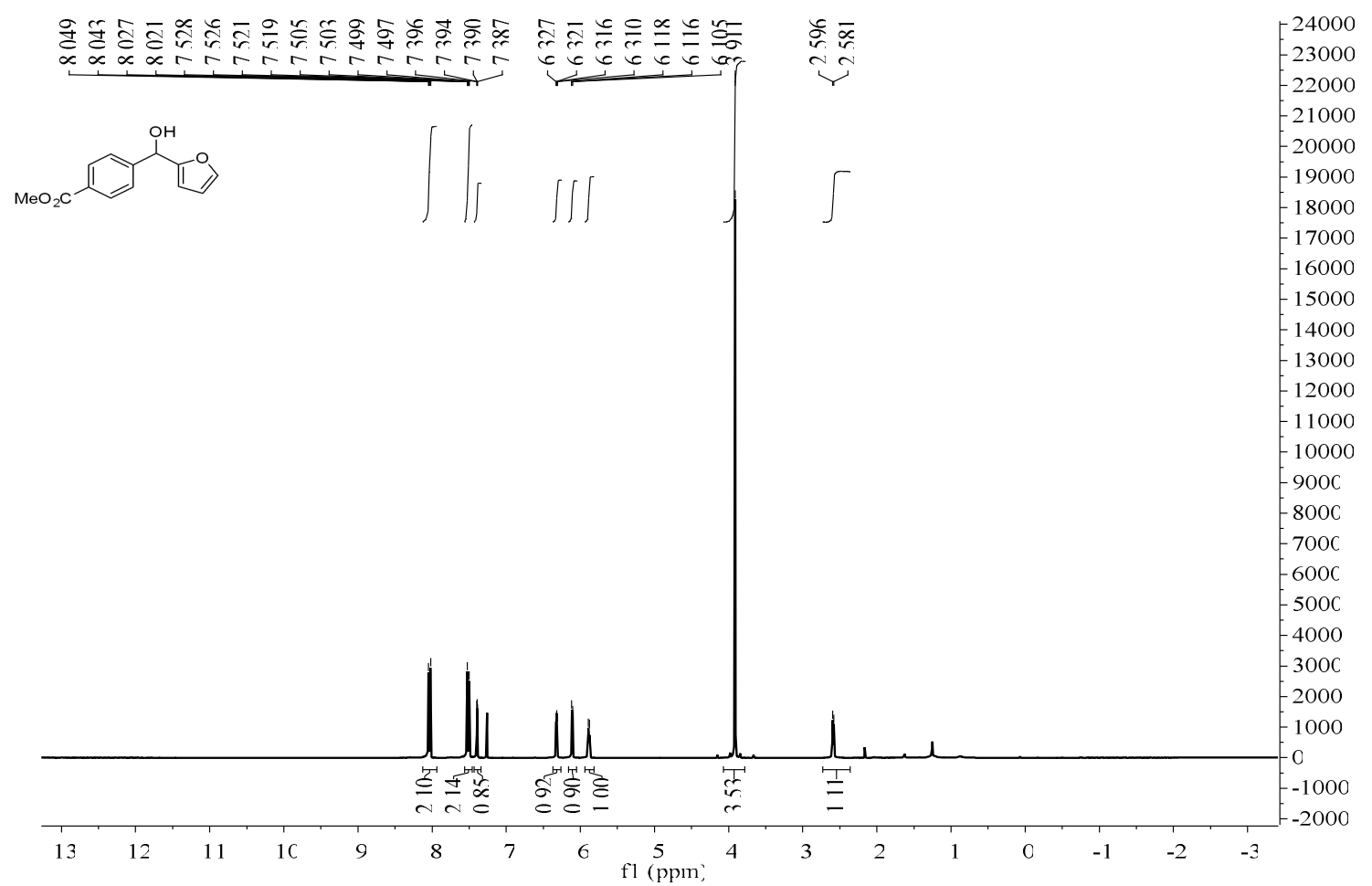

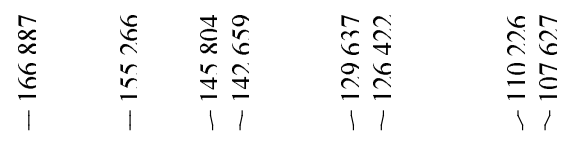

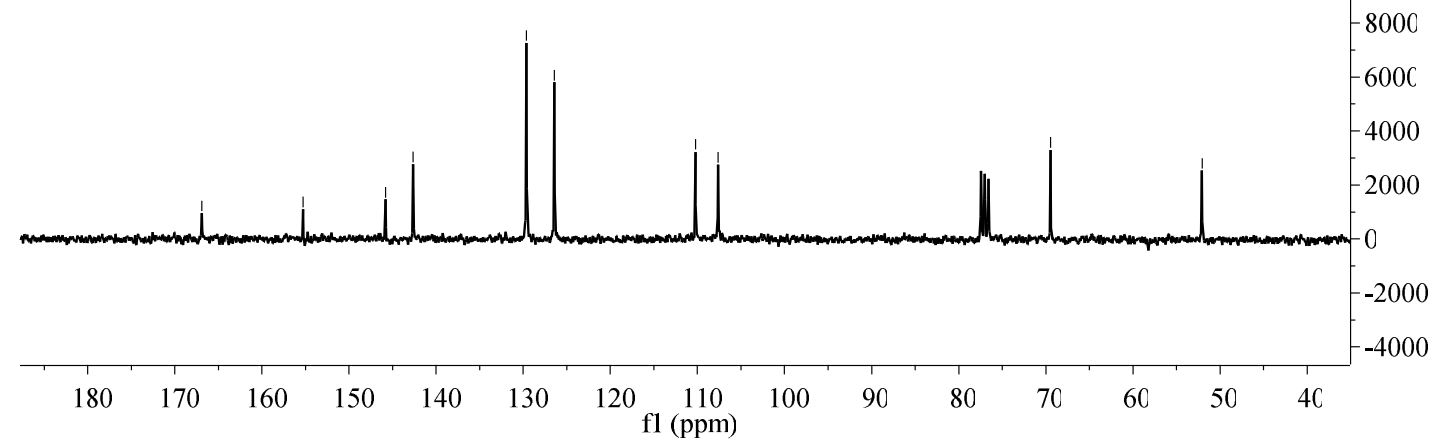



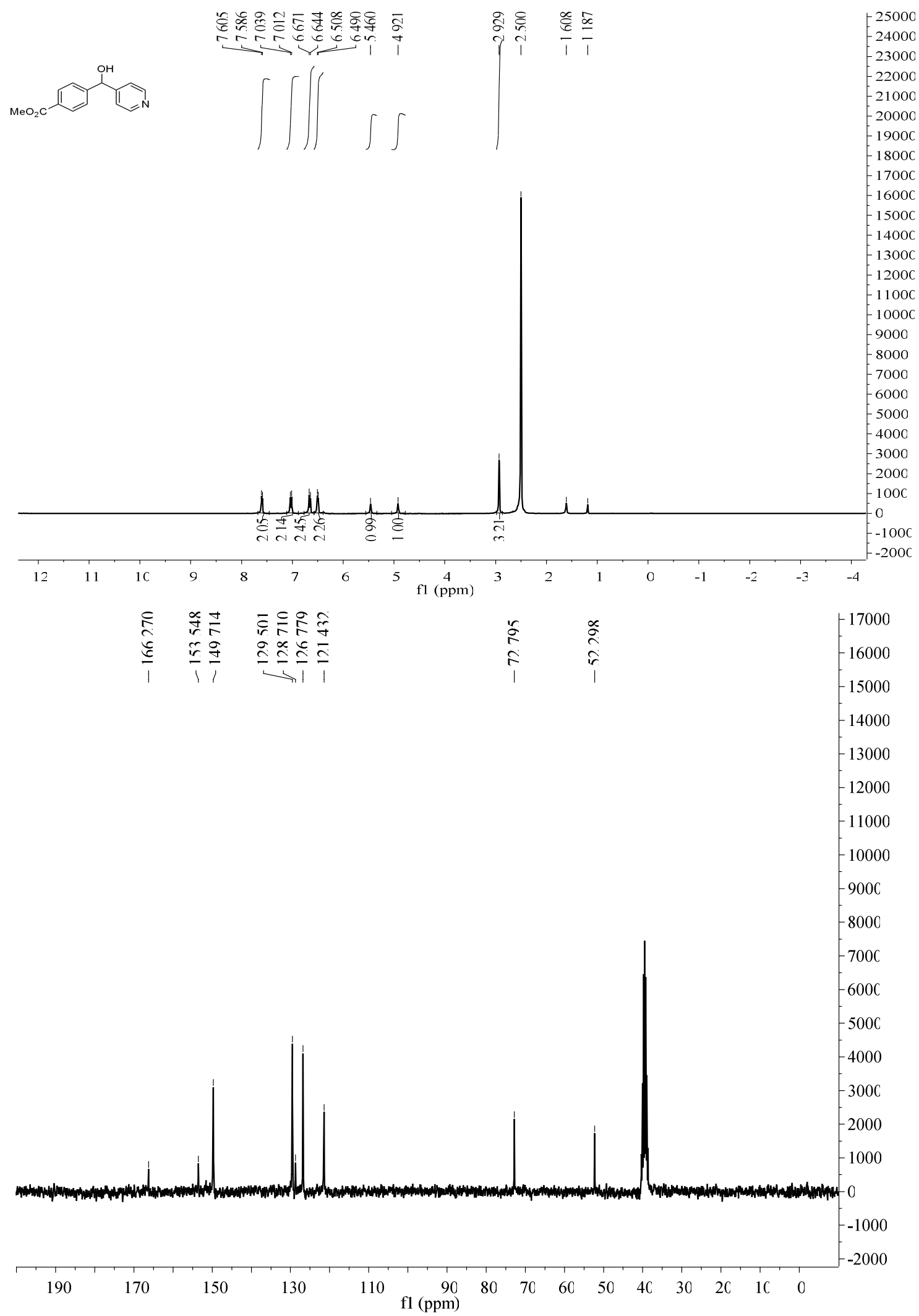
<smiles>N#Cc1cccc(C(O)c2ccccc2)c1</smiles>
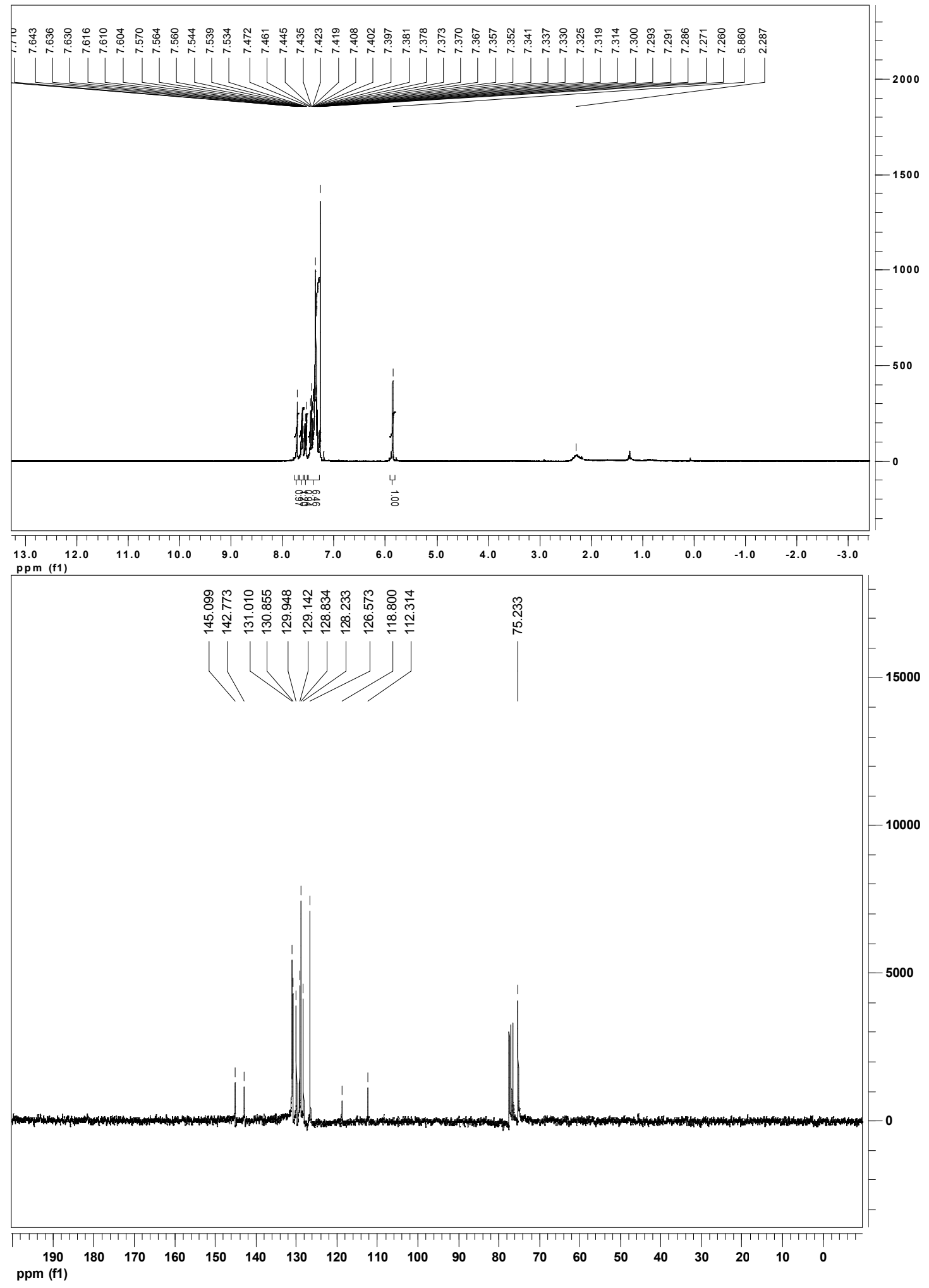

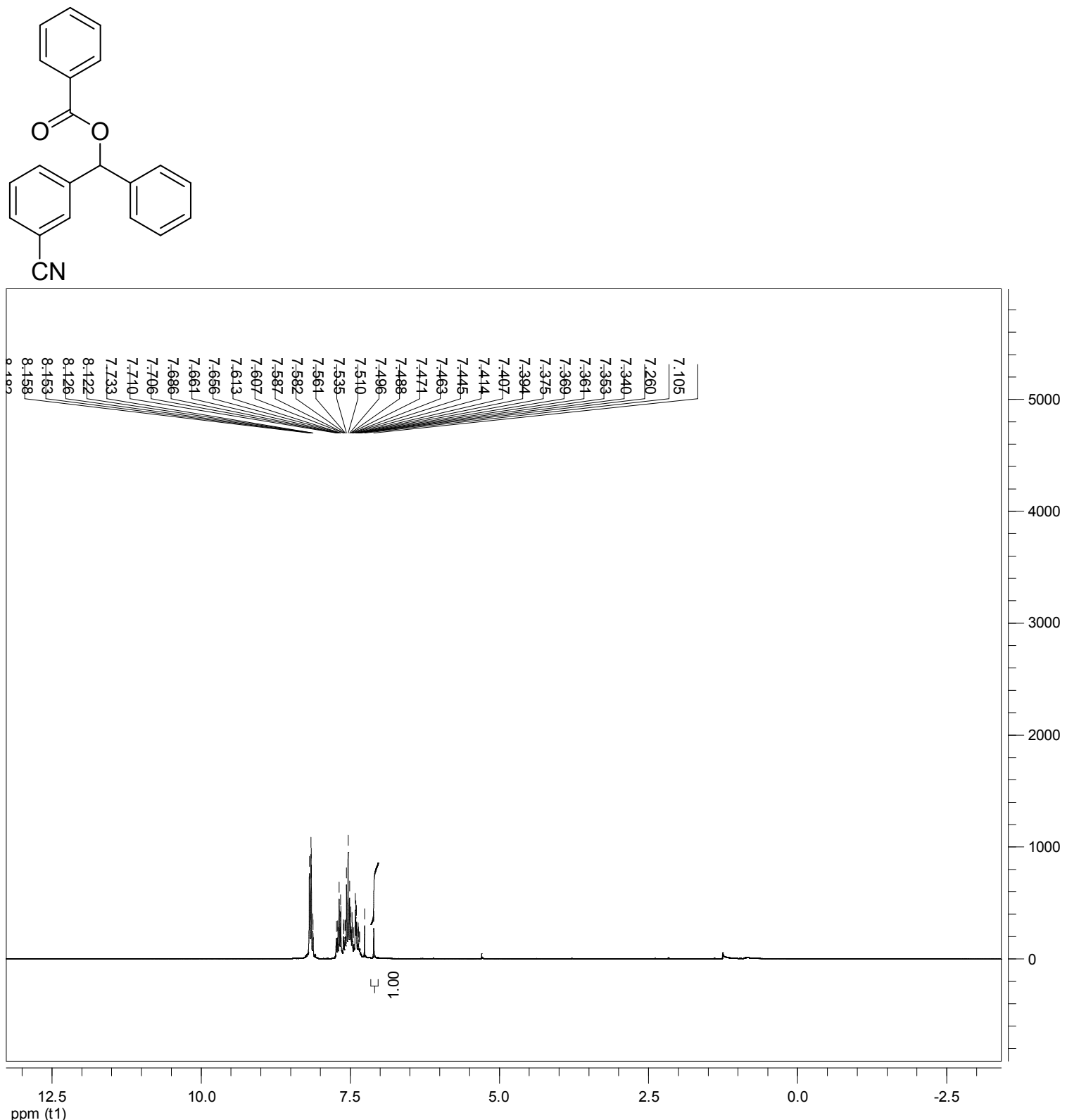


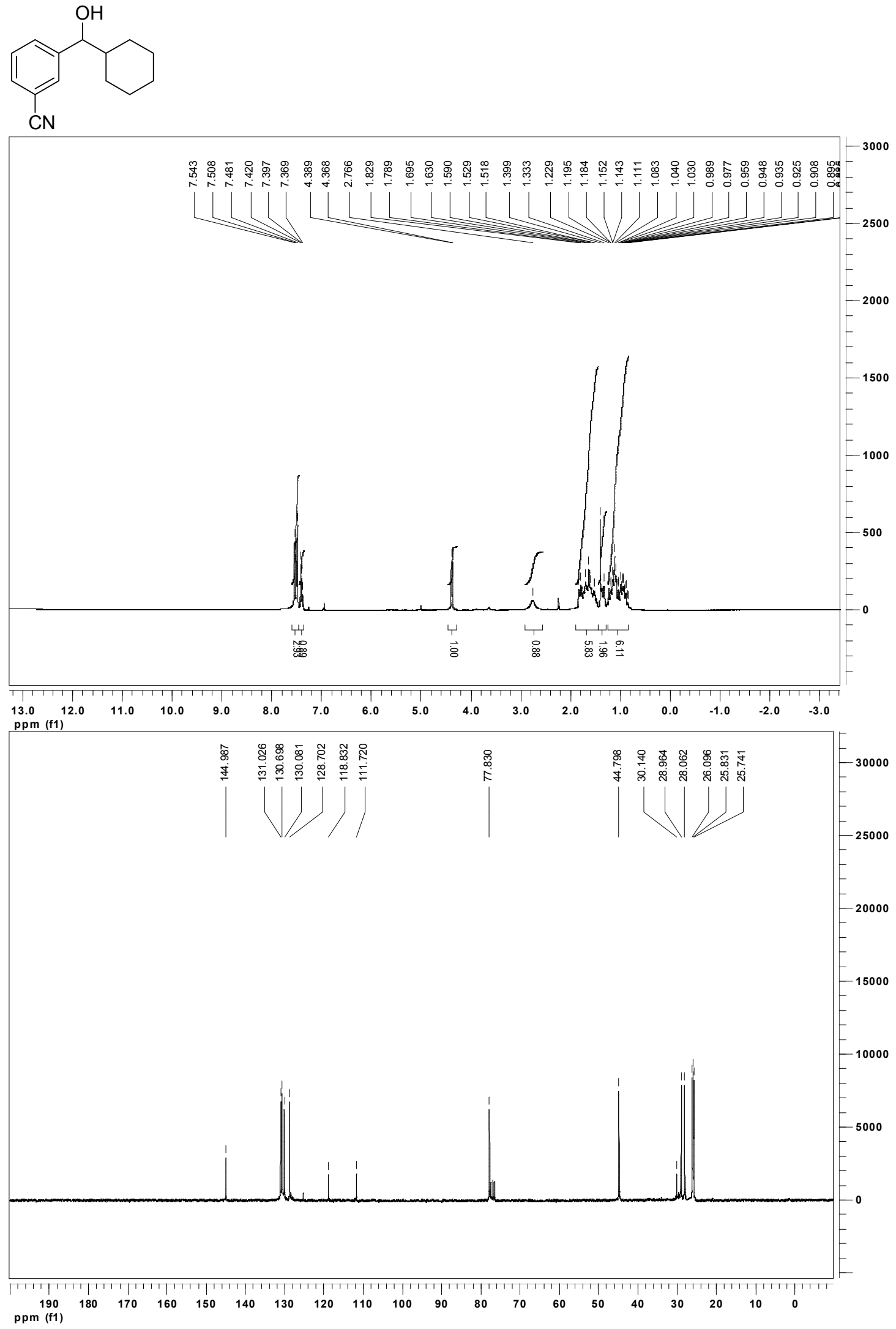



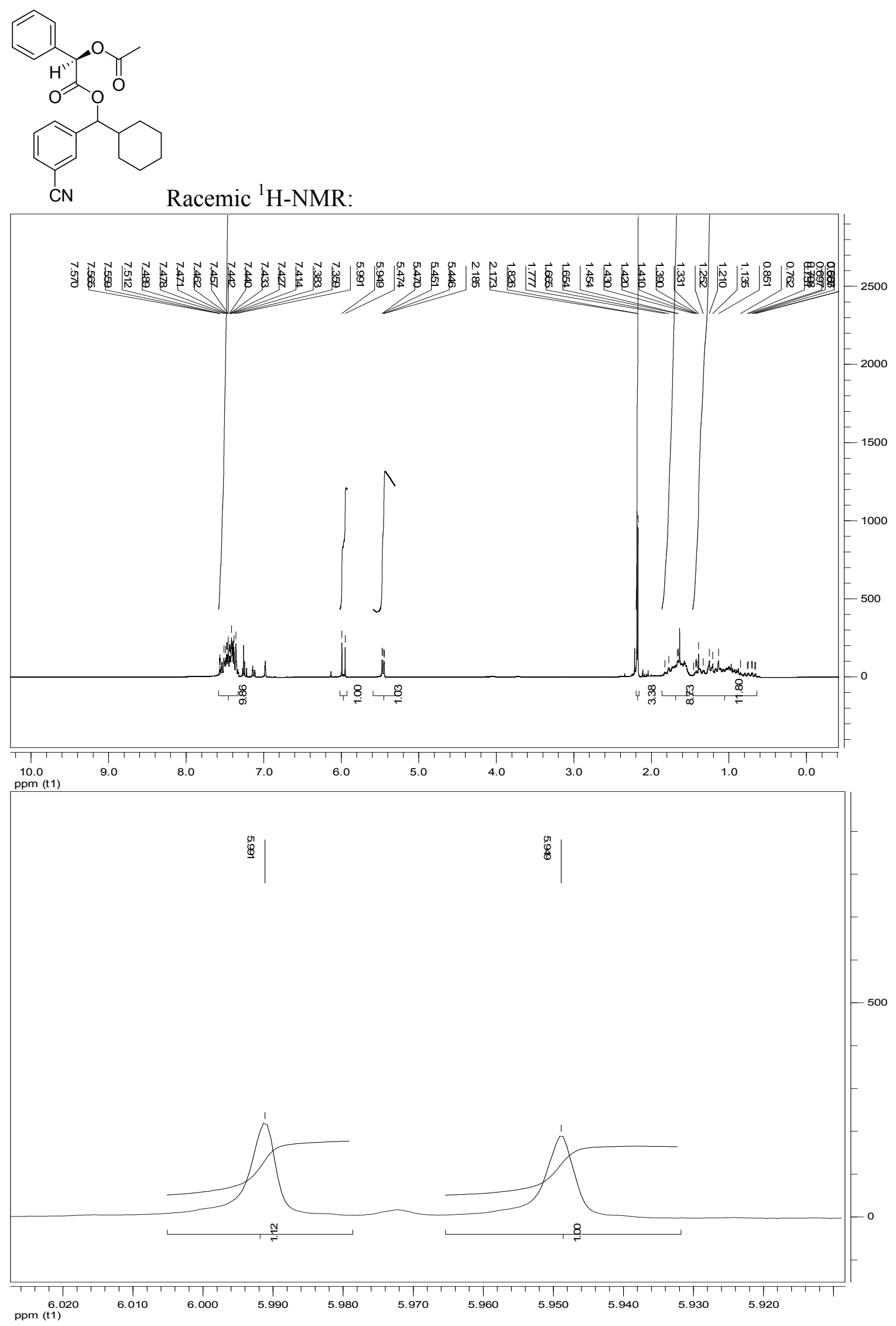
Asymmetric ${ }^{1} \mathrm{H}-\mathrm{NMR}$ :

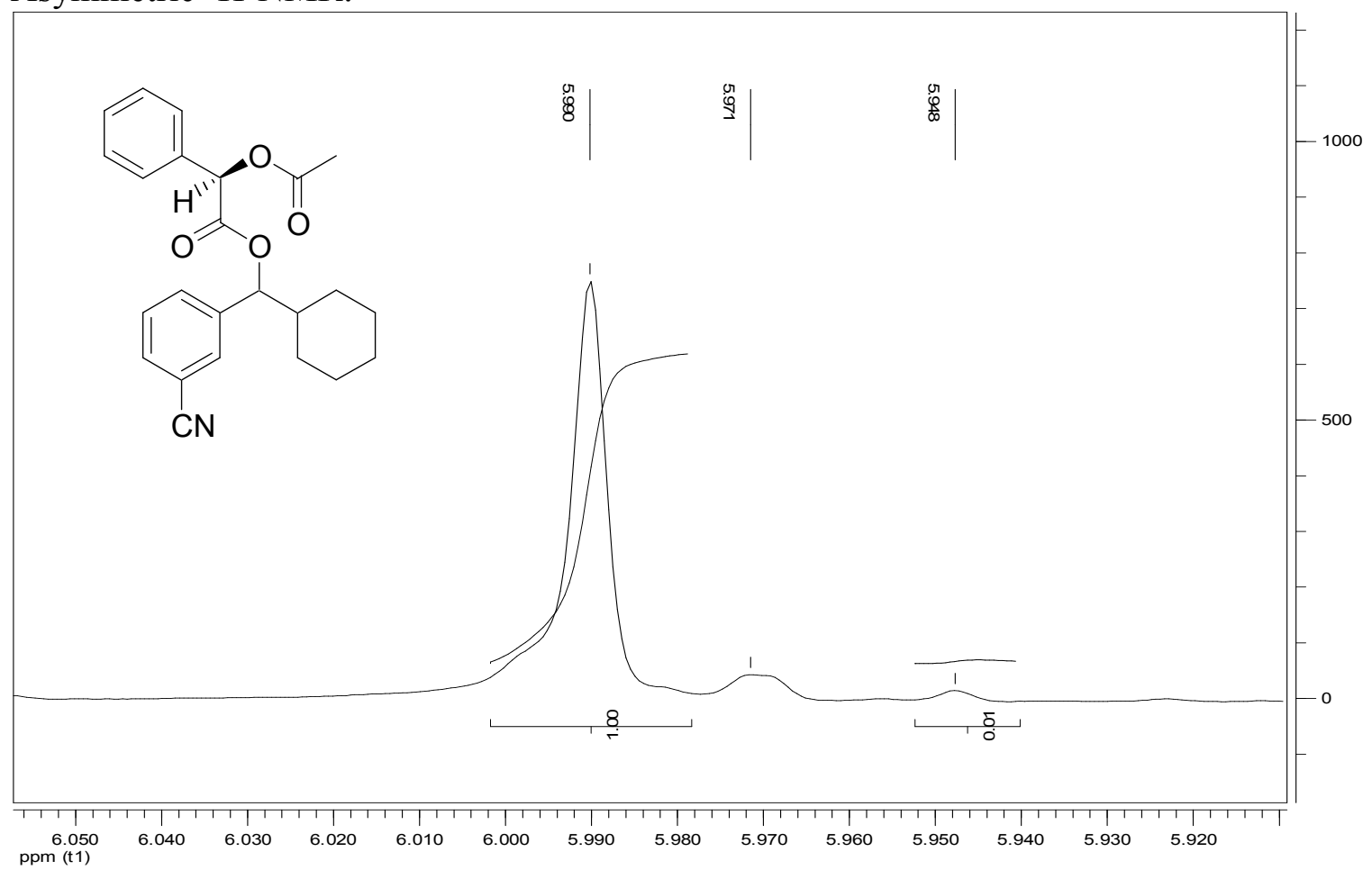


CN $_{\mathrm{OMe}}^{\mathrm{OH}}$

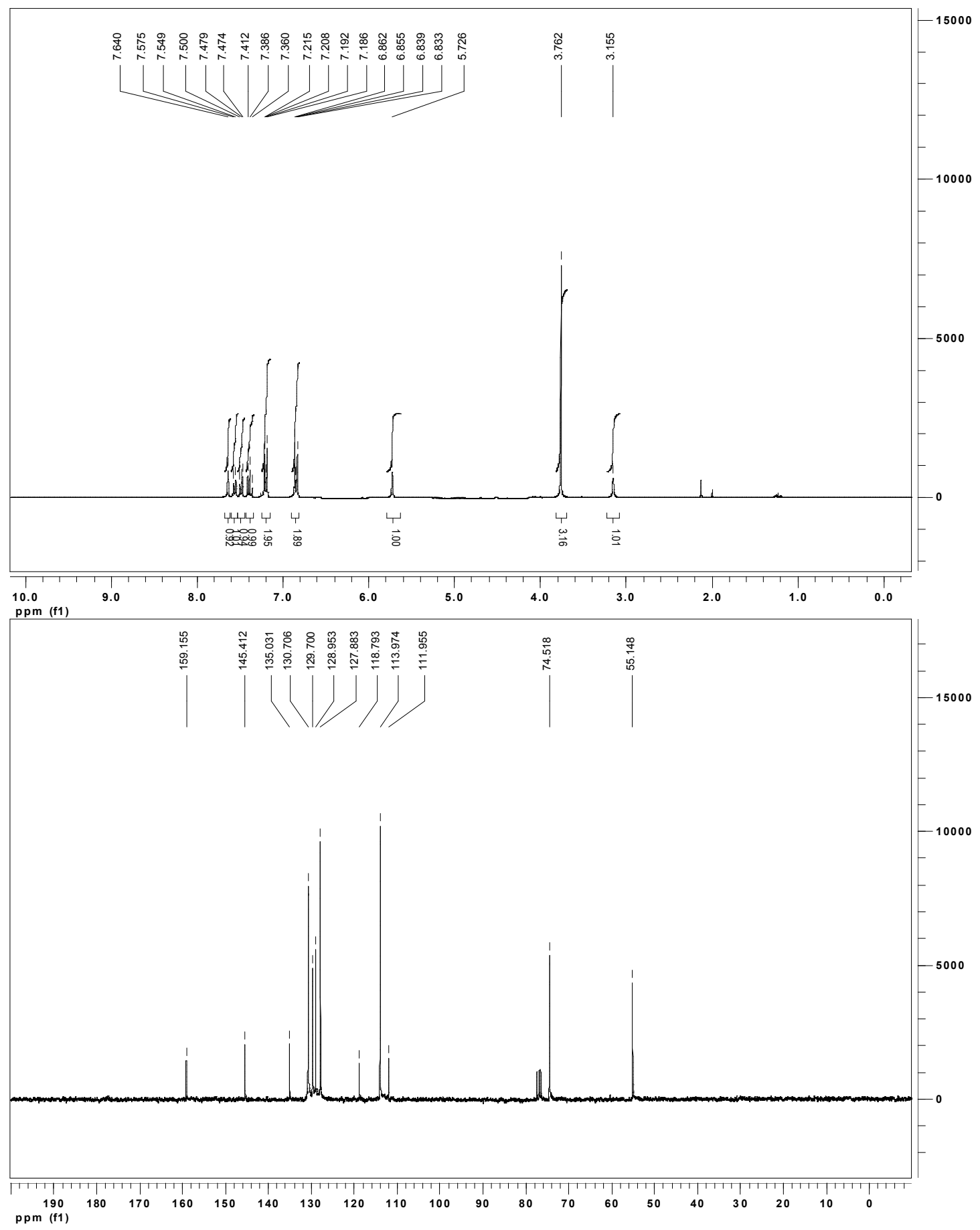



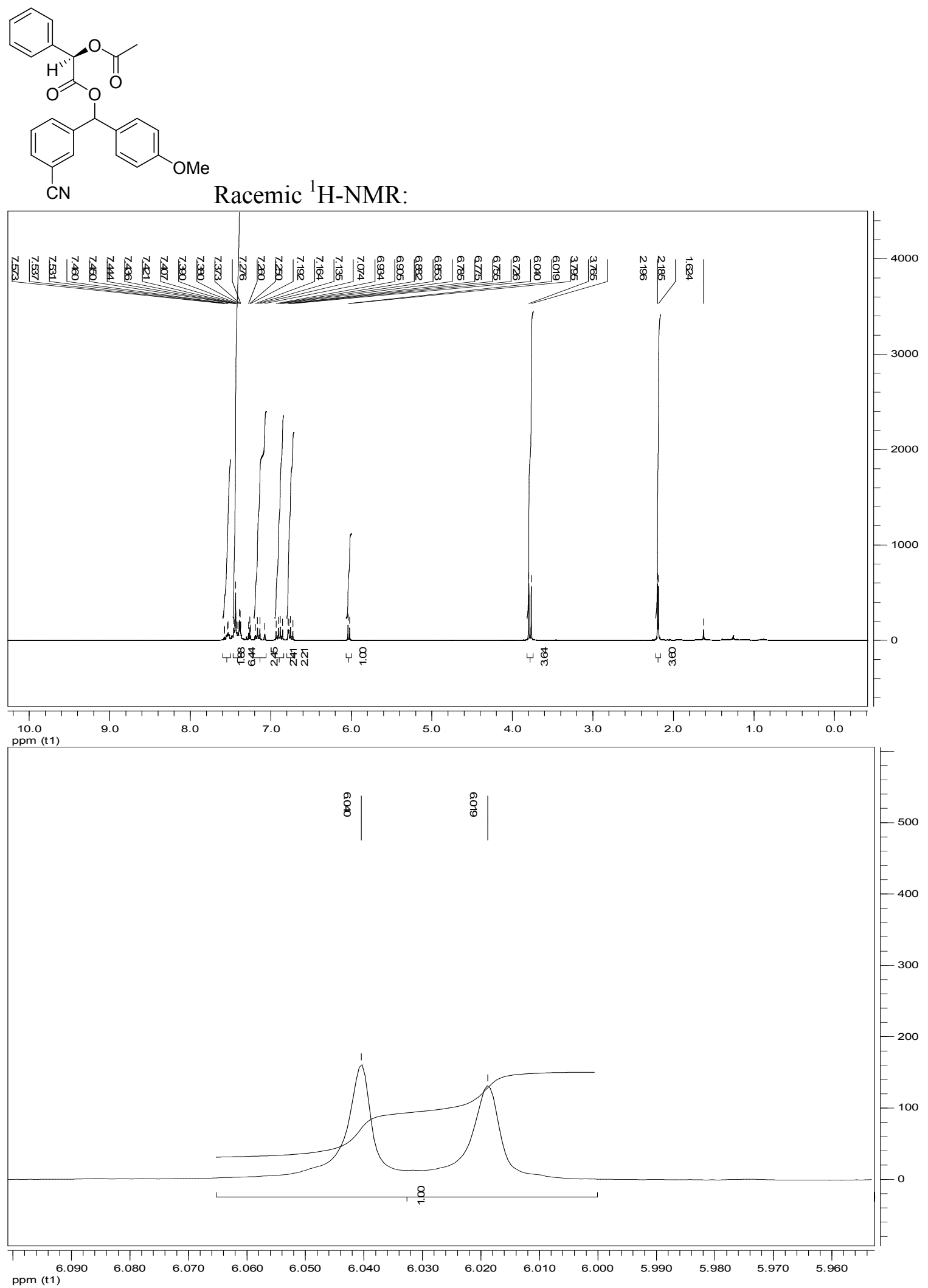
Asymmetric ${ }^{1} \mathrm{H}-\mathrm{NMR}$ :

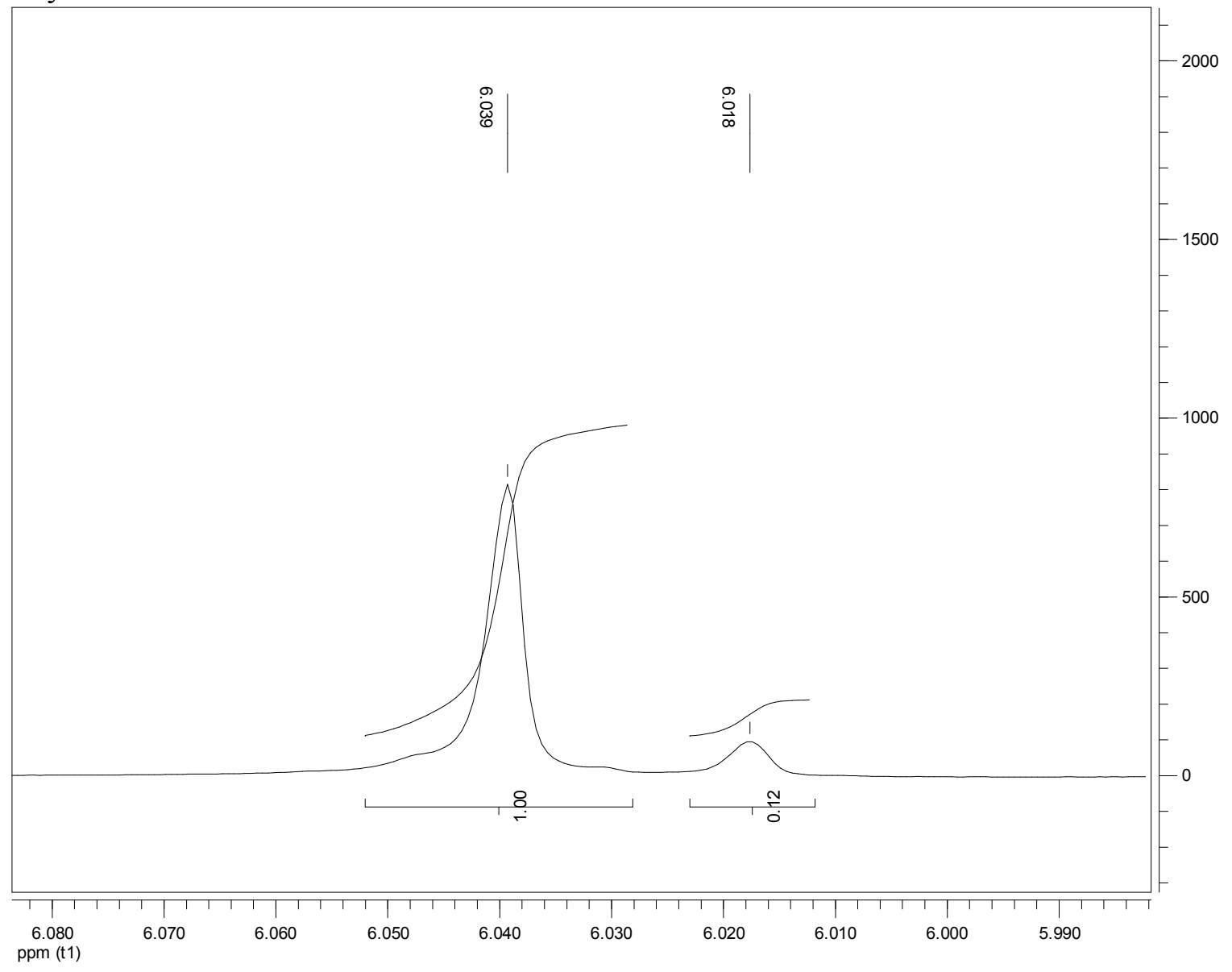




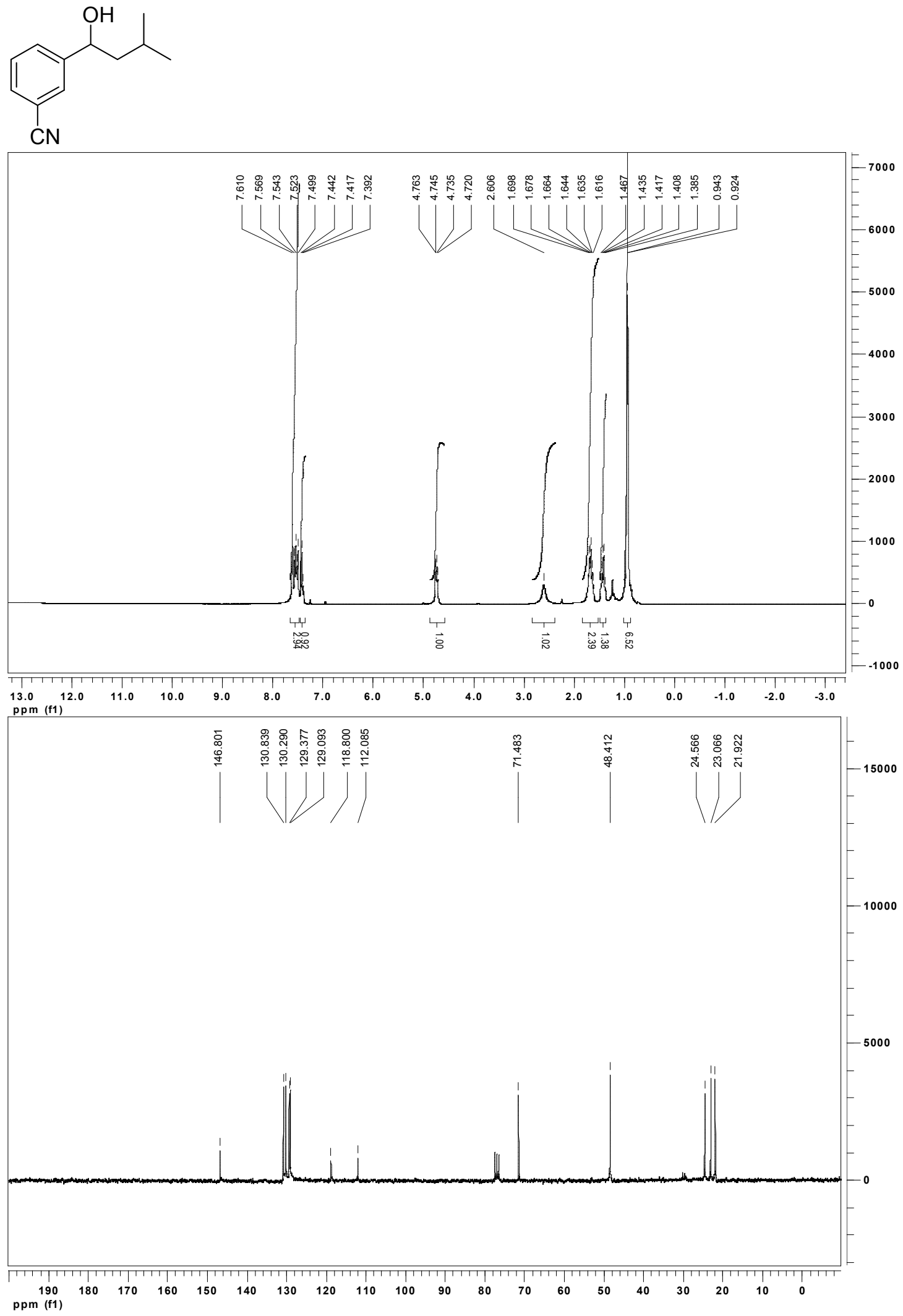




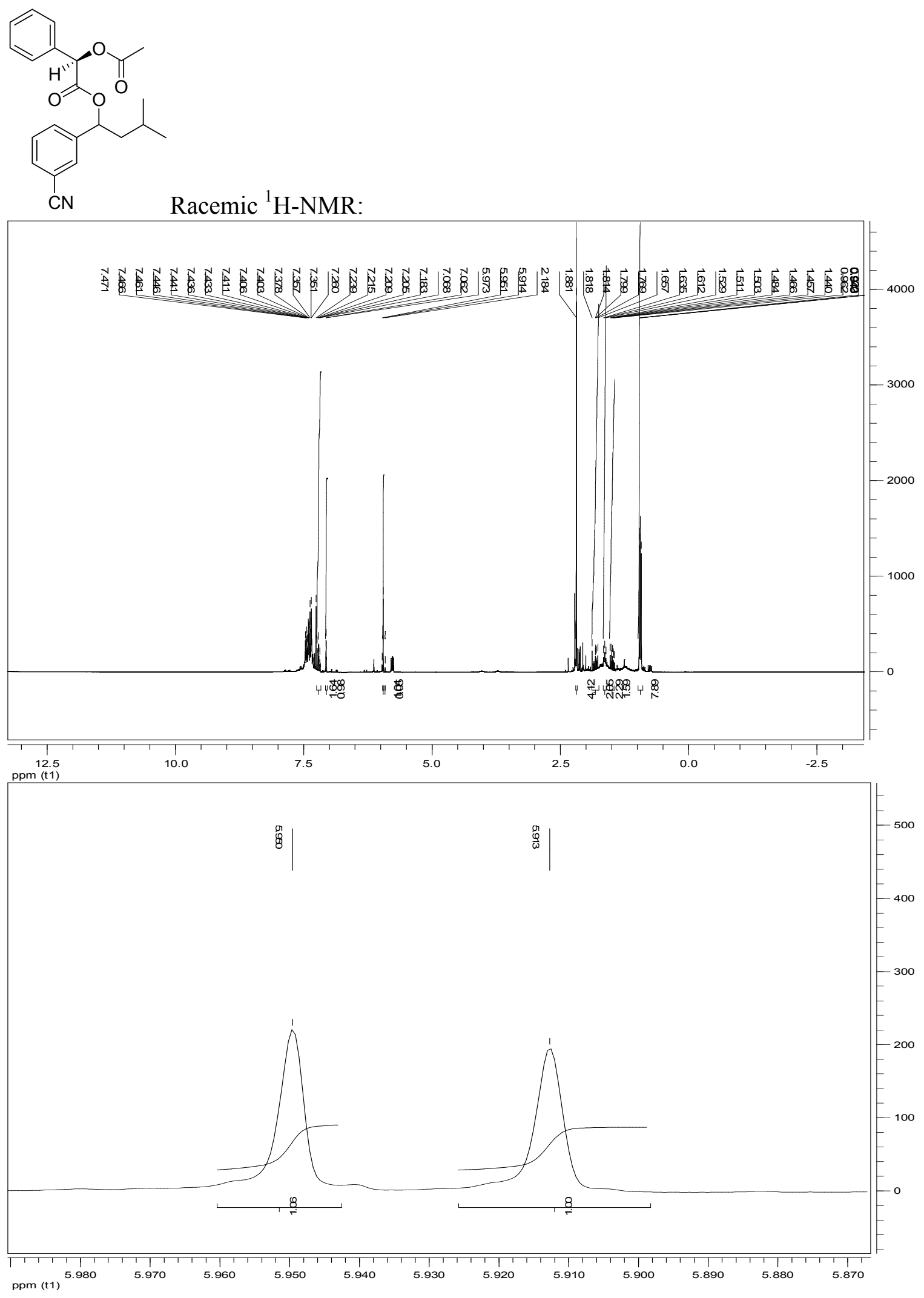


Asymmetric ${ }^{1} \mathrm{H}-\mathrm{NMR}$ :

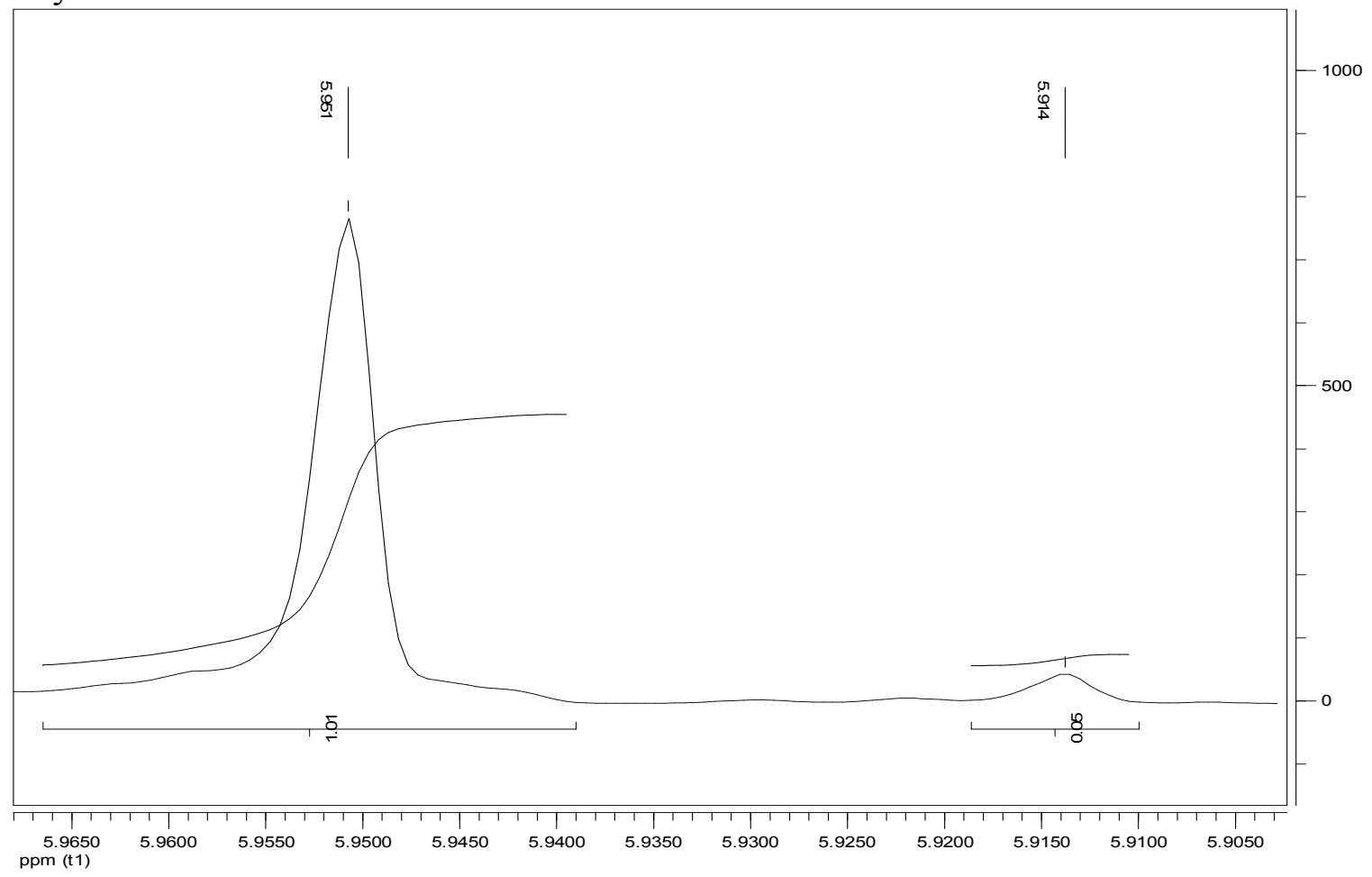

$80 \%$ yield, $91 \%$ ee. (From ligand $(\boldsymbol{S})-\mathbf{7}$ :

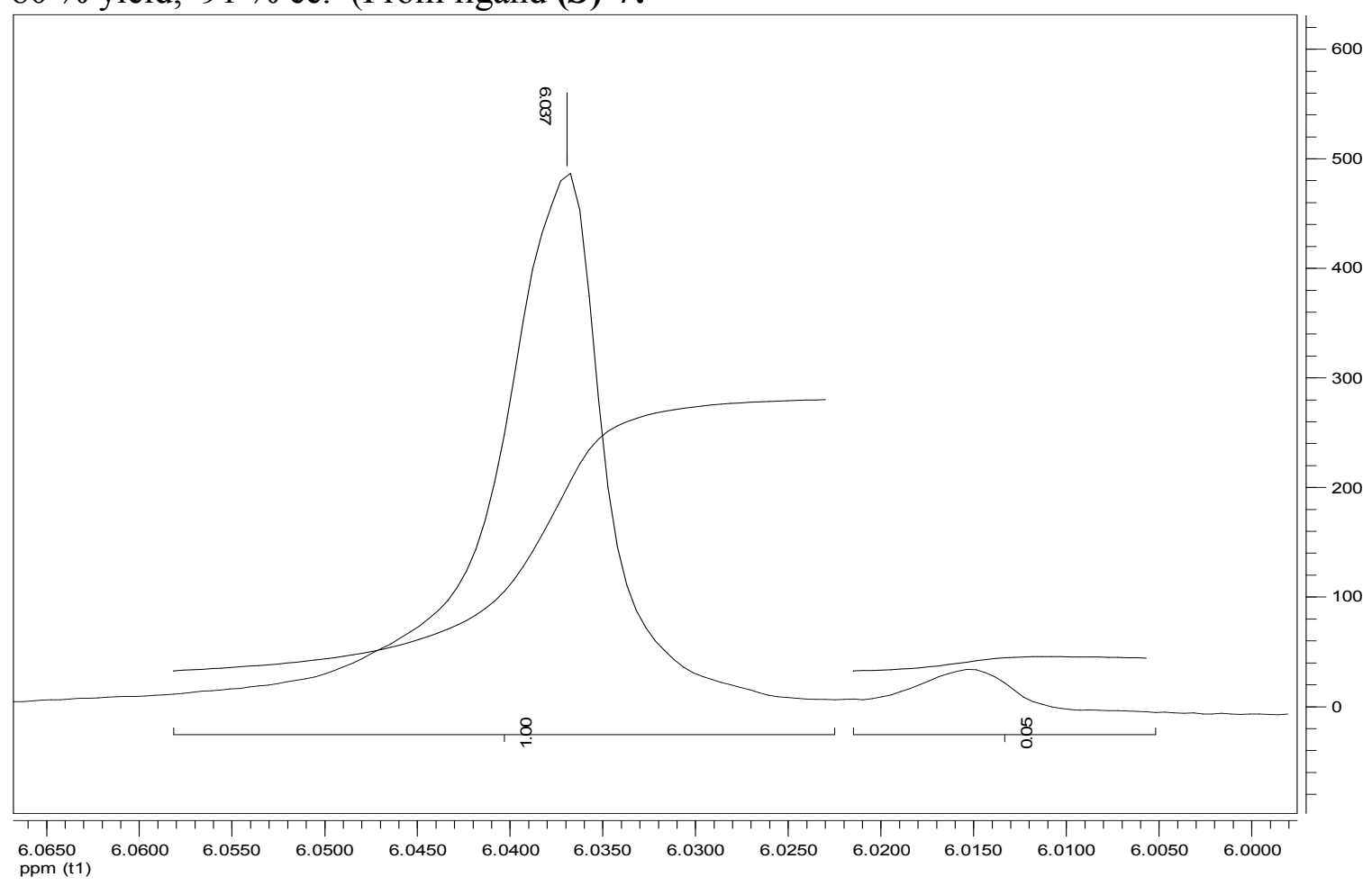




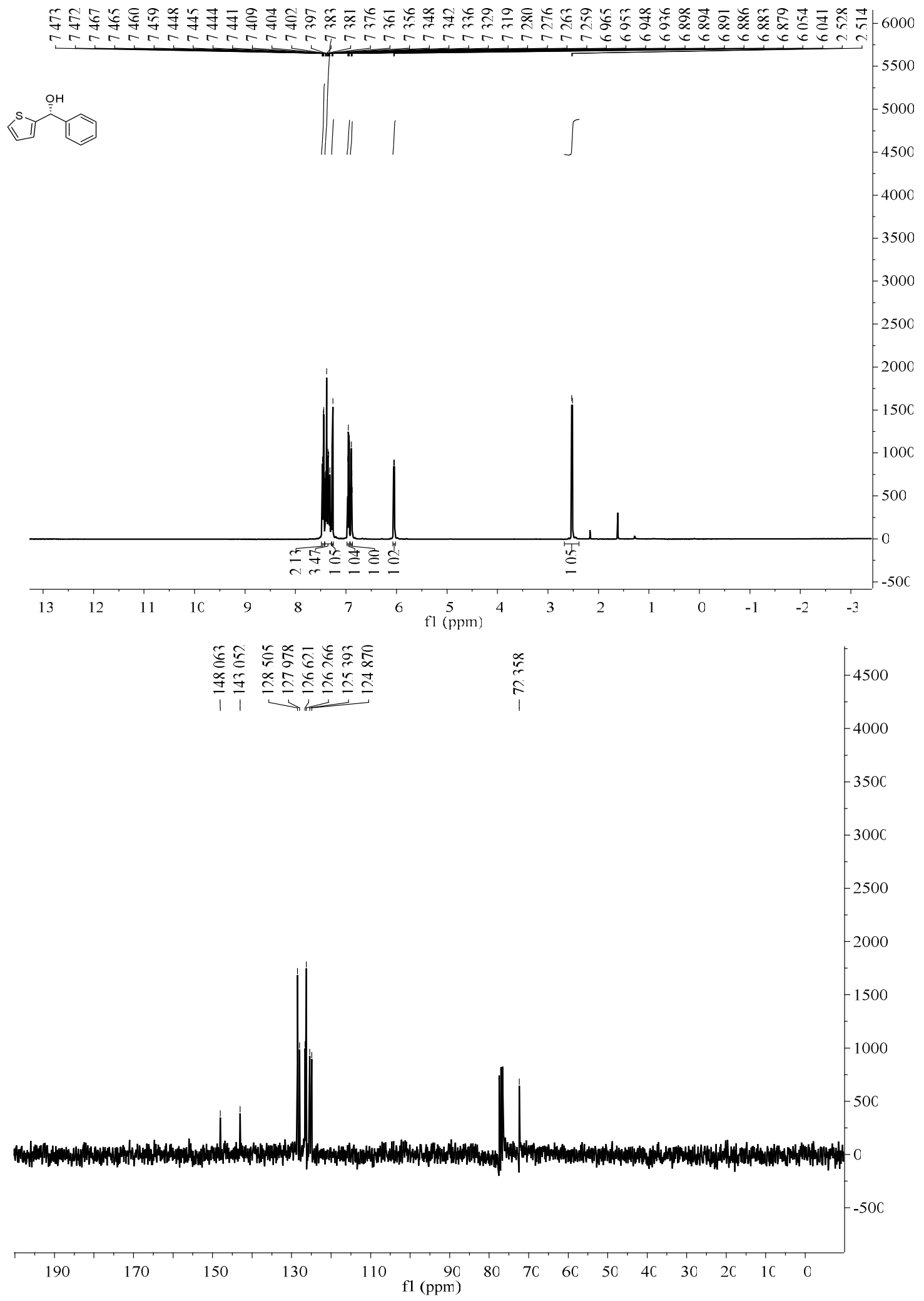




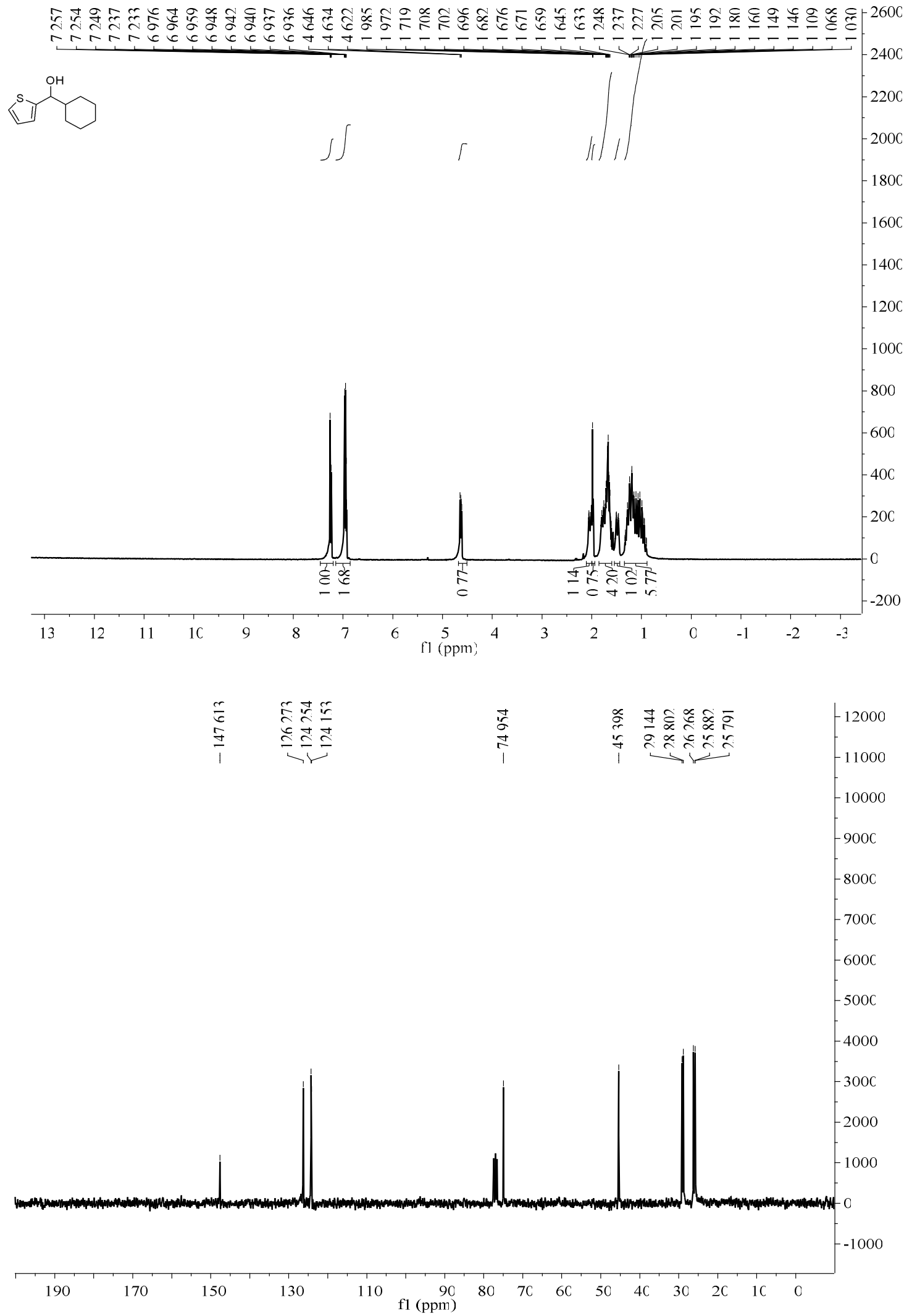




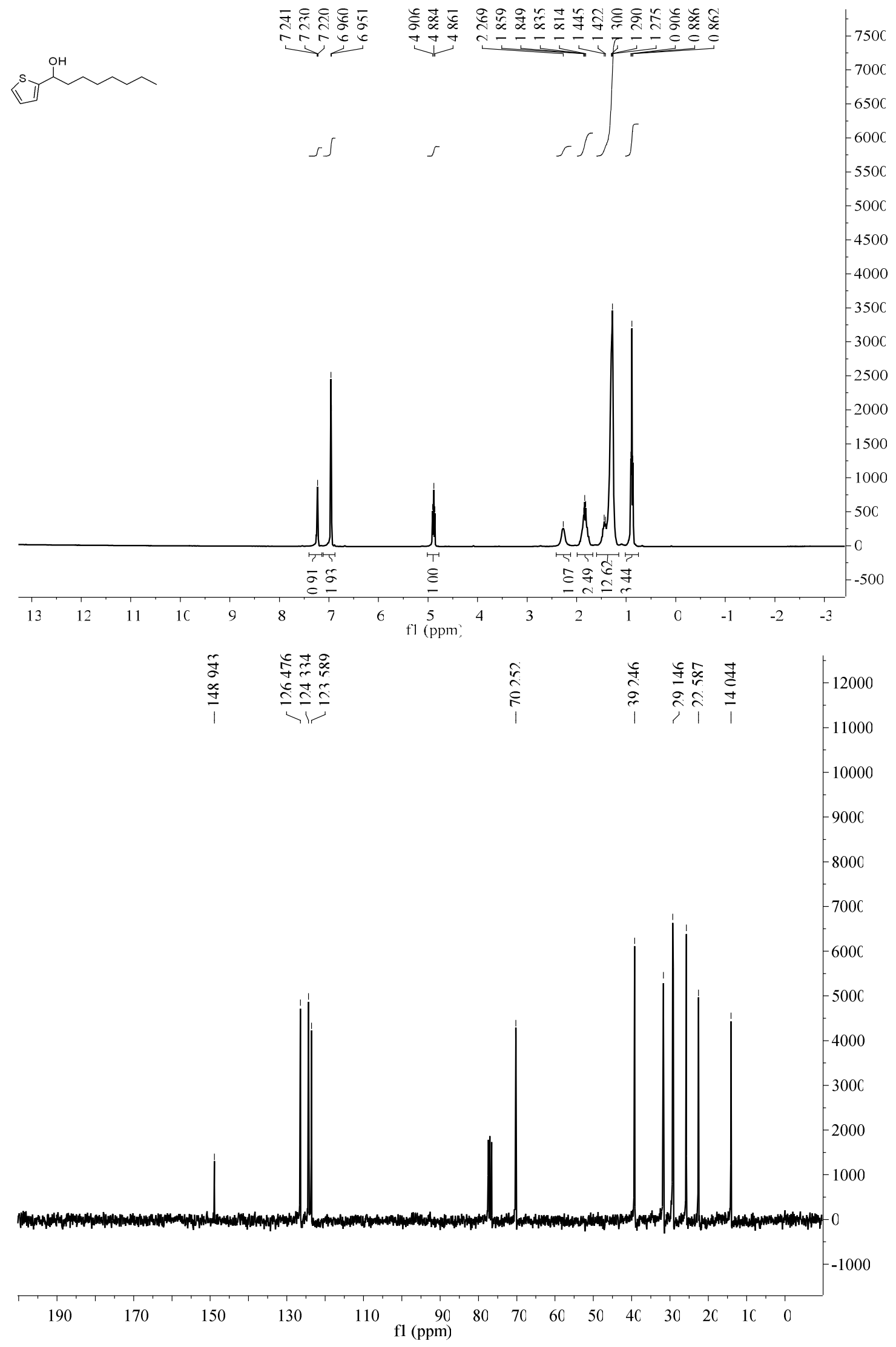




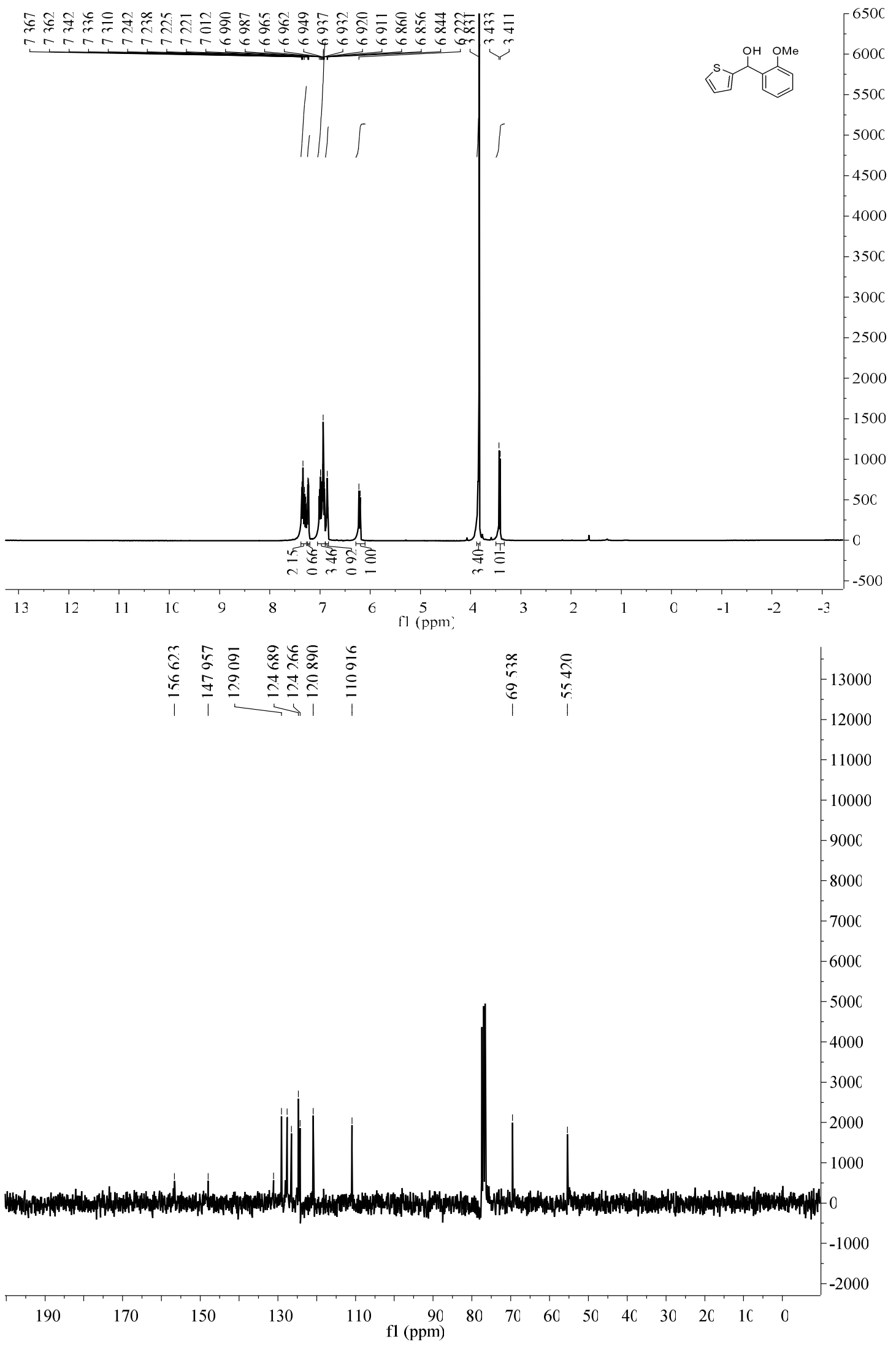




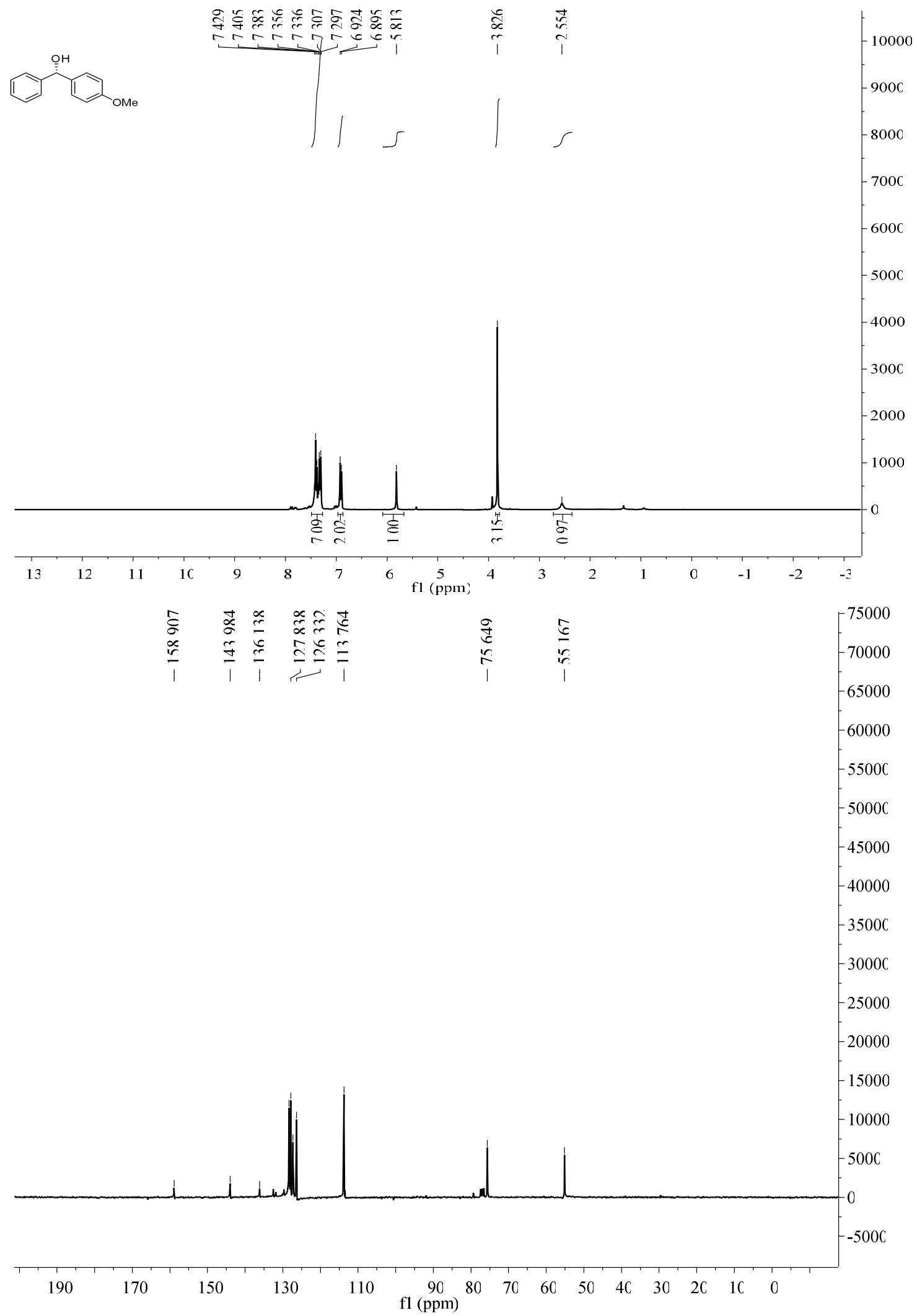




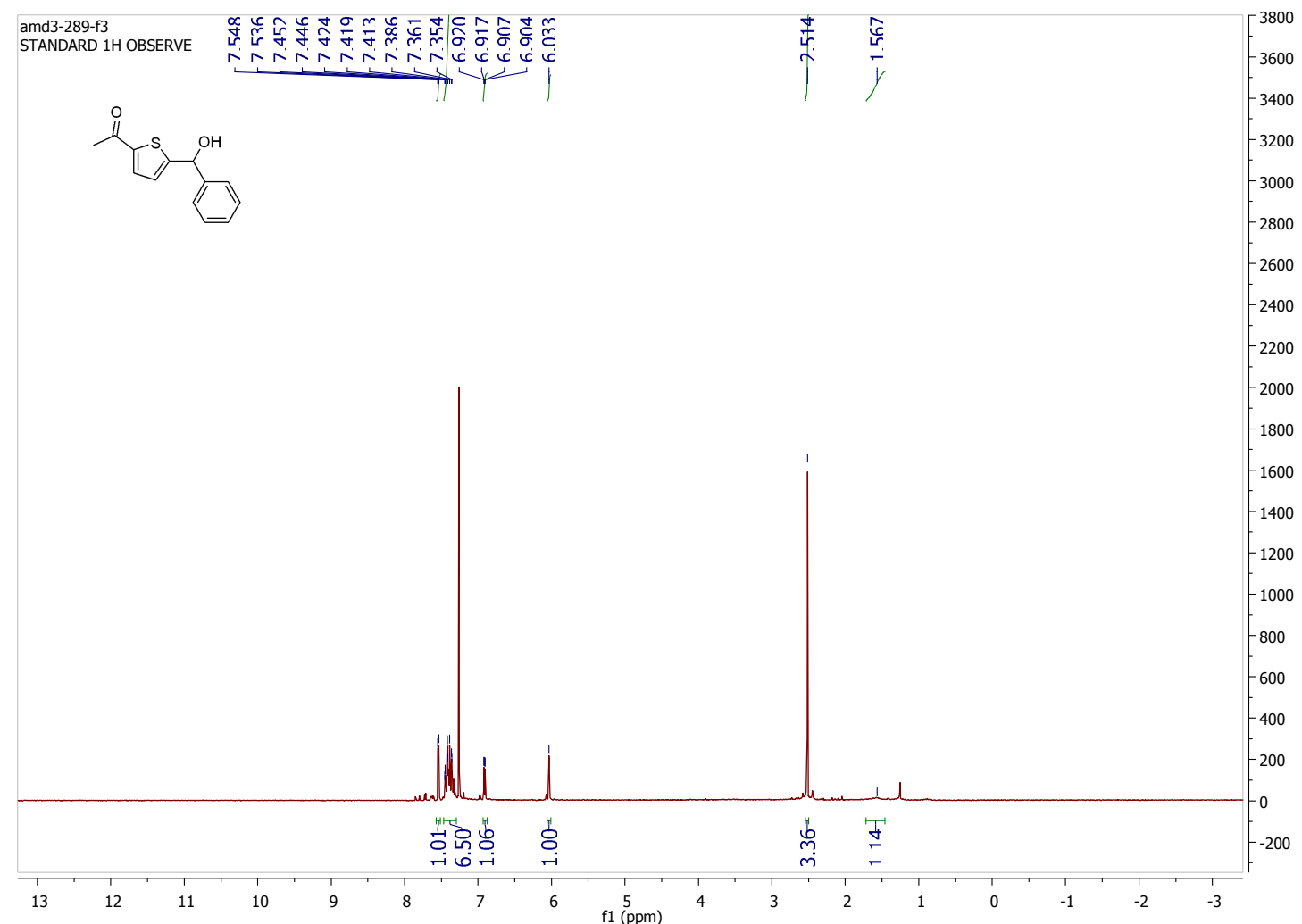

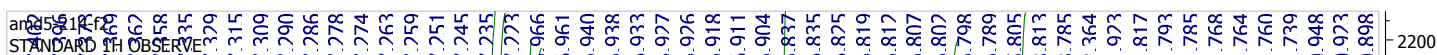

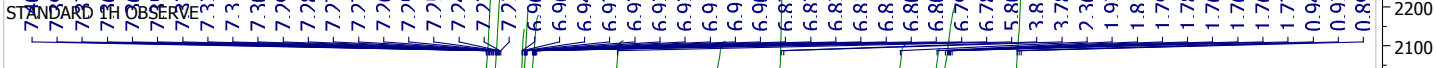
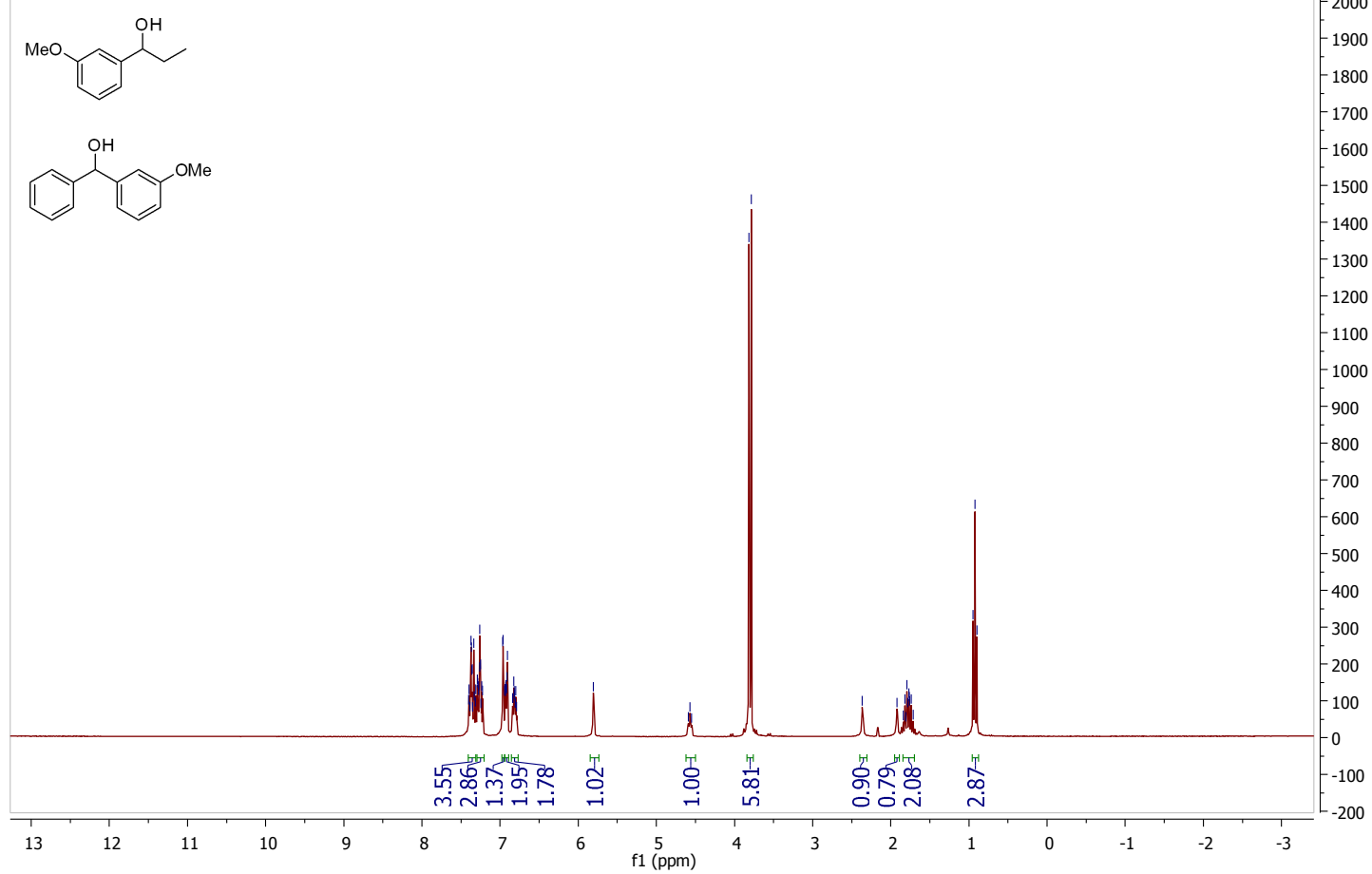


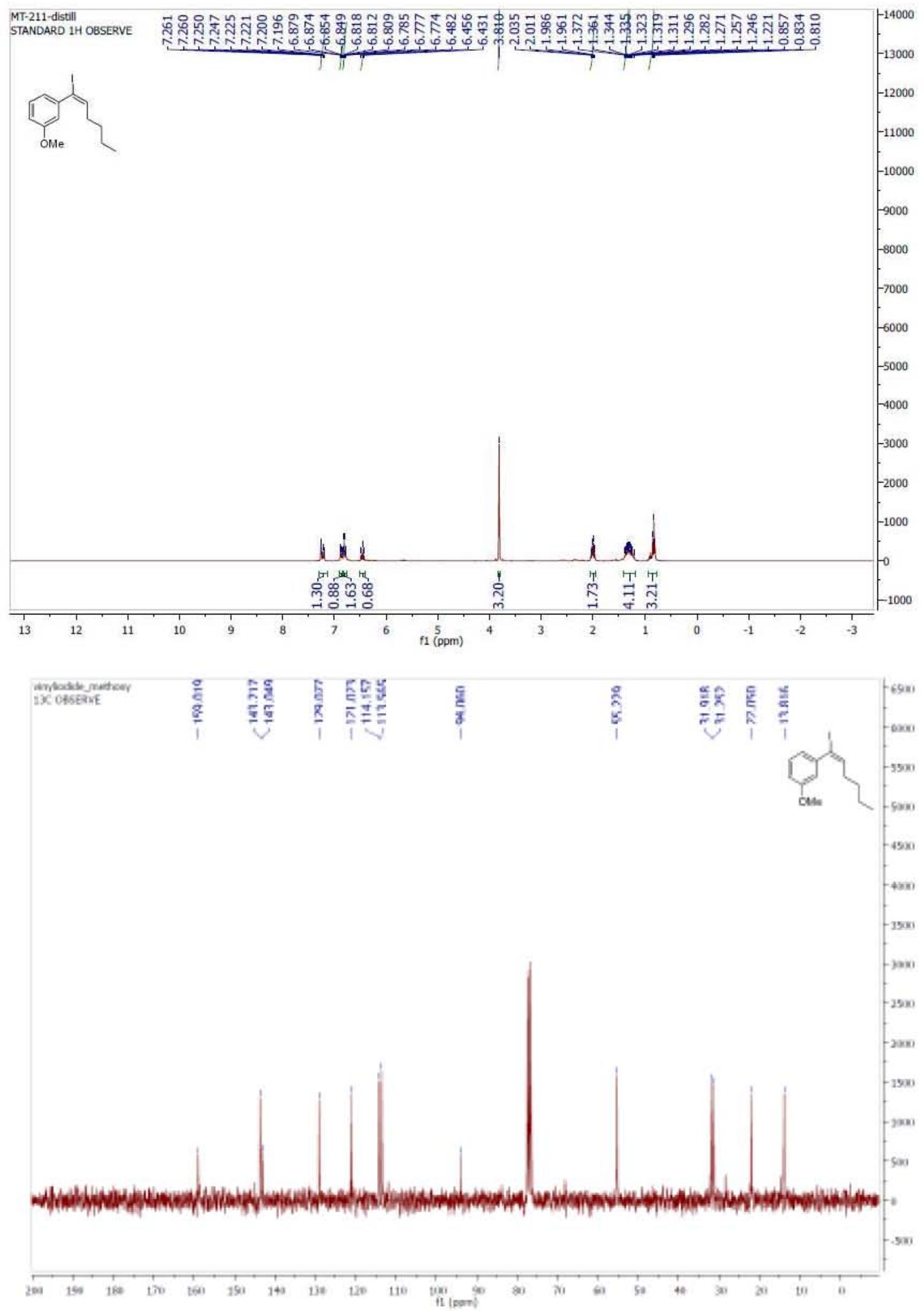




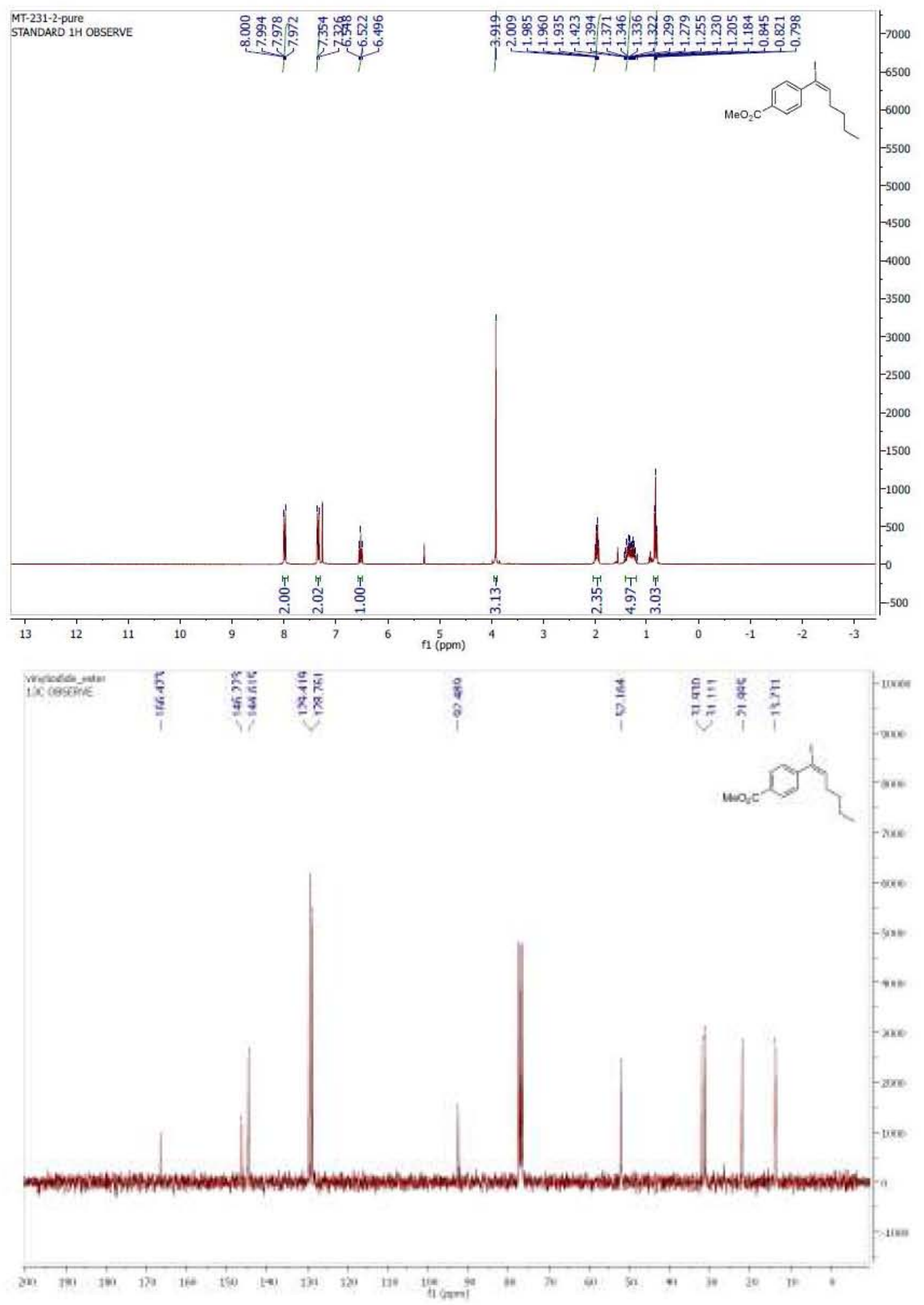




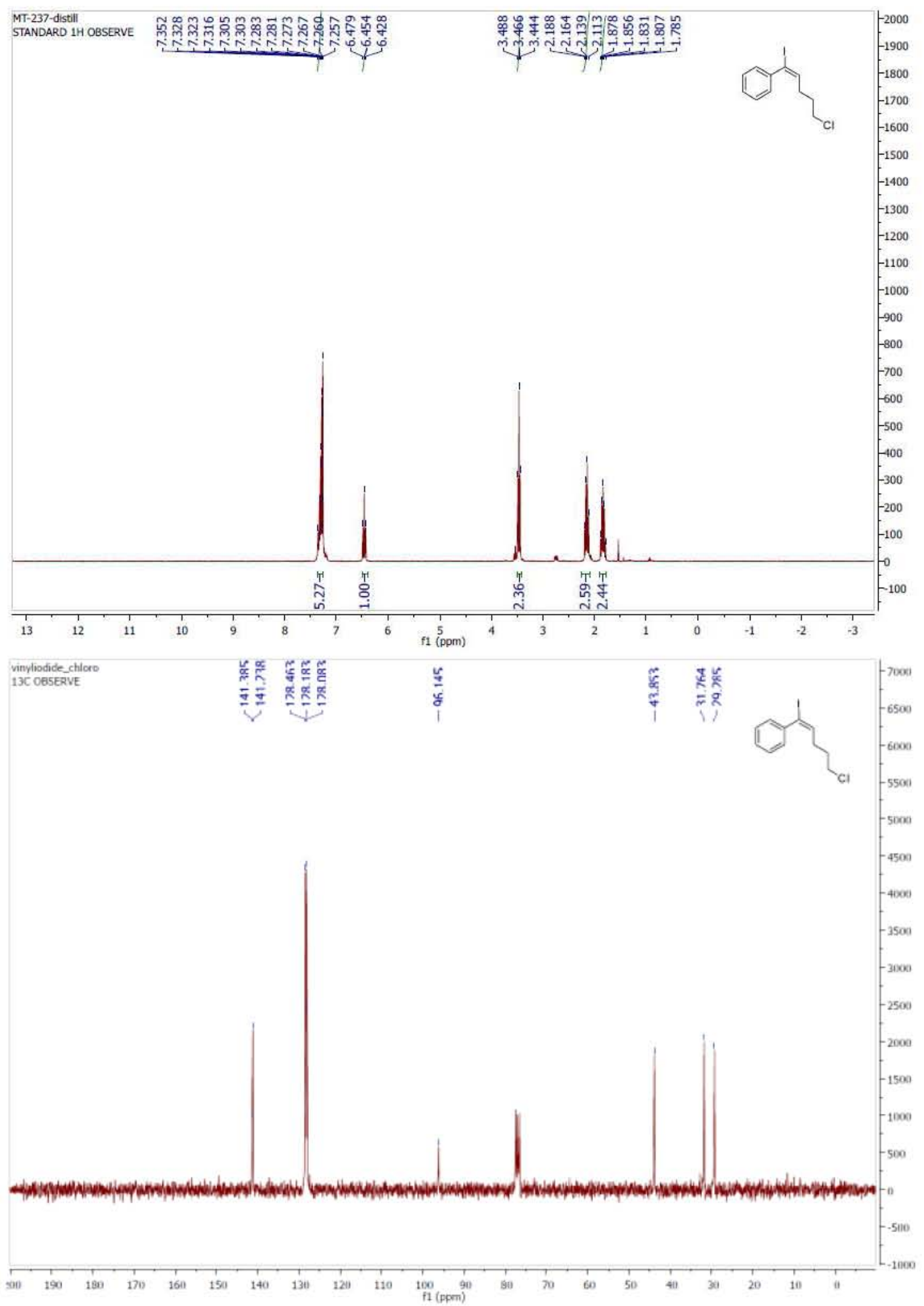




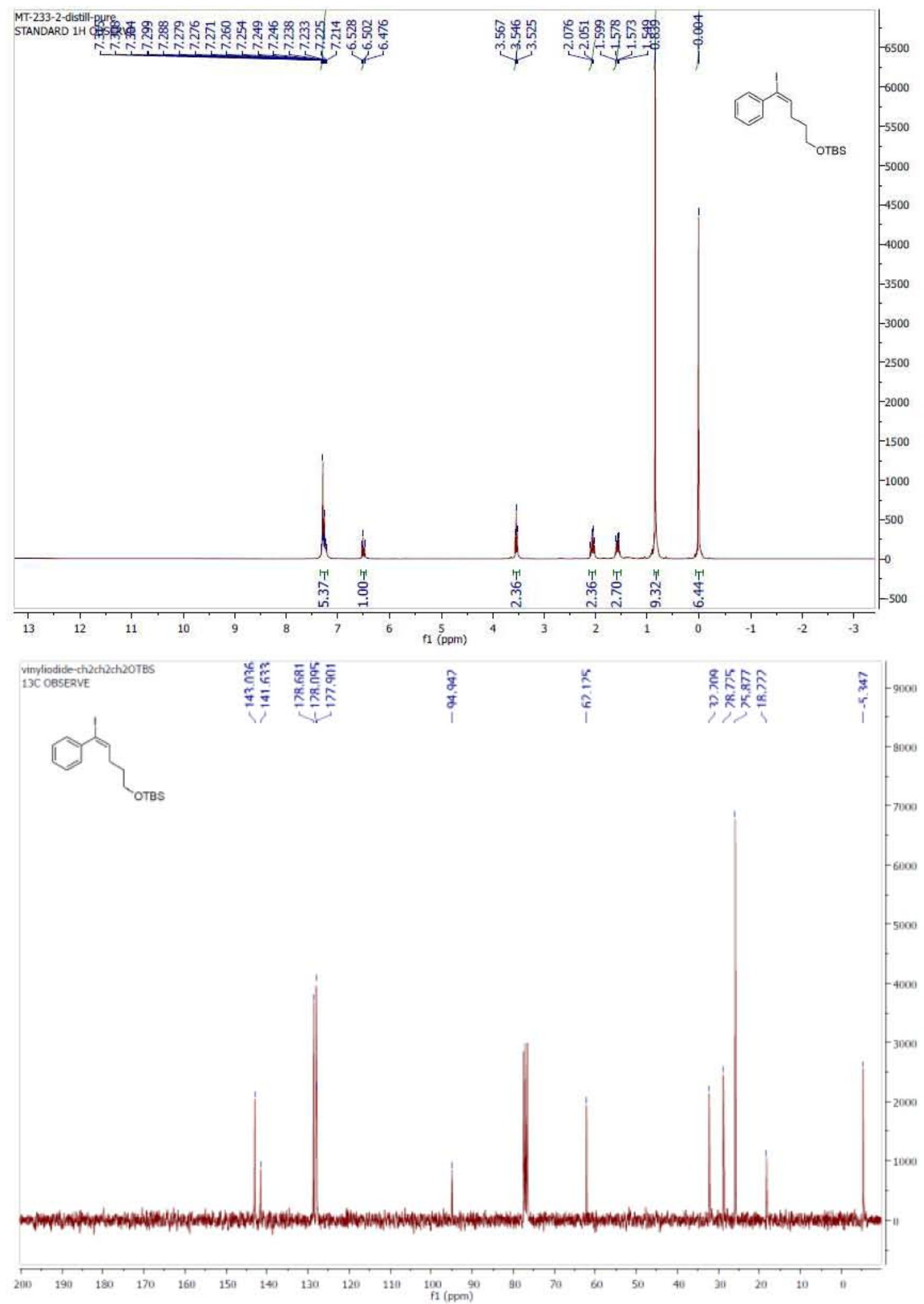




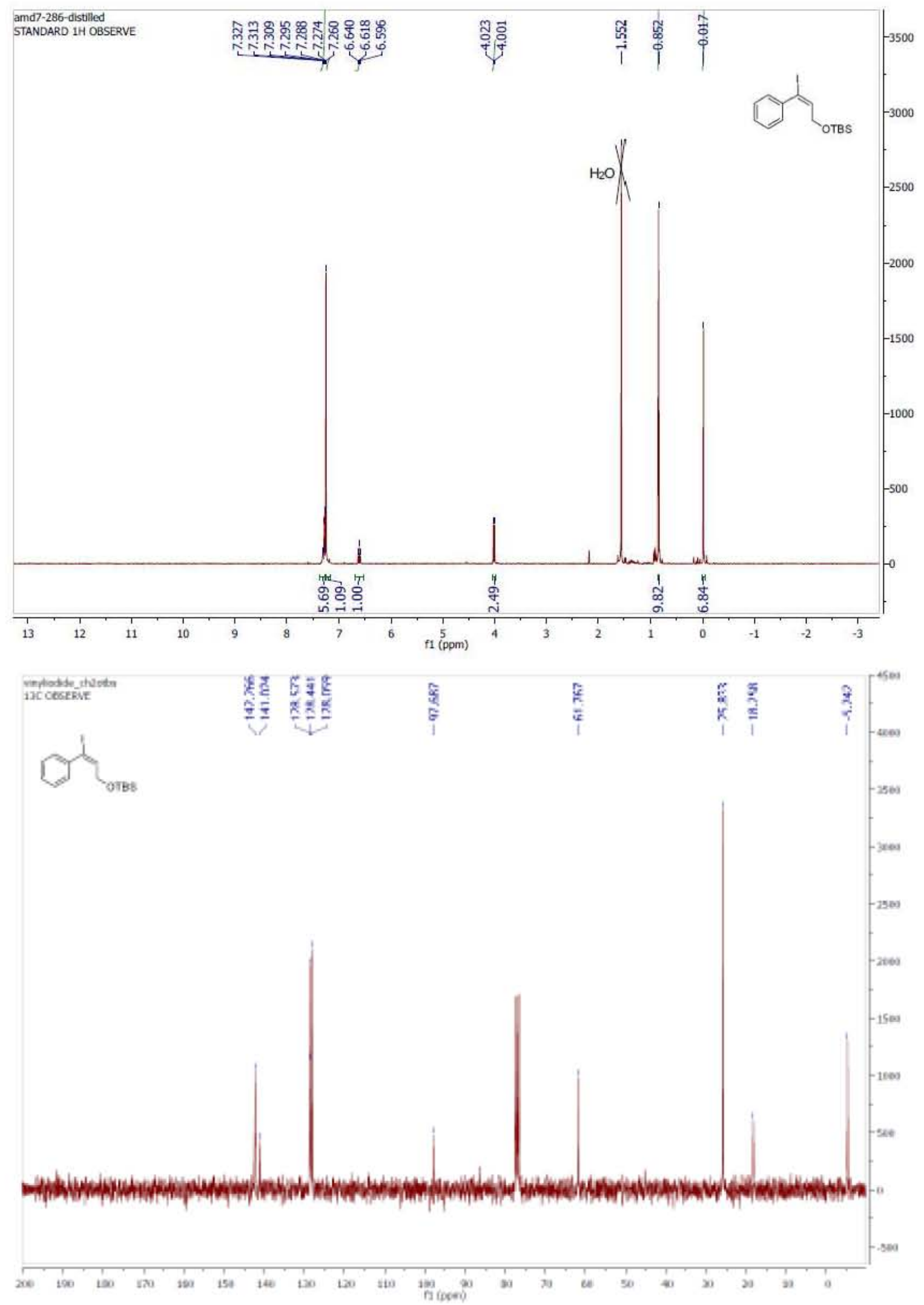




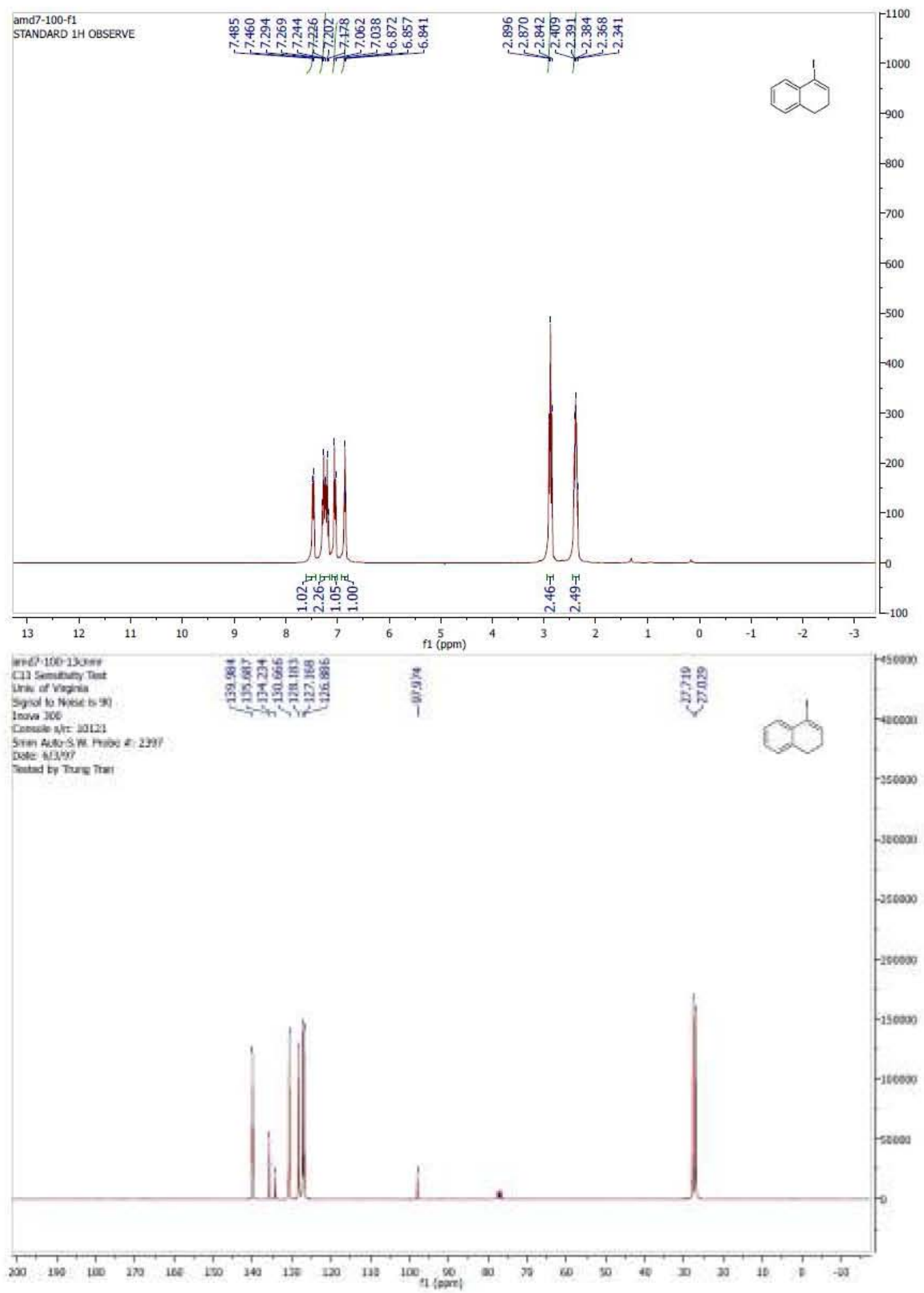




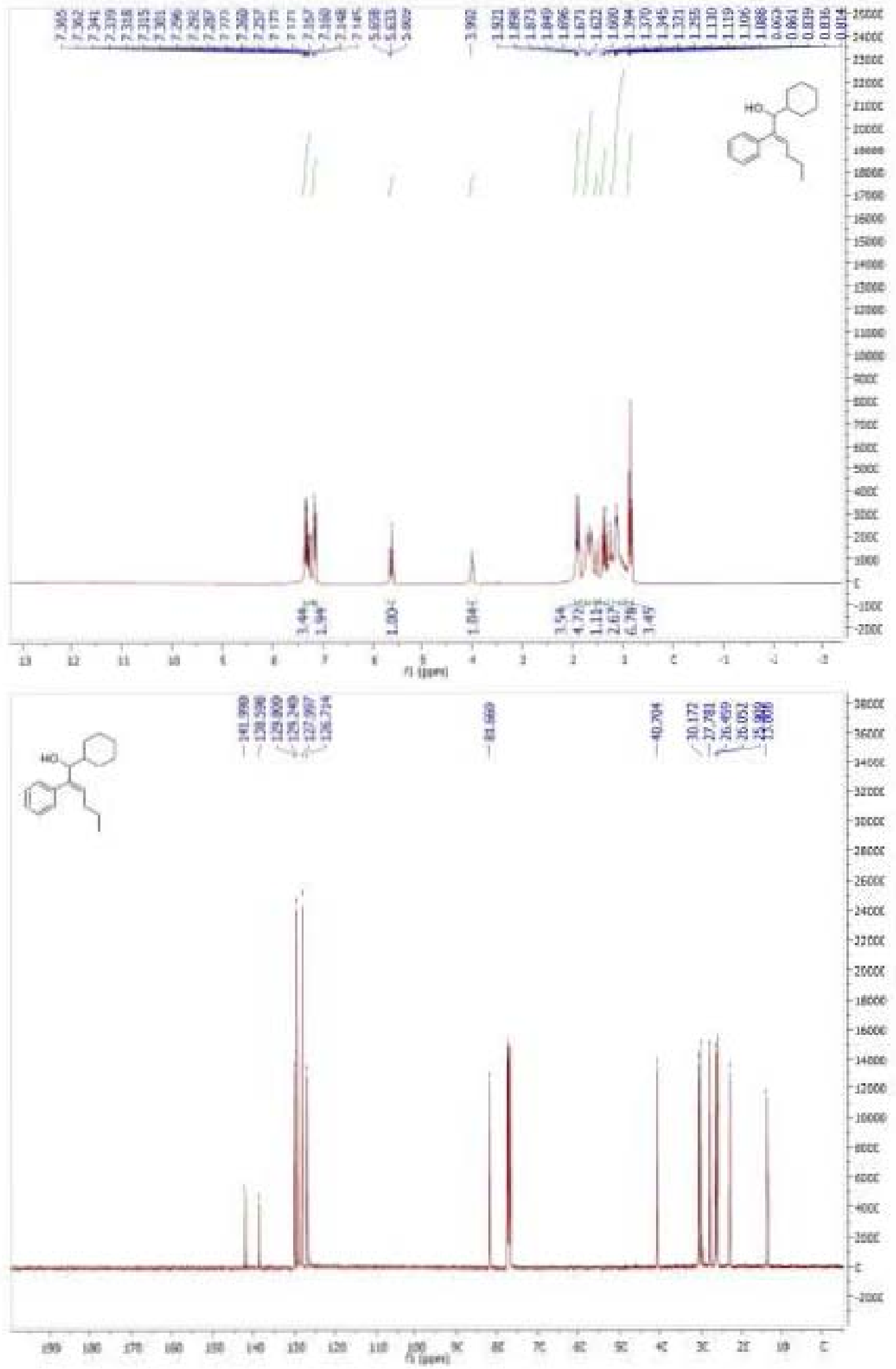




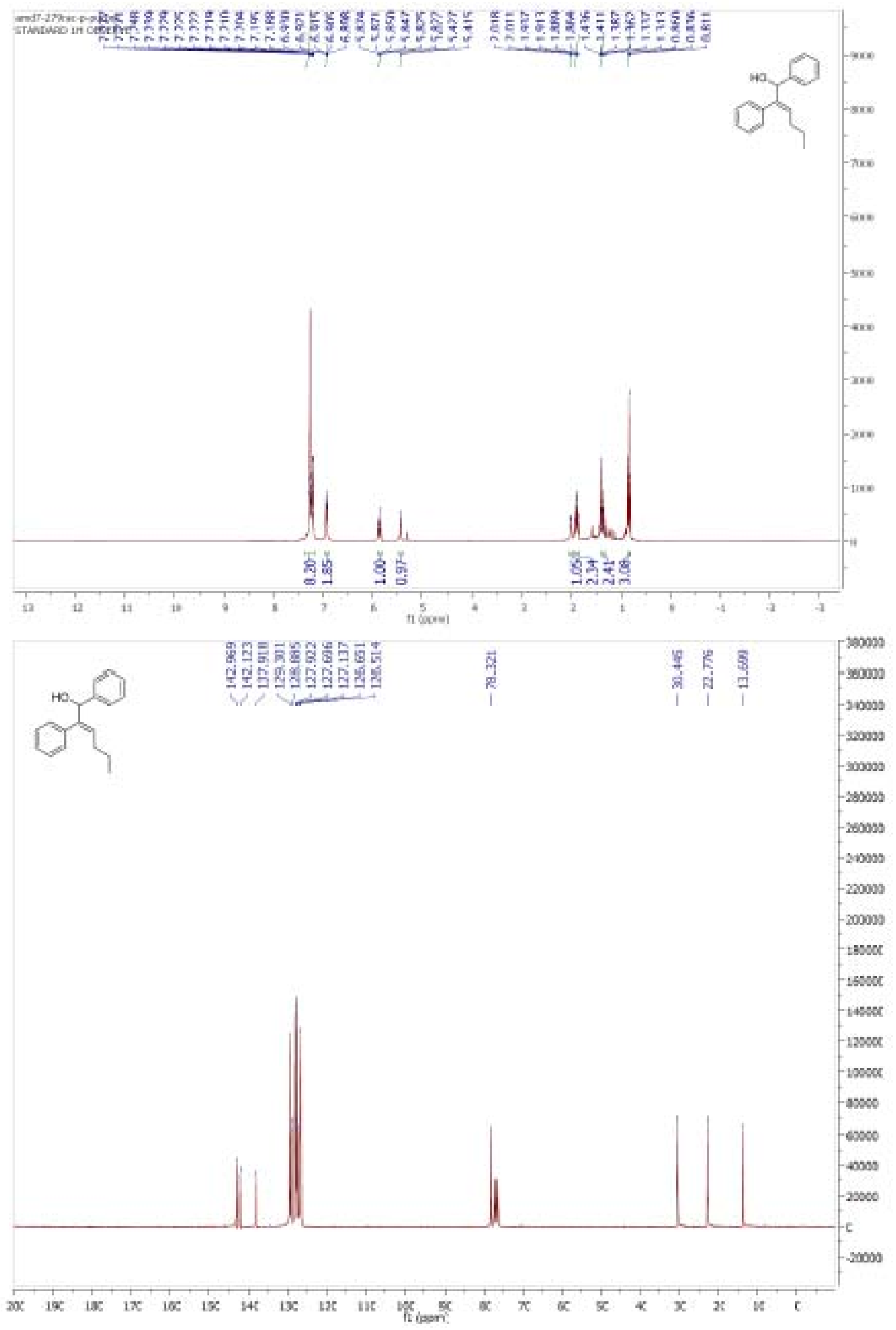




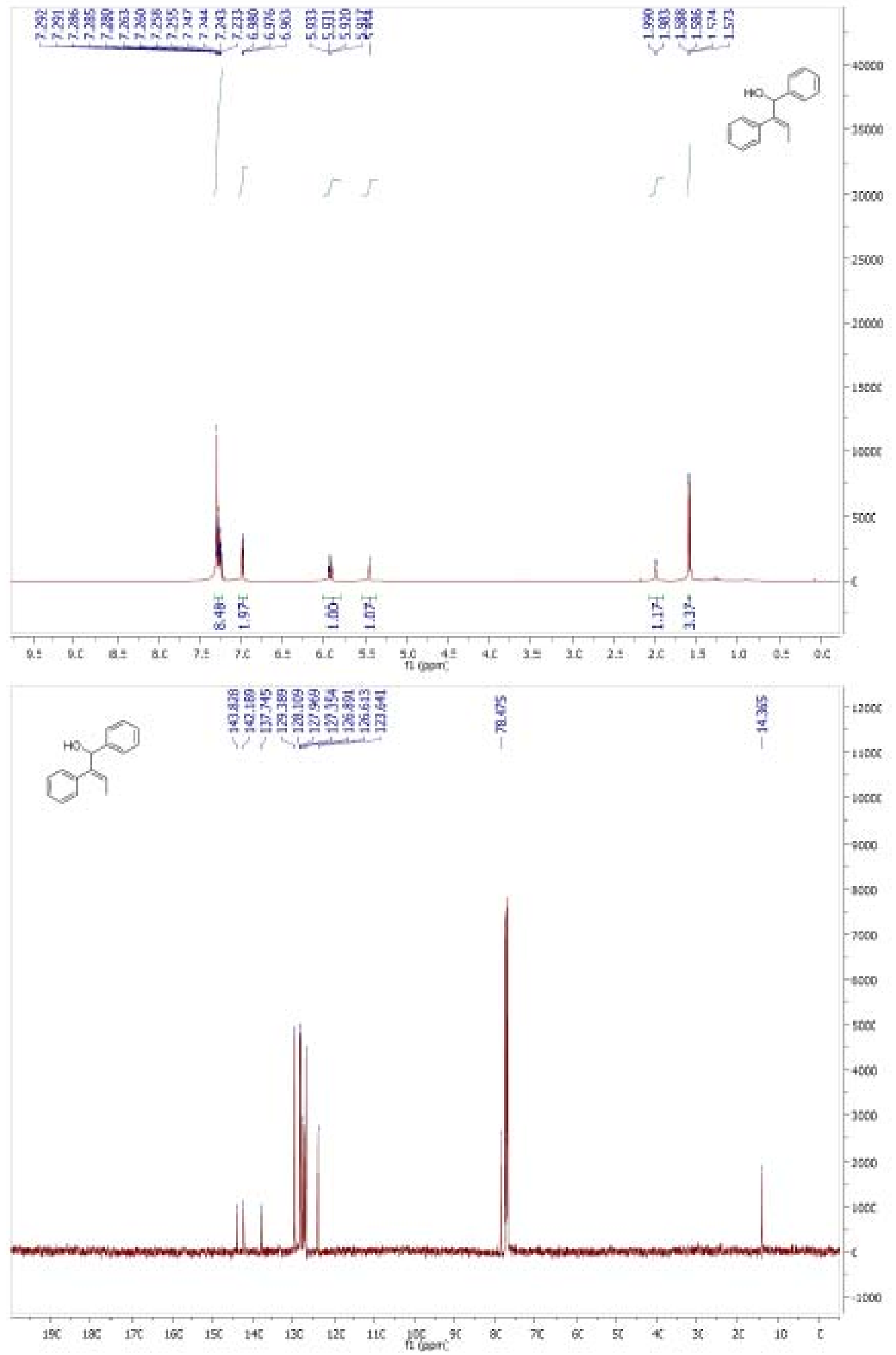


2D (COSY) Spectra of XXX: determination of long-range ${ }^{1} \mathrm{H}-{ }^{1} \mathrm{H}$ spin coupling (chiral allylic proton to vinyl proton and allylic methyl protons)<smiles>CC(C)=C(c1ccccc1)C(O)c1ccccc1</smiles>

Key: $\mathbf{H}_{\mathbf{a}}: 5.45$ ppm, br-s (1H); $\mathbf{H}_{\mathrm{b} \text {-vinyl }}: 5.93$ ppm, dq (1H); $\mathbf{H}_{\mathbf{c}-\mathbf{M e}}$ : $1.58 \mathrm{ppm}, \mathrm{dd}(3 \mathrm{H})$; --O-H: 1.99 ppm, d (1H)

Analysis of the 2D (COSY) spectra shows the following couplings. Long-range couplings: (a) $\mathbf{H}_{\mathbf{a}}-\mathbf{H}_{\mathbf{c}-\mathbf{M e}}(5.43-1.58)$, strong correlation observed; (b) $\mathbf{H}_{\mathbf{a}}-\mathbf{-} \mathbf{H}_{\mathbf{b} \text {-vinyl }}$ (5.925.45), weaker signal observed; "Shorter-"range couplings: (c) $\mathbf{H}_{\mathbf{a}}-\mathrm{O}-\mathbf{H}(5.45-2.01)$; (d) $\mathbf{H}_{\text {b-vinyl }}-\mathbf{H}_{\mathbf{c}-M e}(5.92-1.58)$. 


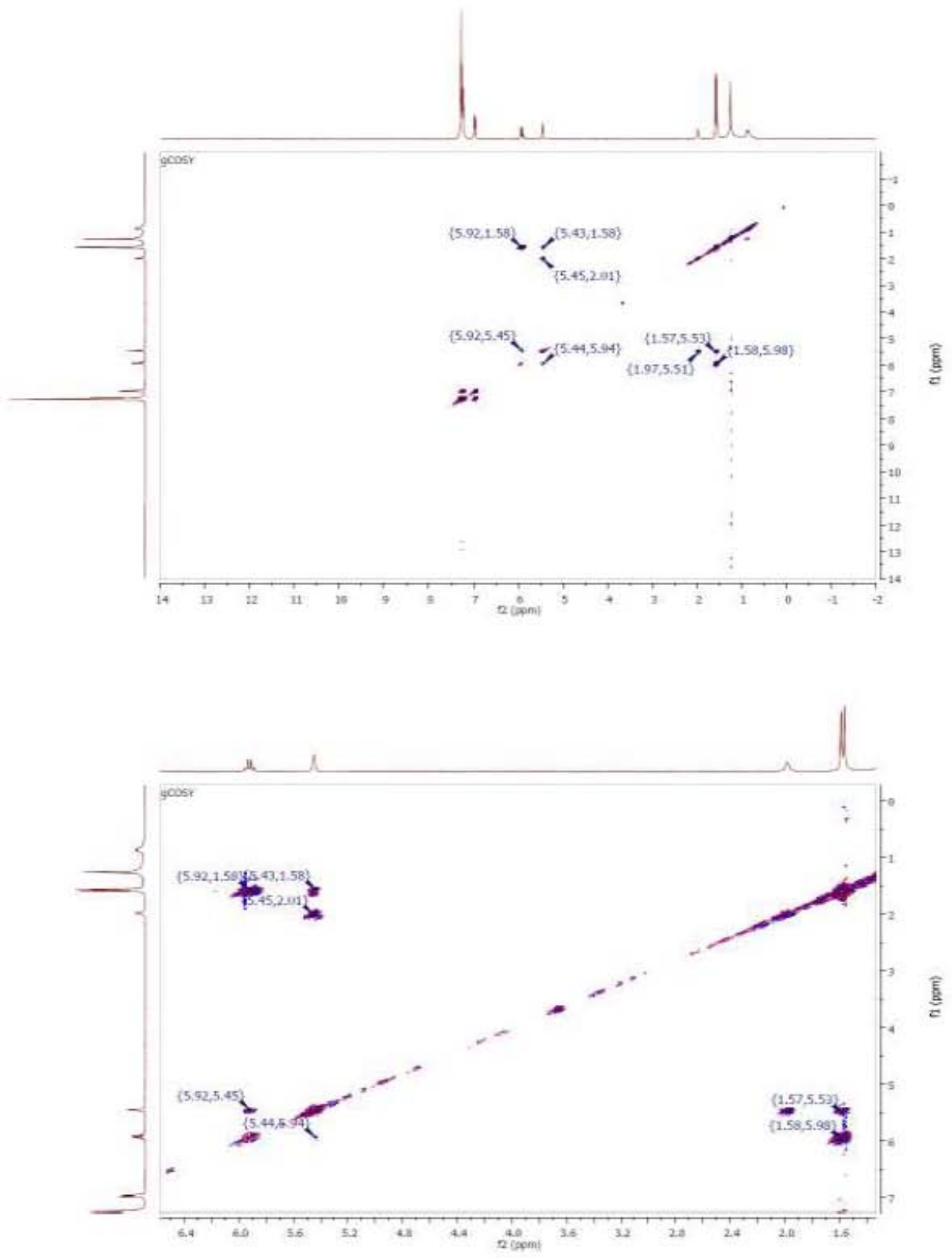




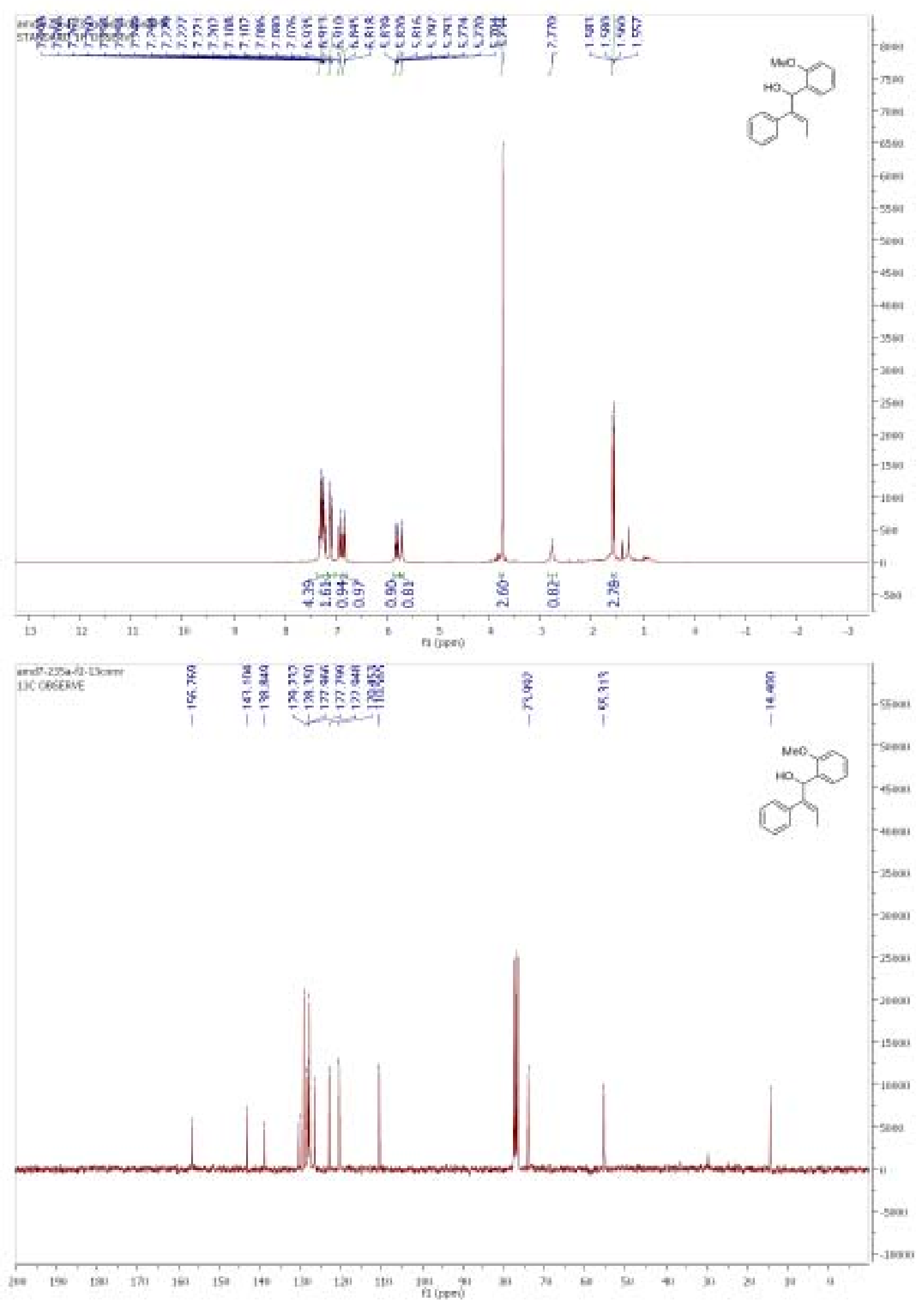




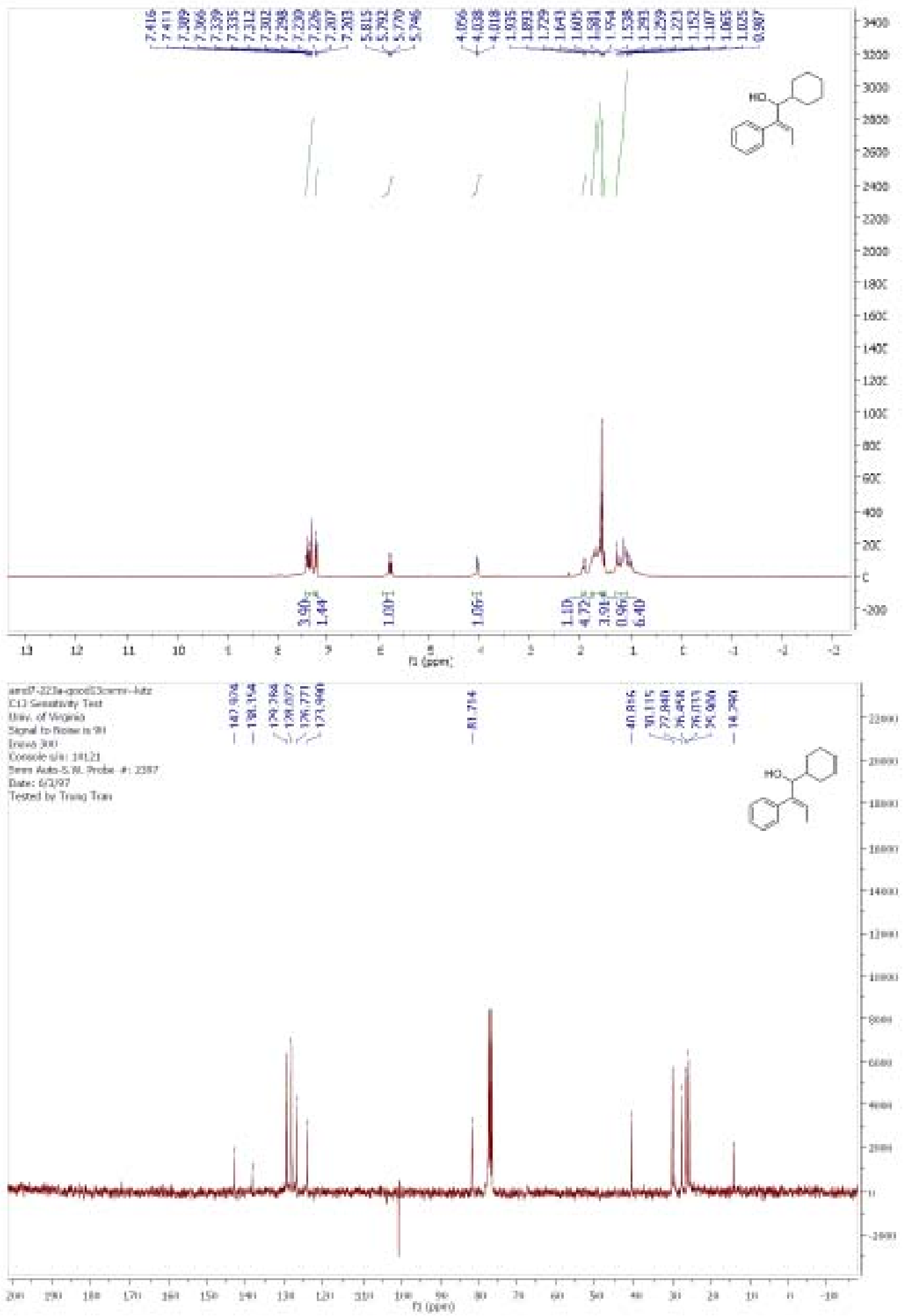



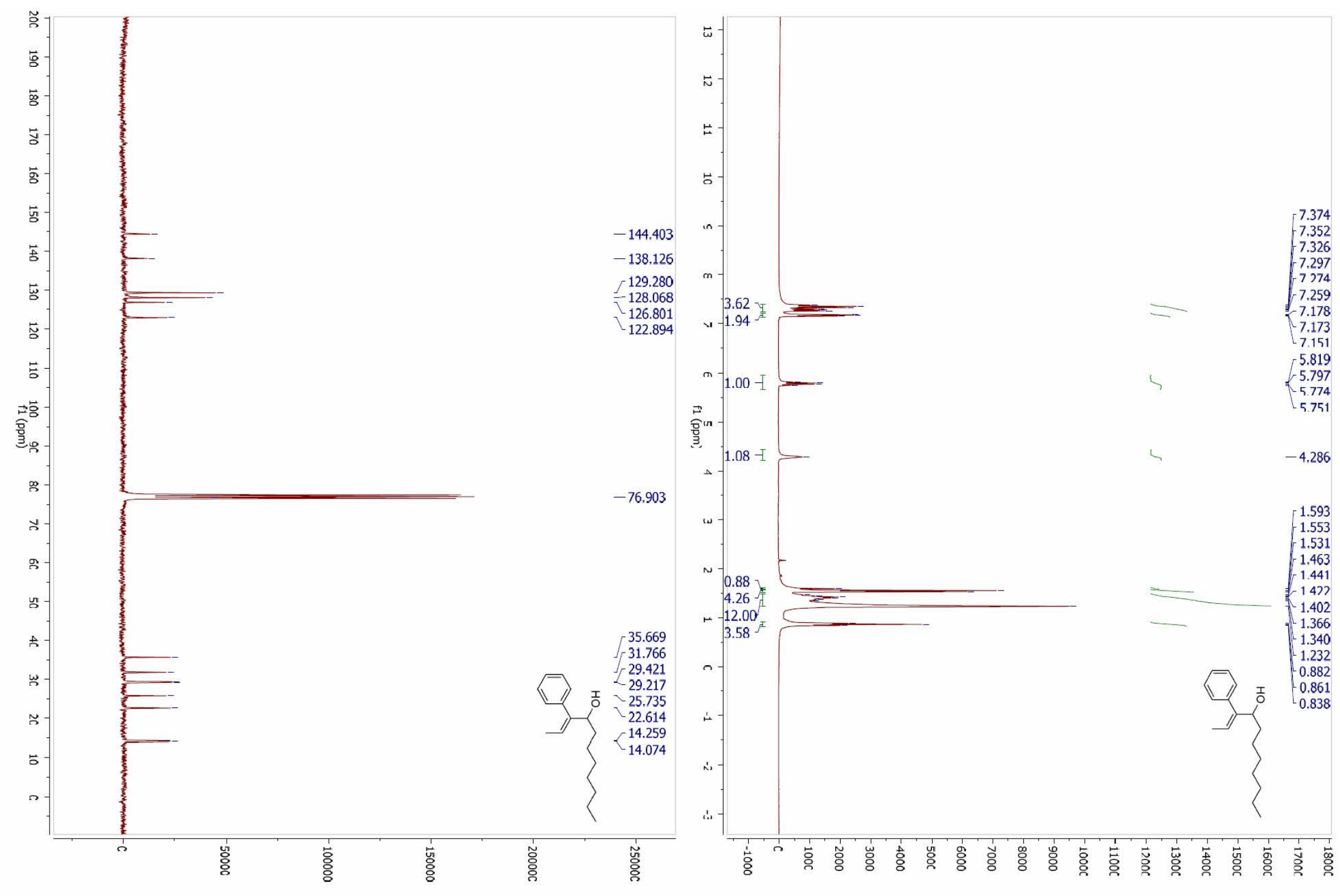


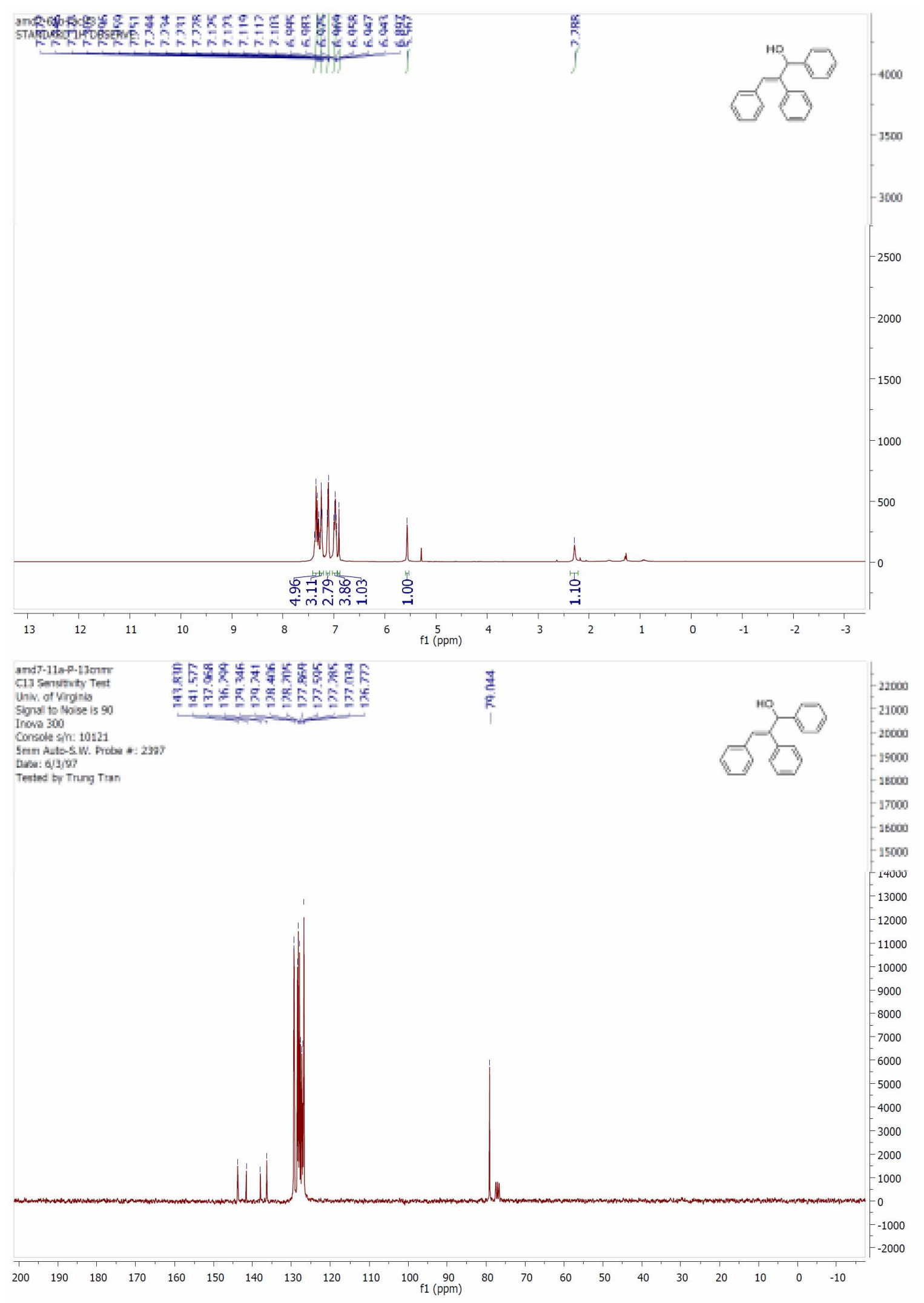




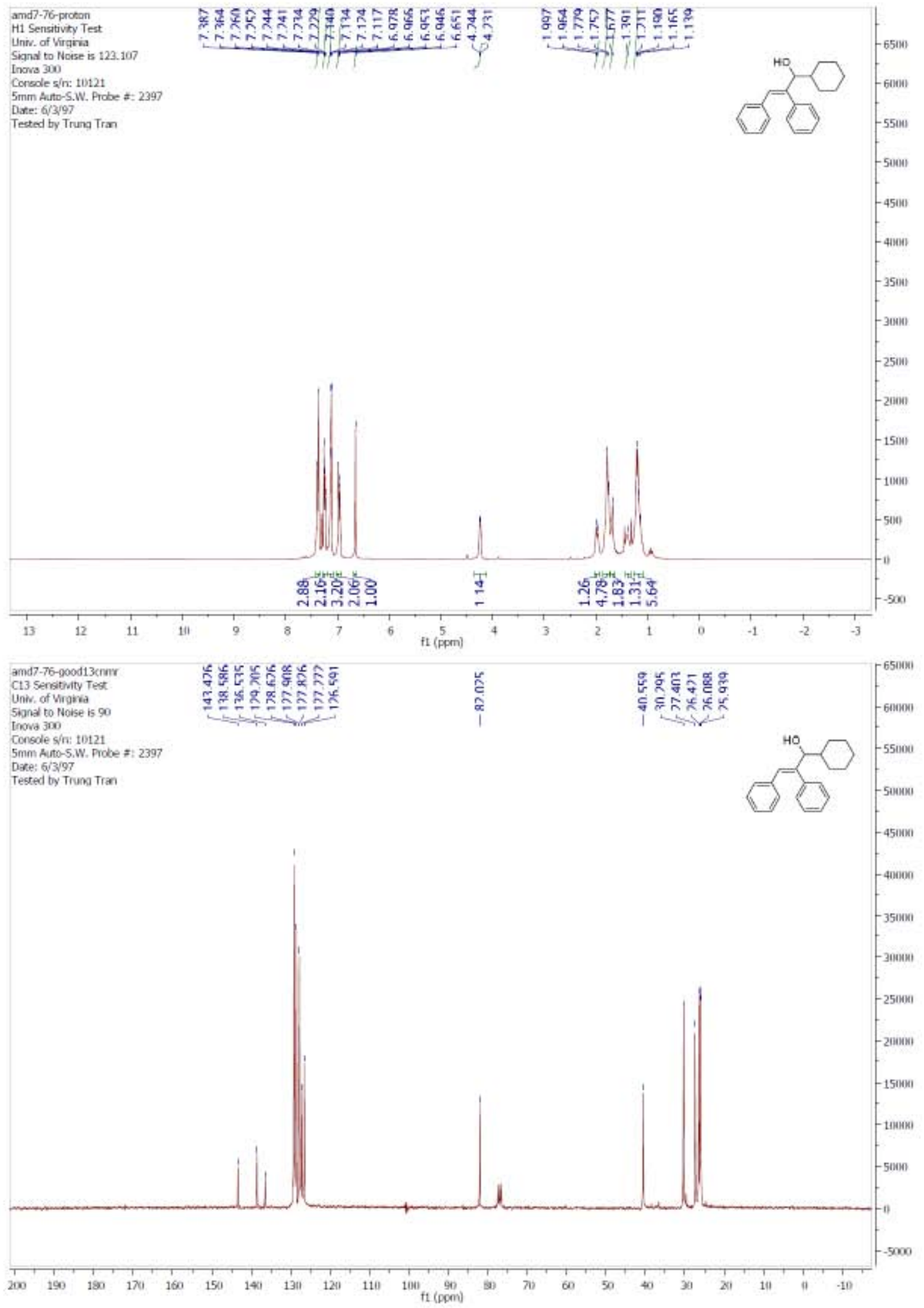




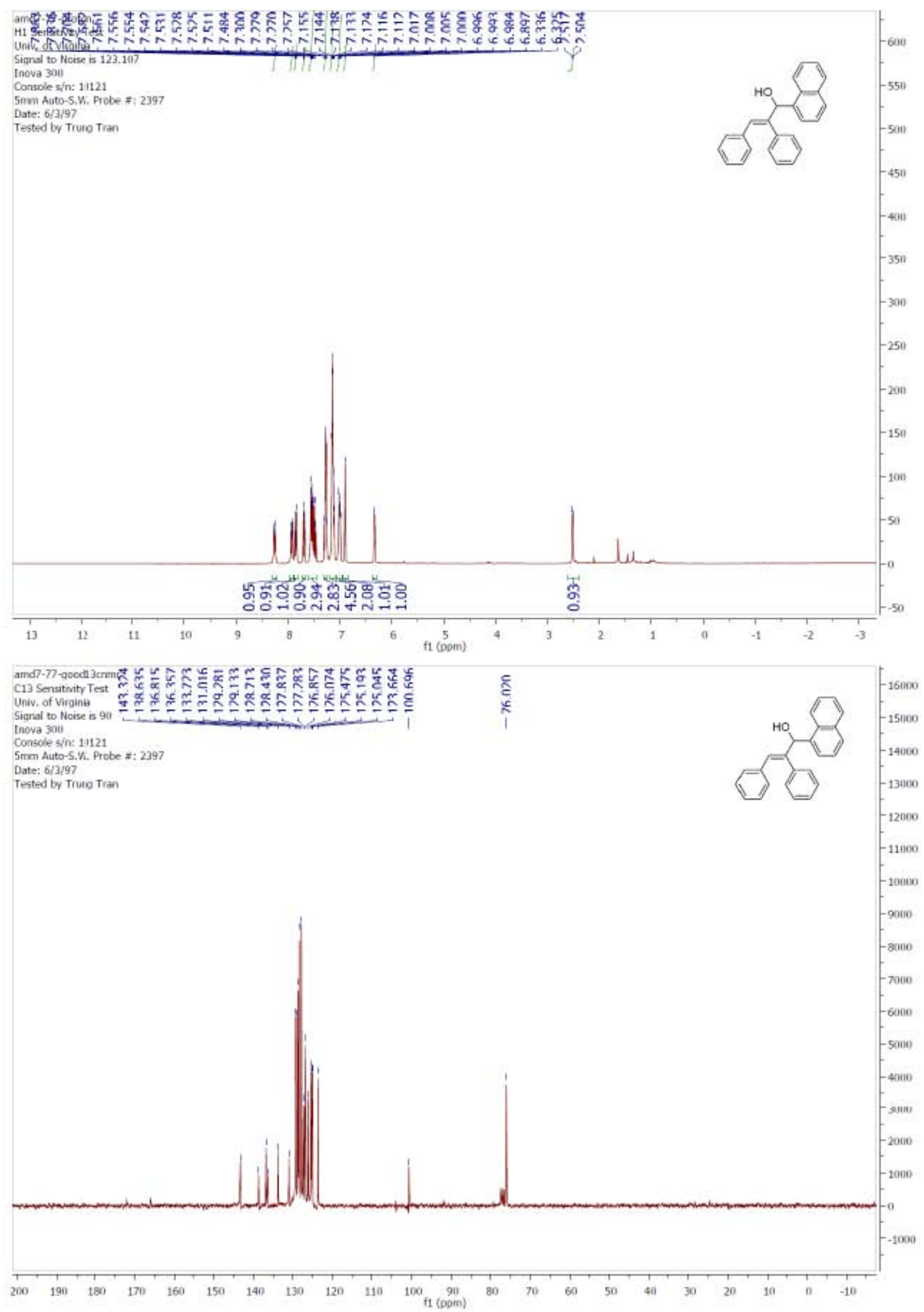




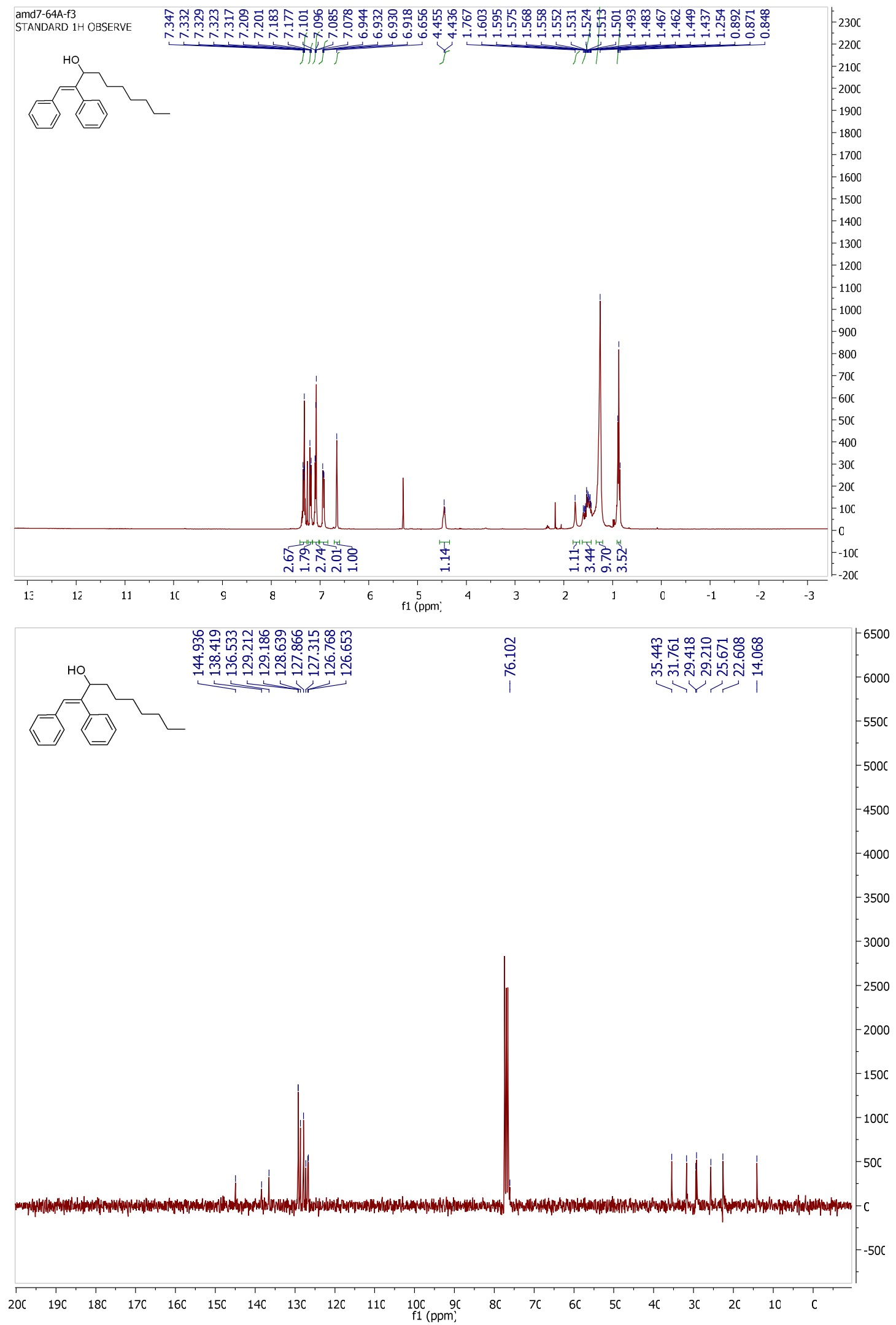




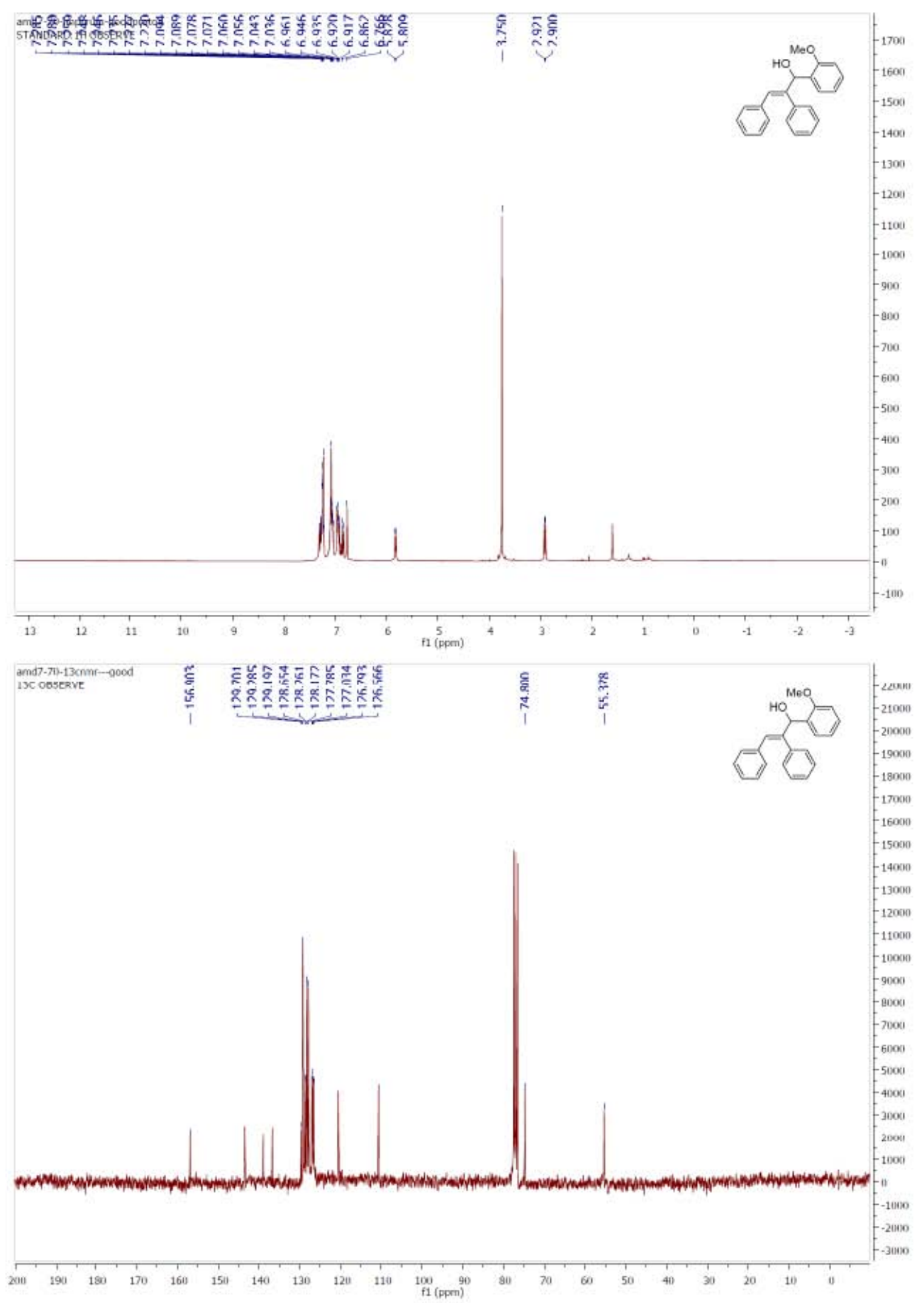




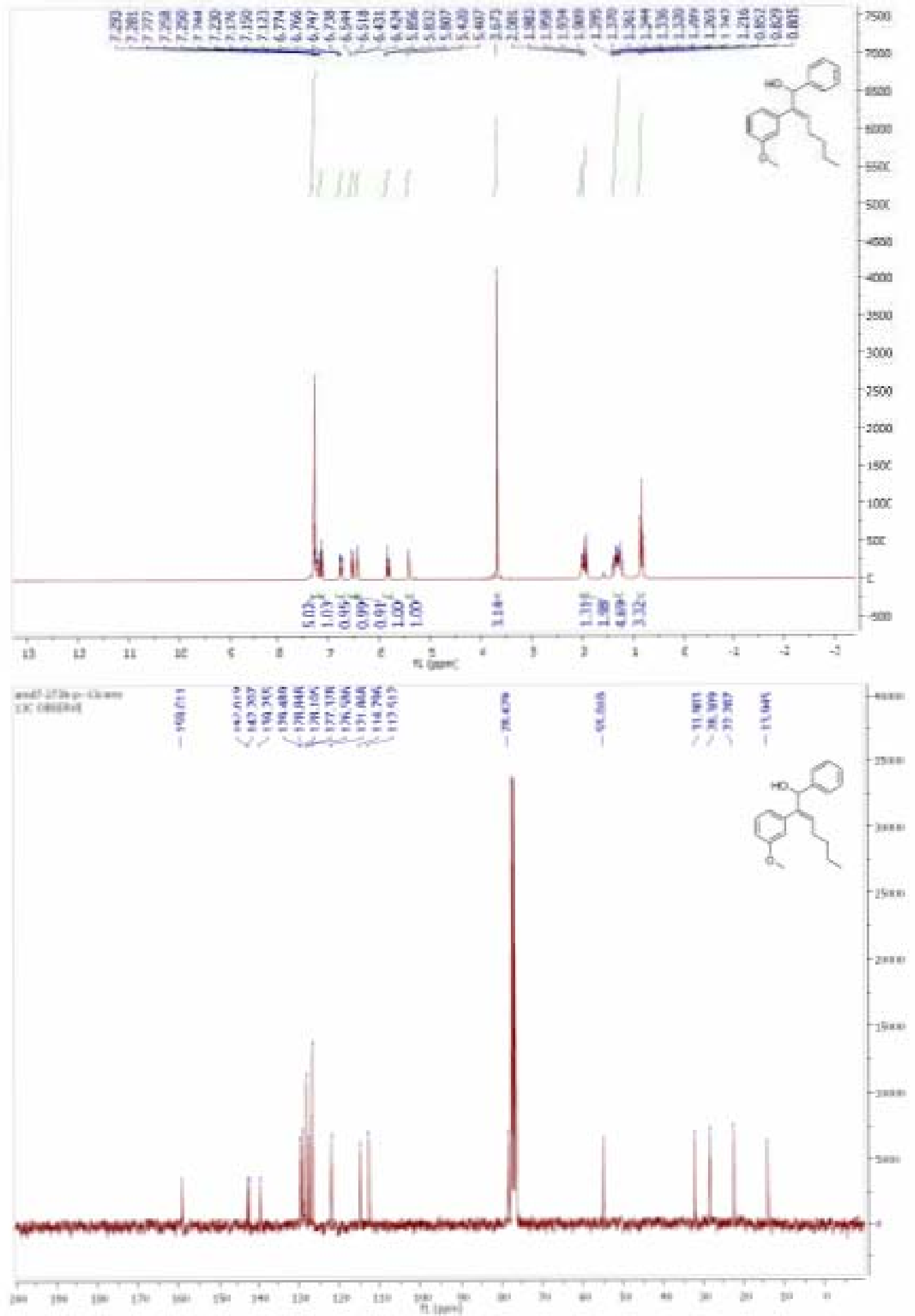




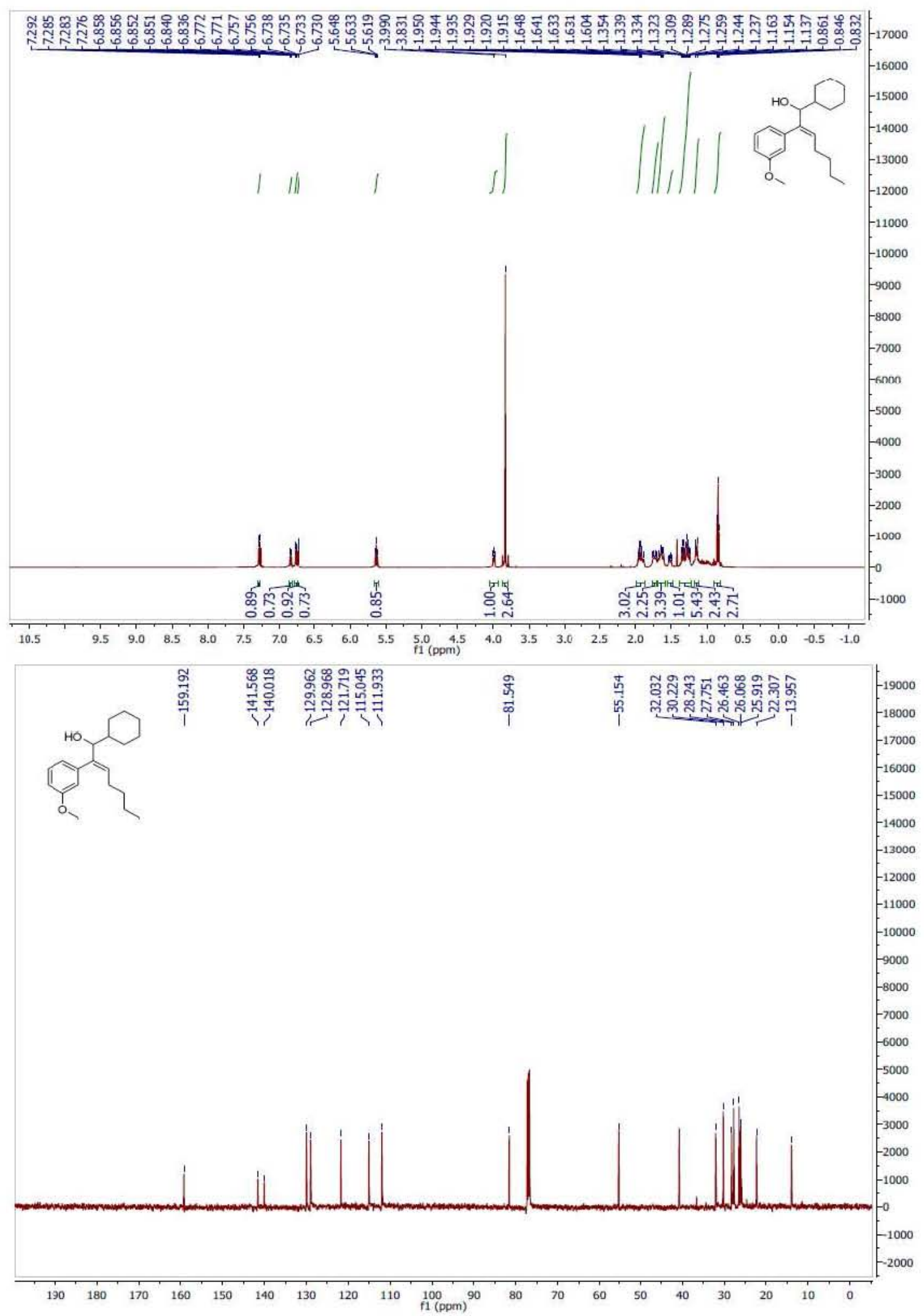




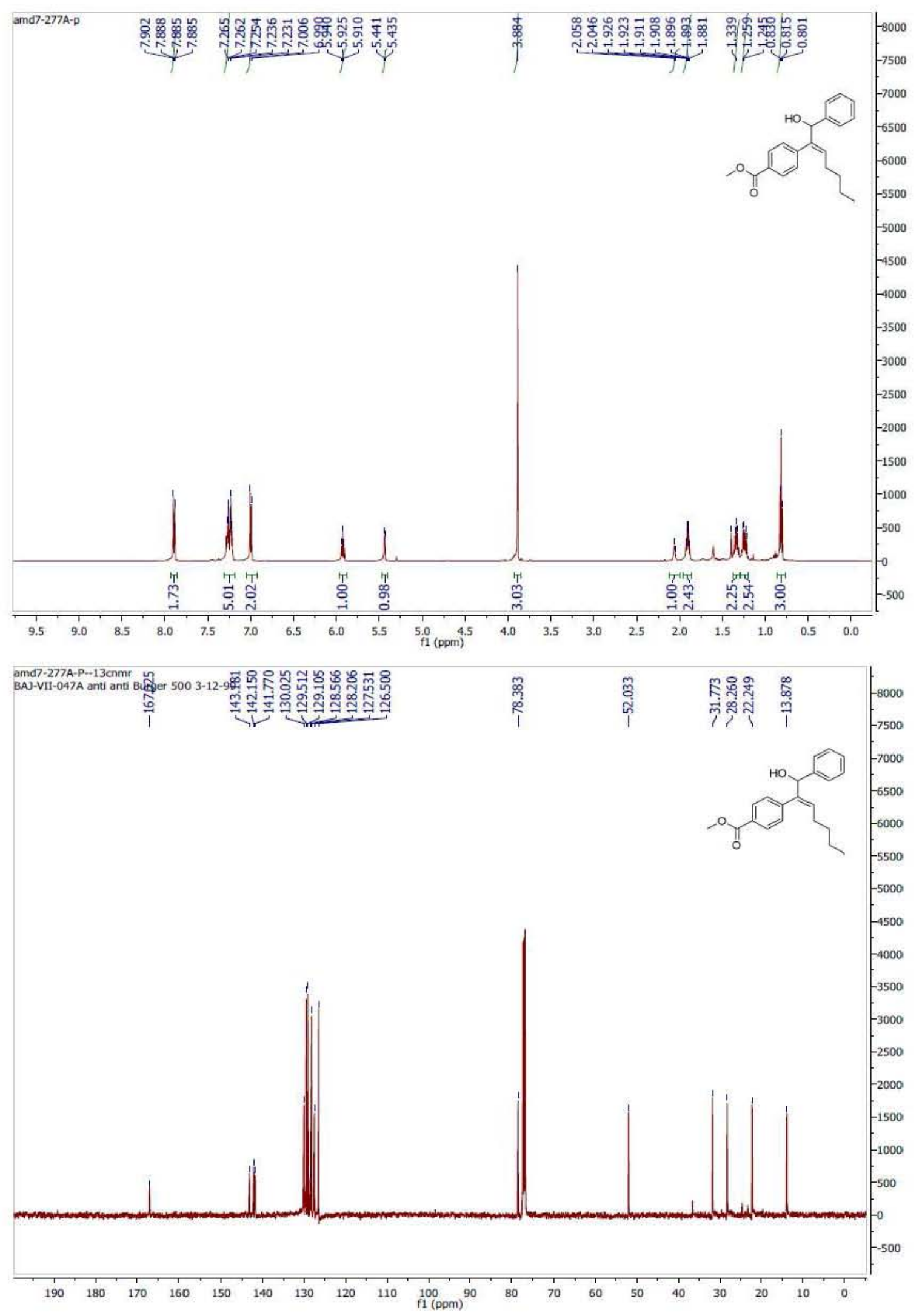




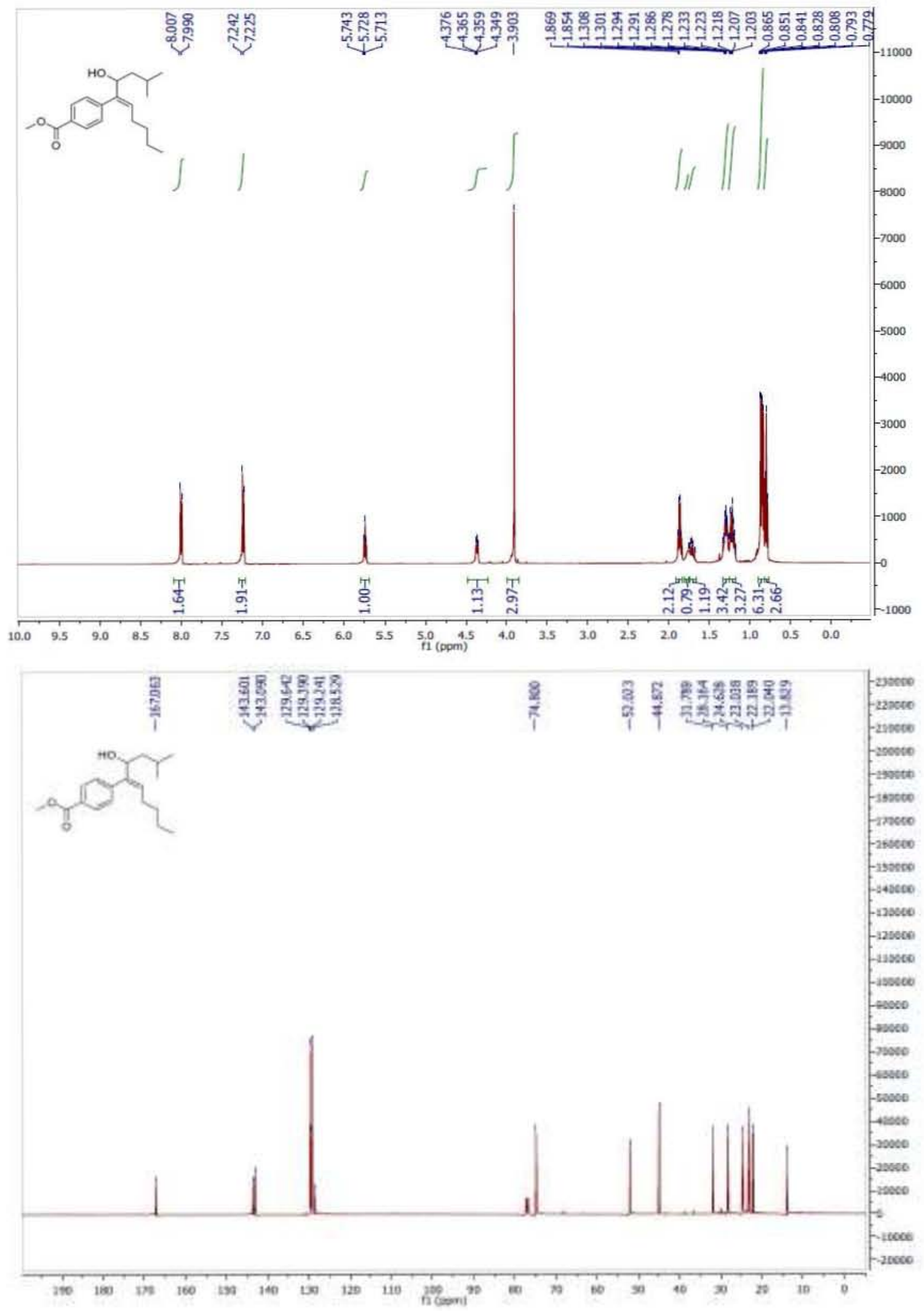


2-D Spectra were collected to determine the stereochemistry of the alkene. The following NOESY and COSY data collected for compound XX established the double bond stereochemistry as shown $(\boldsymbol{E}-)$.

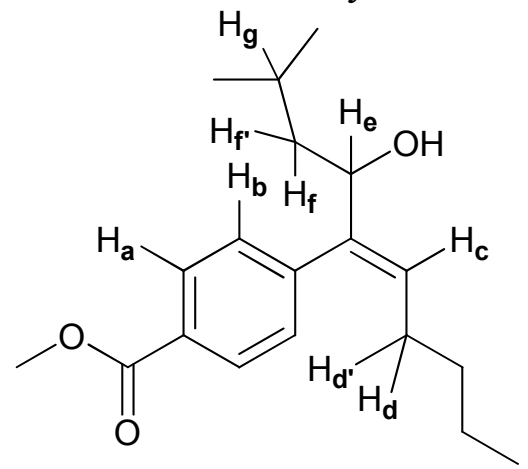

$\mathrm{H}_{\mathrm{a}}: 8.00 ; \mathrm{H}_{\mathrm{b}}: 7.23 ; \mathrm{H}_{\mathrm{c}}: 5.74 ; \mathrm{H}_{\mathrm{d}, \mathrm{d}}: 1.86 ; \mathrm{H}_{\mathrm{e}}: 4.36 ; \mathrm{H}_{\mathrm{f}, \mathrm{f}}: 1.22 ; \mathrm{H}_{\mathrm{g}}: 1.71 \mathrm{ppm}$.

${ }^{1} \mathrm{H}-{ }^{1} \mathrm{H}$ COSY; correlated protons observed (300 MHz): $\mathrm{H}_{\mathrm{a}}-\mathrm{H}_{\mathrm{b}}$ (aromatic protons); $\mathrm{H}_{\mathrm{c}}-$ $\mathrm{H}_{\mathrm{d}}, \mathrm{H}_{\mathrm{d}}$ ' (vinyl to allylic protons); $\mathrm{H}_{\mathrm{e}}-\mathrm{H}_{\mathrm{f}, \mathrm{f}^{\prime}}$ (chiral allylic proton to methylene protons of

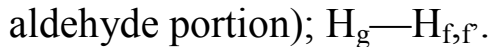

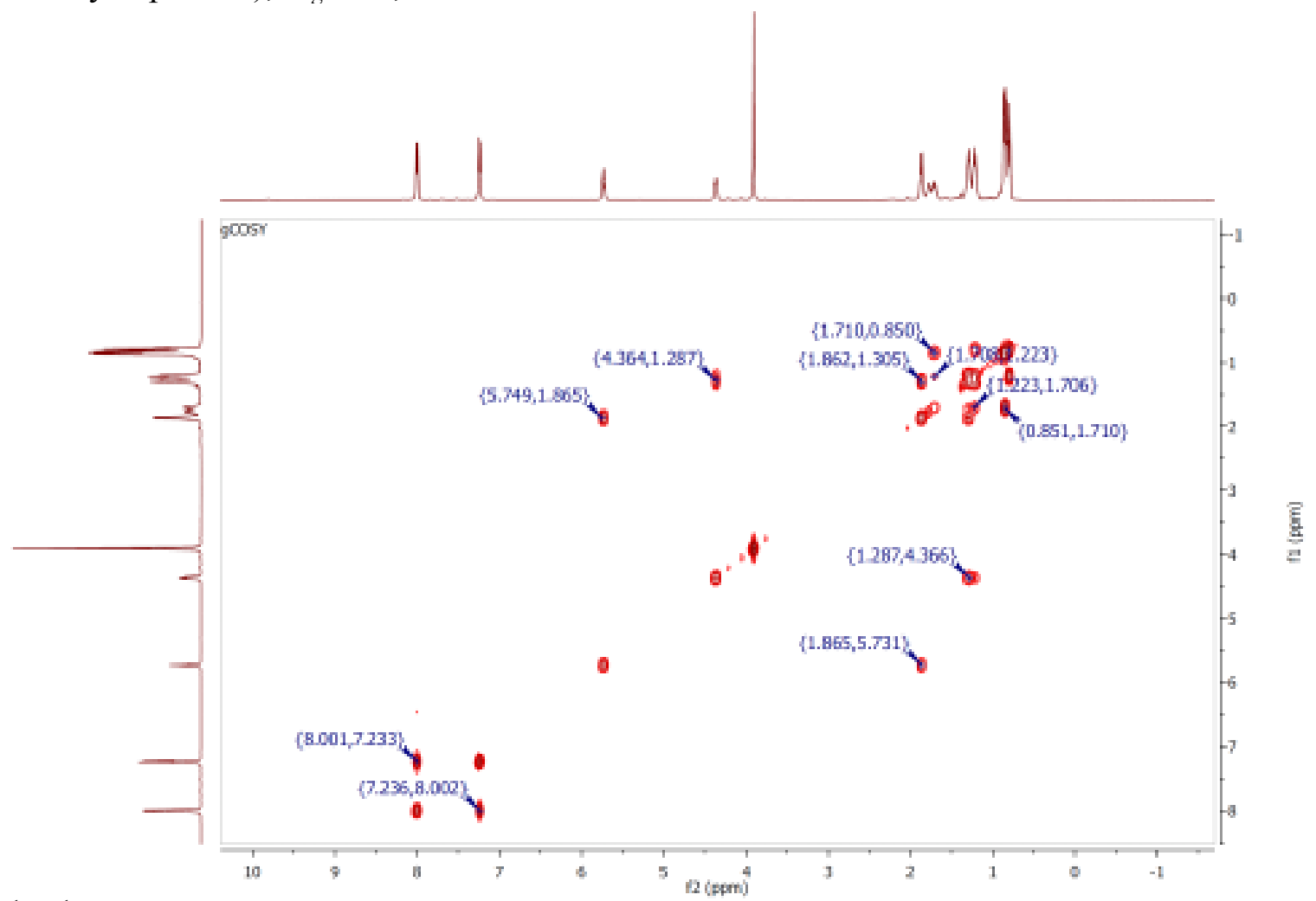

${ }^{1} \mathrm{H}-{ }^{1} \mathrm{H}$ NOESY key interactions (300 MHz): $\mathrm{H}_{\mathrm{a}}-\mathrm{H}_{\mathrm{b}} ; \mathrm{H}_{\mathrm{a}}-\mathrm{H}_{3} \mathrm{C}\left(\right.$ ester) $; \mathrm{H}_{\mathrm{b}}-\mathrm{H}_{\mathrm{e}} ; \mathrm{H}_{\mathrm{b}}-$ $\mathrm{H}_{\mathrm{d}, \mathrm{d}} ; \mathrm{H}_{\mathrm{b}}-\mathrm{H}_{\mathrm{f}, \mathrm{f}}$ [NOTE: no $\mathrm{H}_{\mathrm{b}}-\mathrm{H}_{\mathrm{c}}$ interaction is observed]; $\mathrm{H}_{\mathrm{c}}-\mathrm{H}_{\mathrm{e}}$ [nOe interaction

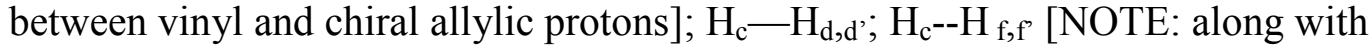
methylene protons of aldehyde portion are remaining methylenes (other than allylic) on original vinyl iodide; these appear to show nOe with $\mathrm{H}_{\mathrm{c}}$ as well $] ; \mathrm{H}_{\mathrm{e}}-\mathrm{H}_{\mathrm{g}} ; \mathrm{H}_{\mathrm{e}}-\mathrm{H}_{\mathrm{f}, \mathrm{f}} ; \mathrm{H}_{\mathrm{e}}-$ $\left(\mathrm{H}_{3} \mathrm{C}\right)_{2}$ (isopropyl) [Note: no $\mathrm{H}_{\mathrm{e}}-\mathrm{H}_{\mathrm{d}, \mathrm{d}}$, nOe interaction is observed]. 


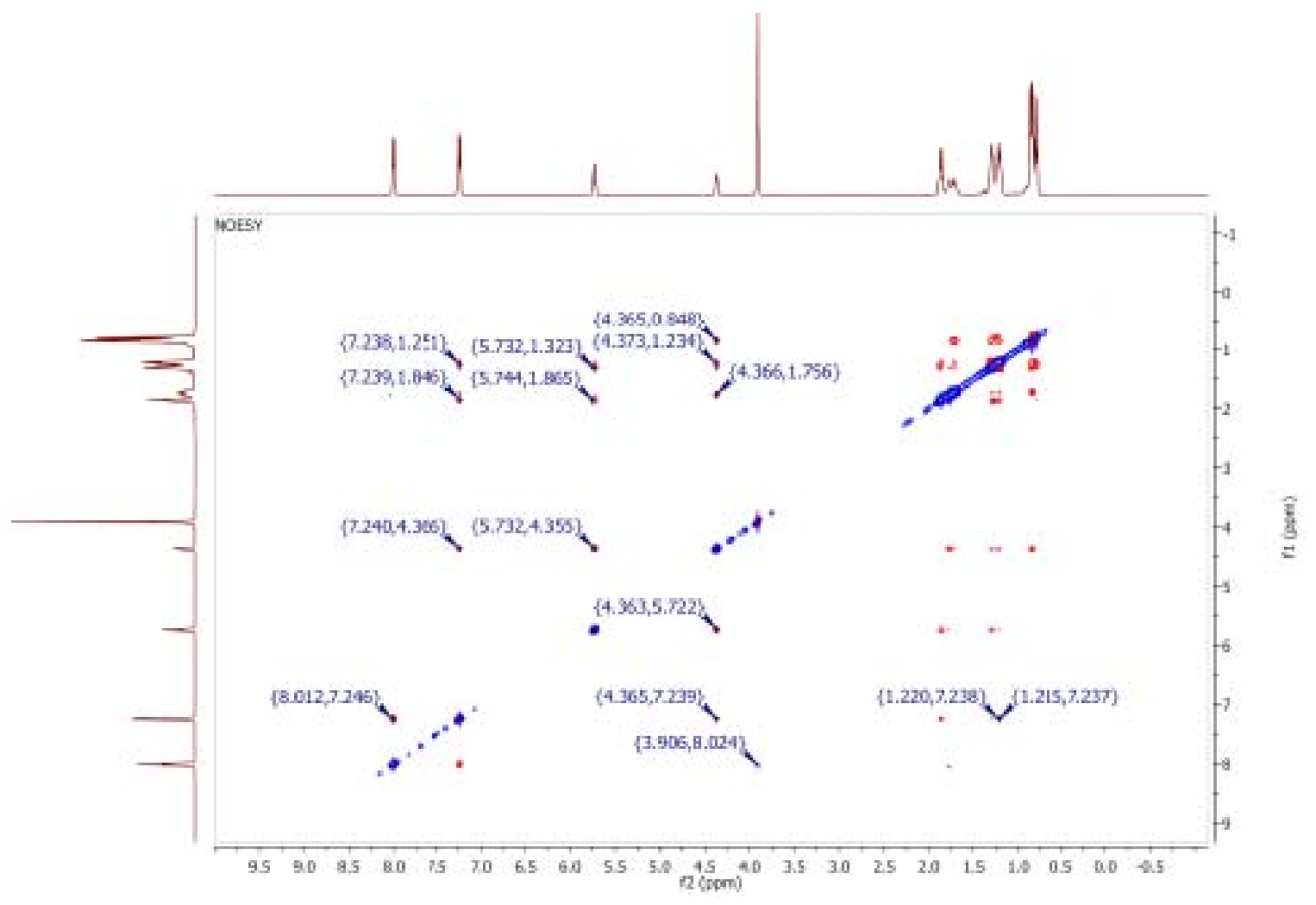



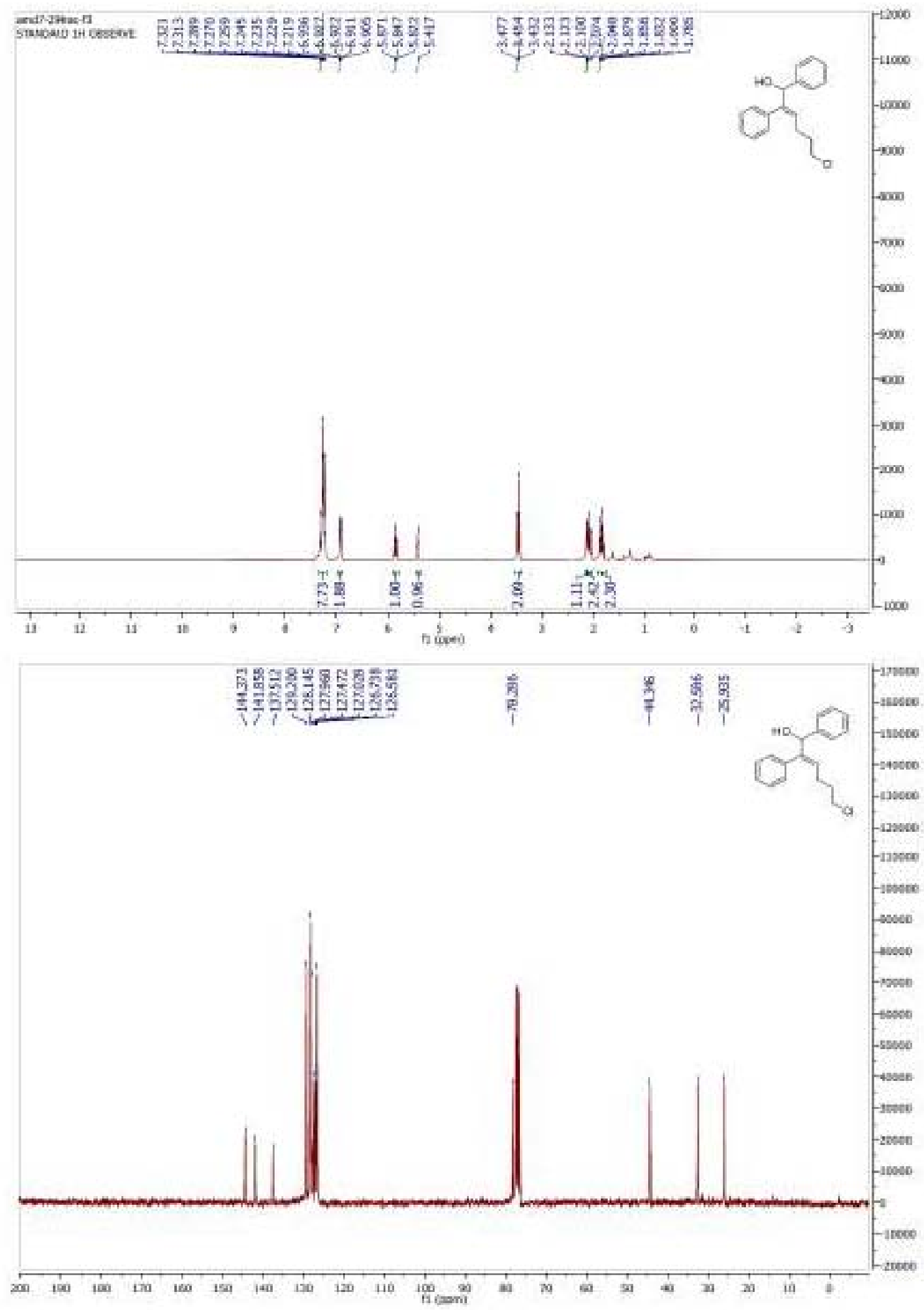


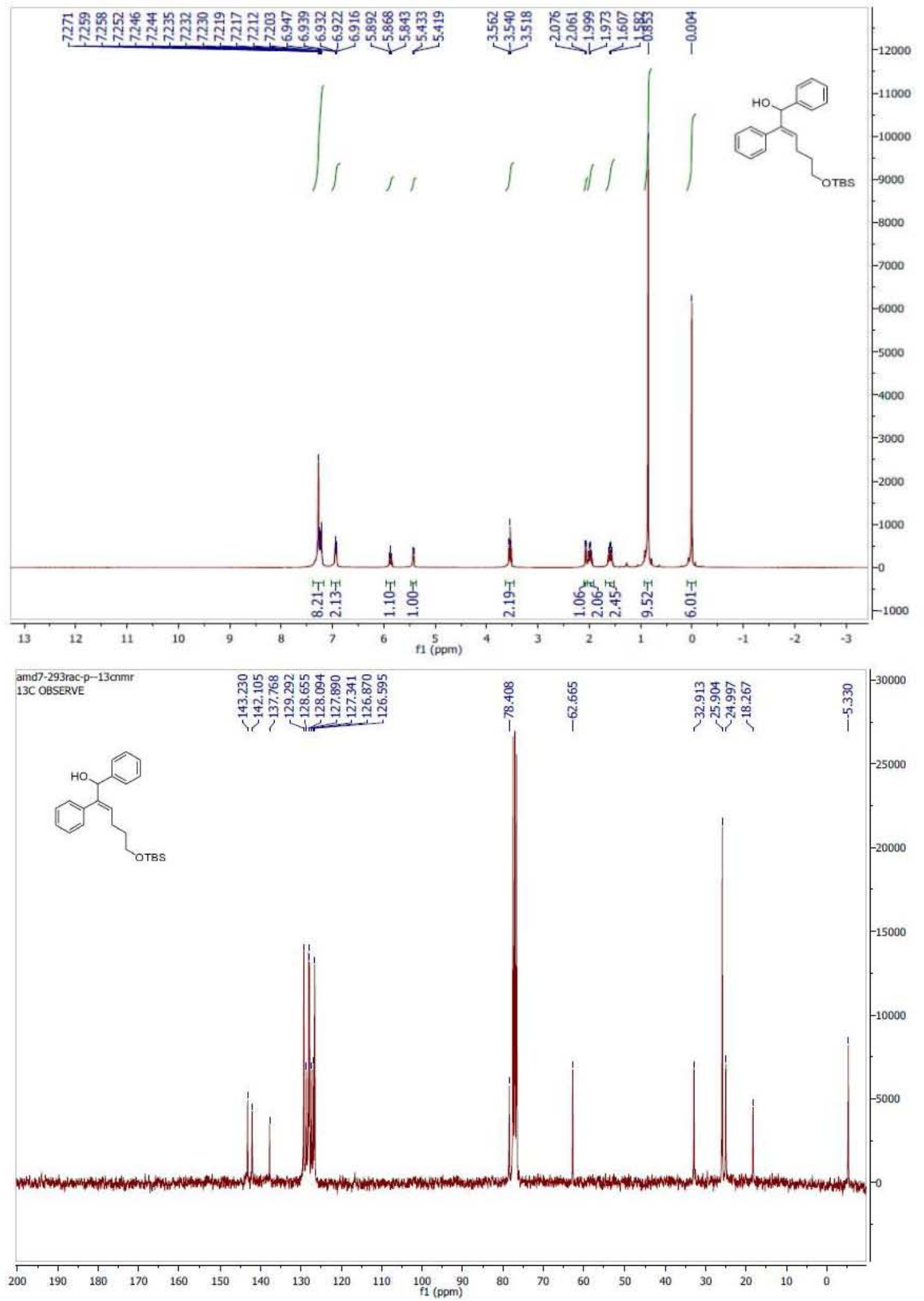




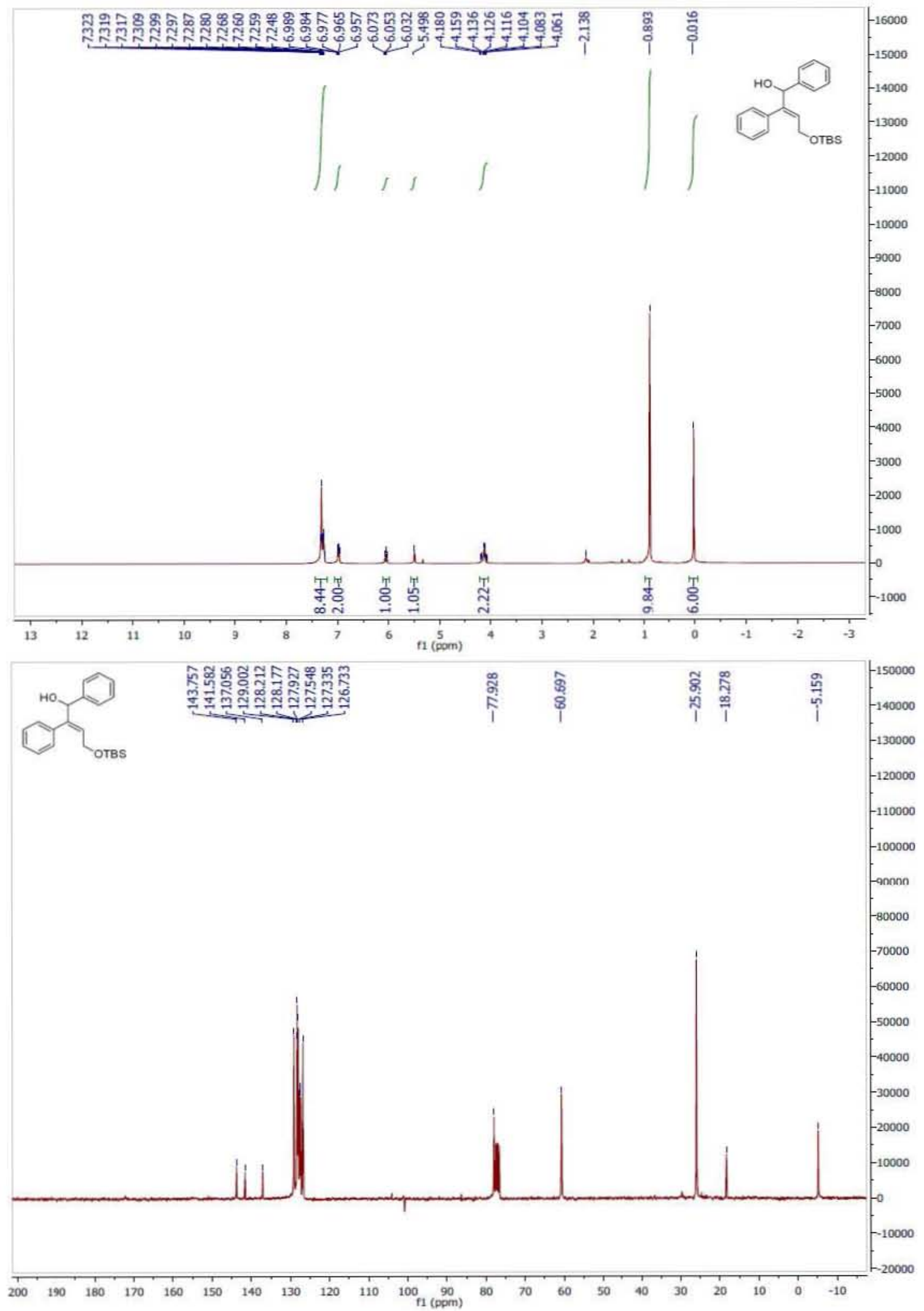




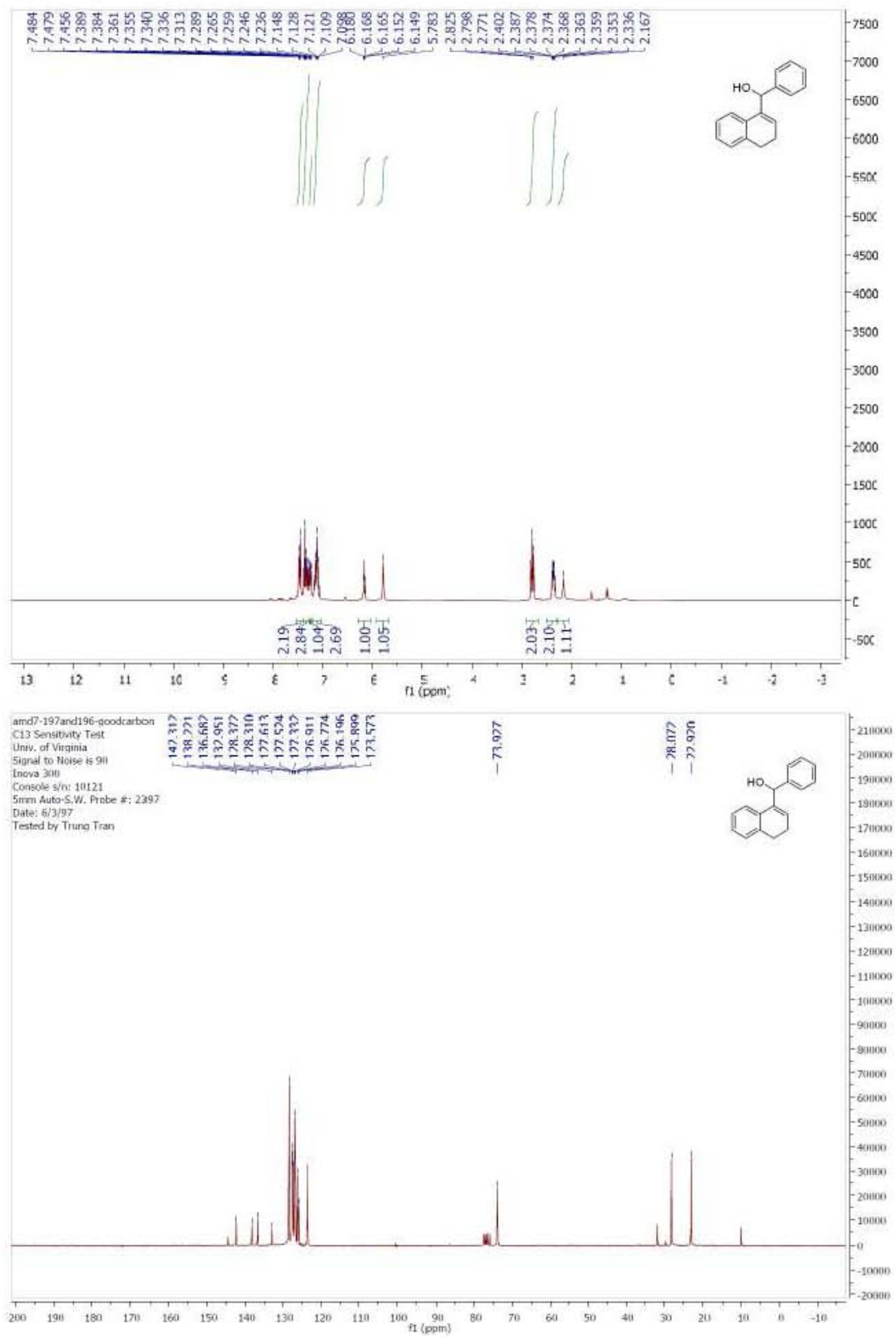




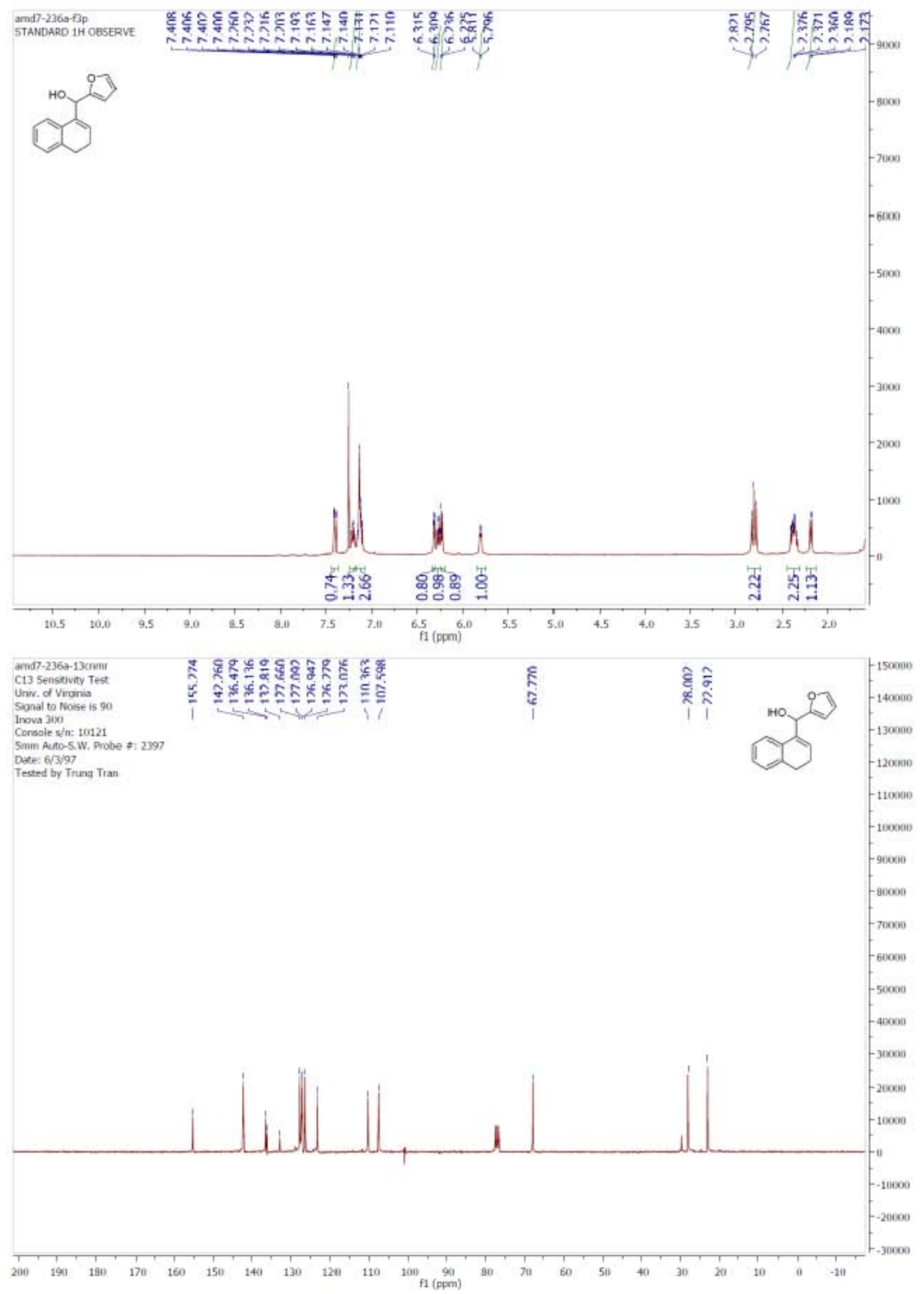




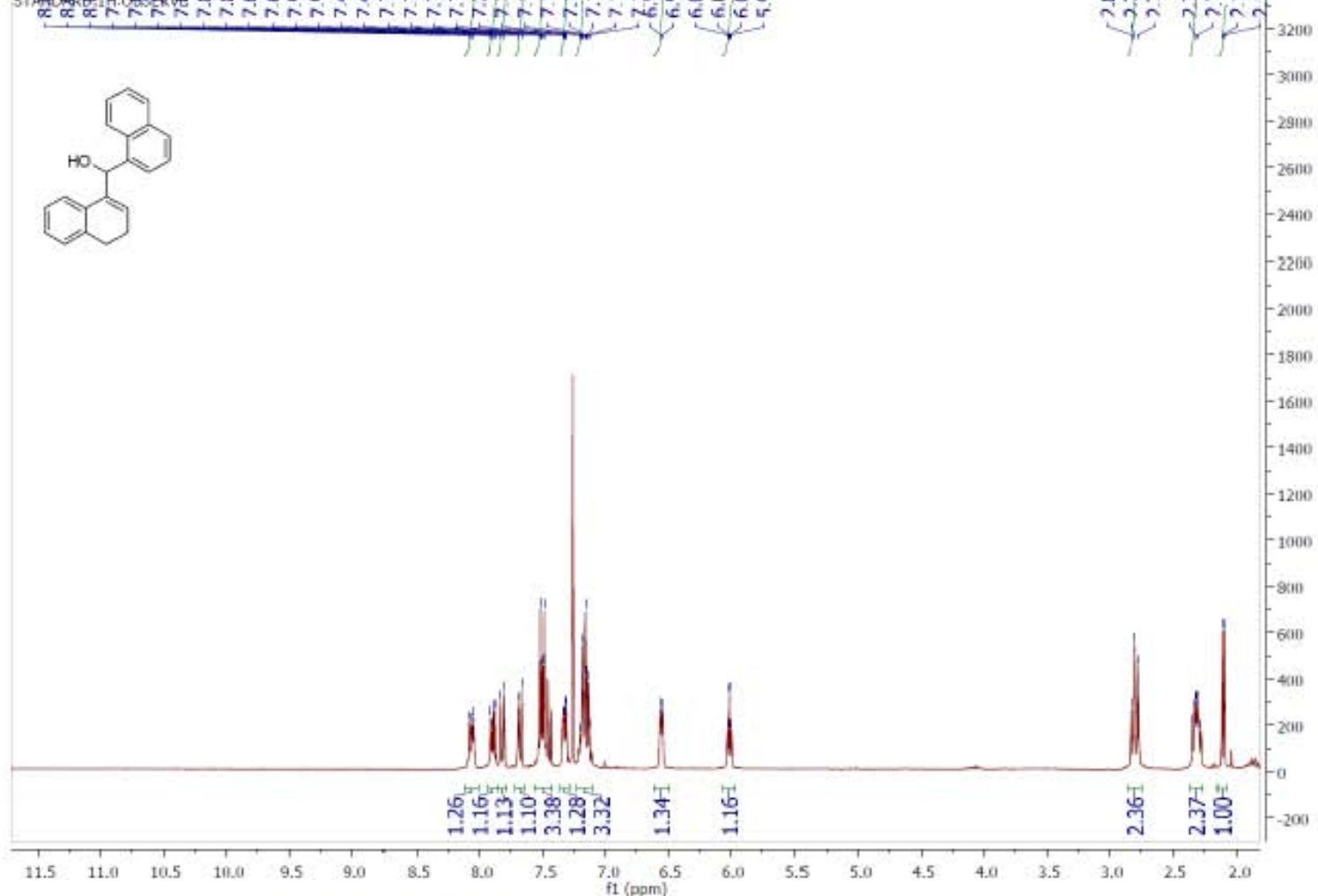

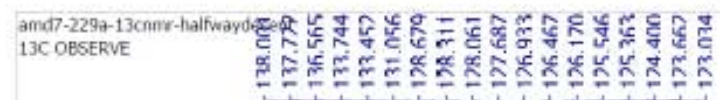

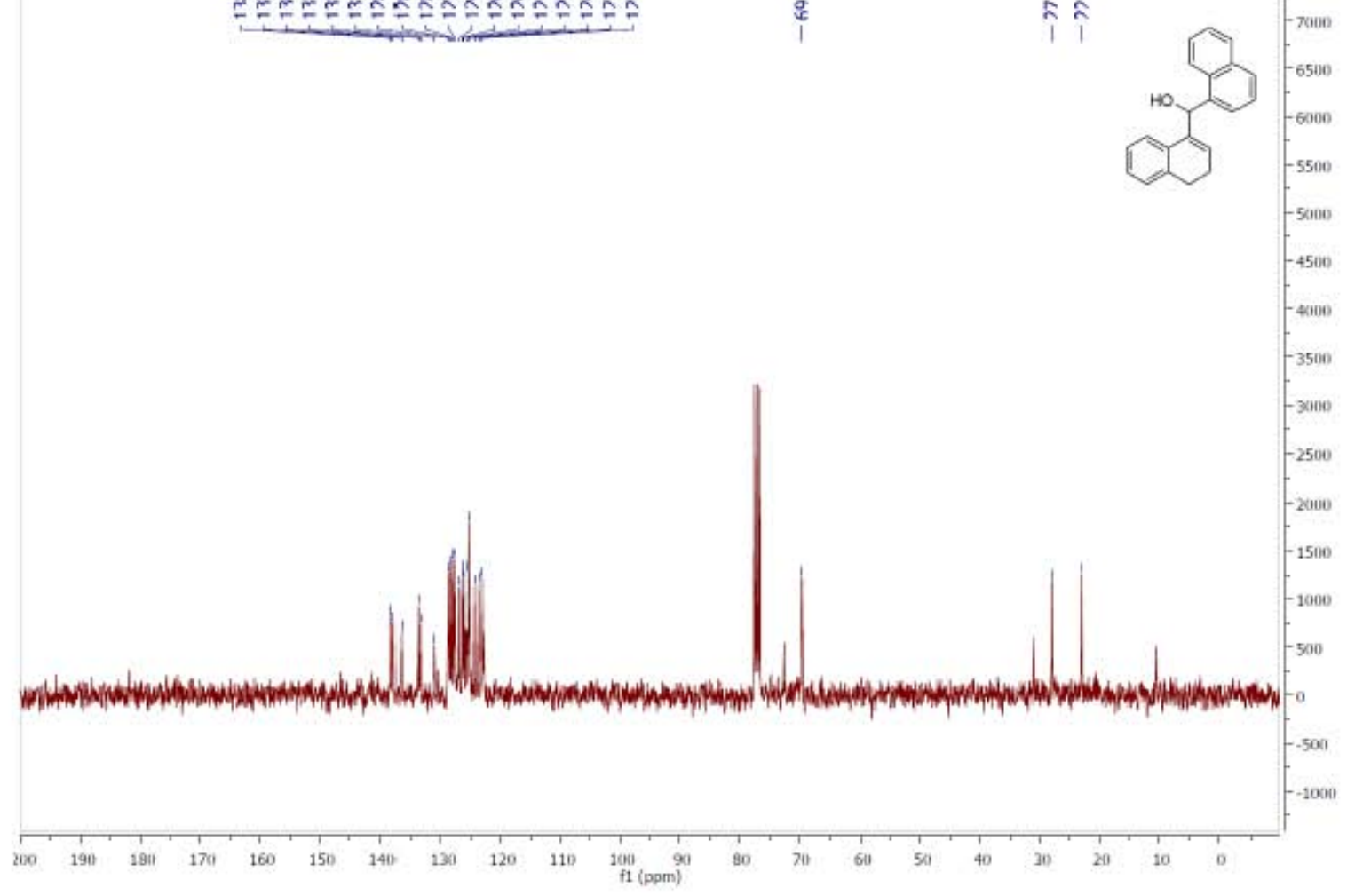




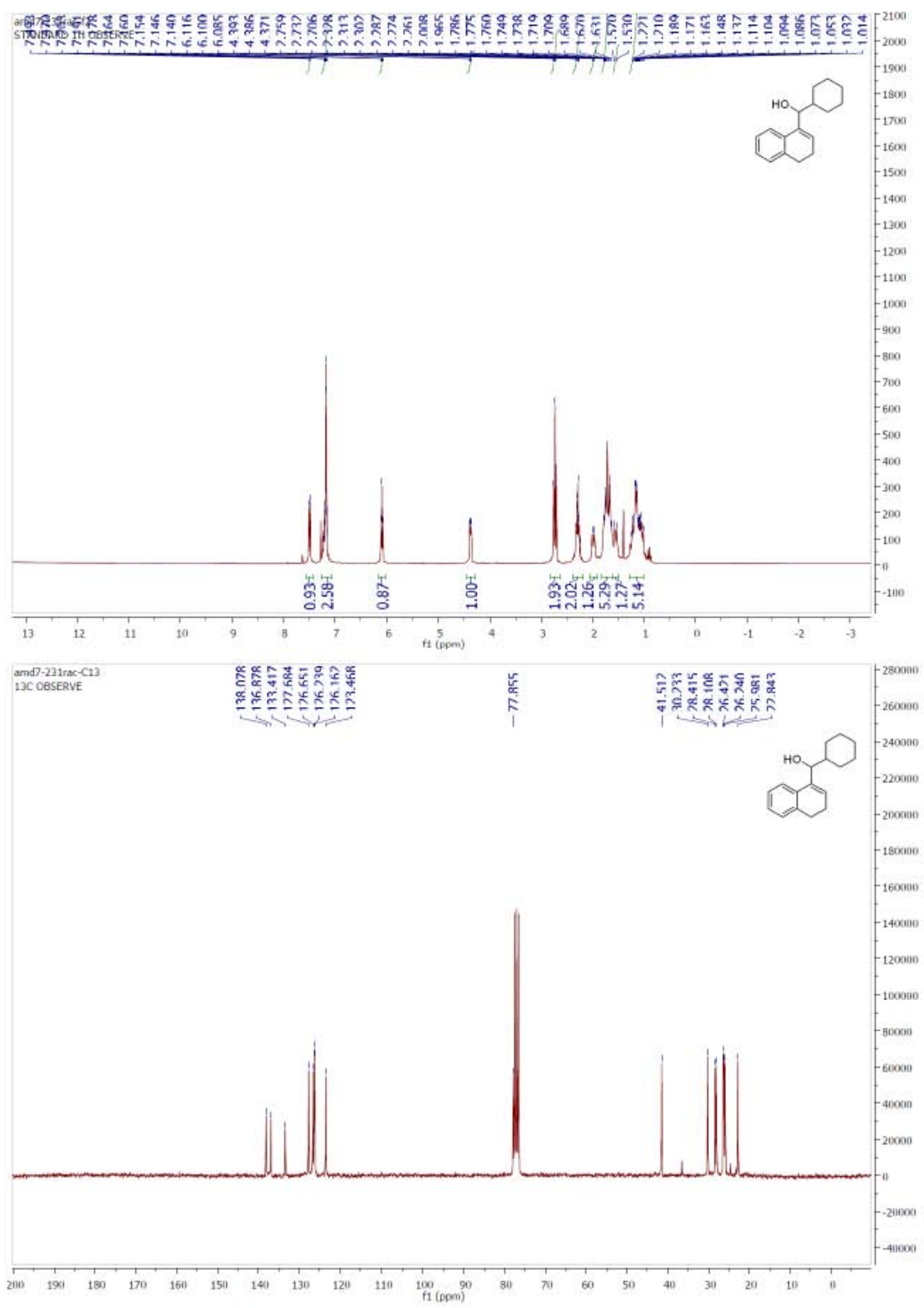




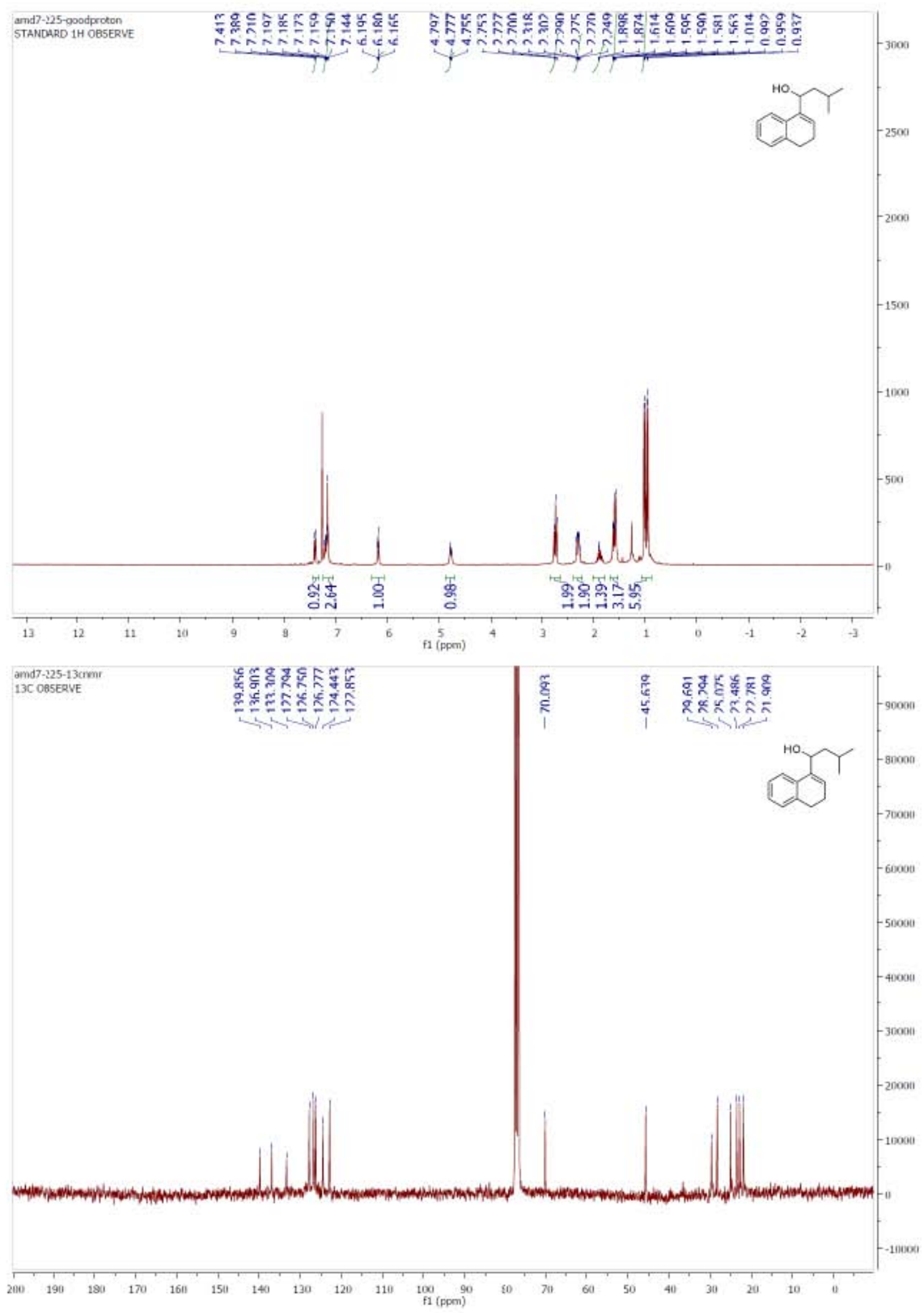




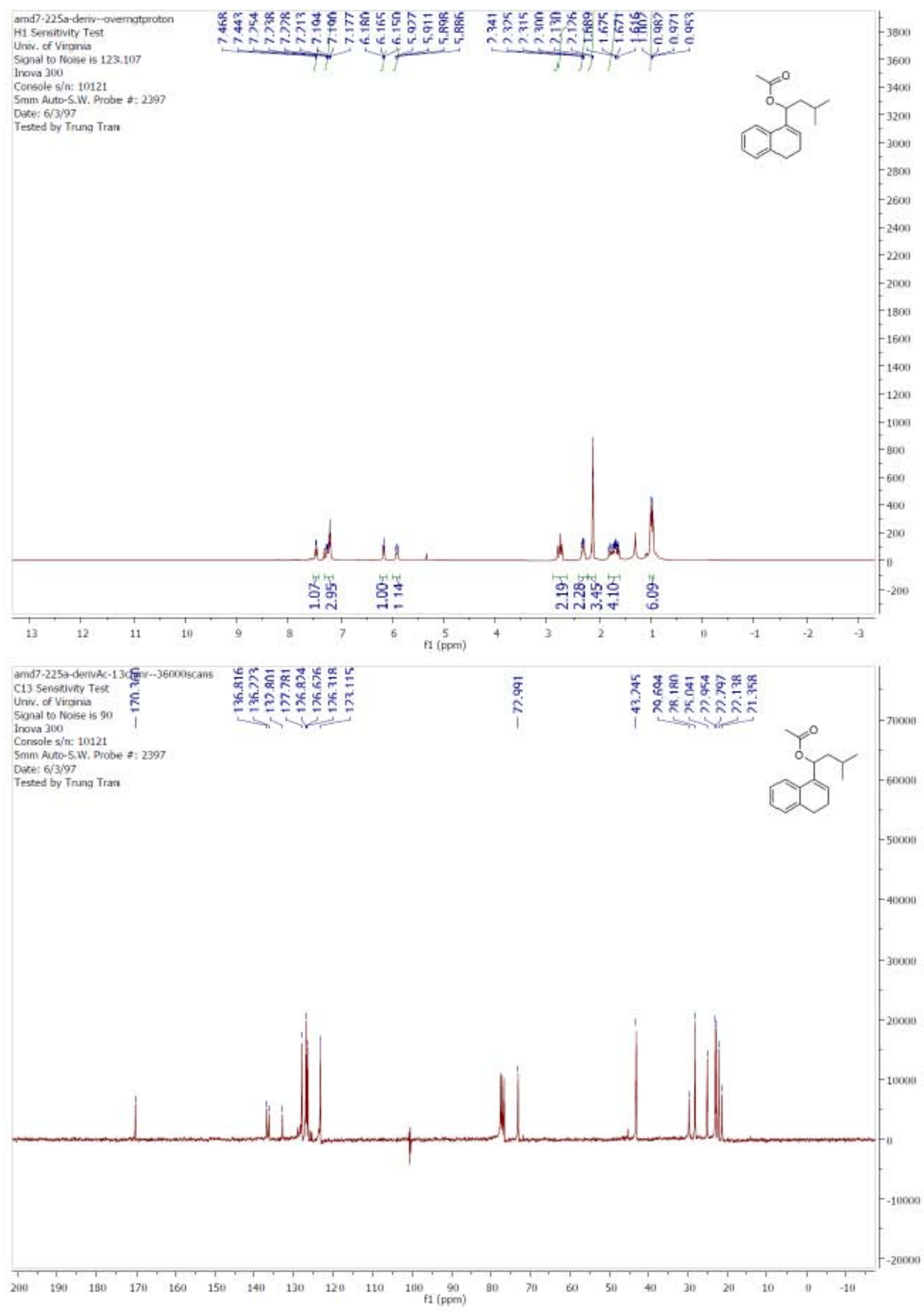




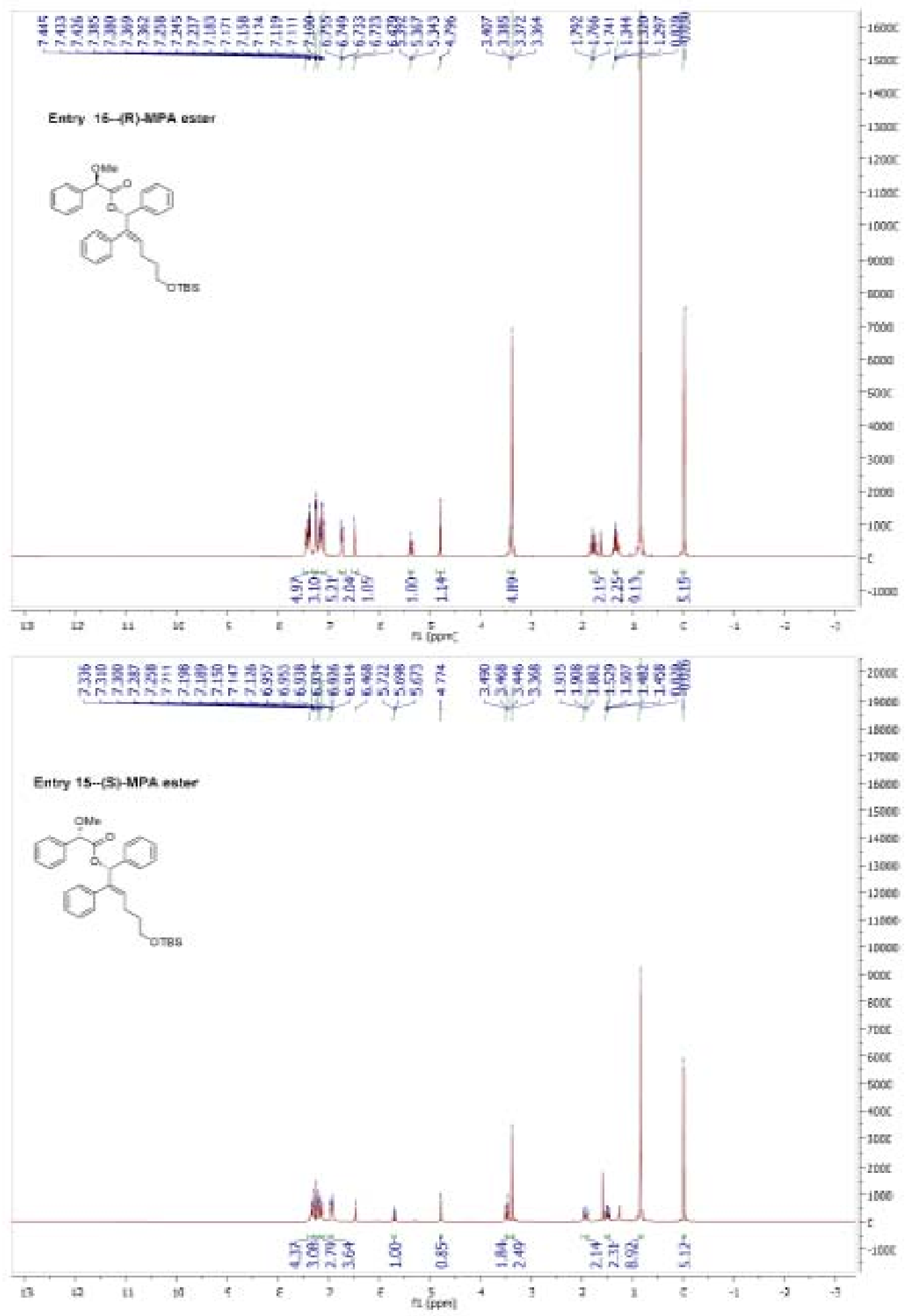



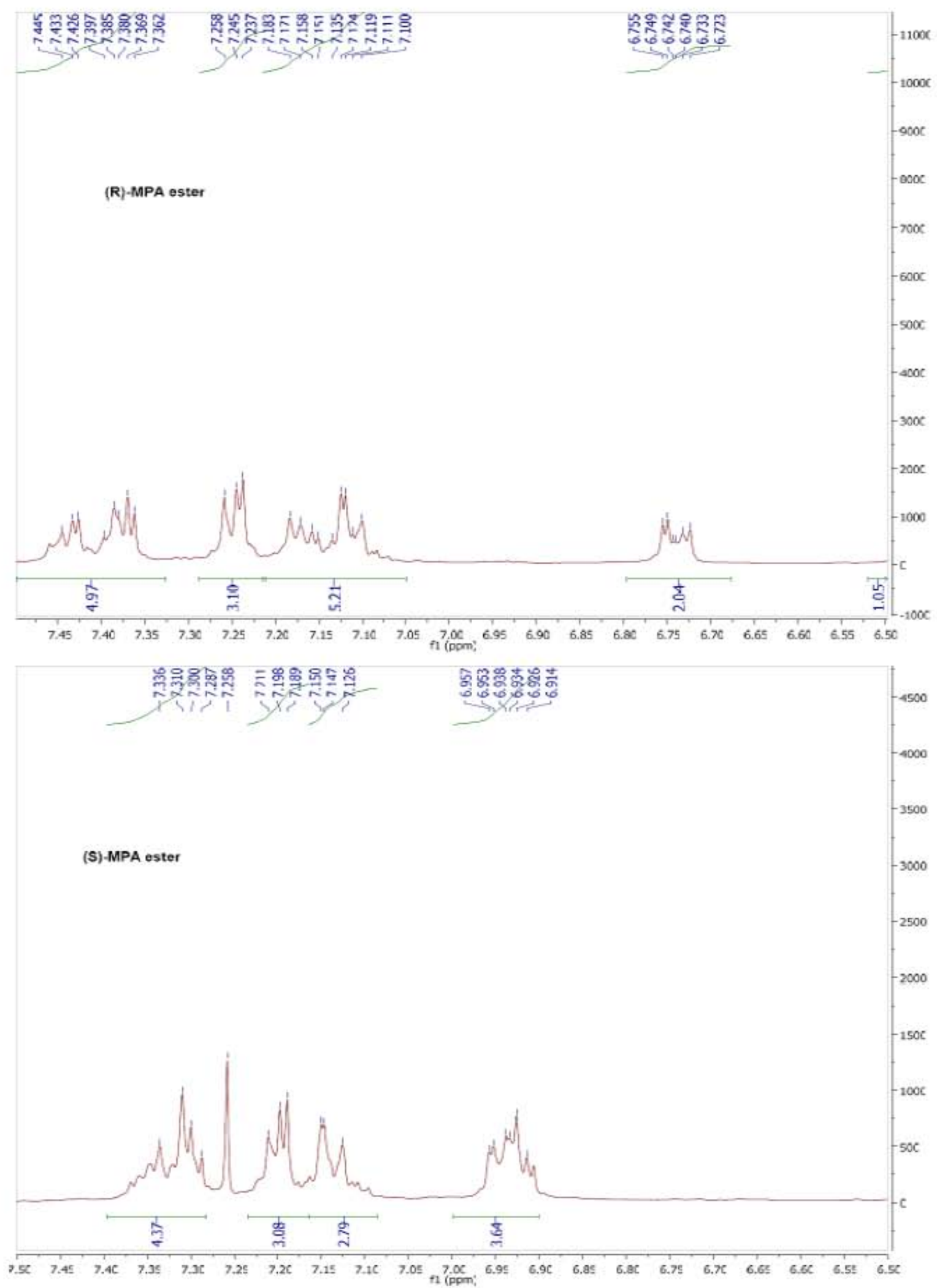
6.2 to $5.2 \mathrm{ppm}$ :
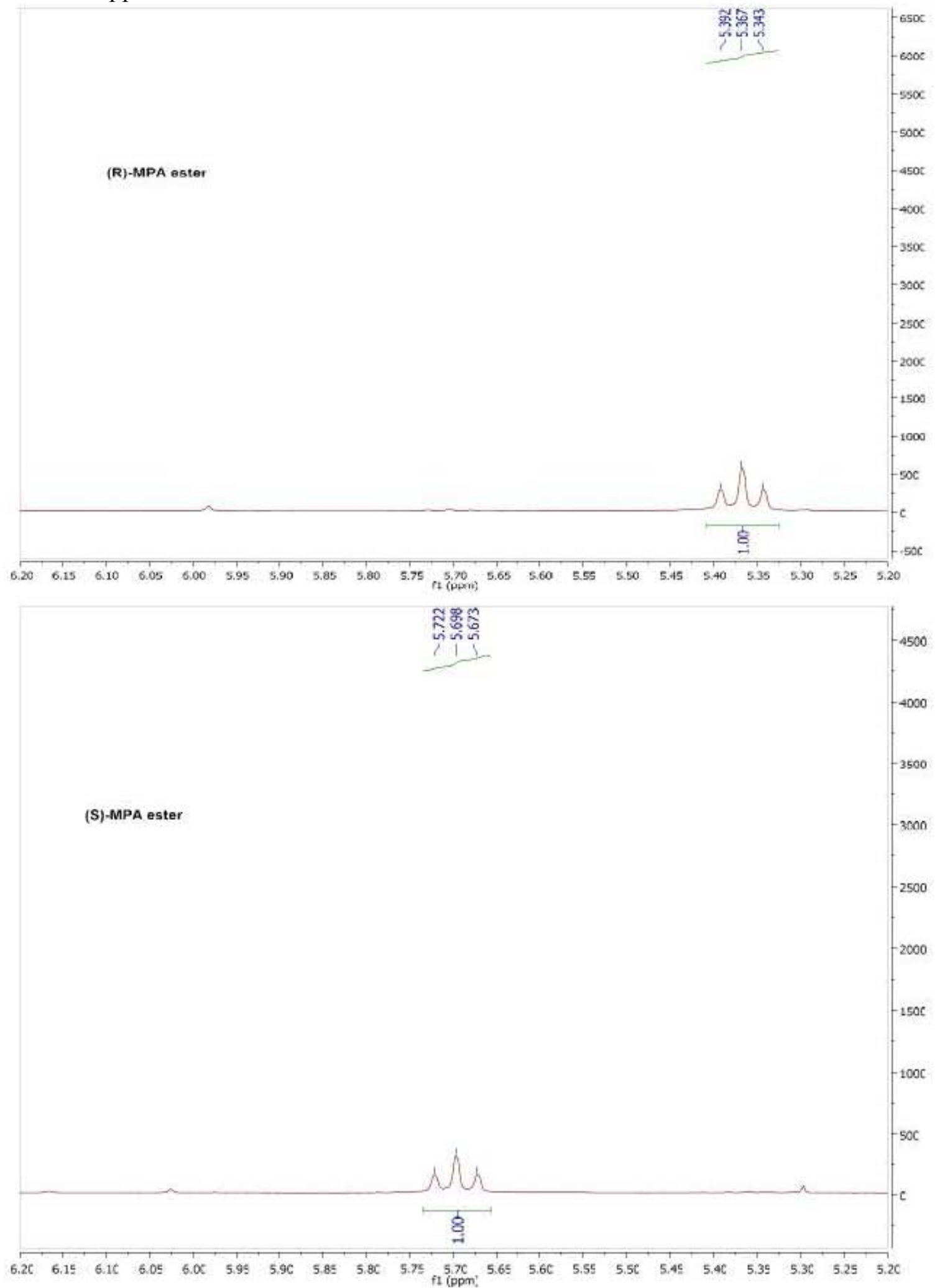
4.0 to $3.0 \mathrm{ppm}$ :
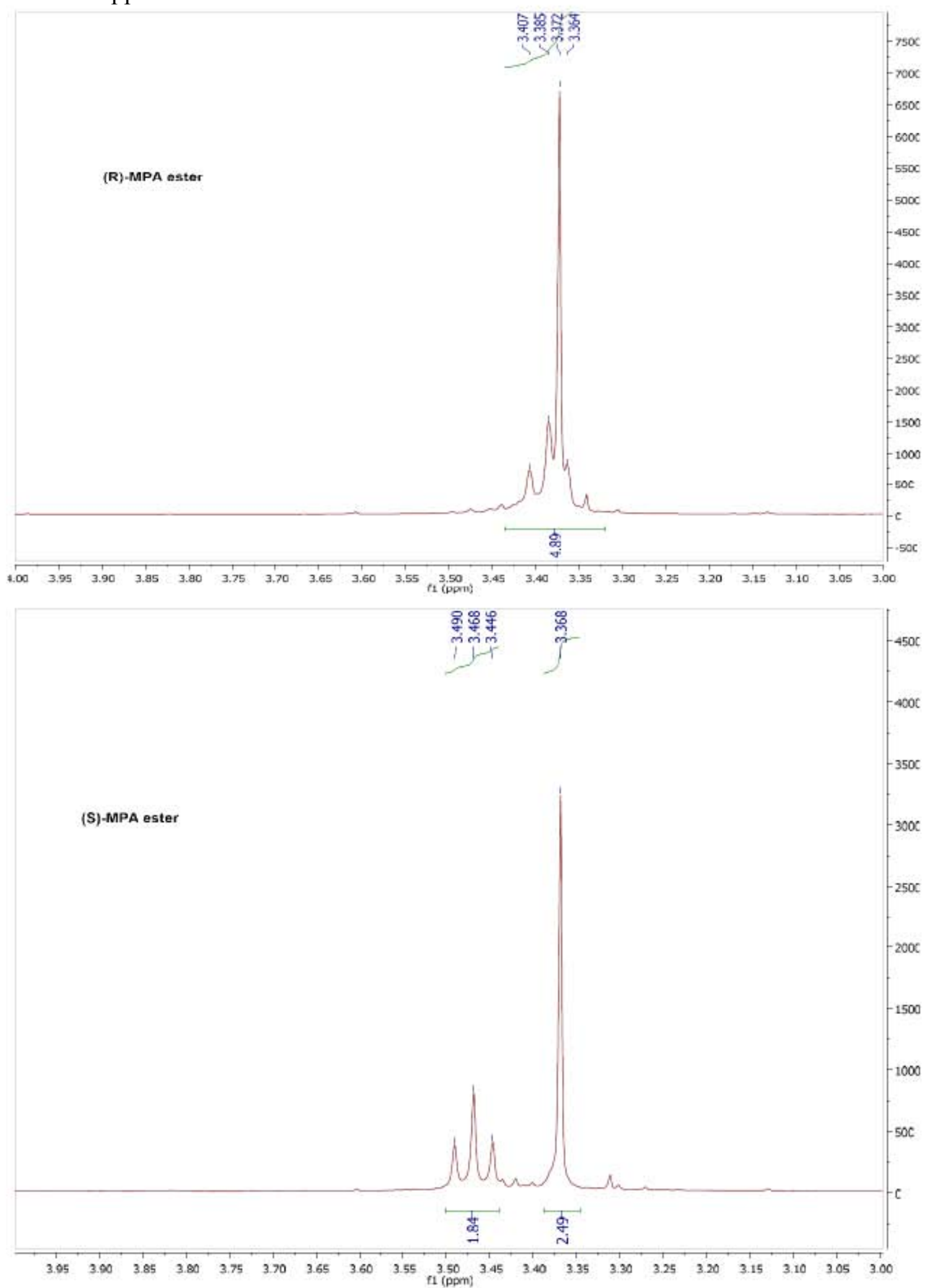
2.5 to $-0.2 \mathrm{ppm}$ :

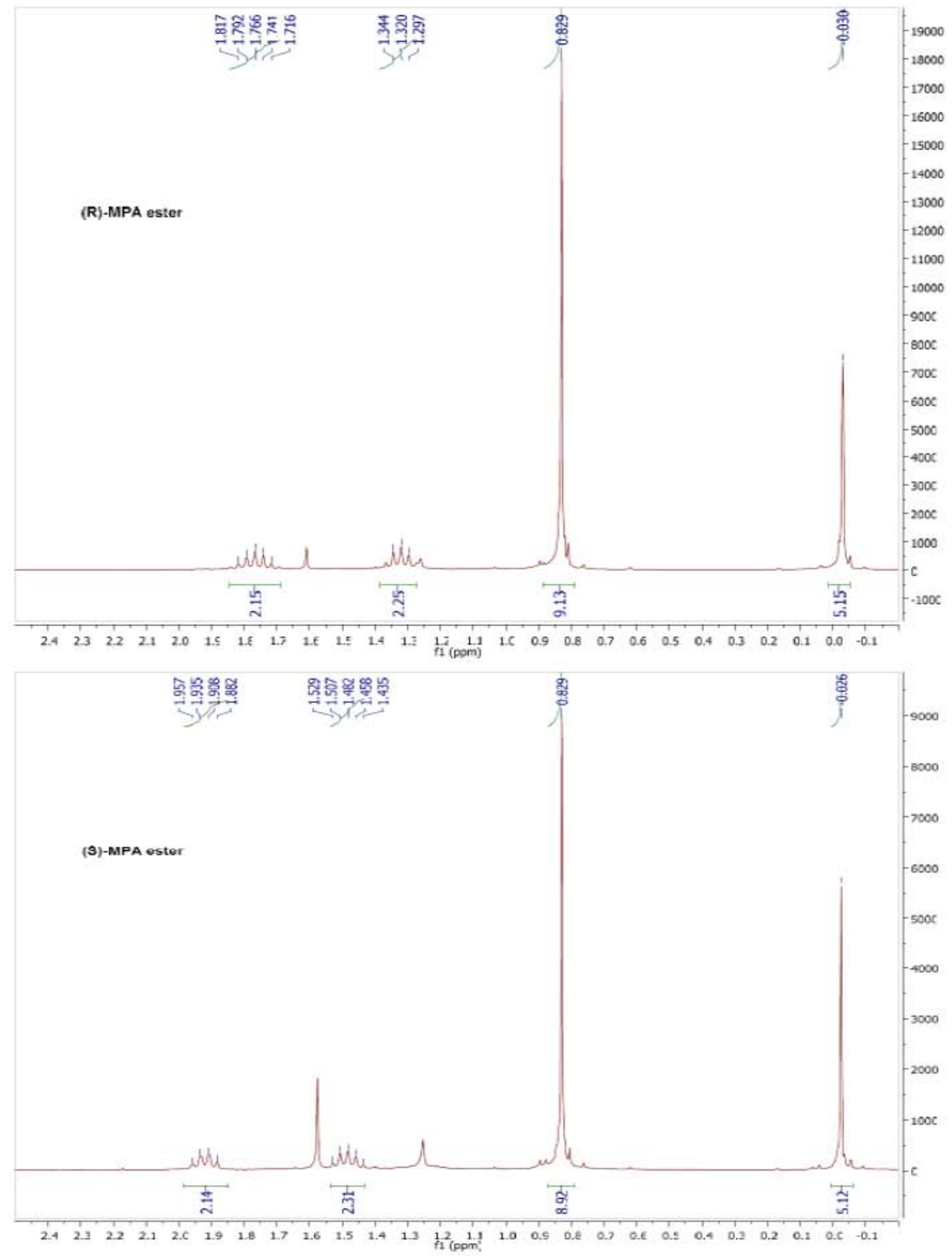




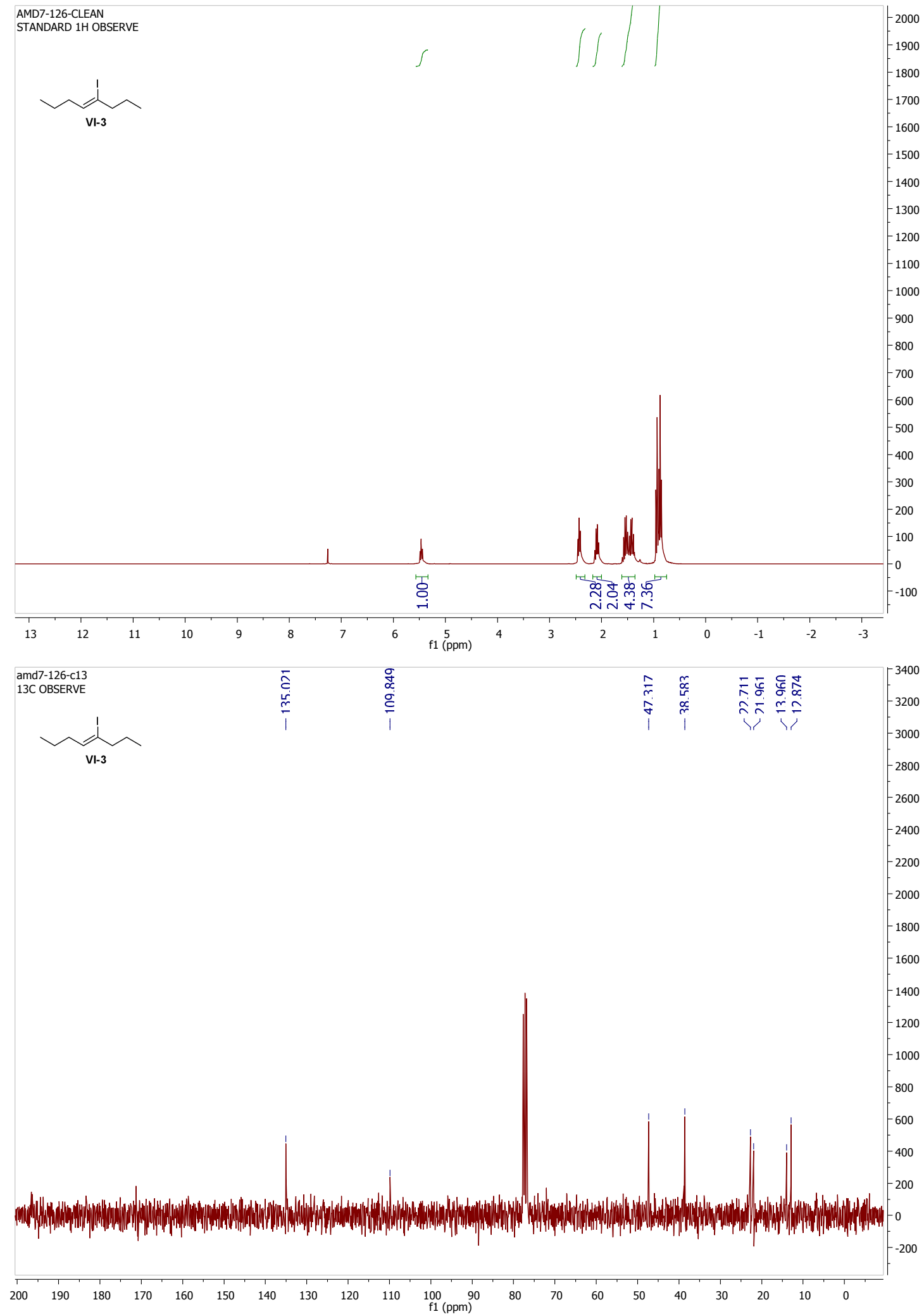




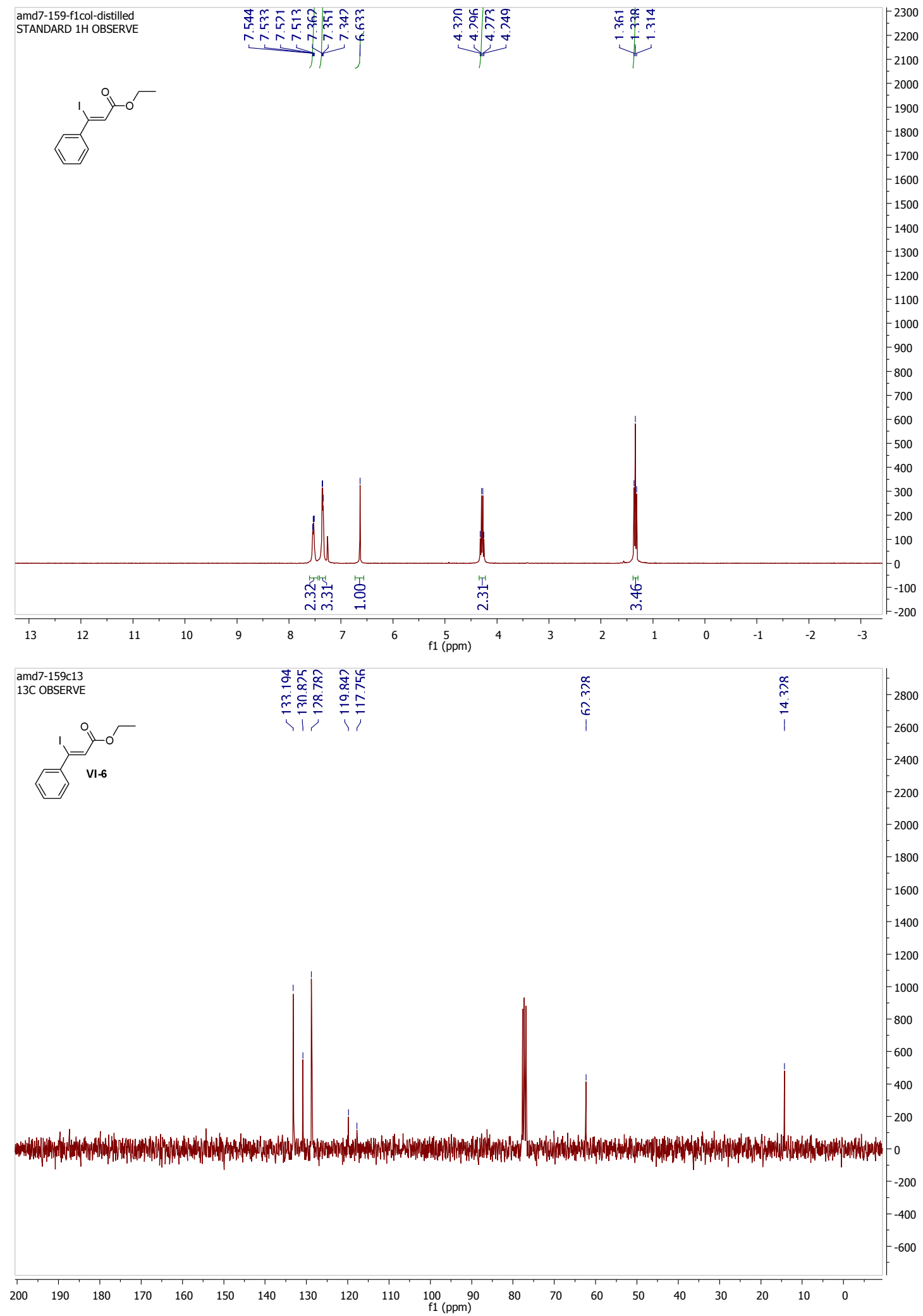




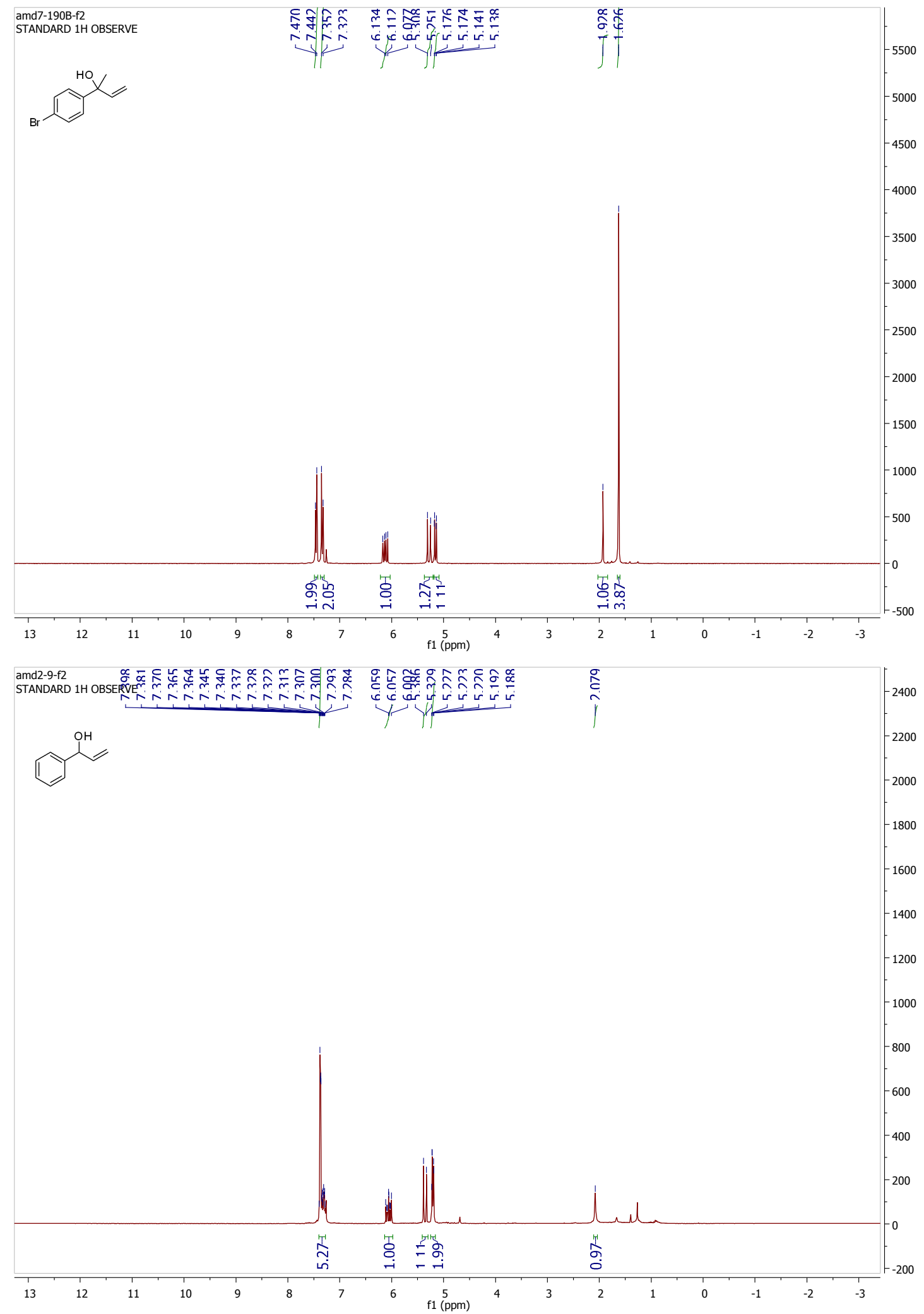



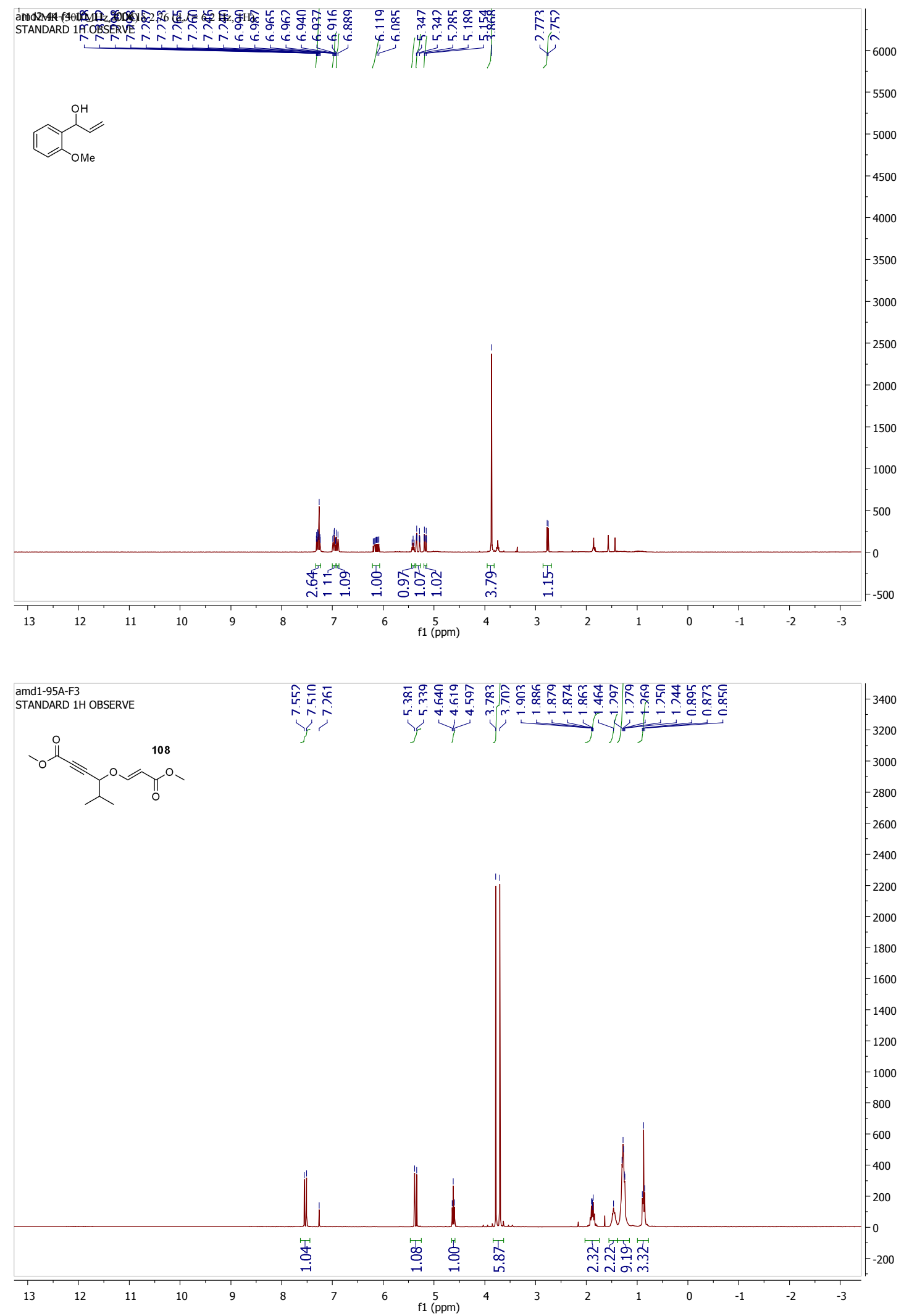
amd1-198A-f4

STANDARD 1H OBSERVE

6000

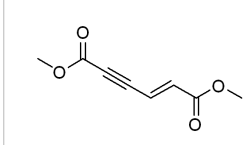

5500

5000

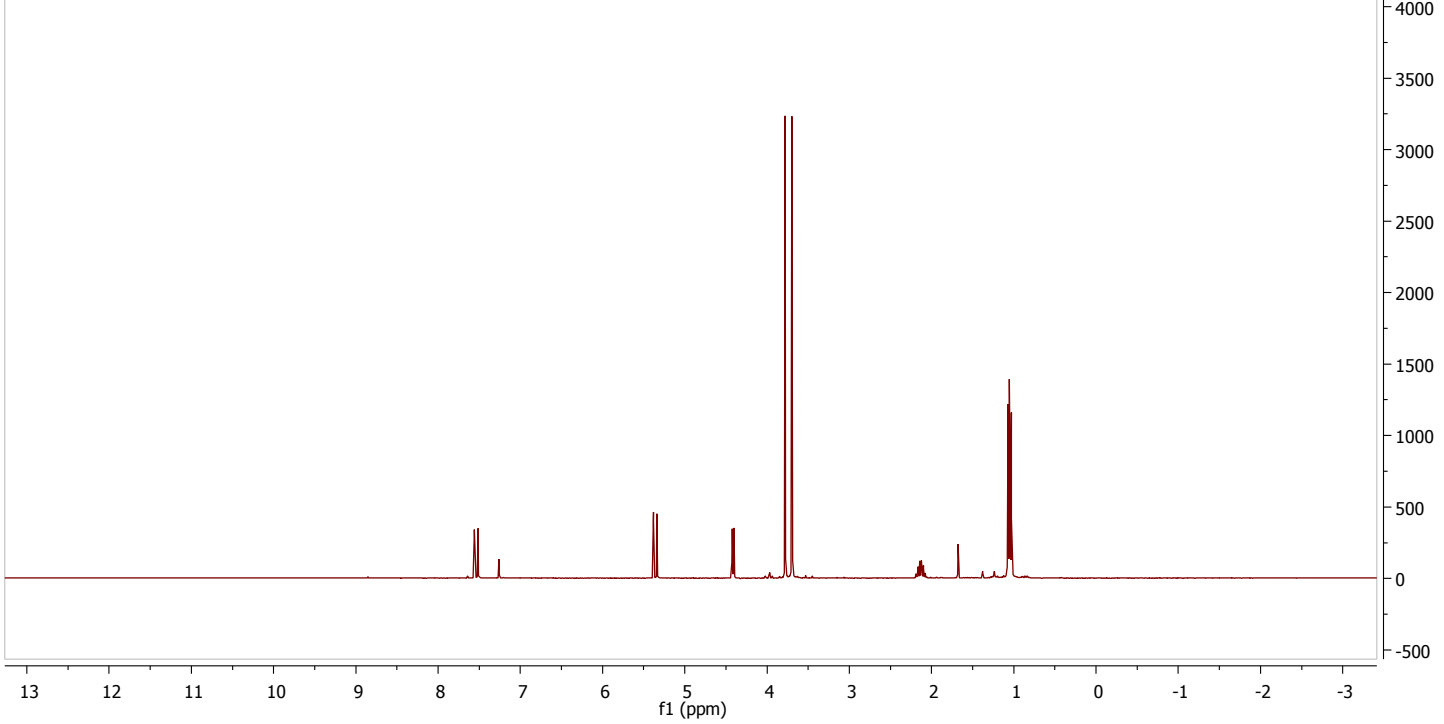

amd1-198b-f4

STANDARD $1 \mathrm{H}$ OBSERVE

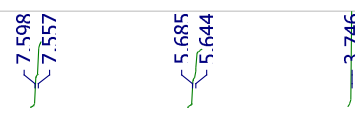

战

- $\stackrel{\text { I }}{\mathrm{Cl}}$
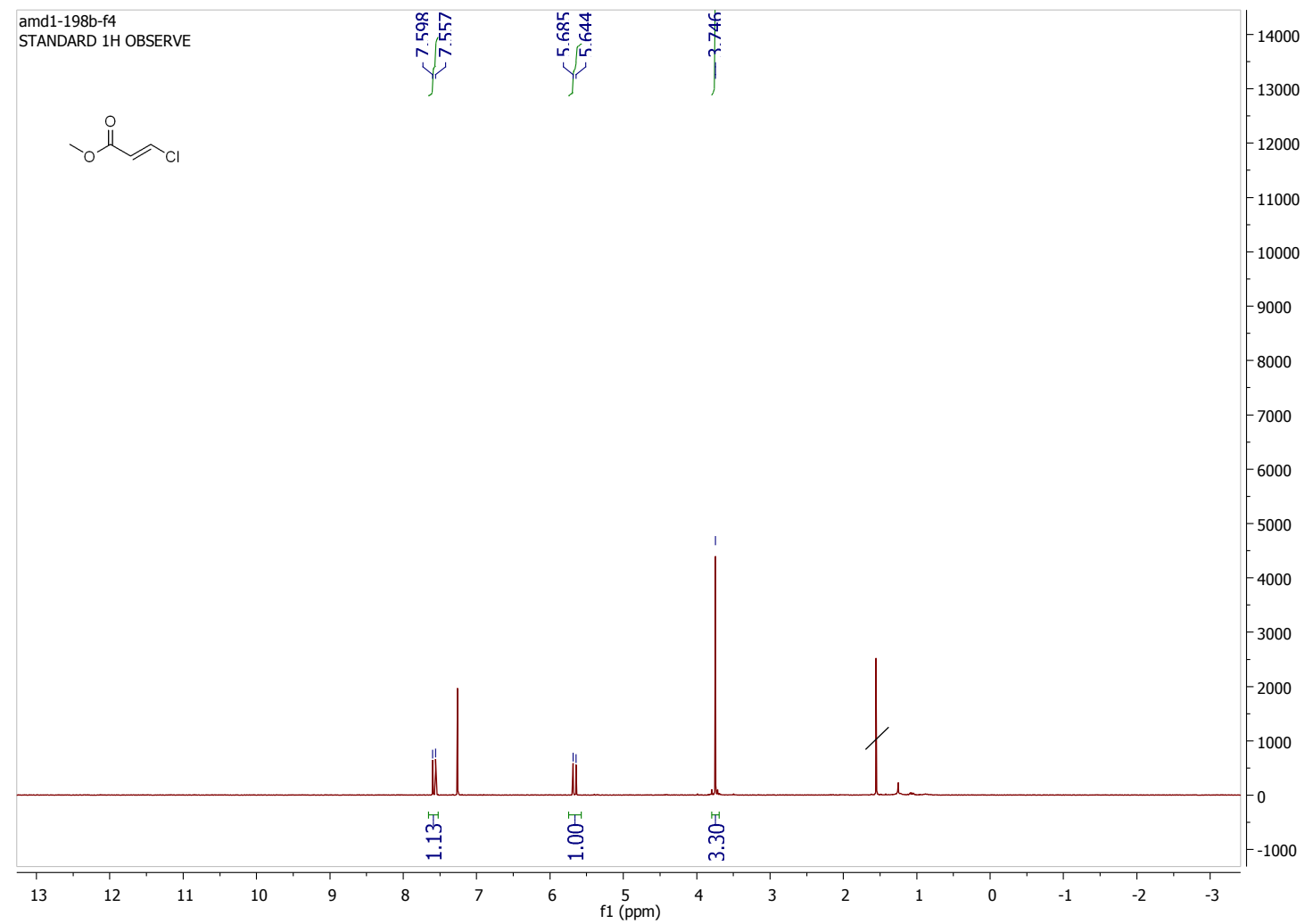


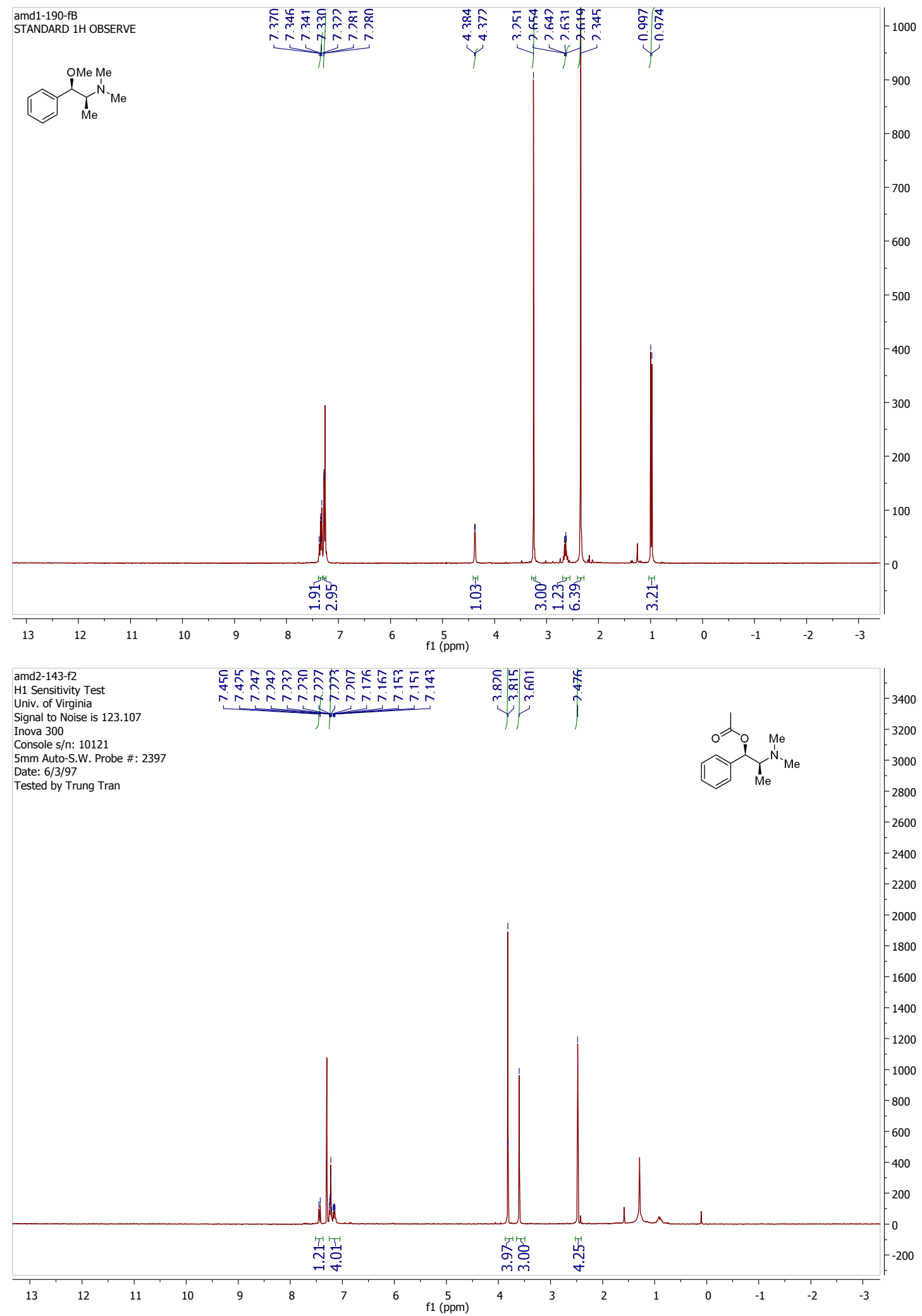




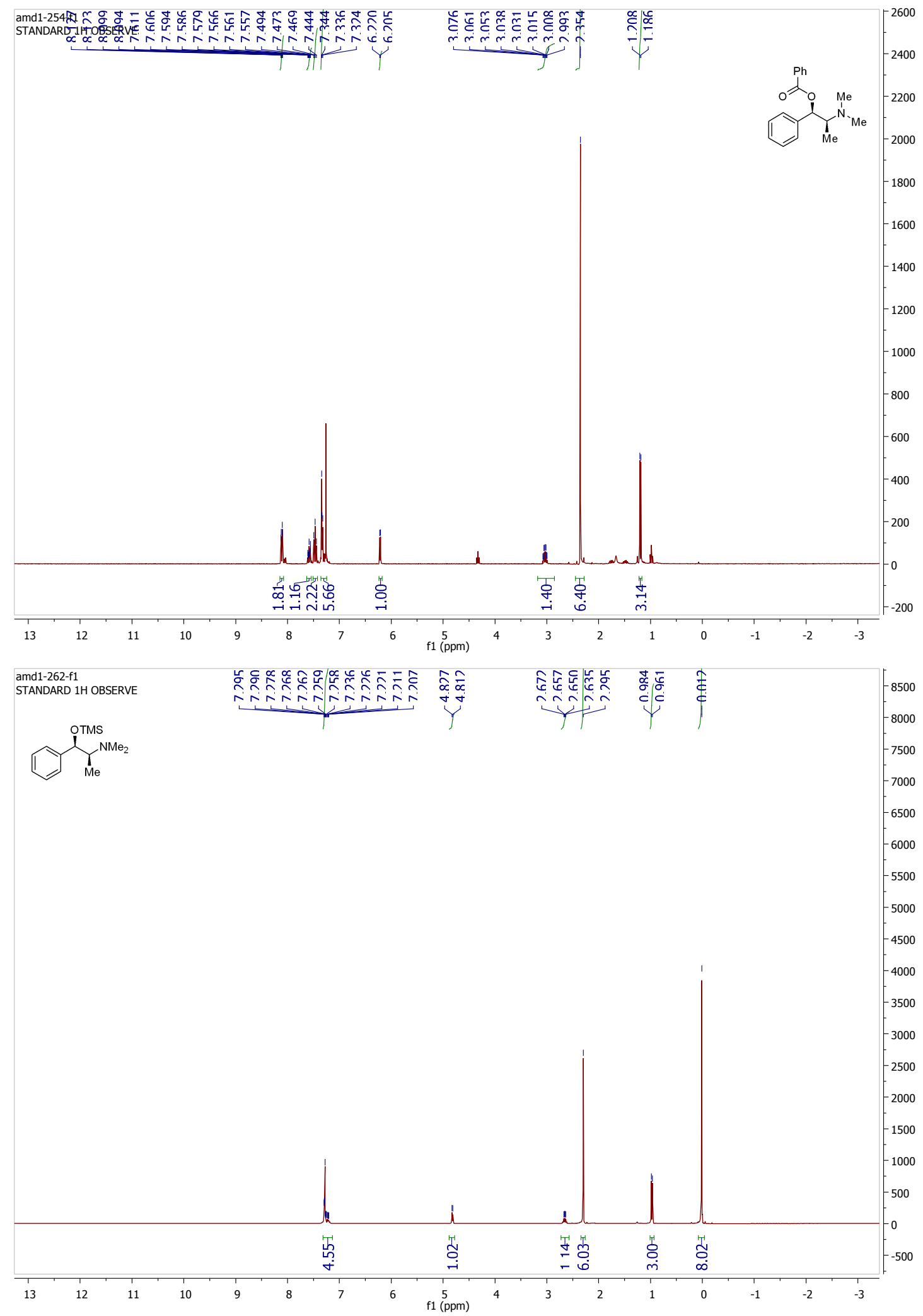



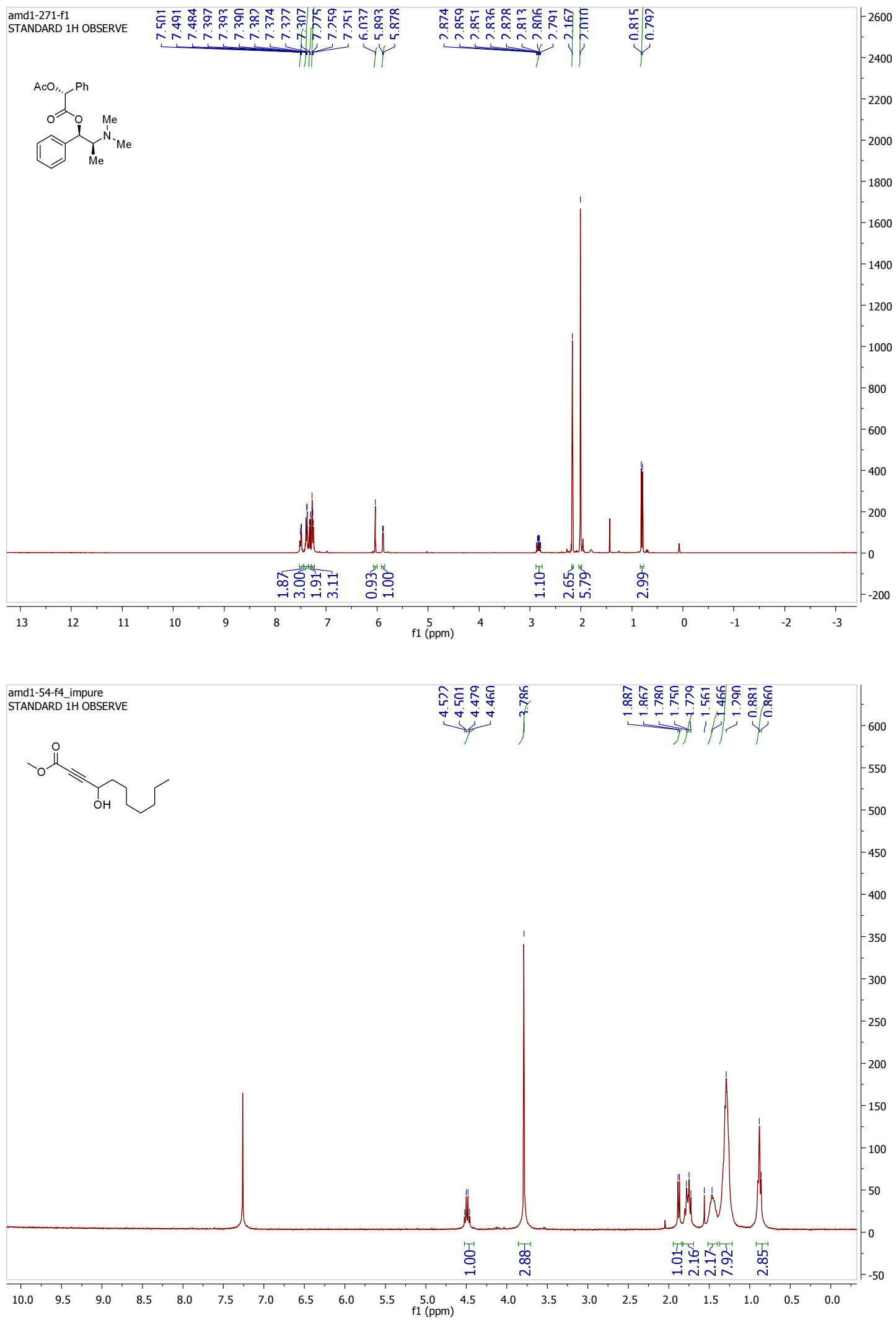


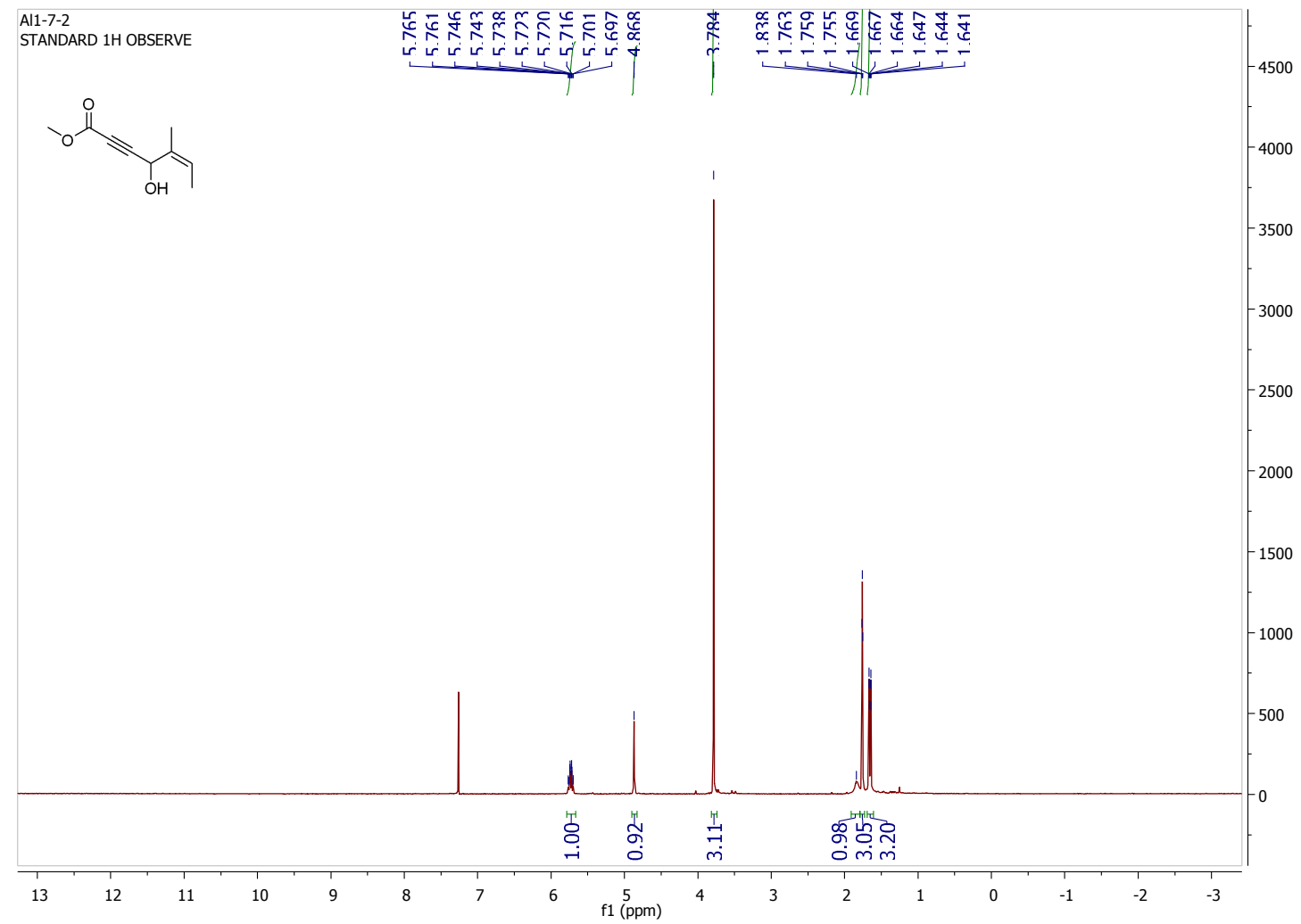



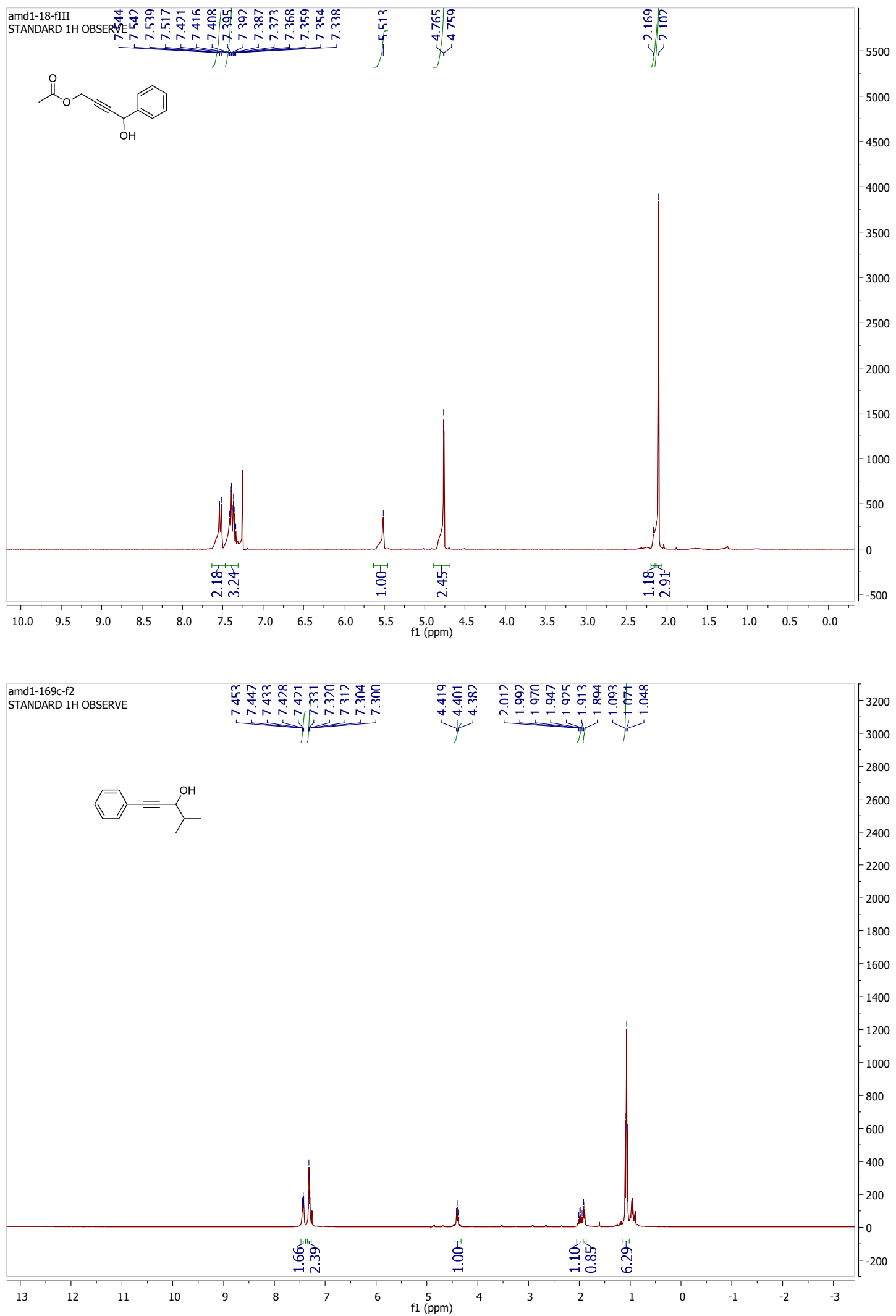


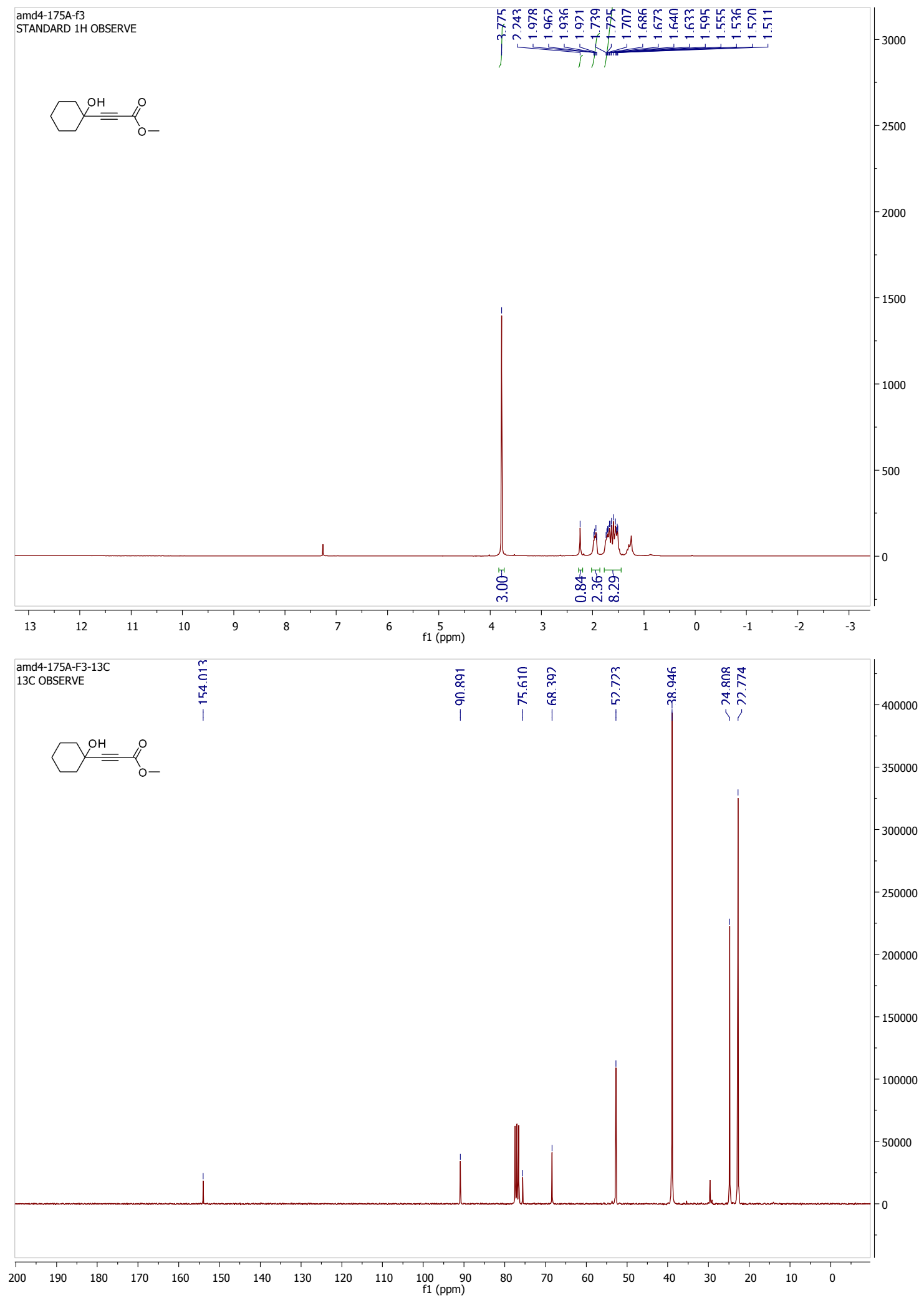




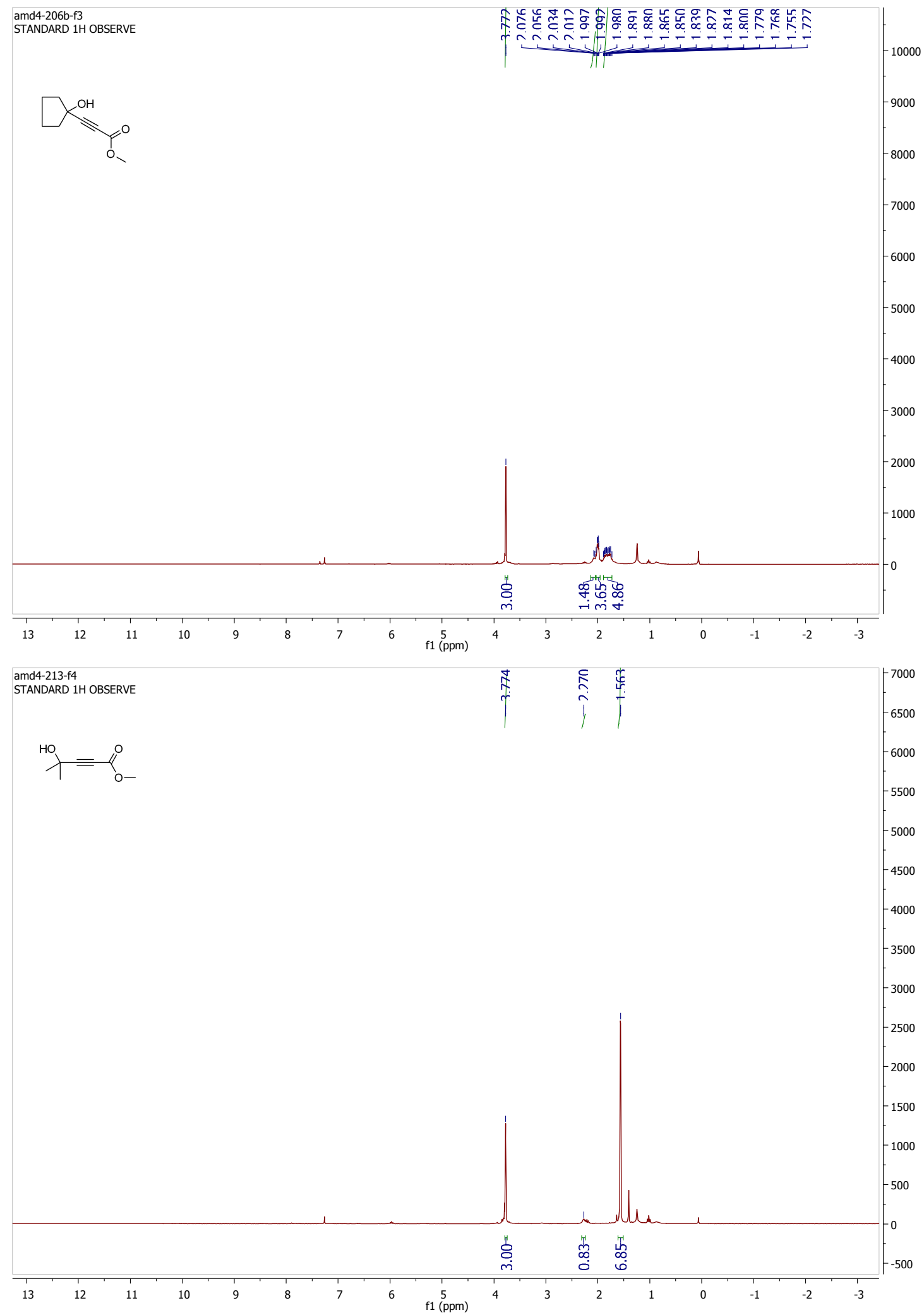




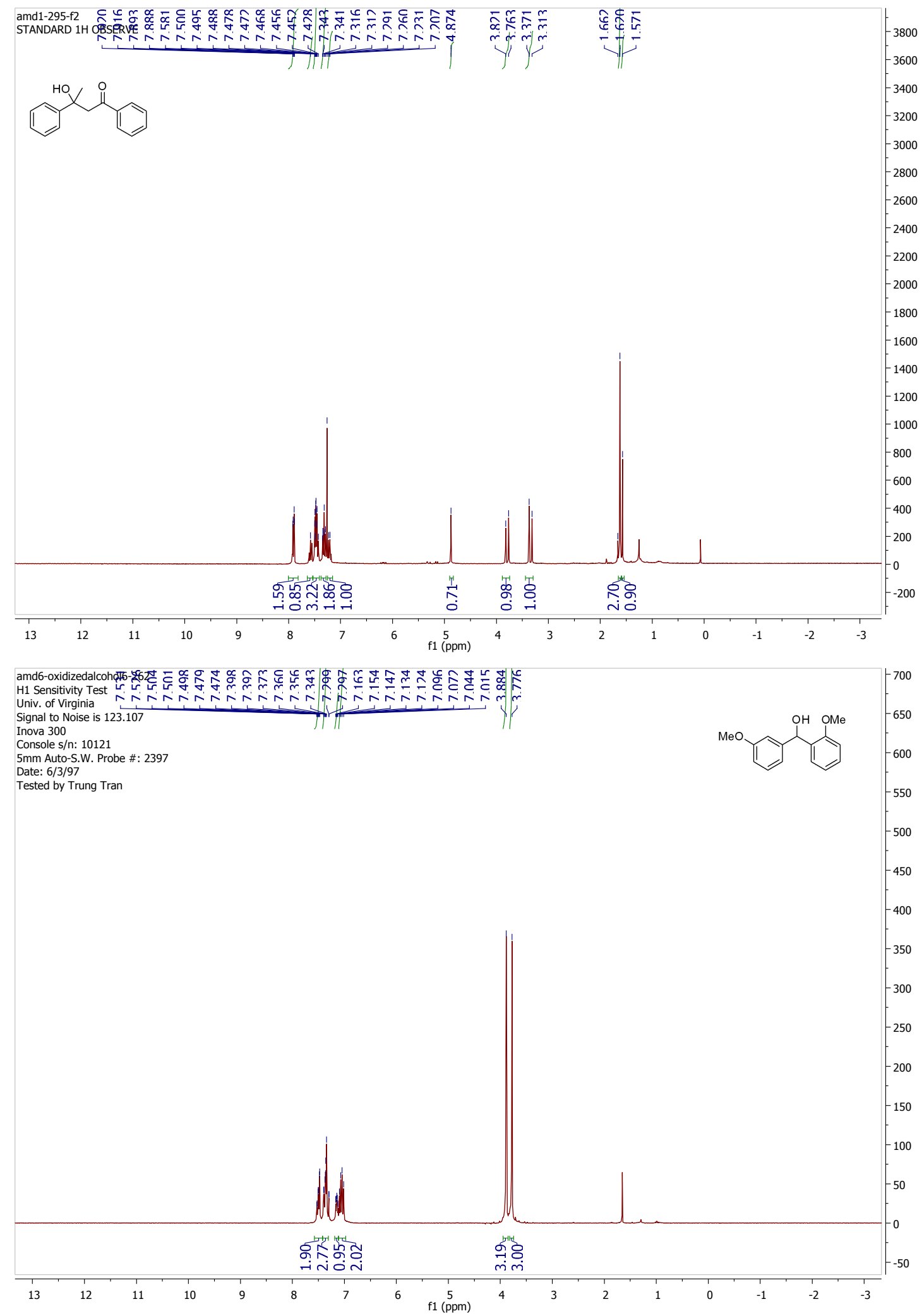




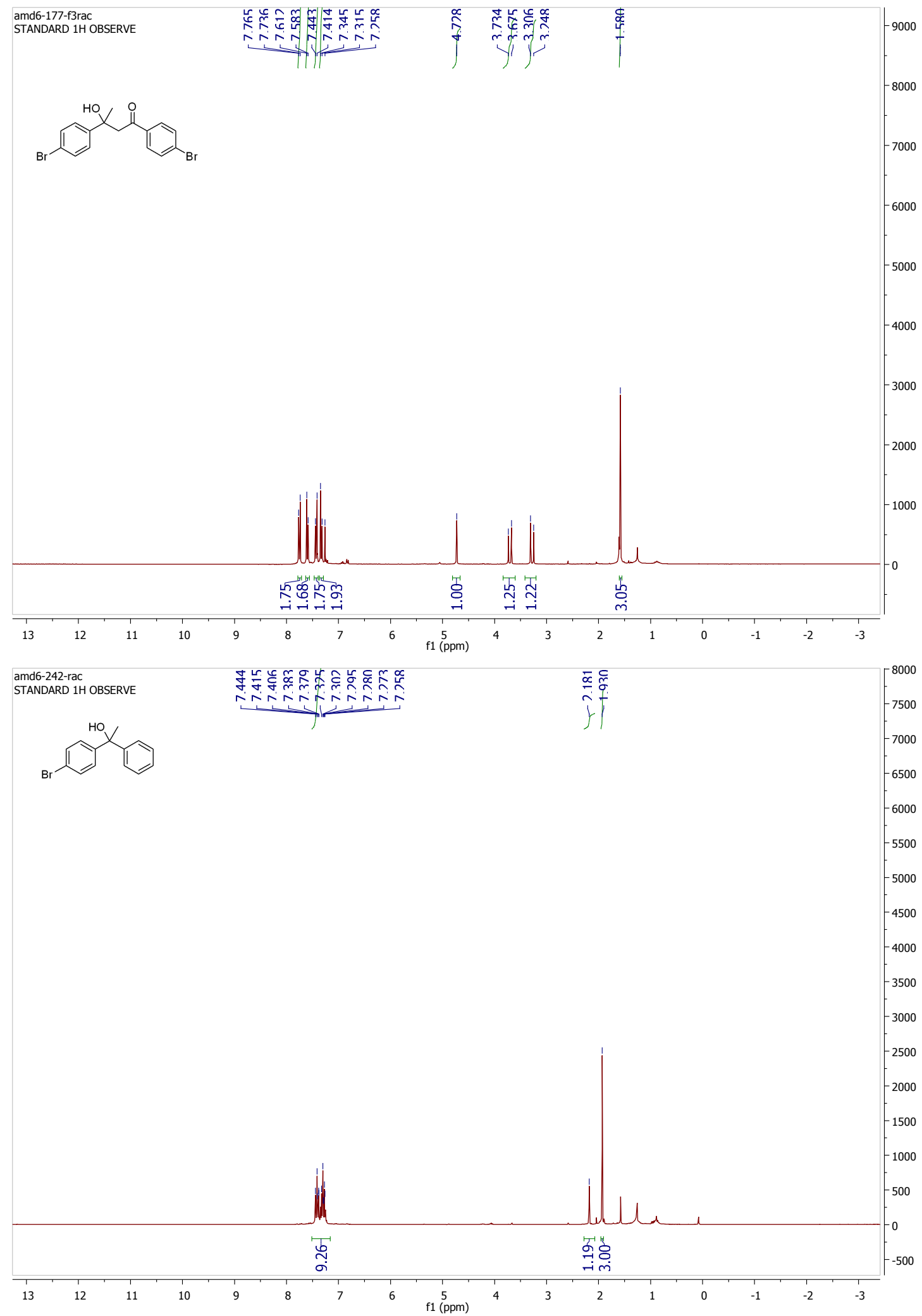




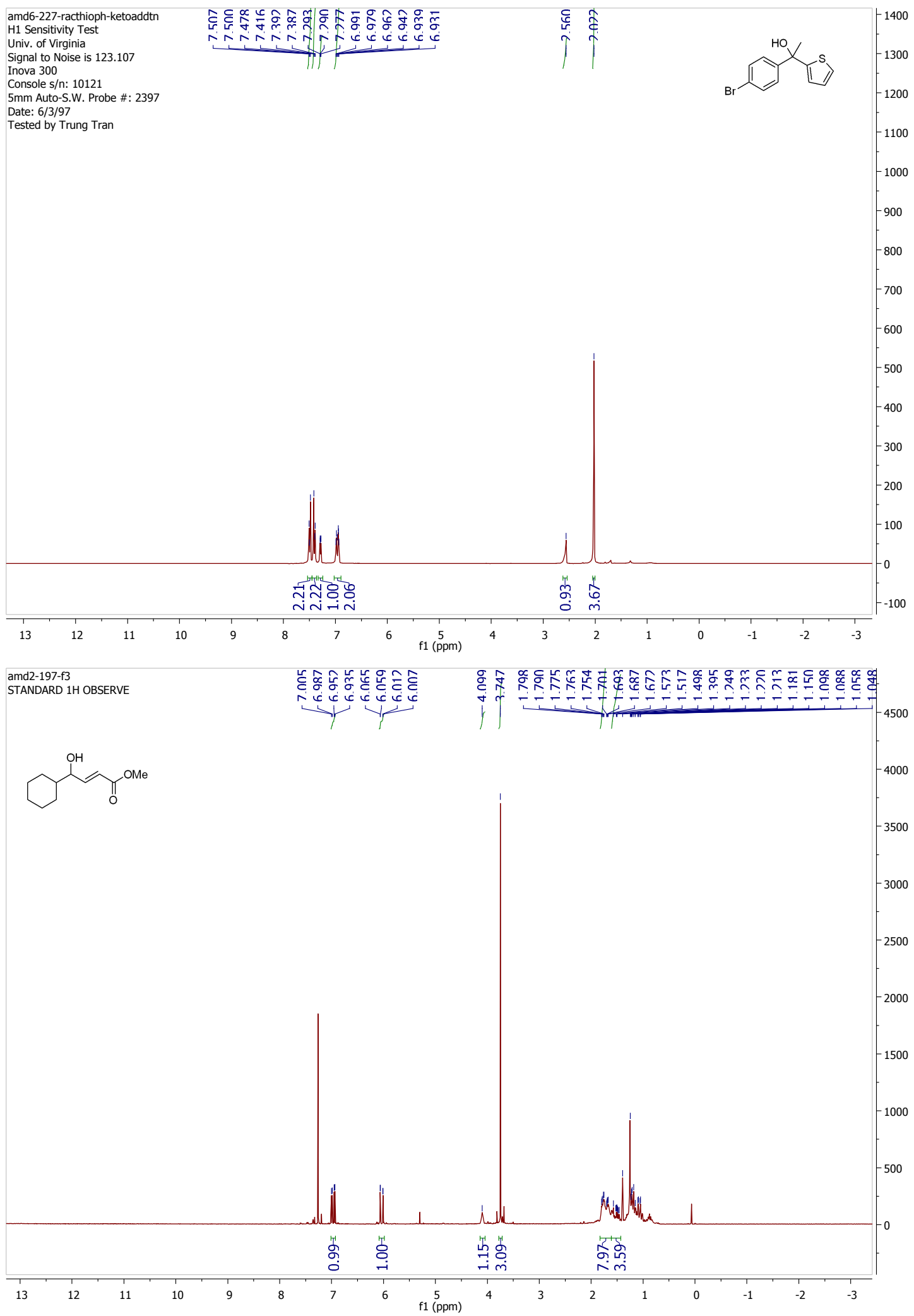



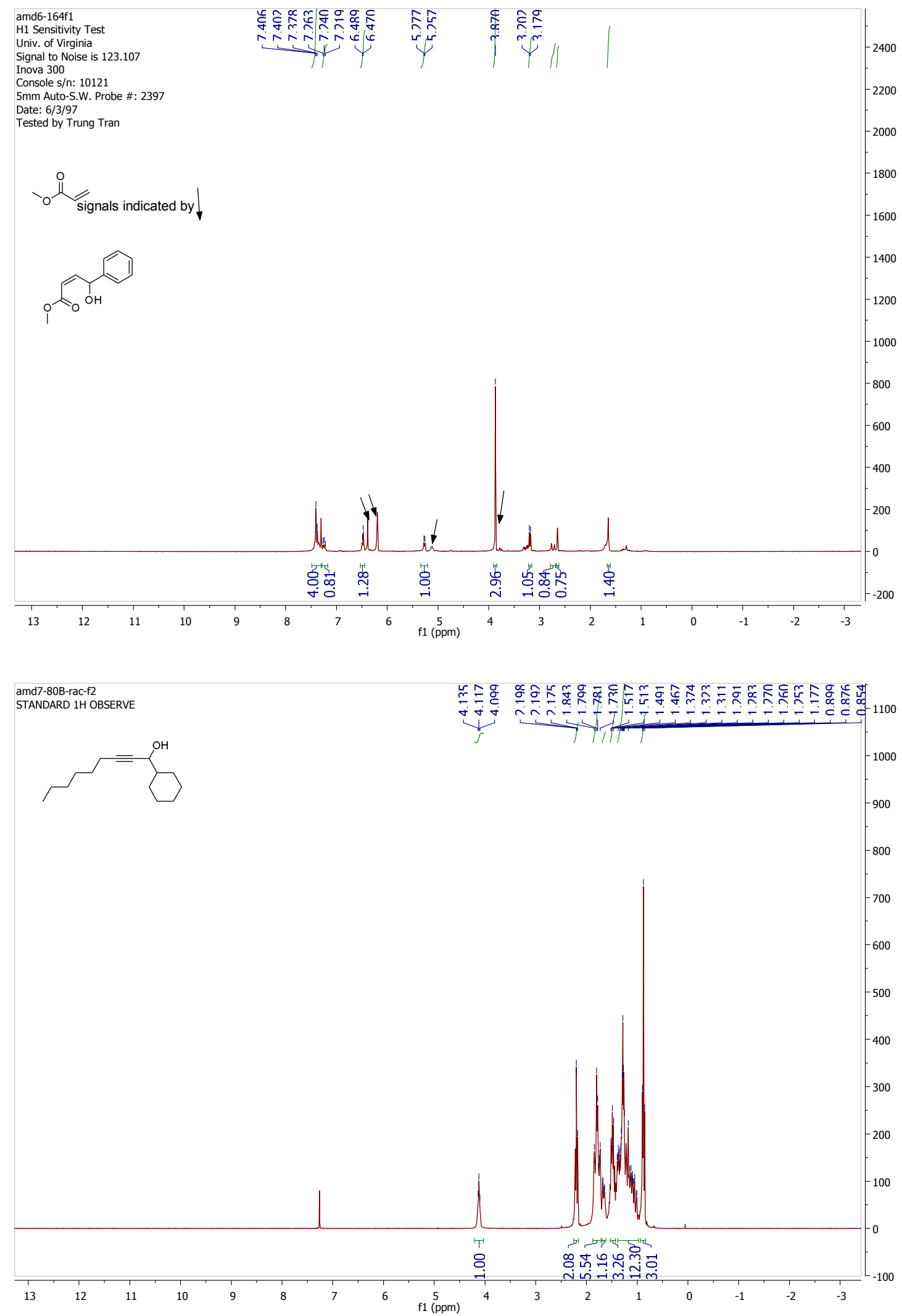


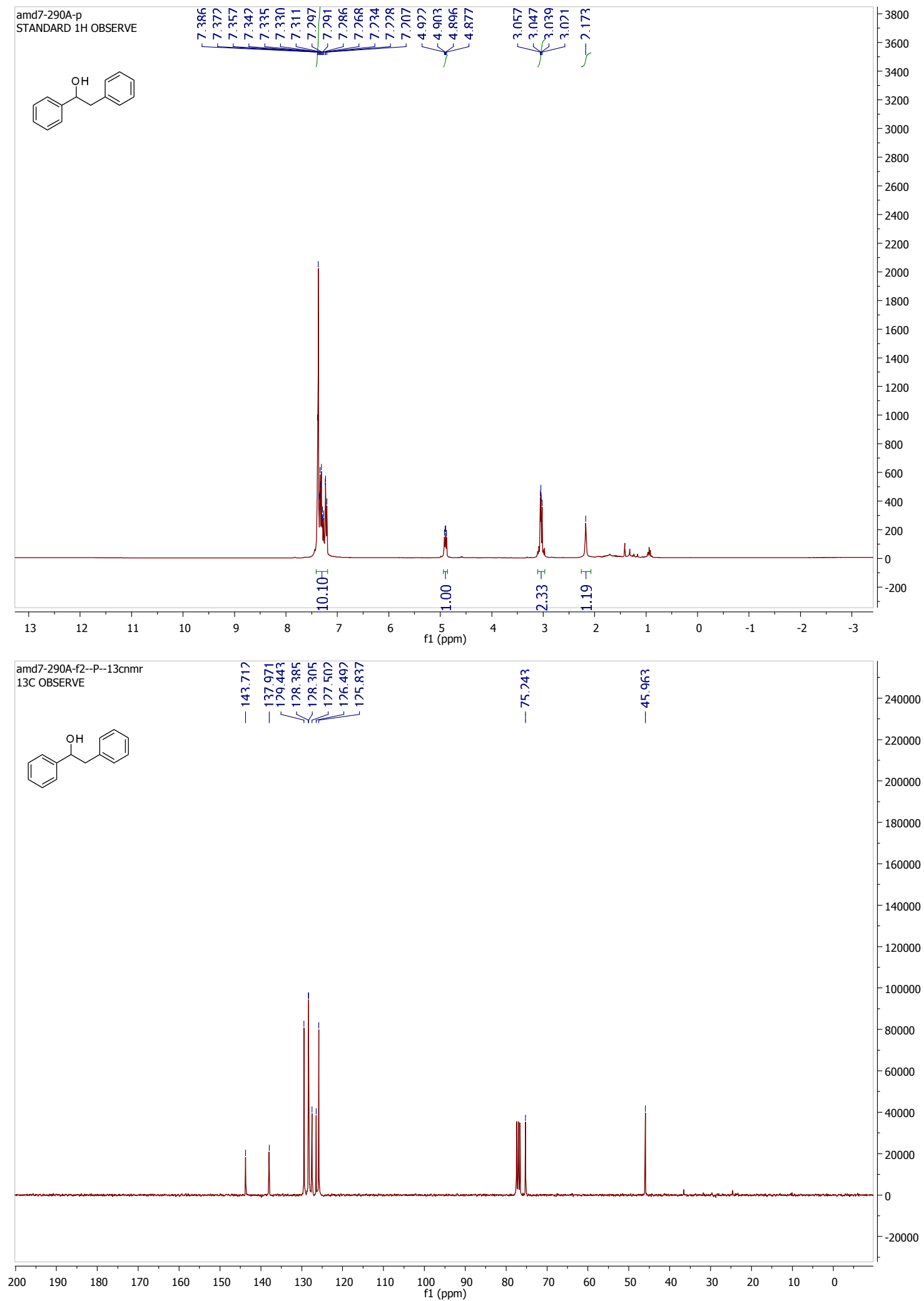



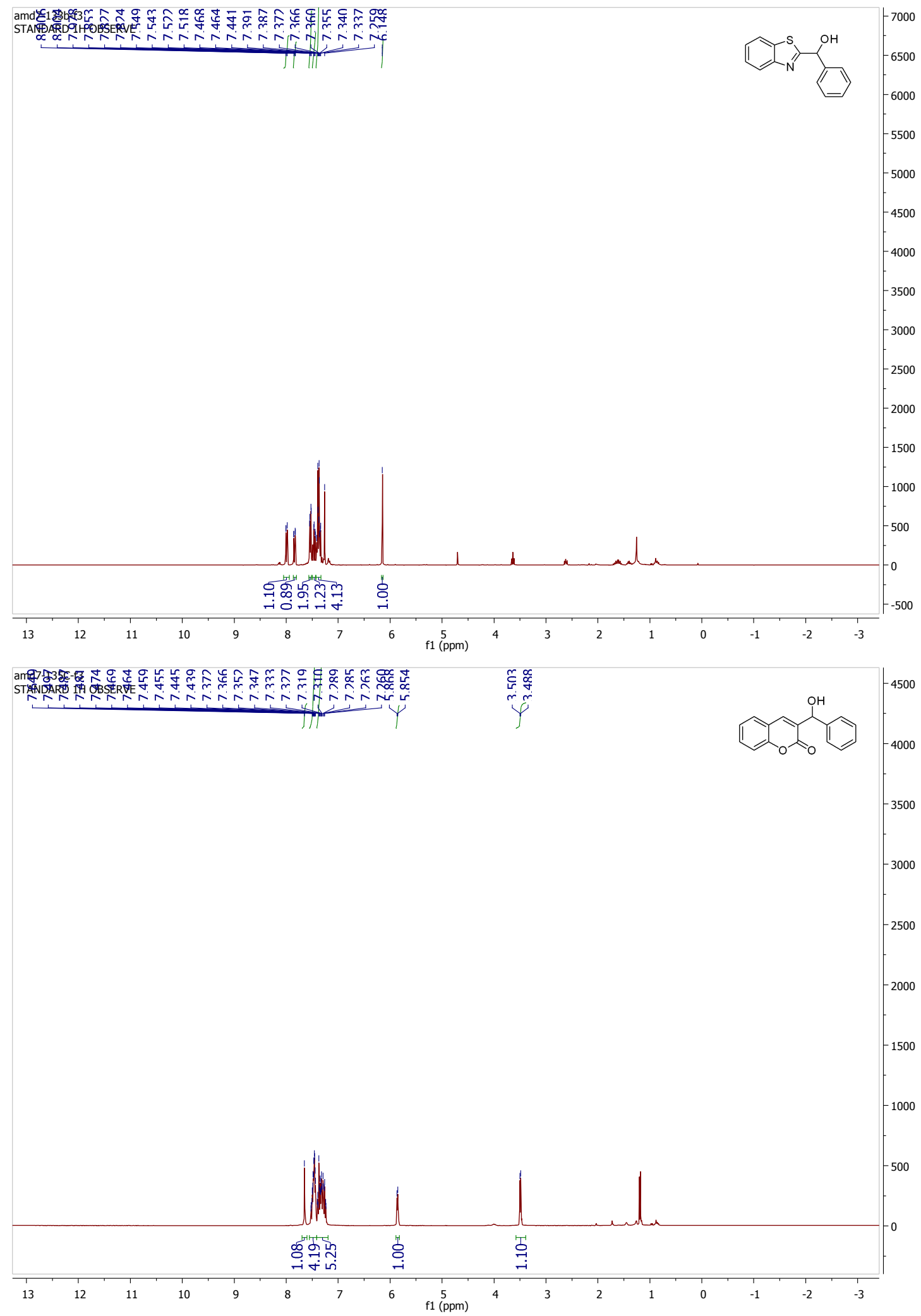
amd6-166-f2

H1 Sensitivity Test

Univ. of Virginia
Signal to Noise is 123.107

Inova 300

Console s/n: 10121

$5 \mathrm{~mm}$ Auto-S.W. Probe \#: 2397

Tested by Trung Tran

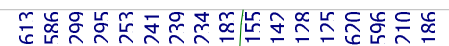

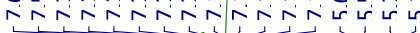

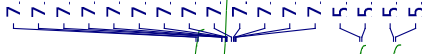

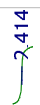
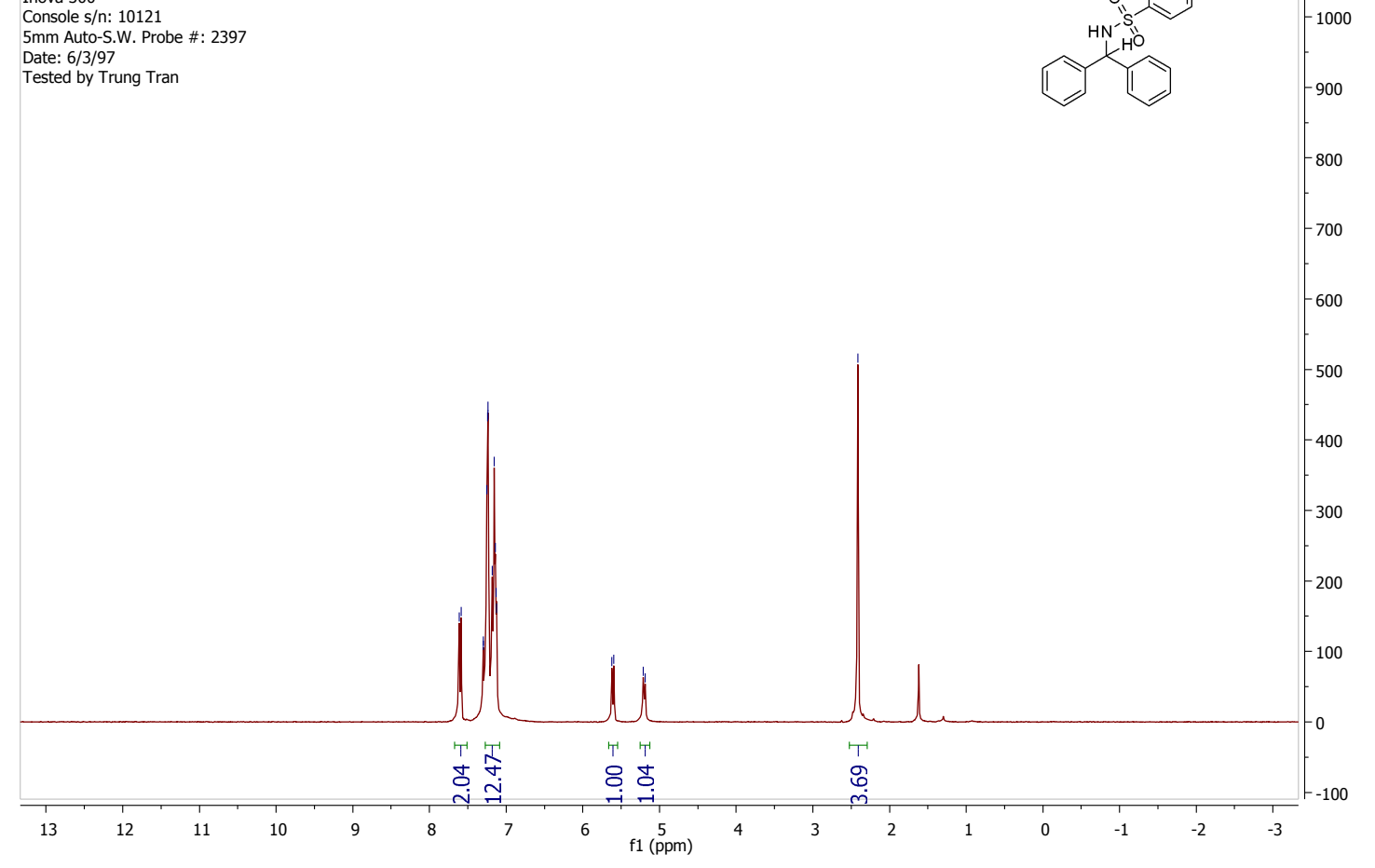

700

$-600$

500

400

300

200

100

T⿱宀

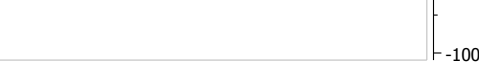

STANDARD $1 \mathrm{H}$ OBSERVE

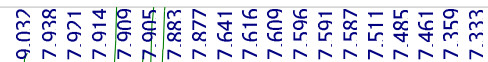

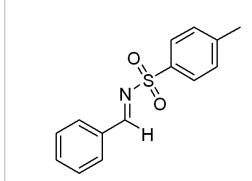

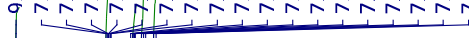

f
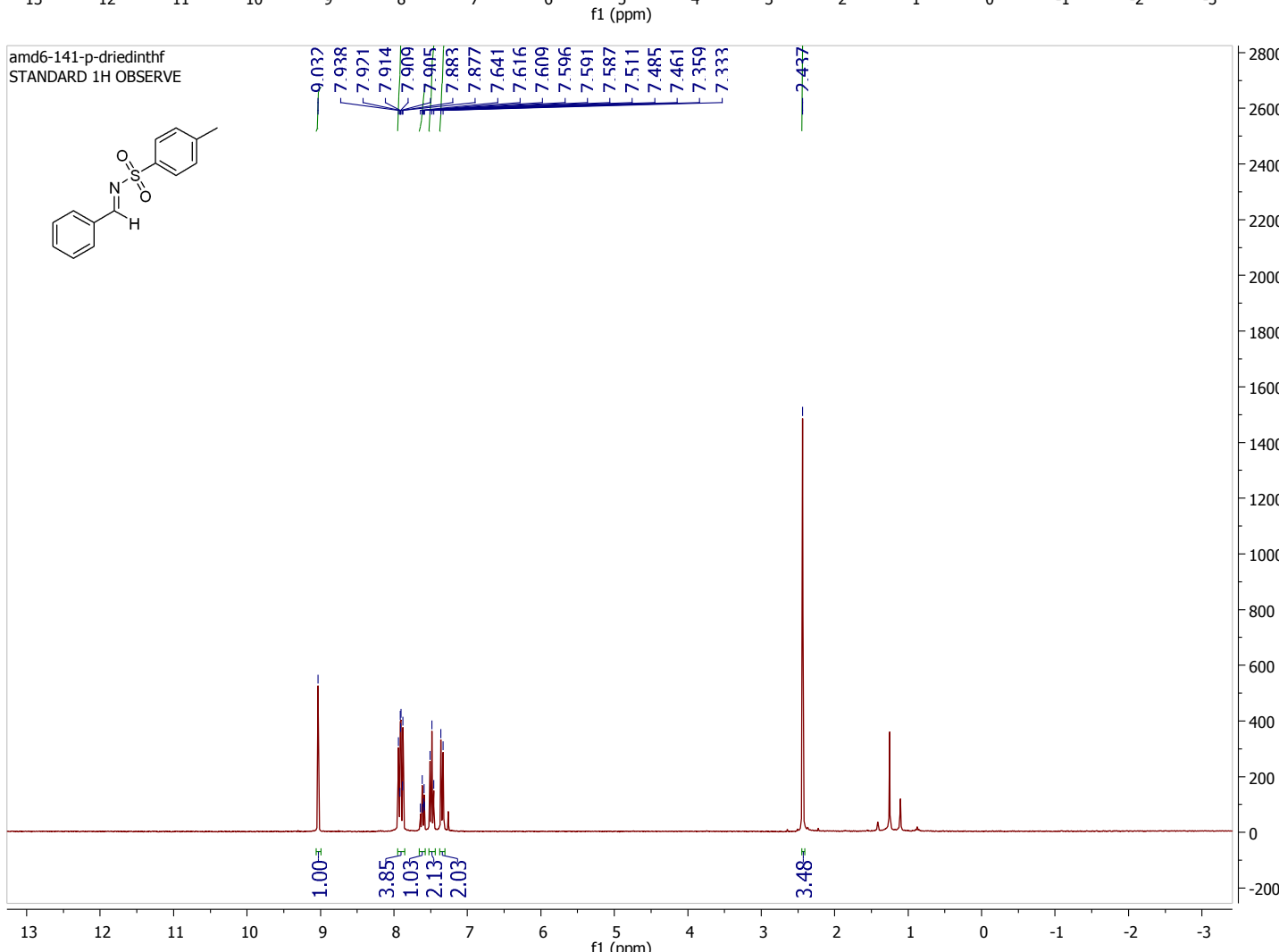

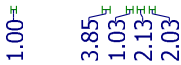

के
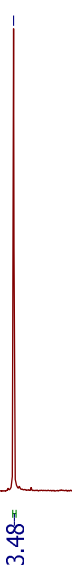

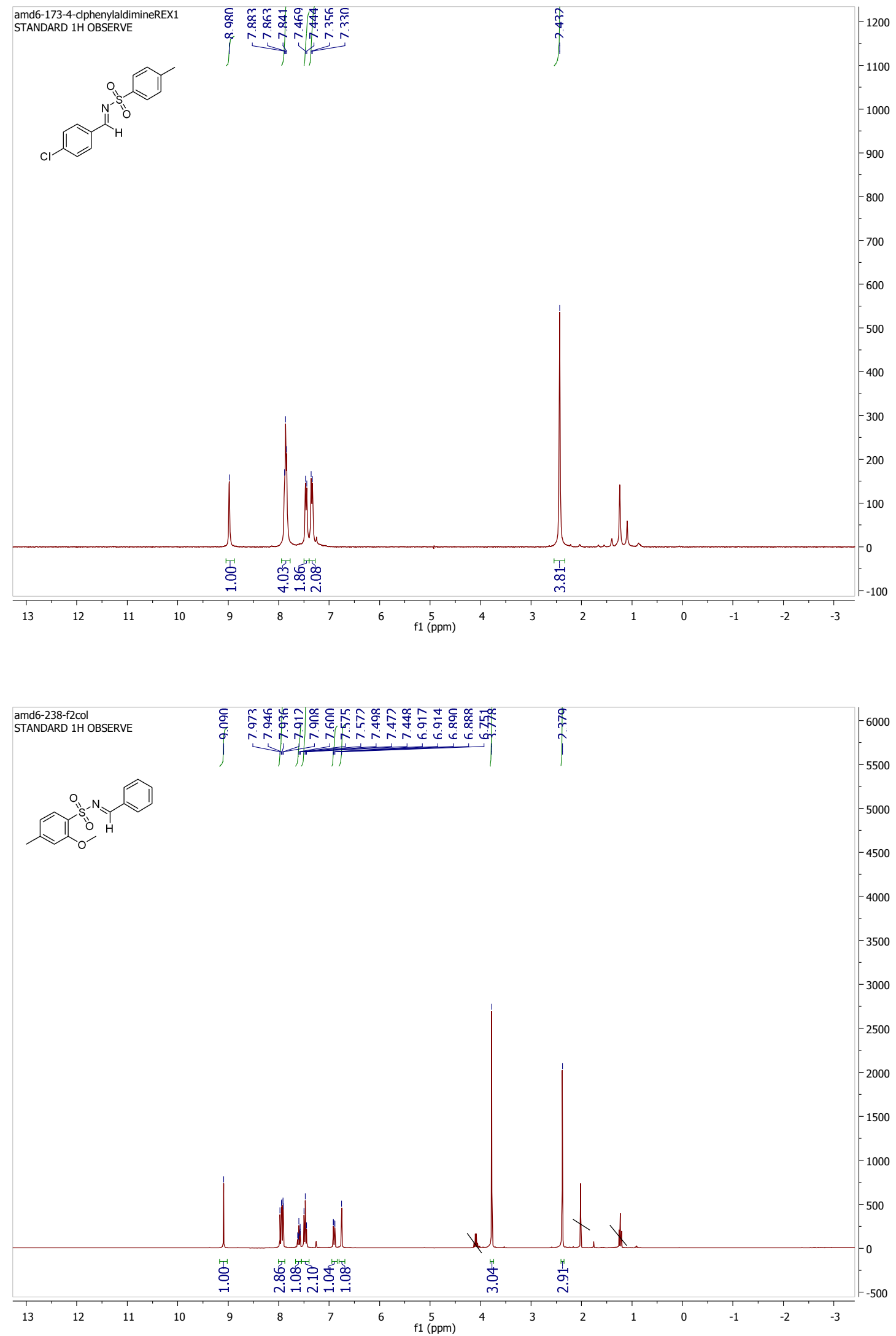


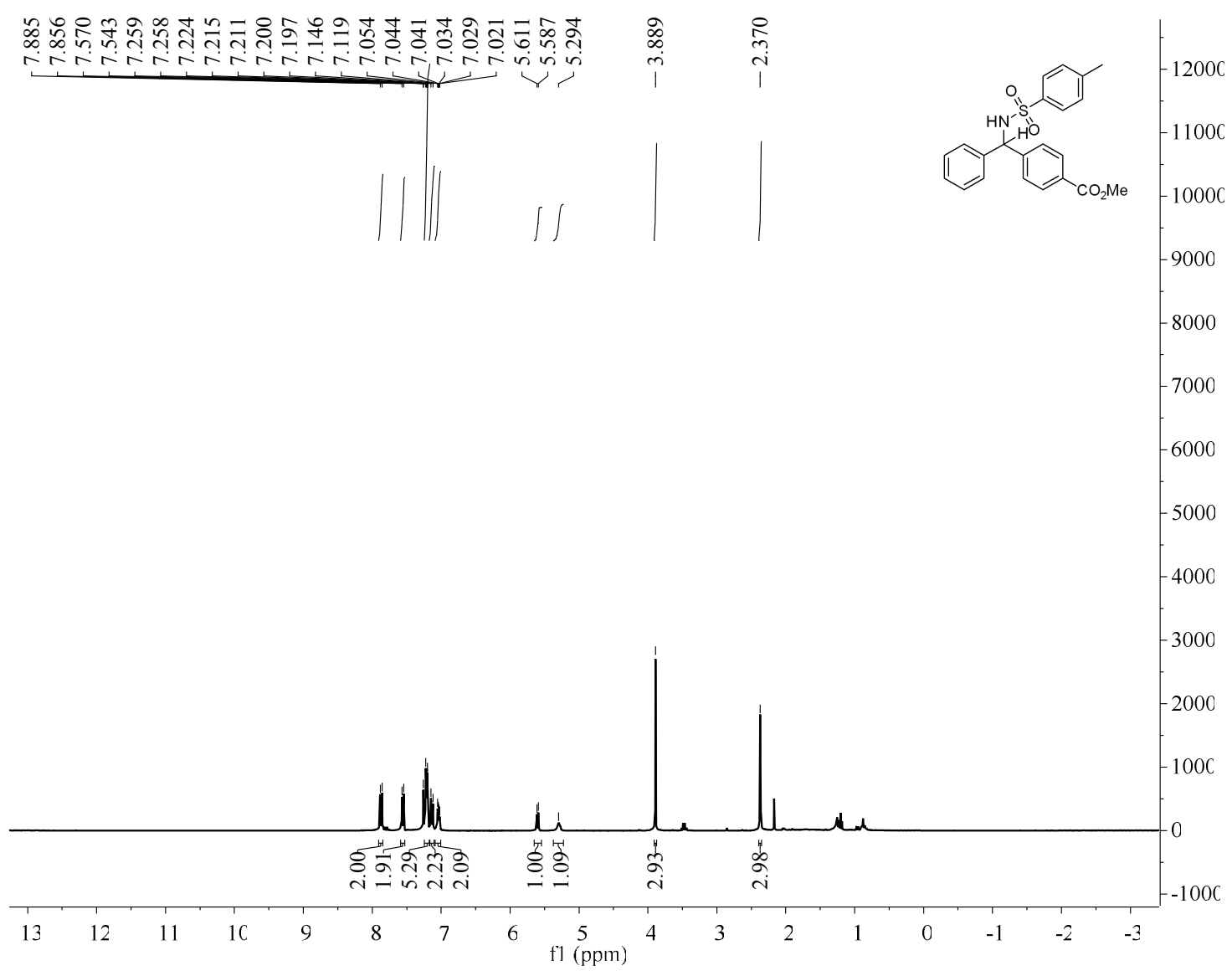



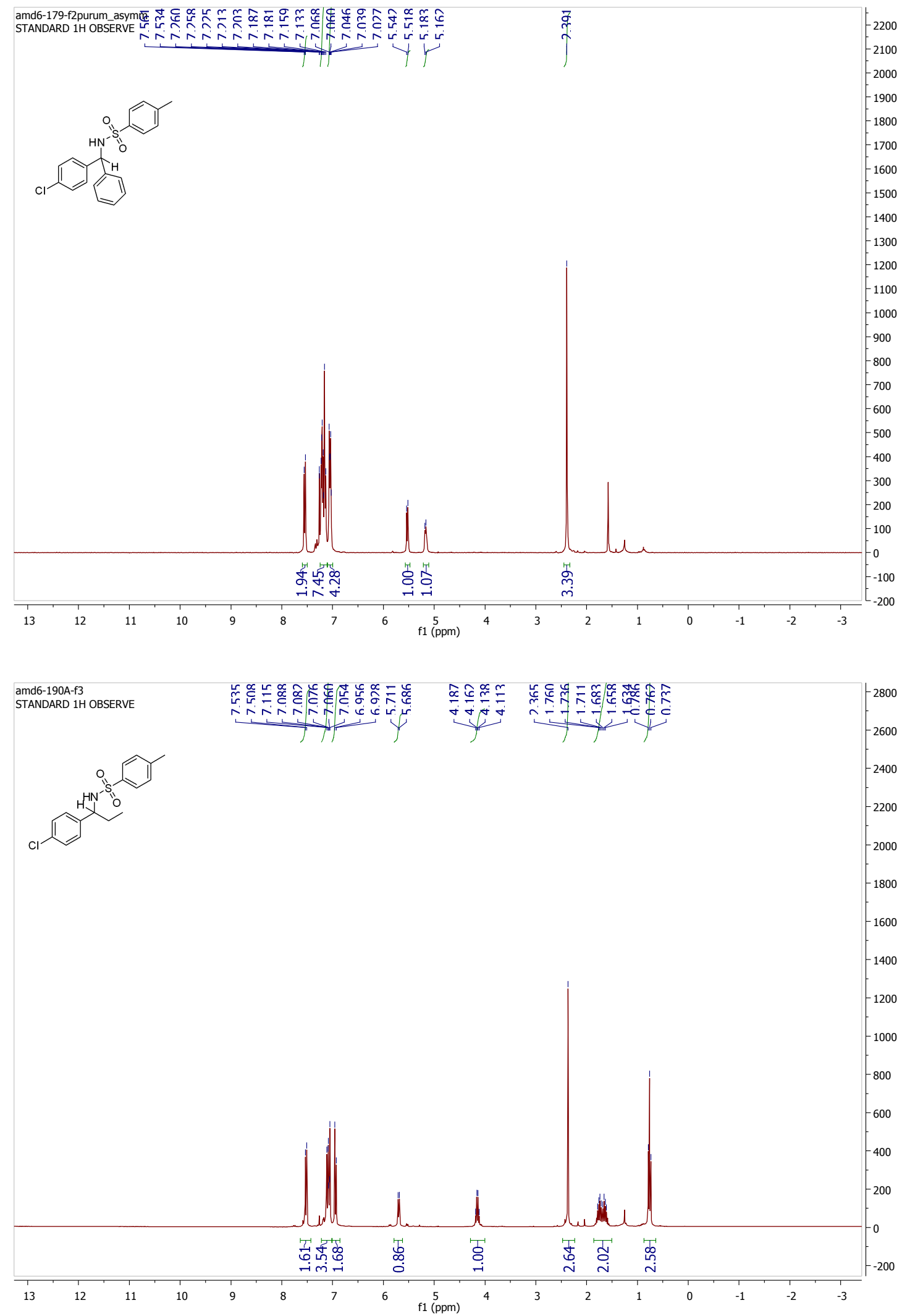


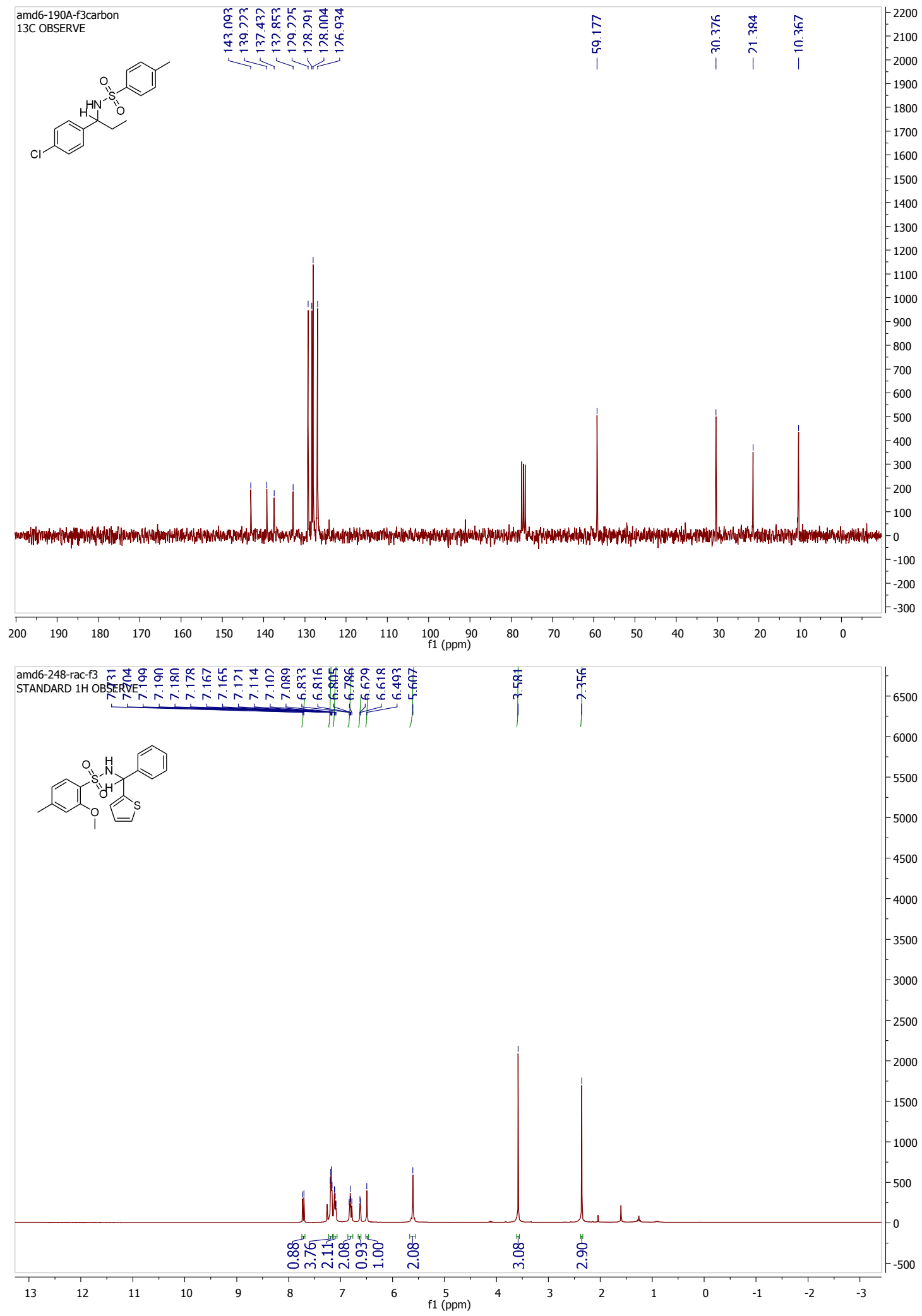



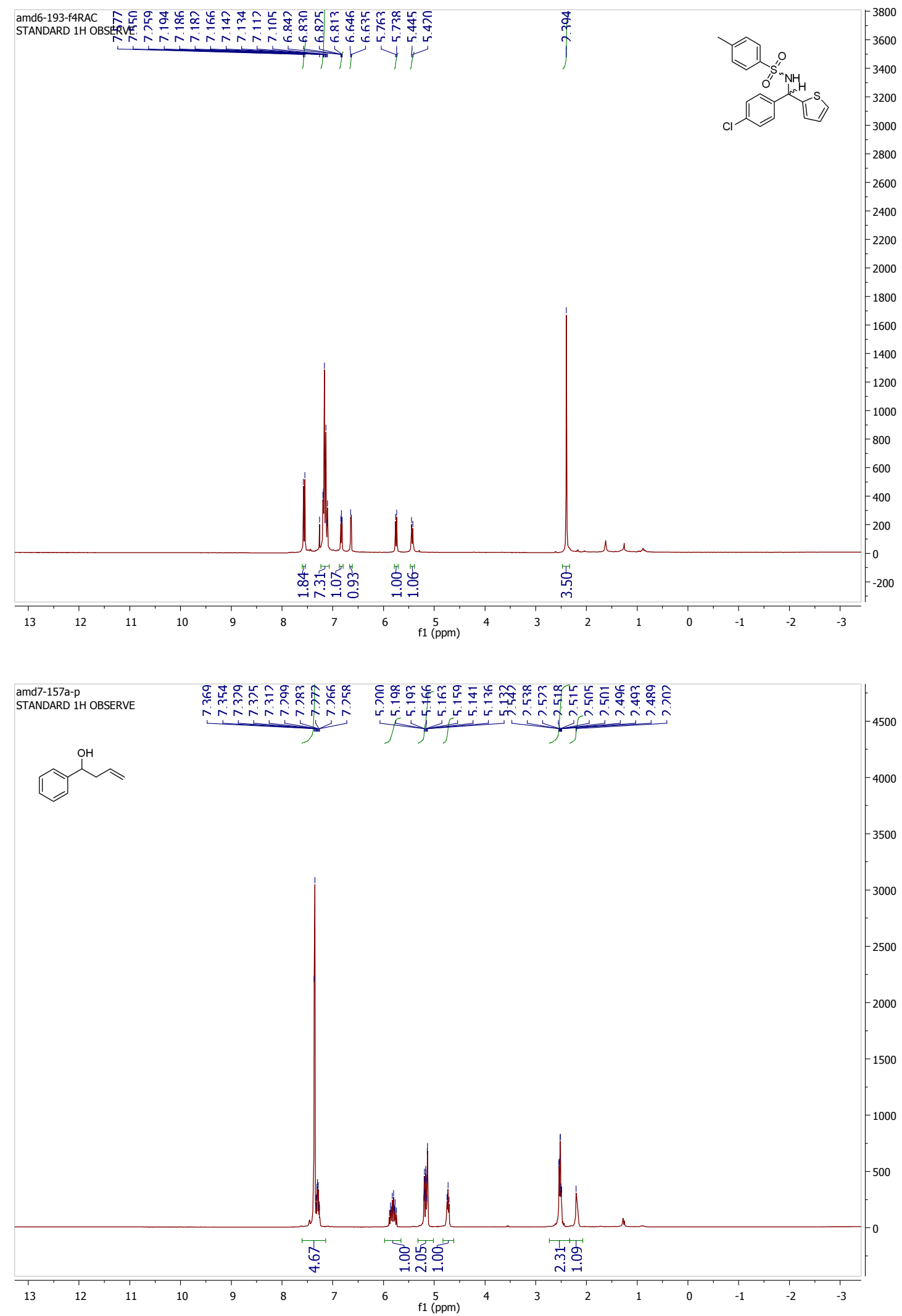


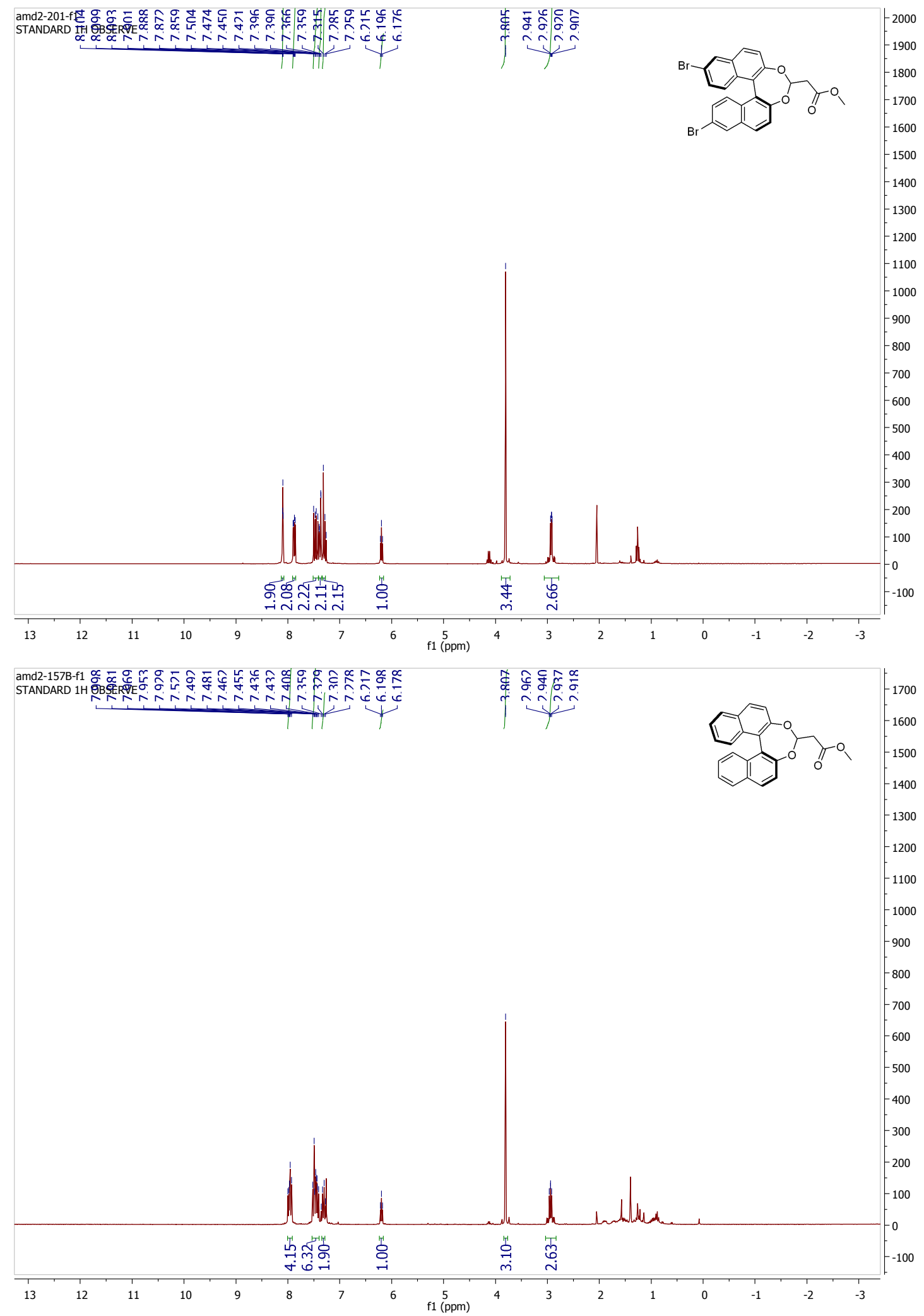




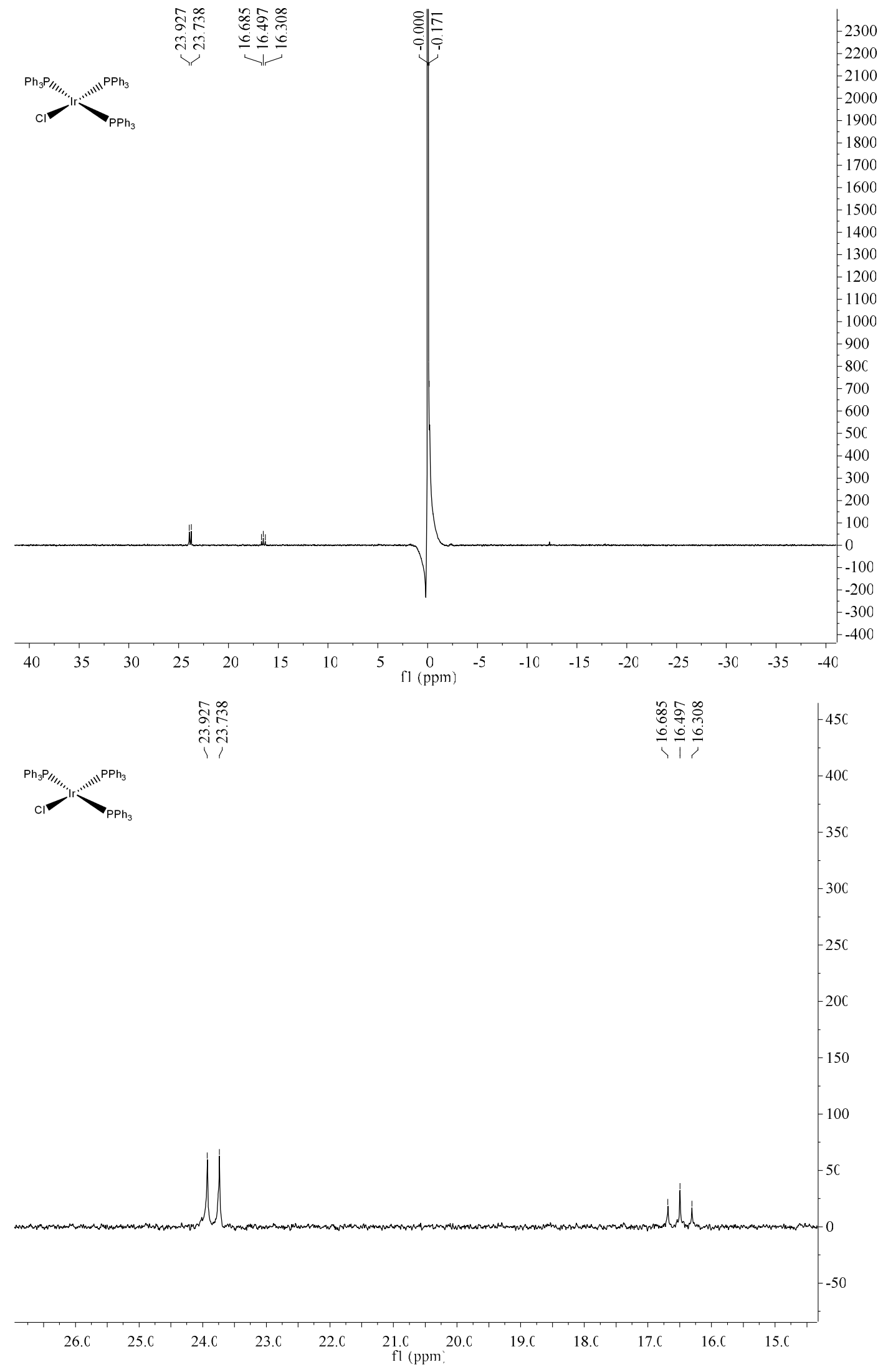

